\title{
The Missing Entrepreneurs 2021
}

POLICIES FOR INCLUSIVE ENTREPRENEURSHIP AND SELF-EMPLOYMENT

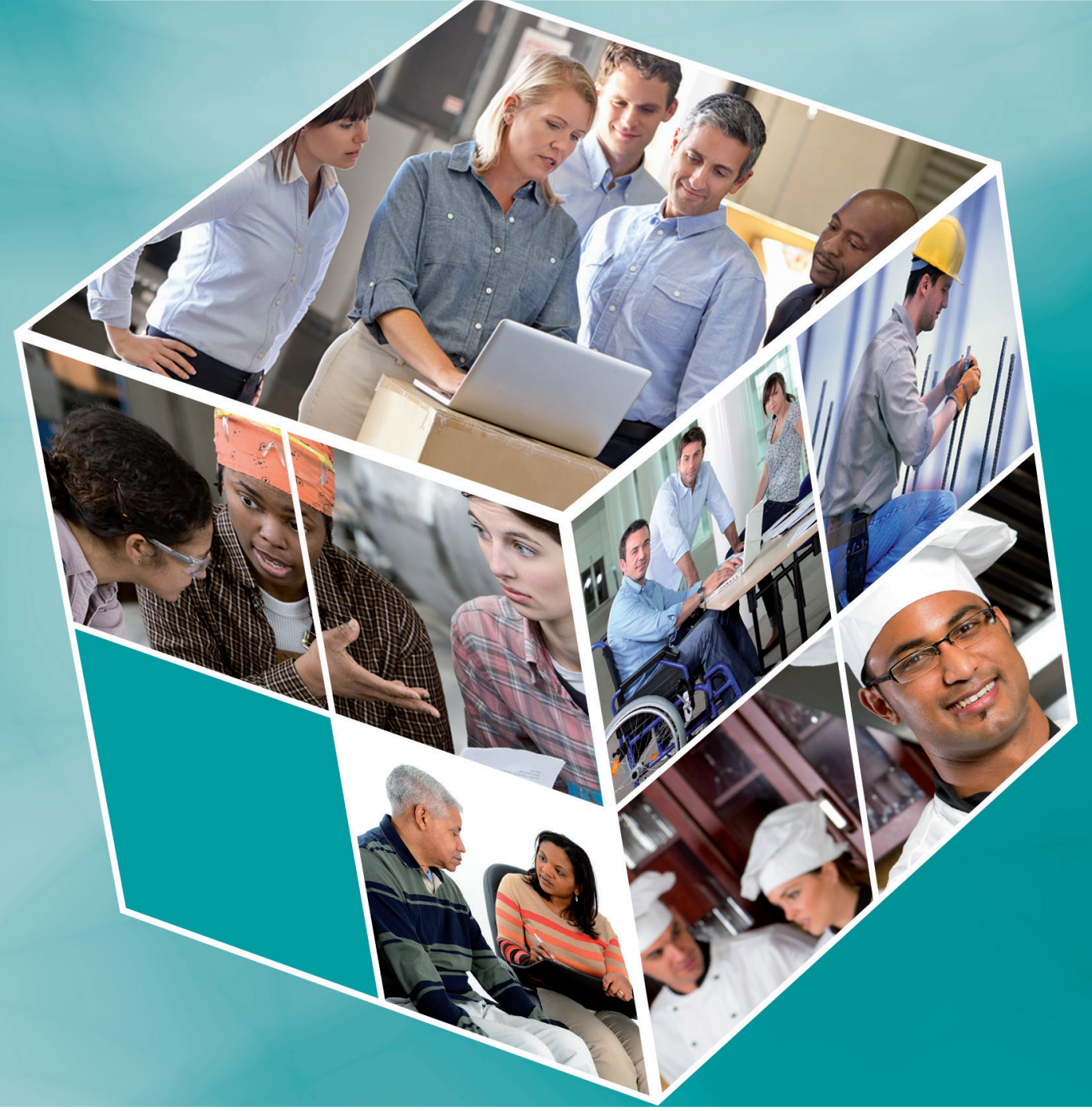

0)
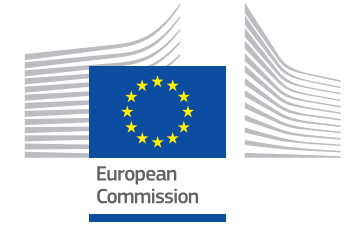



\section{The Missing Entrepreneurs 2021}

POLICIES FOR INCLUSIVE ENTREPRENEURSHIP AND SELF-EMPLOYMENT 
This document reproduces a report jointly prepared by the OECD and the European Commission, approved by the OECD's Co-operative Action Programme on Local Employment and Economic Development Directing Committee (the LEED Committee) by written procedure on 27 October 2021, and prepared for publication by the OECD Secretariat.

The opinions expressed and arguments employed herein do not necessarily reflect the official views of all member countries of the European Union.

This document, as well as any data and map included herein, are without prejudice to the status of or sovereignty over any territory, to the delimitation of international frontiers and boundaries and to the name of any territory, city or area.

The statistical data for Israel are supplied by and under the responsibility of the relevant Israeli authorities. The use of such data by the OECD is without prejudice to the status of the Golan Heights, East Jerusalem and Israeli settlements in the West Bank under the terms of international law.

Note by Turkey

The information in this document with reference to "Cyprus" relates to the southern part of the Island. There is no single authority representing both Turkish and Greek Cypriot people on the Island. Turkey recognises the Turkish Republic of Northern Cyprus (TRNC). Until a lasting and equitable solution is found within the context of the United Nations, Turkey shall preserve its position concerning the "Cyprus issue".

Note by all the European Union Member States of the OECD and the European Union

The Republic of Cyprus is recognised by all members of the United Nations with the exception of Turkey. The information in this document relates to the area under the effective control of the Government of the Republic of Cyprus.

Please cite this publication as:

OECD/European Commission (2021), The Missing Entrepreneurs 2021: Policies for Inclusive Entrepreneurship and Self-

Employment, OECD Publishing, Paris, https://doi.org/10.1787/71b7a9bb-en.

ISBN 978-92-64-93580-8 (print)

ISBN 978-92-64-84061-4 (pdf)

The Missing Entrepreneurs

ISSN 2664-4843 (print)

ISSN 2664-4851 (online)

European Union:

Catalogue number: KE-03-21-433-EN-C (Print)

Catalogue number: KE-03-21-433-EN-N (PDF)

ISBN: 978-92-76-43533-4 (Print)

ISBN: 978-92-76-43532-7 (PDF)

Photo credits: Cover () ririro/Shutterstock.com; (c) auremar-Fotolia.com; @ Rob - Fotolia.com; @ michaeljung - Fotolia.com; @ Monkey Business Images/Shutterstock.com; @ Stockbyte/Collection/Guetty Images; @ jetta production/Collection/Guetty Images.

Corrigenda to publications may be found on line at: www.oecd.org/about/publishing/corrigenda.htm.

๑ OECD/European Union 2021

The use of this work, whether digital or print, is governed by the Terms and Conditions to be found at $h t t p: / / w w w . o e c d . o r g / t e r m s a n d c o n d i t i o n s$. 


\section{Preface by the OECD}

Throughout the COVID-19 pandemic, we saw entrepreneurs confront unparalleled challenges while they navigated their business through a health crisis and economic lockdowns. But these challenges were even greater for entrepreneurs in under-represented and disadvantaged groups such as women, immigrants, youth, seniors, people with disabilities and those starting a business from unemployment, especially as they were more likely to operate a business in the most heavily impacted sectors and often struggled to qualify from support measures. Not surprisingly, many closed their business due to the crisis.

Many of the challenges they faced are not new, nor unique to the current crisis. This crisis, however, magnified them. Gaps in entrepreneurship activity rates and business survival rates across the population are long-standing. While Governments had made progress in closing them, through a wide range of tools, COVID-19 has undone some of what has been achieved.

This $6^{\text {th }}$ edition of the Missing Entrepreneurs comes at a critical time as governments look to map out a pathway to a strong and sustainable recovery. The report highlights many lessons about how we can seize the opportunity presented by large-scale recovery packages to "build back" economies and societies that are more inclusive.

The OECD is determined to support governments in unleashing entrepreneurial talents across the population. Diversity and inclusion are now priority issues for many OECD committees, including the newly created OECD Committee on SMEs and Entrepreneurship and the Local Employment and Economic Development (LEED) Committee. The commitment of the OECD in this regard, and its member countries, is also visible through the updated OECD Youth Action Plan and ongoing monitoring of the OECD Gender Recommendation (2012), which calls on countries to address gender gaps in employment, education and entrepreneurship.

I would like thank the European Commission for this long-term partnership on inclusive entrepreneurship policy. We have achieved a lot together but there is still much more to do in order to leverage on the full potential of our missing entrepreneurs.

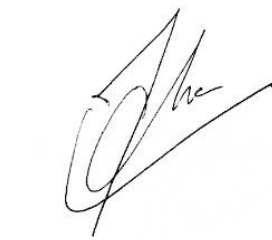

Lamia Kamal-Chaoui

Director

Centre for Entrepreneurship, SMEs, Regions and Cities 


\section{Preface by the European Commission}

Inclusive entrepreneurship refers to the range of policies helping certain groups to set up and grow their business. Women, young people and migrants face specific and often greater hurdles on the path to entrepreneurship, as do people with disabilities, seniors or the unemployed.

Major progress has been achieved during the last decades. Targeted support programmes have been put in place and mentoring and training schemes are now offered in many EU Member States. Above all, it seems that awareness of the problem has grown. Today, administrations know that several million entrepreneurs are missing from the EU labour market! I am particularly proud that the European Commission, thanks to its excellent collaboration with the OECD, has contributed to this common understanding.

Sadly, the Covid-19 pandemic shows there is no room for complacency. The Report demonstrates that the crisis had a negative impact on the self-employed and even more severe for those groups for which it was difficult to access compensation measures.

Our efforts must therefore continue. More than ever we need to find ways to empower and mobilise all entrepreneurial talent, irrespective of background. I hope this Report will contribute to improving understanding about what works and what still remains to be done.

The Report is complementary to other joint work we have undertaken with the OECD. For example, our "Policy Briefs" and our joint OECD/EU website Better Entrepreneurship Policy Tool are further resources to help policy-makers and stakeholders find relevant material to make their entrepreneurship policies more inclusive and social.

Progress in entrepreneurship needs to go hand in hand with social progress. In this regard, I attach great importance to the 2019 Council Recommendation on access to social protection for all. The Commission will be monitoring its implementation. It also called on Member States to further extend access to social protection, using the exceptional COVID-19 measures as a source of inspiration for structural reforms to improve the protection notably of the self-employed.

I am confident that all our actions for a more empowering environment for the self-employed will increase the number of new entrepreneurs... and reduce the number of missing ones!

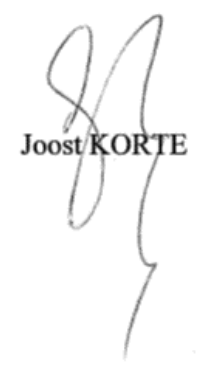

Joost Korte

Director-General,

Directorate General for Employment, Social Affairs and Inclusion,

European Commission 


\section{Foreword}

The COVID-19 pandemic has been devastating for entrepreneurs and business owners. This is even more true for entrepreneurs from under-represented and disadvantaged groups such as women, immigrants, youth and seniors. A growing body of international evidence shows that self-employed people and entrepreneurs from these groups were disproportionately impacted by the crisis, often due to the sector in which they operate, poor access to resources and the inaccessibility to the policy response. Although many governments implemented a range of measures to support the self-employed and micro businesses, these supports were not always accessible to those from under-represented and disadvantaged groups due to minimum revenue and hours worked thresholds, linkages between support and previous tax returns, poor communication and more.

As the policy focus shifts to economic recovery, inclusive entrepreneurship policies can help governments "build back better" by untapping the entrepreneurial potential among women, immigrants, ethnic minorities, youth, seniors and people with disabilities. Inclusive entrepreneurship policies seek to give everyone an opportunity to create a successful and sustainable business, regardless of their gender, age, place of birth, work status or other personal characteristics. Expanding entrepreneurship can create jobs, fight social and financial exclusion, leverage technologies and help respond to economic challenges. The Missing Entrepreneurs series of publications of the Organisation for Economic Co-operation and Development (OECD) and the European Union discuss how public policies and programmes can support inclusive entrepreneurship. This includes:

- Reducing disincentives to business creation in regulatory and welfare institutions;

- Facilitating access to finance:

- Building entrepreneurship skills through training, coaching and mentoring;

- Strengthening entrepreneurial culture and networks for target groups; and

- Putting strategies and actions for inclusive entrepreneurship together in a co-ordinated and targeted way.

This sixth edition of The Missing Entrepreneurs has several new features. Most notably, it contains a systematic policy mapping across the $27 \mathrm{EU}$ Member States that describe policy approaches in inclusive entrepreneurship such as the instruments used and the characteristics of these instruments. This qualitative information was collected during the preparation of biennial notes that are prepared on inclusive entrepreneurship policy in each country. Moreover, the report contains new estimates of the number of "missing" entrepreneurs.

This report was developed by the Centre for Entrepreneurship, SMEs, Regions and Cities (CFE), as part of the Programme of Work and Budget of the OECD Local Employment and Economic Development (LEED) Programme. It also supports the Programme of Work and Budget of the OECD Committee on SMEs and Entrepreneurship (CSMEE). A first draft of selected chapters were discussed on 21-22 April 2021 (CFE/LEED(2021)11/ and CFE/LEED(2021)12) and the final report was approved by written procedure on 27 October 2021 (CFE/LEED(2021)7). 


\section{Acknowledgements}

This report is the sixth edition in the series of Missing Entrepreneurs reports produced through an ongoing collaboration on inclusive entrepreneurship policies between the Centre for Entrepreneurship, SMEs, Regions and Cities (CFE) of the Organisation for Economic Co-operation and Development (OECD) led by Lamia Kamal-Chaoui, Director, and the Directorate General for Employment, Social Affairs and Inclusion (DG EMPL) of the European Commission, led by Joost Korte, Director-General.

This report is part of the programme of work of the OECD Local Economic and Employment Development (LEED) Programme within the CFE, led by Karen Maguire, Head of the Local Employment, Skills and Social Innovation Division. It also contributes to the work of the Committee on SMEs and Entrepreneurship, led by Céline Kauffmann, Head of the Entrepreneurship, SME and Tourism Division.

The report was prepared by David Halabisky, Project Co-ordinator, Inclusive and Sustainable Entrepreneurship, and Helen Shymanski, Junior Policy Analyst, under the direction of Jonathan Potter, Head of the OECD CFE Entrepreneurship Policy and Analysis Unit. Contributions were also made by Prof. Robert Blackburn, University of Liverpool (Chapter 1), Prof. Marcella Corsi, Sapienza University of Rome (Chapter 7), Dr. Fabrizio Botti, Guglielmo Marconi University (Chapter 7), Dr. Giulia Zacchia, Sapienza University of Rome (Chapter 7), Prof. Thomas Cooney, Dublin Institute of Technology (Chapter 8) and Osa Godwin Osaghae (Chapter 8). Mattia Corbetta, Policy Analyst of the OECD CFE also contributed inputs and suggestions in Chapter 8.

The report benefited from inputs and comments from the European Commission under the direction of Ruth Paserman, Director for "Funds, Programming and Implementation" of DG EMPL. Key contributions were made by Julien De Beys, Policy officer - Inclusive and social entrepreneurship, and Guy Lejeune, Senior Expert - Inclusive and social entrepreneurship. Additional inputs and comments were received from Bernardo Urrutia Garro, Policy officer; Laurent Aujean, Policy officer; Dimitrios Niafas, Policy officer; and Cristina Viezzer, Programme Assistant - EaSI Financial instruments and social finance, all of DG EMPL; and Clemence Ghighi, Policy officer of the Directorate-General for Migration and Home Affairs.

In addition, the authors are grateful for comments and suggestions from Nadim Ahmad, Deputy Director of the OECD CFE; Karen Maguire; Céline Kauffmann; and Andrew Paterson, Senior advisor, OECD CFE. Comments and suggestions were also received from Jean-Christophe Dumont, Head of the International Migration Division of the OECD Directorate of Employment, Labour and Social Affairs (ELS); Jonathan Chaloff, Senior Policy Analyst, ELS; Thomas Liebig, Principal Administrator, ELS; and Yves Breem, Policy analyst, ELS.

Important data contributions were received from Prof. Jonathan Levie of the Global Entrepreneurship Research Association.

The country profiles in Part III of this report were based on a set of Country Assessment Notes that were prepared for each EU Member State by a network of national inclusive entrepreneurship policy experts under the direction of David Halabisky, Cynthia Lavison and Jonathan Potter of the OECD CFE:

- Austria: Eva Heckl and Karin Petzlberger, Austrian Institute for SME Research; 
- Belgium: Dr. Wouter Broekaert and prof. Dr. Johan Lambrecht, both of the Center for Sustainable Entrepreneurship (CenSE) and KU Leuven;

- Bulgaria: Prof. Zhelyu Vladimirov, Sofia University;

- Croatia: Prof. Slavica Singer, Josip Juraj Strossmayer University in Osijek;

- Cyprus: Prof. Angelika I. Kokkinaki, University of Nicosia; Dr. Paraskevi (Evi) Dekoulou, University of Nicosia; Dr. Chrysostomi Maria Kyrillou, University of Nicosia; and Mr. Kyriakos Riskos, Aristotle University of Thessaloniki;

- Czech Republic: Lucie Bučinová, Regio-Partner;

- Denmark: Annemarie Jepsen;

- Estonia: Marina Kaas, Serioso Ltd.;

- Finland: Prof. Jarna Heinonen, Turku School of Economics;

- France: Prof. Nadine Levratto, University Paris Nanterre;

- Germany: Prof. Dr. Rolf Sternberg, Leibniz University Hannover;

- Greece: Dr. Dimitris Karantinos, EKKE - National Centre of Social Research;

- Hungary: Dr. Petra Reszkető, Budapest Institute;

- Ireland: Prof. Thomas Cooney, Dublin Institute of Technology;

- Italy: Prof. Sergio Destefanis, University of Salerno;

- Latvia: Prof. Arnis Sauka, Stockholm School of Economics in Riga;

- Lithuania: Dr. Boguslavas Gruzevskis, Labor Market Research Institute;

- Luxembourg: Prof. Denise Fletcher, University of Luxembourg;

- Malta: Prof. Leonie Baldacchino and Ms. Kristina Buhagiar, University of Malta;

- Netherlands: Dr. Jacqueline Snijders and Amber van der Graaf, both of Panteia;

- Poland: Prof. Krzysztof Wach, Cracow University of Economics;

- Portugal: Prof. Carla Susana da Encarnação Marques, University of Trás-os-Montes and Alto Douro;

- Romania: Dr. Catalin Ghinararu, National Scientific Research Institute;

- Slovak Republic: Prof. Anna Pilkova, Comenius University in Bratislava; Marian Letovanec, Slovak Business Agency; Prof. Marian Holienka, Comenius University in Bratislava; and Prof. Juraj Mikuš, Comenius University in Bratislava;

- Slovenia: Prof. Katja Crnogaj, University of Maribor;

- Spain: Prof. Francisco Liñán, University of Seville; and

- Sweden: Prof. Carin Holmquist, Stockholm School of Economics.

These Country Assessment Notes benefited from feedback and inputs from relevant national ministries and key stakeholders in each Member State.

Finally, this report would not have been possible without administrative support from Sorrel Stewart and Heather Mortimer Charoy, publication support from Pilar Philip and François Iglesias, and communications support from Shayne Maclachlan and Lukasz Lech, all of the OECD CFE. 


\section{Table of contents}

Preface by the OECD

Preface by the European Commission 4

Foreword 5

$\begin{array}{ll}\text { Acknowledgements } & 6\end{array}$

$\begin{array}{ll}\text { Reader's guide } & 15\end{array}$

$\begin{array}{ll}\text { Executive summary } & 21\end{array}$

1 Recent trends and policy priorities in inclusive entrepreneurship 25

COVID-19 had a strong negative impact on the self-employed $\quad 27$

The missing entrepreneurs $\quad 40$

Addressing the crisis with inclusive entrepreneurship policy 46

The next generation of inclusive entrepreneurship policies $\quad 51$

References $\quad 55$

Notes $\quad 62$

Part I Inclusive entrepreneurship indicators: Activity rates and barriers 63

2 Women's self-employment and entrepreneurship activities 64

Policy context for women's self-employment and entrepreneurship 66

$\begin{array}{ll}\text { Trends in self-employment by women } & 71\end{array}$

Characteristics of self-employed women and their activities $\quad 73$

Activities by women over the entrepreneurship life-cycle $\quad 85$

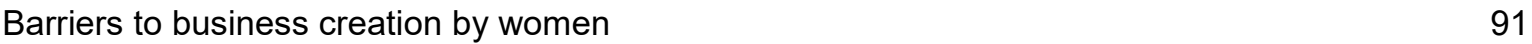

Characteristics of women's entrepreneurship 96

$\begin{array}{lr}\text { Conclusions } & 99\end{array}$

$\begin{array}{ll}\text { References } & 99\end{array}$

3 Immigrants' self-employment and entrepreneurship activities 103

Policy context immigrant entrepreneurship support 105

$\begin{array}{ll}\text { Trends in self-employment by immigrants } & 109\end{array}$

Characteristics of self-employed immigrants and their activities $\quad 115$

Business activities by self-employed immigrants $\quad 118$

$\begin{array}{ll}\text { Conclusions } & 121\end{array}$ 
References

4 Youth self-employment and entrepreneurship activities

Policy context

Trends in self-employment by youth

Characteristics of self-employed youth and their activities

Activities by youth over the entrepreneurship life-cycle

Barriers to business creation by youth

Characteristics of youth entrepreneurship

Conclusions

References

5 Seniors' self-employment and entrepreneurship activities

Policy context 157

Trends in self-employment by seniors

Characteristics of self-employed seniors and their activities

Activities by seniors over the entrepreneurship life-cycle

Barriers to business creation by seniors

Characteristics of senior entrepreneurship

Conclusions

References

6 Self-employment and entrepreneurship by the unemployed 185

Policy context

Seeking self-employment from unemployment

Entering self-employment from unemployment

Conclusions

199

References

Part II Policies for inclusive entrepreneurship 203

7 Designing effective microfinance schemes for inclusive entrepreneurship 204

The growing demand for microfinance 206

Microfinance in the European Union and beyond $\quad 209$

Challenges faced in the wake of the COVID-19 217

Policy actions to prepare the microfinance sector for the future 220

$\begin{array}{ll}\text { Conclusions } & 230\end{array}$

References $\quad 230$

Notes $\quad 234$

8 Leveraging immigrant entrepreneurship for job creation and growth 237

The changing nature of immigrant entrepreneurship 239

The potential benefits of immigrant entrepreneurship 243

Challenges faced by immigrant entrepreneurs $\quad 245$

Policies to unlock the potential of immigrant entrepreneurship $\quad 246$

Conclusions $\quad 255$

$\begin{array}{ll}\text { References } & 256\end{array}$ 
Part III Country profiles: Key inclusive entrepreneurship trends, issues and recent policy actions

9 Reader's guide for the country profiles

10 Austria

11 Belgium

12 Bulgaria

13 Croatia

14 Cyprus

15 Czech Republic

16 Denmark

17 Estonia

18 Finland

19 France

20 Germany

21 Greece

22 Hungary

23 Ireland

24 Italy

25 Latvia

26 Lithuania

27 Luxembourg

28 Malta

29 Netherlands

30 Poland

31 Portugal 


\section{Tables}

Table 1.1. Barriers to entrepreneurship for under-represented and disadvantaged groups

Table 2.1. Entrepreneurial intentions among young female students are driven by entrepreneurial attitudes

Table 4.1. Unemployment has both positive and negative influences on youth self-employment

Table 4.2. Entrepreneurship education in Korea appears to be more effective among older students

Table 5.1. More than one-quarter of unretiring people in Sweden become self-employed

Table 5.2. About $4 \%$ of older employees in the US transition to self-employment before retirement

Table 7.1. Women-oriented MFIs are smaller and less profit-driven than other MFIs

Table 7.2. Financial sustainability and social impact for European MFIs after the 2007-08 financial crisis

\section{Figures}

Figure 1.1. The number of employees has rebounded more quickly than the self-employed

Figure 1.2. The self-employed are more likely than employees to report financial difficulties

Figure 1.3. Up to $60 \%$ of entrepreneurs have reduced expectations for business growth

Figure 1.4. Self-employment are under-represented in teleworkable sectors

Figure 1.5. Some entrepreneurs report that COVID-19 has created opportunities for their business

Figure 1.6. Self-employment levels vary more within some countries than across EU Member States

Figure 1.7. Phases of policy measures for individuals and businesses in 2020-21

Figure 1.8. The majority of policy measures for the self-employed aimed to keep the business afloat

Figure 1.9. Early-stage entrepreneurship rates vary across population groups

Figure 1.10. The number of "missing" entrepreneurs represent $52 \%$ of all early-stage entrepreneurs in the EU Figure 1.11. The majority of the "missing" entrepreneurs are women and those over 50 years old

Figure 1.12. Female-led businesses were more likely to close during the COVID-19 pandemic

Figure 1.13. Approaches to inclusive entrepreneurship

Figure 1.14. Inclusive entrepreneurship policy across EU Member States

Figure 2.1. Policy frameworks for women's entrepreneurship are shared across national and sub-national governments

Figure 2.2. Women's entrepreneurship schemes vary in quality across EU Member States

Figure 2.3. The gender gap in self-employment has closed slightly since 2002

Figure 2.4. The gender gap in self-employment closed in $80 \%$ of Member States over the past decade

Figure 2.5. Less than one-quarter of self-employed women in the EU have employees

Figure 2.6. The gender gap in employer rates increased in about half of EU Member States since 2011

Figure 2.7. Self-employed women with employees tend to be older than those without

Figure 2.8. The share of self-employed in the EU with a tertiary education is increasing faster than for men

Figure 2.9. Self-employed women are more likely to have a tertiary education than self-employed men

Figure 2.10. Average weekly hours are declining for the self-employed

Figure 2.11. Self-employed women work slightly more hours a week than those who work as employees

Figure 2.12. Self-employed women are as likely as men to have autonomy over their working time

Figure 2.13. There earnings gap between full-time self-employed men and women is negligible

Figure 2.14. Self-employed women earn less than those working as employees in most EU Member States

Figure 2.15. Women are more likely to be self-employed than men in the Other service activities sector

Figure 2.16. More than half of self-employed women are professionals and service and sales workers

Figure 2.17. There is a gender gap in early-stage entrepreneurship across all EU Member States 
Figure 2.18. Women are more likely to be "necessity" entrepreneurs in countries with high unemployment and informality rates

Figure 2.19. Fewer than one-in-six women entrepreneurs started the business in a team

Figure 2.20. Women are half as likely as men to be established business owners

Figure 2.21. Most entrepreneurs, whether women or men, exit their business because it is not profitable

Figure 2.22. Nearly $50 \%$ of women report that fear of failure is a barrier to business creation

Figure 2.23. Female entrepreneurs continue to have greater difficulties accessing finance sought

Figure 2.24. About four-in-ten women report that they have the skills needed to start a business

Figure 2.25. Nearly one-third of women entrepreneurs report introducing a new product or service

Figure 2.26. About four-in-ten women entrepreneurs report having customers in other countries

Figure 2.27. Few women entrepreneurs in the EU expect high growth

Figure 3.1. Policy objectives for immigrant entrepreneurship support are often not well defined across EU

Member States

Figure 3.2. Immigrant entrepreneurship schemes less developed than for other target groups

Figure 3.3. Immigrants are less likely to be self-employed than non-immigrants in the EU

Figure 3.4. The gender gap in self-employment has changed little but immigrant women are now as likely as

their non-immigrant peers to be self-employed

Figure 3.5. Self-employment rates for immigrants vary greatly across countries

Figure 3.6. Most immigrant settlement services do not support entrepreneurship due to other priorities and a lack of funding

Figure 3.7. Immigrants account for a growing share of the self-employed

Figure 3.8. Immigrants from outside the EU account for the majority of self-employed immigrants in nearly all EU Member States

Figure 3.9. Nearly one-third of self-employed immigrants in the EU are employers

Figure 3.10. One-quarter of self-employed immigrant women are employers

Figure 3.11. Self-employed immigrants are less likely to be employers in the majority of EU Member States

Figure 3.12. Self-employment rates by sector vary little by place of birth

Figure 3.13. Solo self-employed immigrants are over-represented in professional occupations

Figure 4.1. Youth entrepreneurship policy benefited from investments following the financial crisis

Figure 4.2. Youth entrepreneurship schemes widely available and use a range of instruments

Figure 4.3. About 7\% of working youth in the EU are self-employed

Figure 4.17. More than half the students surveyed in EU and OECD countries had received entrepreneurship education during their studies 
Figure 5.11. Nearly one-quarter of seniors started businesses out of necessity in the EU 173 Figure 5.12. Around one-fifth of seniors started a business in a team 174

Figure 5.13. Nearly $9 \%$ of seniors in the EU are owners of an established business

Figure 5.14. One-quarter of seniors who stopped their business were more likely to cite lack of profit over retirement

Figure 5.15 . Nearly $45 \%$ of seniors report a fear of failure as a barrier to business creation

Figure 5.16. Seniors in the EU are as likely as the overall average to report having the skills to start a business 178

Figure 5.17. Nearly a third of early-stage senior entrepreneurs offered new products or services 179

Figure 5.18. Nearly half of early-stage senior entrepreneurs sold to foreign customers

180

Figure 5.19 . Nearly $10 \%$ of early-stage senior entrepreneurs expected to create 19 or more jobs in the next five years

Figure 6.1. Unemployment among youth rose sharply after financial crises

Figure 6.2. Governments in the EU commonly offer schemes to support the unemployed in business creation 190

Figure 6.3. Entrepreneurship schemes for the unemployed focus on building skills and offering finance 192

Figure 6.4. Few unemployed people seek self-employment

Figure 6.5. Unemployed seeking self-employment varies by EU Member State

196

Figure 6.6. Recently unemployed people are most likely to try to become self-employed 198

Figure 6.7. More unemployed people become self-employed than those seeking it 199

Figure 7.1. Women and rural populations are the most frequently served client groups 206

Figure 7.2. There is substantial unmet demand for microfinance in the EU 209

Figure 7.3. Regulatory approaches in Europe, including EU accession countries 214

Figure 10.1. Entrepreneurship and self-employment data for Austria 272

Figure 11.1. Entrepreneurship and self-employment data for Belgium 274

Figure 12.1. Entrepreneurship and self-employment data for Bulgaria 276

Figure 13.1. Entrepreneurship and self-employment data for Croatia 278

Figure 14.1. Entrepreneurship and self-employment data for Cyprus 280

Figure 15.1. Entrepreneurship and self-employment data for the Czech Republic 282

Figure 16.1. Entrepreneurship and self-employment data for Denmark 284

Figure 17.1. Entrepreneurship and self-employment data for Estonia 286

Figure 18.1. Entrepreneurship and self-employment data for Finland 288

Figure 19.1. Entrepreneurship and self-employment data for France 290

Figure 20.1. Entrepreneurship and self-employment data for Germany 292

Figure 21.1. Entrepreneurship and self-employment data for Greece 294

Figure 22.1. Entrepreneurship and self-employment in Hungary 296

Figure 23.1. Entrepreneurship and self-employment in Ireland 298

Figure 24.1. Entrepreneurship and self-employment in Italy 300

Figure 25.1. Entrepreneurship and self-employment in Latvia 302

Figure 26.1. Entrepreneurship and self-employment in Lithuania 304

Figure 27.1. Entrepreneurship and self-employment in Luxembourg 306

Figure 28.1. Entrepreneurship and self-employment in Malta 308

Figure 29.1. Entrepreneurship and self-employment in the Netherlands 310

Figure 30.1. Entrepreneurship and self-employment in Poland 312

Figure 31.1. Entrepreneurship and self-employment in Portugal 314

Figure 32.1. Entrepreneurship and self-employment in Romania 316

Figure 33.1. Entrepreneurship and self-employment in the Slovak Republic 318

Figure 34.1. Entrepreneurship and self-employment in Slovenia 320

Figure 35.1. Entrepreneurship and self-employment in Spain 322

Figure 36.1. Entrepreneurship and self-employment in Sweden 324

\section{Boxes}

Box 1.1. Consequences of COVID-19 for the tourism sector 33

Box 1.2. Consequences of COVID-19 on self-employment in cultural and creative sectors 34

Box 1.3. How is COVID-19 different than previous economic shocks? 39

Box 2.1. Country spotlight: Access to finance as a barrier to business creation in the Netherlands 92

Box 2.2. Country spotlight: Developing entrepreneurial intentions through entrepreneurship education in

Australia

Box 3.1. Country spotlight: Immigrant self-employment and local unemployment, Sweden

Box 3.2. Country spotlight: Entrepreneurship programming for immigrant women, Canada 
Box 4.1. The relationship between youth unemployment and self-employment in the EU 133

Box 4.2. Supporting the development of entrepreneurship skills through the OECD EECOLE network 138

Box 4.3. Country spotlight - effectiveness of entrepreneurship education for youth, Korea 149

Box 5.1. "Unretirement" and retirement transitions among seniors in the EU 158

Box 5.2. Country spotlight - Bridging to retirement through self-employment, United States 165

Box 6.1. Self-employment and alternative work arrangement trends: Italy, United Kingdom and United States 189

Box 7.1. What is microfinance?

Box 7.2. A profile of the "average" European MFI 211

Box 7.3. Microfinance in non-EU OECD countries 212

Box 7.4. European Code of Good Conduct for Microcredit Provision 213

Box 7.5. Examples of approaches to microcredit legislation in the EU 214

Box 7.6. Micro-finance under InvestEU 2021-27 216

Box 7.7. Examples of MFIs adapting their activities during the COVID-19 pandemic 218

Box 7.8. Setting up a microfinance scheme 221

Box 7.9. COVID-19 support measures under the EaSI Guarantee Instrument 223

Box 7.10. Example of MFI non-financial services, Microfinance and Development Onlus Association, Italy 224

Box 7.11. Microinsurance, Compartamos Banco, Mexico 225

Box 7.12. Adie's e-Signature for better delivery of microfinance services, France 227

Box 7.13. Green and Sustainable Development Microcredits, Belgium 229

Box 8.1. Ethnic minority entrepreneurship 239

Box 8.2. Forms of immigrant entrepreneurship 242

Box 8.3. Support measures for immigrant entrepreneurs, Sweden 248

Box 8.4. Migrant Entrepreneurs Team-Up with Mentors (MEnt), EU 249

Box 8.5. Information Packages to Attract Immigrant Entrepreneurs to Prince Edward Island, Canada 251

Box 8.6. E-entrepreneurs, Estonia 252

Box 8.7. Poland Prize 253

Box 8.8. iStart, Norway 254

Box 8.9. Back for Business, Ireland $\quad 255$

\section{Follow OECD Publications on:}

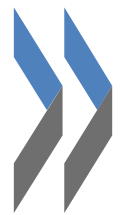

http://twitter.com/OECD_Pubs

3 http://www.facebook.com/OECDPublications

in. http://www.linkedin.com/groups/OECD-Publications-4645871

- http://www.youtube.com/oecdilibrary

AECD http://www.oecd.org/oecddirect/

This book has...

StatLinks : तोISL

A service that delivers Excel $^{\circledR}$ files from the printed page!

Look for the StatLinks तiाs at the bottom of the tables or graphs in this book. To download the matching Exce ${ }^{\circledR}$ spreadsheet, just type the link into your Internet browser, starting with the $h t t p s: / / d o i . o r g$ prefix, or click on the link from the e-book edition. 


\section{Reader's guide}

\section{What will I learn from this report?}

The Missing Entrepreneurs 2021 report provides an overview of the scope of inclusive entrepreneurship policy, which seeks to give everyone an equal opportunity of creating a successful and sustainable business, regardless of their gender, age, place of birth, work status or other personal characteristics. The 2021 edition is the sixth edition in the series of Missing Entrepreneurs reports and presents updated indicators on entrepreneurship activities, which are benchmarked across countries and population groups; addresses existing challenges; and, provides concrete policy examples and lessons learned - notably recent developments in inclusive entrepreneurship and the important role inclusive entrepreneurship policy has in the COVID-19 recovery. Two thematic policy chapters discuss current policy issues and present the range of policy actions currently used in EU and OECD countries.

- Interested in policies addressing the COVID-19 crisis? Chapter 1 provides discussion on the impact of COVID-19 on entrepreneurs - notably women, youth, seniors and immigrants - and the greater role inclusive entrepreneurship policy can play in the post COVID-19 economy. Chapter 7 discusses how microfinance markets were impacted by the COVID-19 crisis. This covers both microfinance institutions, as well as clients who are overwhelmingly people from under-represented and disadvantaged groups. The chapter outlines how governments can address the liquidity crisis in microfinance markets and support microfinance institutions in filling market gaps. In addition, the country profiles in Part III present a brief overview of policy responses to support the self-employed through the crisis and into recovery. Measures that are tailored for entrepreneurs from underrepresented and disadvantaged groups are highlighted.

- Looking for data on entrepreneurship and self-employment characteristics used to monitor and evaluate different types of policies and programmes? Part I contains cross-country data on entrepreneurship and self-employment indicators, including activity rates, characteristics and barriers to business creation. These data are presented across five chapters that each focus on a specific population group: women (Chapter 2), immigrants (Chapter 3 ), youth (Chapter 4), seniors (Chapter 5) and the unemployed (Chapter 6).

- Searching for adapted policy measures and tailored programmes aimed at supporting immigrant entrepreneurs and their high growth potential? Chapter 3 provides key indicators and data on entrepreneurship and self-employment among immigrants. Chapter 8 provides concrete policy examples.

- Interested in how microfinance can be leveraged as an important tool for inclusive entrepreneurship? Chapter 7 explores the development of microfinance markets and how products and services offered by microfinance institutions can be tailored to better meet the needs of entrepreneurs from under-represented and disadvantaged groups.

- Looking for examples of recent policy actions and trends in each of the 27 EU Member States? Chapter 9 provides country profiles which highlight recent trends and overall conditions for inclusive entrepreneurship. 


\section{How can I read this report?}

While this report can be read linearly, it is designed as an interactive resource, allowing readers to identify easily the sections of interest and access relevant examples. This publication consists of three main parts:

- Part 1 includes five chapters which present entrepreneurship and self-employment data on one of the key target groups of inclusive entrepreneurship policy: women (Chapter 2), immigrants (Chapter 3), youth (Chapter 4), seniors (Chapter 5) and the unemployed (Chapter 6). To the extent possible, these chapters present harmonised data for EU and OECD countries.

- Part II contains two thematic chapters which focus on the potential for public policy to facilitate microfinance as a tool for inclusive entrepreneurship (Chapter 7 ) and the potential for public policy to better capitalise on the potential of high-skilled immigrants as well as to encourage more and better business creation (Chapter 8 ).

- Part III presents country profiles for each EU Member State. Each country profile presents recent trends for key inclusive entrepreneurship indicators, overall entrepreneurship conditions and policy developments related to inclusive entrepreneurship, notably actions to mitigate the impact the COVID-19 pandemic.

\section{What are the main data sources?}

This report draws on several data sources, the concepts and definitions used in the different sources are not always consistent. Efforts have been made to harmonise the data reported to the greatest extent possible but differences remain. The figures and text highlight the definitions presented and discussed.

\section{The Global Entrepreneurship Monitor}

The Global Entrepreneurship Monitor (GEM) is an international initiative that measures entrepreneurship activities and attitudes around the world through annual surveys of the adult population (ages 18 and older) in participating countries. Unlike business enterprise surveys, GEM surveys people so it can identify those involved in different phases of entrepreneurship, providing individual-level data on entrepreneurial motivations and aspirations among other characteristics.

The GEM survey covered 46 countries in 2020 , the most recent year for which data are available. To improve the reliability of the results for each social target group (i.e. men, women, youth and seniors), data presented in this report were pooled (i.e. combined) for each country in the period 2016-20. Survey responses are weighted by age and gender to make the results representative of the national populations. The averages for the EU and OECD were computed using weighted country averages for the period. The COVID-19 pandemic impacted survey results for 2020 in many but not all countries (Bosma et al., 2021 [1]). Early-stage activities declined in 15 out of 35 countries that participated in the survey in 2019 and 2020, including a decline of more than $25 \%$ in 9 countries. Conversely, early-stage entrepreneurship activities increased in 8 countries, including by more than $25 \%$ in 4 countries. Early-stage activity rates showed little difference between 2019 and 2020 in the remaining 12 countries. Moreover, results related to motivations for entrepreneurship were impacted. The proportion of people reporting that they started a business due to a lack of other options for work increased in about half of countries and declined in the other half.

Between 2016 and 2020, 21 of the 27 EU Member States participated in the survey in at least one year and 18 participated in all years. The Member States that did not participate in the GEM survey during this period were Belgium, Czech Republic, Denmark, Lithuania, Malta and Romania. The total sample size for EU Member States for this period was 107286. 
31 of the 38 OECD countries participated at least once and 23 participated in all years in the period 201620. Those countries that did not participate were Belgium, Costa Rica, Czech Republic, Denmark, Iceland, Lithuania and New Zealand. The total sample size for OECD countries for this period was 459992.

Several GEM indicators are presented in this report:

- The Nascent Entrepreneurship Rate is the proportion of the population that is actively involved in setting up a business they will own or co-own; this business has not paid salaries, wages or any other payments to the owners for more than three months.

- The New Business Ownership Rate is the proportion of the population that is currently an ownermanager of a new business that has paid salaries, wages or any other payments to the owners for more than three months, but not more than 42 months.

- The most well-known measure that the GEM publishes is the Total Early-stage Entrepreneurial Activity (TEA) Rate, which is the sum of the proportion of the population involved in nascent entrepreneurship activities and those who have started new business within the last 42 months. This is a measure of the stage in advance of the start of a new firm (nascent entrepreneurship) and the stage directly after the start of a new firm (owning-managing a new firm)

- The Established Business Ownership Rate measures the proportion of the population that is currently an owner-manager of an established business that has paid salaries, wages or any other payments to the owners for more than 42 months. This measure provides information on the stock of businesses in an economy.

For more information on methodologies used by the Global Entrepreneurship Monitor, please see (Global Entrepreneurship Monitor, 2021 [2]).

\section{Eurostat Labour Force Survey}

The Eurostat Labour Force Survey (LFS) is a monthly household survey in all EU Member States that captures information on labour market activities (Eurostat, 2021[3]). It is the largest European household sample survey, providing quarterly and annual results on persons aged 15 and over, on persons inside and outside the labour market. Eurostat currently publishes results for 34 participating countries, including 26 of the 38 OECD countries. These countries include the EU Member States, three EFTA countries (Iceland, Norway and Switzerland) and four EU candidate countries (Montenegro, North Macedonia, Serbia and Turkey).

The sample size is about 1.7 million persons per quarter. Data collection is through individual interviews and proxy interviews (i.e. an interview with another person in the household) are allowed in most countries. The published data include only private households. To ensure that the statistical results are comparable across countries and over time, LFS uses the same concepts and definitions, follows International Labour Organisation (ILO) guidelines, uses common classifications (e.g. NACE, ISCO, ISCED, NUTS) and records the same set of characteristics in each country.

This report draws on the self-employment data presented in the Eurostat LFS. Eurostat has defined selfemployed individuals as those who work in their own business, farm or professional practice and receive some form of economic return for their labour, including wages, profits, in-kind benefits or family gain. Volunteers are excluded from this definition. An individual's self-employment status does not change depending on the purpose of the business (i.e. the business could have profit motives or be a non-profit or social enterprise).

Eurostat also distinguishes between own-account self-employed and self-employed employers:

- Own-account self-employed are those self-employed people that do not have other employees working for them.

- Employers are self-employed people that have employees. 
In addition to the core survey, Eurostat began using "ad hoc modules" in 1999 to collect complementary information on selected themes, which cover clearly defined labour market topics. These topics are selected in co-operation between the National Statistics Institutes, various policy Directorate Generals of the European Commission and Eurostat, on the basis of policy and analysis needs.

For more information on the Eurostat Labour Force Survey, please refer to: http://ec.europa.eu/eurostat/web/labour-market/methodology.

\section{What is the difference between self-employment data and entrepreneurship data?}

It is important to distinguish between self-employment data and entrepreneurship data presented in this report. The OECD-Eurostat Entrepreneurship Indicators Programme, which launched in 2006, developed definitions for entrepreneur, entrepreneurship and entrepreneurship activity while still acknowledging the contention and different perspective between researchers who confront this issue (Ahmad and Seymour, 2008[4] $)$. The OECD and Eurostat based their definitions on their relevance and measurability while emphasising entrepreneurial action over intention. These definitions differentiate entrepreneurial activity from "ordinary" business activity:

- An entrepreneur is an individual (business owner) who seeks to generate value, through the creation or expansion of economic activity, by identifying and exploiting new products, processes or markets.

- An entrepreneurial activity is the enterprising human action in pursuit of the generation of value, through the creation or expansion of economic activity, by identifying and exploiting new products, processes or markets.

- Entrepreneurship is the phenomenon associated with entrepreneurial activity.

The self-employment data presented in this report come from the Eurostat Labour Force Survey (LFS) and the Global Entrepreneurship Monitor (GEM). Eurostat defines the self-employment rate as the number of self-employed people, both own-account self-employed and self-employed employers, relative to the number of employed people. Those data cover owner-managers of businesses who pay themselves profits from work that they undertake on their own account in the business and who declare themselves as self-employed. Self-employment data pick up people who generally employ only themselves or very few additional people in non-incorporated business. Individuals running larger incorporated businesses tend not to report themselves as self-employed because they appear on the payrolls of their businesses and are, therefore, considered employees. The data also exclude individuals who are in the process of starting a business but have yet to fully realise its creation as well as business owners who are not active in the day-to-day operations of the business. Other broader definitions also exist, including the other data in this report. GEM reports self-employed people as those actively trying to start or are already operating their own business or any type of self-employment or selling goods or services to others. In this case, self-employed people are included together with all other types of business owners.

Due to the differences in definitions between LFS data and GEM data, discrepancies in the selfemployed count are present. For example, GEM data include owner-managers of incorporated businesses, whereas they are excluded from the LFS self-employment data. Furthermore, individuals who may be running businesses as a secondary activity are considered self-employed in GEM data, while the LFS data report on the principal labour market activity only. Therefore, LFS will only capture those who spend more time in self-employment than employment, whereas the GEM data also include part-time entrepreneurs. 


\section{OECD country-level inclusive entrepreneurship policy assessments}

The OECD Centre for Entrepreneurship, SMEs, Regions and Cities undertakes a biennial assessment of inclusive entrepreneurship policies and programmes in each of the $27 \mathrm{EU}$ Member States with support from the Directorate-General for Employment, Social Affairs and Inclusion of the European Commission. These assessments were done in collaboration with a network of inclusive entrepreneurship experts across the EU. Information was collected through desk research and interviews (i.e. telephone, face-to-face, email) with policy officers, entrepreneurship support organisations and other stakeholders. The descriptions and assessments were then verified by government ministries, programme managers and other inclusive entrepreneurship stakeholders through exchanges and online seminars.

Each assessment uses a common framework that considers 1) the policy frameworks for inclusive entrepreneurship; and 2) the schemes in place to promote and support business creation by women, immigrants, youth, seniors and the unemployed. The assessments focus on national-level policies and schemes but where relevant, sub-national initiatives and actions by the non-government sector are considered.

\section{Policy frameworks}

The characterisation of the policy frameworks describes the approach taken to support entrepreneurship by women, immigrants, youth, seniors and the unemployed in each Member State. It identifies whether policies are implemented by national, regional and/or local governments for each group and whether there is an entrepreneurship strategy for each group with clear objectives and targets. In addition, it considers whether there is regular monitoring and evaluation activities to track interventions, measure their effectiveness and feed learnings back into policy design. The figures in Chapters 2-6 present the proportion of Member States reporting "yes" to each assessment criterion.

\section{Entrepreneurship schemes}

The assessments also examine the extent to which entrepreneurship schemes (e.g. entrepreneurship training, coaching and mentoring, microfinance) effectively support business creation by women, immigrants, youth, seniors and the unemployed. Both dedicated approaches and general support schemes are considered. While dedicated approaches can have greater impacts since they are typically designed to address the barriers faced by the target clients, general schemes can also be effective for supporting entrepreneurs from disadvantaged and under-represented groups. The assessments consider the following nine issues:

1. Tailored: Are public programmes tailored for the target group?

2. Consultation: Are the targeted entrepreneurs consulted during the design of programmes?

3. Outreach: Are appropriate outreach methods used for different target groups?

4. Delivery: Are specialist organisations used to deliver programmes?

5. Take-up: Does the support have high take-up among target group?

6. Scale: Is the scale of available support sufficient?

7. Impact: Does evaluation evidence show a positive impact?

8. Integrated: Is the programme linked to other types of support (e.g. training and finance)?

9. Links: Are tailored entrepreneurship link to general support programmes?

There is a great deal of diversity of entrepreneurship schemes in most countries, particularly those where both national and sub-national governments are actively involved. The assessments consider the "typical" scheme that an entrepreneur can use in the country. A focus was placed on public schemes and those funded by government even if they were delivered by non-government actors. 
The figures in Chapters 2-6 present an unweighted average of the assessment scores across the 27 EU Member States. The figures present the scores out of 9 for each type of intervention in four areas of policy intervention:

- Entrepreneurship skills

$\circ \quad$ Entrepreneurship training

- Entrepreneurship coaching and mentoring

- Business consultancy, including incubators/accelerators

- Access to finance

- Grants for business creation

- Loan guarantees

- Microfinance and loans

○ Other instruments (e.g. crowdfunding, risk capital)

- Entrepreneurship culture and social capital

- Entrepreneurship campaigns, including role model initiatives

- Networking initiatives

- Regulatory measures and instruments

- Support with understanding and complying with administrative procedures

- Measures to address group-specific regulatory challenges (e.g. Student business legal form for young entrepreneurs)

For more information and to access the collection of notes, please visit: https://www.oecd.org/cfe/smes/Inclusive-Entrepreneurship-Policies-Country-Assessment-Notes.htm.

\section{References}

Ahmad, N. and R. Seymour (2008), Defining Entrepreneurial Activity: Definitions Supporting

Frameworks for Data Collection, OECD Publishing, https://dx.doi.org/10.1787/243164686763.

Bosma, N. et al. (2021), Global Entrepreneurship Monitor 2020/2021 Global Report, Global Entrepreneurship Research Association, https://www.gemconsortium.org/file/open?fileld=50691 (accessed on 31 May 2021).

Eurostat (2021), Labour Force Survey, https://ec.europa.eu/eurostat/web/lfs/data/database.

Global Entrepreneurship Monitor (2021), 2020/2021 Global Report, Global Entrepreneurship Research Association.

OECD (2020), Inclusive Entrepreneurship Policies: Country Assessment Notes, https://www.oecd.org/cfe/smes/inclusive-entrepreneurship-policies-country-assessmentnotes.htm (accessed on 6 June 2021). 


\section{Executive summary}

\section{With millions of missing entrepreneurs, countries are missing out on potential innovation, growth and jobs}

Not everyone has an equal opportunity to transform their ideas into a business. There could be an additional 9 million people starting and managing new business in the European Union (EU) - and 35 million across OECD countries - if everyone was as active in business creation as core age men (30-49 years old). This would be $50 \%$ more people engaged in early-stage entrepreneurship in the EU and $40 \%$ more in OECD countries. About three-quarters of these "missing" entrepreneurs are women, half are over 50 years old and one-in-eight are under 30 years old.

These missed opportunities are due to several factors, including greater difficulties accessing finance, skills gaps, under-developed networks and institutional barriers (e.g. lack of childcare, discouraging social attitudes). These obstacles are often inter-related and are greater, on average, for women, immigrants, youth, seniors and the unemployed. For example, women in both EU and OECD countries are $75 \%$ as likely as men to report having the skills to start a business. These obstacles to business start-up also affect ambitions in entrepreneurship - women for example are $60 \%-70 \%$ as likely as men to expect that their business would create 20 jobs or more over the next five years - as well as business survival rates and performance.

The COVID-19 pandemic increased many of the gaps in entrepreneurship. Entrepreneurs from underrepresented and disadvantaged groups were more likely to work reduced hours or close their business. For example, results from the OECD/Facebook/World Bank survey suggested that women were more likely to close their business in 2020 than men. In August 2020, women in Europe were 20\% more likely than men to report that they had closed their business. These disproportionate impacts were often due to a higher concentration of businesses in the hardest hit sectors such as hospitality and personal services, less access to resources and more difficulty accessing government support measures due to eligibility criteria.

Inclusive entrepreneurship policy aims to open up opportunities in entrepreneurship to everyone with an idea for a sustainable business, regardless of their background and characteristics. Harnessing this untapped potential can uncover new ideas, create jobs and contribute to economic growth, which are central to plans for economic recovery. While many governments deliver tailored support for these groups, current offers do not always adequately address biases in entrepreneurship ecosystems and institutional conditions, nor the needs of diverse groups of entrepreneurs. Three priorities for governments are:

1. Finance: Increase funding to start-ups, particularly microfinance designed for people who face barriers in mainstream financial markets, including women, youth and immigrants. It is estimated that unmet demand for microfinance in the EU is currently EUR 14 billion per year. Governments need to inject more capital into this market since the majority of lenders target clients from underrepresented and disadvantaged groups. 
2. Skills: Entrepreneurs need better skills programmes to support their aspirations and increase the chances that they develop sustainable businesses, including on financial literacy, digital skills and business acumen. Skills gaps in these areas are typically greater among entrepreneurs from under-represented and disadvantaged groups. A greater use of coaching can address these gaps by improving the relevance of support to individual needs, particularly those who face barriers to training programmes.

3. Tailored support: Evaluations typically find that tailored support schemes have higher take-up rates, high satisfaction levels and more positive outcomes than general support schemes. Entrepreneurs from under-represented and disadvantaged groups need more tailored support to address systemic biases and greater obstacles to business creation, including training, coaching and networking. This needs to reflect the different needs of different groups and local conditions in a coherent way. Governments can achieve this by engaging more diverse groups in the policy design to help ensure that is it sensitive to varied needs.

\section{Closing gender and generation gaps is critical to unleashing a new era of entrepreneurship}

\section{Youth create fewer businesses in the EU than those over 50 years old}

Nearly one-quarter of the 18 million people involved in starting or managing a new business in the EU in 2020 were over 50 years old - a greater share than those who were between 18 and 30 years old. While this is similar to the situation in non-EU OECD countries, after adjusting for differences in age profiles, the generation gap raises questions for the EU about how the current population of businesses will be regenerated when older entrepreneurs move into retirement. This exit will be particularly strong for the selfemployed since $45 \%$ are over 50 years old compared to the one-third of all employees that are over 50.

More needs to be done to support youth in realising their entrepreneurial potential. Surveys suggest that nearly $45 \%$ of university students intend to start a business within five years of graduation, yet only $5 \%$ of youth aged 18 to 30 are actively working on a start-up. Governments have renewed their commitment to support youth following the pandemic so now is the time to strengthen youth entrepreneurship support. Priority actions need to address the finance gap faced by young entrepreneurs and improve the appeal of support initiatives by better capturing youth perspectives in the design of initiatives.

\section{Women are less active than men in business creation}

Women are less likely than men to be involved in starting and managing new businesses. Over the period 2016-20, less than $5 \%$ of women in the EU were involved in creating a business or managing one less than 42 months old relative to $8 \%$ of men. A similar gap appears in OECD countries where $9 \%$ of women were starting and managing new businesses relative to $13 \%$ of men. These gender gaps are caused by several factors, including barriers in financial markets, skills gaps and institutional conditions that affect motivations. This gender gap represents a missed opportunity for economic growth.

Governments can do more to cultivate entrepreneurial aspirations among women, address market failures in the areas of skills and finance, and support for growth-oriented female entrepreneurs. In addition to addressing institutional conditions that influence entrepreneurship decisions (e.g. access to childcare, taxation), governments need to increase funding for dedicated initiatives and increase gender sensitivity in general entrepreneurship programmes by setting gender objectives and tracking progress. 


\section{Immigrants account for a growing share of entrepreneurs}

The share of immigrants among the self-employed in the EU nearly doubled over the past decade, increasing from $6 \%$ in 2011 to $11 \%$ in 2020 . This growth is due to many factors, including an increase in immigration flows. However, entrepreneurship policy has not sufficiently recognised this trend and the scale of public support has changed little. This policy gap is being filled by grassroots organisations. More support and financing is needed to improve the quality of businesses started by immigrants to increase the chances of becoming sustainable and encourage them away from sectors with an over-supply. Governments also need to pay greater attention to attracting high potential entrepreneurs by improving outreach and simplifying administrative requirements for those utilising start-up visas. 



\section{Recent trends and policy priorities in inclusive entrepreneurship}

Micro-businesses and the self-employed faced many challenges during from the COVID-19 pandemic, including reduced demand for their goods and services and a need to adjust business operations in response to temporary operating restrictions and social distancing measures. As a result, the majority faced a significant reduction in hours worked and income. However, evidence suggests that women, immigrant, youth and senior entrepreneurs faced even greater challenges because of their concentration in sectors that were the most heavily impacted and having less access to resources. Moreover, they often had greater difficulties utilising government emergency measures. This chapter presents evidence on the impact of the COVID-19 pandemic on the self-employed, including differences across population groups. It also discusses the role of inclusive entrepreneurship policies in addressing the economic crisis and how inclusive entrepreneurship policies should be strengthened in the future. 


\section{Key messages}

- COVID-19 had a strong negative impact on self-employment in terms of business closures, hours worked, income, mental health and well-being. For example, international surveys show that the self-employed were about 1.6 times more likely than employees to become unemployed in 2020. Those from groups that are under-represented in entrepreneurship (e.g. women, immigrants, youth, seniors) had worse outcomes since they tend to operate in sectors and locations that have been hit hardest by COVID-19 and have had the most difficulty accessing resources to manage the crisis. For example, about $27 \%$ of womenoperated businesses around the world closed between January and May 2020 relative to $20 \%$ of men-led businesses.

- Governments supported the self-employed during the COVID-19 pandemic with a range of measures including tax and rent deferrals, grants and wage subsidies. Whilst the initial government measures were rolled out with great speed, it became clear throughout 2020 and 2021 that the supports did not reach many of the self-employed. Some could not qualify for support due to the eligibility criteria (e.g. revenue thresholds), and evidence suggests that takeup of support was low among some groups, including women and immigrants.

- Inclusive entrepreneurship policy can play a greater role in a post COVID-19 economy to address the growth in inequalities. These policies aim to ensure that anyone can have an opportunity to start a sustainable business by removing market barriers, addressing information asymmetries and providing tailored support. Recent developments in the European Union include a greater visibility for inclusion issues in entrepreneurship strategies, more sophisticated instruments being used to support women entrepreneurs (e.g. growth-oriented programmes, risk capital), growing experimentation with new financial instruments and fintech (e.g. crowdfunding) and a greater focus on individualised supports such as coaching and mentoring. However, some gaps and areas for improvement remain, including an uneven quality of support, an insufficient focus on business development and growth, too few support offers for immigrants, seniors and people with disabilities, and a continued reliance on financial supports.

- Government COVID-19 recovery plans place a greater spotlight on inclusion and diversity so there is an opportunity to make greater use of inclusive entrepreneurship policies. In designing inclusive entrepreneurship policies for the future, governments can:

- Make entrepreneurship policy more gender-sensitive by increasing the use of tailored measures and making the policy making process more gender inclusive;

- Open up pathways to work for young people through youth entrepreneurship programmes to help avoid long-term scarring effects following the pandemic;

- Improve the tailoring of policy measures that support the broad range of immigrant entrepreneurs to better tap into their overall potential to create jobs in the recovery;

- Increase the use of repayable financial instruments such as microfinance to support inclusive entrepreneurship and use these instruments to meet other policy objectives by, for example, increasing funds for green and sustainable projects;

- Adapt, design and deliver measures at the local level to ensure that they appropriately reflect the context (e.g. sector, market size) and diverse needs of targeted entrepreneurs;

- Go further in embracing digitalisation - both by ensuring that inclusive entrepreneurship schemes sufficiently prepare entrepreneurs for opportunities offered by the digital economy and by leveraging digital delivery mechanisms to increase the reach of schemes. This also requires greater attention to digital skills development among the target groups. 


\section{COVID-19 had a strong negative impact on the self-employed}

As the severity of the impact of the COVID-19 pandemic on the health of the world population became increasingly apparent throughout 2020 , governments responded with measures to contain the spread of the COVID-19 virus. This has been in the form of "lockdown" measures that seek to reduce face-to-face interactions between people and the strengthening of their public healthcare systems (OECD, 2021 [1]; United Nations, 2021 [2] $)$. Although necessary to combat the COVID-19 pandemic, government containment measures and reductions in consumer demand have come at an economic price. Global GDP fell by about $3.4 \%$ in 2020 , but is expected to rebound more quickly than initially anticipated with growth of $5.6 \%$ in 2021 and $4.0 \%$ in 2022 (OECD, 2021 $1_{[3]}$ ). Governments have also introduced a range of support measures aimed at mitigating the effects of containment measures as businesses face substantial uncertainties and peoples' livelihoods are threatened (OECD, 2020[4]; OECD, 2021[5]).

There is a growing recognition that the COVID-19 pandemic and public policy containment measures have increased inequalities in society and the economy as they exacerbated existing structural inequalities. This asymmetry is multidimensional, interacting with and producing different socio-economic-geographic outcomes. For example, there have been differences in the ability of cities to respond to COVID-19. Those that are more affluent, densely and highly populated, better educated and have faster broadband provisions, present more opportunities for teleworking to mitigate some of the negative effects (OECD, 2020[6]; Crowley and Doran, 2020[7]). This, however, does not make all large cities immune from turbulence in local labour markets. While rural areas and small towns tended to experience larger impacts due to the COVID-19 crisis, urban areas with a large share of place-dependent employment in sectors like hospitality and commerce, retail and wholesale were also greatly impacted (Eurofound, 2020[8]). A growing body of research suggests that it has been the most vulnerable members of the population (e.g. women, youth, minorities and the less educated) that have been most affected, notably through reductions in working hours and elevated levels of health risk, exacerbating existing inequalities in society (Blundell et al., 2020[9]).

\section{Business creation and early-stage entrepreneurship decreased in most countries...}

The COVID-19 pandemic has had a negative impact on new business creations overall. The number of new start-ups dropped significantly during the first lockdowns in early 2020, but entry rates have recovered across some countries. Countries such as Australia, Canada, Norway, the United Kingdom (UK) and the United States experienced a V-type recovery and others such as Italy, Portugal and Spain experienced a U-type recovery with slower growth in business registrations in the second half of 2020 (OECD, 2021 $\left.1_{[10]}\right)$. Some countries appear to be in between these two groups (e.g. Belgium, France, Germany, Hungary), while data for the Netherlands show a continued drop-off in business entry in the third quarter of 2020.

\section{...but "necessity" entrepreneurship increased in only half of the countries surveyed}

Data from the Global Entrepreneurship Monitor (GEM) also paint a mixed picture of the COVID-19 pandemic's impact on new entrepreneurs that were motivated "to build great wealth or very high income" and "to earn a living because jobs are scarce." The share of new entrepreneurs who were motivated by wealth creation declined in about half of the countries, notably in Spain (from $60 \%$ in 2019 to $35 \%$ in 2020) (Bosma et al., 2021[11]). However, it increased in the other half of countries, including the Netherlands (22\% to $41 \%$ ). Similarly, the share of new entrepreneurs who started a business because they could not secure a job increased in about half of the countries, including substantial increases in Poland (16\% to $62 \%)$ and Spain (42\% to $72 \%)$. That the share declined in about half of the countries challenges the hypothesis that the COVID-19 pandemic has forced many people into entrepreneurship due to lack of employment alternatives. 


\section{The self-employed were more likely than employees to face job insecurity...}

Early evidence on the impact of COVID-19 on the self-employed suggests that they have faced a greater reduction in hours worked and are more likely to be at risk of losing their job than employees. In an European Union (EU)-wide survey in April and July 2020, the self-employed were twice as likely as employees to report a reduction in hours worked $-51 \%$ for the self-employed with employees and $53 \%$ for those without employees relative to $27 \%$ of employees (Eurofound, $2020_{[8]}$ ). Moreover, the self-employed without employees were the most likely to become unemployed $(13 \%)$ relative to employees $(8 \%)$ and the self-employed with employees (2\%) (Eurofound, 2020 $\left.{ }_{[8]}\right)$. Similar results were found in country level surveys. For example, evidence from Germany indicates that $60 \%$ of the self-employed faced sales and income losses between March and May 2020, a period dominated by the nationwide shutdown, while less than $20 \%$ of employed individuals experienced earnings losses (Kritikos, Graeber and Seebauer, 2020[12]). In Norway, twice the share of self-employed workers than employees experienced reduced work time and $40 \%$ of the self-employed faced income loss relative to $11 \%$ of employees and $19 \%$ of temporary employees (Ingelsrud, $2021_{[13]}$ ).

These survey findings are reflected in employment and self-employment trends at the EU-level and for most EU Member States. At the EU-level, the number of self-employed people has declined by more than $6 \%$ between 2019Q4 and 2021Q1, which is about double the decline in the number of employees (Figure 1.1). Furthermore, the number of self-employed people with employees - which account for $30 \%$ of the self-employed - declined by about $5 \%$. However, not all of these self-employed workers necessarily stopped operating because some would have shed employees to become solo self-employed. Survey results from the first half of 2020 show that only $2 \%$ of self-employed with employees reported losing their job, but $6 \%$ reported that they "let employees go" to become solo self-employed (Eurofound, $2020_{[8]}$ ). Despite the overall decline in self-employment at the EU-level, there were eight Member States where selfemployment increased between 2019Q4 and 2021Q1. This growth in self-employment was typically driven by an increase in solo self-employment.

The impact of COVID-19 on the self-employed in non-EU OECD countries also varied considerably. For example, the self-employed were not impacted strongly in Australia. The share of workers who are self-employed dropped marginally from $7.9 \%$ to $7.5 \%$ between February and April 2020 which was accompanied by a strong decline in hours worked per week for both self-employed (-9.3 hours) and employees (-3.1 hours) (Biddle et al., 2020[14]). However, the self-employed were strongly impacted in Canada, the UK and the United States. Between February and July 2020, the number of those operating incorporated businesses in Canada fell by $22.2 \%$, while the overall number of those operating unincorporated businesses declined 12.5\% (Beland, Fakorede and Mikola, 2020[15]; Beland, Fakorede and Mikola, $\left.2020_{[16]}\right)$. Similarly, self-employment decreased in the UK by approximately $10 \%$ between January and September 2020 (ONS, 2021 [17]) and the number of active business owners (including the selfemployed and business owners $)^{1}$ in the US decreased by $8 \%$ between February and December 2020 (Fairlie, 2021 ${ }_{[18]}$ ). These country differences are most likely to be a result of the different experiences of the pandemic and public policy containment measures. However, evidence suggests vulnerable population groups, namely young, female and non-white self-employed individuals in the US, experienced greater risk (Grashuis, 2021 $[19])$. 
Figure 1.1. The number of employees has rebounded more quickly than the self-employed

Quarterly trends in the number of self-employed workers and employees relative to 2019Q4 employment and selfemployment

a. EU27, $2019 Q 4=100$

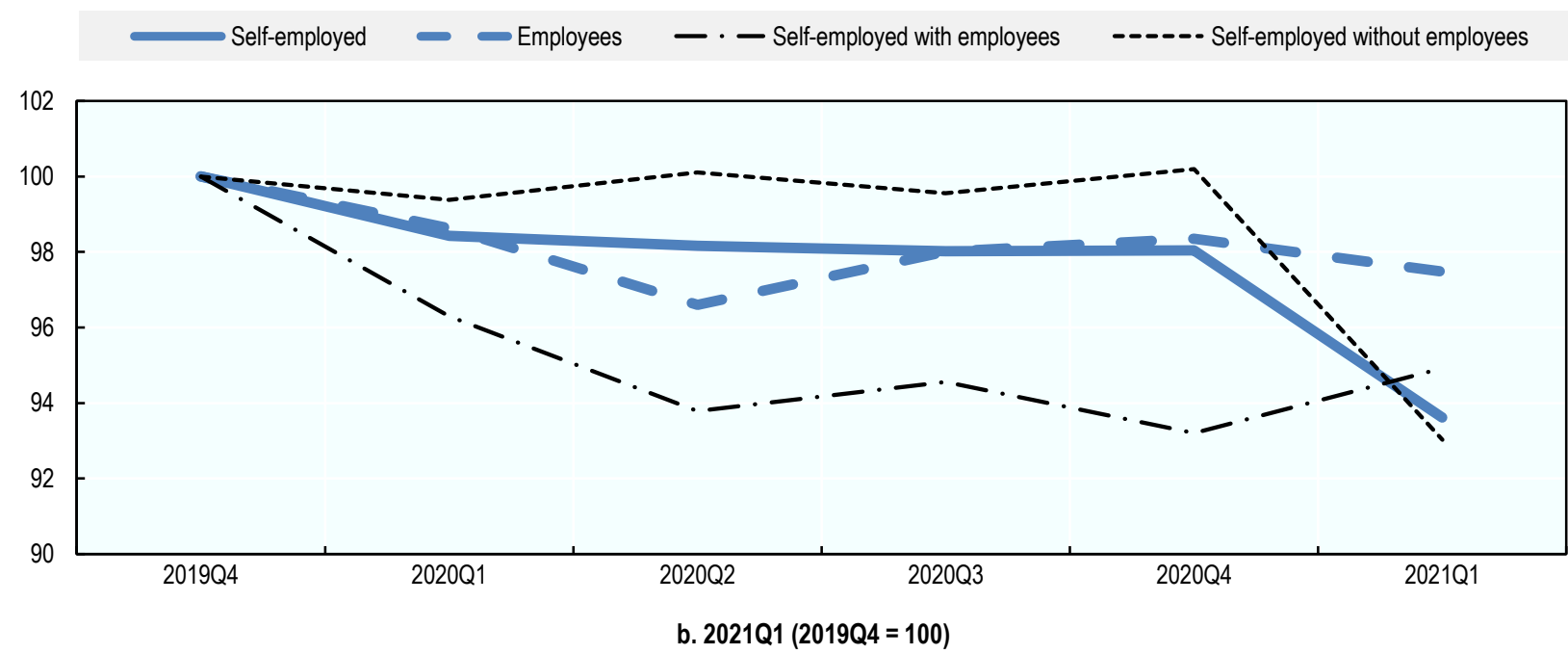

- Self-employed $\quad \diamond$ Employees

- Self-employed with employees

OSelf-employed without employees

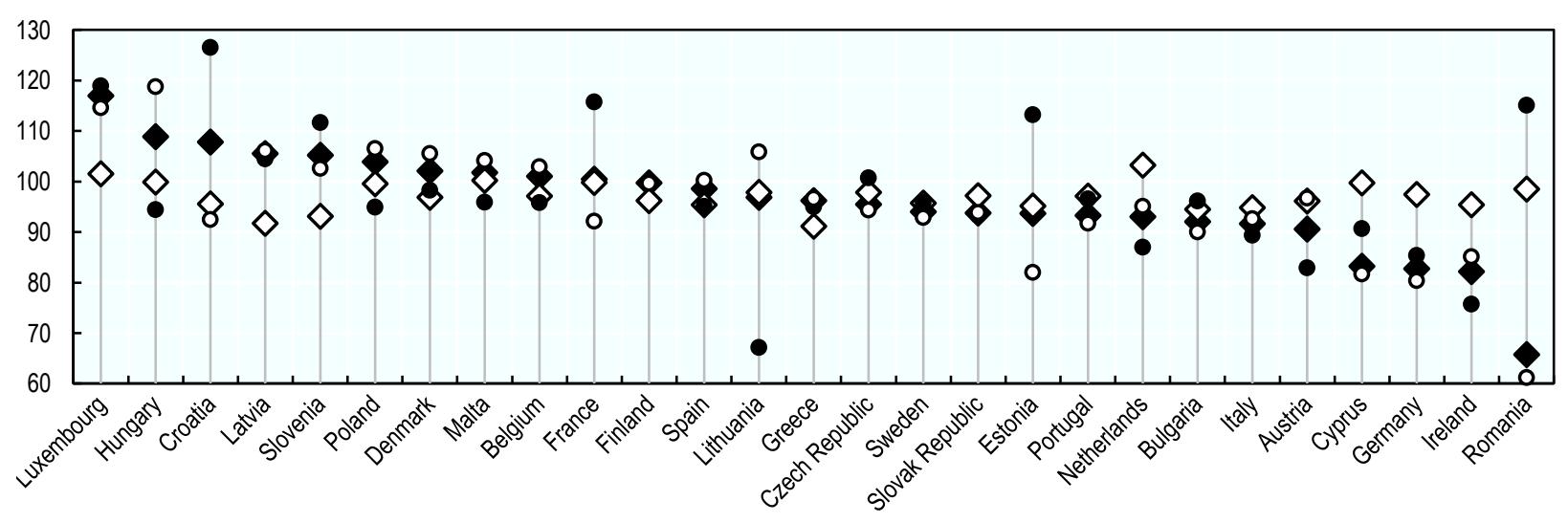

Source: (Eurostat, 2021[20])

StatLink sins https://doi.org/10.1787/888934279396

\section{...which has led to greater financial insecurity...}

The self-employed were $\mathbf{3 0} \%$ more likely than employees to report that they would not be able to maintain their current standard of living for three months without additional (new) income sources. An international survey by Eurofound in February-March 2021 found that about half of people in the EU could not sustain their current income and savings or could not maintain their current living standard for more than three months (Ahrendt et al., 2021[21]). This level of financial fragility has remained fairly constant since the start of the COVID-19 pandemic. However, financial fragility varies according to labour market activities and individual characteristics. In Spring 2021, about $46 \%$ of the self-employed indicated that their household could maintain their standard of living for up to three months (Figure 1.2). This was down from $58 \%$ in Spring 2020 but above the overall average for all respondents $(50 \%)$. 
Figure 1.2. The self-employed are more likely than employees to report financial difficulties

"If your household would not receive any income, how long would your household be able to maintain the same standard of living?" The figure shows the sum of "no savings" and "less than 3 months", EU27

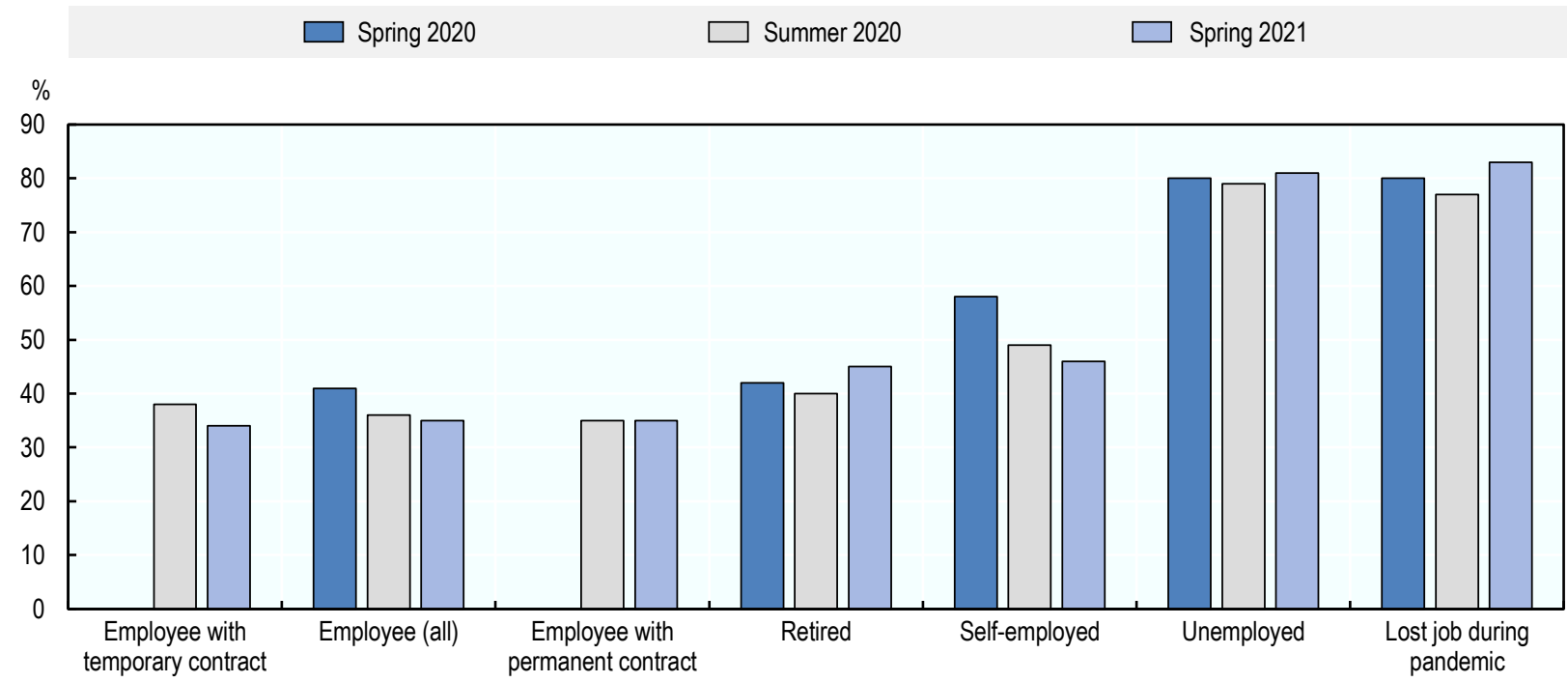

Source: (Ahrendt et al., 2021[21])

StatLink 제개 https://doi.org/10.1787/888934279415

Similar evidence about the financial fragility of the self-employed is emerging in non-EU OECD countries. The self-employed in Australia faced greater reductions in income than employees, experiencing an AUD 66.70 (EUR 42) larger drop in weekly income than employees (Biddle et al., 2020[14]). Between February and April 2020, more than four out of five self-employed workers reported a negative effect of the impact of COVID-19 on their profitability and only one-third indicated that their business would be viable over the next two months. Similarly, $24 \%$ of self-employed in the UK reported that they would be able to save for the year ahead at the beginning of the pandemic compared to 30\% in December 2020, relative to $45 \%$ to $49 \%$ of employees over the same period (ONS, 2021 [22]).

The negative short-term effects of the COVID-19 pandemic on the self-employed is also affecting their outlook for future business prospects. The 2020 GEM survey was conducted between April and June 2020 and shows that up to $60 \%$ of early-stage entrepreneurs indicated that they expected "somewhat" or "much lower" growth in the next year (Figure 1.3). 
Figure 1.3. Up to $60 \%$ of entrepreneurs have reduced expectations for business growth

Proportion of early-stage entrepreneurs reporting "somewhat" or "much lower" growth, 18-64 years old, 2020

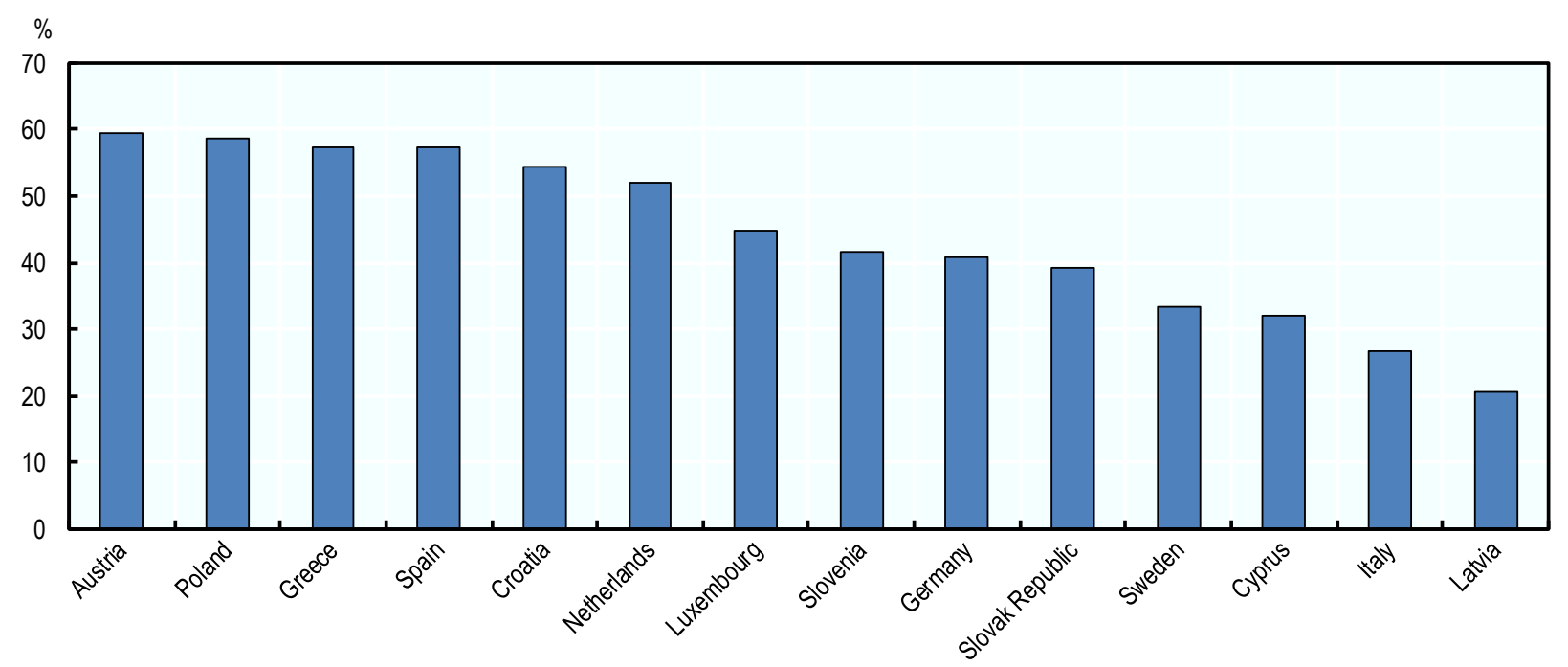

Note: Early-stage entrepreneurs are those who are in the process of starting a business or managing one that is less than 42 months old. Source: (Bosma et al., 2021 $[111)$

StatLink 제 sh https://doi.org/10.1787/888934279434

\section{... and poor mental health and well-being outcomes}

There is a growing body of evidence that shows a disproportionate decline in subjective well-being and happiness of the self-employed as a result of the COVID-19 pandemic. Evidence from the UK shows that the self-employed had a fall in their subjective well-being relative to employees, which is likely to be associated with the greater decline in hours worked since the subjective well-being of the selfemployed is more sensitive to reductions in hours worked than income reductions (Yue and Cowling, $2021_{[23]}$ ). These findings are consistent with a long-term international study (covering the pre-COVID context) that found that financial distress led the self-employed to suffer more severe negative well-being than full-time waged workers (Berrill et al., 2020[24]). This relationship was particularly strong for the solo self-employed.

The disproportionate decline in mental health and well-being among the self-employed is a result of greater levels of satisfaction drawn from their work and greater levels of income insecurity. The self-employed enjoy higher levels of autonomy (Benz and Frey, 2008[25]), benefit more from meaningfulness at work (Stephan, 2018[26]), and report higher levels of happiness than employees even when their incomes are lower (Binder and Blankenberg, 2021[27]; Millan et al., 2013[28]). Thus, a deterioration in working conditions would be expected to lead to different well-being and mental health outcomes for the self-employed compared with those in other forms of employment. In addition, negative economic shocks tend to increase financial insecurity and financial distress for the self-employed. This leads to increased stress so the negative consequences for their well-being are assumed to be more severe (Berrill et al., 2020[24]). Evidence from France shows burnout among entrepreneurs during the pandemic was largely linked to three primary factors: risk of contracting COVID-19, risk of bankruptcy and effects associated with lockdown measures (Torrès et al., 2021 29$]$ ). Moreover, women entrepreneurs were found to be more likely than men to have higher levels of burnout. 


\section{These negative effects on the self-employed have been uneven across sectors...}

Although the self-employed operate in all areas of the economy, they are concentrated in specific sectors and are over-represented in the sectors most affected by social distancing measures. Across EU Member States and OECD countries, own-account workers and micro-enterprises account for approximately $70 \%$ of employment in retail trade and almost $60 \%$ in the accommodation and food services sector. The self-employed have been particularly hard-hit in the tourism (Box 1.1) and cultural and creative sectors (Box 1.2). This sector-specific vulnerability of the self-employed is shown in numerous national studies, including in EU Member States such as France (Lambert et al., 2020[30]) as well as non-EU OECD countries such as Canada (Beland, Fakorede and Mikola, 2020[15]; Beland, Fakorede and Mikola, 2020[16]), the UK (Reuschke, Mason and Syrett, 2021[31]) and the United States (Fairlie, 2020[32]; Fairlie, 2020[33]; Fairlie, 2021 [18] $)$. While such analyses are important in mapping the effects of COVID-19 on the economy, they present an incomplete picture because they cannot pick up the extent to which containment measures restrict activities, nor the extent to which the self-employed can and are responding to containment measures to do their business in a different way.

The self-employed appear to have had fewer opportunities to telework. It is estimated that the selfemployed account for about $11 \%$ of "teleworkable" work, which is below their share of workers in the EU economy (14\%) (Figure 1.4). Conversely, the self-employed accounted for nearly $22 \%$ of workers in closed sectors, well above their overall share (14\%) (Fana et al., 2020[34]; Fana, Torrejón Pérez and FernándezMacías, 2020[35]). ${ }^{2}$ A similar result was found in all EU Member States except for Denmark, Ireland and Romania, where the self-employed were under-represented in closed sectors. However, COVID-19 has also created opportunities for the self-employed as they are over-represented in 'essential' sectors in a few countries: Romania (accounting for $33 \%$ in essential sectors but $22 \%$ overall), Poland (29\% vs. $17 \%$ ), Greece $(42 \%$ vs. $16 \%)$, Portugal ( $22 \%$ vs. $13 \%)$, Ireland (16\% vs. $13 \%)$ and Lithuania (13\% vs. $10 \%)$.

\section{Figure 1.4. Self-employment are under-represented in teleworkable sectors}

Share of self-employment among "essential", "teleworkable" and "closed" sectors, 2020

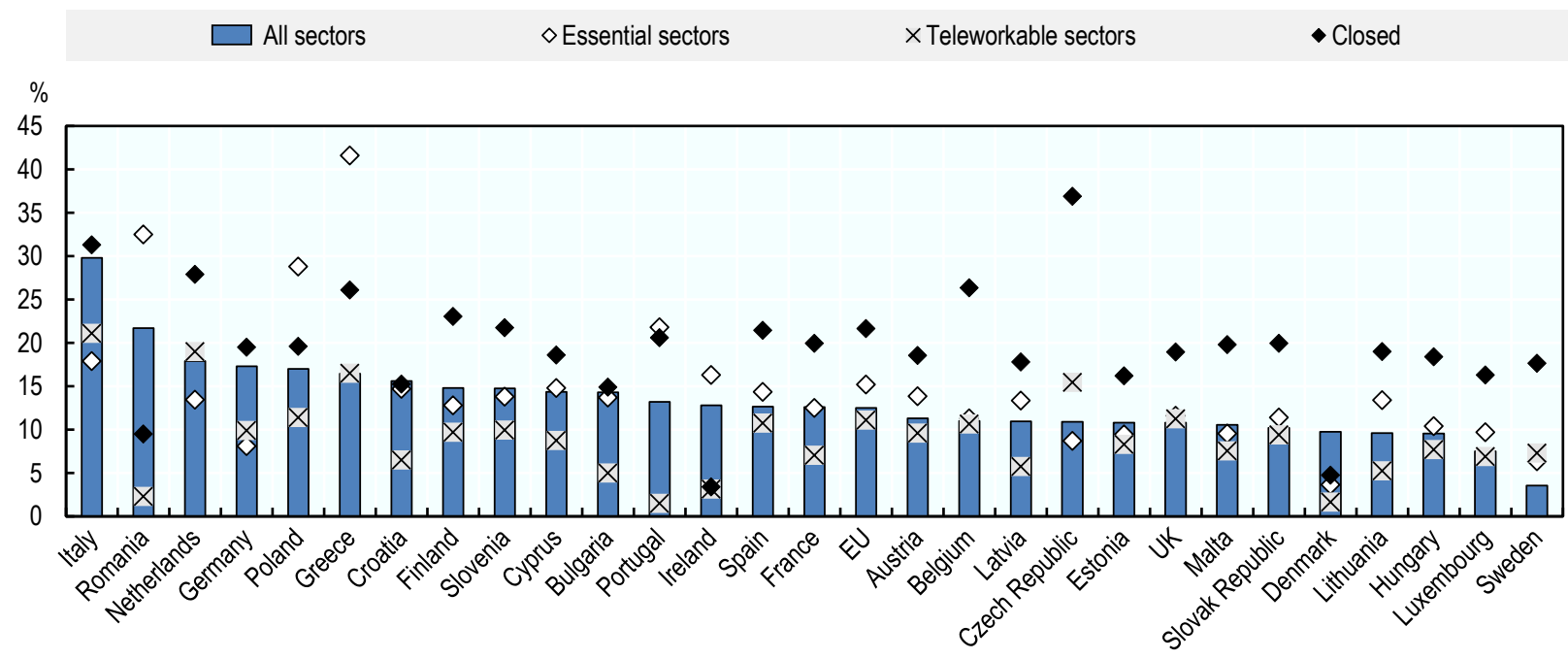

Note: Essential sectors include food production, utilities, health and all the other sectors identified as essential in all countries. Teleworkable sectors include education, most of public administration, finance, insurance and telecommunications. Most employment in these sectors is also maintained even in strict confinement, but with telework. This includes professional, scientific and technical activities, even though they are explicitly considered as non-essential in the three countries. Closed sectors include hotels, restaurants and accommodation, estate and travel agencies, plus leisure and recreation services. These are explicitly closed by confinement decrees and cannot continue to function via telework. Source: (Fana et al., 2020[34]) 


\section{Box 1.1. Consequences of COVID-19 for the tourism sector}

\section{Consequences of COVID-19 for tourism sector}

It is estimated that the international tourism economy declined nearly $80 \%$ in 2020 and about one-third of jobs in the sector were lost between March and October 2020. This has been catastrophic for the self-employed who along with micro-businesses, account for $85 \%$ of businesses operating in this sector.

These impacts are often highly localised. For example, the tourism sector contributes over $33 \%$ of GDP to the regional economy of Corsica (France) with approximately 11000 tourism establishments (mostly family-run). As a result of a $75 \%$ decrease in hotel bookings in 2020 , about 3600 jobs were lost.

\section{Policy responses}

Government support for the self-employed in the tourism sector has included financial support, retraining and a push towards digitalisation. Many countries have designed policy responses to prepare the tourism workforce for the digital future and these measures vary greatly in scale and focus. This included virtual training programmes such as Developing Leaders for Hospitality and Tourism (Ireland) and Tourism Innovation (Lithuania).

Source: (OECD, 2021 [36]; OECD, 2021 [37]) 


\section{Box 1.2. Consequences of COVID-19 on self-employment in cultural and creative sectors}

\section{Cultural and creative sectors have been among the most affected sectors}

Many activities in cultural and creative sectors (CCS) have been suspended in 2020-21 due to COVID19 containment measures. For example, France's art market experienced an estimated total loss of EUR 184 million in the second quarter 2020 with about one-third of all French art galleries at risk of shutting down before the end of 2020 . This has resulted in substantial job losses of up to $5.5 \%$ of total employment in these sectors across OECD countries between March and September 2020.

The self-employed have been heavily impacted by these job losses because they account for a large share of workers in CCS. About 32\% of CCS workers in the EU were self-employed in 2019, reaching nearly half in the Netherlands and Italy (Eurostat, 2020[38]). This challenging context for the selfemployed is expected to continue in the short- and medium-term because of lower levels of investment in the sector and potential shifts in consumer preferences.

\section{Policy responses}

The CCS have responded to lockdown measures with massive and rapid digitalisation. Creative content has been moved on-line to keep audiences engaged with creative and cultural content, such as the streaming of events. However, great challenges remain since these sectors face digital skill shortages and free digital content does not replace paying audiences.

Governments have injected funding into these sectors using both direct (e.g. grants, subsidies) and indirect mechanisms (e.g. payment deferrals). Grants and subsidies for individual artists, who are mostly self-employed, have been the most common policy response. For example, Austria's COVID-19 Fund for Artists and Cultural Educators awarded individual grants of up to EUR 2000 per month for up to three months for workers in cultural and creative sectors and an additional 15000 artists and freelance workers received EUR 1000 per month for up to six months from a separate fund of EUR 90 million. Similar approaches have been used in Lithuania, New Zealand and Brussels (Belgium).

Source: (OECD, 2020[39])

Containment measures have created opportunities for some of the self-employed. Between $25 \%$ and $40 \%$ of new entrepreneurs surveyed in the first half of 2020 across EU Member States indicated that they "somewhat" or "strongly agree" that the COVID-19 pandemic created new business opportunities (Figure 1.5). Many businesses with an online presence have been able to continue and grow their business during periods of containment and lockdowns. This has been highlighted in food and retail, where enterprises with an online presence, including the use of "apps", have shown buoyancy compared to those without (Blundell et al., 2020[9]). Although evidence suggests that the importance of having an online presence has been elevated during the crisis, there are indications that this form of trade - with customers and suppliers - will become the "new" normal (OECD, 2021 [40]). However, the limited capabilities and resources of the self-employed may restrict their ability to re-orientate their business operations and external market relations. Digitalisation and having an online presence rises with size of enterprise and without support, this may lead to the self-employed and smaller enterprises experiencing long-term decline. 
Figure 1.5. Some entrepreneurs report that COVID-19 has created opportunities for their business

Proportion of early-stage entrepreneurs indicating that they "somewhat" or "strongly agree" that the COVID-19 pandemic provided new opportunities for their business, 18-64 years old, 2020

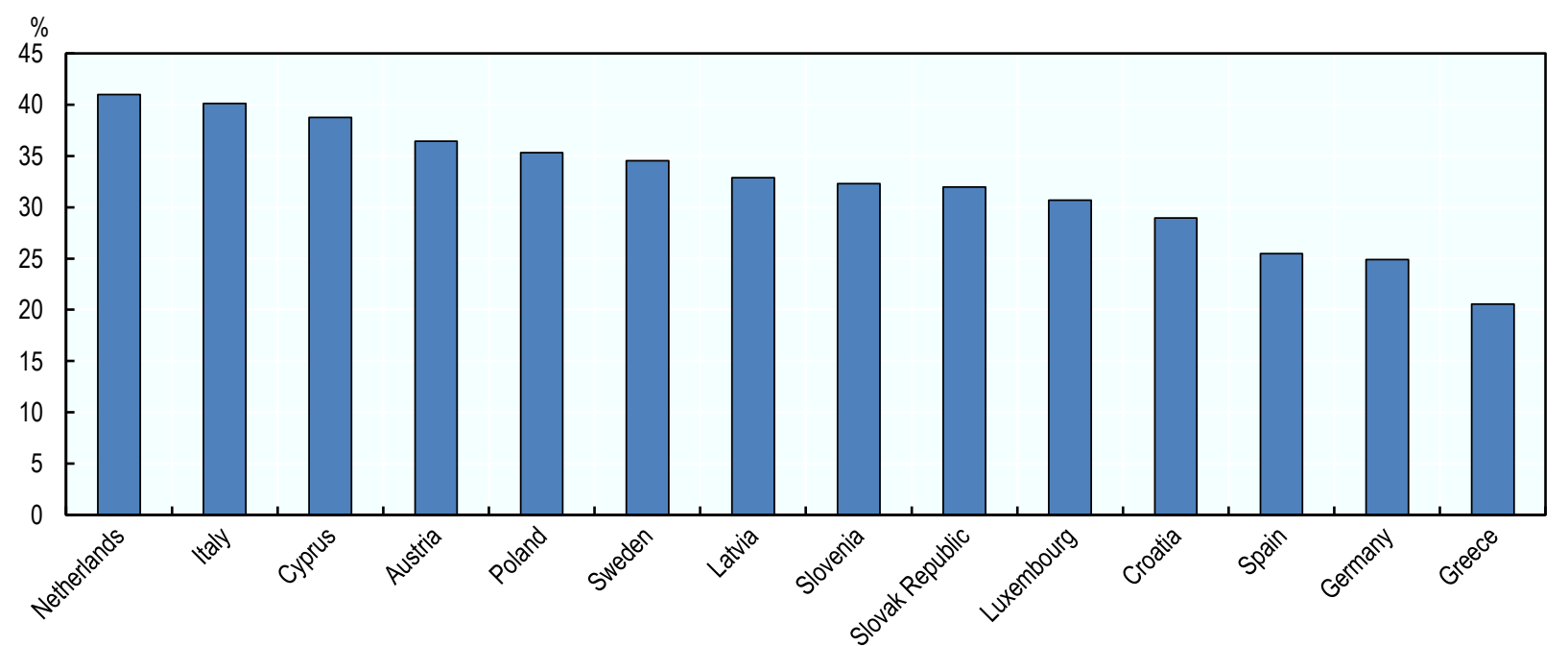

Note: Early-stage entrepreneurs are those who are in the process of starting a business or managing one that is less than 42 months old. Source: (GEM, 2021[41])

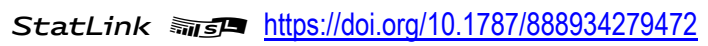

\section{...and uneven across locations}

COVID-19 has had uneven health, economic, social and fiscal impacts across regions and cities. The share of workers who are self-employed varies greatly across countries and within countries. For example, the share of workers who are self-employed in Romania ranges from $4 \%$ in Bucharest-llfov to $44 \%$ in the North-East region (Figure 1.6). These regional differences can largely be explained by economic structure and demography, which were also determinants of the impacts of the pandemic across regions. In the UK for example, a large amount of variation was found across regions in the share of the self-employed who are at-risk of stopping their business activity because of COVID-19. Following the onset of the pandemic, the self-employed in London, who are on average more likely to be younger, were the hardest hit (Henley et al., 2021 [42]). In the 2020Q1, self-employment in London dropped by $12 \%$ - double the decrease in self-employment in England outside of London. There are also differences in the impact of the pandemic within the same locations depending on the demographics of the self-employed. For example, self-employed women were more heavily impacted than men in Northern Ireland. Women's selfemployment decreased by about $9 \%$ compared to an $8 \%$ increase among men. Conversely, selfemployment among women in Scotland increased in the same period $(+0.5 \%$. vs. $-5.5 \%)$. The pattern for employees was quite different as they were most likely impacted in London and to a lesser extent in Scotland (UK) (Henley and Reuschke, 2020[43]). 
Figure 1.6. Self-employment levels vary more within some countries than across EU Member States

Share of self-employed among employed at the NUTS2 level, 2020

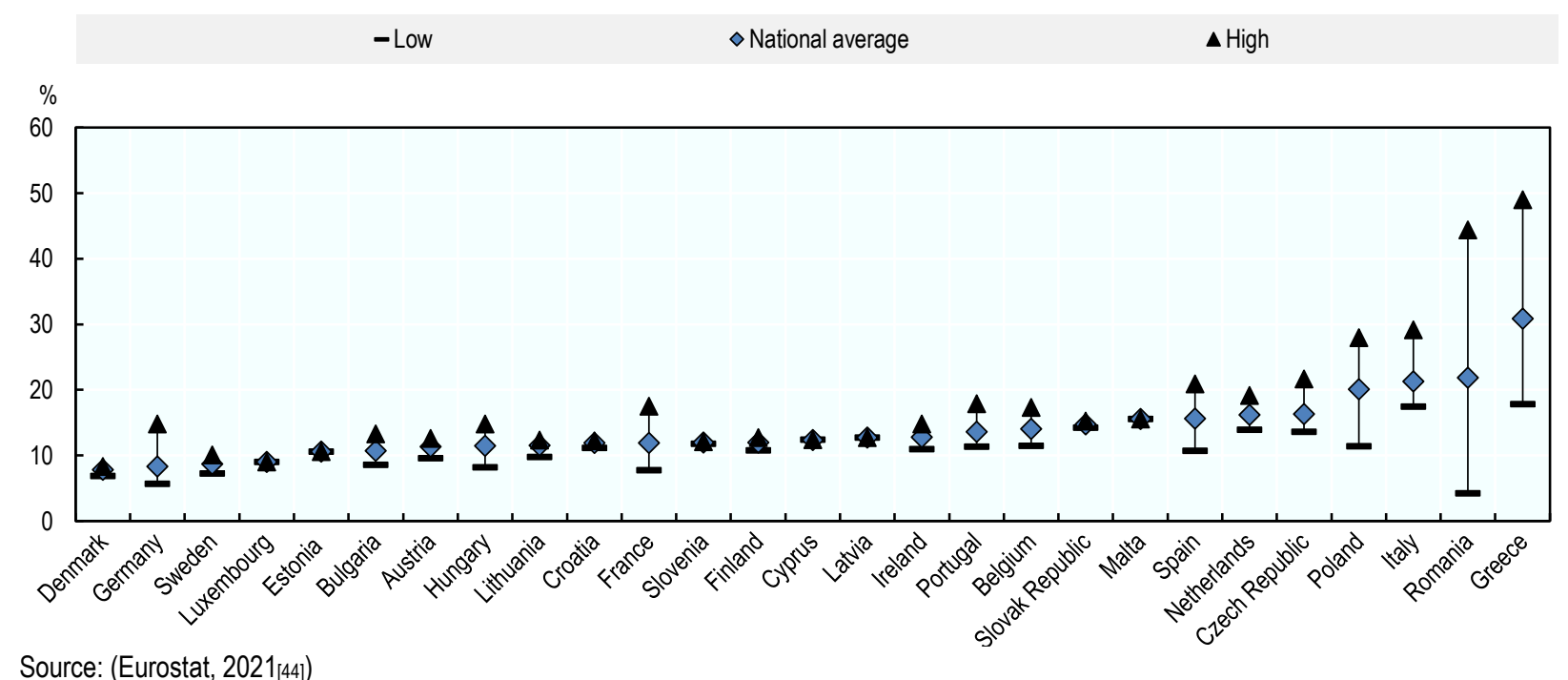

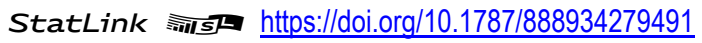

Policy has responded to support the self-employed...

Governments have responded to the COVID-19 pandemic with a wide range of measures to support the self-employed and entrepreneurs. The OECD has been tracking the impacts of COVID-19 on entrepreneurs and SMES along with the policy responses: see (OECD, 2021 [45]). Overall, public policy responses to COVID-19 have been predominantly at national and regional levels with some attention to sectors that have been hardest hit (OECD, 2021 $\left.{ }_{[5]}\right)$. The responses are best described as comprehensive but with gaps and so far, have been subject to incremental adjustments depending on the stringency of the containment rules and feedback from stakeholders.

The first phase included the launch of support measures from around March $\mathbf{2 0 2 0}$ to provide an immediate mitigation of the impact of COVID-19 and government restrictions (Figure 1.7). These included income support for employees and the self-employed for around three months. Businesses were supported with grants, loans and deferrals of payments to enable their survival. Such measures were rushed through the apparatus of governments worldwide, often in emergency sittings in legislatures. In addition to these economic measures, support was provided for childcare where nursery and school closures existed, to enable those who were able or required to work to do so. These were overwhelmingly protective measures, designed to be a response to the containment rules, as governments both suspended and supported existing economic capacity until the COVID-19 pandemic was under control.

The second phase of measures responded to the identification of gaps in provision and in the face of a prolongation of the COVID-19 pandemic. Given the temporary nature of the initial measures, this phase included the extension, adjustment or stopping of specific measures according to need. For example, disproportionately affected sectors were often targeted with particular assistance. There was also growing recognition and concern regarding the cost of the support measures and the rising national debt accompanied by an acceptance that the economy needed support to avoid complete collapse. 
Figure 1.7. Phases of policy measures for individuals and businesses in 2020-21

\begin{tabular}{|c|c|}
\hline \multicolumn{2}{|c|}{ Phase 1 and 2: Immediate responses and subsequent adjustments } \\
\hline $\begin{array}{l}\text { Support for individuals } \\
\text { - } \quad \text { Wage subsidies } \\
\text { - } \quad \text { Job retention schemes (furlough) } \\
\text { - } \quad \text { Self-employment income support } \\
\text { - } \quad \text { Benefits and sick pay }\end{array}$ & $\begin{array}{l}\text { Support for businesses } \\
\text { - } \text { Grants } \\
\text { - Loans } \\
\text { Deferrals of national (VAT; income and company) } \\
\text { - } \text { and local taxation \& social security payments } \\
\text { Deferrals of private rent and utility payments }\end{array}$ \\
\hline
\end{tabular}

\begin{tabular}{|c|c|}
\hline \multicolumn{2}{|c|}{ Phase 3: A shift from emergency measures to structural programmes } \\
\hline $\begin{array}{l}\text { Support for individuals } \\
\text { - Phasing out of income support and self- } \\
\text { employment schemes } \\
\text { - Training programmes }\end{array}$ & $\begin{array}{l}\text { Support for businesses } \\
\text { - } \\
\text { - }\end{array}$ \\
\hline
\end{tabular}

A third and current phase comprises the phasing out of employment and financial support measures and a switch to new policies to enable the economy and businesses to emerge from the crisis. Yet, careful timing of switching support from measures for business and job "retention and protection" to re-booting is crucial. This is illustrated by the different phases of support offered by the TOZO measures in the Netherlands, which became more stringent over time and shifted to helping the selfemployed pivot their business activities (see the country profile in Part III for more information on TOZO). The TOZO-measures were ended in October 2021.

The earlier phases of support may have had some unintended consequences. For example, some less viable enterprises may have become dependent on government support, while others, not eligible for support, may have been struggling to compete. Evidence suggests that business closures have slowed and some firms may have continued to survive because of government assistance. Structural measures to re-boot economies have also been introduced (i.e. finance for start-ups, innovation, training). A key issue is the digitalisation of enterprises as customers, suppliers and other stakeholders have shifted away from physical to virtual connections. Some governments regard the re-booting of the economy as an opportunity to find new markets, boosting a green economy and internationalisation (OECD, 2021 [45]).

To date, the Eurofound policy watch tool reports 53 measures for the solo self-employed, 97 for the self-employed, 112 for SMEs and 252 for employees on national and subnational levels (as of 2 August 2021). ${ }^{3}$ The bulk of the measures relate to income support for individuals and businesses (Figure 1.8.). For the self-employed, "Supporting businesses to stay afloat" is the most common policy measure followed by "Income protection beyond short-time work." These measures primarily aim to protect businesses from the effects of lockdown measures rather than helping firms discover new opportunities.

These COVID-19 support measures vary not only in approach but also in who they target. There are examples of measures that are targeted at specific sectors such as creative and cultural and tourism sectors, while others are differentiated by business size. For example, supports for the self-employed in 
the Slovak Republic differentiate between those with and without employees (see the country profiles in Part III for more information on the Slovak Republic and other countries).

\section{Figure 1.8. The majority of policy measures for the self-employed aimed to keep the business afloat}

Number of policy measures in EU Member States since onset of COVID-19

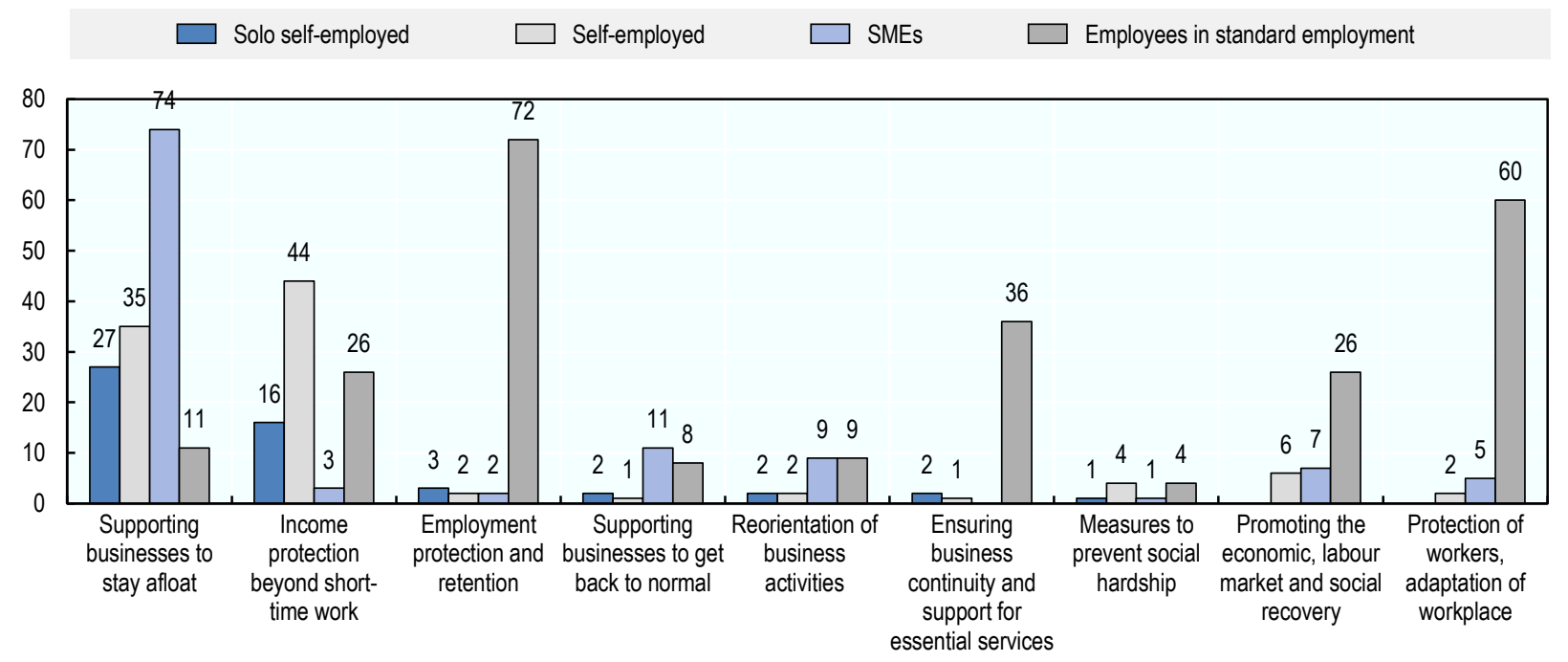

Note: Policy measures as of 4 August 2021, covering the period 31 March 2020 to 29 July 2021.

Source: (Eurofound, 2021 ${ }_{[46]}$ )

StatLink 제 sh https://doi.org/10.1787/888934279510

\section{...but the suite of support measures did not reach everyone}

The economic support measures were welcomed but have also been subject to some debate and criticism. Although governments have rolled out extensive sets of measures with unprecedented speed, a number of criticisms can be made regarding their appropriateness for supporting the self-employed (Juergensen, Guimón and Narula, 2020 [47]; Moreira and Hick, 2021 ${ }_{[48]}$ ). One of the main critiques is that the initial packages had coverage gaps for certain types of self-employed and micro, new and start-up enterprises. For example, an estimated 3 million people in the UK did not meet the criteria for furlough or self-employment income support because of their company director status or newness to self-employment (IPSE, 2021 ${ }_{[49]}$ ). This is the result of the need for quick action by governments given the uncertainty of the severity and length of the crisis. Unlike typical policy development processes, little opportunity existed for early consultation with entrepreneurship stakeholders or the piloting of measures before implementation.

The administration of support measures and eligibility conditions were often difficult to understand and prevented some from accessing support (Cribb, Delestre and Johnson, 2021 [50]). The amount of support for the self-employed in the form of income or business grants and subsidies is mainly contingent on previous tax returns, and in some countries means-tested benefits based on savings and profit levels. As with any policy intervention, some of the financial supports had cliff edges, which may lead to unforeseen consequences and distortions in markets (Adam, Miller and Waters, 2020[51]). If selfemployment was not a main source of income, this could also disqualify applicants from receiving income support, creating eligibility problems for part-timers and those with mixed income sources. For example, in the UK, someone with $51 \%$ of declared income from self-employment could claim the maximum support, while someone with $49 \%$ can claim nothing. There were also challenges in processing applications, adding to the time it took to receive payments (Adam, Miller and Waters, 2020[51]). Take-up of support schemes 
also varied. Estimates suggest take-up of support was about three-quarters of those eligible but some groups such as women had lower take-up rates (Cribb, Delestre and Johnson, 2021 [50]).

In addition, support for innovative start-ups and firms - which could include the self-employed was effectively paused as governments implemented emergency measures and support providers were impacted by lockdown measures. Initial COVID-19 measures placed an emphasis on protecting and saving existing economic capacity. However, little attention was paid to maintaining the pipeline of business start-ups or innovation in existing firms. While it would be expected that the number of new startups would decline during the crisis due to increased market uncertainties (Blundell, Machin and Ventura, $\left.2020_{[52]}\right)$, there is evidence that COVID-19 has introduced particular challenges including greater difficulty accessing bridging loans and equity due to a lack of client-financier interaction (Brown, Rocha and Cowling, 2020[53]) (for additional discussion on differences between the COVID-19 pandemic and previous recessions, please see Box 1.3). Moreover, this challenge has been greater for some groups such as women (Villaseca, Navío-Marco and Gimeno, 2020[54]). Incumbent firms are also impacted since they require support to innovate, re-orientate their activities, digitalise their operations and interface with suppliers and customers. Lessons from earlier recessions suggest that smaller enterprises particularly experience greater reductions in spending on research and development (Roper and Turner, 2020[55]). Governments have addressed this gap to some extent in the current phase of support measures, yet only a small share of policy measures aim to support businesses in re-orienting their activities (Figure 1.8).

\section{Box 1.3. How is COVID-19 different than previous economic shocks?}

During previous economic crises, the self-employed have shown resilience and agility through their ability to be flexible and continue business operation despite reduced income. Some recessions have even led to an increase in new firm-formation and self-employment, as the unemployed and laid-off employee workers, unable to find work, start their own business out of necessity (Foreman-Peck, 1985[56]; Fossen, 2020[57]). Recessions can also create new business opportunities, through the opening of gaps in markets as incumbent businesses close and human and financial capital becomes cheaper.

However, what is distinctive about the downturn associated with the COVID-19 pandemic is its genesis, speed, scale and levels of future uncertainty (Moreira and Hick, 2021 ${ }_{[48]}$ ). This has made the selfemployed particularly vulnerable because of their relatively low levels of readily accessible resources to absorb the speed and depth of the shock.

The current crisis is a result of a combination of factors that are exogenous to the economic system: a public healthcare crisis and government interventions in the form lockdowns. Unlike previous recessions or crises that have been slower to build up momentum, the current crisis is a result of rapid responses to the COVID-19 pandemic involving economic and societal lockdown measures. The latter take various forms but have been nationwide, regional and sector based, and the severity of measures are associated with the level of containment needed to arrest the spread of the virus. The interventions by governments have often been sharp and without much warning. This appears to have heightened uncertainties among business owners. Hence, although there may be some lessons from previous economic crises, the effects of an environmental shock of the type and scale associated with the COVID-19 pandemic are likely to be very different from previous crises.

Finally, policy responses to support the self-employed through the COVID-19 crisis have not considered the specific needs from those groups that are under-represented or disadvantaged in entrepreneurship. It is clear that certain groups of the labour force and business population have suffered more under COVID-19 than others (for further discussion, please see the next section: The missing entrepreneurs), yet only a very small number of support measures in EU Member States and OECD 
countries have been designed specifically for those who are from the following groups: women, immigrants, youth, seniors and people with disabilities (OECD, 2021 $\left.{ }_{[45]}\right)$.

\section{The missing entrepreneurs}

\section{Many groups have fewer opportunities to be entrepreneurs...}

While many people are interested in becoming an entrepreneur, not everyone has the same opportunity to start a business. Nearly $4 \%$ of the population between the ages of 18 and 64 years old in the EU and 7\% in OECD countries were actively trying to start a new business in the period 2016-20 (i.e. pre-COVID pandemic) (Figure 1.9). Across EU Member States, women were about $60 \%$ as likely as men to be involved in business creation and seniors were $70 \%$ as likely as adults. While youth were relatively active in pre start-up activities, fewer than two-out-of-three go on to create a new business, whereas more than $70 \%$ of the total number of nascent entrepreneurs go on to create a new business.

There are also differences in many business characteristics. These include the likelihood of employing others, growth ambitions, activity levels in international markets and likelihood of introducing new products and services. For example, women entrepreneurs, on average, are less likely to have employees and growth ambitions than men entrepreneurs. Further discussion on these gaps is provided in Chapters 2-6.

\section{Figure 1.9. Early-stage entrepreneurship rates vary across population groups}

Share of the population (18-64 years old), population weighted average for the period 2016-20

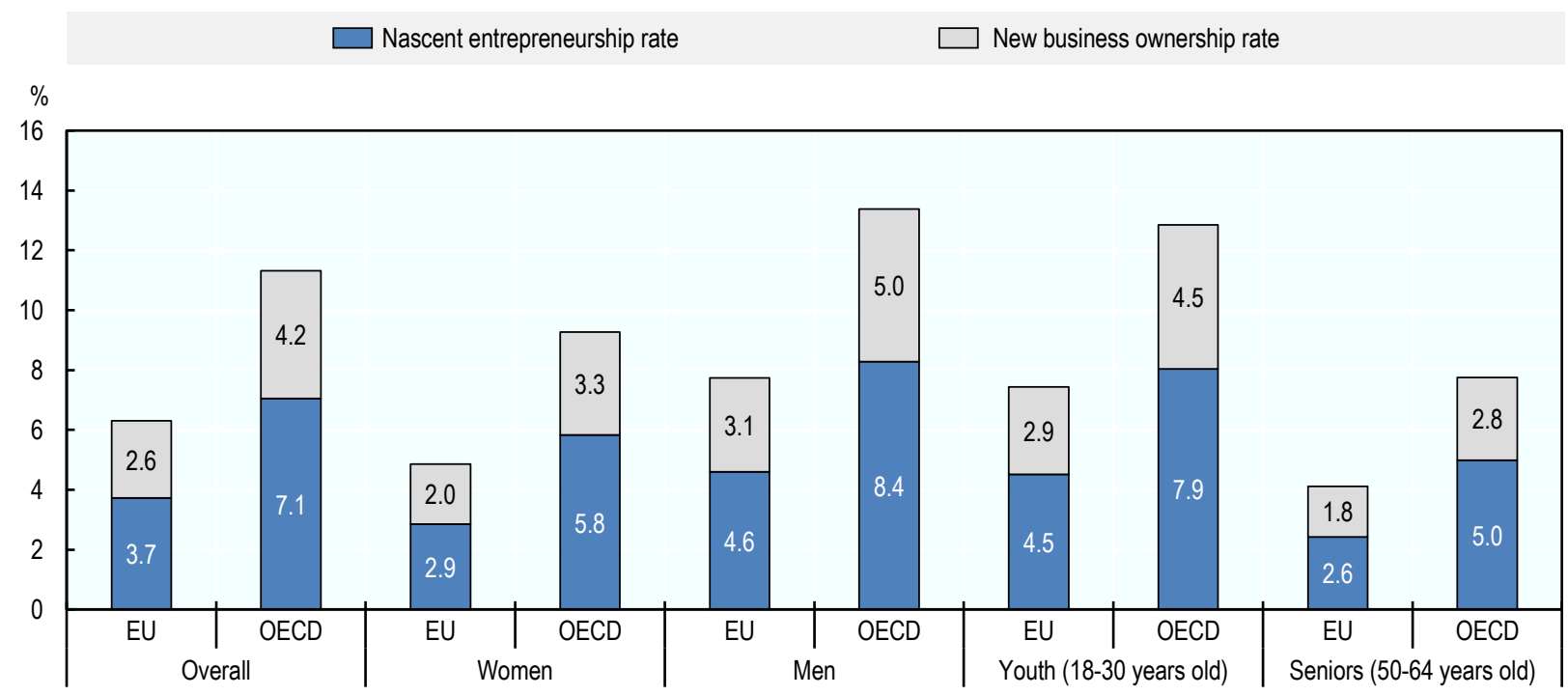

Note: The nascent entrepreneurship rate measures the proportion of the population 18-64 years old that is actively involved in setting up a business they will own or co-own. This business has not paid salaries, wages or any other payments to the owners for more than three months. The new business ownership rate measures the proportion of the population that is currently an owner-manager of a new business that has paid salaries, wages or any other payments to the owners for more than three months, but not more than 42 months. Data for the EU exclude the following member states because they did not participate in the GEM survey over this period: Czech Republic, Denmark, Lithuania and Malta. Data for the OECD exclude the following countries because they did not participate in the GEM survey over this period: Czech Republic, Denmark, Iceland, Lithuania and New Zealand.

Source: (GEM, 2021[41]) 


\section{...since they face greater obstacles to business creation}

All entrepreneurs face a range of challenges starting their business but some face more and greater barriers. These fall into four broad categories: institutional barriers, difficulties accessing to finance, a lack of entrepreneurship skills, and small or ineffective networks (Table 1.1). Many different barriers are often inter-related. For example, someone with low levels of entrepreneurship skills will have more difficulty identifying sources of potential financing for their business and will likely have difficulties building strong networks since they are less effective at identifying opportunities. These barriers are influenced by a range of factors including gender, age, ethnicity and immigration status, as well as health, employment status, work experience and education. The interaction of these factors results in differences in barriers across different groups of entrepreneurs (e.g. women, immigrants, youth, seniors, people with disabilities) as well as within groups (e.g. young women, immigrant women, highly-educated women).

The greater likelihood of facing barriers does not mean that all people in these groups are disadvantaged in entrepreneurship. There are numerous examples of successful entrepreneurs across all groups. This, however, does not mean that everyone should be pursuing entrepreneurship and that policies and programmes should seek to turn everyone into an entrepreneur.

\section{Table 1.1. Barriers to entrepreneurship for under-represented and disadvantaged groups}

\begin{tabular}{|c|c|c|}
\hline \multicolumn{2}{|c|}{ Types of barriers } & Examples \\
\hline \multirow[b]{2}{*}{ 1. Institutional barriers } & a. Normative barriers & $\begin{array}{l}\text { - Gender norms that influence labour market participation by women. } \\
\text { - Stereotypes and prejudices for people with disabilities in the labour market. }\end{array}$ \\
\hline & b. Regulatory barriers & $\begin{array}{l}\text { - Income tax policies that favour single-income households } \\
\text { - Income support benefits for people with disabilities may be reduced or removed } \\
\text { when income is earned. }\end{array}$ \\
\hline \multicolumn{2}{|l|}{ 2. Access to finance } & $\begin{array}{l}\text { - Youth have lower levels of savings and collateral, making access to external debt } \\
\text { financing more difficult. } \\
\text { Unconscious investor bias is one of several factors that results in women } \\
\text { entrepreneurs receiving lower amounts of risk capital. }\end{array}$ \\
\hline \multicolumn{2}{|l|}{ 3. Entrepreneurship skills } & $\begin{array}{l}\text { - Gender gaps in self-perceived levels of entrepreneurship skills. } \\
\text { - People over } 50 \text { years old are less likely to have digital skills. }\end{array}$ \\
\hline \multicolumn{2}{|l|}{ 4. Networks } & $\begin{array}{l}\text { Language challenges can prevent immigrant entrepreneurs from building } \\
\text { networks in their new business community. } \\
\text { Senior entrepreneurs may have outdated networks, or irrelevant networks if they } \\
\text { operate a business that is unrelated to their earlier career. }\end{array}$ \\
\hline
\end{tabular}

Source: (OECD/The European Commission, 2013[58]; Marchese, 2014[59]; OECD/EU, 2015[60])

\section{Three-quarters of the 9.4 million "missing" entrepreneurs in the EU are women...}

Another way to look at gaps in entrepreneurship is to estimate the number of "missing" entrepreneurs, which is the number of entrepreneurs that there would be if there were no gaps in entrepreneurship activity rates. If the early-stage entrepreneurship rate of the overall population was set to the same rate as core-age males (30-49 years old), there would be an additional 9.4 million early-stage entrepreneurs in the EU and 34.6 million in OECD countries. These shares represent $52 \%$ and $37 \%$ of the total number of early-stage entrepreneurs (Figure 1.10). 
At the country level, the relative number of "missing" entrepreneurs is inversely related to the actual number of entrepreneurs. Countries with high levels of early-stage entrepreneurship tend to have a low number of "missing" entrepreneurs (e.g. Greece, the Netherlands) and countries with low levels of early-stage entrepreneurship tend to have a high number of "missing" entrepreneurs (e.g. Finland, Italy).

Figure 1.10. The number of "missing" entrepreneurs represent $52 \%$ of all early-stage entrepreneurs in the EU

Ratio of "missing" entrepreneurs relative to the total number of early-stage entrepreneurs, average for 2016-20

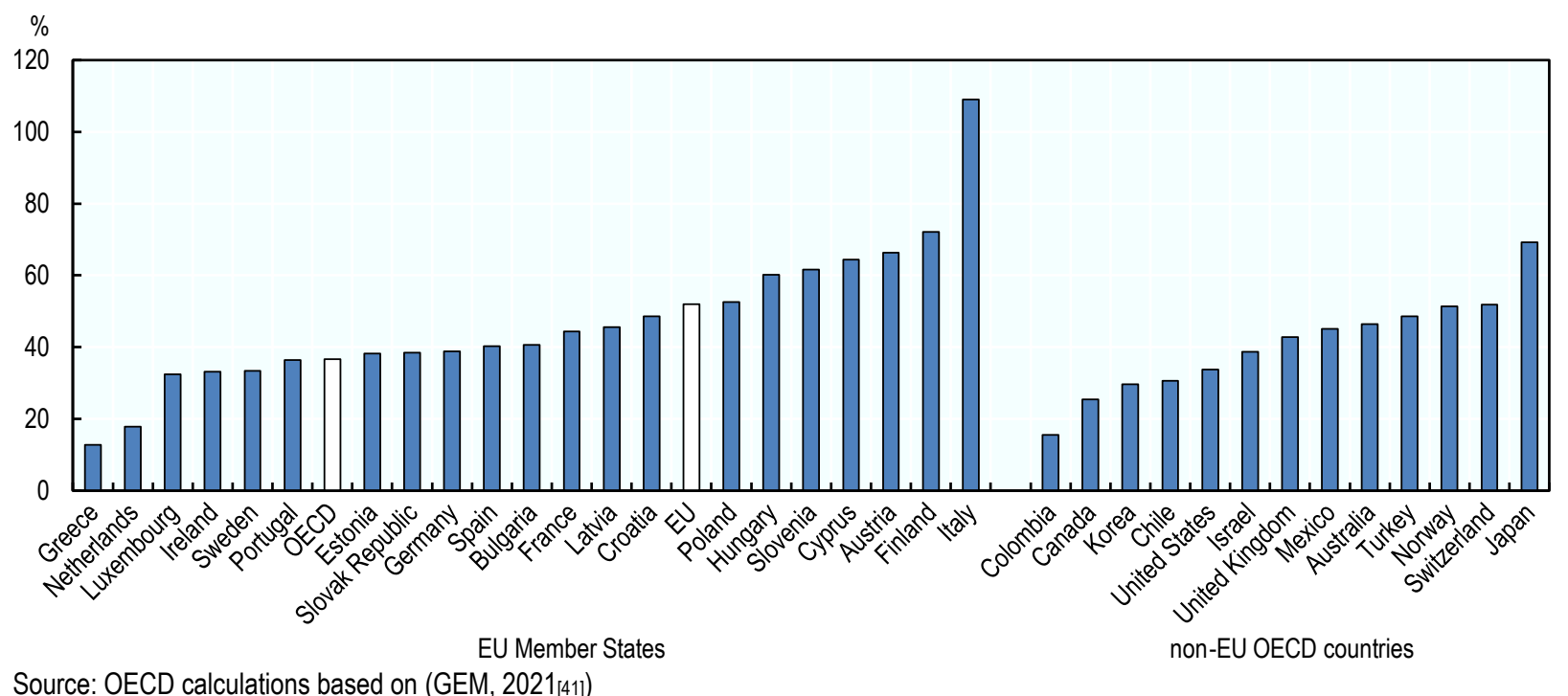

StatLink त्ञाज् https://doi.org/10.1787/888934279548

A more nuanced picture emerges when this exercise is taken a step further to look at the number of "missing" entrepreneurs in each target group. Across EU Member States and OECD countries, about three-quarters of the "missing" entrepreneurs are women and slightly more than half are over 50 years old (Figure 1.11). This underlines that women and seniors are the most under-represented groups in entrepreneurship and that policy needs to put greater efforts into addressing the barriers for these groups. 
Figure 1.11. The majority of the "missing" entrepreneurs are women and those over 50 years old

Distribution of the "missing" entrepreneurs by gender and age, average for 2016-20

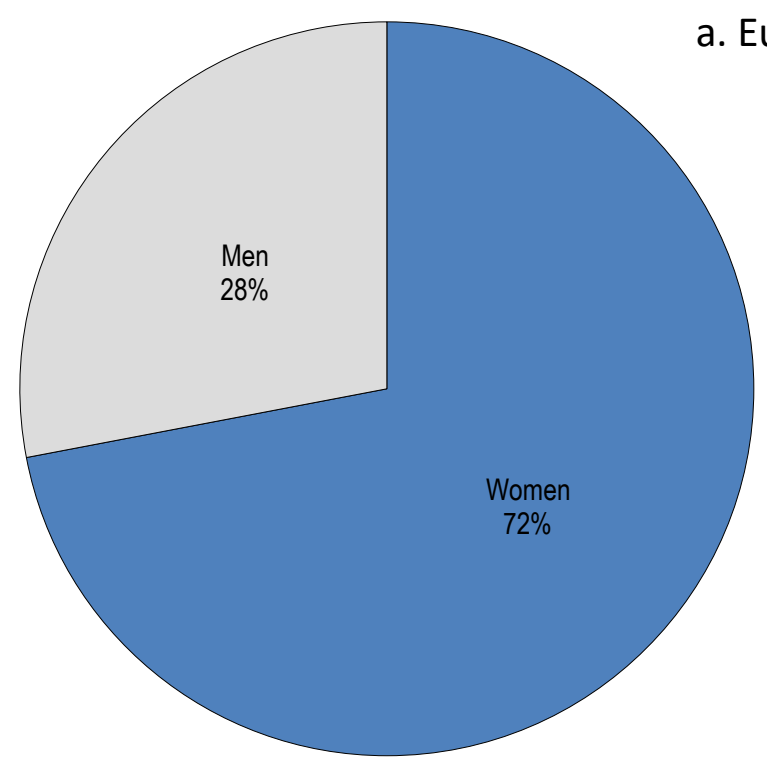

a. European Union

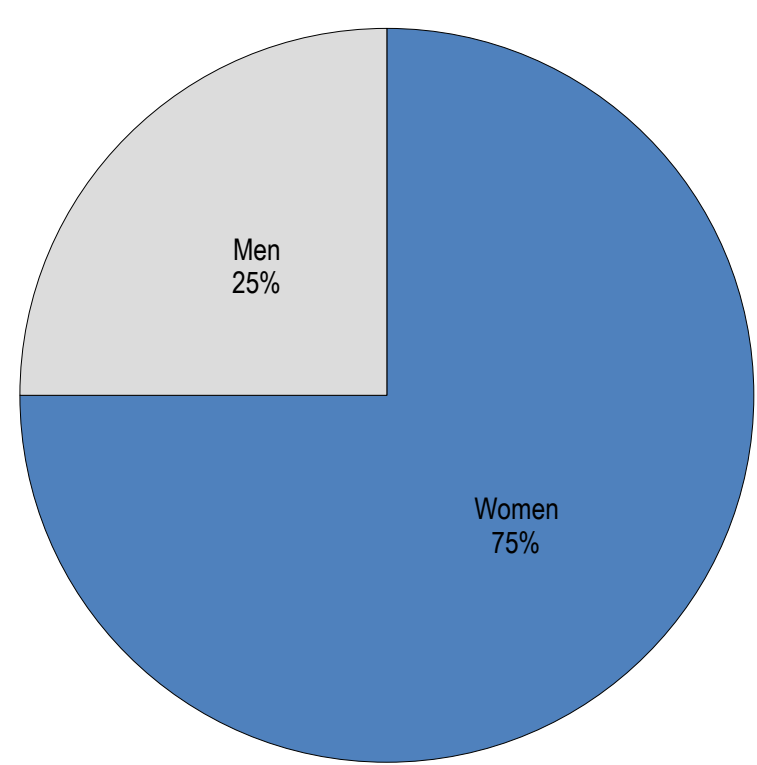

b. OECD

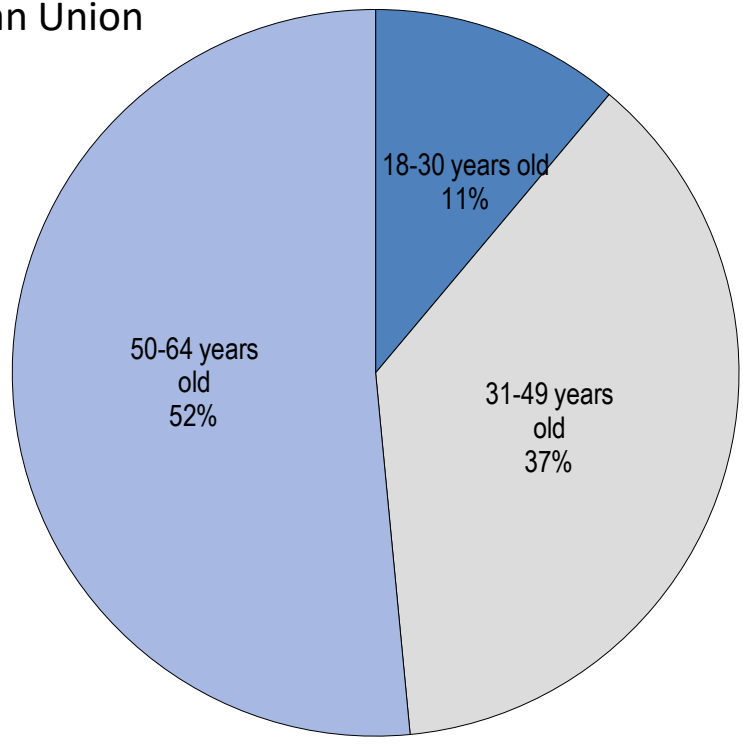

Source: OECD calculations based on (GEM, 2021 $\left.{ }_{[41]}\right)$

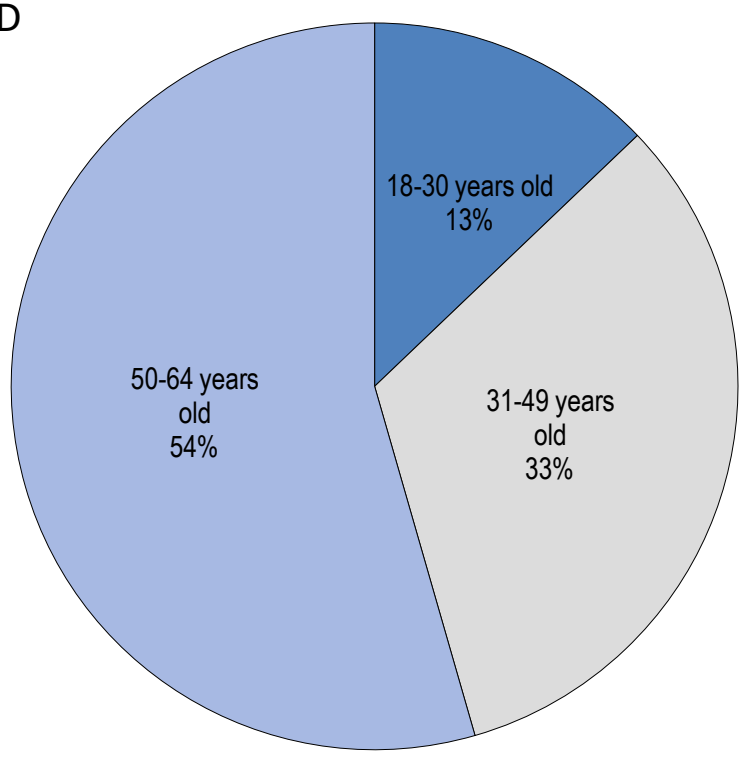

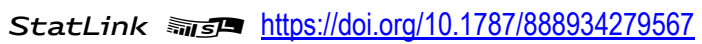

\section{... and women entrepreneurs were disproportionately impacted during COVID-19}

Women-led businesses across the world have been more likely to close during the COVID-19 pandemic than their men-led counterparts (Figure 1.12). The global closure rate for women-led businesses (27\%) was about seven percentage points (p.p.) higher than for men-led SMEs $(20 \%)$ between January and May 2020. While this gap in business closure rates has closed over time, the closure rate for women-led businesses remained two p.p. higher than for men-led businesses in October 2020 (16\% vs. $14 \%)$. This gender gap in closure rates narrowed across all regions between May and October 2020, 
except for sampled countries in Europe and the Middle East and North Africa region where the gender gap increased slightly.

\section{Figure 1.12. Female-led businesses were more likely to close during the COVID-19 pandemic}

Business closure rates, 2020

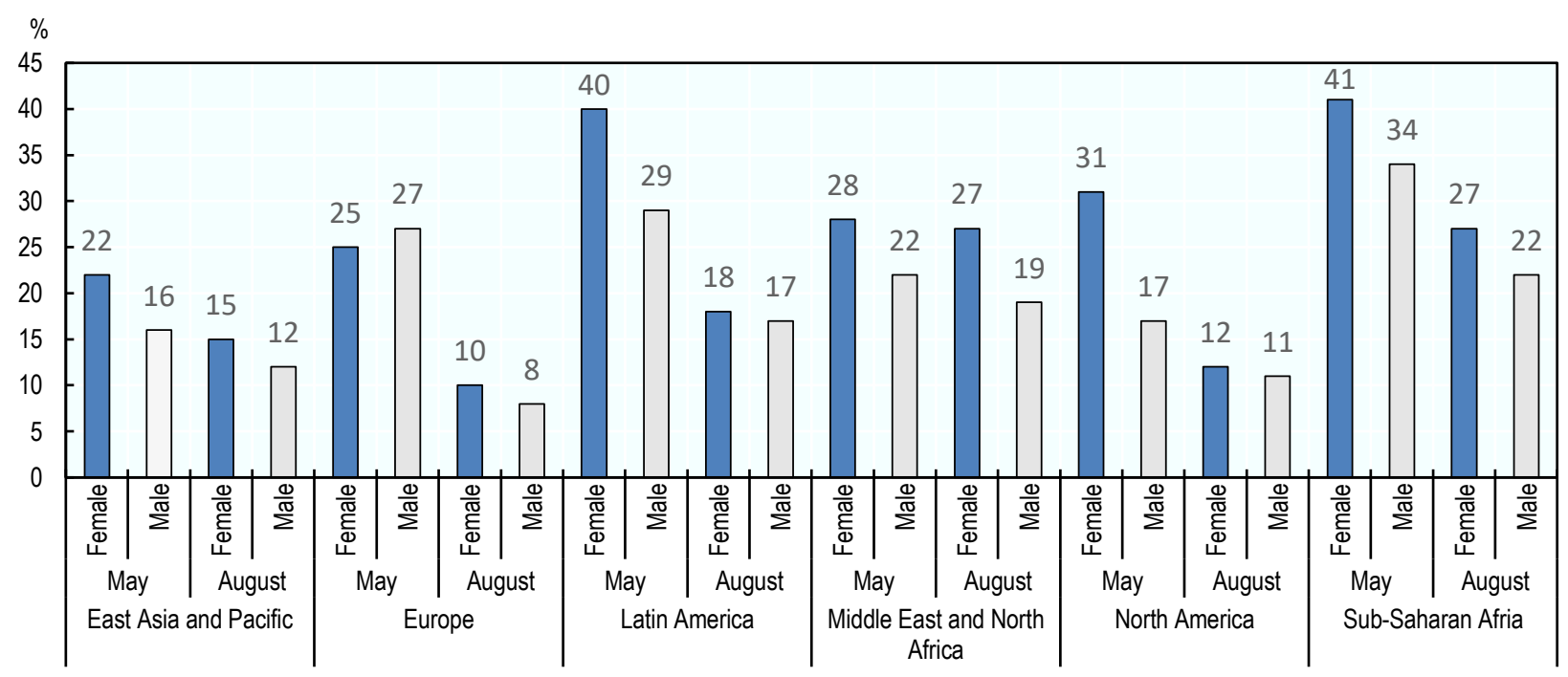

Source: (Facebook/OECD/World Bank, 2020[61])

A growing body of evidence at the country-level confirms that a higher proportion of women entrepreneurs have closed their businesses than men. In Germany, for example, self-employed women were more likely than men to experience an income loss of more than 35\% (Graeber, Kritikos and Seebauer, 2021 [62]). Similar evidence is also found in non-EU OECD countries. In the United States, the number of female business owners fell by $10 \%$ between February and June 2020, compared with $7 \%$ for males (Fairlie, 2020[32]; Fairlie, 2021 [18]). Self-employed women were also 13 p.p. more likely to experience work absence and 24 p.p. more likely to be unemployed than self-employed men (Grashuis, 2021 [19]). However, the number of female business owners recovered in the second half of the year to the level of February 2020, whereas the number of male business owners declined by $9 \%$ for the year (Fairlie, $\left.2021_{[18]}\right)$. Similarly, an intersectional analysis of the effects of the COVID-19 pandemic on women in the UK underlines that low-income earners and immigrant women were the most affected (Martinez Dy and Jayawarna, 2020[63]). While self-employed exits in the UK were not found to have a gender gap, selfemployed women were more likely to experience reductions in hours worked and earnings (Reuschke et al., 2021[64]). A similar gap was found in Canada and this gap was greater among women who have a disability or were an immigrant (Mo et al., 2020[65]).

Several factors explain the higher closure rates for women-operated businesses, of which the sector of operation is one of the strongest explanatory variables. Across most EU Member States and OECD countries, women are over-represented among the hardest hit sectors (both as self-employed and employees), namely personal services, accommodation and food services, arts and entertainment, and retail trade. International evidence shows that women are also over-represented among sectors that have been closed in EU Member States due to containment measures (Fana et al., 2020[34]). Sector effects are exacerbated by the pre-existing vulnerable position of women entrepreneurs who, on average, operate smaller businesses than men, are more reliant on self-financing and have smaller networks upon which they can draw social and financial resources (OECD/European Union, 2019[66]; OECD/EU, 2016[67]). 
Women entrepreneurs have also been much more likely to have greater household responsibilities during the COVID-19 pandemic. This has led to a reduction in the time available to spend working on their business. About one-quarter of all women business leaders stated that they spent six hours or more per day on domestic responsibilities between May and October 2020 , whereas only $11 \%$ of all male business leaders reported undertaking this amount of household work (Facebook/OECD/World Bank, 2020[61]). These responsibilities include home-schooling and childcare, both of which were more likely to be reported as having a negative impact on business activities by women entrepreneurs.

\section{Immigrant entrepreneurs have been hit hard by the COVID-19 pandemic...}

There is a growing body of evidence that shows that the effects of COVID-19 on self-employed immigrants have been disproportionately negative in terms of business closures and hours worked. For example, the number of immigrant-owned businesses dropped in Canada by $16 \%$ between February and May 2020 compared with an overall drop of 13\% (Beland, Fakorede and Mikola, 2020[15]). Moreover, the number of hours worked by self-employed immigrants in Canada also declined $44 \%$ over this period. Similarly, the number of immigrant business owners in the United States declined $18 \%$ between February and June 2020, which is more than double the overall rate of decline (8\%) (Fairlie, 2020[33]). These findings are also confirmed by research in the UK (Reuschke, Henley and Daniel, 2020[68]).

These negative effects are driven by several factors, notably the sectors in which self-employed immigrants operate. Self-employed immigrants are over-represented in sectors that have been most heavily impacted by containment measures such as the hospitality sector. Immigrants account for more than $40 \%$ of self-employment in the hospitality sector in several EU Member States such as Denmark, Germany, Luxembourg and Sweden and non-EU OECD countries such as Canada and Norway (OECD, $\left.2020_{[69]}\right)$. Additionally, there is evidence suggesting that geographical location and living accommodation conditions exert a significant influence on the health and economic experiences of immigrant populations. Geographically, immigrant populations tend to live in urban areas (International Organization for Migration, $\left.2019_{[70]}\right)$, and often within poorer neighbourhoods where the health effects of COVID-19 are reportedly higher and COVID-19 testing capabilities significantly lower. Immigrants are also more likely to live in substandard accommodation and are twice as likely to live in overcrowded dwellings (OECD, 2020[69]). Such conditions present an environment that facilitates a greater risk of exposure to COVID-19, often resulting in higher incidences of mortality (Bambra et al., 2020[71]).

Finally, there is also evidence that self-employed immigrants vary in their resource capabilities, which impacts their ability to respond to an economic crisis. A common challenge for immigrant households is their low levels of savings. For example, surveys in the UK found that $30 \%$ of Bangladeshis, black Caribbean and black Africans were found to live in households with enough savings to cover one month of income, compared with $60 \%$ of the rest of the population (Platt and Warwick, 2020[72]). Such low levels of savings remove any ability to absorb a negative economic shock. This affects both their resilience and opportunity to respond when there is an upturn in the economy.

For additional discussion on the impacts of the COVID-19 pandemic on immigrant entrepreneurship, please see Chapter 8.

\section{...the youth and senior entrepreneurs have also been disproportionately affected in most countries}

The COVID-19 pandemic poses considerable challenges for youth related to education, employment, mental health and disposable income. Youth have experienced higher rates of job loss and drops in working hours than all other age groups (Adams-Prassl et al., 2020[73]; Eurofound, 2020[8]; OECD, $\left.2021_{[1]}\right)$. This is particularly concerning for youth first entering the labour market as their job 
prospects have evaporated (Gardiner and Slaughter, 2020[74]) and for disadvantaged youth (e.g. school drop-outs) who already faced difficulties entering work.

There is evidence to suggest that young self-employed people have been more likely to be negatively impacted by COVID-19. An analysis of labour force survey data in the UK found that about $26 \%$ of self-employed youth (16-29 years old) were at risk of losing their work due to sector of operation relative to $23 \%$ of those working as employees (Henley and Reuschke, 2020[43]). Moreover, the analysis found nearly half (47\%) of young self-employed women (16-29 years old) were at risk relative to $16 \%$ of young self-employed men. However, evidence from Canada suggests that while young entrepreneurs have been impacted by the pandemic, the effects were smaller overall than for other age groups. Between February and July 2020, there was a decline in business ownership by those aged 25-34 years old of 9.8\%, the lowest drop of all age categories (Beland, Fakorede and Mikola, 2020[16]). The 25-34 years old category also had the smallest decline in hours worked (-5.9\%).

Self-employed seniors have faced greater impacts of COVID-19 than those in their 30s and 40s in some but not all countries. An analysis in Belgium found that self-employed seniors (50-59 years old) were among the most affected $-28 \%$ reported being impacted compared to $24 \%$ of those aged 30 to 39 years old (Marchal et al., 2021 $\left.{ }_{[75]}\right)$. However, research in Canada found that there was a $14 \%$ decline in business ownership between February and July 2020 in those over 55 years old, less than the drop in those 35-54 years old (-21\%) (Beland, Fakorede and Mikola, 2020[16]).

Although the reasons for these results may be related to location, timescale and methodological differences, there appear to be clear differences in the impact of COVID-19 on the self-employed by age. There are several factors that can explain these differences. First, there is an unequal access to resources across age groups since younger self-employed typically have less savings that can be used to weather a crisis and smaller networks that can be used to access resources. Second, self-employed youth are much less likely to employ other people so they have little ability to scale-back their business activities without exiting.

\section{Addressing the crisis with inclusive entrepreneurship policy}

\section{The COVID-19 pandemic calls for a greater emphasis on inclusion in entrepreneurship policy}

The COVID-19 pandemic has exposed and amplified inequalities in self-employment and entrepreneurship. Those with greater access to resources and those who can pivot their activity have fared better through the COVID-19 pandemic. Moreover, the supportive ecosystem for many entrepreneurs from under-represented and disadvantaged groups has been eroded. Many support organisations have eliminated face-to-face activities and services, and also face declining memberships. In addition, there is emerging evidence that the self-employed, particularly self-employed women, have suffered more adverse effects on mental health than employees.

Inclusive entrepreneurship policies aim to ensure that all people, regardless of their personal characteristics and background, have an opportunity to start and run their own businesses. They seek to support groups such as women, immigrants, youth, seniors, the unemployed, and people with disabilities. In some countries, other groups may be of particular importance too, such as the Roma minority. The objective of inclusive entrepreneurship policies is twofold:

- Ensure that people in these groups are aware of the potential that entrepreneurship may have for them as a labour market activity and to build motivations for pursuing them;

- Address market, institutional and behavioural failures that disproportionately affect people in underrepresented and disadvantaged groups. This includes addressing barriers in financial markets and 
barriers to acquiring entrepreneurship skills, building entrepreneurial networks and fostering an entrepreneurial culture. It would be expected that by addressing these barriers, there would be an increase in the amount of entrepreneurship activities by these groups as well as an increase in the quality of the businesses created so that they are more sustainable and innovative.

Despite these objectives, governments need to resist trying to turn everyone into an entrepreneur since not everyone will be successful. However, another outcome sought is to improve labour market attachment. By helping people acquire skills and work experience, and build networks, they also become more employable. Moving people from these groups into employment is a desirable outcome as entrepreneurship may not be an appropriate career path for all. Inclusive entrepreneurship policies can contribute to government actions in the aftermath of the COVID-19 pandemic to:

- Strengthen societies by increasing participation in work and society and supporting diversity in the labour market;

- Stimulate growth and create jobs by harnessing the entrepreneurial talents across all population groups;

- Prepare people for the future of work by helping everyone develop entrepreneurial mindsets and learn how to work in flexible ways;

- Address rising unemployment by upskilling the unemployed and supporting them in business creation.

Approaches to inclusive entrepreneurship policy vary greatly across countries. Depending factors include political priorities, cultural attitudes towards inclusion and equality, budget allocations for entrepreneurship policies and programmes and approaches to active labour market policy. One important area of action is to improve the conditions for entrepreneurship with attention paid to how the determinants of entrepreneurship impact groups differently (Figure 1.13). This includes, for example, removing disincentives in regulatory systems for some groups (e.g. tax policies that favour single income households), positively influencing social attitudes towards labour market participation and entrepreneurship by everyone (e.g. women, seniors, people with disabilities) and improving access to entrepreneurship education and training for everyone. Many governments use targeted and tailored schemes to provide support to specific groups, which typically seek to build entrepreneurship skills, facilitate access to finance, raise awareness about the potential of entrepreneurship, build entrepreneurship networks and use regulatory instruments to enhance entrepreneurship opportunities.

While the use of dedicated support schemes can be effective, their success is often determined by the extent to which they are designed and delivered in an appropriate manner for the target group. Programme evaluations show a critical success factor is whether or not the schemes reach their intended target clients. This calls for special attention to outreach methods since people access information through different channels. For example, a youth entrepreneurship mentoring scheme would likely be more effective at reaching young people if it was promoted on social media. However, this approach is likely not effective for seniors. Similarly, the content and delivery methods can also be more effective if they are designed for the particular needs of the target group. This can also hold true for general entrepreneurship schemes. Efforts to adjust outreach, content and delivery for specific groups can make the schemes more attractive and more effective for different target groups (OECD/The European Commission, 2013[58]).

Evaluation is an important but under-utilised tool in inclusive entrepreneurship policies and programmes. This includes ongoing monitoring and ex post evaluation to identify strengths, weaknesses and gaps in support, as well as ex ante evaluation that is used to inform policy design. In general, evaluation practices for inclusive entrepreneurship policy lag behind those of other policy areas. This represents a missed opportunity to design effective policy interventions (OECD/EU, 2013 $\left.{ }_{[76]}\right)$. 
Figure 1.13. Approaches to inclusive entrepreneurship

\begin{tabular}{|c|c|c|c|c|c|c|c|c|c|c|c|}
\hline \multirow{6}{*}{$\begin{array}{l}\text { 1. Improving the } \\
\text { conditions for } \\
\text { entrepreneurship }\end{array}$} & \multicolumn{11}{|c|}{ Regulatory framework } \\
\hline & \multicolumn{11}{|c|}{ Market conditions } \\
\hline & \multicolumn{11}{|c|}{ Availability of finance } \\
\hline & \multicolumn{11}{|c|}{ Knowledge creation and diffusion } \\
\hline & \multicolumn{11}{|c|}{ Entrepreneurial capabilities } \\
\hline & \multicolumn{11}{|c|}{ Culture } \\
\hline & \multicolumn{3}{|c|}{$\begin{array}{l}\text { Entrepreneurship } \\
\text { skills }\end{array}$} & \multicolumn{4}{|c|}{ Access to finance } & \multicolumn{2}{|c|}{$\begin{array}{l}\text { Social capital } \\
\text { and culture }\end{array}$} & \multicolumn{2}{|c|}{ Regulations } \\
\hline $\begin{array}{l}\text { 2. Delivering tailored } \\
\text { support through } \\
\text { dedicated programmes }\end{array}$ & 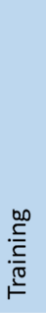 & 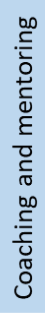 & 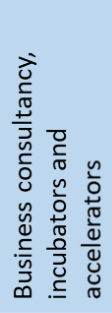 & 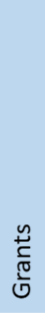 & 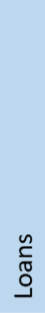 & 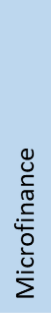 & 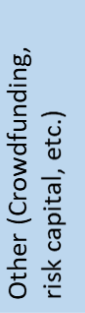 & 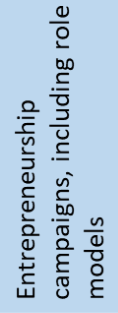 & 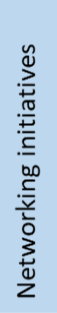 & 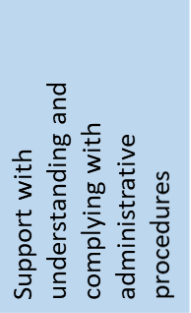 & 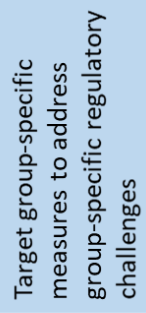 \\
\hline \multirow{5}{*}{$\begin{array}{l}\text { 3. Ensuring appropriate } \\
\text { design and delivery } \\
\text { mechanisms in } \\
\text { dedicated and general } \\
\text { programmes }\end{array}$} & \multicolumn{11}{|c|}{ Outreach } \\
\hline & \multicolumn{11}{|c|}{ Selection criteria } \\
\hline & \multicolumn{11}{|c|}{ Content } \\
\hline & \multicolumn{11}{|c|}{ Delivery methods } \\
\hline & \multicolumn{11}{|c|}{ Packages of inter-related supports } \\
\hline $\begin{array}{l}\text { 4. Using evaluation as a } \\
\text { policy development tool }\end{array}$ & \multicolumn{11}{|c|}{ Ex ante, monitoring, ex post, feedback } \\
\hline
\end{tabular}

\section{There have been several positive developments in the EU over the past decade...}

Inclusive entrepreneurship policy has advanced over the previous decade as awareness of these types of policies has grown since the 2008-09 financial crisis. The OECD monitors inclusive entrepreneurship policies across EU Member States through a regular biennial assessment of inclusive entrepreneurship policies and programmes across EU Member States (for more information, please see Reader's Guide). Through this assessment, four important developments have been identified: increased profile of inclusive entrepreneurship issues in high-level policy documents; a growing sophistication of support for women entrepreneurs; experimentation with new financing instruments to support inclusion in entrepreneurship, and strong attention paid to tailored entrepreneurship coaching and mentoring. Member States tended to group together along two axes: the number of "missing" entrepreneurs and the level of consideration given to inclusion in the suite of entrepreneurship policies and programmes (Figure 1.14). Those with relatively more "missing" entrepreneurs are those countries where the ratio of "missing" entrepreneurs to actual early-stage entrepreneurs is above the EU average. Similarly, those countries with relatively high attention to inclusion in entrepreneurship policy are those that had policy scores above the EU median. 
Figure 1.14. Inclusive entrepreneurship policy across EU Member States

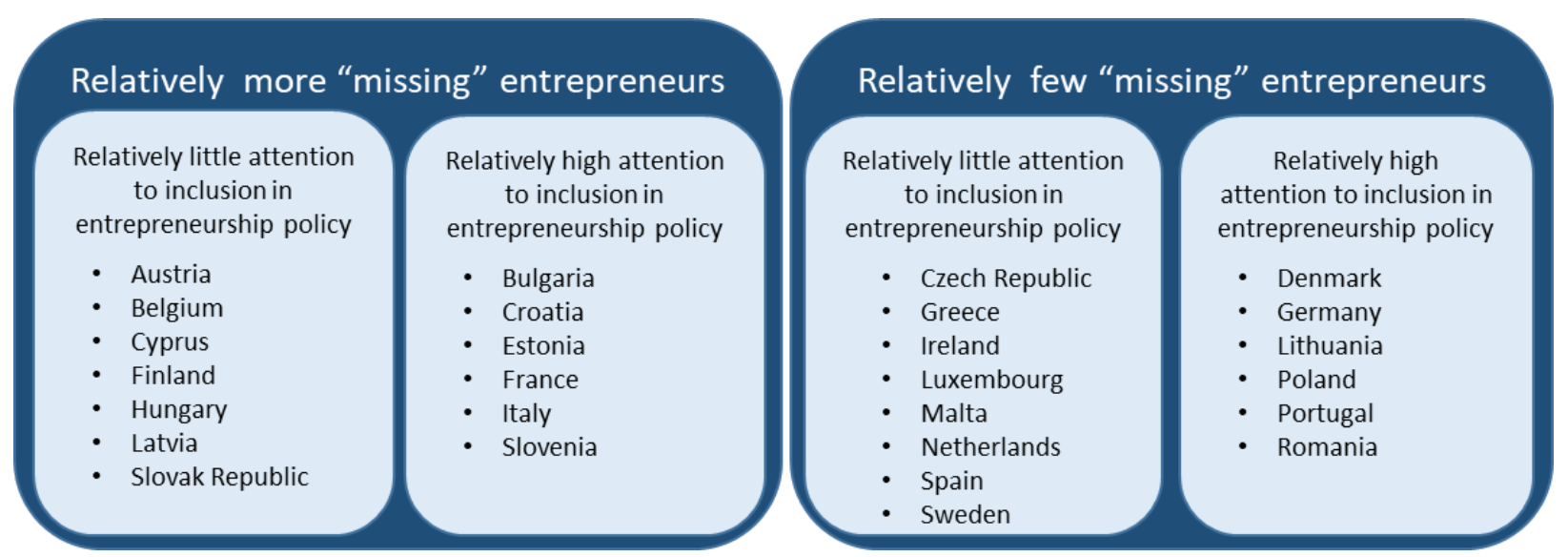

Note: For individual country assessment notes, please see (OECD, 2020[77]).

The awareness and visibility of inclusive entrepreneurship issues has increased. Since the financial crisis in 2008-09, numerous high-level policy documents and action plans such as the Europe 2020 Strategy and the EU Entrepreneurship Action Plan have drawn attention to gaps in entrepreneurship. As a result, EU Member States and regions are increasingly considering the needs of different population groups when designing and implementing entrepreneurship schemes. In 2020, more than $60 \%$ of EU Member States had tailored entrepreneurship strategies for youth and about half had strategies for supporting women and the unemployed in entrepreneurship. However, many of these countries can go further to more clearly define their objectives and targets for supporting these groups in entrepreneurship. Moreover, it is clear that less consideration is given to immigrants and seniors in the design of entrepreneurship policy.

The entrepreneurship landscape is also changing and governments are reacting, including some initial experiments with fintech. About a handful of EU Member States have started to experiment with these new methods of supporting finance for inclusive entrepreneurship. While a small number of public risk capital schemes were identified (OECD, 2020[77]), the most common approach currently used is public crowdfunding platforms. Regional and national governments are supporting these platforms in various ways, including matching funds raised and creating platforms that specialise in projects that focus on inclusion and social issues. For more on the potential of fintech in inclusive entrepreneurship policy, please see (OECD/EU, forthcoming[78]).

The use of tailored entrepreneurship coaching and mentoring is also growing and appears to now be as common as tailored entrepreneurship training for all target groups. Evaluations often show that entrepreneurship coaching and mentoring is an effective method of helping someone develop entrepreneurship skills since the support is based on an individual's needs (OECD/European Union, $\left.2014_{[79]}\right)$. Several different models are used, including the use of professional coaches and mentors, volunteer coaches and mentors from large corporations, group coaching and peer coaching. The keys for successful coaching and mentoring are to ensure an effective match between the entrepreneur and the coach/mentor considering type of business, sector and ambitions, and to ensure that the relationship is focussed on learning and development to avoid creating a dependence on the coach/mentor.

\section{...but some gaps and areas for improvement remain}

Despite the growth in tailored entrepreneurship support for youth and women, the quality of offers is uneven. Moreover, there is an insufficient focus on business development and growth. The majority of 
inclusive entrepreneurship support schemes focus on business creation (e.g. training, grants) and much less support is offered to help entrepreneurs develop and grow their business (OECD, 2020[77]).

A second gap in the suite of inclusive entrepreneurship policy in the EU is that less attention is paid to groups such as immigrants, seniors and people with disabilities. Despite being slightly underrepresented among business owners, immigrants are over-represented among high-growth entrepreneurs in many countries such as Canada (Picot and Rollin, 2019[80]) and the United States (Lofstrom and Wang, $\left.2019_{[81]}\right)$. High-skilled immigrants workers and entrepreneurs boost innovation - a key to long term growth (Aydemir, 2020[82] - and can also have positive spill overs including increasing wages for low-skilled workers and non-immigrants (Aydemir, 2020[82]) and greater innovation among non-immigrants (CandelHaug, Cuntz and Falck, 2018[83]). However, public policy efforts to tap into this potential appear to be limited (see Chapter 8 for further discussion). In addition, despite the awareness of the potential of senior entrepreneurship raised by the EU Year of Active Aging (2012), there are still few tailored schemes to support senior entrepreneurs. Governments could do more to help seniors who are interested in extending their career by transitioning into self-employment before full retirement. Similarly, self-employment holds potential for people with disabilities since they can manage their work in accordance with their personal circumstances, particularly in a context of increased telework. Despite being as likely to be self-employed as the overall population, entrepreneurs with disabilities have difficulties benefiting from support schemes because they are inaccessible, inflexible or irrelevant for the types of businesses operated by this group. Most support for people with disabilities is offered through the non-governmental sector and some countries may have unmet demand for entrepreneurship support. For further discussion on entrepreneurship by people with disabilities.

Finally, there continues to be a strong reliance on non-repayable financial instruments to support inclusive entrepreneurship, especially for youth and the unemployed. For these two groups, grants are the most common form of start-up financing offered by governments. This can be justified by the low levels of savings and collateral that youth and the unemployed typically have and some countries require that the funds are paid back if the business does not survive a minimum length of time (e.g. two years in Latvia). However, non-repayable financial support is often not sufficient to launch a sustainable business and does not create strong incentives for the entrepreneur to ensure that their business survives. Other instruments such as microfinance (see Chapter 7) and loan guarantees create risk sharing between the public and private sectors to reduce the cost of debt.

\section{The COVID-19 crisis also reinvigorated the debate about social protection for the self- employed...}

Social protection schemes are policies and programmes aimed to support a standard of living. These measures are designed to reduce poverty and vulnerability by diminishing risk exposure and augmenting capacity to manage economic and social risks. Overall, the lack of social protection constitutes a major obstacle to economic and social development and leads to higher economic uncertainty and heightened vulnerability among individuals who do not have sufficient coverage. In the long run, the gaps in access to social protection may put at risk the welfare and health of individuals, contribute to increasing economic uncertainty, poverty risk and inequalities, and may also lead to suboptimal investment in human capital, reduce trust in institutions and limit inclusive economic growth.

Social security systems were primarily developed for and remain geared towards workers in "standard employment relations", implying a long-term, full-time work relationship. Self-employed and other non-standard workers can lack (full) social protection coverage either because they cannot contribute and therefore benefit (lack of formal coverage), or because they declare their own income which can fluctuate or be the result of a combination of different income sources. Another issue may be the difficulty in defining and capturing non-standard workers for social security purposes. Globalisation and digitalisation have opened the labour market to new work arrangements, lowering transaction costs and 
extending the boundaries of enterprises (OECD, 2018[84]). However, these changes expose workers to new risks and pose new challenges for non-standard workers such as the inability to rely on insurance functions of a standard employment contracts, lower effectiveness of minimum wage floors, an increase of income insecurity due to a lack of fixed working hours, and the inability to access social protection measures (OECD, 2018[84]).

The European Commission adopted a proposal for a Council Recommendation "Access to social protection for all" in December 2018 as part of the European Pillar of Social Rights. This Recommendation was formally adopted by the Council on 8 November 2019 and aimed to support access to social protection schemes for all including non-standard workers and the self-employed not sufficiently covered by social security systems (European Commission, 2018[85]). Key objectives include closing formal coverage gaps, improving effective coverage, enhancing programme adequacy and increasing transparency. EU Member States are recommended to ensure that all workers - especially the selfemployed - can adhere to social protection schemes, build-up (transferable) entitlements, receive sufficient benefits in a timely manner, and are informed about their rights and obligations (European Commission, 2021[86]).

A monitoring framework has been established to support implementation. This framework provides performance indicators for formal coverage, effective coverage and adequate coverage across EU Member States and includes a pilot data collection and the mapping of relevant policy levers and data from the Eurostat Survey on Living and Working Conditions. The latest data show a significant gap remains in the social protection coverage of the self-employed and non-standard workers. As of Spring 2021, selfemployed workers (or at least groups of them) do not have access to sickness benefits in 4 Member States, to protection for accidents at work and occupational diseases in 8 Member States, and to unemployment insurance in 12 Member States. Moreover, their coverage is voluntary (mostly opt-in systems) for sickness benefits in 13 Member States, for accidents at work and occupational diseases in 7 Member States and for pensions in 9 Member States. Opt-in systems often lead to low take-up rates and therefore in practice to non-coverage for the majority of self-employed. Moreover, access to social protections remains more limited for some groups compared to others such as casual, on-demand work; simplified, short-term fixed contracts; seasonal work; apprenticeships or traineeships and country-specific contracts. These include mini-jobs in Germany, civil law contracts in Poland, agreements to perform a job in Czech Republic, work agreements with irregular income in the Slovak Republic and domestic workers in Spain.

\section{....and the pandemic offers some lessons for the future}

The COVID-19 crisis acted as a catalyst for extending social protection coverage to previously uncovered population groups. While many measures have been presented as exceptional and temporary, the COVID-19 crisis has sped up the implementation of the Recommendation. For example, many EU Member States scaled up existing social protection schemes in the early-stages of the pandemic (e.g. extension of short-time work schemes and unemployment benefits) and most provided support to vulnerable population groups through emergency measures, such as flat rate allowances for self-employed workers in Greece (EUR 800), Italy (EUR 600) and Poland (PLN 2000 or EUR 440). However, these supports were not always extended to the self-employed and non-standard workers or were offered at later stages of the crisis relative to those with standard employment situations. As the recovery phase continues to unfold, sustained effort in maintaining and reinforcing social protection schemes for all, notably vulnerable and previously unprotected population groups, needs to be upheld.

\section{The next generation of inclusive entrepreneurship policies}

As the COVID-19 pandemic comes under control, government economic policy has to switch attention to the post-COVID-19 landscape and economic recovery. It has been recognised widely that 
the pandemic has both highlighted and accentuated economic and societal inequalities, which calls for a greater use of inclusive entrepreneurship policies. However, the pre COVID-19 suite of policy actions may not be sufficient or appropriate for a post COVID-19 economy.

\section{Make entrepreneurship policy more gender sensitive}

To strengthen the suite of support for women entrepreneurs, an important first step is to adopt a more inclusive policy making process. This calls for greater involvement of women entrepreneurs, experts and advisers to develop policies and support schemes that address both entrepreneurs' needs and the root causes of gender inequality in entrepreneurship. This could include, for example, setting up a high-level women entrepreneurship committee and women expert policy advisors to advise governments. Another important factor for successful policy making is to advance the collection of more genderdisaggregated data to monitor the effectiveness and impact of entrepreneurship policies for women entrepreneurs.

In addition, governments could invest more in strengthening women enterprise ecosystems. Women's entrepreneurship is supported by a whole ecosystem of business support organisations - often in the non-profit sector - offering access to finance, advice, peer learning, mentoring and more to women entrepreneurs. Governments could do more to leverage this expertise by working with them in policy design and delivery. These organisations have also faced strong impacts due to COVID-19 and may need support to continue their level of services.

Finally, governments can do more to segment support services for women entrepreneurs, especially by increasing support for growth-oriented women entrepreneurs. This can be accomplished by increasing the pool of women business angels and decision-makers in venture capital funds, ensuring that growth-oriented women entrepreneurs have dedicated support programmes, increasing accountability for gender balance in mainstream business growth programmes, and increasing the pipeline of women growth entrepreneurs by supporting young women in STEM fields in their studies and women in leadership senior management positions.

For more discussion on women's entrepreneurship and women's entrepreneurship policy, please see Chapter 2.

\section{Open up pathways to work for young people through youth entrepreneurship programmes}

The COVID-19 pandemic has severely disrupted life for young people, including access to education and employment. While it may be too early to fully anticipate the long-term impact of the crisis, increasing levels of youth unemployment and other repercussions may significantly delay their transition to an autonomous life.

Governments can make greater use of youth entrepreneurship schemes to increase access to the labour market for young people. Lessons from evaluations suggest that some approaches to supporting youth entrepreneurship, including using a "funnel" approach that offers small amounts of support to many and more intensive to support to those who can demonstrate success (OECD/European Commission, $\left.2020_{[87]}\right)$. This approach calls for short, basic entrepreneurship support offered to a large number of young people, with more intensive follow-up training and grants to those who show an interest in pursuing business creation. Those who are successful in launching a business (or at least advancing towards it) can then access coaching and mentoring, and larger financial supports. This type of approach has demonstrated success with even the most disadvantaged youth, e.g. the Prince's Trust Enterprise Programme (OECD/European Commission, 2020[87]). 
At the same time, governments need to continue to support youth entrepreneurs in higher education. These entrepreneurs can bring innovations into the market that respond to the COVID-19 crisis, particularly in digitalisation, and have a strong potential role in helping to drive the economic recovery. The business incubator model holds promise for this profile of youth entrepreneurs since they can effectively deliver packages of support and help them to build their networks.

For more discussion on youth entrepreneurship and youth entrepreneurship policy, please see Chapter 4 .

\section{Leverage the potential of immigrant entrepreneurs to create jobs in the recovery}

Immigrant entrepreneurs have been, on average, severely affected by the pandemic due to the complex intersection of health, economic and location effects. This has led to substantial drops in the numbers of self-employed and reduced entrepreneurship opportunities. Before the pandemic, the share of immigrants among the self-employed across the EU nearly doubled between 2006 and 2018, increasing from about $6 \%$ to $11 \%$ (these data exclude Germany because data are not available prior to 2017). Moreover, immigrant entrepreneurs are a driver of job creation, growth and innovation in many countries.

Future inclusive entrepreneurship policies need to do a more effective job of targeting support at immigrants who operate high-potential businesses. Some governments have launched start-up visa programmes to attract immigrant entrepreneurs and a small number offer financial incentives. While many of these schemes reach only a small number of immigrant entrepreneurs, they hold potential for creating jobs, strengthening trade linkages and diffusing innovation. A key to success for these approaches is to build strong linkages between the immigrant-led business and the local community and business support infrastructure (e.g. incubators). However, it also appears to be critical to simplify administrative requirements for moving from an entrepreneurship visa to a residency permit since evaluations often show that entrepreneurs close their business and leave in response to difficulties and delays in receiving a longer-term residency permit.

Furthermore, solo self-employment is an important activity for many immigrants because it provides a means to earn an income and support a family. Governments can do more to improve the sustainability of these businesses, including offering more tailored training, coaching and mentoring to improve the productivity of these businesses. These supports can be offered in different languages and emphasis is needed on building networks with other entrepreneurs and professional support organisations in local communities. However, governments must also recognise that self-employment is not likely to be an effective tool of upward economic mobility for low-skilled immigrants. This calls for support to be concentrated on those with potential for creating productive businesses.

For more discussion on policies to support immigrant entrepreneurs, please see Chapter 8.

\section{Increase use of repayable financial instruments to support inclusive entrepreneurship}

All EU Member States continue to use grants to support business creation for people from underrepresented and disadvantaged groups, yet there are several disadvantages to this approach (OECD/The European Commission, 2013[58]; Marchese, 2014[59]). First, the funds provided to entrepreneurs will not be directly recovered although a sustainable start-up could repay the grant indirectly through taxes. Second, the entrepreneur may have less of an incentive to ensure the sustainability of their business since they do not have to repay the start-up funds.

Shifting to a greater use of repayable instruments addresses these issues and can also lead to a more effective allocation of funds. The use of microfinance and other debt instruments typically transfers the funding decisions from government policy officers to private sector actors that have an expertise in assessing business proposals. Microfinance schemes are commonly run by non-government or private sector organisations with financial support and risk sharing from governments. 
In addition to increasing the use of microfinance, governments can better align the use of these policy priorities, including green and sustainable projects. A key success factor for increasing the impact of microfinance sector will be to get the level of digitalisation correct. There are two competing perspectives on digitalisation in the microfinance sector. One side views the sector as lagging greatly in terms of the adoption of digital tools and practices in microfinance institutions, which leads to inefficiencies with high costs. The other side views face-to-face interaction as a critical success factor in microfinance schemes and that increasing digitalisation in the sector would transform microfinance institutions into fintech companies. There is room to find middle ground by streamlining processes with digital applications and using digital tools to monitor microfinance clients.

For more discussion on the future of microfinance for inclusive entrepreneurship, please see Chapter 7.

\section{Adapt, design and deliver measures at the local level}

The impacts of COVID-19 have been uneven across countries, regions and cities, underscoring the need to tailor inclusive entrepreneurship policy interventions to the local conditions. As outlined in this chapter, the impacts of the pandemic on entrepreneurs and the self-employed are largely determined by sector, local containment measures that restrict economic activities and access to resources. Each of these factors is heavily influenced by where the entrepreneur lives and operates their business. Therefore, inclusive entrepreneurship policies need to be designed and implemented in accordance with the local institutional, cultural and social contexts. This includes, for example, ensuring that the trainers, coaches and advisors delivering support reflect the population of entrepreneurs in terms of gender, age and cultural background.

Another recurring theme in examining the uneven impacts of COVID-19 on the self-employed has been the significance and value of working with the existing structures and ecosystems. This is particularly the case for the inclusive entrepreneurship groups that have often developed their enterprises with support from local networks and organisations. Such organisations are more likely to be deeply embedded in different communities (e.g. immigrants), engendering trust and an understanding of the requirements of these groups. Evaluation evidence tends to suggest that this can lead to higher take-up rates among the targeted populations and a greater impact on the business (OECD/The European Commission, 2013[58]).

\section{Go further in embracing digitalisation}

A critical future direction of future inclusive entrepreneurship policy is to place a greater emphasis on digitalisation. There has been an irreversible move to the digitalisation of economic activity during the COVID-19 pandemic. This has changed the ways in which enterprises engage with their supply chains and how they meet the changing purchasing behaviour of customers. The pandemic has also stimulated a move towards more digital ways of working including homeworking and a decline in workplace attendance. These trends create new opportunities for entrepreneurs, but also create new challenges. Not all entrepreneurs have access to these opportunities due to a lack of digital skills and other barriers such as lack of funds to invest in digital technologies (OECD/European Union, 2019[66]). The accelerated move towards digitalisation may also increase the gap between those that are digitally aware and those that are not (Sostero et al., 2020[88]). This calls for increased actions to develop basic digital skills across the population including an increase in the availability of training programmes that are designed for and delivered to specific groups.

Governments can increase support for the self-employed and entrepreneurs to support them in adopting digital technologies, practices and models. This could include, for example, actions that increase awareness about the benefits of digitalisation, such as information campaigns and workshops. More can also be done to support the development of advanced digital skills (e.g. online marketing, digital 
security, process management) through tailored workshops and training sessions. Those entrepreneurs with higher potential for digitalising their businesses could be offered more intensive support through specialised business development services and technology extension programmes.

At the same time, more can be done to increase digitalisation within inclusive entrepreneurship programmes. Throughout the pandemic, programmes have had to adapt to containment measures by delivering support through online channels. Programme managers have often reported improved reach of programmes as well as improved monitoring of participants, without a noticeable decline in client satisfaction. This calls for a more thorough evaluation of digital delivery mechanisms during the pandemic to understand what worked well and how digital delivery mechanisms can be improved in the future.

\section{References}

Adam, S., H. Miller and T. Waters (2020), Income protection for the self-employed and employees during the coronavirus crisis, The Institute for Fiscal Studies, https://www.ifs.org.uk/uploads/publications/bns/BN277-Income-protection-for-the-selfemployed-and-employees-during-the-coronavirus-crisis.pdf (accessed on 31 May 2021).

Adams-Prassl, A. et al. (2020), "The impact of the coronavirus Lockdown on mental health: evidence from the US”, Cambridge-INET Working Paper Series, No. 2020/21.

Ahrendt, D. et al. (2021), Living, working and COVID-19 (Update April 2021): Mental health and trust decline across EU as pandemic enters another year, Eurofound, https://www.eurofound.europa.eu/publications/report/2021/living-working-and-covid-19update-april-2021 (accessed on 11 May 2021).

Aydemir, A. (2020), "Skill-based immigration, economic integration, and economic performance", IZA World of Labor, http://dx.doi.org/10.15185/izawol.41.v2.

Bambra, C. et al. (2020), "The COVID-19 pandemic and health inequalities", Journal of Epidemiology and Community Health, http://dx.doi.org/10.1136/jech-2020-214401.

Beland, L., O. Fakorede and D. Mikola (2020), “Canadian Small Businesses' Employees and Owners during COVID-19", GLO Discussion Paper Series, No. 650, Global Labor Organization (GLO).

Beland, L., O. Fakorede and D. Mikola (2020), "Short-Term Effect of COVID-19 on SelfEmployed Workers in Canada", Canadian Public Policy, Vol. 46/s1, http://dx.doi.org/10.3138/cpp.2020-076.

Benz, M. and B. Frey (2008), "The value of doing what you like: Evidence from the self-employed in 23 countries", Journal of Economic Behavior \& Organization, Vol. 68/3-4, pp. 445-455, https://doi.org/10.1016/j.jebo.2006.10.014.

Berrill, J. et al. (2020), "The relationship between financial distress and well-being: Exploring the role of self-employment”, International Small Business Journal: Researching Entrepreneurship, http://dx.doi.org/10.1177/0266242620965384.

Biddle, N. et al. (2020), The initial impacts of COVID-19 on the self-employed, ANU Centre for Social Research and Methods, https://openresearchrepository.anu.edu.au/bitstream/1885/213199/1/The initial impacts of COVID19 self employment 2020.pdf (accessed on 19 March 2021). 
Binder, M. and A. Blankenberg (2021), "Self-employment and Subjective Well-Being", GLO

Discussion Paper, No. 744, Global Labor Organization (GLO), Essen,

https://www.econstor.eu/bitstream/10419/228453/1/GLO-DP-0744.pdf (accessed on

19 May 2021).

Blundell, J., S. Machin and M. Ventura (2020), "Covid-19 and the self-employed: Six months into the crisis", Covid-19 Analysis Series, No. 12, Centre for Economic Performance, https://cep.Ise.ac.uk/pubs/download/cepcovid-19-012.pdf (accessed on 19 March 2021).

Blundell, R. et al. (2020), "COVID-19 and Inequalities", Fiscal Studies, Vol. 41/2, http://dx.doi.org/10.1111/1475-5890.12232.

Bosma, N. et al. (2021), Global Entrepreneurship Monitor 2020/2021 Global Report, Global Entrepreneurship Research Association, https://www.gemconsortium.org/file/open?fileld=50691 (accessed on 31 May 2021).

Brown, R., A. Rocha and M. Cowling (2020), "Financing entrepreneurship in times of crisis: Exploring the impact of COVID-19 on the market for entrepreneurial finance in the United Kingdom", International Small Business Journal: Researching Entrepreneurship, Vol. 38/5, http://dx.doi.org/10.1177/0266242620937464.

Candel-Haug, K., A. Cuntz and O. Falck (2018), "Polish immigrants stimulate innovation in Germany", LSE Business Review, http://i. http://eprints.Ise.ac.uk/89794/1/businessreview2018-05-10-polish-immigrants-stimulate-innovation-in.pdf (accessed on 4 August 2021).

Cribb, J., I. Delestre and P. Johnson (2021), Who is excluded from the government's Self Employment Income Support Scheme and what could the government do about it, Institute for Fiscal Studies, https://www.ifs.org.uk/publications/15276 (accessed on 19 March 2021).

Crowley, F. and J. Doran (2020), "COVID-19, occupational social distancing and remote working potential: An occupation, sector and regional perspective", Regional Science Policy \& Practice, Vol. 12/6, http://dx.doi.org/10.1111/rsp3.12347.

Eurofound (2021), COVID-19 EU Policy Watch: Database of national-level responses, https://static.eurofound.europa.eu/covid19db/database.html (accessed on 11 May 2021).

Eurofound (2020), Living, working and COVID-19, Publications Office of the European Union, Luxembourg.

European Commission (2021), Access to social protection, https://ec.europa.eu/social/main.jsp?catld=1312\&langld=en.

European Commission (2018), "Proposal for a COUNCIL RECOMMENDATION on access to [85] social protection for workers and the self-employed", COM(2018) 132 final, 2018/0059 (NLE).

Eurostat (2021), Employment by sex, age, full-time/part-time, professional status and NUTS 2 regions.

Eurostat (2021), Labour Force Survey, https://ec.europa.eu/eurostat/web/lfs (accessed on 6 May 2021).

Eurostat (2020), Culture statistics - cultural employment, https:/lec.europa.eu/eurostat/statisticsexplained/index.php?title=Culture statistics - cultural employment (accessed on 19 May 2021). 
Facebook/OECD/World Bank (2020), The Future of Business Survey, https://dataforgood.fb.com/global-state-of-smb (accessed on 6 May 2021).

Fairlie, R. (2021), Update on data presented in: The impact of COVID-19 on small business owners: Evidence from the first three months after widespread social-distancing restrictions.

Fairlie, R. (2020), "The impact of COVID-19 on small business owners: Evidence from the first three months after widespread social-distancing restrictions", Journal of Economics \& Management Strategy, Vol. 29/4, http://dx.doi.org/10.1111/jems.12400.

Fairlie, R. (2020), The Impact of Covid-19 on Small Business Owners: Evidence of Early-Stage Losses from the April 2020 Current Population Survey, National Bureau of Economic Research, Cambridge, MA, http://dx.doi.org/10.3386/w27309.

Fana, M. et al. (2020), The COVID confinement measures and EU labour markets, Publications Office of the European Union, Luxembourg, https://op.europa.eu/en/publication-detail//publication/fe5d685b-93fb-11ea-aac4-01aa75ed71a1/language-en (accessed on 10 May 2021).

Fana, M., S. Torrejón Pérez and E. Fernández-Macías (2020), "Employment impact of Covid-19 crisis: from short term effects to long terms prospects", Journal of Industrial and Business Economics, Vol. 47/3, http://dx.doi.org/10.1007/s40812-020-00168-5.

Foreman-Peck, J. (1985), "Seedcorn or Chaff? New Firm Formation and the Performance of the Interwar Economy", The Economic History Review, Vol. 38/3, pp. 402-422.

Fossen, F. (2020), "Self-employment over the business cycle in the USA: a decomposition", Small Business Economics, http://dx.doi.org/10.1007/s11187-020-00375-3.

Gardiner, L. and H. Slaughter (2020), The effects of the coronavirus crisis on workers Flash findings from the Resolution Foundation's coronavirus survey, Resolution Foundation, https://www.resolutionfoundation.org/publications/the-effects-of-the-coronavirus-crisis-onworkers/ (accessed on 25 May 2021).

GEM (2021), Special tabulations for the OECD of the Global Entrepreneurship Monitor (GEM) adult population survey for the years 2016 to 2020.

Graeber, D., A. Kritikos and J. Seebauer (2021), "COVID-19: a crisis of the female selfemployed", GLO Discussion Paper, No. 788, Global Labor Organization (GLO), https://www.econstor.eu/bitstream/10419/230677/1/GLO-DP-0788.pdf (accessed on 19 March 2021).

Grashuis, J. (2021), "Self-employment duration during the COVID-19 pandemic: A competing risk analysis", Journal of Business Venturing Insights, Vol. 15, http://dx.doi.org/10.1016/j.jbvi.2021.e00241.

Henley, A. and D. Reuschke (2020), "Covid-19 and self-employment in the UK", ERC Insight Paper, https://www.researchgate.net/publication/344386677 Covid-19 and selfemployment in the UK (accessed on 1 June 2021).

Henley, A. et al. (2021), "Self-employment in Wales during the COVID-19 Pandemic", Welsh Economic Review, Vol. 28/0, p. 1, http://dx.doi.org/10.18573/wer.259. 
Ingelsrud, M. (2021), "Standard and non-standard working arrangements in Norway consequences of COVID-19", Labour \& Industry: a journal of the social and economic relations of work, http://dx.doi.org/10.1080/10301763.2021.1979449.

International Organization for Migration (2019), World Migration Report 2020, International Organization for Migration, https://publications.iom.int/system/files/pdf/wmr 2020.pdf (accessed on 1 June 2021).

IPSE (2021), Coronavirus Report, Association of Independent Professionals and the SelfEmployed, https://www.ipse.co.uk/coronavirus-hub/coronavirus-report.html (accessed on 20 March 2021).

Juergensen, J., J. Guimón and R. Narula (2020), "European SMEs amidst the COVID-19 crisis: assessing impact and policy responses", Journal of Industrial and Business Economics, Vol. 47/3, http://dx.doi.org/10.1007/s40812-020-00169-4.

Kritikos, A., D. Graeber and J. Seebauer (2020), "Corona-Pandemie wird zur Krise f"ur Selbst"andige", DIW aktuell, No. 47, https://www.econstor.eu/bitstream/10419/222877/1/1702052729.pdf (accessed on 11 May 2021).

Lambert, A. et al. (2020), "How the COVID-19 epidemic changed working conditions in France", Population Societies, Vol. 7/1-4, https://www.cairn-int.info/revue-population-and-societies2020-7-page-1.htm (accessed on 19 May 2021).

Lofstrom, M. and C. Wang (2019), "Immigrants and entrepreneurship", IZA World of Labor, http://dx.doi.org/10.15185/izawol.85.v2.

Marchal, S. et al. (2021), "The distributional impact of the COVID-19 shock on household incomes in Belgium”, COVIVAT, No. 2, https://repository.uantwerpen.be/docstore/d:irua:4247 (accessed on 4 October 2021).

Marchese, M. (2014), "Entrepreneurial Activities in Europe - Finance for Inclusive Entrepreneurship”, OECD Employment Policy Papers, No. 5, OECD Publishing, Paris, https://dx.doi.org/10.1787/5jxrcmkgkzzs-en.

Martinez Dy, A. and D. Jayawarna (2020), "Bios, mythoi and women entrepreneurs: A Wynterian analysis of the intersectional impacts of the COVID-19 pandemic on self-employed women and women-owned businesses", International Small Business Journal: Researching Entrepreneurship, Vol. 38/5, http://dx.doi.org/10.1177/0266242620939935.

Millan, J. et al. (2013), "Determinants of job satisfaction: a European comparison of selfemployed and paid employees", Small Business Economics, Vol. 40/3, http://dx.doi.org/10.1007/s11187-011-9380-1.

Mo, G. et al. (2020), "Differential Impacts during COVID-19 in Canada: A Look at Diverse Individuals and Their Businesses", Canadian Public Policy, Vol. 46/s3, http://dx.doi.org/10.3138/cpp.2020-072.

Moreira, A. and R. Hick (2021), "COVID-19, the Great Recession and social policy: Is this time different?", Social Policy \& Administration, Vol. 55/2, http://dx.doi.org/10.1111/spol.12679. 
OECD (2021), Business dynamism during the COVID-19pandemic: Which policies for an inclusive recovery?, https://read.oecd-ilibrary.org/view/?ref=1060 1060390-

Omgjvd9j7t\&title=Business-dynamism-during-the-COVID-19pandemic\& ga=2.67484177.103687934.1622452121-1493467873.1593590312 (accessed on 2 June 2021).

OECD (2021), Coronavirus (COVID-19): SME policy responses, OECD Publishing, Paris, http://www.oecd.org/coronavirus/policy-responses/coronavirus-covid-19-sme-policyresponses-04440101/ (accessed on 20 March 2021).

OECD (2021), Managing tourism development for sustainable and inclusive recovery, https://doi.org/10.1787/23071672.

OECD (2021), OECD Economic Outlook, Interim Report March 2021, OECD Publishing, Paris, https://dx.doi.org/10.1787/34bfd999-en.

OECD (2021), OECD SME and Entrepreneurship Outlook 2021, OECD Publishing, Paris, https://dx.doi.org/10.1787/97a5bbfe-en.

OECD (2021), One year of SME and entrepreneurship policy responses to COVID-19: Lessons learned to "build back better", https://www.oecd.org/coronavirus/policy-responses/one-yearof-sme-and-entrepreneurship-policy-responses-to-covid-19-lessons-learned-to-build-backbetter-9a230220/ (accessed on 19 May 2021).

OECD (2021), Preparing for the Tourism Workforce for the Digital Future - Final Report, https://one.oecd.org/document/CFE/TOU(2020)4/FINAL/en/pdf (accessed on 19 May 2021).

OECD (2021), Tackling coronavirus (COVID-19), https://www.oecd.org/coronavirus/en/ (accessed on 10 May 2021).

OECD (2020), Culture shock: COVID-19 and the cultural and creative sectors, https://www.oecd.org/coronavirus/policy-responses/culture-shock-covid-19-and-the-culturaland-creative-sectors-08da9e0e/ (accessed on 19 May 2021).

OECD (2020), From pandemic to recovery: Local employment and economic development, OECD Publishing, Paris, https://www.oecd.org/coronavirus/policy-responses/from-pandemicto-recovery-local-employment-and-economic-development879d2913/?utm source=Adestra\&utm medium=email\&utm content=More $\% 20$ on $\% 20$ the $\% 2$ 0OECD\%20Covid19\%20Hub\&utm campaign=July $\% 20$ GD $\% 20$ NEWS $\% 20$ Covid $19 \% 20$ Jobs $\% 20 \% 26 \% 20$ Digita lisation\&utm term=sti (accessed on 10 May 2021).

OECD (2020), Inclusive Entrepreneurship Policies: Country Assessment Notes, https://www.oecd.org/cfe/smes/inclusive-entrepreneurship-policies-country-assessmentnotes.htm (accessed on 6 June 2021).

OECD (2020), OECD Economic Outlook, Volume 2020 Issue 2, OECD Publishing, Paris, https://dx.doi.org/10.1787/39a88ab1-en.

OECD (2020), What is the impact of the COVID-19 pandemic on immigrants and their children?, http://www.oecd.org/coronavirus/policy-responses/what-is-the-impact-of-the-covid-19pandemic-on-immigrants-and-their-children-e7cbb7de/ (accessed on 6 April 2021). 
OECD (2018), The Future of Social Protection: What Works for Non-standard Workers?, OECD

Publishing, Paris, https://dx.doi.org/10.1787/9789264306943-en.

OECD/EU (2016), Policy Brief on Women's Entrepreneurship,

https://www.oecd.org/cfe/smes/Policy-Brief-on-Women-s-Entrepreneurship.pdf.

OECD/EU (2015), Policy Brief on Expanding Networks for Inclusive Entrepreneurship, OECD,

Paris, https://doi.org/10.1787/23114886.

OECD/EU (2013), Policy Brief on Evaluation of Inclusive Entrepreneurship Programmes, https://www.oecd-ilibrary.org/docserver/5jxrcmkm81then.pdf?expires $=1622818901 \&$ id=id\&accname $=$ ocid84004878\&checksum $=5$ EB999E25ECE59 DFE902BE739E26E124 (accessed on 4 June 2021).

OECD/EU (forthcoming), Policy brief on access to finance for inclusive and social entrepreneurship: What role can fintech and financial literacy play?

OECD/European Commission (2020), "Policy brief on recent developments in youth entrepreneurship", OECD SME and Entrepreneurship Papers, No. 19, OECD Publishing, Paris, https://dx.doi.org/10.1787/5f5c9b4e-en.

OECD/European Union (2019), The Missing Entrepreneurs 2019: Policies for Inclusive Entrepreneurship, OECD Publishing, Paris, https://dx.doi.org/10.1787/3ed84801-en.

OECD/European Union (2014), The Missing Entrepreneurs 2014: Policies for Inclusive Entrepreneurship in Europe, OECD Publishing, Paris, https://dx.doi.org/10.1787/9789264213593-en.

OECD/The European Commission (2013), The Missing Entrepreneurs: Policies for Inclusive Entrepreneurship in Europe, OECD Publishing, Paris, https://dx.doi.org/10.1787/9789264188167-en.

ONS (2021), Labour market overview, UK: 26 January, Office for National Statistics, Statistical Bulletin 26 January 2021, https://www.ons.gov.uk/employmentandlabourmarket/peopleinwork/employmentandemployee types/bulletins/uklabourmarket/january2021 (accessed on 18 May 2021).

ONS (2021), Personal and economic well-being in Great Britain: January 2021, Statistical

Bulletin,

https://www.ons.gov.uk/peoplepopulationandcommunity/wellbeing/bulletins/personalandecon omicwellbeingintheuk/january2021\#personal-and-economic-well-being-data (accessed on 19 March 2021).

Picot, G. and A. Rollin (2019), "Immigrant Entrepreneurs as Job Creators: The Case of Canadian Private Incorporated Companies", Analytical Studies Branch Research Paper Series, No. 423, Statisitics Canada, Ottawa, https://www150.statcan.gc.ca/n1/en/pub/11f0019m/11f0019m2019011-eng.pdf?st=g5OILrhR.

Platt, L. and R. Warwick (2020), "COVID-19 and Ethnic Inequalities in England and Wales <sup $>^{*}</$ sup>”, Fiscal Studies, Vol. 41/2, http://dx.doi.org/10.1111/1475-5890.12228. 
Reuschke, D., A. Henley and E. Daniel (2020), "First findings on the impact of COVID-19 on selfemployment in the UK - evidence from the Understanding Society household survey", ERC Insight Papers, No. 18, https://www.understandingsociety.ac.uk/research/publications/526243 (accessed on 1 June 2021).

Reuschke, D. et al. (2021), "Testing the Differential Impact of COVID-19 on Self-Employed Women and Men in the United Kingdom", IZA Discussion Papers, No. 14216, IZA, https://www.iza.org/publications/dp/14216/testing-the-differential-impact-of-covid-19-on-selfemployed-women-and-men-in-the-united-kingdom (accessed on 4 October 2021).

Reuschke, D., C. Mason and S. Syrett (2021), "Digital futures of small businesses and entrepreneurial opportunity", Futures, Vol. 128, http://dx.doi.org/10.1016/j.futures.2021.102714.

Roper, S. and J. Turner (2020), "R\&D and innovation after COVID-19: What can we expect? A review of prior research and data trends after the great financial crisis", International Small Business Journal: Researching Entrepreneurship, Vol. 38/6, http://dx.doi.org/10.1177/0266242620947946.

Sostero, M. et al. (2020), Teleworking and the COVID-19 crisis: a new digital divide? Living, working and COVID-19, Eurofound, https://ec.europa.eu/jrc/en/publication/eur-scientific-andtechnical-research-reports/teleworkability-and-covid-19-crisis-new-digital-divide (accessed on 3 June 2021).

Stephan, U. (2018), “Entrepreneurs' Mental Health and Well-Being: A Review and Research Agenda", Academy of Management Perspectives, Vol. 32/3, https://doi.org/10.5465/amp.2017.0001.

Torrès, O. et al. (2021), "Risk of burnout in French entrepreneurs during the COVID-19 crisis", Small Business Economics, http://dx.doi.org/10.1007/s11187-021-00516-2.

United Nations (2021), Coronavirus global health emergency, https://www.un.org/coronavirus. (accessed on 10 May 2021).

Villaseca, D., J. Navío-Marco and R. Gimeno (2020), "Money for female entrepreneurs does not grow on trees: start-ups' financing implications in times of COVID-19", Journal of Entrepreneurship in Emerging Economies, Vol. ahead-of-print/ahead-of-print, http://dx.doi.org/10.1108/JEEE-06-2020-0172.

Yue, W. and M. Cowling (2021), "The Covid-19 lockdown in the United Kingdom and subjective well-being: Have the self-employed suffered more due to hours and income reductions?", International Small Business Journal: Researching Entrepreneurship, Vol. 39/2, http://dx.doi.org/10.1177/0266242620986763. 


\section{Notes}

${ }^{1}$ The measure of business ownership in the CPS captures all business owners including those who own incorporated or unincorporated businesses, and those who are employers or non-employers.

${ }^{2}$ Essential and fully active sectors are food production, utilities, health and all the other sectors identified as essential in each country. In these sectors, most employment continues operating with normality. Active but via telework includes education, most of public administration, finance, insurance and telecommunications. Most employment in this sector is also maintained even in strict confinement, but with telework. This also includes professional, scientific and technical activities, even though they are explicitly considered as non-essential in the three countries. Mostly essential and partly active, not teleworkable includes a significant part of retail and manufacturing of chemicals and paper, which remain to some extent active even in the strict confinement situation. Mostly non-essential and partly active, not teleworkable includes the majority of manufacturing sectors not previously mentioned, as well as some machine and computer repair activities and construction. These activities are not essential nor teleworkable; but since they generally do not involve direct interaction with clients, in regular confinement situations they are normally allowed to function (under strict conditions). Closed includes hotels, restaurants and accommodation, estate and travel agencies, plus leisure and recreation services. These are not essential and explicitly closed by all the confinement decrees analysed, and they cannot continue to function via telework.

${ }^{3}$ The same measure may be included in more than one business type. 


\section{Part I Inclusive entrepreneurship indicators: Activity rates and barriers}




\section{Women's self-employment and entrepreneurship activities}

While the gender gap has closed slightly over the past decade, it persists according to many metrics such as self-employment rates and business creation rates. There are also gender differences, on average, in the nature of self-employment and entrepreneurship activities. This includes sector of operation, likelihood of creating additional jobs and more. One explanation for these gaps are differences in motivations and aspirations between men and women, as well as differences in barriers faced. This chapter presents updated data and trends for European Union Member States and OECD countries. 


\section{Key messages}

- The data presented in this chapter are based on Eurostat Labour Force Survey data covering the self-employed and Global Entrepreneurship Monitor data on pre start-up and early-stage business activities. These data are complemented with country-specific statistics to provide additional insights.

- Women are outnumbered in self-employment by two-to-one by men. In 2020 , just under $10 \%$ of working women in the European Union (EU) were self-employed relative to $17 \%$ of men. Among EU Member States, the proportion of working women who are self-employed ranged from just under $5 \%$ in Denmark to more than $20 \%$ in Greece. These shares are determined by a number of factors, including social attitudes towards entrepreneurship, gender roles, economic structure, barriers to entrepreneurship and more.

- Although the gender gap in self-employment has closed over the past decade, the COVID-19 pandemic has reversed some of this progress. The gender gap in selfemployment in the EU was almost 9 percentage points and it closed to nearly 7 percentage points by 2019. However, estimates from 2021 suggest that this gender gap is increasing again.

- Self-employed women tend to operate different types of businesses than men. Selfemployed women are more likely than self-employed men to be working in personal and household services and, on average, worked three fewer hours per week.

- Consequently, self-employed women were less likely than self-employed men to have created jobs for others. In the EU, about one-quarter of self-employed women had at least one employee in 2020 relative to one-third of self-employed men. This gap between men and women grew in about half of EU Member States between 2011 and 2020.

- Women are less likely than men to be active in starting a business. Over the period 201620 , less than $5 \%$ of women in the EU were involved in creating a business or managing a new business relative to about $10 \%$ of men. This gap is due to several factors, including attitudes towards entrepreneurship and barriers such as access to finance and a lack of entrepreneurship skills. For example, only $38 \%$ of women in the EU over this period reported that they have the skills to start a business relative to more than half of men.

- There is also a gender gap in the nature of entrepreneurship activities. Women entrepreneurs are $60 \%$ as likely to expect that their start-up will create more than 19 jobs over the next five years. This is consistent with women entrepreneurs being less likely to operate in growth-oriented sectors and a greater level of risk aversion, on average. However, women entrepreneurs are as likely as men entrepreneurs to report introducing a new product or service over the period 2016-20.

- Tailored policies and programmes to support women entrepreneurs are widely used across EU Member States and OECD countries. Common interventions include entrepreneurship training, coaching and mentoring, grants and microfinance. Relative to other inclusive entrepreneurship target groups, support for women entrepreneurs is more comprehensive and generally of higher quality. However, more tailored support is needed and governments could strengthen the policy frameworks that underpin programmes and going further to tailor schemes to local contexts. 


\title{
Policy context for women's self-employment and entrepreneurship
}

\section{Looking for the "missing" women entrepreneurs}

The longstanding gender gap in entrepreneurship represents a missed opportunity for innovation, social and economic value creation, and job creation. A large body of research underlines the untapped potential of women entrepreneurs (OECD, 2012[1]) and some estimates suggest that closing the gender gap in entrepreneurship could add 2\% to global GDP (Blomquist, 2014[2]). Another way to approximate the size of the gender gap in entrepreneurship is to estimate the number of "missing" entrepreneurs. If women participated in early-stage entrepreneurship at the same rate as "core age" men (i.e. 30-49 years old), there would be an additional 6.8 million "missing" women entrepreneurs in the European Union (EU). This accounts for about $72 \%$ of the total number of "missing" entrepreneurs in the EU, which is about the same as the share for OECD countries (75\%), representing 25.8 million "missing" women entrepreneurs.

Governments have been working to harness the potential of women's entrepreneurship since the 1970s. Dedicated women's entrepreneurship policies and programmes have become common across developed countries, seeking to help women overcome barriers to business creation and self-employment and to build motivations for entrepreneurship. Nonetheless, work remains to strengthen these policy frameworks by addressing the remaining gaps and by better linking schemes to policy objectives related to entrepreneurship, employment, innovation and industrial policy (OECD, 2012[1]).

\begin{abstract}
About half of EU Member States have taken steps towards building a policy framework to underpin entrepreneurship programmes for women. The majority of Member States have clearly defined a ministry or department responsible for developing policy to support women entrepreneurs -22 at the national level and 13 at the sub-national level - which is an important first step for strengthening policy in this area (Figure 2.1). Moreover, about half of the Member States (13) have a clear women's entrepreneurship strategy, either as a standalone strategy or embedded within a broader entrepreneurship or labour market strategy. The development of a tailored strategy can be a useful tool for bringing a coherence and consistency to women's entrepreneurship programmes, as well as raising the visibility of women's entrepreneurship issues. It also makes the support programmes less susceptible to fluctuations in funding due to economic and political cycles. However, many of these strategies remain quite general. Only a handful of Member States have clearly outlined targets in their strategies for boosting and strengthening women's entrepreneurship.
\end{abstract}


Figure 2.1. Policy frameworks for women's entrepreneurship are shared across national and subnational governments

Share of EU Member States, 2020

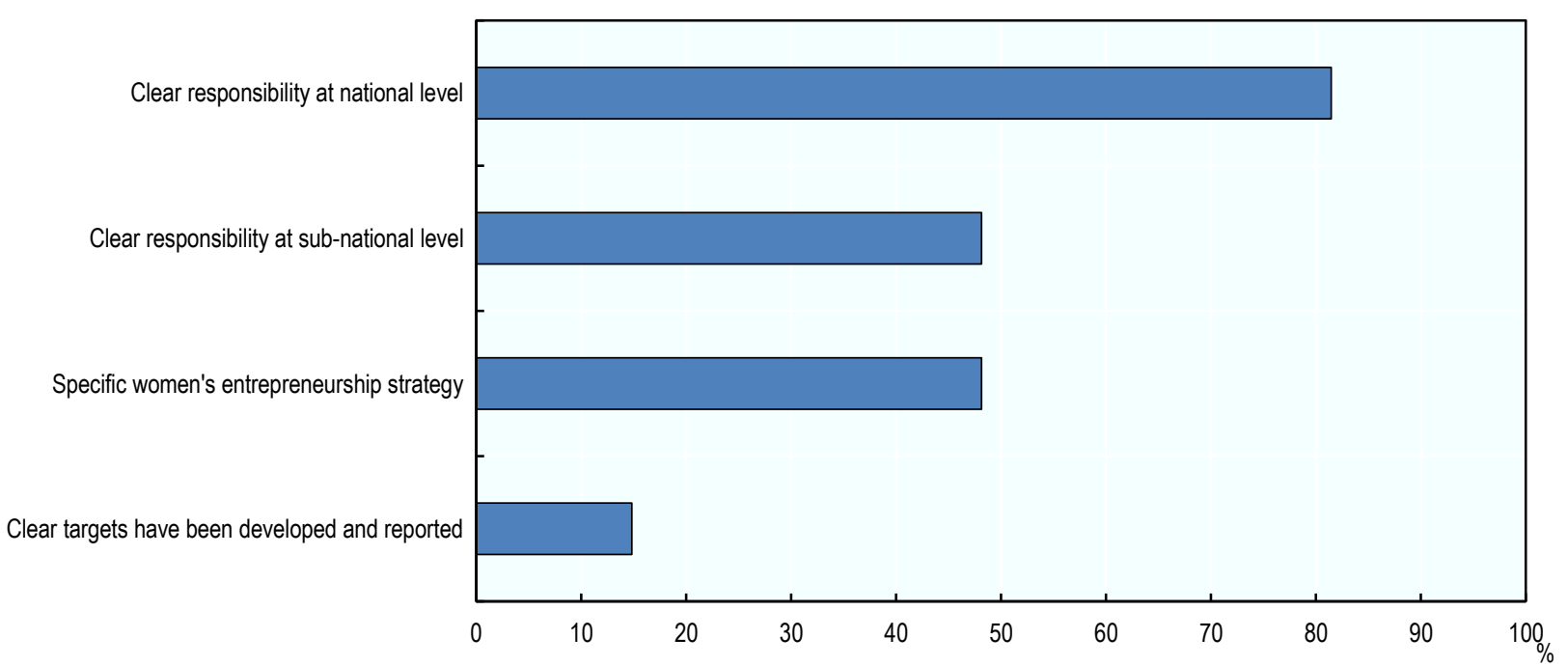

Note: It is possible for countries to have clear policy responsibility at both the national and sub-national levels; these are not mutually exclusive. Source: (OECD, 2020[3])

StatLink त्ञाज https://doi.org/10.1787/888934279605

\section{Programmes to support women entrepreneurs remain small-scale and some gaps persist}

The gender gap in entrepreneurship is explained by several factors, notably gender differences in motivations and ambitions for entrepreneurship as well as differences in the number and scale of barriers faced by potential women entrepreneurs. These barriers include, for example, lower perceived levels of entrepreneurship skills, more difficulty accessing entrepreneurship training programmes and greater difficulties accessing start-up financing (OECD/EU, 2016[4]). Many of these barriers are interrelated, so the challenges faced can quickly become compounded.

Governments in EU Member States have responded with a wide range of schemes to build motivations and ambitions for entrepreneurship. They include initiatives to help women acquire entrepreneurship skills through training programmes, coaching and mentoring initiatives, business counselling and networking opportunities. They have also improved access to start-up finance with grants, microcredit and loan guarantee programmes. Governments also continue to improve the regulatory environment for new start-ups and have increased support in recent years for women entrepreneurs with care responsibilities.

Relative to tailored entrepreneurship schemes for other inclusive entrepreneurship target groups, those for women are more comprehensive and tend to be of higher quality (Figure 2.2). The OECD inclusive entrepreneurship policy assessment notes examine women's entrepreneurship schemes in each EU Member State across four dimensions: building entrepreneurship skills; facilitating starting finance; building entrepreneurship networks and attitudes; and group-specific regulatory instruments that support entrepreneurship. Different types of schemes are assessed under these four categories according to a nine-point scale. For more information on these assessment criteria, please refer to the Reader's Guide.

Overall, there are a number of areas where entrepreneurship schemes in EU Member States for women entrepreneurs could be improved (OECD, 2021[5]). First, programmes and schemes could be more strongly rooted in policy frameworks to ensure that the system of schemes are cohesive and better- 
integrated. In many EU Member States, schemes and initiatives are designed in isolation and do not consider overarching policy objectives related to supporting women in entrepreneurship, employment and innovation. Second, governments can go further to ensure that support schemes are appropriate for the local conditions. Women's entrepreneurship policy can be effective in any context, but the objectives, instruments and delivery mechanisms need to be selected accordingly. Finally, much greater efforts are needed overall to monitor and assess the impacts of policy interventions. Policy makers routinely face information gaps when designing support schemes for women entrepreneurs, including an understanding of the effectiveness of different approaches in different contexts, success factors, the relative impact of different interventions (e.g. training vs. coaching vs. microfinance), the effectiveness of combinations of interventions, and the role of measures in influencing institutional conditions. The lack of evaluation evidence represents a lost opportunity to learn from high impact policy interventions and may lend to the vulnerability of women's enterprise programme funding.

\section{Figure 2.2. Women's entrepreneurship schemes vary in quality across EU Member States}

Average OECD assessment scores for inclusive entrepreneurship schemes across EU Member States, 2020

a. Entrepreneurship skills

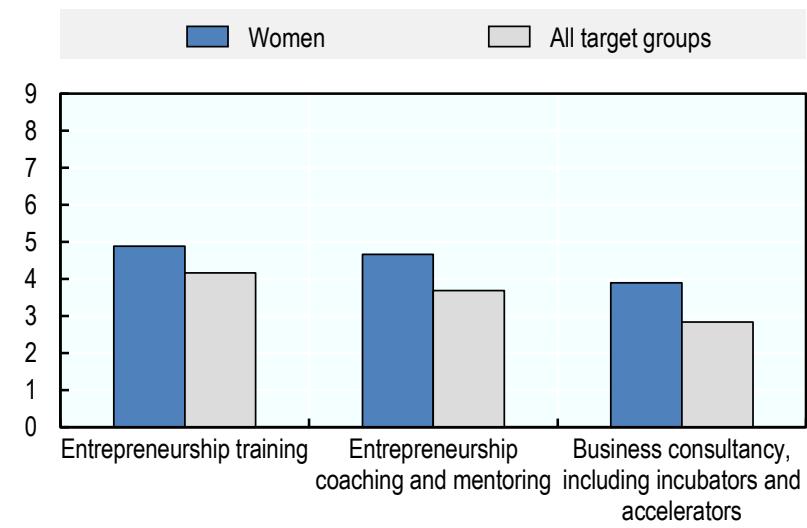
accelerators b. Entrepreneurship finance

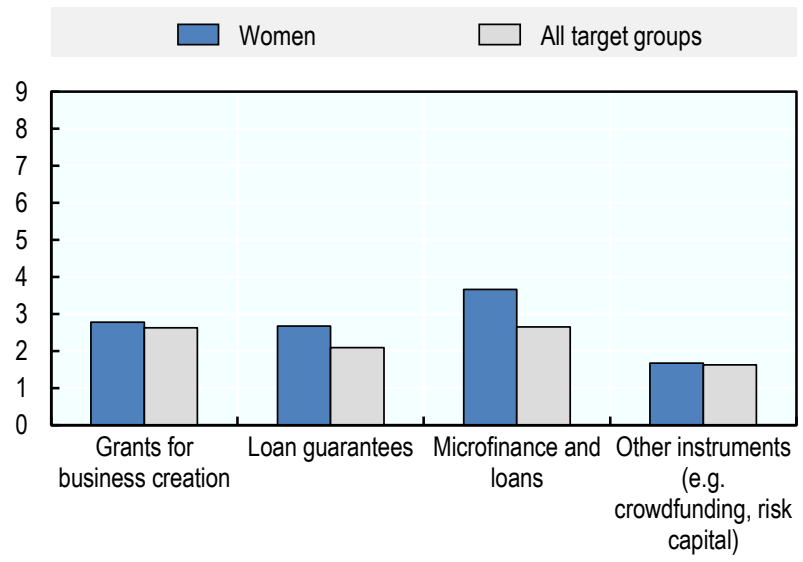

c. Entrepreneurship culture and social capital

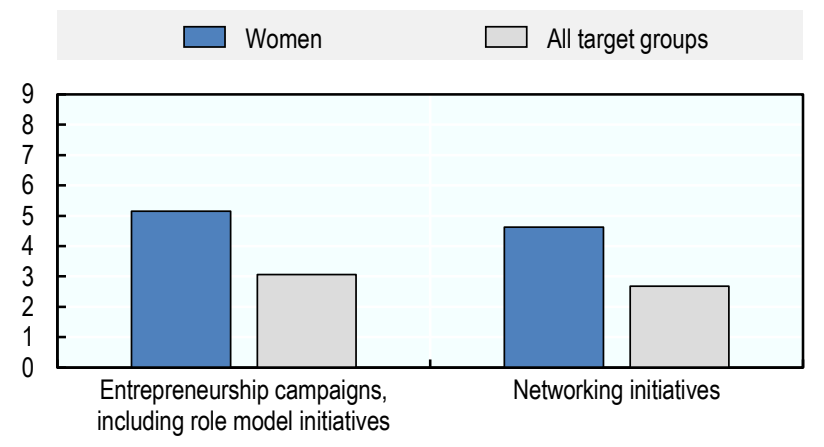

d. Regulatory environment

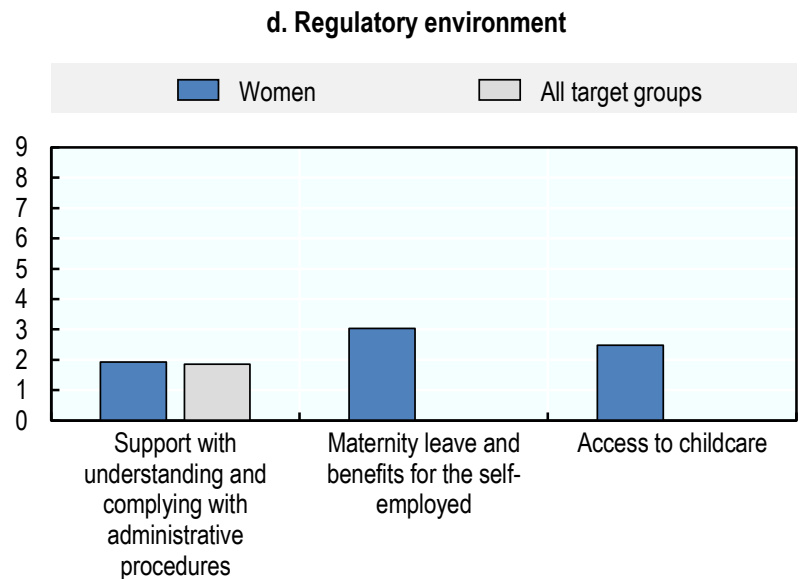

Note: The panels in this figure present an unweighted average of policy assessment scores for EU Member States. Each policy instrument (e.g. Entrepreneurship training) is assessed a scored out of 9 as described in the Reader's Guide. The figure shows the average score for schemes for women entrepreneurs relative to the score for all inclusive entrepreneurship groups combined (i.e. women, immigrants, youth, seniors and the unemployed). Some of the policy instruments in panel $\mathrm{d}$ are designed specifically for women entrepreneurs so there is no comparative policy assessment score for all inclusive entrepreneurship target groups.

Source: (OECD, 2020[3]) 


\section{Building entrepreneurship skills}

Most EU governments offer tailored entrepreneurship training for women who are interested in starting a business. Many of these training initiatives are dedicated programmes, which can be an effective method of attracting women into the entrepreneurship support system. However, there are several areas where entrepreneurship training programmes for women in the EU can be improved. First, as with inclusive entrepreneurship schemes in general, few are well-evaluated so it is difficult to fully understand the impact that training schemes have for women entrepreneurs. In addition, it does not appear to be a common practice to develop the training programmes in consultation with women entrepreneurs or women entrepreneurship organisations, which can help ensure that the obstacles faced are addressed. Finally, very few countries report that the scale of tailored entrepreneurship training for women entrepreneurs is sufficient.

Another important mechanism for building entrepreneurship skills is through entrepreneurship coaching and mentoring programmes. This type of scheme is now nearly as common across EU Member States and regions as entrepreneurship training programmes. Coaching and mentoring are often designed and implemented according to good practice principles, including the use of targeted outreach efforts. However, more can be done to scale up successful schemes since fewer than half of Member States have reported the scale of tailored entrepreneurship coaching and mentoring schemes for women is sufficient for demand.

The use of tailored or dedicated incubators is a less common method used to build entrepreneurship skills for women entrepreneurs. A priority for governments going forward is to improve access to business incubators and accelerators for women entrepreneurs since support and financing for growth-oriented entrepreneurs is still largely received by men entrepreneurs.

\section{Facilitating access to start-up finance}

Governments in EU Member States use a range of instruments to facilitate access to finance for women entrepreneurs. Commonly used mechanisms include microfinance schemes, loan guarantees and grants. There are a small but growing number of crowdfunding platforms that support inclusive entrepreneurship, but platforms dedicated to women's entrepreneurship are rare.

Overall, public start-up financing schemes for women entrepreneurs appear to be designed to meet their needs. It is common to have strong links with other types of support (e.g. entrepreneurship coaching and mentoring), which can increase the chances of success for participants. However, strong monitoring and evaluation practices were only found in a small number of EU Member States so this remains an area that can be strengthened.

\section{Expanding entrepreneurship networks}

Women's entrepreneurship is heavily promoted in most EU Member States. Common approaches used include promoting successful women entrepreneurs as role models in education (e.g. speaking to students, examples in learning materials), general promotional campaigns and awards that celebrate successful women entrepreneurs. While these types of activities are popular, it is very difficult to know whether they make an impact given that entrepreneurial decisions are influenced by many factors and are not always made in the short-term following inspiration from a role model.

It is also common for governments in EU Member States to support networking initiatives and business associations. Many of these initiatives appear to be well-linked with other entrepreneurship support initiatives for women entrepreneurs, which reinforces their value for helping women entrepreneurs access resources. However, it is also difficult to measure the impact of these schemes. It is therefore difficult to know if the scale of these activities is appropriate. 


\section{Supporting women entrepreneurs with regulatory tools}

A growing number of Member States are offering support for women entrepreneurs with families, including improved access to maternity benefits and increasing childcare availability. This includes for example, increased investments in childcare in Germany and maternity supports for women entrepreneurs in Austria, i.e. Mutterschaftsbetriebshilfe ("Business continuation aide in case of motherhood") and Wochengeld für Unternehmerinnen ("Maternity allowance for women entrepreneurs").

\section{Recent developments in women's entrepreneurship policy}

Policy discussions in 2020 and 2021 have been dominated by COVID-19 pandemic. The initial priority was to contain the virus outbreak with a range of measures including temporarily halting certain economic activities and limiting face-to-face interactions. Governments have now shifted their focus to economic recovery. As a result, nearly all policy developments over the past year have been in response to the COVID-19 pandemic.

Women entrepreneurs were impacted disproportionately during the COVID-19 pandemic, largely due to the concentration of women in the hardest hit sectors and increased demands from household responsibilities (see Chapter 1 for further discussion of the impacts of COVID-19 on women's entrepreneurship). Governments rolled-out a wide range of support measures to help entrepreneurs sustain their activity through the crisis, including measures aimed to support the liquidity of entrepreneurs and structural measures aimed to help entrepreneurs adapt to the changed business environment. Liquidity measures included job retention schemes (e.g. wage subsidies), payment deferrals (e.g. income and corporate tax payments, value added tax, social security contributions) and financial supports (e.g. loan guarantees, loans, grants). Structural support measures include those to help transform business activities (e.g. digitalisation, innovation) through a range of instruments such as business development services and advice, vouchers, grants, training and networking. Now that countries are shifting their focus to economic recovery packages, these structural support measures are becoming part of wider public investment schemes and demand stimulus. For more on policy responses to support entrepreneurs and SMEs through the COVID-19 pandemic, please see (OECD, 2021[6]).

Despite the large number of schemes developed for entrepreneurs and the self-employed, few were specifically designed for women. At the national level, only a small number EU Member States implemented COVID-19 support schemes for women entrepreneurs. In Malta, the Microinvest Cash Conversion Scheme enables a conversion of up to EUR 2000 of tax credits in Malta Enterprise's Microinvest Tax Credit Scheme into grants; and up to EUR 2500 - for women entrepreneurs, family-run enterprises and entrepreneurs based in Gozo (OECD, 2020[3]). In Italy, the Ministry for Equal Opportunities and the Family provided an extra allocation of EUR 5 million within the fund for SMEs for female entrepreneurship (OECD, 2020[3]).

Furthermore, only a small number of governments outside of the EU provided dedicated support to women entrepreneurs. Most of these initiatives provided increased support for those already being supported by a programme. In Canada for example, the government boosted funding for the Women Entrepreneurship Strategy (WES) Ecosystem Fund by CDN 15 million (approximately EUR 10.2 million) to support women business organisations that already receive support through the Fund. Other examples include increased cash transfers (by INR 500 or EUR 6 per month) for self-employed and women entrepreneurs in India for the 200 million women Jan Dhan account holders (OECD, 2021[6]).

COVID-19 also had a strong impact on the delivery of long-standing women's entrepreneurship schemes since face-to-face interactions were restricted in most EU Member States. One of the most common developments was moving programmes online, which required adjusting delivery formats and content so that support could continue on a digital platform. There are many examples across the EU of how women's entrepreneurship support schemes are going digital, including the group coaching and peer- 
learning sessions in the Going for Growth schemes in Ireland being moved onto an online meeting platform. There are also examples of schemes such as Force Femmes in France that used the move online to expand their activities. This network introduced a series of virtual webinars on entrepreneurship for women over 45 years old and a virtual conference on digital entrepreneurship for older women.

For additional examples of recent policy developments, please see the country profiles in Part III of this report.

\section{Trends in self-employment by women}

\section{Women are $40 \%$ less likely than men to be self-employed}

The self-employment rate for women in the EU has been constant over the past two decades. About $10 \%$ of working women were self-employed between 2002 and 2020 (Figure 2.3). In 2020, nearly 8.5 million of the 88.6 million working women in the EU were self-employed. This proportion was about $55 \%$ lower than that of men in 2020 , when 17.4 million of the 103.4 million working men were self-employed $(17 \%)$.

The gender gap in self-employment in the EU has closed by about $15 \%$ since 2002, falling from 8.5 percentage points (p.p.) in 2002 to 7.5 p.p. in 2020. This slight closing of the gender gap in selfemployment is due to a decrease in the share of men who are self-employed. While the share of working women who are self-employed has been constant, the rate for men declined nearly 2 p.p. over the past decade, falling from $19 \%$ in 2011 to $17 \%$ in 2020.

\section{Figure 2.3. The gender gap in self-employment has closed slightly since 2002}

Self-employment in the European Union as a percentage of employment (15-64 years old)

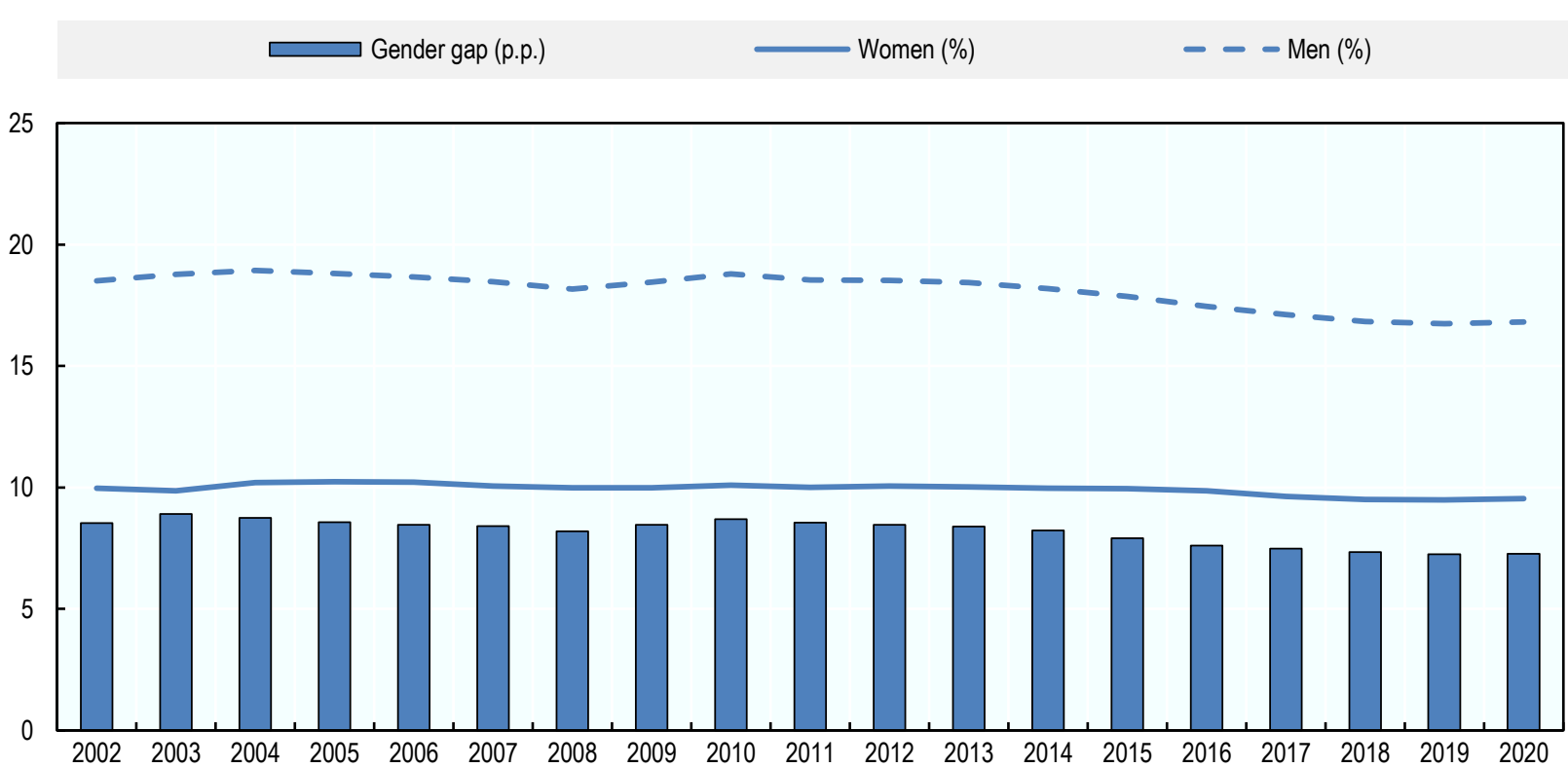

Source: (Eurostat, 2021[7]) 


\section{The gender gap in self-employment was closing across most EU Member States pre- COVID-19}

There is a substantial amount of variation in the self-employment rate for women and the gender gap in self-employment across EU Member States. Self-employment rates for women tend to be lower in northern EU Member States such as Denmark and Sweden (approximately 5\% in 2020) and are higher in southern Member States, notably in Greece (21\% in 2020) and Italy (15\%) (Figure 2.4). Self-employment rates for women are positively correlated with the overall self-employment rates, which are explained by several factors. In northern EU Member States such as Denmark and Sweden, unemployment rates tend to be lower and social welfare systems provide greater amounts of support so individuals are less likely to be in a situation where they need to generate income for themselves out of desperation. These Member States also often have a higher share of employment in the public sector.

Figure 2.4. The gender gap in self-employment closed in $80 \%$ of Member States over the past decade

Self-employment as a percentage of employment (15-64 years old), 2020

\section{a. Self-employment rate}

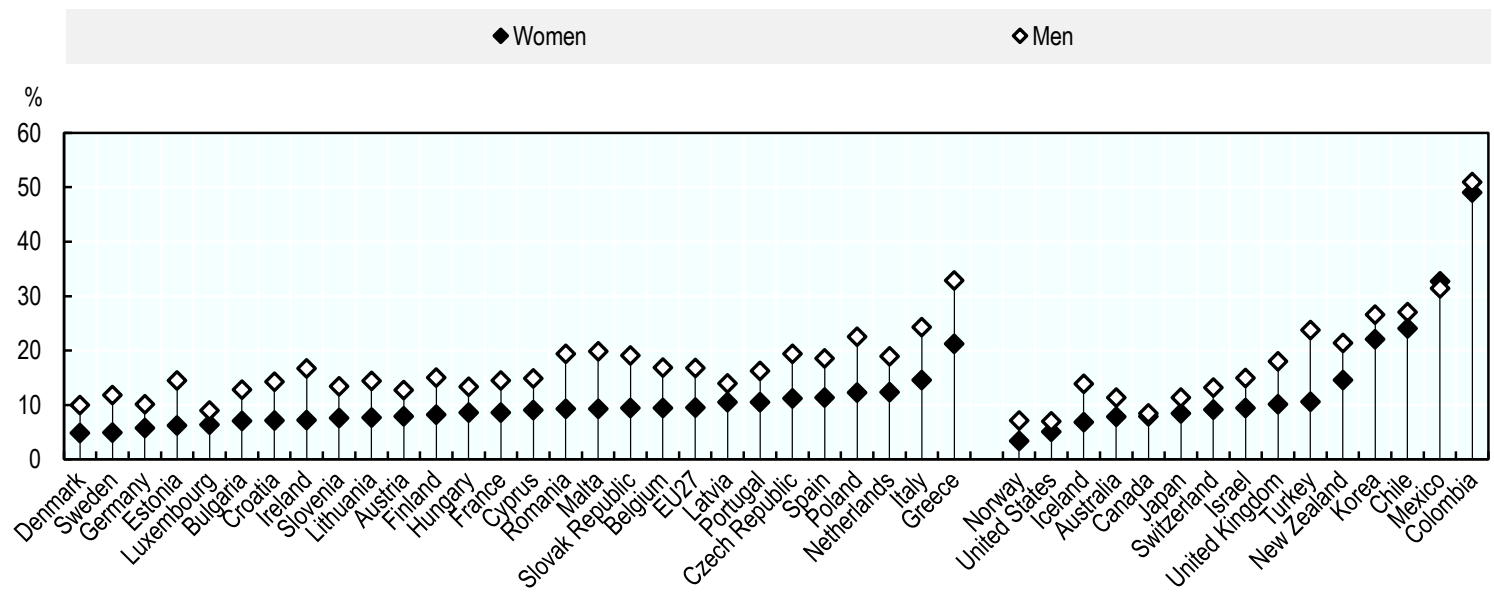

EU Member States

non-EU OECD countries

b. Change in gender gap, 2011-20

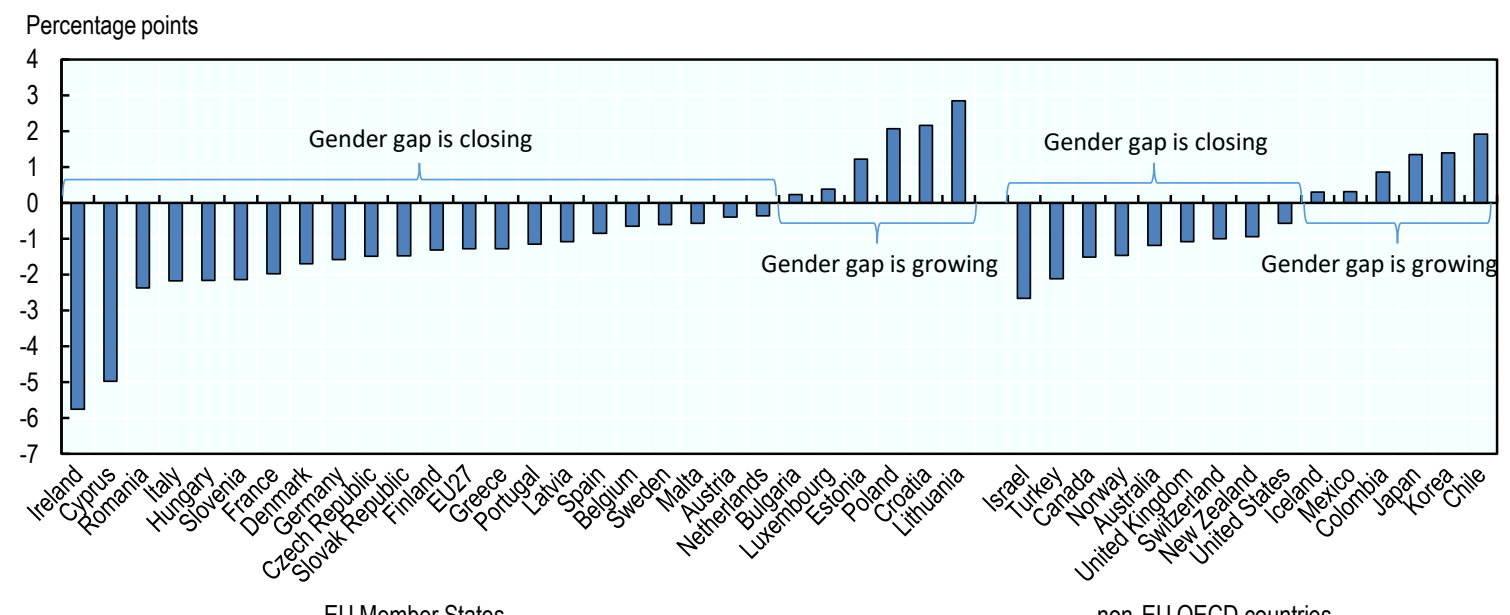

EU Member States

non-EU OECD countries

Note: Data for Australia, Canada, Chile, Colombia, Israel, Japan, Korea, Mexico, New Zealand, Turkey, United Kingdom, United States, are for 2019 in panel a and 2011 and 2019 in panel b. Data for Korea in panel b are based on preliminary estimates.

Source: (Eurostat, 2021 [7]; OECD, 2021[8])

StatLink ज्ञाज https://doi.org/10.1787/888934279662 
Self-employment rates can also be influenced by a range of other country-specific factors. For example, some Member States such as Lithuania and Estonia have several possible legal forms of business activity for individuals. In Lithuania, the personal income tax law (Law No. IX-1007) defines two forms of individual activity: (i) performed on the basis of an individual activity certificate; (ii) carried out under a business license. These different forms determine the activities that are permitted and the amount of tax that is paid. Having multiple potential legal forms for small-scale business activities could reduce the amount of self-employment picked up by official statistics since some of these activities could be classified as business activities rather than self-employment. Conversely, countries such as France have mechanisms such as micro-entrepreneur (formerly auto-entrepreneur) that facilitate people moving into self-employment. Since the auto-entrepreneur status was introduced in 2009 , self-employment has been markedly higher.

The gender gap in self-employment fell in most EU Member States over the past decade, notably in Ireland where the gender gap closed by about 6 p.p. This was due to an influx of self-employed women - a $24 \%$ increase - coupled with a decrease in the number of self-employed men over this period (9\%). Most of this growth was concentrated in Human health and social work activities (55\% increase), Other services ( $40 \%$ increase) and Professional, scientific and technical activities (33\% increase). There was also a disproportionate increase in self-employment among women over 50 years old, which may be related to differences in availability of maternity and family supports and benefits for the self-employed relative to employees (OECD, 2020[3]).

\section{Characteristics of self-employed women and their activities}

\section{Self-employed women are $30 \%$ less likely to be employers than self-employed men}

Self-employed women in the EU are less likely to have employees than self-employed men. About one-in-four self-employed women in the EU have employees, relative to about one-in-three self-employed men (Figure 2.5). Both of these shares have declined slightly since 2002 - from about $28 \%$ to $24 \%$ in 2020 for women and $38 \%$ to $33 \%$ for men - and they are expected to decline further in the short-term due to the COVID-19 pandemic. Prior to COVID-19, the growth in solo self-employment was driven by an increase in part-time self-employment and freelance work (OECD/European Union, 2017[9]). However, some of the self-employed with employees have become solo self-employed workers over the past year since a common response to the economic crisis was to let employees go.

The gender gap in the share of the self-employed who employ others is explained by several factors, including gender differences in motivations and ambitions. Some research shows that many self-employed workers do not want to have employees of whom women are more likely to not want employees (OECD/European Union, 2019[10]). This is confirmed by country level research such as in Finland (Sutela and Pärnänen, 2019[11]). Moreover, women on average have different attitudes towards growth (page 97) and there are gender differences among the self-employed in terms of hours worked (page 79) and type of business activities, including sector (page 83), occupation (page 84), innovation rate (page 96) and scale of export activities (page 96). The legal status that women business owners use can also influence their size and growth path. For example, women create around $40 \%$ of new microenterprises in France, which are primarily categorised into two legal statuses. The first is autoentrepreneurs, which is a business status that has earning restrictions that can make it difficult to hire employees and grow the business in the first few years of operations. In contrast, sole-proprietors classified as an individual enterprise (l'entreprise individuelle) are not limited by income caps and are more likely to hire employees. 
Figure 2.5. Less than one-quarter of self-employed women in the EU have employees

Percentage of self-employed (15-64 years old) in the European Union

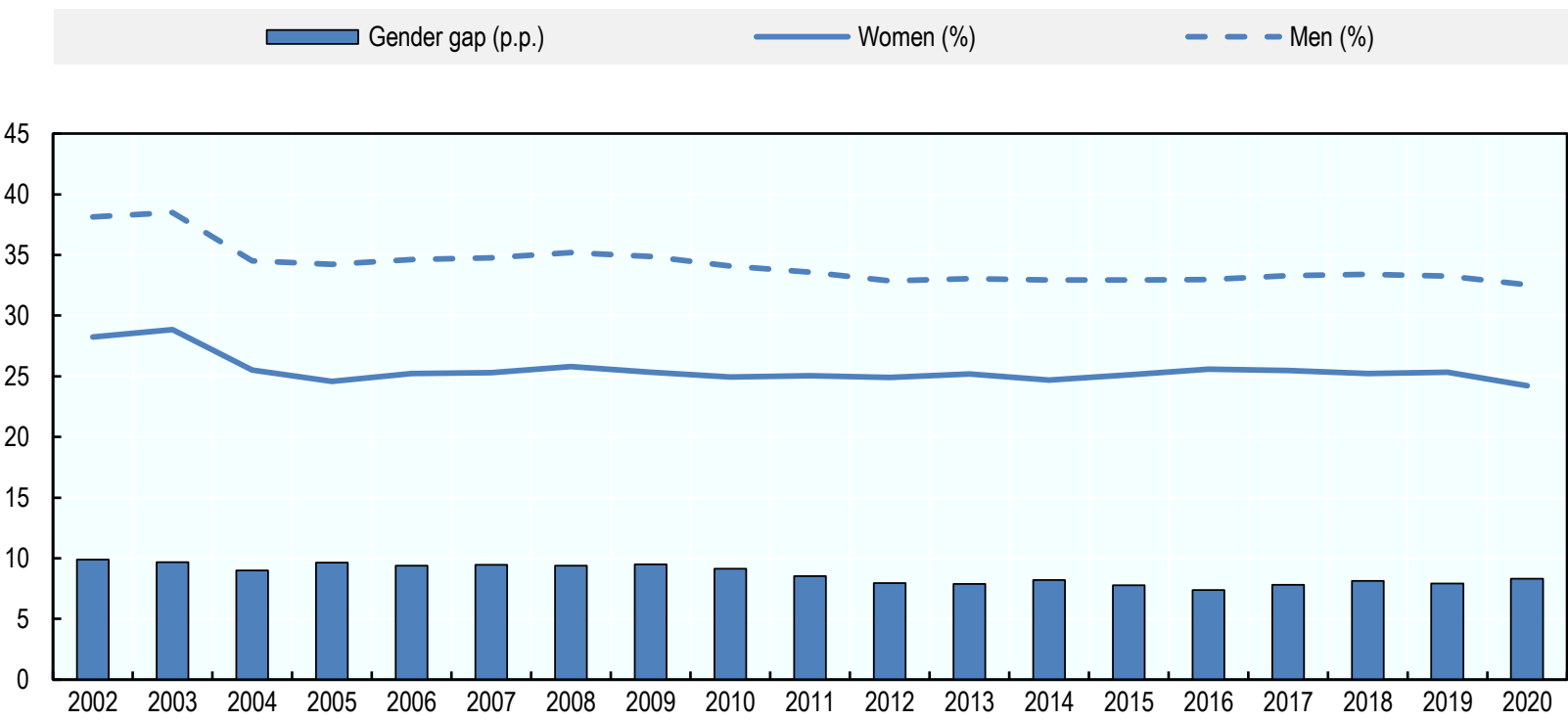

Source: (Eurostat, $\left.2021_{[7]}\right)$

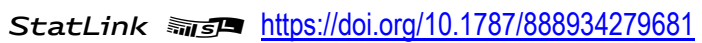

While the share of self-employed women (and men) who employed others declined over the past two decades, there was also a decline in the gender gap in the share of self-employed who are employers. The difference between the share of self-employed women and men who employ others declined from 9.5 p.p. in 2002 to 7.4 p.p. in 2016 but has since increased to 8.3 p.p. in 2020.

At the country level, the share of self-employed women who employ others in 2020 ranged from about $\mathbf{7 \%}$ in Romania to more than $\mathbf{4 0 \%}$ in Croatia (Figure 2.6). There is also a large variation in the difference of the share of self-employed women and men who employ others. In countries such as Ireland and Poland, there is essentially no gender difference, but there is a gap of more than $35 \%$ in Austria, Cyprus, Denmark, Estonia, Finland, France, Germany, Lithuania and the Netherlands.

The gender gap in the share of self-employed who employ others increased in about half of EU Member States over the past decade. The largest increases were observed in Malta (9.3 p.p.), Denmark (7.1 p.p.) and Slovenia (5.1. p.p.). This positive trend in Denmark is consistent with the Entrepreneurship Barometer Report (2019) which found around 30\% of Danish entrepreneurs planned to hire additional staff in 2019. The majority of entrepreneurs reported the intention of hiring 1-2 workers (69\%) while $8 \%$ expected to hire 10 or more new employees (Væksthus Sjælland, 2019 ${ }_{[12]}$ ). 
Figure 2.6. The gender gap in employer rates increased in about half of EU Member States since 2011

Percentage of the self-employed (15-64 years old), 2020

a. Share with employees

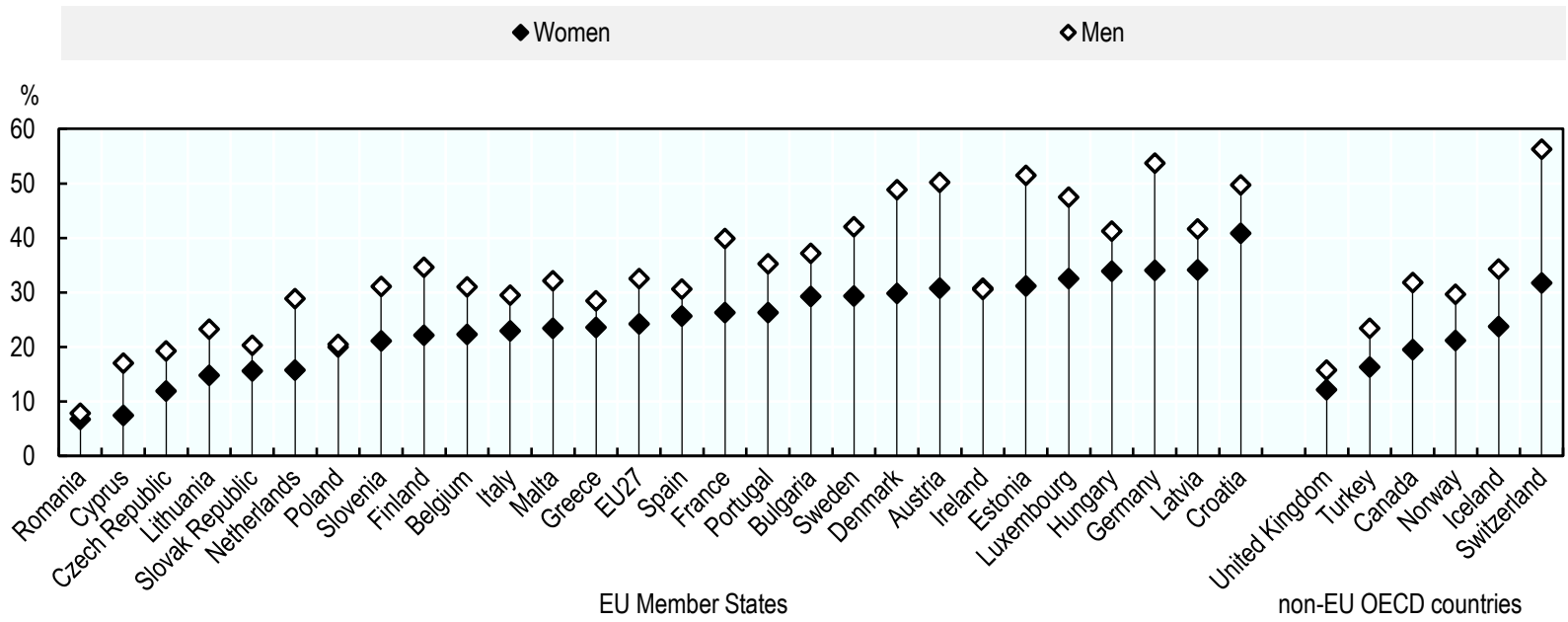

b. Change in gap in share of self-employed with employees, 2011-20

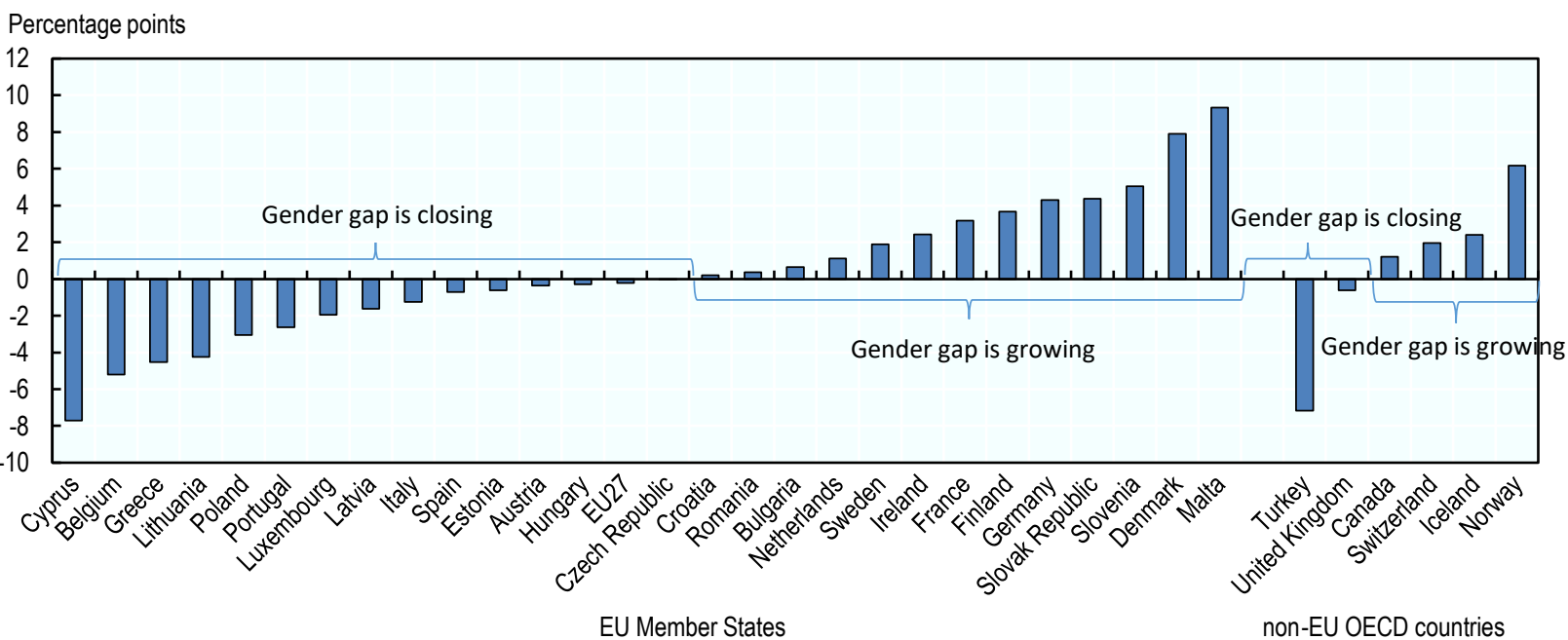

Source: (Eurostat, 2021 $1_{[7]}$; Statistics Canada, 2021 $\left.[13]\right)$

StatLink : *ils ht htps://doi.org/10.1787/888934279700

\section{Self-employed women are slightly younger than self-employed men...}

\section{Self-employed women in the EU are, on average, slightly younger than self-employed men.}

In 2020, self-employed women were about 2 p.p. more likely than men to be between 25 and 39 years old. Similarly, about $27 \%$ of self-employed women were between 40 and 49 years old relative to one-quarter of self-employed men. Thus, $53 \%$ of self-employed women were between 25 to 49 years old relative to $49 \%$ of self-employed men. 
Self-employed women with employees tend to be older than those without employees. Nearly $80 \%$ of self-employed women with employees were older than 40 years old in 2020 relative to about $72 \%$ of those without employees (Figure 2.7). These shares were approximately the same for self-employed men with employees. However, self-employed women with employees are, on average, younger than selfemployed men with employees. About $22 \%$ of self-employed women with employees were between 25 and 39 years old relative to $19 \%$ of self-employed men.

\section{Figure 2.7. Self-employed women with employees tend to be older than those without}

Age distribution of the self-employed in the EU, 2020

a. Self-employed with employees

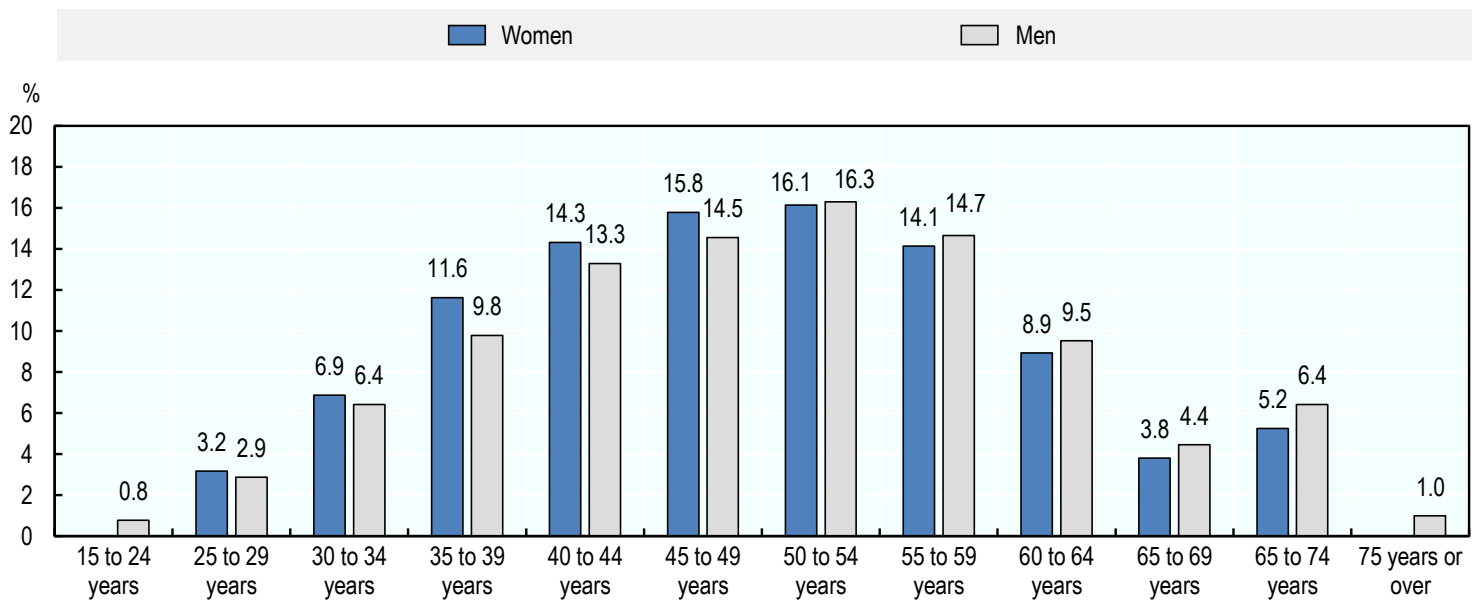

b. Self-employed without employees

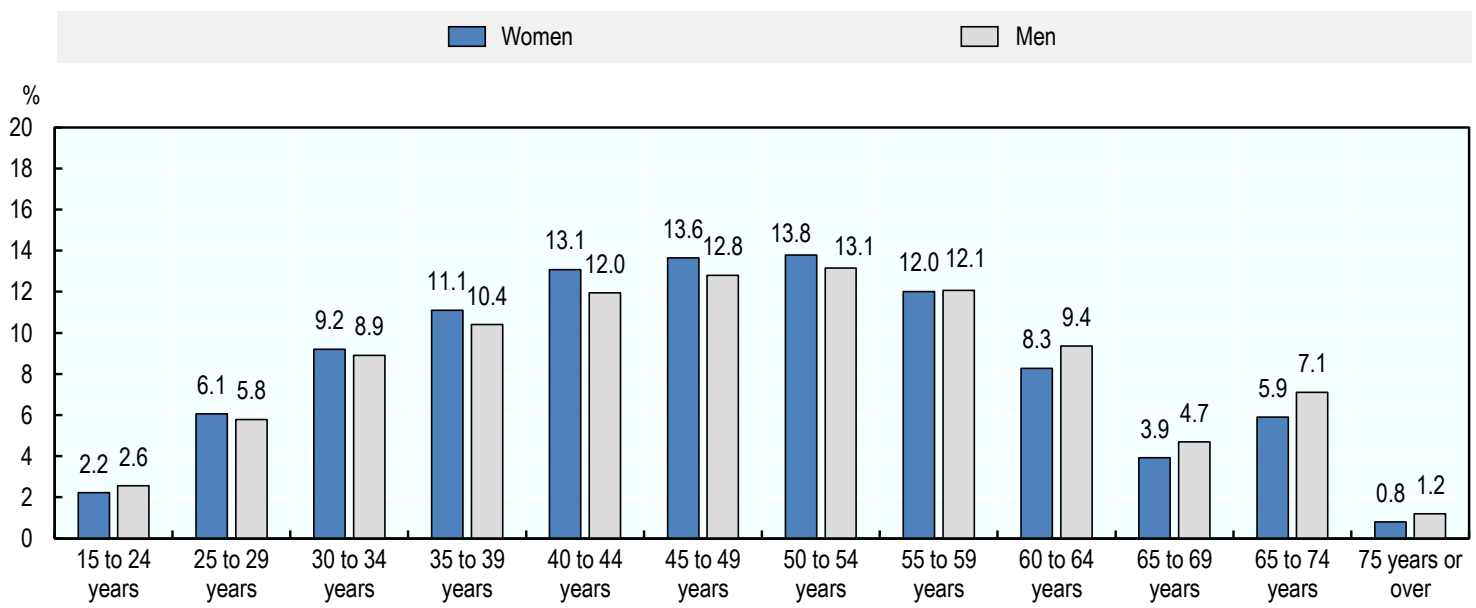

Source: (Eurostat, $2021_{[7]}$ )

StatLink त्ञाज https://doi.org/10.1787/888934279719

\section{....and are more likely to have a tertiary education}

The share of self-employed with a tertiary education more than doubled since 2002, increasing from $21 \%$ in 2002 to $46 \%$ in 2020 . This increase was largely offset by a decline in the share who have less than an upper secondary education, which fell from $35 \%$ to $14 \%$ (Figure 2.8). This shift was also observed among self-employed men during this period, but the increase in the share who have at least a tertiary education was smaller - from $20 \%$ in 2002 to $33 \%$ in 2020 . This trend is consistent with the increasing share of women earning tertiary degrees and the slightly younger age profile of self-employed women. However, self-employed women are more likely than employees to have completed tertiary education. 
Figure 2.8. The share of self-employed in the EU with a tertiary education is increasing faster than for men

Distribution of the self-employed and employees (15-64 years old) in the EU by educational attainment
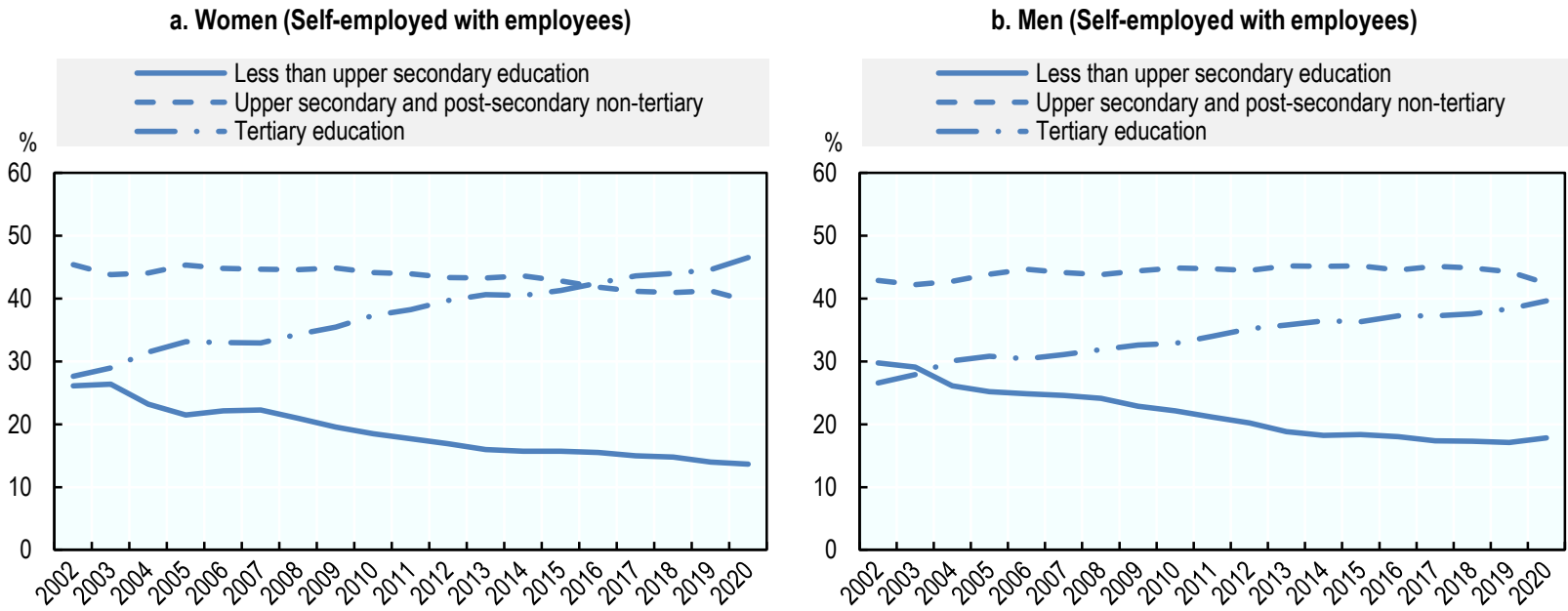

c. Women (Self-employed without employees)

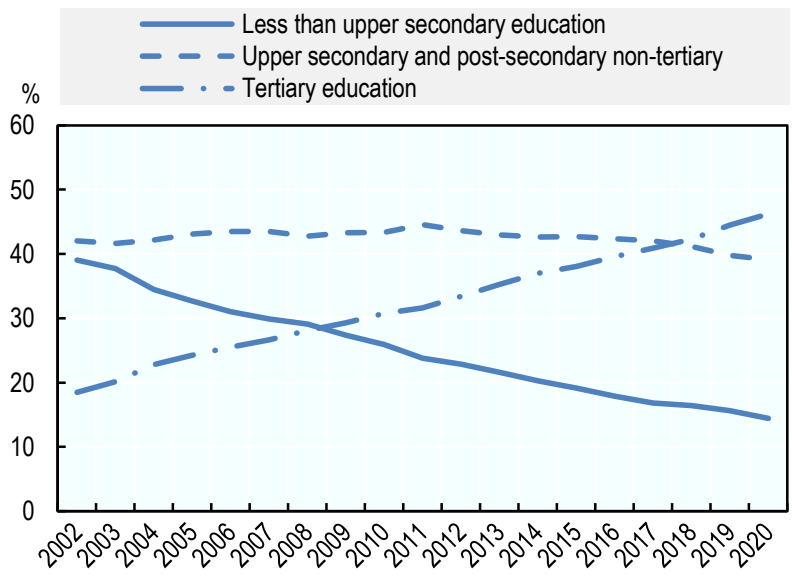

d. Men (Self-employed without employees)

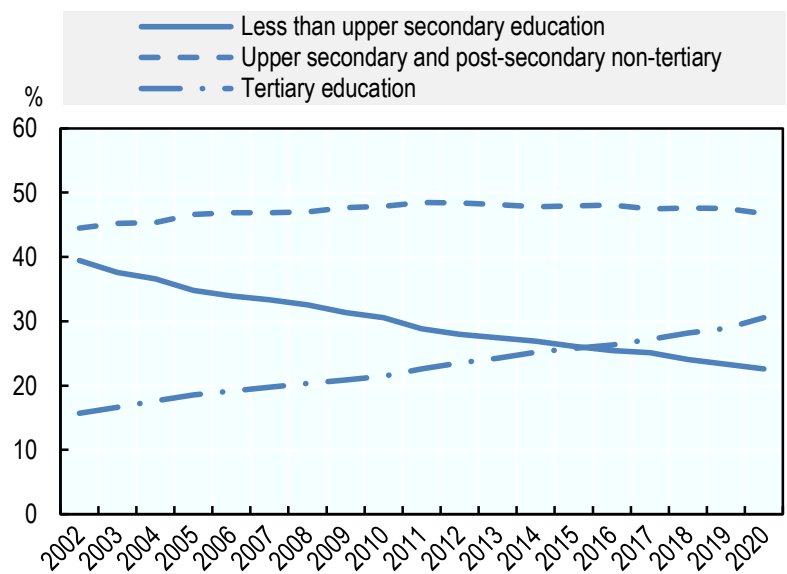

e. Women (Employees)

f. Men (Employees)
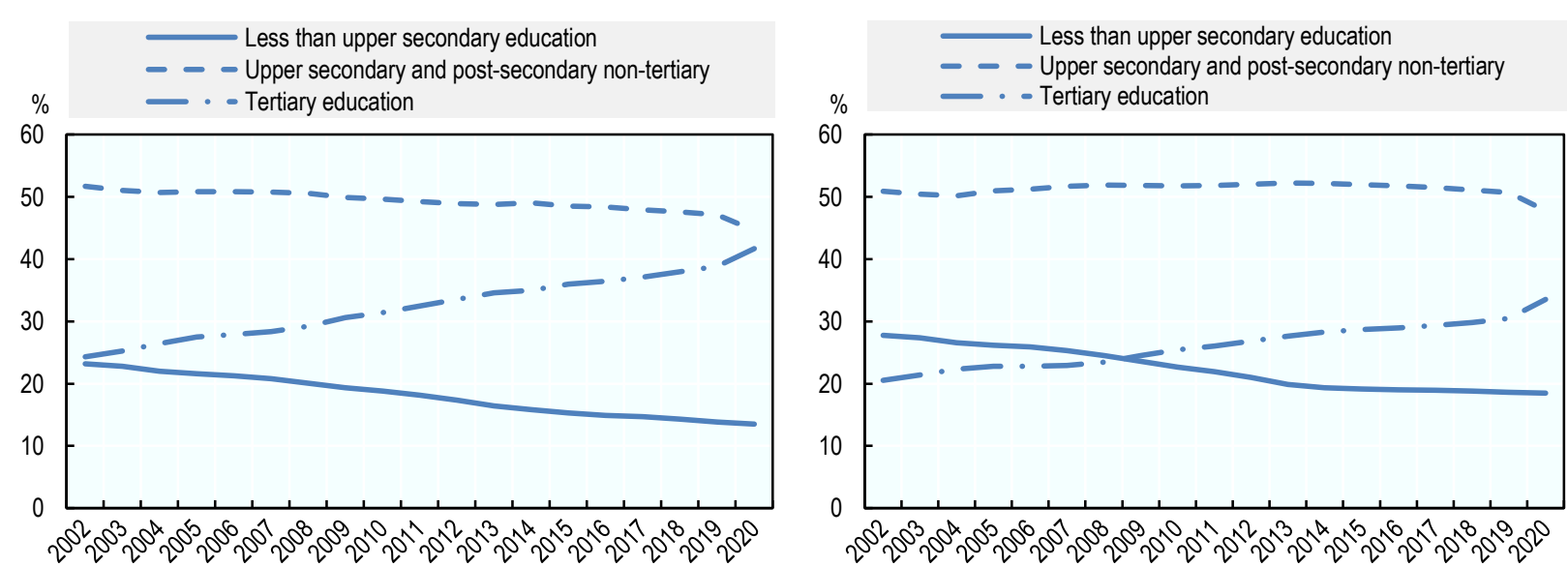

Source: (Eurostat, 2021[7])

StatLink 게 sh https://doi.org/10.1787/888934279738 
Among self-employed women, there was little difference in the educational attainment of those with employees and those without in 2020. While this may appear to cast doubt on the notion that someone with a higher educational attainment is more likely to create a business that creates jobs for others, the data do not indicate how many people are employed. Moreover, this is a relatively recent finding. Between 2002 and 2015, self-employed women with a tertiary education were more likely to have employees than those without a tertiary education.

Although tertiary education attainment rates vary across EU Member States, self-employed women were more likely to have completed tertiary education than self-employed men in nearly all Member States. In most Member States, the share of self-employed women with a tertiary education reflected general trends in education attainment. However, in Germany self-employed women were nearly twice as likely as employees to have a tertiary education (Figure 2.9). This can be explained in part by the lower share of the population in Germany that has obtained a tertiary education since there is a strong vocational education system. This is also observed in Austria for similar reasons. However, the opposite is observed in Greece, Poland, Romania and Sweden, where self-employed women are much less likely to have a tertiary education than those working as employees.

\section{Figure 2.9. Self-employed women are more likely to have a tertiary education than self-employed} men

Share of workers (18-64 years old) with a tertiary education, 2020

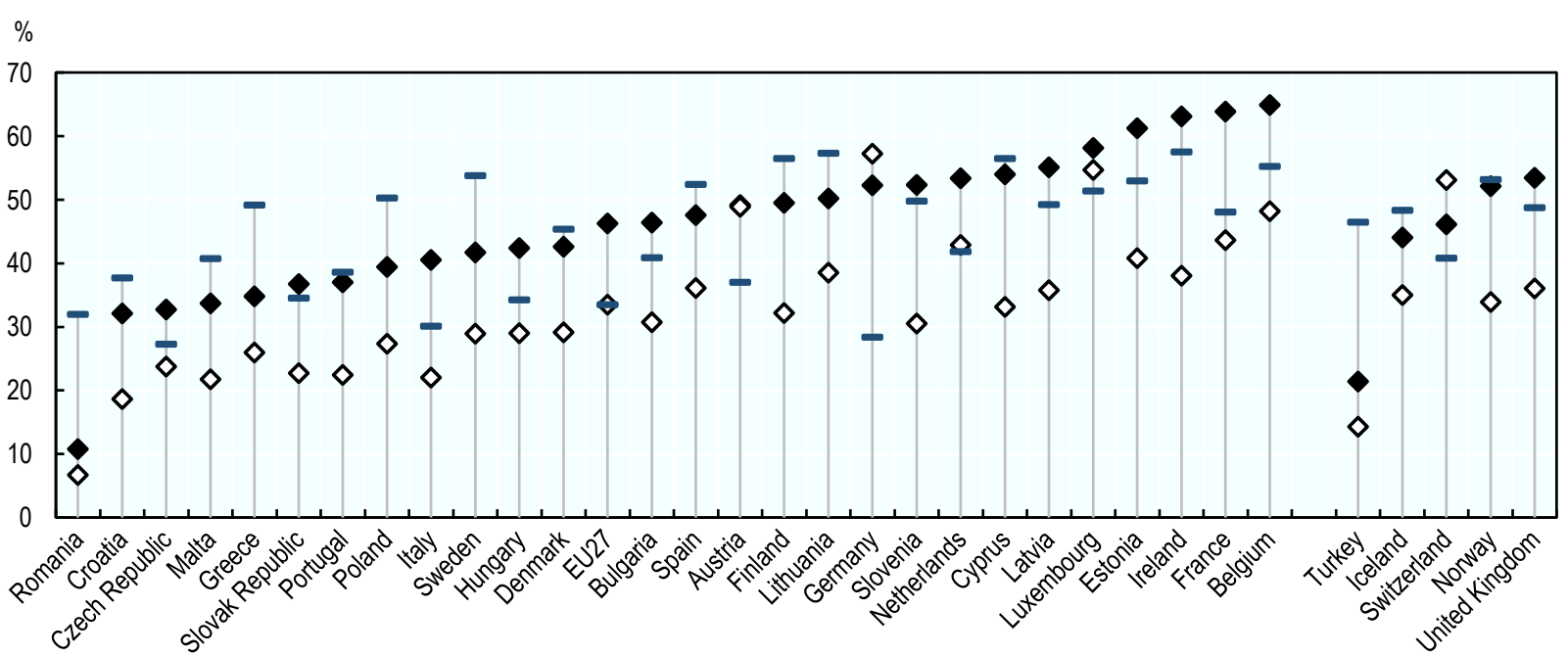




\section{Self-employed women work fewer hours per week than self-employed men...}

Among EU Member States, the median hours worked by full-time workers varied greatly by employment type. Overall, the self-employed with and without employees work, on average, more hours per week than employees. In addition, the self-employed with employees tend to work about 45 minutes more per day. In 2020, full-time self-employed women with employees worked, on average, 3.5 hours less per week than full-time self-employed men with employees (Figure 2.10). This gap has been fairly constant since 2015. A similar gap of about 3.3 hours per week is also found between self-employed men and women without employees.

\section{Figure 2.10. Average weekly hours are declining for the self-employed}

Average weekly hours for full-time workers (15-64 years old), 2020

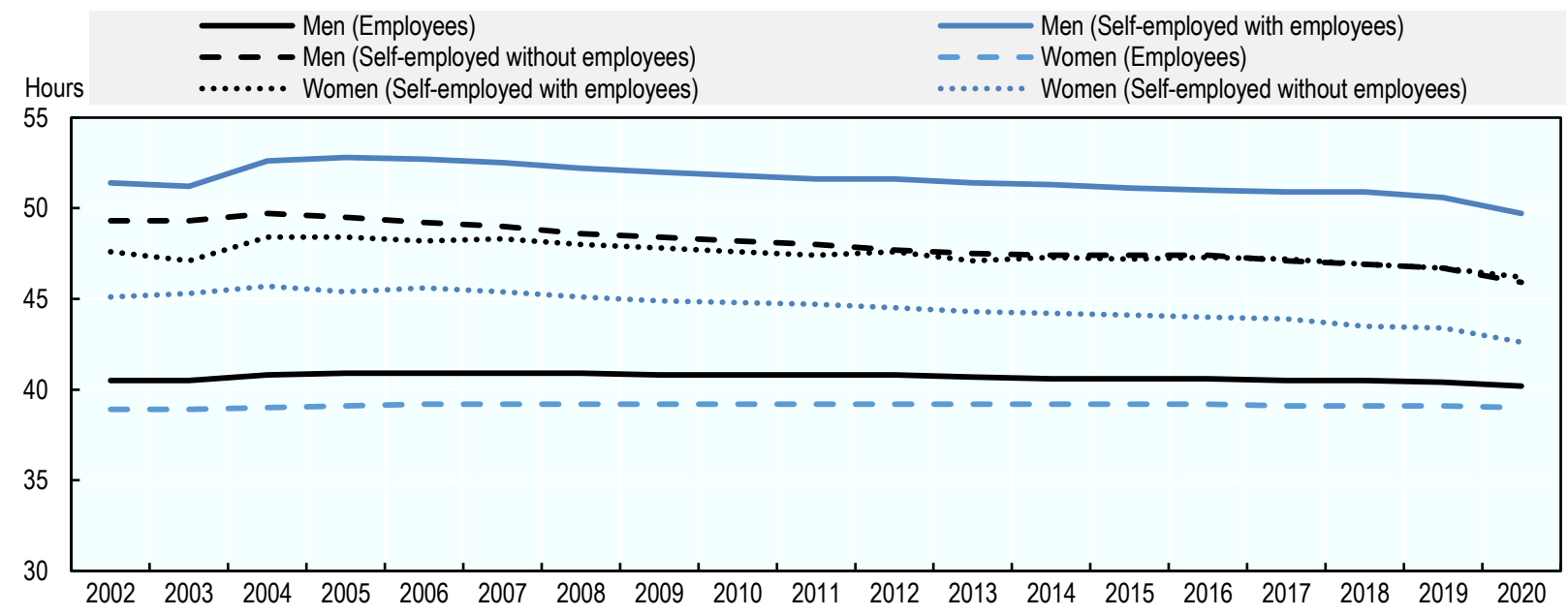

Note: Full-time work is not defined in most EU Member States and is defined by the survey respondent. However, full-time work is defined as more than 35 hours per week in the Netherlands and Iceland. In Sweden, full-time work is defined as more than 36 hours per week but survey respondents who work between 32 and 36 hours per week can specify if they work full-time or part-time.

Source: (Eurostat, $\left.2021_{[7]}\right)$

StatLink 제내 https://doi.org/10.1787/888934279776

These differences in hours worked are also observed across most EU Member States, with the exception of Estonia, Latvia, Lithuania and Malta were there was little gender gap (Figure 2.11). Fulltime self-employed women worked the most hours per week in Belgium (52.8 hours for self-employed women with employees and 47.3 hours for those without employees), Austria ( 50.3 hours and 46.2 hours) and Greece ( 50.1 hours and 46.6 hours), yet they worked fewer hours per week on average than selfemployed men. In Belgium, for example, self-employed men worked on average 54.2 hours per week in 2020 , which was about 4 hours more than self-employed women (50.1 hours per week). 
Figure 2.11. Self-employed women work slightly more hours a week than those who work as employees

Average weekly hours for full-time workers (15-64 years old), 2020

a. Employees

Women

$\diamond$ Men

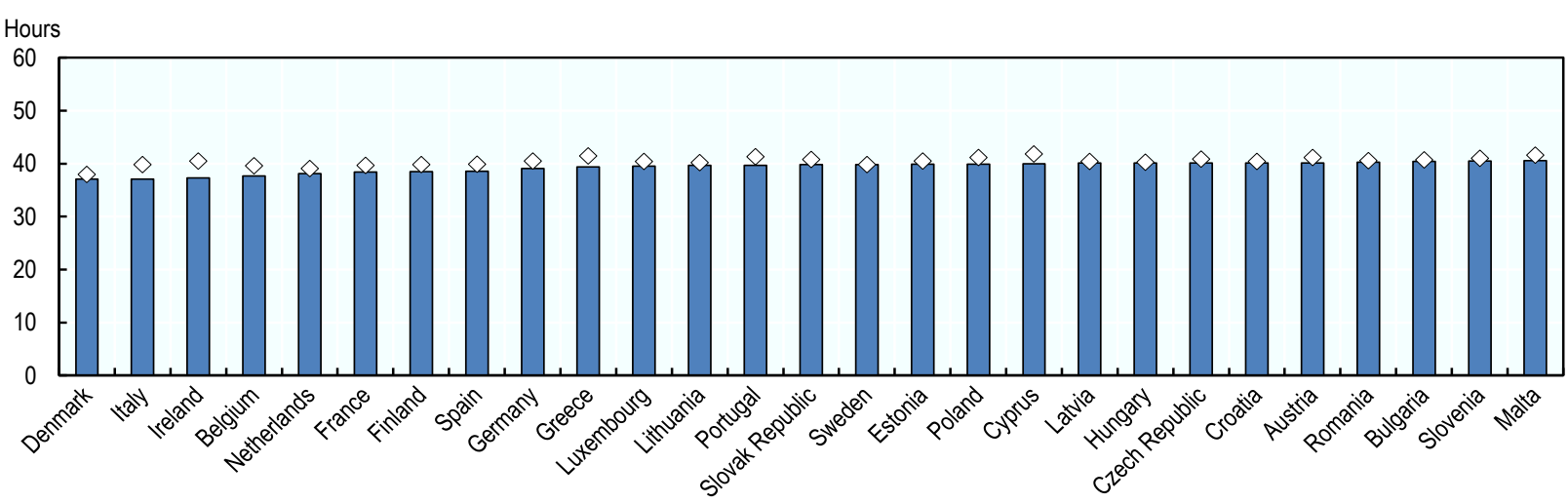

b. Self-employed with employees

$\square$ Women $\diamond$ Men

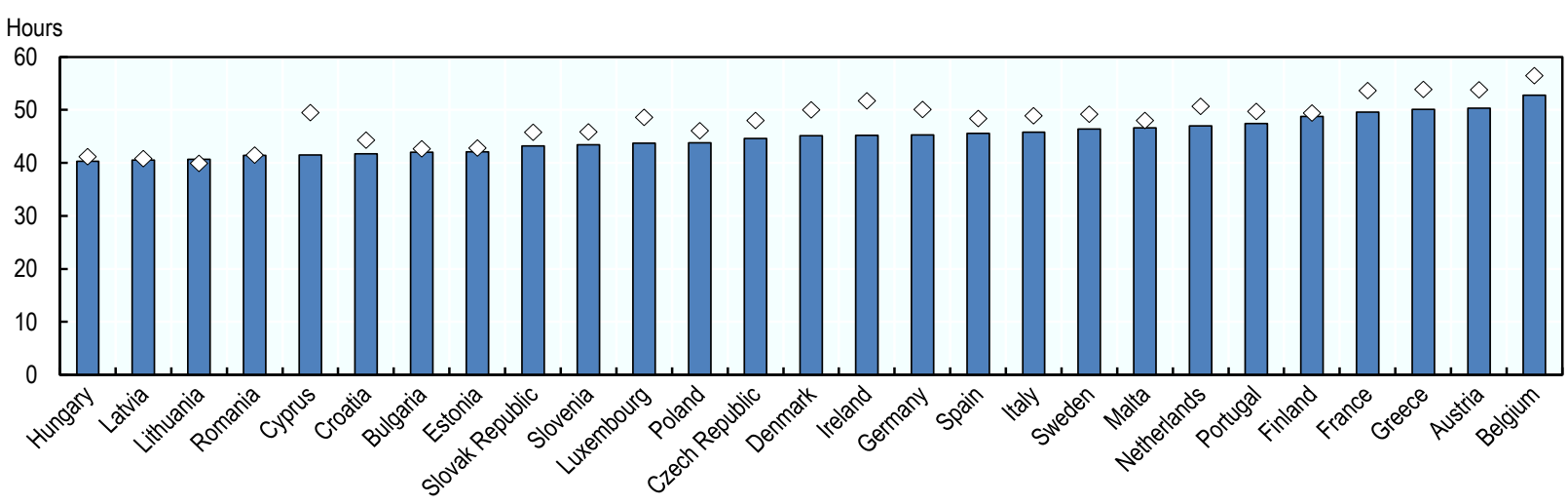

c. Self-employed without employees

$\square$ Women $\diamond$ Men

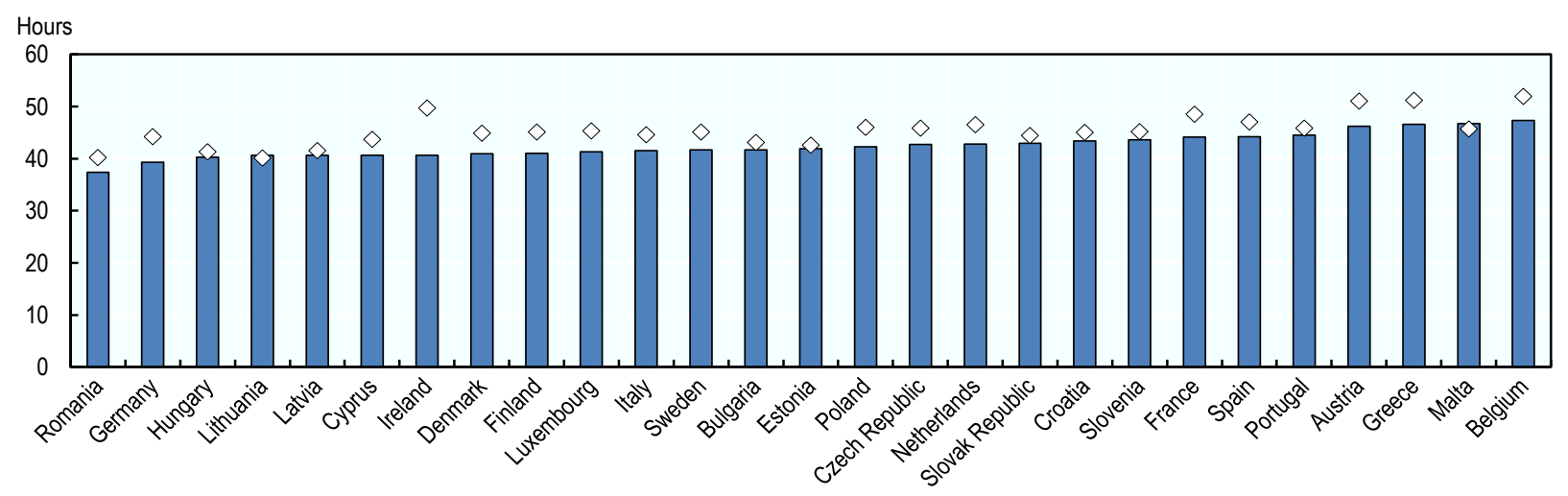

Note: Full-time work is not defined in most EU Member States and is defined by the survey respondent. However, full-time work is defined as more than 35 hours per week in the Netherlands and Iceland. In Sweden, full-time work is defined as more than 36 hours per week but survey respondents who work between 32 and 36 hours per week can specify if they work full-time or part-time.

Source: (Eurostat, 2021[7])

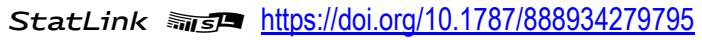




\section{...but self-employed women are as likely to report full autonomy over their working time}

About $15 \%$ of self-employed workers report that another organisation (i.e. a single client) is responsible for making decisions about working time. Self-employed men and women were about as likely to report that they fully control their working time across the EU $(61 \%$ for self-employed women and $65 \%$ for self-employed men) (Figure 2.12). Furthermore, it is somewhat surprising that there is essentially no difference in the proportion of self-employed with and without employees that have full autonomy over their working time.

\section{Figure 2.12. Self-employed women are as likely as men to have autonomy over their working time}

Distribution of autonomy over working time for workers (15-64 years old) in the EU, 2019

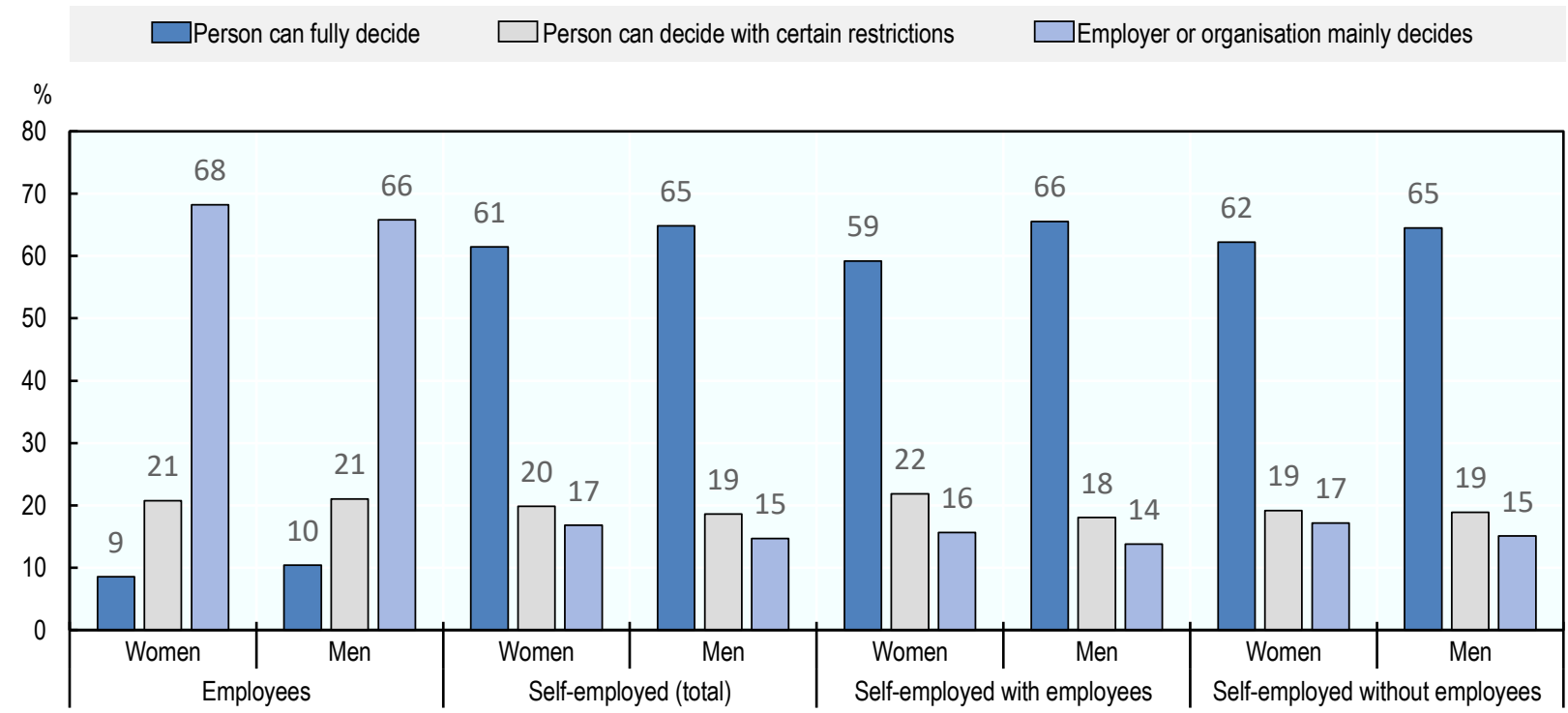

Source: (Eurostat, 2019[14])

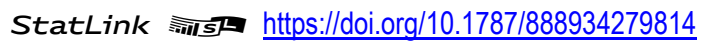

\section{Self-employed women earn less than employees but the gender gap is relatively small}

The median net income for full-time self-employed women and self-employed men was approximately equal over the period 2010-19. However, self-employed women had a lower median net income compared to women who worked as employees (EUR 20620 vs EUR 17326 in 2019) (Figure 2.13). In 2019, full-time self-employed women earned slightly more than self-employed men in 16 EU Member States (Figure 2.14). The largest difference was in Denmark where full-time self-employed women earned, on average, EUR 7324 more per year than self-employed men. Conversely, the largest gender pay gap was in Slovenia where self-employed women made, on average, EUR 2388 less in median net income than self-employed men. 
Figure 2.13. There earnings gap between full-time self-employed men and women is negligible Median equivalised net income for full-time workers (16-64 years old) in the EU

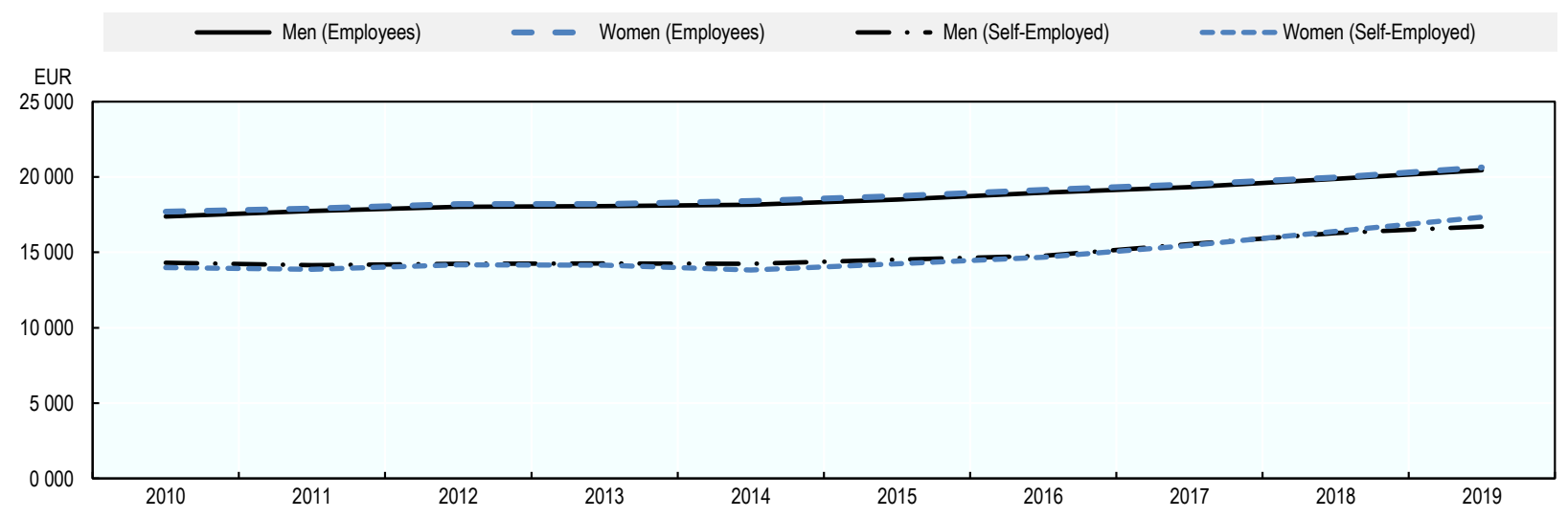

Note: Full-time work is not defined in most EU Member States and is defined by the survey respondent. However, full-time work is defined as more than 35 hours per week in the Netherlands and Iceland. In Sweden, full-time work is defined as more than 36 hours per week but survey respondents who work between 32 and 36 hours per week can specify if they work full-time or part-time.

Source: (Eurostat, 2021 $[15])$

StatLink 제 Sh https://doi.org/10.1787/888934279833

Figure 2.14. Self-employed women earn less than those working as employees in most EU Member States

Median equivalised net income for full-time workers (16-64 years old), 2019

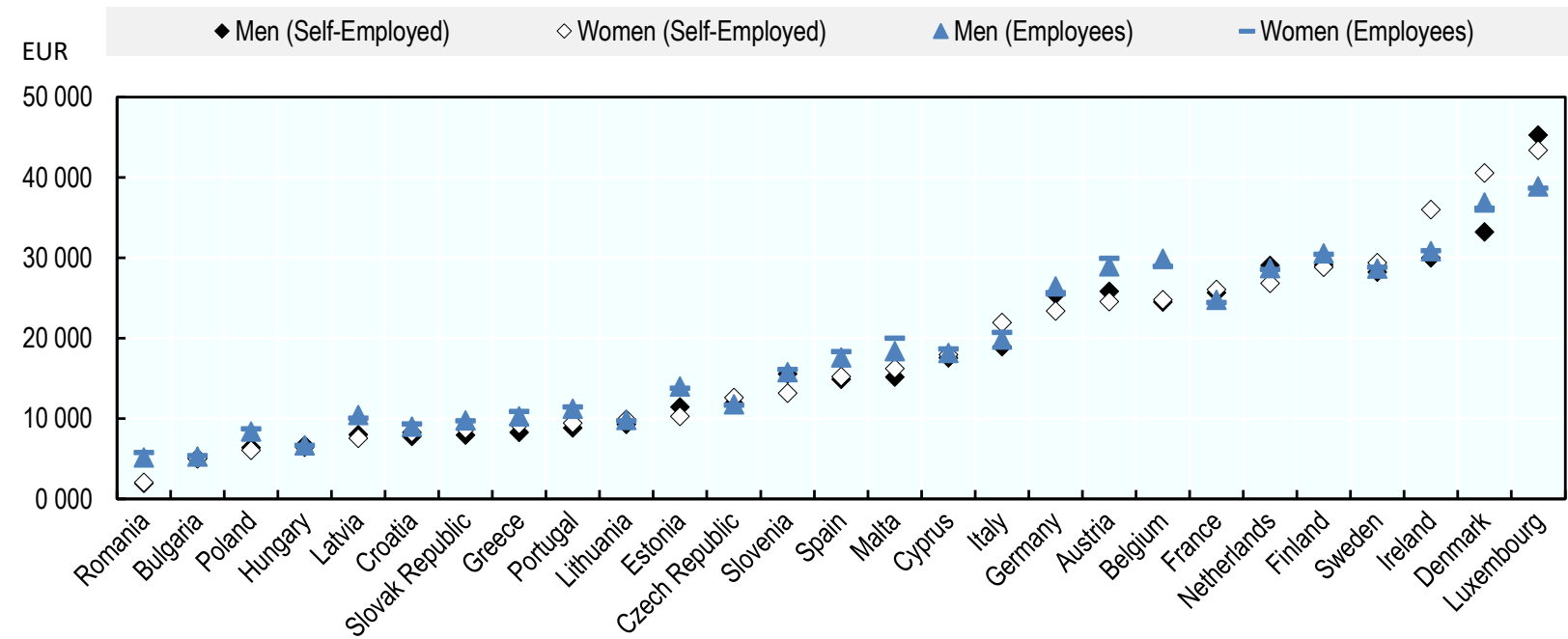

Note: Full-time work is not defined in most EU Member States and is defined by the survey respondent. However, full-time work is defined as more than 35 hours per week in the Netherlands and Iceland. In Sweden, full-time work is defined as more than 36 hours per week but survey respondents who work between 32 and 36 hours per week can specify if they work full-time or part-time.

Source: (Eurostat, 2021 $[15])$ 


\section{Women have lower self-employment rates across all sectors except other services...}

Women were less likely to be self-employed than men in all sectors except for other services, where about one-third of all women were self-employed relative to $26 \%$ of men. This sector includes activities of membership organisations, repair of computers, personal and household goods and other personal service activities (e.g. Washing and (dry-) cleaning of textile and fur products, Hairdressing and other beauty treatment, Physical well-being activities). However, the sector where women were the most likely to be self-employed was Agriculture, forestry and fishing. More than $40 \%$ of women working in this sector in 2020 were self-employed, which was a lower than the share of men (53\%) (Figure 2.15). These findings have been constant over the past decade.

The sectors where self-employed women are concentrated varies across EU Member States, which is largely driven by the economic structure of different economies. For example, self-employed women in Romania are concentrated in agriculture, which accounts for $24 \%$ of total employment - the largest share in the EU. This mainly consists of self-employed and contributing family workers, with the vast majority in the latter category being women. In other countries such as Portugal, self-employed women are heavily concentrated in accommodation and food service activities, which account for a larger share of the self-employed in Portugal due to the significance of tourism in the economy.

In some countries, specific administrative requirements lead to an increase in self-employment in some sectors. In Austria, for example, there is a disproportionate number of self-employed workers in health and social work since care workers (Personenbetreuer) are mostly registered as sole-proprietors. The vast majority of these workers are women, so it is a dominant activity of self-employed women. Another example is the Slovak Republic, which has very low levels of self-employment in the agriculture sector since the previous political regime required individual farmers to merge into agricultural co-operatives.

\section{Figure 2.15. Women are more likely to be self-employed than men in the Other service activities sector}

Self-employment as a percentage of employment (15-64 years old), 2020

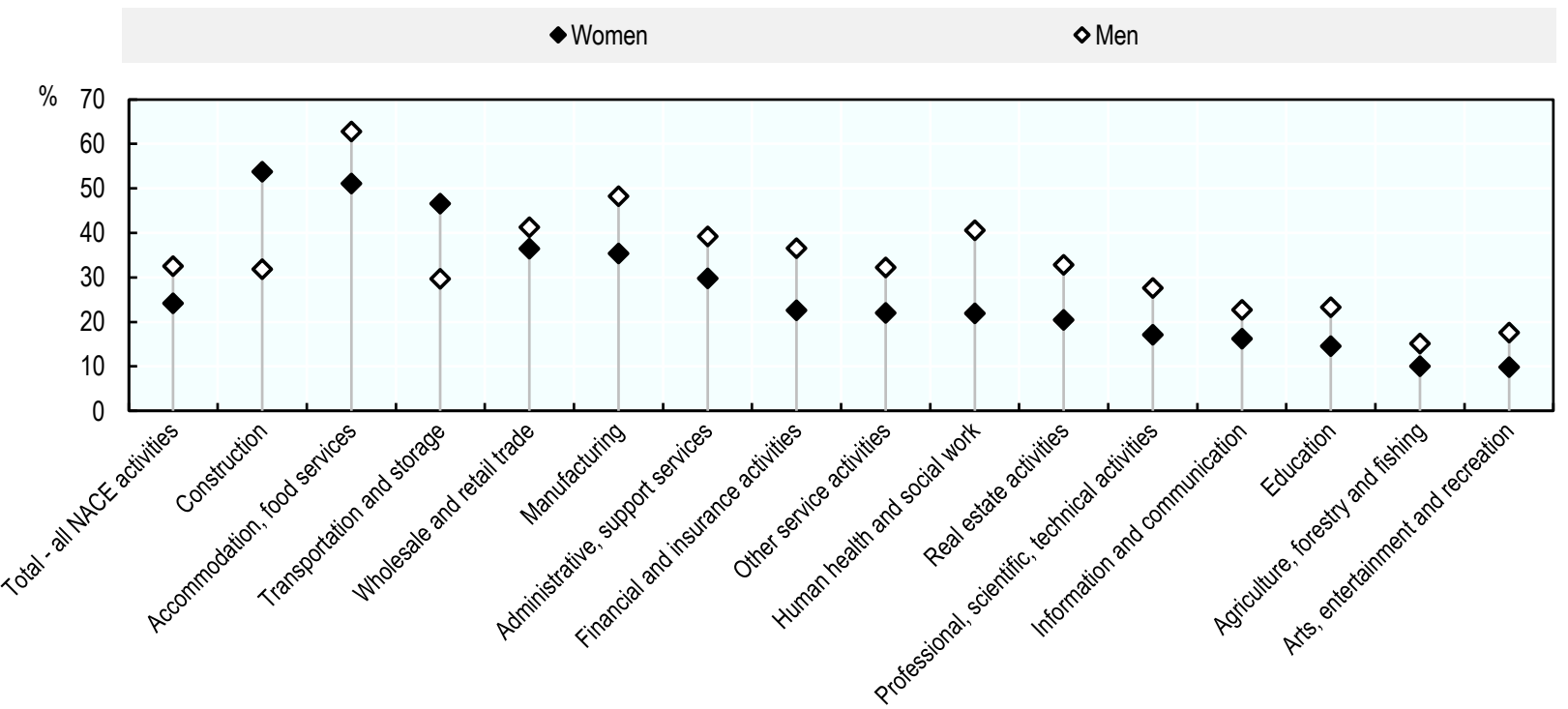

Note: The following sectors were excluded because the self-employment rate was less than $1 \%$ or the data were could not be reported due to a low reliability of the estimate: Public administration and defence, compulsory social security; Mining and quarrying; and Electricity, gas, steam and air conditioning supply.

Source: (Eurostat, 2021[7]) 


\section{....and the majority of self-employed women are professionals or service and sales workers}

More than half of self-employed women worked as professionals $(30 \%)$ or service and sales workers $(27 \%)$ in 2020 , compared to $19 \%$ and $11 \%$ of self-employed men. This concentration in professional and service and sales worker occupations is observed among employees, but the concentration is not as significant. Conversely, self-employed women were much less likely than men to be working as craft and related trades workers (4\% vs. 21\%) (Figure 2.16). The occupations of selfemployed women are influenced by a range of factors, including level of education and sector.

Figure 2.16. More than half of self-employed women are professionals and service and sales workers

Distribution of workers (15-64 years old) in the EU, 2020

a. Self-employed

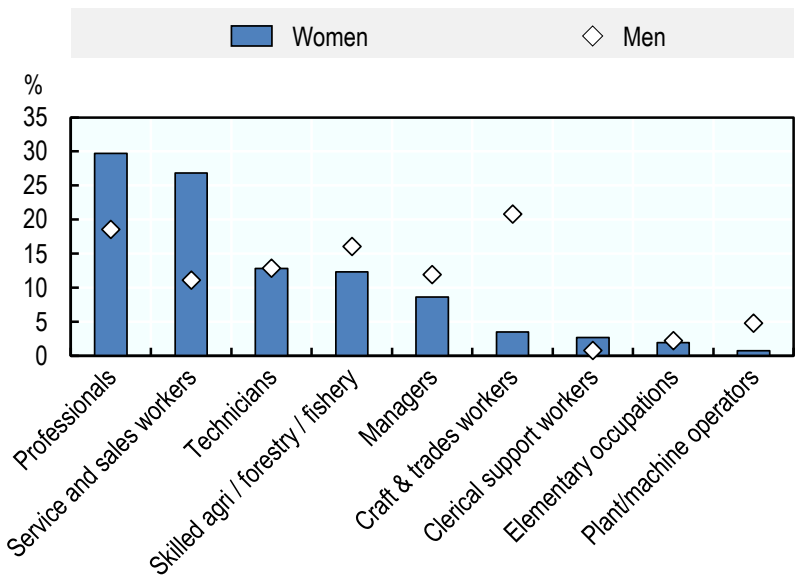

c. Self-employed with employees

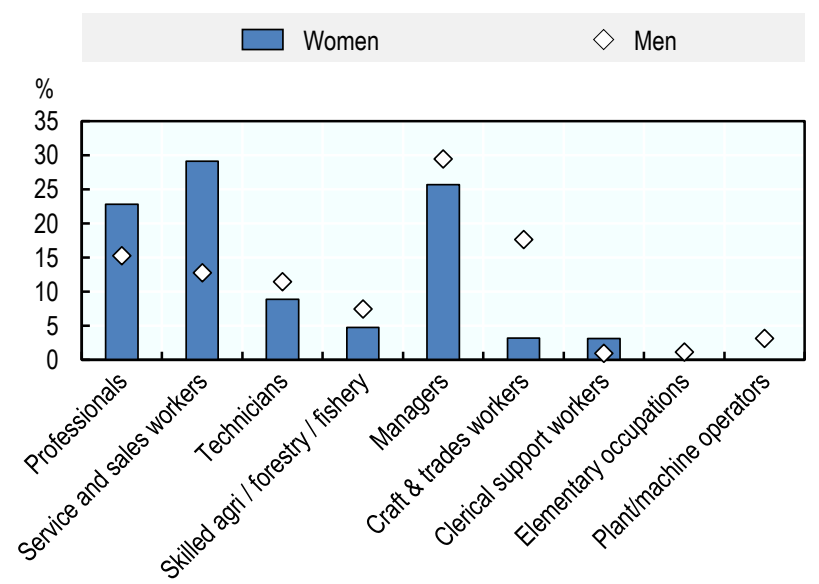

Source: (Eurostat, 2021 $1_{[7]}$ ) b. Employees

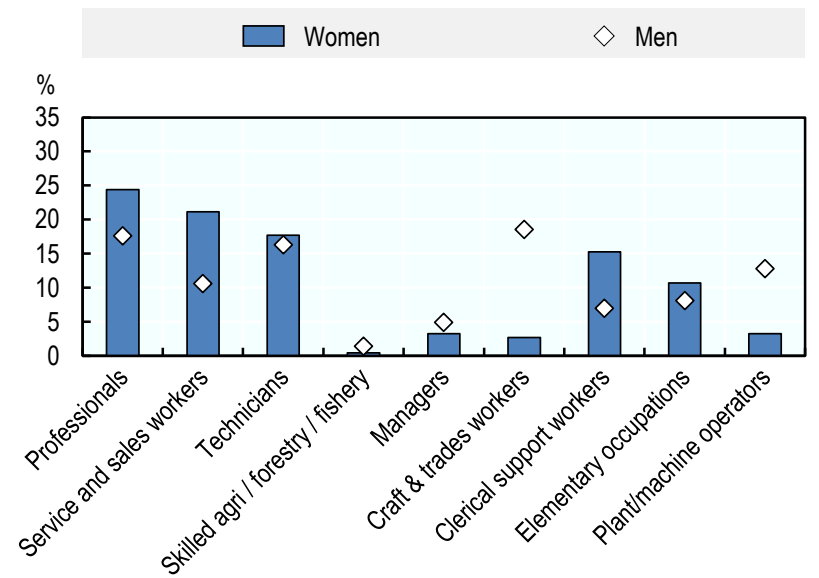

d. Self-employed without employees

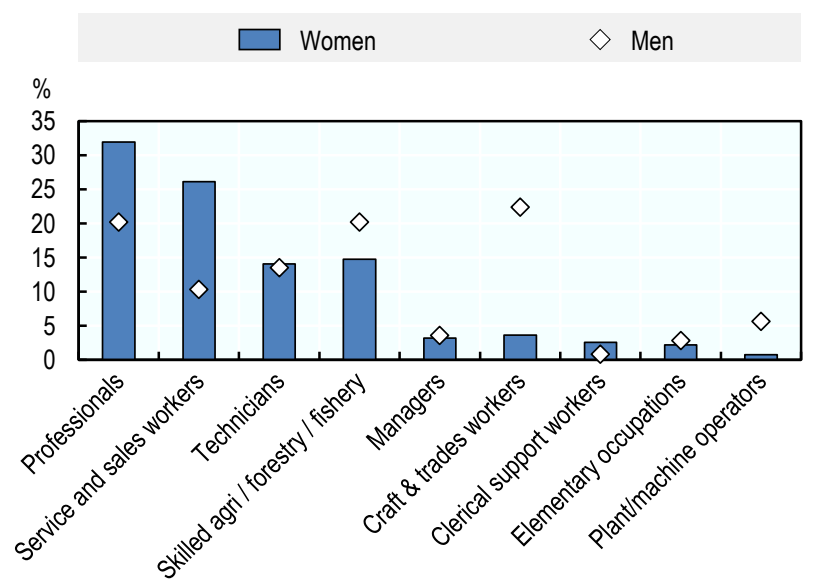

StatLink त्गाडम https://doi.org/10.1787/888934279890 


\section{Activities by women over the entrepreneurship life-cycle}

Women are less involved in early-stage entrepreneurship than men...

Another way to examine entrepreneurship activities by women is to consider the proportion of women who are involved in starting or managing businesses. The Global Entrepreneurship Monitor (GEM) is an international study of entrepreneurship that is produced by a consortium of researchers and research institutions using a common population survey. This survey divides entrepreneurship activities into four stages: nascent entrepreneurship, new business ownership, established business ownership and business exit. For more information, please see the Reader's Guide at the beginning of the report.

Women are less likely than men to be actively working towards starting a business. Overall, about $3 \%$ of women in the EU were involved in nascent entrepreneurship between 2016 and 2020 (Figure 2.17), i.e. actively involved in setting up a business they will own or co-own but have not yet paid salaries, wages or any other payments to the owner(s) for more than three months. This was below the proportion of men (nearly $5 \%$ ) and also below the share of women in OECD countries involved in nascent entrepreneurship $(6 \%)$.

This gender gap in nascent entrepreneurship was also observed across all EU Member States over this period, although the size of the gender gap varies substantially. Women were the most active in nascent entrepreneurship in Latvia (6\%), Slovak Republic (7\%) and Estonia (9\%), but these countries had lower rates than many OECD countries: United States (9\%), Colombia (14\%) and Chile (17\%). Moreover, the EU Member States with the highest nascent entrepreneurship rates among women were not the countries with the smallest gender gap. The gender gap in nascent entrepreneurship was the greatest in Hungary (119\%) and Latvia (103\%), and smallest in Finland (15\%) and Spain (18\%).

Women in the EU were less than half as likely as men to self-report that they were new business owners between 2016 and 2020 (Figure 2.17). Across the EU, about $2 \%$ of women and $5 \%$ of men indicated that they were the owner-manager of a new business that has paid salaries, wages or any other payments to the owners for more than three months, but not more than 42 months. The share of women identifying as new business owners was also below the OECD average of $3 \%$.

There tends to be a strong corelation between nascent entrepreneurship rates and new business ownership rates. For example, both the nascent and new business ownership rates were high in countries such as Latvia and Estonia. However, there are a few exceptions such as the Slovak Republic which had high levels of nascent entrepreneurship among women but relatively low level of new business ownership. Early-stage entrepreneurship rates are influenced by a large range of factors, including the regulatory framework, market conditions, access to finance, creation and diffusion of knowledge, entrepreneurial capabilities and social and cultural attitudes towards entrepreneurship. Each of these factors vary greatly across Member States and these factors have different influences for men and women. 
Figure 2.17. There is a gender gap in early-stage entrepreneurship across all EU Member States

Percent of the population (18-64 years old), 2016-20

a. Nascent entrepreneurship rate

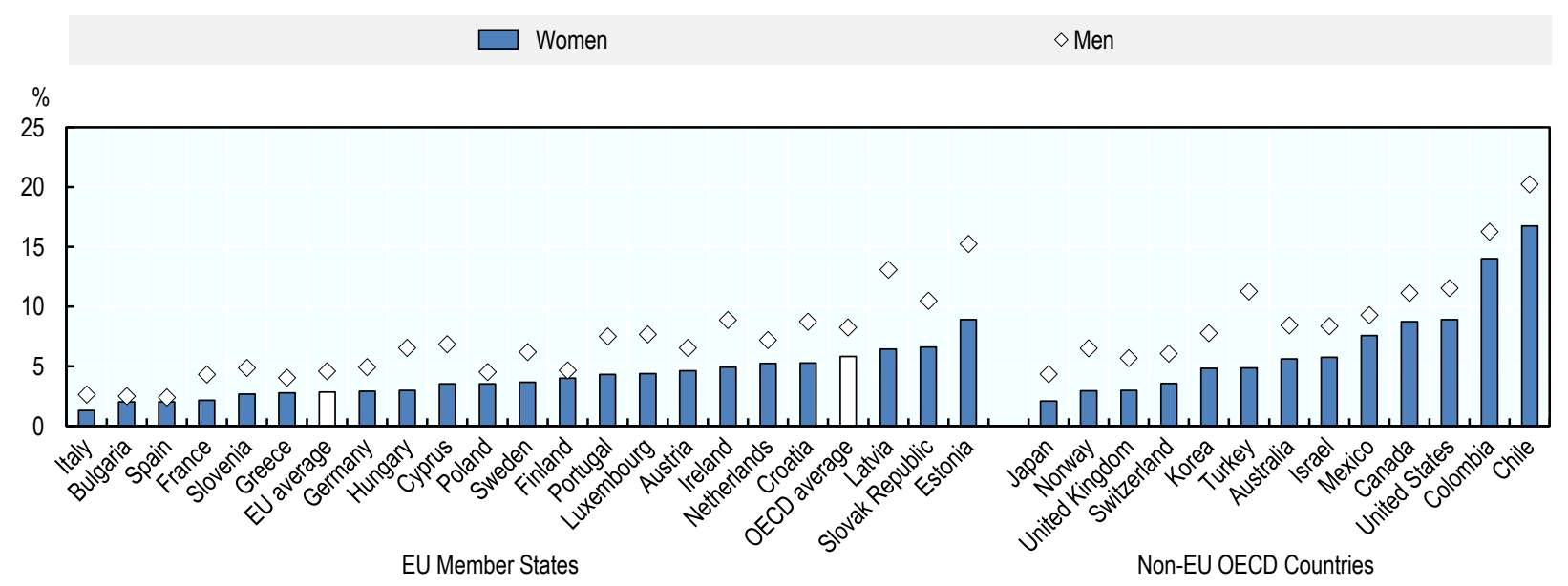

b. New business ownership rate

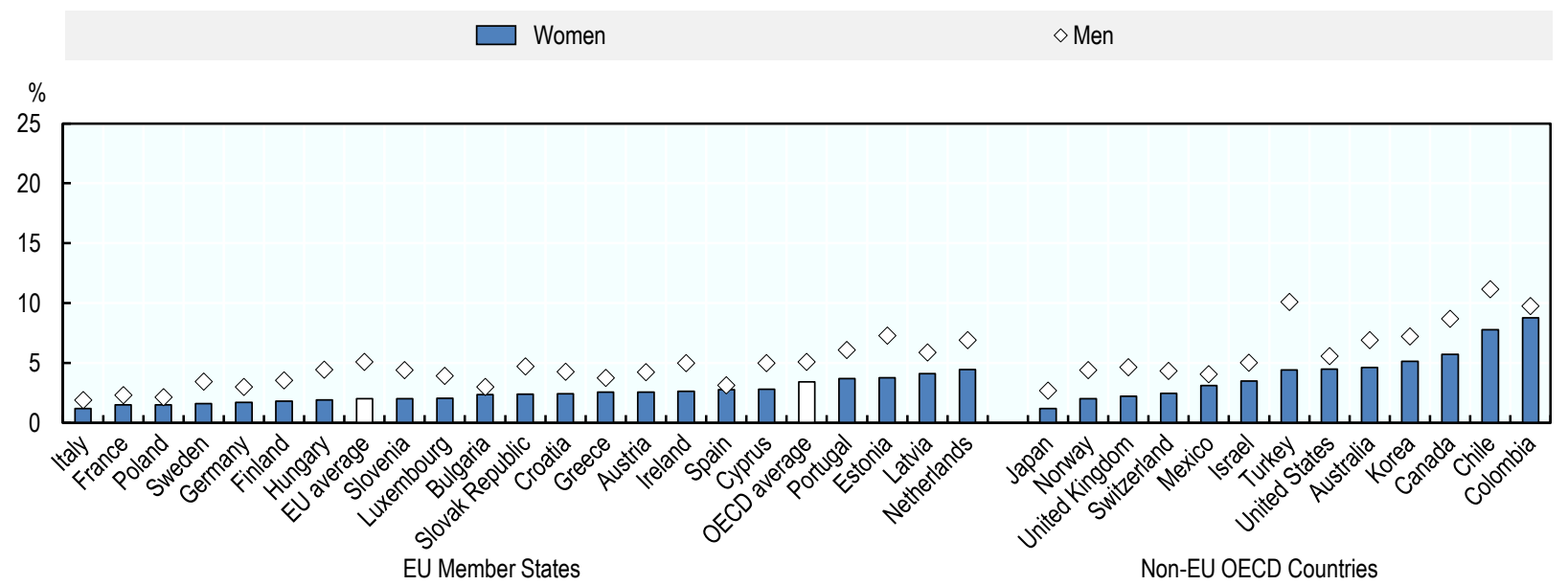

Note: Nascent entrepreneurship rate is the proportion of the population that is actively involved in setting up a business they will own or co-own; this business has not paid salaries, wages or any other payments to the owners for more than three months. New business ownership is the proportion of the population that is currently an owner-manager of a new business that has paid salaries, wages or any other payments to the owners for more than three months, but not more than 42 months. All EU Member States participated in the GEM survey between 2016 and 2020 except for Belgium, Czech Republic, Denmark, Lithuania, Malta and Romania. Furthermore, the following countries did not participate in the survey in every year over this period (years of participation are indicated): Austria (2016, 2018, 2020), Bulgaria (2016-18), Estonia (201617), Finland (2016), France (2016-18), Hungary (2016), Ireland (2016-19), Latvia (2016-17, 2019-20) and Portugal (2016, 2019). Similarly, the following OECD countries did not participate in the GEM survey between 2016 and 2020: Belgium, Czech Republic, Denmark, Iceland, Lithuania and New Zealand. The following countries did not participate in the survey in every year (years of participation are indicated): Australia (201617, 2019), Austria (2016, 2018, 2020), Estonia (2016-17), Finland (2016), France (2016-18), Hungary (2016), Ireland (2016-19), Japan (201719), Latvia (2016-17, 2018-19), Mexico (2016-17, 2019), Norway (2019-20), Portugal (2016, 2019) and Turkey $(2016,2018)$.

Source: (Global Entrepreneurship Monitor (GEM), 2021[16])

StatLink तiाs https://doi.org/10.1787/888934279909 


\section{....and are slightly more likely to have started their business out of "necessity"...}

Individuals can be motivated to start a business for several reasons. Some people have an idea that they believe will meet a market demand and generate an income, while others seek to start a business that does something to improve society rather than focussing only on making money. Others create a business because they are unable to find employment but need to earn some income. Policy makers are interested in understanding the different types of motivations and seek to support those who create economic and social value. However, in practice these different motivations can be difficult to distinguish because it is possible for entrepreneurs to have multiple motivations and these motivations can easily change. For example, an entrepreneur who creates a business because they cannot find a job may start a sustainable business that meets a market demand and the business may end up growing. Conversely, an entrepreneur that starts a business to meet a market demand may lack the finance or skills to convert the idea into a sustainable business.

Early-stage women entrepreneurs in the EU were slightly more likely to indicate that they started a business out of "necessity" than early-stage men entrepreneurs between 2016 and 2020 (Figure 2.18). Among early-stage entrepreneurs, $21 \%$ of women indicated that they started their business because they could not find employment relative to $17 \%$ of men. These rates were similar to the OECD average for this period: $18 \%$ of early-stage women entrepreneurs and $15 \%$ of early-stage men entrepreneurs.

\section{Figure 2.18. Women are more likely to be "necessity" entrepreneurs in countries with high unemployment and informality rates}

Percent of early-stage entrepreneurs (18-64 years old), 2016-20

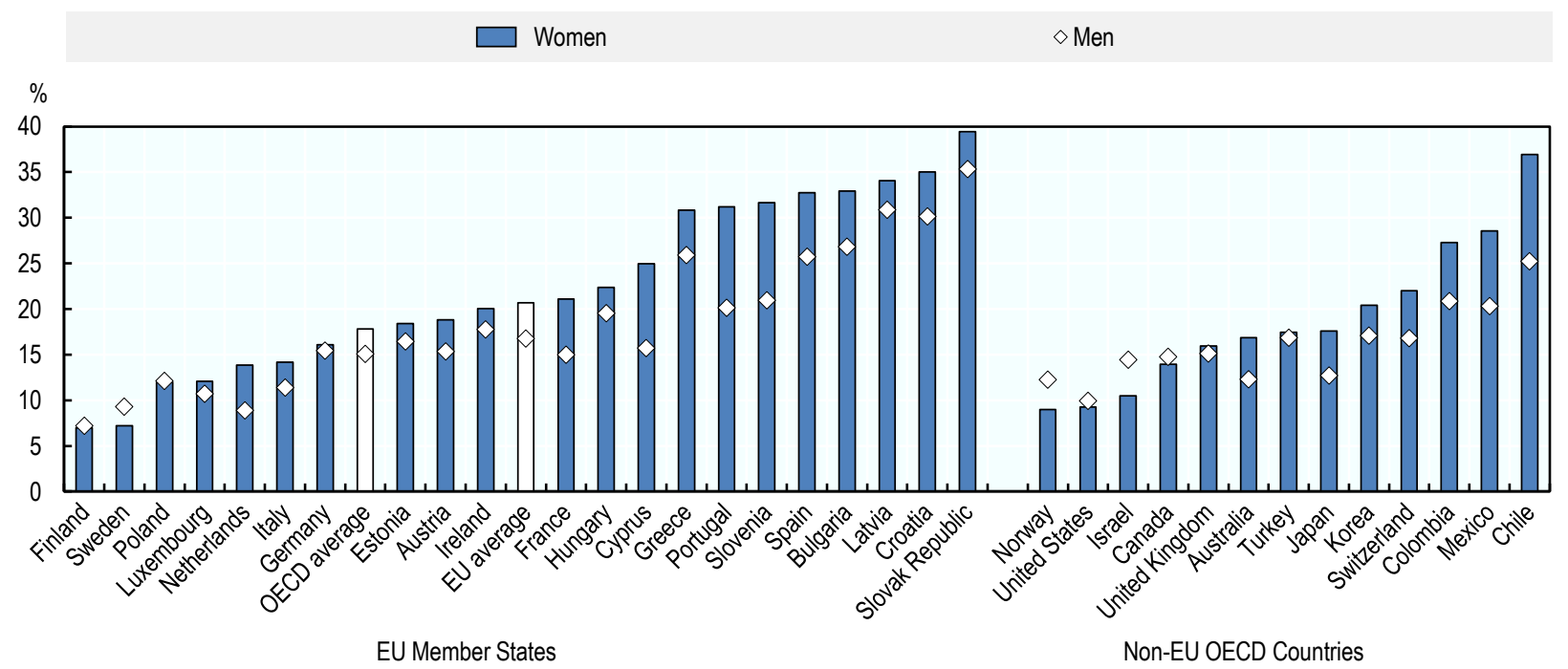

Note: Necessity entrepreneurship rate is the proportion of early-stage entrepreneurs (i.e. nascent entrepreneurs and new business owners) who launched their business due to a lack of other opportunities in the labour market. All EU Member States participated in the GEM survey between 2016 and 2020 except for Belgium, Czech Republic, Denmark, Lithuania, Malta and Romania. Furthermore, the following countries did not participate in the survey in every year over this period (years of participation are indicated): Austria (2016, 2018, 2020), Bulgaria (2016-18), Estonia (2016-17), Finland (2016), France (2016-18), Hungary (2016), Ireland (2016-19), Latvia (2016-17, 2019-20) and Portugal (2016, 2019). Similarly, the following OECD countries did not participate in the GEM survey between 2016 and 2020: Belgium, Czech Republic, Denmark, Iceland, Lithuania and New Zealand. The following countries did not participate in the survey in every year (years of participation are indicated): Australia (2016-17, 2019), Austria (2016, 2018, 2020), Estonia (2016-17), Finland (2016), France (2016-18), Hungary (2016), Ireland (2016-19), Japan (2017-19), Latvia (2016-17, 2018-19), Mexico (2016-17, 2019), Norway (2019-20), Portugal (2016, 2019) and Turkey (2016, 2018). Source: (Global Entrepreneurship Monitor (GEM), 2021[16]) 
Necessity entrepreneurship rates tend to be highest in Member States that have high levels of unemployment or have high levels of informal work. For example, Latvia and Romania are estimated to have the highest levels of undeclared work among the self-employed (Williams et al., 2019[17]). Conversely, it is low in countries where cultural attitudes dictate a preference for employment and where countries have relatively larger public sectors. This includes, for example, Finland where salaried employment is a cultural norm (European Commission, 2019[18] $)$. In some countries, women are motivated by earnings gaps between men and women in employment. For example, in Ireland, the pay differential has been increasing, rising from 5.9\% in 2017 to $7.5 \%$ in 2018 (PWC, 2020[19]).

\section{....and less likely to start businesses in teams}

Women who are working on a new business start-up are about two-thirds as likely as men to be working in teams of three or more people. Between 2016 and 2020, about 15\% of women nascent entrepreneurs in the EU were working in teams of at least three people relative to $22 \%$ of men (Figure 2.19). These proportions were essentially the same as the proportions in OECD countries - 16\% of women nascent entrepreneurs and $23 \%$ of men nascent entrepreneurs were working in teams of at least three people.

\section{Figure 2.19. Fewer than one-in-six women entrepreneurs started the business in a team}

Percent of nascent entrepreneurs (18-64 years old), 2016-20

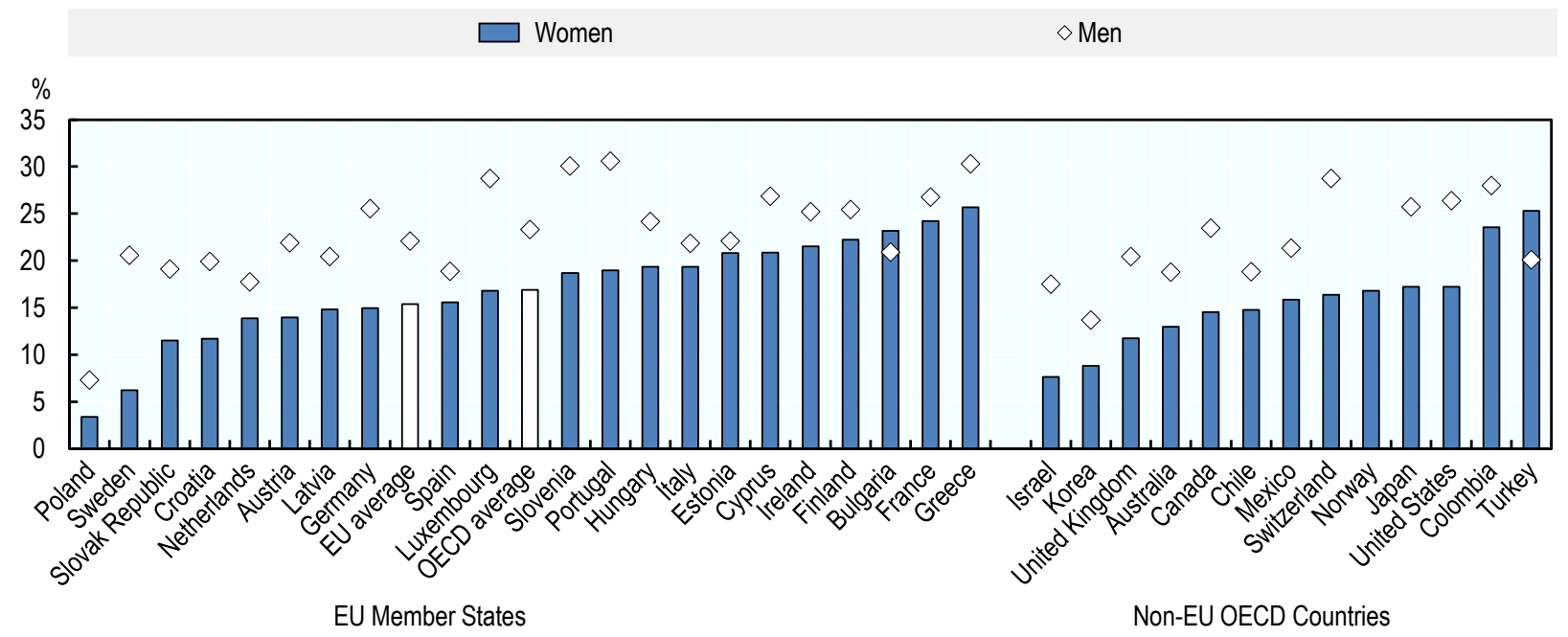

Note: Nascent entrepreneurship rate is the proportion of the population that is actively involved in setting up a business they will own or co-own; this business has not paid salaries, wages or any other payments to the owners for more than three months. All EU Member States participated in the GEM survey between 2016 and 2020 except for Belgium, Czech Republic, Denmark, Lithuania, Malta and Romania. Furthermore, the following countries did not participate in the survey in every year over this period (years of participation are indicated): Austria (2016, 2018, 2020), Bulgaria (2016-18), Estonia (2016-17), Finland (2016), France (2016-18), Hungary (2016), Ireland (2016-19), Latvia (2016-17, 2019-20) and Portugal $(2016,2019)$. Similarly, the following OECD countries did not participate in the GEM survey between 2016 and 2020 : Belgium, Czech Republic, Denmark, Iceland, Lithuania and New Zealand. The following countries did not participate in the survey in every year (years of participation are indicated): Australia (2016-17, 2019), Austria (2016, 2018, 2020), Estonia (2016-17), Finland (2016), France (2016-18), Hungary (2016), Ireland (2016-19), Japan (2017-19), Latvia (2016-17, 2018-19), Mexico (2016-17, 2019), Norway (2019-20), Portugal (2016, 2019) and Turkey $(2016,2018)$.

Source: (Global Entrepreneurship Monitor (GEM), 2021 ${ }_{[16]}$ ) 


\section{Consequently, women are less likely to operate established businesses than men}

About $5 \%$ of women in the EU self-report that they own an established business, which is nearly half the proportion of men. These businesses are those that have paid salaries, wages or any other payments to the owners for more than 42 months. Established business ownership rates among men and women tend to be highest in countries where early-stage entrepreneurship is highest such as Portugal (6\%), Estonia (7\%) and Latvia (7\%) (Figure 2.20). Combining the three stages of entrepreneurship as defined by GEM - nascent entrepreneurship, new business ownership and established business ownership - nearly $10 \%$ of women in the EU are actively participating in entrepreneurship. This is about half of the proportion of men (19\%).

\section{Figure 2.20. Women are half as likely as men to be established business owners}

Percent of the population (18-64 years old), 2016-20

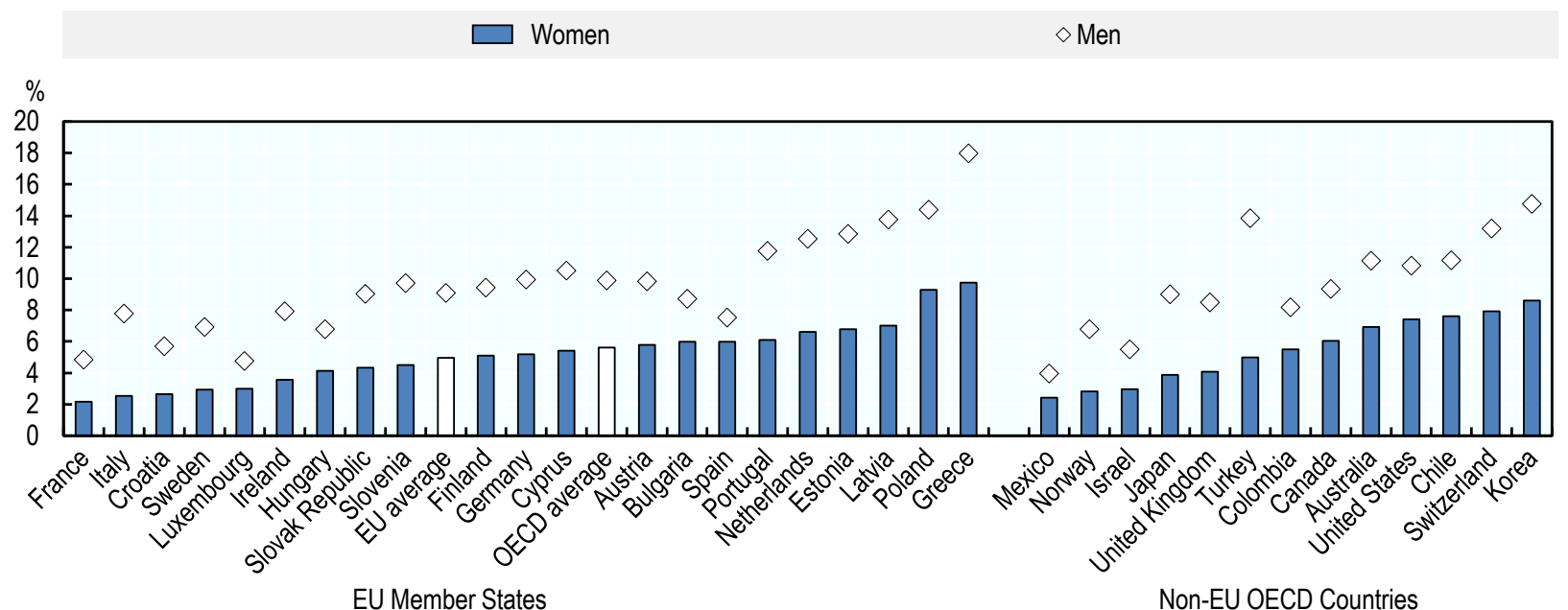

Note: Established business ownership rate is the proportion of the adult population that are currently owner-managers of an established business that has paid salaries, wages or any other payments to the owners for more than 42 months. All EU Member States participated in the GEM survey between 2016 and 2020 except for Belgium, Czech Republic, Denmark, Lithuania, Malta and Romania. Furthermore, the following countries did not participate in the survey in every year over this period (years of participation are indicated): Austria (2016, 2018, 2020), Bulgaria (2016-18), Estonia (2016-17), Finland (2016), France (2016-18), Hungary (2016), Ireland (2016-19), Latvia (2016-17, 2019-20) and Portugal (2016, 2019). Similarly, the following OECD countries did not participate in the GEM survey between 2016 and 2020: Belgium, Czech Republic, Denmark, Iceland, Lithuania and New Zealand. The following countries did not participate in the survey in every year (years of participation are indicated): Australia (2016-17, 2019), Austria (2016, 2018, 2020), Estonia (2016-17), Finland (2016), France (2016-18), Hungary (2016), Ireland (2016-19), Japan (2017-19), Latvia (2016-17, 2018-19), Mexico (2016-17, 2019), Norway (2019-20), Portugal (2016, 2019) and Turkey (2016, 2018).

Source: (Global Entrepreneurship Monitor (GEM), 2021 $\left.{ }_{[16]}\right)$ 


\section{Women entrepreneurs are most likely to stop because their business is not profitable}

About one-quarter of women entrepreneurs in the EU who stopped operating their business indicated that they did so because it was not profitable (Figure 2.21). Similarly, about one-quarter of men indicated that they stopped their business because it was not profitable. This was the most commonly cited reason for stopping business activities by both men and women entrepreneurs.

Overall, there were only small gender differences in the factors for stopping a business. Women were slightly more likely to report that they stopped their business due to "personal reasons" (18\% vs. $15 \%$ ) but were less than half as likely to report that they had an "opportunity to sell their business" (3\% vs. $8 \%)$.

Figure 2.21. Most entrepreneurs, whether women or men, exit their business because it is not profitable

"What was the most important reason for quitting this business?"

Share of entrepreneurs (18-64 years old) that exited their business in the past 12 months, 2016-20

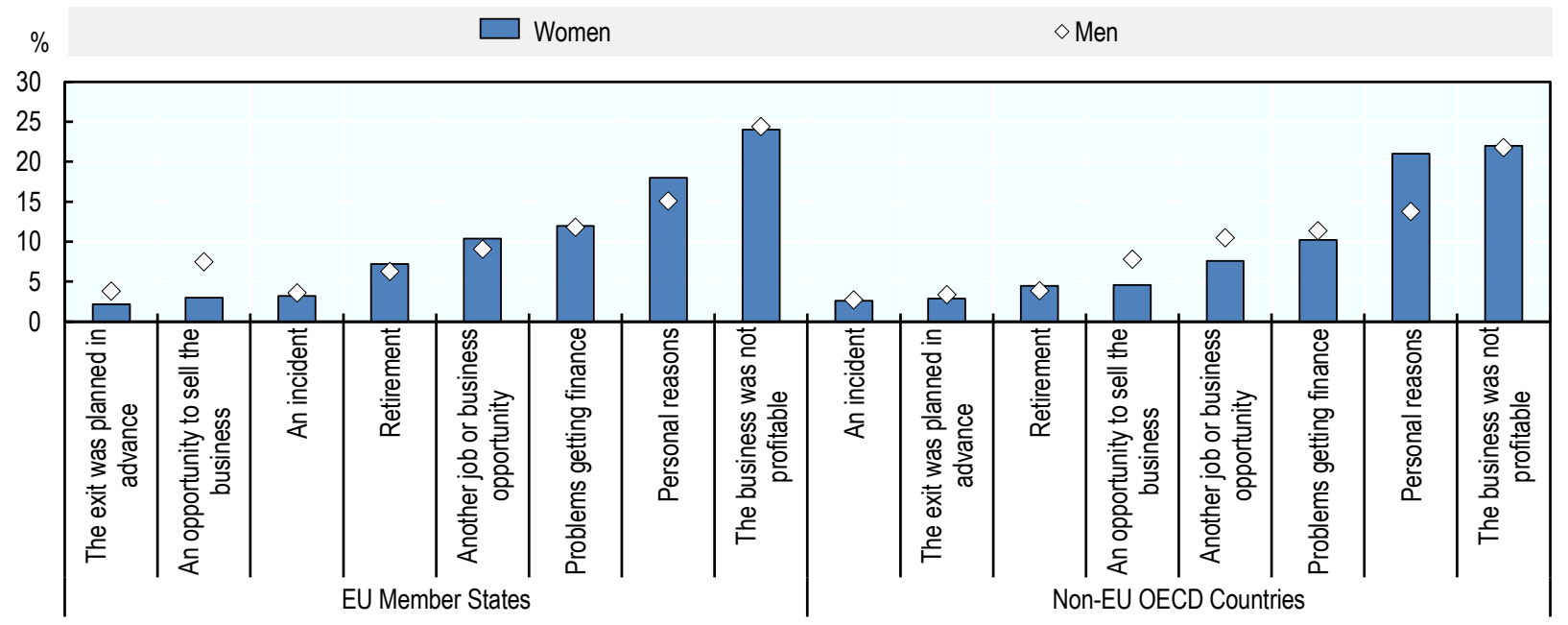

Note: All EU Member States participated in the GEM survey between 2016 and 2020 except for Belgium, Czech Republic, Denmark, Lithuania, Malta and Romania. Furthermore, the following countries did not participate in the survey in every year over this period (years of participation are indicated): Austria (2016, 2018, 2020), Bulgaria (2016-18), Estonia (2016-17), Finland (2016), France (2016-18), Hungary (2016), Ireland (2016-19), Latvia (2016-17, 2019-20) and Portugal $(2016,2019)$. Similarly, the following OECD countries did not participate in the GEM survey between 2016 and 2020: Belgium, Czech Republic, Denmark, Iceland, Lithuania and New Zealand. The following countries did not participate in the survey in every year (years of participation are indicated): Australia (2016-17, 2019), Austria $(2016,2018,2020)$, Estonia (2016-17), Finland (2016), France (2016-18), Hungary (2016), Ireland (2016-19), Japan (2017-19), Latvia (2016-17, 2018-19), Mexico (2016-17, 2019), Norway (2019-20), Portugal $(2016,2019)$ and Turkey $(2016,2018)$.

Source: (Global Entrepreneurship Monitor (GEM), 2021[16]) 


\section{Barriers to business creation by women}

\section{Nearly half of women report that a fear of failure is a barrier to business creation}

Nearly half of women (47\%) surveyed in the EU between 2016 and 2020 reported that a "fear of failure" was a barrier to business creation relative to $\mathbf{4 0} \%$ of men. This proportion of people reporting that "fear of failure" is a barrier to entrepreneurship is slightly higher in the EU than in OECD countries, where about $43 \%$ of women reported this obstacle relative to $37 \%$ of men (Figure 2.22). This is an important barrier to entrepreneurship because it can prevent people from considering entrepreneurship as a career or part-time activity. It can also lead to people reducing their entrepreneurial ambitions.

The significance of this barrier varies across countries according to factors such as social attitudes and regulatory and tax policy. The gender gap in fear of failure was greatest in Latvia $(30 \%)$, Estonia $(34 \%)$ and Germany (35\%) and smallest in Italy, where it was virtually non-existent over this time period. Country-specific research highlights how different factors can influence attitudes towards entrepreneurship. For example, the most significant barriers identified in Bulgaria for young women entrepreneurs are access to finance, corruption and administrative burden (Innovation Region Styria Ltd, $2019_{\text {[20] }}$. Each of these factors is an obstacle, but they also combine to influence how entrepreneurship is viewed in society. When many difficulties are perceived, people are less likely to pursue business creation.

\section{Figure 2.22. Nearly $50 \%$ of women report that fear of failure is a barrier to business creation}

"Does a fear of failure prevent you from starting a business?"

Percentage of population (18-64 years old) who responded "yes", 2016-20

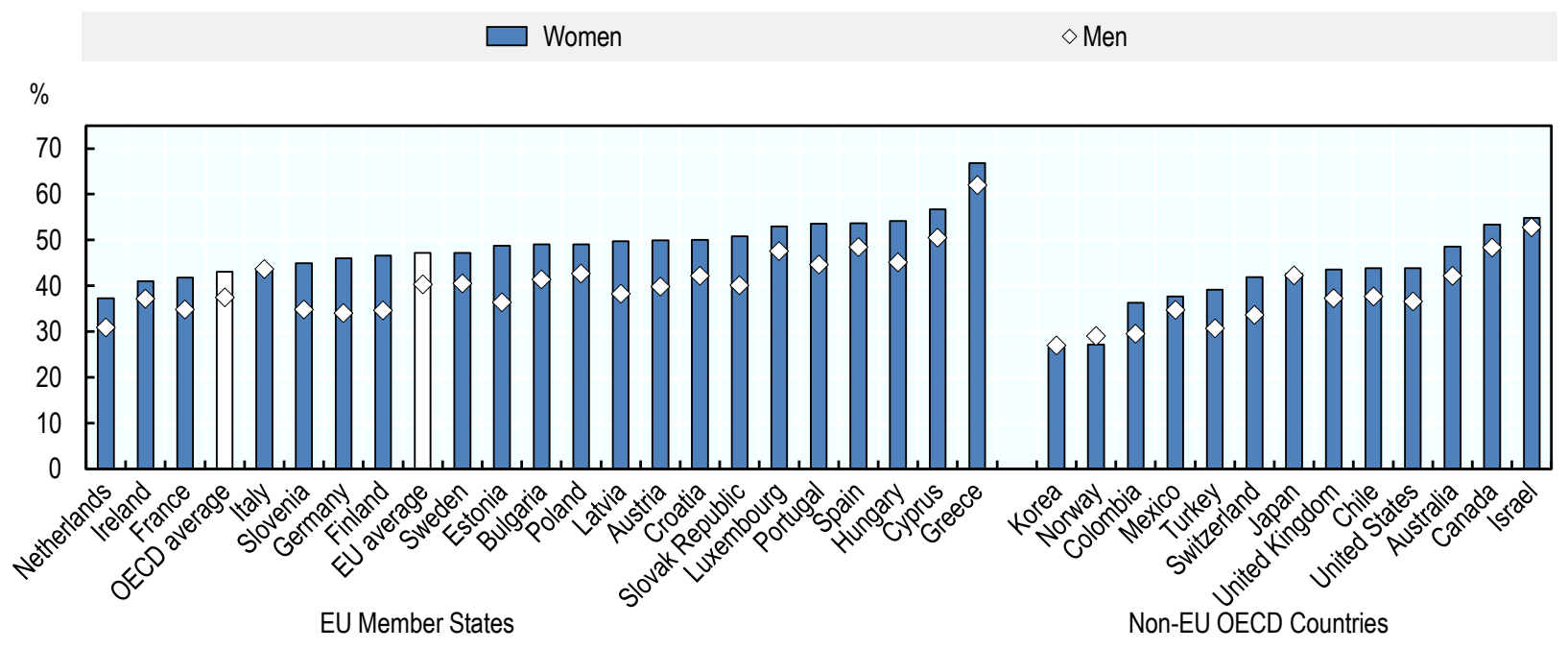

Note: All EU Member States participated in the GEM survey between 2016 and 2020 except for Belgium, Czech Republic, Denmark, Lithuania, Malta and Romania. Furthermore, the following countries did not participate in the survey in every year over this period (years of participation are indicated): Austria (2016, 2018, 2020), Bulgaria (2016-18), Estonia (2016-17), Finland (2016), France (2016-18), Hungary (2016), Ireland (2016-19), Latvia $(2016-17,2019-20)$ and Portugal $(2016,2019)$. Similarly, the following OECD countries did not participate in the GEM survey between 2016 and 2020: Belgium, Czech Republic, Denmark, Iceland, Lithuania and New Zealand. The following countries did not participate in the survey in every year (years of participation are indicated): Australia (2016-17, 2019), Austria (2016, 2018, 2020), Estonia (2016-17), Finland (2016), France (2016-18), Hungary (2016), Ireland (2016-19), Japan (2017-19), Latvia (2016-17, 2018-19), Mexico (2016-17, 2019), Norway (2019-20), Portugal $(2016,2019)$ and Turkey $(2016,2018)$.

Source: (Global Entrepreneurship Monitor (GEM), 2021[16]) 


\section{Box 2.1. Country spotlight: Access to finance as a barrier to business creation in the Netherlands}

Recent evidence from the Netherlands shows that - even after correcting for gender differences in business characteristics - female entrepreneurs who seek external finance at less likely to succeed than males (CBS, 2019[21]). The new research used data from the Financing Monitor (1 July 2017 to 1 July 2019) to examine gender gaps at different phases of seeking and acquiring external finance among employer firms (Figure 2.23). Gender differences are significant at each phase, with the exception of the outcome of the application. Of the companies that are operated by female teams, $19 \%$ identified a need for external finance and $70 \%$ indicate that their activities are oriented towards opportunities offered by lenders and investors. Both of these proportions are below the responses of male entrepreneurs. Female entrepreneurs were also less likely to make funding applications. However, there appears to be little different in the success rates of funding applications, but female entrepreneurs were more likely to report a future financing need. This suggests that women were less successful at securing the amount of funding sought, which is consistent with the broad evidence base on access to external financing by female entrepreneurs (OECD/European Union, 2019[10]).

\section{Figure 2.23. Female entrepreneurs continue to have greater difficulties accessing finance sought}

Share of companies of mainly men and women as underlying entrepreneurs, 2019

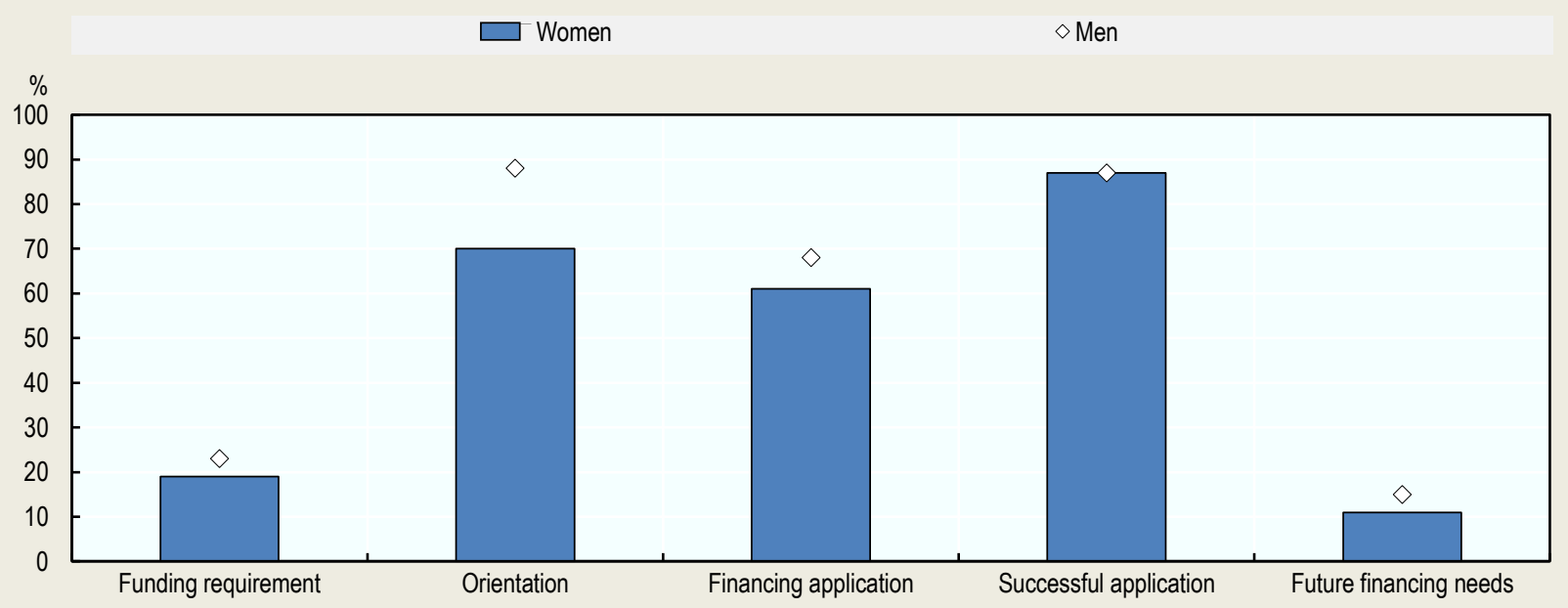

Note: Solo self-employed workers are excluded from this analysis.

Source: (CBS, 2019[21]) 


\section{Women were only $75 \%$ as likely as men to report having the skills to start a business}

Nearly four out of ten women in the EU (38\%) reported during the period 2016-20 that they had the skills and knowledge to start a business, relative to half of men. This means that about six out of ten women entrepreneurs perceive that they do not have the skills to successfully start a business. The share of men and women who perceive that they have entrepreneurship skills is slightly higher in OECD countries. Between 2016 and 2020, 43\% of women and 56\% of men reported that they had the skills and knowledge to start a business (Figure 2.24). A lack of entrepreneurship skills is often considered to be one of the most significant barriers to successful business creation. This set of skills refers to business management skills (e.g. business and financial planning), personal skills and traits (e.g. a sense of initiative, risk management) and technical skills (e.g. problem solving). Although these skills will increase the chances of business survival and growth, formal education and training in these areas do not guarantee success.

Among EU Member States, women were the most likely to report that they had the skills and knowledge to start a business in Latvia (47\%), Poland (48\%) and Croatia (56\%). Many of the countries where women are more likely to report having entrepreneurship skills have launched new schemes to help women acquire entrepreneurship skills. For example, Poland has launched several women's entrepreneurship initiatives including the national project "Entrepreneurial Woman" which was created specifically for women who want to develop and acquire new skills from other successful business owners (OECD, 2020[3]). Moreover, some countries with high positive response rates are countries such as Latvia where informal work is more common. This may lead to a higher frequency of positive responses since the perception of entrepreneurship is likely different.

It is also important to recognise that this question about perceived capabilities to start a business also picks up other issues that influence perceptions, including culture. The case of Sweden illustrates this point. Sweden has a highly educated workforce, among the top five OECD countries with regard to its digital literacy (OECD, 2019[22]). The government has invested in building digital skills among the past five years, as well as lifelong learning initiatives and measures to improve the integration of immigrants into vocational education and training. Yet a small proportion of men and women believe that they have the skills and knowledge to start a business. This low rate is consistent with low early-stage entrepreneurship rates but also likely reflects a cultural bias towards high-tech start-ups (requiring digital skills that not everyone has) as well as "lagom" - the prevailing Swedish attitude that boasting should not be done. 
Figure 2.24. About four-in-ten women report that they have the skills needed to start a business

"Do you have the knowledge and skills to start a business?"

Percentage of population (18-64 years old) who responded "yes", 2016-20

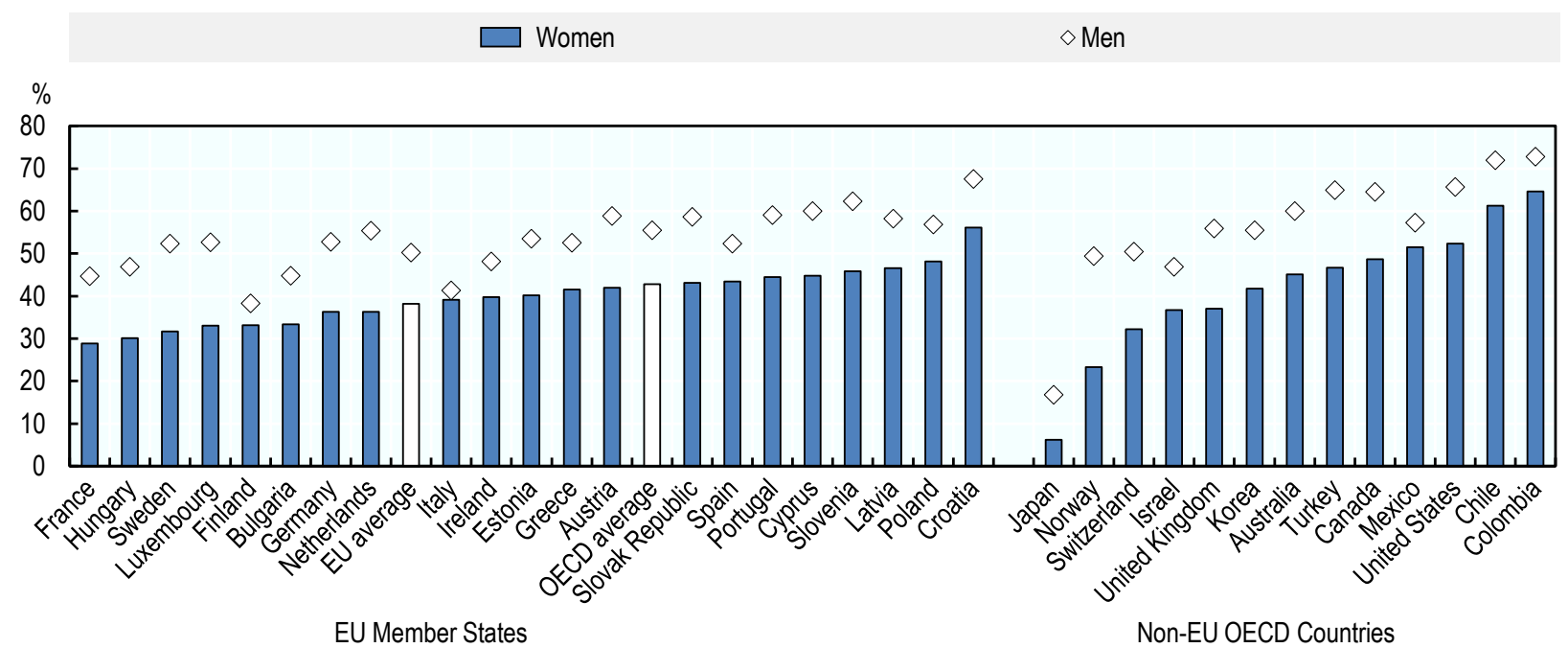

Note: All EU Member States participated in the GEM survey between 2016 and 2020 except for Belgium, Czech Republic, Denmark, Lithuania, Malta and Romania. Furthermore, the following countries did not participate in the survey in every year over this period (years of participation are indicated): Austria (2016, 2018, 2020), Bulgaria (2016-18), Estonia (2016-17), Finland (2016), France (2016-18), Hungary (2016), Ireland (2016-19), Latvia $(2016-17,2019-20)$ and Portugal $(2016,2019)$. Similarly, the following OECD countries did not participate in the GEM survey between 2016 and 2020: Belgium, Czech Republic, Denmark, Iceland, Lithuania and New Zealand. The following countries did not participate in the survey in every year (years of participation are indicated): Australia (2016-17, 2019), Austria (2016, 2018, 2020), Estonia (2016-17), Finland (2016), France (2016-18), Hungary (2016), Ireland (2016-19), Japan (2017-19), Latvia (2016-17, 2018-19), Mexico (2016-17, 2019), Norway (2019-20), Portugal $(2016,2019)$ and Turkey $(2016,2018)$.

Source: (Global Entrepreneurship Monitor (GEM), 2021[16])

StatLink त्ञाज़ https://doi.org/10.1787/888934280042 


\section{Box 2.2. Country spotlight: Developing entrepreneurial intentions through entrepreneurship education in Australia}

A recent evaluation of the OzGirlsEntrepreneurship in Australia found that entrepreneurship education can increase entrepreneurial intentions among female students in secondary school (Shahin et al., $2021_{[23]}$ ). The OzGirlsEntrepreneurship programme is the first of three stages within the Women in STEM and Entrepreneurship Programme (WISE) and targets Year 10 female students (14-16 years old) in Victoria, Australia. In 2019, OzGirlsEntrepreneurship hosted a full-day entrepreneurship workshop for 203 students across 44 secondary schools with varying degrees of prior entrepreneurship knowledge and connection. The girls were grouped into 52 teams of 3-4 students to simulate STEMfocused entrepreneurship which is mostly team-based. The evaluation analyses data from pre- and post-programme surveys - both of which had $97 \%$ response rate with a total of 193 valid responses reviewed. It assesses the relationship between entrepreneurial attitude, entrepreneurial intention, entrepreneurial inspiration and entrepreneurial learning.

The strongest relationship was found between entrepreneurial attitudes and entrepreneurial intentions (Table 2.1). While no effect was found for entrepreneurial inspiration or learning influencing entrepreneurial intention, entrepreneurial attitude was found to play a mediating role therefore having a significant indirect effect. The findings between attitude and intent suggest a positive relationship between entrepreneurial attitude development and positive mentoring and modelling. This programme highlights the shift away from traditional skills and knowledge-based learning styles to those that foster development of attitudes, emotions and mindsets. This conclusion could be helpful in designing future entrepreneurship programming for young women.

\section{Table 2.1. Entrepreneurial intentions among young female students are driven by} entrepreneurial attitudes

\begin{tabular}{l|c|c|r}
\hline \multicolumn{1}{c|}{ Hypothesis } & Coefficient & P-value (SD) & Direct Effect \\
\hline Attitude $\rightarrow$ Intention & 0.638 & $0.000(0.049)$ & Large \\
\hline Inspiration $\rightarrow$ Attitude & 0.317 & $0.001(0.093)$ & Small \\
\hline Inspiration $\rightarrow$ Intention & 0.084 & $0.065(0.045)$ & No effect \\
\hline Inspiration $\rightarrow$ Attitude $\rightarrow$ Intention & 0.202 & $0.001(0.059)$ & (Indirect effect) \\
\hline Learning $\rightarrow$ Attitude & 0.221 & $0.007(0.082)$ & Small \\
\hline Learning $\rightarrow$ Intention & 0.090 & $0.184(0.068)$ & No effect \\
\hline Learning $\rightarrow$ Attitude $\rightarrow$ Intention & 0.141 & $0.012(0.056)$ & (Indirect effect) \\
\hline
\end{tabular}

Source: (Shahin et al., 2021 [23]) 


\section{Characteristics of women's entrepreneurship}

\section{Women entrepreneurs are about as likely as men to introduce new products and services}

Nearly one-third of entrepreneurs in the EU reported that they introduced new products and/or services between 2016 and 2020, and there was virtually no gender gap. Almost $30 \%$ of women entrepreneurs in the EU reported that they introduced new products and/or services to their clients relative to about $32 \%$ of men entrepreneurs (Figure 2.25). These proportions were about the same in OECD countries (32\% of women and 35\% for men). Early-stage women entrepreneurs were more likely to report introducing a new product or service than men in Estonia, Finland, Greece, Ireland, Italy and the Netherlands.

\section{Figure 2.25. Nearly one-third of women entrepreneurs report introducing a new product or service}

Proportion of early-stage entrepreneurs (18-64 years old), 2016-20

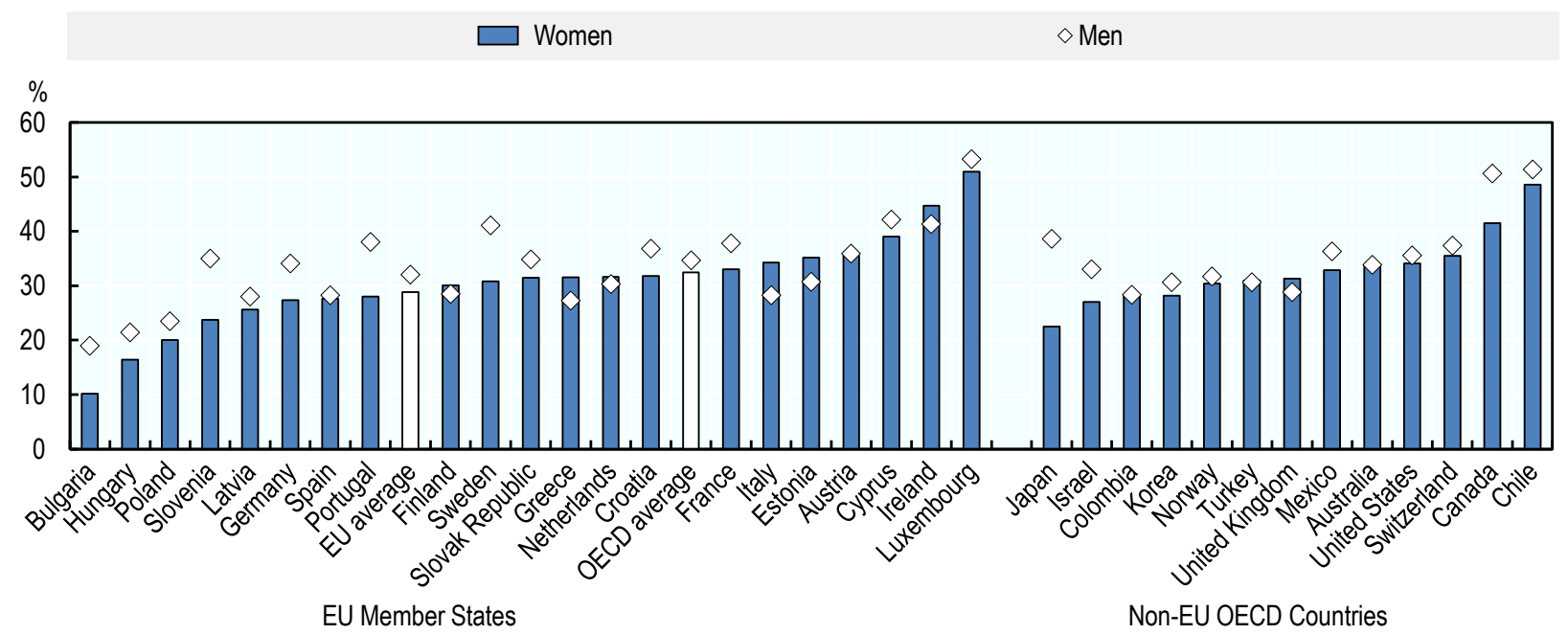

Note: All EU Member States participated in the GEM survey between 2016 and 2020 except for Belgium, Czech Republic, Denmark, Lithuania, Malta and Romania. Furthermore, the following countries did not participate in the survey in every year over this period (years of participation are indicated): Austria (2016, 2018, 2020), Bulgaria (2016-18), Estonia (2016-17), Finland (2016), France (2016-18), Hungary (2016), Ireland (2016-19), Latvia (2016-17, 2019-20) and Portugal (2016, 2019). Similarly, the following OECD countries did not participate in the GEM survey between 2016 and 2020: Belgium, Czech Republic, Denmark, Iceland, Lithuania and New Zealand. The following countries did not participate in the survey in every year (years of participation are indicated): Australia (2016-17, 2019), Austria (2016, 2018, 2020), Estonia (2016-17), Finland (2016), France (2016-18), Hungary (2016), Ireland (2016-19), Japan (2017-19), Latvia (2016-17, 2018-19), Mexico (2016-17, 2019), Norway (2019-20), Portugal $(2016,2019)$ and Turkey $(2016,2018)$.

Source: (Global Entrepreneurship Monitor (GEM), 2021[16])

StatLink त्ताज्ञ https://doi.org/10.1787/888934280061

\section{Women entrepreneurs are $20 \%$ less likely to report having customers in foreign markets}

Nearly half of early-stage entrepreneurs in the EU reported selling their products and services to customers in a foreign country, but women were $20 \%$ less likely than men to have foreign customers. Between 2016 and 2020, about four-in-ten early-stage women entrepreneurs in the EU selfreported having customers in another country relative to more than half of men (52\%) (Figure 2.26). These proportions were slightly higher than those reported in OECD countries over this period $-39 \%$ for early- 
stage women entrepreneurs and $45 \%$ for early-stage men entrepreneurs - likely due to the low barriers to trade within the EU.

The gender gap in the share of early-stage entrepreneurs who self-report having foreign customers varies greatly across EU Member States. Women were slightly more likely to report that they exported their products and services in Finland and Bulgaria, and the gender gap was less than 3 p.p. in Poland, Portugal and Spain. However, early-stage women entrepreneurs in Hungary were only $60 \%$ as likely as early-stage men entrepreneurs to have foreign customers.

\section{Figure 2.26. About four-in-ten women entrepreneurs report having customers in other countries}

Proportion of early-stage entrepreneurs (18-64 years old), 2016-20

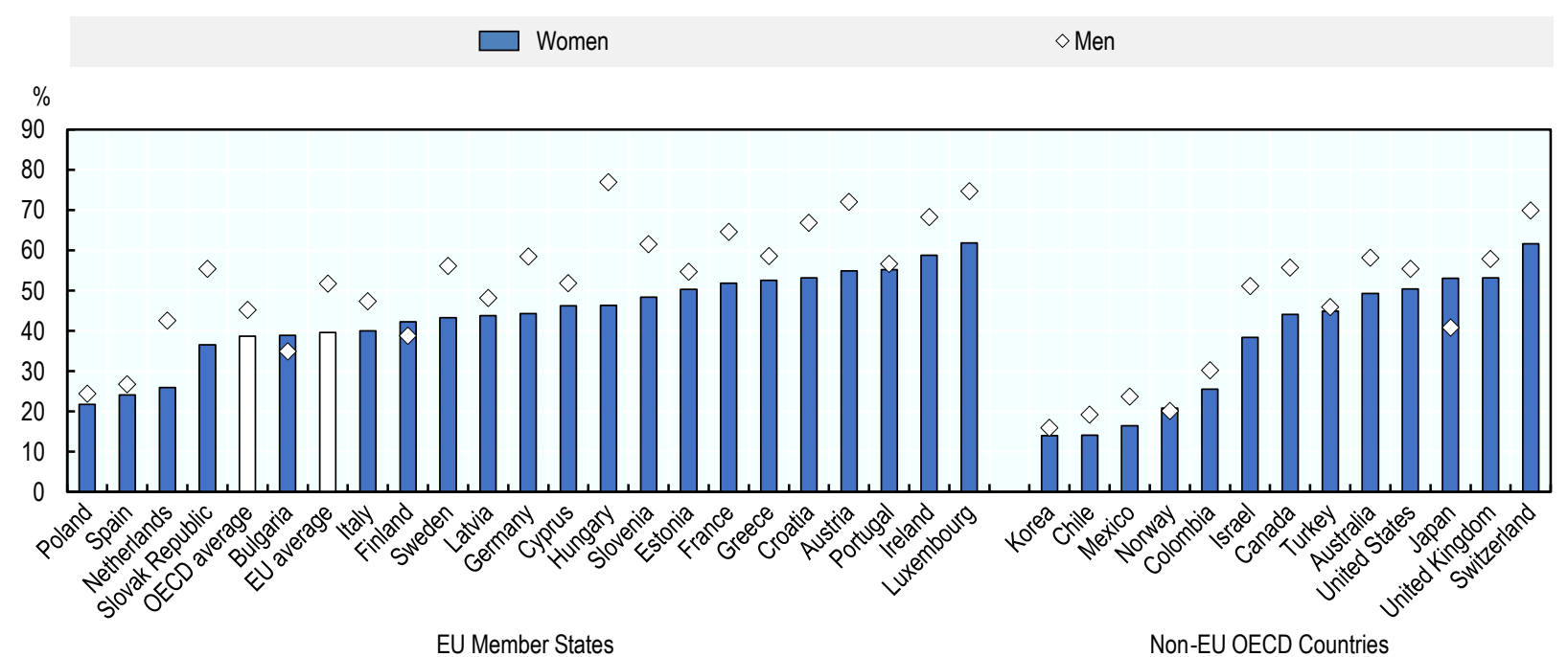

Note: All EU Member States participated in the GEM survey between 2016 and 2020 except for Belgium, Czech Republic, Denmark, Lithuania, Malta and Romania. Furthermore, the following countries did not participate in the survey in every year over this period (years of participation are indicated): Austria (2016, 2018, 2020), Bulgaria (2016-18), Estonia (2016-17), Finland (2016), France (2016-18), Hungary (2016), Ireland (2016-19), Latvia (2016-17, 2019-20) and Portugal (2016, 2019). Similarly, the following OECD countries did not participate in the GEM survey between 2016 and 2020: Belgium, Czech Republic, Denmark, Iceland, Lithuania and New Zealand. The following countries did not participate in the survey in every year (years of participation are indicated): Australia (2016-17, 2019), Austria (2016, 2018, 2020), Estonia (2016-17), Finland (2016), France (2016-18), Hungary (2016), Ireland (2016-19), Japan (2017-19), Latvia (2016-17, 2018-19), Mexico (2016-17, 2019), Norway (2019-20), Portugal $(2016,2019)$ and Turkey $(2016,2018)$.

Source: (Global Entrepreneurship Monitor (GEM), 2021[16])

StatLink त्ञाs https://doi.org/10.1787/888934280080

\section{Women entrepreneurs are less likely to expect their new businesses to achieve high employment growth}

Only small percentage of entrepreneurs are successful at turning their start-up into a high growth firm and women are half as likely as men to expect to achieve this. Between 2016 and 2020, fewer than $5 \%$ of early-stage women entrepreneurs in the EU expected that their new start-up would create at least 19 jobs in the next five years relative to $13 \%$ of early-stage men entrepreneurs (Figure 2.27). These proportions were substantially below the proportions of early-stage entrepreneurs who expected this level of growth in OECD countries: $11 \%$ of early-stage women entrepreneurs and more than $17 \%$ of early-stage men entrepreneurs.

More than $10 \%$ of early-stage women entrepreneurs in Hungary and Ireland reported that they expected to create at least 19 jobs over the next five years. Early-stage women entrepreneurs in 
Ireland were among the most likely to report introducing new products and services and selling to customers in foreign markets, which can fuel business growth. In Hungary, these positive attitudes are somewhat inconsistent with other responses to the GEM survey. While early-stage women entrepreneurs were more likely than the EU to report that they had clients in other countries, they were among the least likely to report that they introduced new products and services.

However, virtually no women entrepreneurs in Italy and Greece (less than $1 \%$ in each), Spain (2\%) and Luxembourg (3\%) expect high growth in the next five years. These low rates can be explained by various factors including difficult domestic market conditions or small local markets, lower export rates and lower growth ambitions. In Finland, where growth expectations are below the EU average, research confirms low levels of entrepreneurial aspirations among women but notes that those aspirations among women vary according to business size and sector (Autio, 2017[24]). Those who already have at least one employee are nearly twice as likely to have a willingness to grow ( $24 \%$ vs. $13 \%$ for solo self-employed), while those working in agriculture and forestry have very low growth ambitions (Sutela and Pärnänen, 2019[11]).

\section{Figure 2.27. Few women entrepreneurs in the EU expect high growth}

Proportion of early-stage entrepreneurs (18-64 years old) who expect to create at least 19 jobs over the next five years, 2016-20

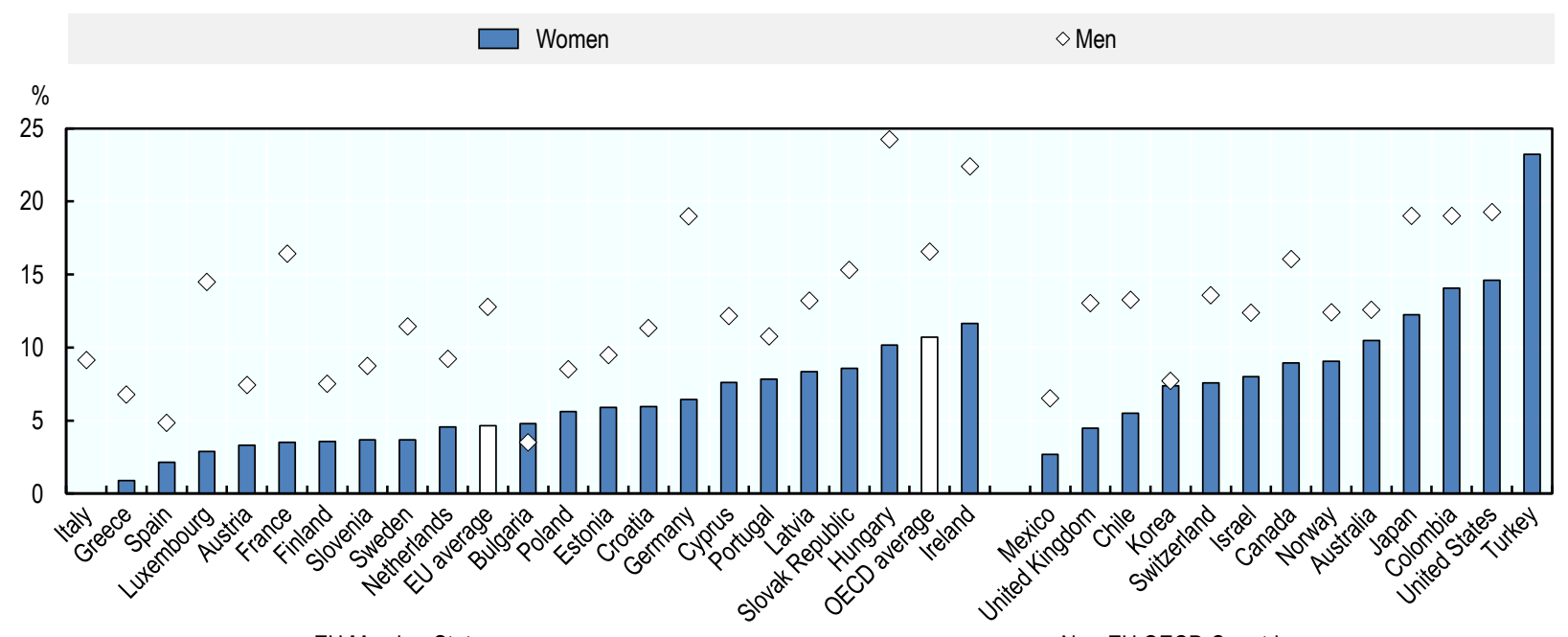

EU Member States

Non-EU OECD Countries

Note: All EU Member States participated in the GEM survey between 2016 and 2020 except for Belgium, Czech Republic, Denmark, Lithuania, Malta and Romania. Furthermore, the following countries did not participate in the survey in every year over this period (years of participation are indicated): Austria (2016, 2018, 2020), Bulgaria (2016-18), Estonia (2016-17), Finland (2016), France (2016-18), Hungary (2016), Ireland (2016-19), Latvia (2016-17, 2019-20) and Portugal (2016, 2019). Similarly, the following OECD countries did not participate in the GEM survey between 2016 and 2020: Belgium, Czech Republic, Denmark, Iceland, Lithuania and New Zealand. The following countries did not participate in the survey in every year (years of participation are indicated): Australia (2016-17, 2019), Austria (2016, 2018, 2020), Estonia (2016-17), Finland (2016), France (2016-18), Hungary (2016), Ireland (2016-19), Japan (2017-19), Latvia (2016-17, 2018-19), Mexico (2016-17, 2019), Norway (2019-20), Portugal $(2016,2019)$ and Turkey $(2016,2018)$.

Source: (Global Entrepreneurship Monitor (GEM), 2021[16]) 


\section{Conclusions}

There continues to be a gender gap in self-employment and entrepreneurship, both in terms of activity rates and also in the types of activities undertaken. The reasons for this gap are not so clearcut. Some of the gender differences can be explained by the institutional barriers that constrain women in entrepreneurship, including family and tax policies that discourage labour market participation and entrepreneurship, and negative social attitudes towards women's entrepreneurship. In addition, there are market failures that make it more difficult for women to be successful in business creation and selfemployment. This includes, for example, bias in financial markets and public policy initiatives that are not effective at reaching potential women entrepreneurs.

Governments have responded to these market and institutional failures with a range of policy interventions, including training, coaching and mentoring, microfinance and support for women's entrepreneurship networks and support organisations. Progress can be seen as the gender gaps have been closing, albeit slowly. While policy has a role, many other factors have also influenced the closing of the gap. This includes, for example, increasing education rates and labour market participation rates. Much work remains and COVID-19 has renewed the urgency of policy action because the pandemic and policy response appear to have increased the gender gap in entrepreneurship.

Countries can reap many benefits if governments continue to pursue this agenda. Estimates show that GDP increases when the gender gap in entrepreneurship closes and there is untapped potential in terms of innovation and job creation among potential women entrepreneurs. Government priorities will depend on context but overall, policy priorities includes:

- Greater use of tailored support for women entrepreneurs;

- Strengthen policy frameworks that underpin programmes so that support systems become more cohesive and efficient; and

- Increase efforts to measure women's entrepreneurship activities and the impacts of policy, which can improve the quality of programmes, strengthen knowledge sharing and increase the number of successful policy transfers.

For further policy discussion on women's entrepreneurship and related policy actions, please refer to (OECD/EU, 2016[4] $)$. Examples of recent policy actions to support women's entrepreneurs are highlighted in Chapters 7 and 8, as well as several country profiles in Part III of this report.

\section{References}

Autio, E. (2017), "Digitalisation, ecosystems, entrepreneurship and policy. Government's analysis, assessment and research activities", Policy Brief 20/2017, https://www.researchgate.net/publication/321944724 Digitalisation ecosystems entrepreneu rship and policy (accessed on 28 June 2021).

Blomquist, M. (2014), Bridging the Entrepreneurship Gender Gap: The Power of Networks, Boston Consulting Group, Boston.

CBS (2019), Financierings - monitor 2019 [Financing Monitor 2019], Centraal Bureau voor de Statistiek, Hague, https://longreads.cbs.nl/financieringsmonitor-2019/vrouwelijkeondernemers-en-hun-zoektocht-naar-financiering/ (accessed on 23 June 2021). 
European Commission (2019), 2019 SBA Fact Sheet Finland, https://ec.europa.eu/docsroom/documents/38662/attachments/10/translations/en/renditions/n ative (accessed on 28 June 2021).

Eurostat (2021), European Union Statistics on Income and Living Conditions.

Eurostat (2021), Labour Force Survey, https://ec.europa.eu/eurostat/web/lfs (accessed on 6 May 2021).

Eurostat (2019), Work organisation and working time arrangements, Labour Force Survey, Ad hoc module, https://ec.europa.eu/eurostat/web/lfs (accessed on 6 May 2021).

Global Entrepreneurship Monitor (GEM) (2021), Special tabulations for the OECD of the Global Entrepreneurship Monitor (GEM) adult population survey for the years 2016 to 2020.

Innovation Region Styria Ltd (2019), Analysis of policies and legislative framework of young women entrepreneurship support in the Danube region, Interreg Danube Transnational Programme 2014-2020. Women in Business, http://www.interregdanube.eu/uploads/media/approved project public/0001/37/b85902f1f0eaa5e4f2505e76015 b641d8a54f2c1.pdf (accessed on 28 June 2021).

OECD (2021), Entrepreneurship Policies through a Gender Lens, OECD Studies on SMEs and Entrepreneurship, OECD Publishing, Paris, https://dx.doi.org/10.1787/71c8f9c9-en.

OECD (2021), One year of SME and entrepreneurship policy responses to COVID-19: Lessons learned to "build back better", https://www.oecd.org/coronavirus/policy-responses/one-yearof-sme-and-entrepreneurship-policy-responses-to-covid-19-lessons-learned-to-build-backbetter-9a230220/ (accessed on 19 May 2021).

OECD (2021), Self-employment rate (indicator), https://dx.doi.org/10.1787/fb58715e-en (accessed on 6 May 2021).

OECD (2020), Inclusive Entrepreneurship Policies: Country Assessment Notes, https://www.oecd.org/cfe/smes/inclusive-entrepreneurship-policies-country-assessmentnotes.htm (accessed on 6 June 2021).

OECD (2019), OECD SME and Entrepreneurship Outlook 2019, OECD Publishing, Paris, https://dx.doi.org/10.1787/34907e9c-en.

OECD (2012), Closing the Gender Gap: Act Now, OECD Publishing, Paris, https://dx.doi.org/10.1787/9789264179370-en.

OECD/EU (2016), Policy Brief on Women's Entrepreneurship, https://www.oecd.org/cfe/smes/Policy-Brief-on-Women-s-Entrepreneurship.pdf.

OECD/European Union (2019), The Missing Entrepreneurs 2019: Policies for Inclusive Entrepreneurship, OECD Publishing, Paris, https://dx.doi.org/10.1787/3ed84801-en.

OECD/European Union (2017), The Missing Entrepreneurs 2017: Policies for Inclusive Entrepreneurship, OECD Publishing, Paris, https://dx.doi.org/10.1787/9789264283602-en.

PWC (2020), Ireland Gender Pay Gap Report 2020, PricewaterhouseCoopers, Dublin. 
Shahin, M. et al. (2021), "The impact of a STEM-based entrepreneurship program on the entrepreneurial intention of secondary school female students", International Entrepreneurship and Management Journal, http://dx.doi.org/10.1007/s11365-020-00713-7.

Statistics Canada (2021), Table 14-10-0027-01: Employment by class of worker, annual (x 1,000).

Sutela, H. and A. Pärnänen (2019), Yrittäjät Suomessa 2017 [Entrepreneurs in Finland 2017], Statistics Finland, http://www.stat.fi/tup/julkaisut/tiedostot/julkaisuluettelo/ytym 201700201821465 net.pdf (accessed on 24 June 2021).

Væksthus Sjælland (2019), Iværksætterbarometer 2019, http://vaekstanalyse.dk/file/668442/ivaerksaetterbarometer2019.pdf (accessed on 2 July 2021).

Williams, C. et al. (2019), An evaluation of the scale of undeclared work in the European Union and its structural determinants: estimates using the Labour Input Method, European Commission, Directorate-General for Employment, Social Affairs and Inclusion, https://ec.europa.eu/social/BlobServlet?docld=19002\&langld=en (accessed on 27 June 2021). 



\section{Immigrants' self-employment and entrepreneurship activities}

The scale and nature of immigrant entrepreneurship has changed dramatically over the past two decades. For example, the share of immigrants among the self-employed has more than doubled in the European Union. At the same time, there is a small but growing body of evidence suggesting that contributions to innovation and job creation by immigrant entrepreneurs are increasing. Policy makers need to be aware of these trends so that policies and schemes for immigrant entrepreneurship are adjusted accordingly. This chapter presents comparable selfemployment indicators for immigrants across countries, including selfemployment rates, the proportion of self-employed immigrants with employees, sector and occupation. These data are complemented with insights gained from country-specific research on immigrant entrepreneurship. 


\section{Key messages}

- The data presented in this chapter are largely based on Eurostat Labour Force Survey data covering the self-employed. These data paint a picture of self-employment activities by people born in another country, including the share who are self-employed, the share who have employees and some of the characteristics of these activities such as sector and occupation. These data are complemented with country-specific statistics to provide additional insights. Relative to other groups such as women and youth, much less data are available.

- About $12 \%$ of working immigrants in the European Union (EU) were self-employed in 2020 , which was slightly below the proportion of non-immigrants (14\%). Comparing immigrants born outside of the EU with those born in another EU Member States shows that the likelihood of being self-employed is almost the same.

- The share of immigrants among the self-employed in the EU more than doubled between 2006 and 2020. This increase was slightly greater among those born in other EU Member States (213\% increase) relative to those born outside of the EU (198\%). This increase was slightly greater than the increase in the share of immigrants among employees (190\%).

- The gender gap among the self-employed was slightly smaller among immigrants relative to non-immigrants. Immigrant men were about 1.6 times more likely to be self-employed than immigrant women, relative to a gap of 1.8 times among non-immigrants.

- The self-employment rate for immigrants born outside of the EU varied greatly across countries in 2020, ranging from about $\mathbf{8 \%}$ in Austria, Germany, Luxembourg and Sweden to $\mathbf{2 8 \%}$ in the Czech Republic. This variation is influenced by a range of factors, notably the scale of immigration and the strength of labour market integration measures.

- Almost one-third of self-employed immigrants in the EU employed at least one employee in 2020 , which was about the same proportion as non-immigrants. Nearly $32 \%$ of selfemployed immigrants from outside of the EU had employees in 2020, which was slightly above the share of those from other EU Member States (28\%). Both proportions are essentially equal to the share of non-immigrant self-employed people that employ others (30\% in 2020).

- The characteristics of self-employment activities in terms of sector do not vary significantly from those of non-immigrants. In 2020, the self-employment rates in the EU across sectors were essentially the same between immigrants and non-immigrants. However, there are some differences across occupations. Relative to non-immigrants, self-employed immigrants are more likely to work in Professional and Service and sales occupations.

- The use of tailored schemes to support immigrant entrepreneurs is widespread among EU Member States. While there are examples of schemes that have been effective, the vast majority of schemes that support immigrants in entrepreneurship are very small and often struggle with their own sustainability. Priorities for governments include scaling-up support for immigrant entrepreneurs to reflect the changing picture of entrepreneurship. It is also critical that financial support measures are used to steer immigrant entrepreneurs away from sectors that already have an over-supply. 


\section{Policy context immigrant entrepreneurship support}

\section{Tapping into the potential of the "missing" immigrant entrepreneurs}

The picture of immigrant entrepreneurship varies greatly across European Union (EU) Member States, reflecting differences in economic and labour market contexts, migration flows and the characteristics of immigrants. It is also important to recognise within the EU context that EU citizens can move freely from one Member State to another. Therefore, it is important to consider immigrants from outside the EU separately from those moving within the EU since EU citizens face far fewer barriers in the immigration process.

Measuring immigrant entrepreneurship is even more challenging than measuring entrepreneurship overall. In addition to the challenges of defining and measuring entrepreneurship (see Reader's Guide), immigrant entrepreneurship poses two additional challenges. First, the concepts of immigrant and ethnic minority can be related and but do not always overlap. It is possible for someone to be an immigrant but not from an ethnic minority group and it is also possible to be from an ethnic minority group but not be an immigrant. Often times these concepts are combined in policy discussions but they are distinct and the challenges faced in entrepreneurship can vary. Second, immigrant entrepreneurship is not always clearly defined in terms of how many generations are considered immigrants. For this chapter, only firstgeneration immigrants (i.e. those people who moved from one country to another) are considered to be immigrant entrepreneurs. Finally, data about individual's ethnicity or immigration background are not collected in many EU Member States due to anti-discrimination policies. Therefore much less data are available on immigrant entrepreneurship than other population groups such as women, youth and seniors. The data in this chapter are largely based on self-employment estimates by place of birth. This has some limitations on depicting the scale, scope and characteristics of immigrant entrepreneurship.

Despite measurement challenges, there is evidence that immigrant entrepreneurs have potential to contribute to job creation and innovation. This is best illustrated by the tech sector in the United States. Estimates from 2016 show that the 50 out of 91 technology companies with a market value over USD 1 billion ("unicorns") were founded by immigrants (Anderson, 2016[1] $)$. Similarly, immigrant founders have a disproportionate impact on job creation and commercialising innovation in many large European cities such as Berlin (KPMG, 2017[2]).

Despite these strong overall contributions to the economy, immigrants in the EU are slightly less likely than non-immigrants to be entrepreneurs as measured by self-employment. Overall, immigrants are less likely to be self-employed in the EU than those born in the reporting country and there is very little difference between those born in another EU Member State and those born outside of the EU. If the self-employed who were born outside of the EU were self-employed at the same rate as those born in the reporting country, there would be about 340000 more self-employed people.

The COVID-19 pandemic has significantly interrupted new immigrant entrepreneurship activities. However, the self-employment and business creation data for immigrants do not yet capture the impact of COVID-19 on immigrant entrepreneurship activities. The data reported in this chapter cover the pre-COVID environment. Nonetheless, some initial evidence is emerging to show that immigrant entrepreneurs have be disproportionately impacted by the pandemic, largely due to sector effects. For additional information on the impacts of COVID-19 on immigrant entrepreneurs, please see Chapter 8.

\section{Policy objectives for immigrant entrepreneurship are not well defined in EU Member States}

Public policy in the EU to support immigrant entrepreneurs largely seeks to provide an option for moving into work but there is growing interest among governments in targeting support at high potential immigrant entrepreneurs. An OECD assessment of inclusive entrepreneurship policies across 
EU Member States examined approaches to promoting and supporting inclusive entrepreneurship, including immigrant entrepreneurship (see Reader's Guide). The assessments found that policies and schemes for immigrant entrepreneurs are often driven by national governments in co-operation with nongovernment organisations. In addition, policy responsibility also rests with sub-national governments in nearly one-third of Member States (Figure 3.1). However, only about one-third of Member States have a clear entrepreneurship strategy for immigrants in place and most policy strategies remain very general, often lacking clear policy objectives and targets. In most of these countries, the policy focus remains on labour market integration and business creation is offered as one potential route. Governments, therefore, typically focus on ensuring that immigrants can access business creation supports, but there is room for governments to be more strategic in their use of policy measures to target greater support on high potential immigrant entrepreneurs that can stimulate job creation and innovation (see Chapter 8).

\section{Figure 3.1. Policy objectives for immigrant entrepreneurship support are often not well defined across EU Member States}

Proportion of EU Member States, 2020

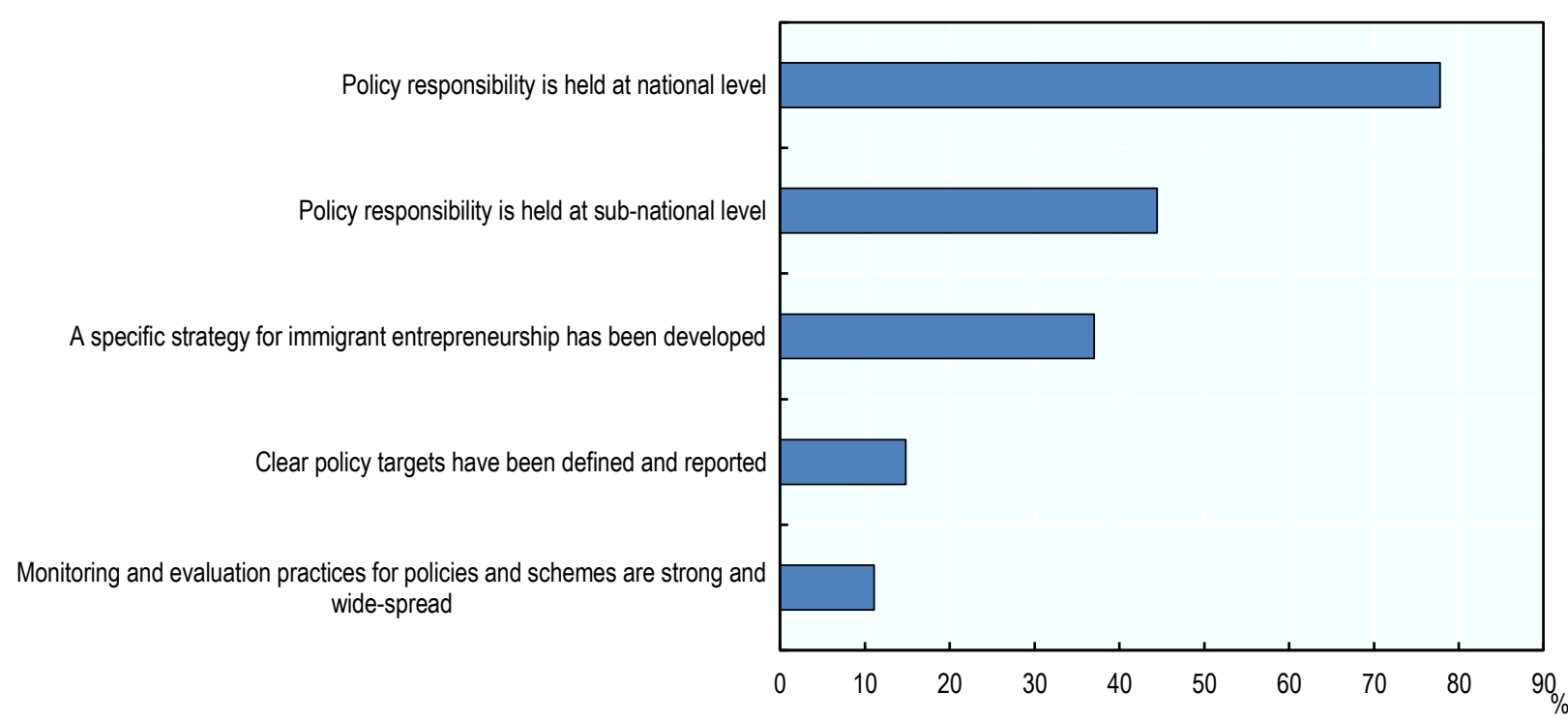

Note: It is possible for countries to have clear policy responsibility at both the national and sub-national levels; these are not mutually exclusive. Source: (OECD, 2020[3])

StatLink 제내 https://doi.org/10.1787/888934280118

\section{Schemes for immigrant entrepreneurs tend to be small and less developed than for other target groups}

Tailored schemes for immigrant entrepreneurs are widely offered across EU Member States. The OECD inclusive entrepreneurship policy assessments across the EU found that schemes tend to cover a wide range of basic entrepreneurship supports, including training, coaching and mentoring and various measures to improve access to finance. Using the OECD's 9-point assessment criteria (see Reader's Guide), schemes to support immigrant entrepreneurs tend to score lower than inclusive entrepreneurship schemes overall (Figure 3.2). Schemes to support immigrant entrepreneurs are often small-scale projects that are often not well-evaluated so it is difficult to assess the impacts of these schemes. Strong take-up of tailored entrepreneurship support for immigrants was reported in only a few countries but this may be partially explained by the role that non-government actors plans in many EU Member States in supporting the labour market integration of immigrants. However, another factor for low take-up rates is that public 
schemes generally do not appear to sufficiently leverage existing infrastructures within various immigrant communities for their outreach and communications.

\section{Figure 3.2. Immigrant entrepreneurship schemes less developed than for other target groups}

Average OECD assessment scores for inclusive entrepreneurship schemes across EU Member States, 2020

\section{a. Entrepreneurship skills}

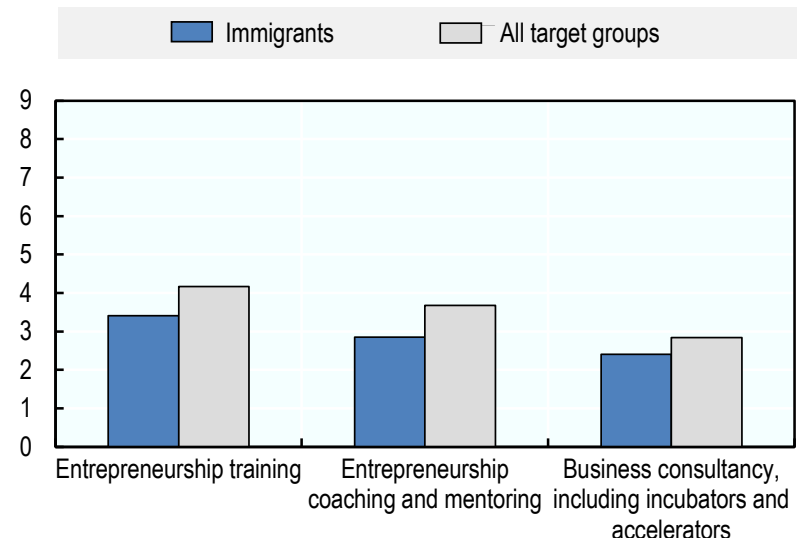

c. Entrepreneurship culture and social capital

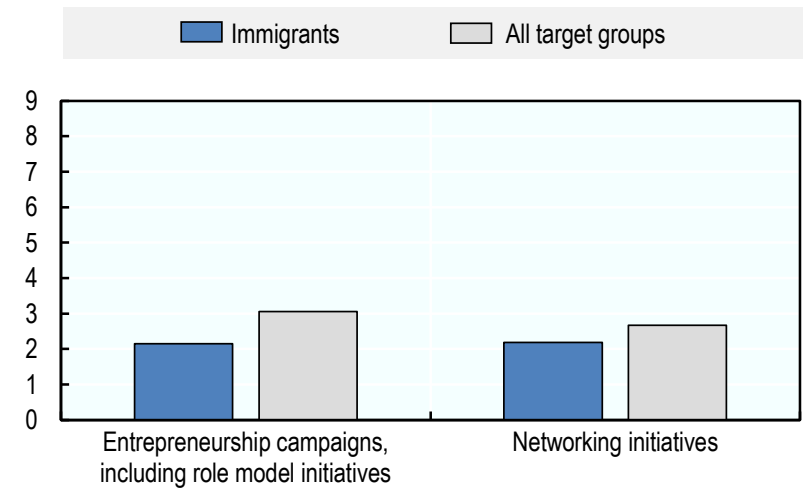

b. Entrepreneurship finance

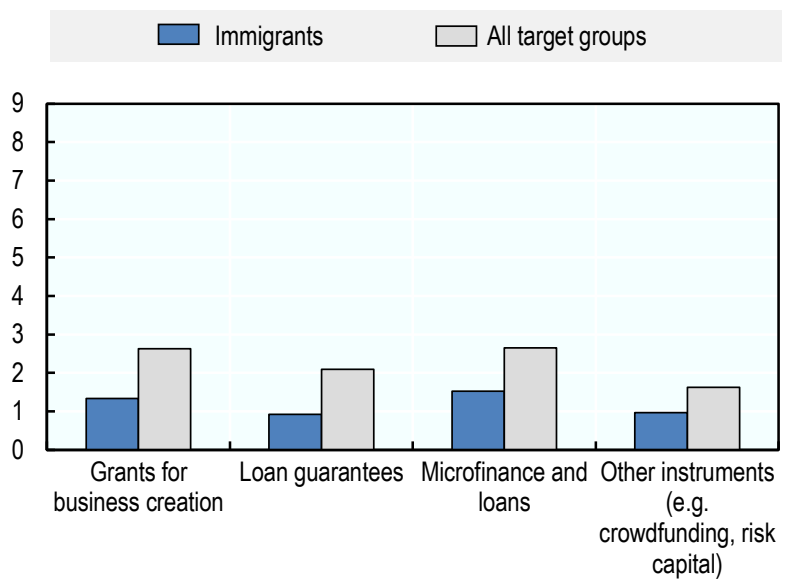

d. Regulatory tools

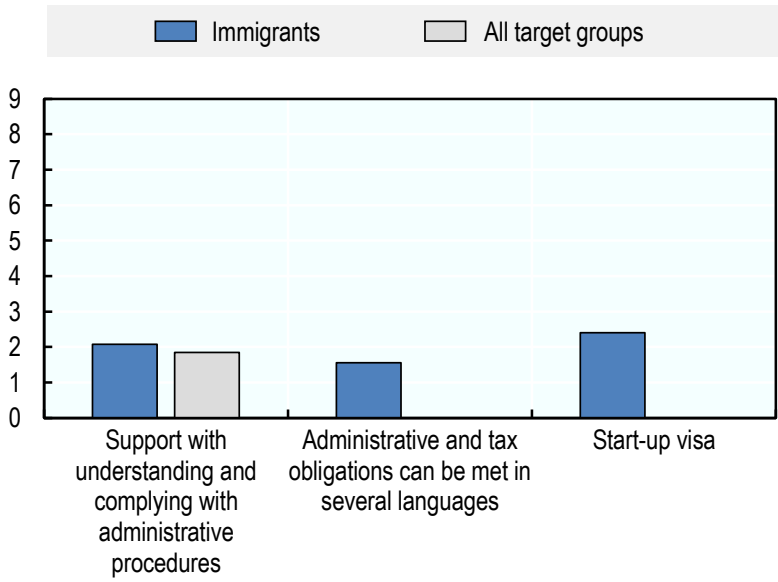

Note: The panels in this figure present an unweighted average of policy assessment scores for EU Member States. Each policy instrument (e.g. Entrepreneurship training) is assessed a scored out of 9 as described in the Reader's Guide. The figure shows the average score for schemes for immigrant entrepreneurs relative to the score for all inclusive entrepreneurship groups combined (i.e. women, immigrants, youth, seniors and the unemployed). Some of the policy instruments in panel $d$ are designed specifically for immigrant entrepreneurs so there is no comparative policy assessment score for all inclusive entrepreneurship target groups.

Source: (OECD, 2020[3])

StatLink त्ञाs https://doi.org/10.1787/888934280137

\section{Building entrepreneurship skills}

The most commonly offered support for immigrant entrepreneurs in the EU is entrepreneurship training. Entrepreneurship training programmes for immigrants typically provide a broad base of entrepreneurship skills (e.g. business and financial planning) but also place a strong focus on access resources in the local ecosystem (e.g. how to access finance, advice) and meeting administrative requirements, which are usually different from their native country. Training programmes for immigrant 
entrepreneurs often include some basic language training to support immigrant entrepreneurs in meeting administrative obligations and building their networks.

Entrepreneurship coaching for immigrant entrepreneurs is less frequently offered than training programmes but are occasionally integrated with training programmes. Although the evaluation evidence on entrepreneurship coaching for immigrants is thin, most programme managers believe that it is a critical element of supporting immigrant entrepreneurs. Entrepreneurship coaches not only play an important role in supporting the creation of a business, but provide broader support to help immigrants settle in their community (OECD/The European Commission, 2013[4]; OECD/European Union, 2014[5]). This includes, for example, introducing the new entrepreneur to community organisations and helping them to register the entrepreneurs' children in school. Coaches often belong to the same community, which helps to build trust quickly with the new entrepreneur and the ability to speak the same language further facilitates the building of a strong and effective relationship (OECD/The European Commission, 2013[4]).

While there are examples of dedicated business incubators for immigrant entrepreneurs, it is not commonly part of the support offers in the EU. Most tailored incubator programmes for immigrant entrepreneurs are very small and tend to be linked to higher education institutions. Evaluation evidence from such incubators tend to suggest that they are effective given their focus providing a package of complementary supports (e.g. training, coaching, networking, finance) but they can be expensive and little is known about the long-term impact of these programmes. For further discussion, please see the Policy Brief on Business Incubators and Accelerators that support Inclusive Entrepreneurship (OECD/EU, 2019[6])

\section{Facilitating access to start-up finance}

Relative to other inclusive entrepreneurship target groups, access to finance schemes for immigrant entrepreneurs tend to be very small-scale and insufficient for demand. The most common approaches are to offer small grants and to support microfinance institutions in the provision of small loans to immigrant-owned businesses. However, the vast majority of these schemes tend to, on average, support a small number of entrepreneurs and are not well-linked with other support schemes (Figure 3.2). See Chapter 7 for further discussion on microfinance.

\section{Promoting entrepreneurship and expanding entrepreneurship networks}

Entrepreneurship is promoted to immigrants through tailored approaches in the EU, often through public employment services, incubator programmes or through special visa programmes that seek to attract high-potential entrepreneurs. About one-third of countries have specific actions to inform immigrants about the potential of entrepreneurship and these initiatives are typically well-linked to support schemes so that interested potential entrepreneurs can easily access further support (Figure 3.2). While many Member States believe that such actions can attract high-potential entrepreneurs to their Member States, there is little evidence to support this anecdotal view.

Schemes to support the development of entrepreneurship networks for immigrant entrepreneurs tend to be uncommon in the EU. However, other types of initiatives such as coaching and business incubator programmes do seek to support beneficiaries in growing their entrepreneurship networks. As noted earlier, these actions appear to be rather small-scale. While it is clear that individual immigrant entrepreneurs can benefit greatly from networking opportunities, the overall impact is not clear because few evaluations assess the impact of networking initiatives for immigrant entrepreneurs.

\section{Supporting immigrant entrepreneurs with regulatory tools}

Immigrant entrepreneurs can access individual support in meeting their administrative obligations through several different mechanisms. These include government websites that offer advice in different languages, help desks in government offices and through entrepreneurship coaches and advisers. More 
than one-third of EU Member States provide these types of support services to immigrant entrepreneurs and they typically have fairly strong take-up. However, the scale of support appears to be below demand.

More than half of EU Member States offer start-up visas to attract immigrant entrepreneurs. The rationale for these types of programmes is that governments are seeking to attract high-potential entrepreneurs with a streamlined and fast-tracked visa process. Some of these programmes also offer other incentives, such as financial support (e.g. grants) and access to business incubator programmes. While increasing popular, most start-up visa programmes are very small-scale and evaluation evidence often shows a short-term impact as many entrants leave after the initial visa period expires, which almost always results in a business closure.

For further discussion on entrepreneurship policies and schemes and the barriers that they address, please see Chapter 8.

\section{Recent developments in immigrant entrepreneurship policy}

Entrepreneurship policy over the past two years has been dominated by the COVID-19 pandemic, yet very little attention has been given to the specific challenges and needs of immigrant entrepreneurs. As noted in Chapter 1, there are very few examples of governments in EU Member States introducing tailored emergency support for immigrant entrepreneurs despite them being impacted disproportionately. One example is the "ReCOVer20" Programme in Cyprus, which finances small-scale pilot actions (up to EUR 5 000) to seek to address the effects of the COVID-19 pandemic for vulnerable groups, including asylum seekers and refugees. This scheme is managed by the Youth Board of Cyprus (a public legal entity) (OECD, 2020[3]).

Prior to the COVID-19 pandemic, there was a growing interest in many countries in finding ways to attract high potential immigrant entrepreneurs. A commonly used tool is a special start-up visa and there are now 16 start-up visa programmes in the EU, including Start-up Entrepreneur Programme (STEP) in Ireland (2012), Italia Start-up Visa (launched in 2014), Start-up Visa in Portugal (2017), French Tech Visa in France (2017) and many more. Among these countries, some such as Estonia have launched special programmes that allow for a virtual presence including digital entrepreneurs. Further discussions on start-up visas, please see Chapter 8.

\section{Trends in self-employment by immigrants}

\section{Immigrants in the EU are slightly less likely than non-immigrants to be self-employed}

Immigration to the EU has increased over the past $\mathbf{2 0}$ years and more than $\mathbf{4 . 2}$ million immigrants arrived in EU Member States in 2019. Of those arrivals in 2019, about two-thirds were born outside of the EU. Employment rates vary greatly across immigrant groups. Those born in another EU Member State have slightly higher employment rates (71\% in 2020) than non-immigrants (69\%), while those born outside of the EU lag behind (61\%). Immigrants also face higher rates of unemployment in all EU Member States than non-immigrants (8\% in 2020 for those born in another EU Member State and 14\% for those born outside of the EU relative to $6 \%$ of non-immigrants. The gap in these outcomes between immigrants and non-immigrants has narrowed for immigrants born in another EU Member State but has increased for those born outside of the EU.

Immigrants are slightly less likely than non-immigrants to be self-employed in the EU. Just under $12 \%$ of immigrants in the EU were self-employed in 2020 relative to $14 \%$ of non-immigrants (Figure 3.3). The likelihood of being self-employed is approximately the same for those immigrants born in another EU Member State and those born outside of the EU. However, the difference in self-employment rates between immigrants and non-immigrants has converged over the past 15 years. The self-employment rates for 
immigrants have been fairly stable over the past decade, but a small decline in the self-employment rate for immigrants was observed after 2016. This is consistent with the overall decline in self-employment.

Self-employment data on immigrants pick up a wide range of different profiles, which vary greatly across countries. Some are wealthy investors that immigrate on special economic or investor visas and may operate businesses in several countries. These self-employed immigrants typically operate larger businesses that have greater potential for creating employment. Some countries such as Canada have a relatively high proportion of immigrant business owners that fit this profile, due largely to their immigration policies. For example, immigrant business owners are twice as like to be educated in STEM fields and three times more likely to be educated in engineering or computer science relative to Canadian-born business owners (Ostrovsky and Picot, 2020[7]). Other immigrant entrepreneurs have a much lower level of resources at their disposal (i.e. human capital, social capital, financial capital) and face greater difficulties overcoming these resource gaps. However, even among groups such as refugees, some appear to have the potential to create successful businesses that create employment for others (OECD, 2019[8]). Please see Chapter 8 for discussion on how skills levels of immigrants entrepreneurs varies across countries.

\section{Figure 3.3. Immigrants are less likely to be self-employed than non-immigrants in the EU}

Self-employment in the EU as a percentage of employment (15-64 years old)

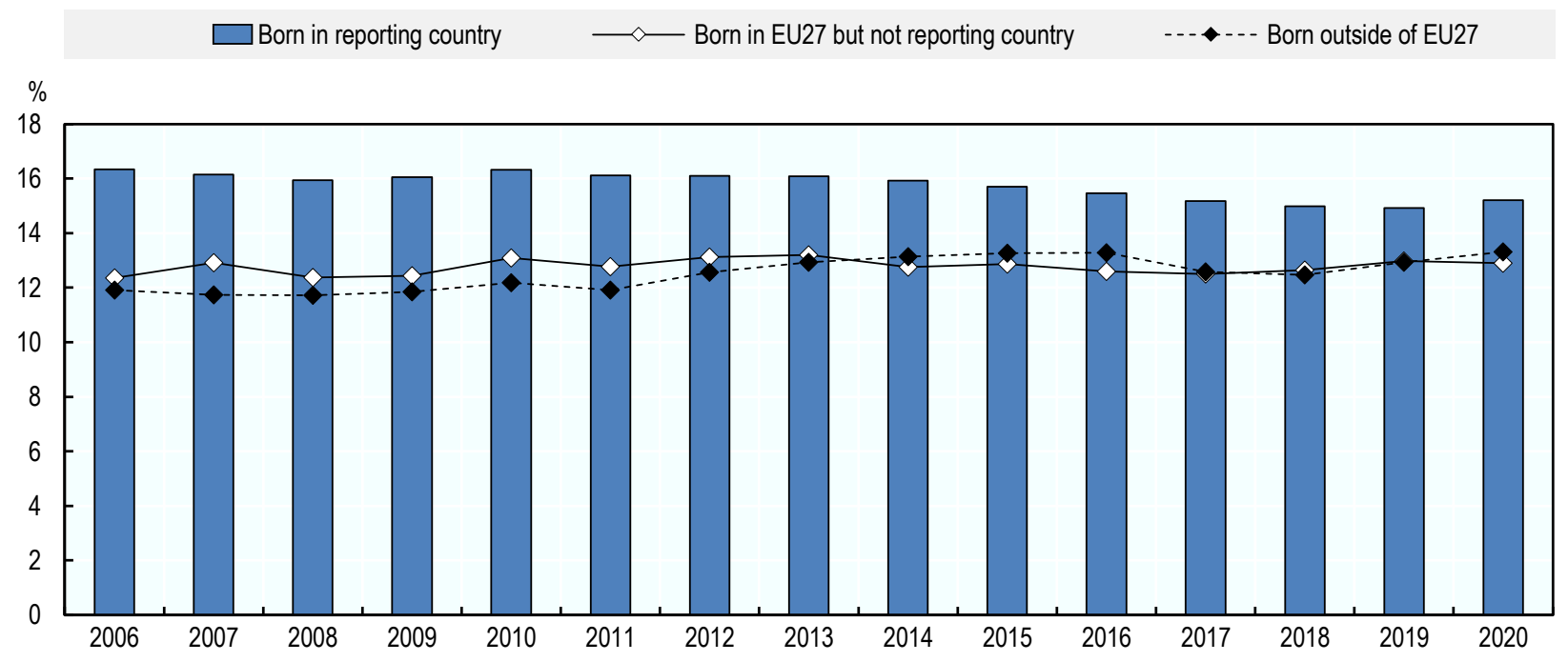

Note: The data presented in this figure do not include Germany to maintain comparability over time since self-employment data by place of birth were not reported for Germany prior to 2017.

Source: (Eurostat, $2021_{[9]}$ )

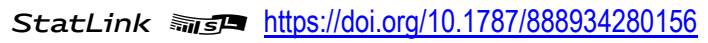

As with the overall population of the self-employed, there is a gender gap among those who are immigrants. In 2020 , about $16 \%$ of working immigrant men (regardless of where they were born) were self-employed (Figure 3.4). This was about 1.6 times greater than the proportion of immigrant women who were self-employed and below the proportion (19\%) who were born in the reporting country (i.e. nonimmigrants). While the gender gap in self-employment for immigrants has changed little since over the past 15 years, the convergence in self-employment rates between immigrants and non-immigrants has been greater for women than for men. 
Figure 3.4. The gender gap in self-employment has changed little but immigrant women are now as likely as their non-immigrant peers to be self-employed

Self-employment in the EU as a percentage of employment (15-64 years old)

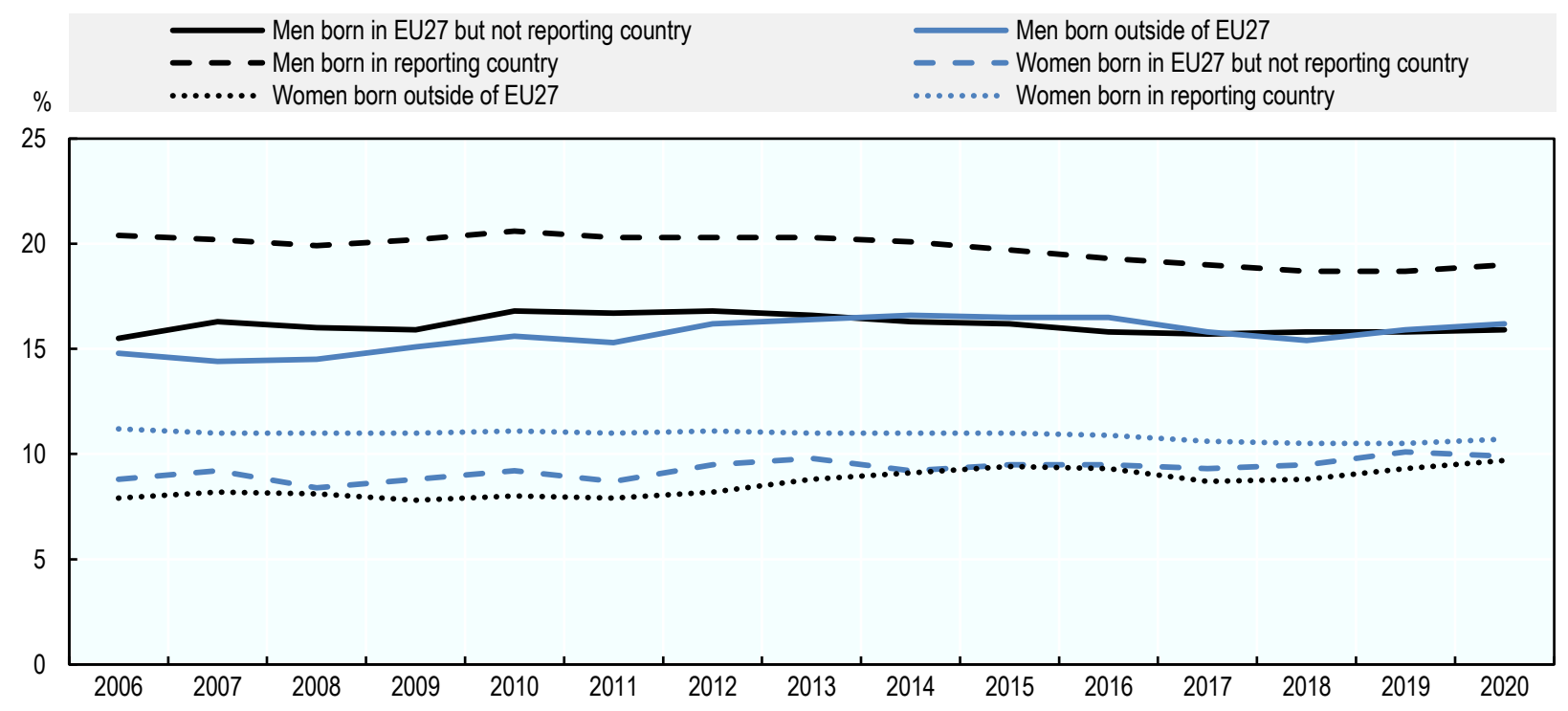

Note: The data presented in this figure do not include Germany to maintain comparability over time since self-employment data by detailed place of birth were not reported for Germany prior to 2017.

Source: (Eurostat, 2021 $[9]$ )

StatLink 제개 https://doi.org/10.1787/888934280175

Self-employment rates for immigrants varied greatly across EU Member States in 2020, reflecting variations in context such as immigration flows, labour market conditions and the scope and scale of supports offered to immigrants. Self-employment rates for immigrants were highest in Malta $(20 \%$ for those born outside of the EU), Slovak Republic (24\%) and Czech Republic (28\%), where the proportion of immigrants (born outside of the EU) working as self-employed was nearly double the proportion of nonimmigrants (Figure 3.5). Conversely, immigrants were the least likely to be self-employed in Austria, Sweden, Luxembourg and Germany, where about $8 \%$ of immigrants born outside of the EU were selfemployed in 2020. These proportions were well below the self-employment rates for non-immigrants.

Differences across countries can be explained by a number of factors, including labour market conditions, expected earnings in self-employment relative to employment, and the strength of labour market supports. Research focusing on country-specific contexts helps to illustrate these factors. Much like non-immigrants, the decision to become self-employed is strongly influenced by the quality of employment opportunities. Recent research from Sweden shows that different immigrant groups are influenced in different ways by labour market conditions as measured by unemployment in the local area (Box 3.1). Moreover, German research highlights the role of expected earnings in self-employment relative to working as an employee. Over a 30-year period, immigrants entering self-employment due to perceived earnings potential tended to earn more than Germans in self-employment, but this effect is uneven across countries of origin (Hopp and Martin, 2017 $[10]$ ). The effect tended to be greatest for Turkish migrants and smallest from those born in southern EU Member States. Other factors that explain the variation across countries include the strength of labour market integration measures, including the availability and accessibility of entrepreneurship support programmes for immigrants. In Canada, for example, recent research has identified an unmet demand for entrepreneurship support schemes from immigrant women (Box 3.2). This gap is explained by several factors, notably constraints faced by project managers such as competing priorities and a lack of resources. 


\section{Figure 3.5. Self-employment rates for immigrants vary greatly across countries}

Self-employment as a percentage of employment (15-64 years old), 2020

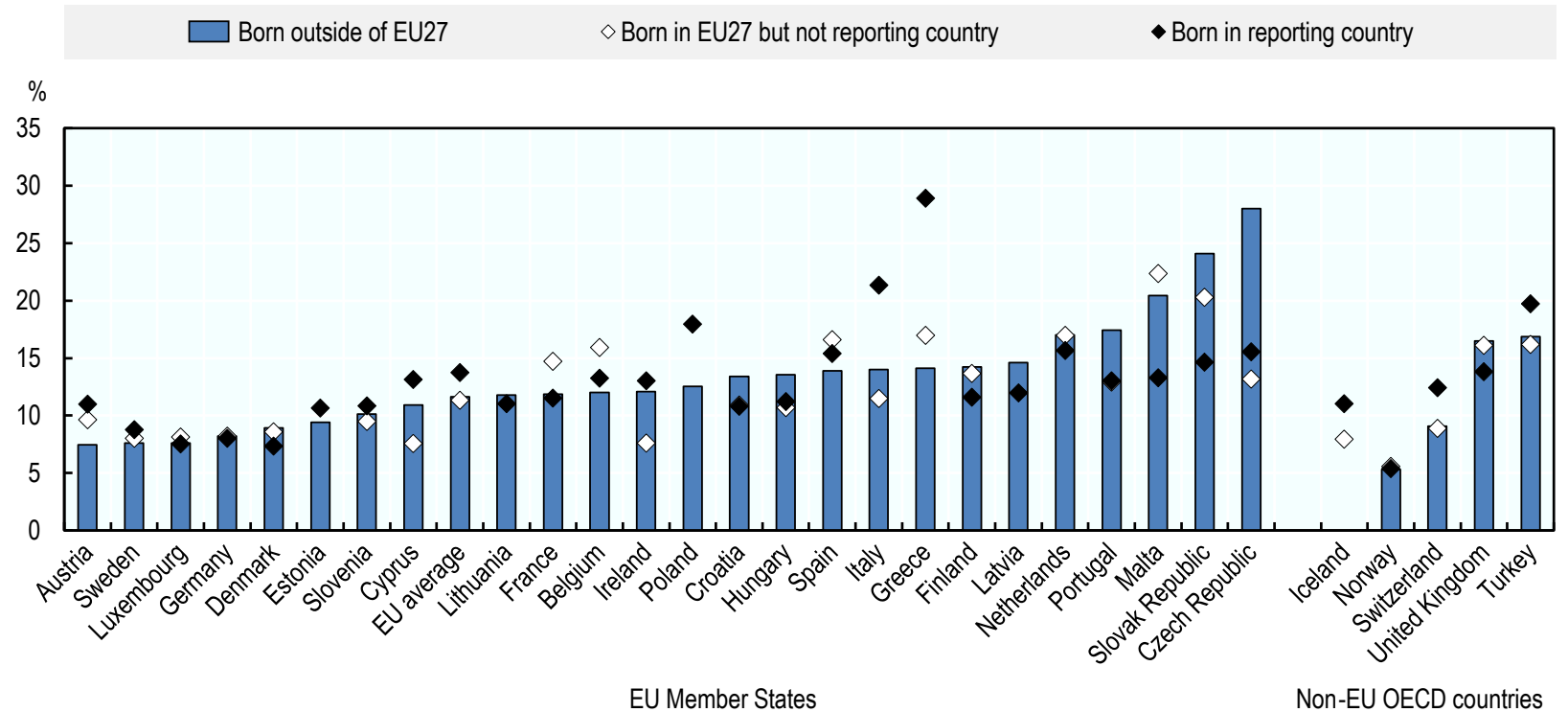

Note: The EU average does not match the data in Figure 3.3 because data for Germany are included in this total. Data on place of birth for the self-employed are not available for Bulgaria and Romania. Data for Germany are provisional estimates and data for Croatia, Poland, Slovak Republic and Slovenia have a low level of reliability. Data for the United Kingdom are for 2019.

Source: (Eurostat, 2021[9])

StatLink 제프 https://doi.org/10.1787/888934280194

\section{Box 3.1. Country spotlight: Immigrant self-employment and local unemployment, Sweden}

A recent study examines the relationship between self-employment and unemployment in Sweden, investigating if immigrants are more likely to be pushed or pulled into self-employment (Miao, 2020[11]). The analysis uses population register data in the period 1996-2007 at the individual level from the Longitudinal Integration Database for Health Insurance and Labour Market Studies (LISA) from Statistics Sweden and annual unemployment data from the Swedish Public Employment Office (Arbetsförmedlingen). The dataset covers 2172420 men and 2092032 women (30-60 years old). In 2019 , about $20 \%$ of the Swedish population was foreign-born with around $55 \%$ of immigrants coming from non-European countries. Through an individual fixed effect model, the unemployment effect on self-employment is found using variations of the unemployment rate within individuals over time.

The study shows that the local unemployment rates impacts self-employment decisions differently across the population. Swedish natives and European immigrants are more likely to become selfemployed when the economy is improving, i.e. local unemployment is falling. Immigrants from the Middle East, however, are more likely to become self-employed as unemployment increases. Possible reasons for these differences include differences in labour market attachment across population groups. However, there may also be sectors effects. Data show immigrants from the Middle East are overrepresented in less capital-intensive sectors with lower barriers to entry (e.g. service sector), which may be less affected by recessions. Moreover, the study finds self-employment among women is less affected by economic conditions than among men, aligning with previous research that indicates women and men often enter employment for different reasons.

Source: (Miao, 2020[11]) 


\section{Box 3.2. Country spotlight: Entrepreneurship programming for immigrant women, Canada}

A new study in Canada sought to identify the greatest obstacles faced in business creation by immigrant women and assess the demand and supply dynamics of entrepreneurship support services for new immigrant women in the Toronto Census Metropolitan Area, Ontario, Canada (Kalu and Okafor, 2021 [12]). This study uses a bottom-up mixed method approach to explore the available entrepreneurship support services through a series of open- and close-ended questions to all immigrant settlement service providers in the Toronto area.

The study identified the following perceived challenges faced by new immigrant women entrepreneurs:

- Unfamiliarity with the local environment (average score of 6.19 out of 7 );

- Small scale of business activity (4.80);

- Discrimination (3.95); and

- Barriers in settlement policies and business regulations (3.88).

A key finding of the study is that although the majority of settlement service providers $(57 \%)$ agree that there is a demand for entrepreneurship support services, but $76 \%$ of them do not currently provide any entrepreneurship support services. The main reason for this low supply of entrepreneurship support services is reported as competing priorities (63\%) and a lack of funding (46\%) (Figure 3.6).

Nonetheless, the support organisations had ideas on how new immigrant women entrepreneurs could be better supported. About $60 \%$ of support organisations indicated that language training should be boosted and one-third noted that they need better information on how to access entrepreneurship support services, networking events and funding opportunities.

\section{Figure 3.6. Most immigrant settlement services do not support entrepreneurship due to other priorities and a lack of funding}

Perceived reasons for lack of entrepreneurship support towards immigrant women, 2020

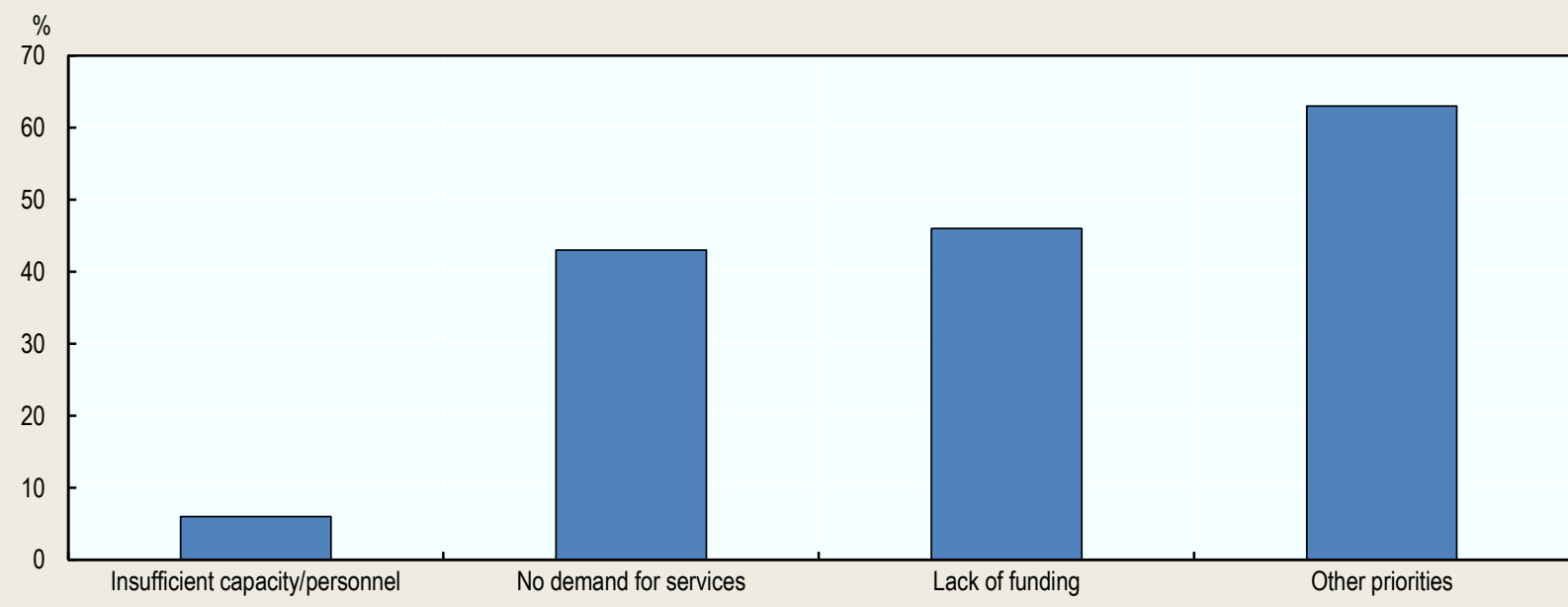

Source: (Kalu and Okafor, 2021 $\left.{ }_{[12]}\right)$ 


\section{The share of immigrants among the self-employed continues to grow}

Immigrants account for an increasing share of the self-employed in the EU. There were 25.6 million self-employed people in the EU in 2020 , of which 2.7 million were immigrants (10.6\%). This was comprised of 1.8 million people born outside of the EU ( $68 \%$ of self-employed immigrants) and 885200 people born in another EU Member State (32\%). The share of immigrants among the self-employed in the EU more than doubled between 2006 and 2020 (Figure 3.7). This increase was slightly greater among those born in other EU Member States (increase by 113\%) relative to those born outside of the EU (increase by $98 \%$ ). This increase was slightly greater than the increase in the share of immigrants among employees (increase by $95 \%)$.

\section{Figure 3.7. Immigrants account for a growing share of the self-employed}

Share of immigrants among the self-employed (15-64 years old) in the EU

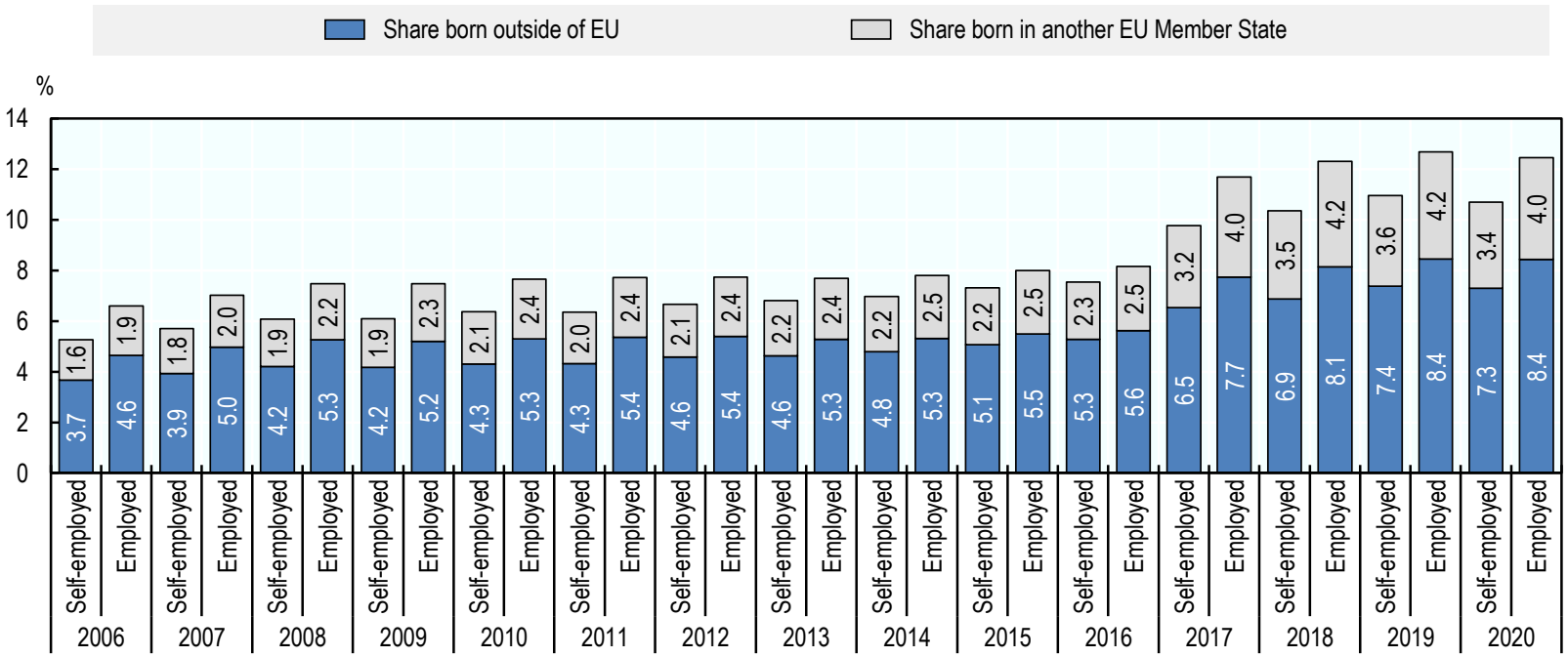

Source: (Eurostat, $\left.2021_{[9]}\right)$

The proportion of self-employed people who were born in another country varies substantially across EU Member States. The Member States with the highest shares of immigrants from outside of the EU among the self-employed were Malta (25\%), Cyprus (16\%) and Ireland (15\%) (Figure 3.8), which tend to have an above average number of immigrants arriving from outside of the EU. Country-level research often identifies a strong link between the overall share of immigrants in the labour market and the share of self-employed people that were born in another country. This includes for example, research in Belgium (SPF Economie, 2019 $9_{[13]}$ ), Finland (Statistics Finland, 2020 ${ }_{[14]}$ ) and Germany (Hopp and Martin, 2017[10]). 
Figure 3.8. Immigrants from outside the EU account for the majority of self-employed immigrants in nearly all EU Member States

Share of immigrants among the self-employed (15-64 years old), 2020

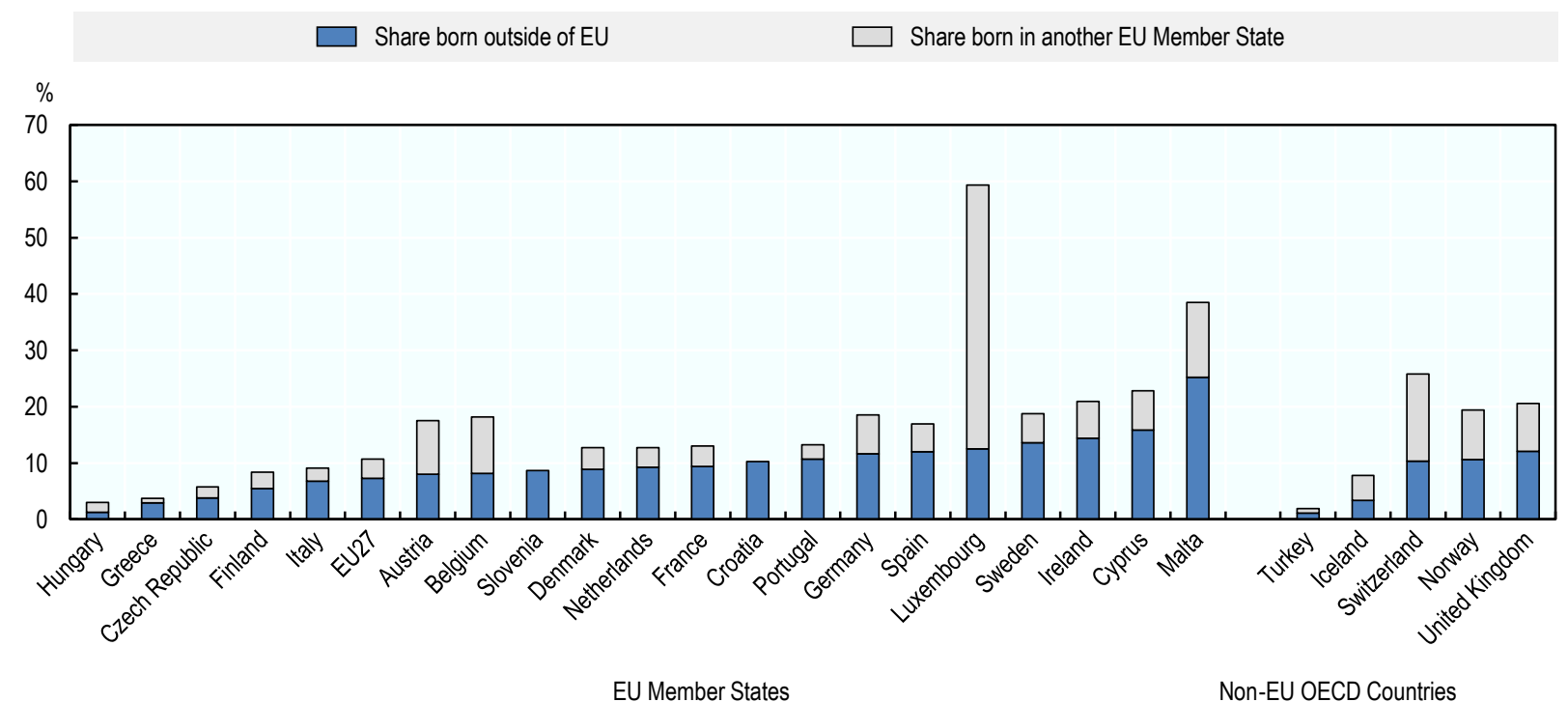

Note: The EU average does not match the data in Figure 6.1 because data for Germany is included in this total. Data for Bulgaria, Estonia, Latvia, Lithuania, Poland, Romania, Slovenia and the Slovak Republic are not reported because the estimates are unreliable due to a small sample size. Similarly, the share of immigrants to Croatia that were born in other EU Member States among the self-employed is not reported due to reliability issues Data for the United Kingdom are for 2019.

Source: (Eurostat, 2021 $[9]$ )

StatLink त्ञाज https://doi.org/10.1787/888934280251

\section{Characteristics of self-employed immigrants and their activities}

\section{Self-employed immigrants are as likely as non-immigrants to have employees}

Nearly one-third of self-employed immigrants in the EU employed at least one employee in 2020, which was about the same proportion as non-immigrants. Nearly $32 \%$ of self-employed immigrants from outside of the EU had employees in 2020, which was slightly above the share of those from other EU Member States $(28 \%)$. Both rates are relatively equal to the share of non-immigrant self-employed people that employ others (30\% in 2020) (Figure 3.9). 
Figure 3.9. Nearly one-third of self-employed immigrants in the EU are employers

Share of self-employed (15-64 years old) in the EU with employees

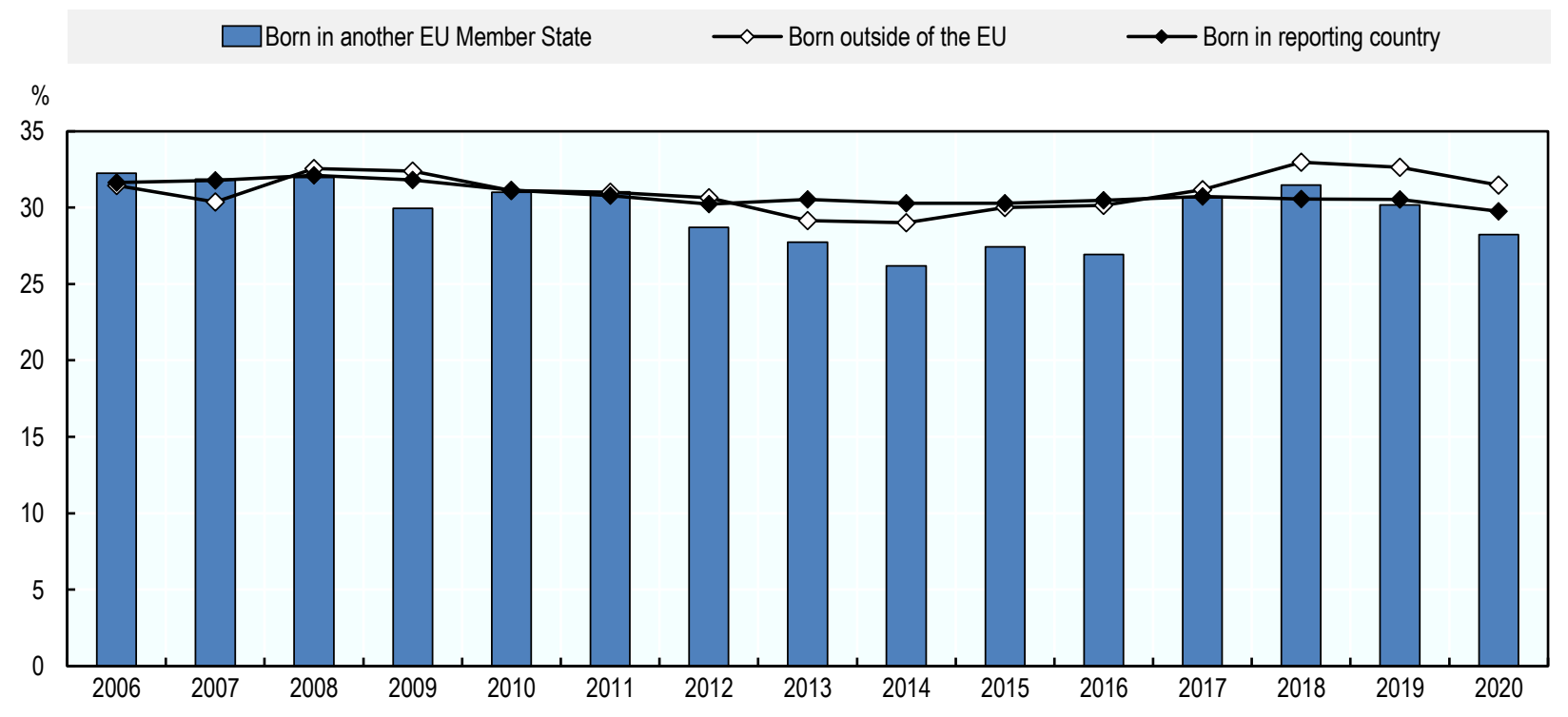

Source: (Eurostat, 2021 $\left.{ }^{29}\right)$

StatLink त्गाs https://doi.org/10.1787/888934280270

Self-employed immigrant women are two-thirds as likely as self-employed immigrant men to be employers. In 2020, place of birth did not have a significant impact on the proportion of self-employed women who had employees $-24 \%$ of self-employed women born outside of the EU had at least one employee, as did $24 \%$ of those born in the reporting country and $23 \%$ born in another EU Member State (Figure 3.10). Each of these rates were all about below the share of self-employed immigrant men with employees $-35 \%$ of those born outside of the EU, 32\% born in the reporting country and $31 \%$ born in another EU Member State. This gender gap is consistent with the overall gender gap in the share of selfemployed workers who are employers (see Chapter 2). 
Figure 3.10. One-quarter of self-employed immigrant women are employers

Share of self-employed (15-64 years old) in the EU with at least one employee

a. Born outside of the EU
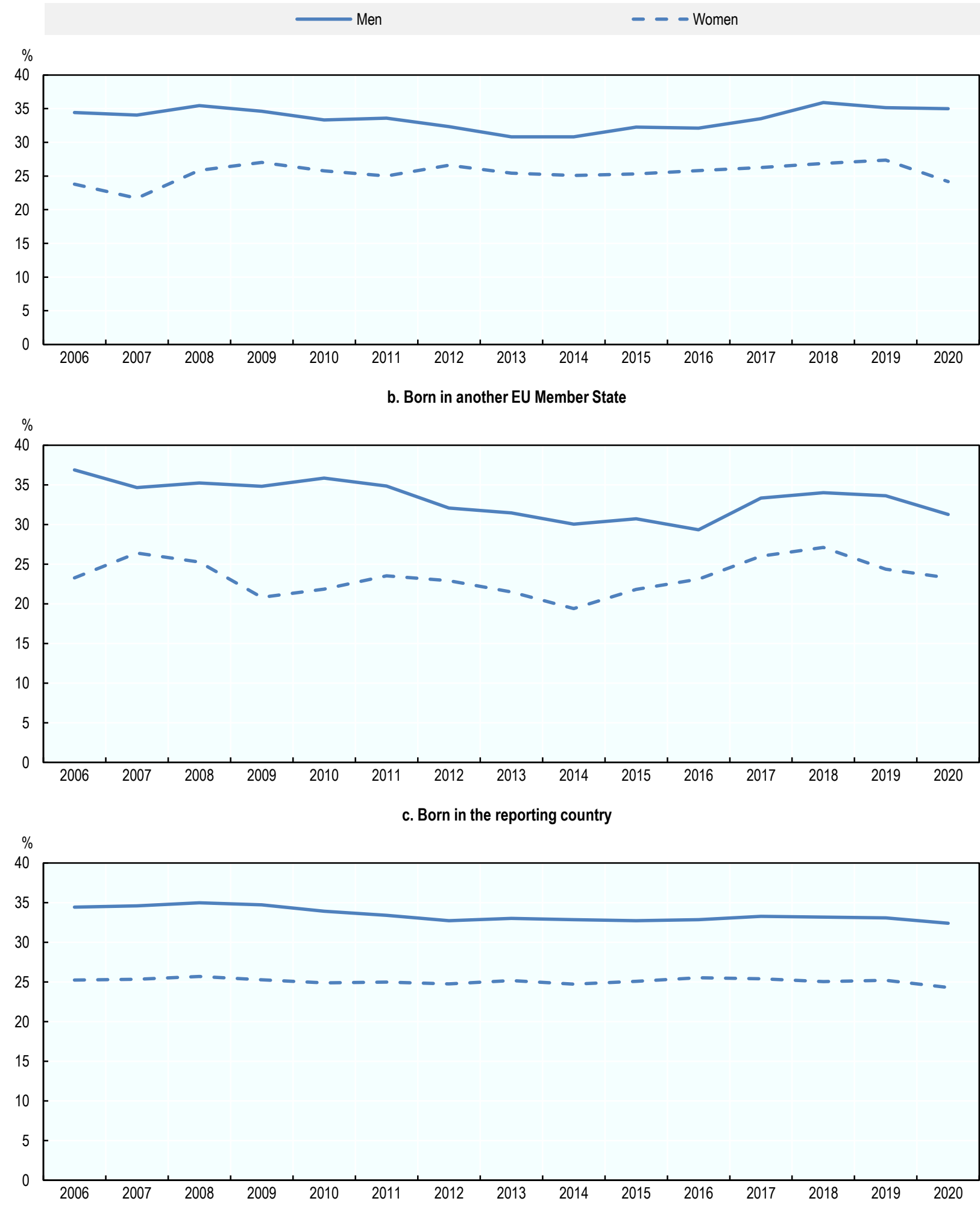

Source: (Eurostat, 2021 ${ }_{[9]}$ ) 
The share of self-employed immigrants with employees varied substantially across EU Member States in 2020. Considering self-employed immigrants born outside of the EU, the proportion with employees ranged from about $22 \%$ in the Netherlands to $52 \%$ in Austria (Figure 3.11). This share was greater than the proportion of self-employed immigrants who were born in another Member State in all Member States (where data are available) except for France and Portugal.

Figure 3.11. Self-employed immigrants are less likely to be employers in the majority of EU Member States

Share of self-employed who employ others, 2020

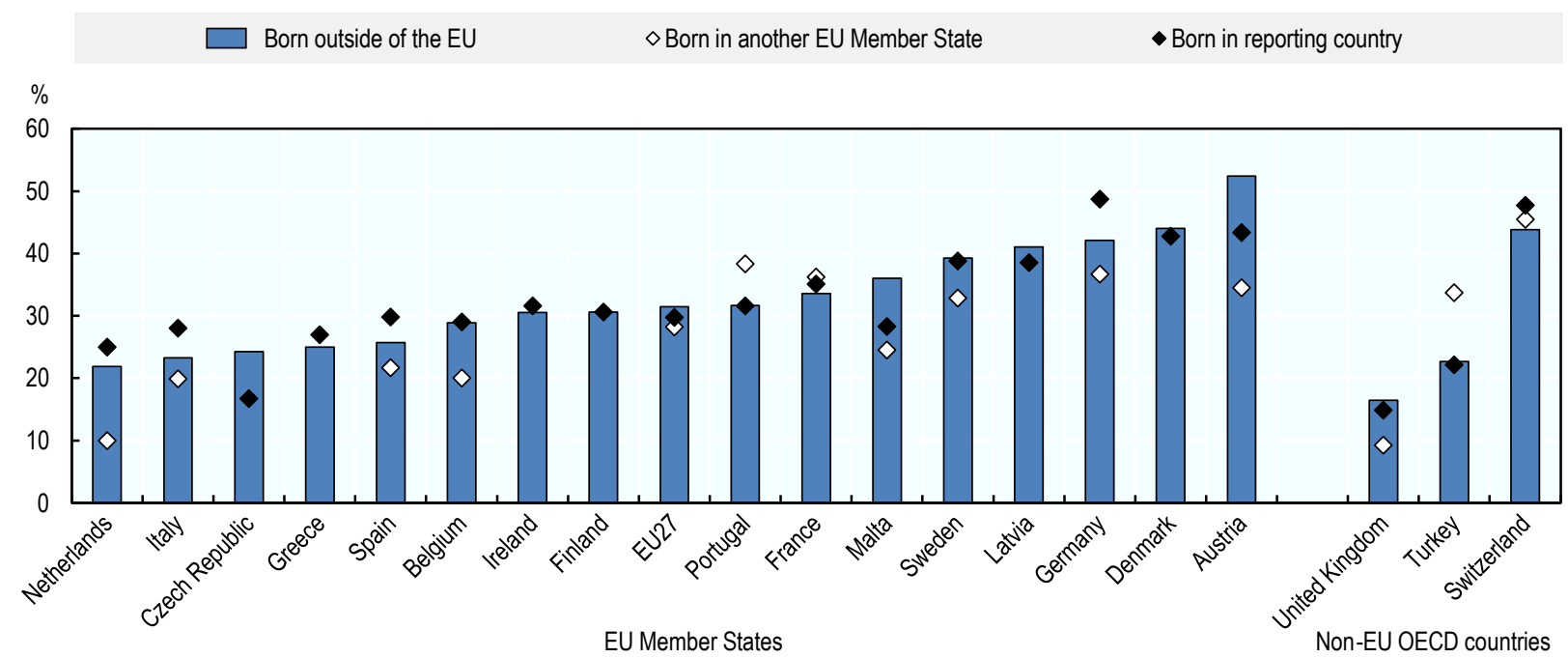

Note: Data for the United Kingdom are for 2019.

Source: (Eurostat, 2021 $[9]$ )

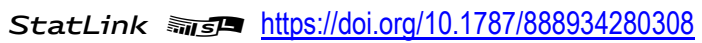

\section{Business activities by self-employed immigrants}

\section{Immigrants have similar self-employment rates by sector as non-immigrants}

Overall, self-employment rates for immigrants by sector were similar to those who were born in the reporting country in 2020. However, some differences can be observed for those born outside of the EU. For example, the self-employment rate for this group is slightly lower in professional, scientific and technical activities $(27 \%$ vs. $32 \%$ for those born in the reporting country) and construction (18\% vs. $24 \%)$ (Figure 3.12). On the other hand, the self-employment rate is slightly higher in wholesale and retail trade $(19 \%$ vs. $15 \%)$. Similarly, among those born in another EU Member State, the self-employment rate was lower in professional, scientific and technical activities ( $27 \%$ vs. $32 \%$ for those born in the reporting country) and manufacturing ( $3 \%$ vs. $6 \%$ ). However, data for some significant sectors including agriculture, forestry and fishing and ICT sectors are suppressed due to the low level of reliability of the estimates. 
Figure 3.12. Self-employment rates by sector vary little by place of birth

Self-employment in the EU as a percentage of employment (15-64 years old) by section, 2019

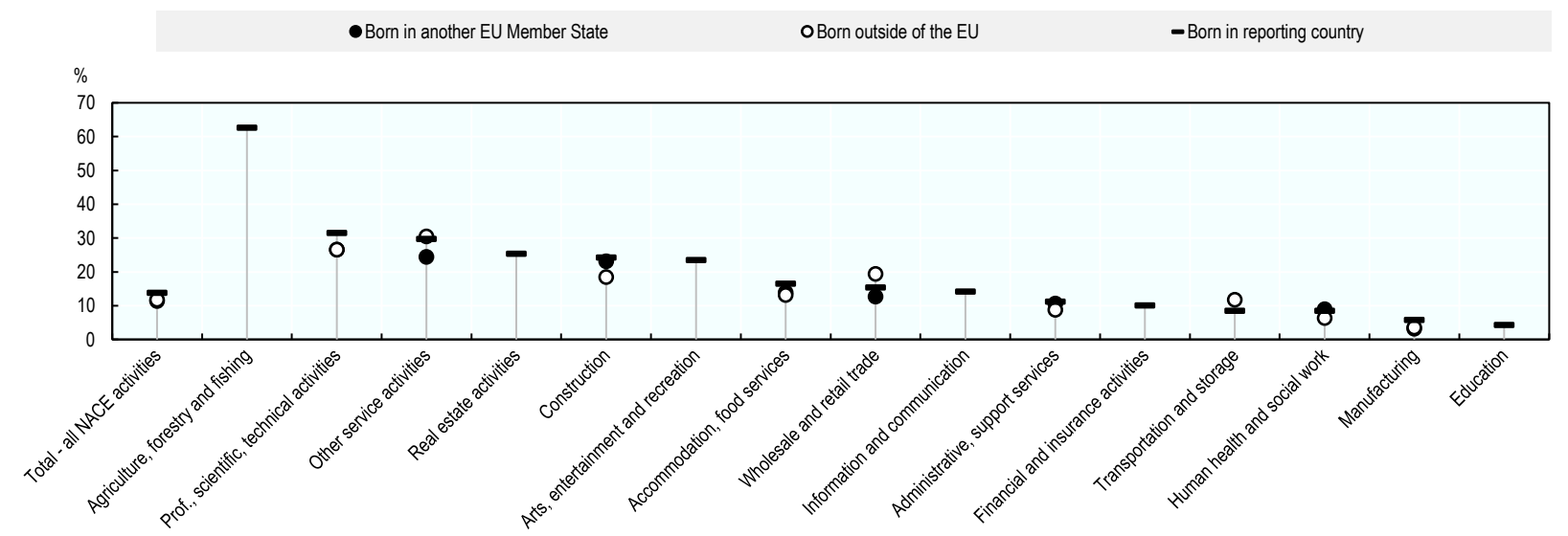

Note: The following sectors were excluded because the self-employment rate was less than $1 \%$ or the data were could not be reported due to a low reliability of the estimate: Public administration and defence, compulsory social security; Mining and quarrying; and Electricity, gas, steam and air conditioning supply.

Source: (Eurostat, 2021[9])

StatLink 제 sh https://doi.org/10.1787/888934280327

\section{Self-employed immigrants are more likely than non-immigrants to work as Professionals or Service and sales workers}

The distribution of self-employed immigrants by occupation largely consistent with the distribution of non-immigrants. The majority of self-employed immigrants with employees are managers $(28 \%$ of those born outside of the EU and 30\% of those born in another EU Member States), which is the same as self-employed non-immigrants (29\%) (Figure 3.13). However, self-employed immigrants who were working as professionals in 2020 were less likely to have employees than non-immigrants but those working as service and sales workers were much more likely to have employees. 
Figure 3.13. Solo self-employed immigrants are over-represented in professional occupations

Distribution of workers (15-64 years old) by sector in the EU, 2020

a. Self-employed with employees

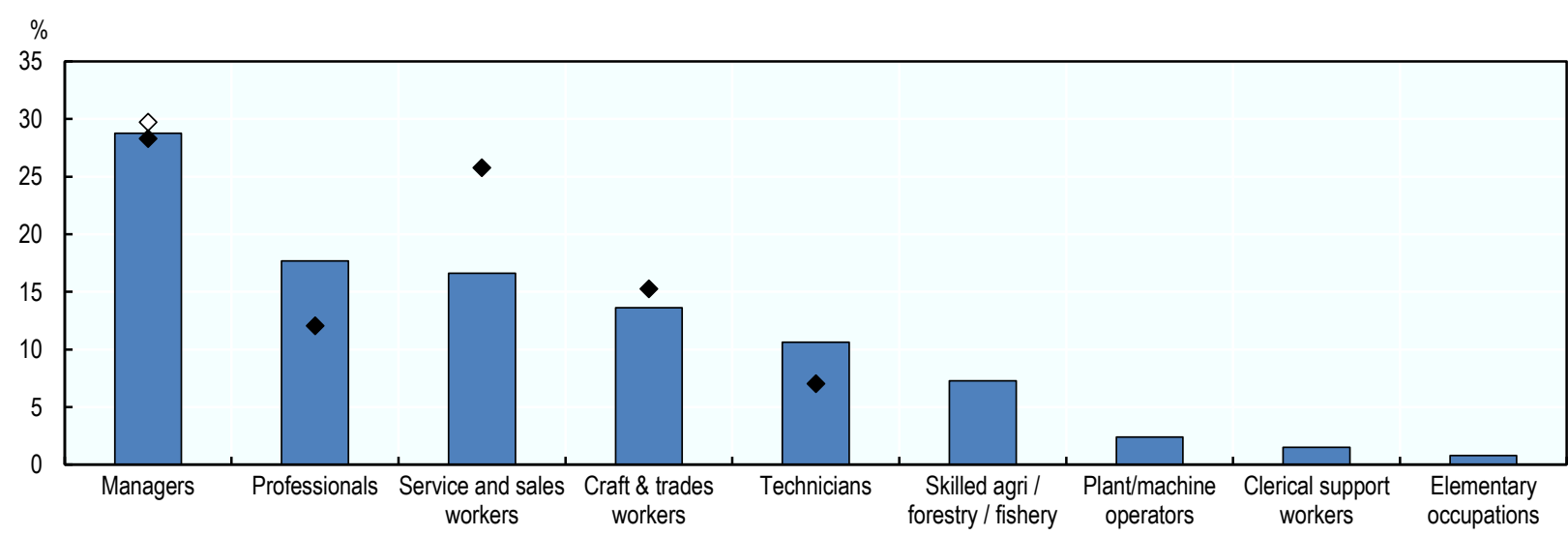

b. Self-employed without employees

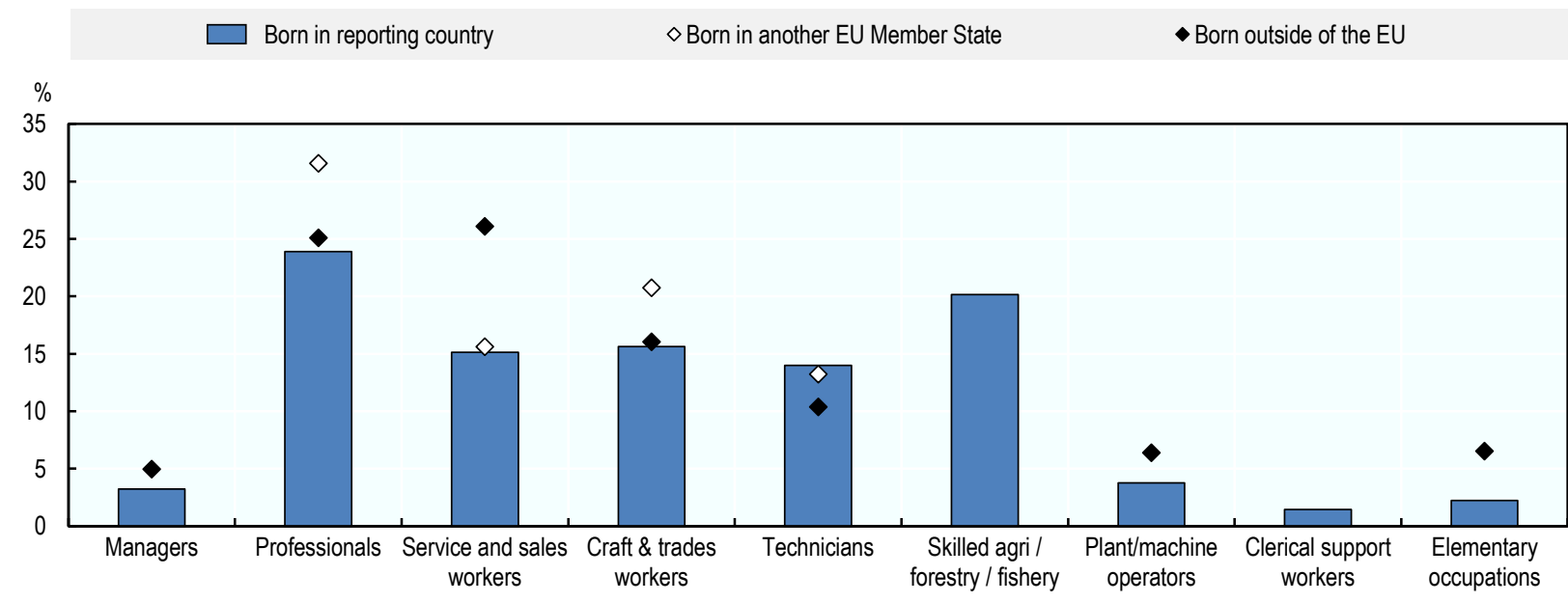

c. Employees

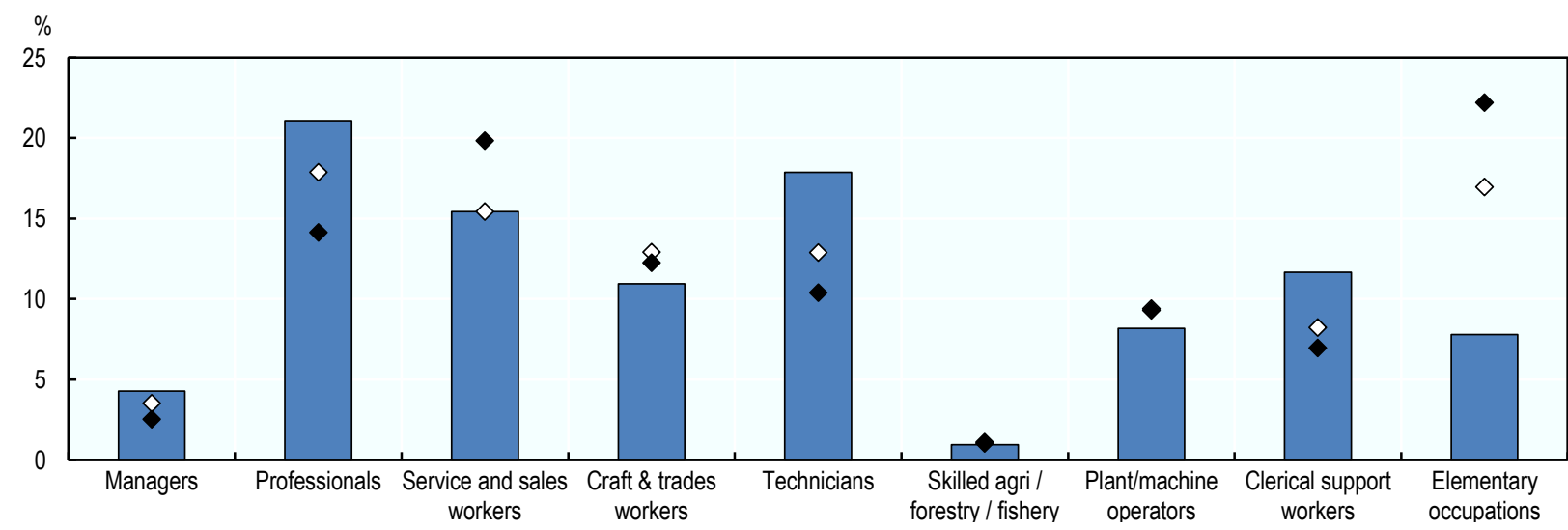

Source: (Eurostat, 2021 ${ }_{[9]}$ ) 


\section{Conclusions}

Overall, immigrants are slightly less likely to be self-employed in the EU than people who were born in their country of residence. Immigrant entrepreneurs often face greater barriers to entrepreneurship than the non-immigrants. These challenges are linked to language barriers, adjusting to a new culture, navigating a new institutional environment, a lack of credit history, legal status and eligibility to work, and small professional networks. These obstacles compound the typical barriers to business creation. Moreover, immigrants often have low levels of awareness of available support (e.g. entrepreneurship training programmes, grant schemes), and report that it is not accessible (e.g. support is not provided in multiple languages) or sufficiently adapted to their needs. However, these barriers vary greatly within the population of immigrants since some have very high levels of human, social and financial capital (e.g. international investors), while others typically have low levels of capital (e.g. refugees). Priority actions for governments include:

- Increasing the scale of immigrant entrepreneurship support to keep pace with the relative and absolute growth in immigrant entrepreneurship;

- Use financial supports for immigrant entrepreneurs to steer them away from sectors with oversupply.

For more information and policy discussion on immigrants' self-employment and entrepreneurship activities and policy, please refer to Chapter 8. Additional information on policies to support entrepreneurship by refugees can be found in a recent OECD policy brief (OECD, $\left.2019_{[8]}\right)$.

\section{References}

Anderson, S. (2016), "Immigrants and billion dollar startups"', Policy Brief, National Foundation for American Policy, https://www.immigrationresearch.org/system/files/lmmigrants-and-BillionDollar-Startups.NFAP-Policy-Brief.March-2016.pdf (accessed on 26 July 2021).

Eurostat (2021), Labour Force Survey, https://ec.europa.eu/eurostat/web/lfs (accessed on 6 May 2021).

Hopp, C. and J. Martin (2017), "Does entrepreneurship pay for women and immigrants? A 30 year assessment of the socio-economic impact of entrepreneurial activity in Germany", Entrepreneurship \& Regional Development, Vol. 29/5-6, http://dx.doi.org/10.1080/08985626.2017.1299224.

Kalu, K. and O. Okafor (2021), "Programming for Immigrant Women in Canada: Is Entrepreneurship Neglected?", International Migration, Vol. 59/1, http://dx.doi.org/10.1111/imig.12724.

KPMG (2017), Deutscher Startup Monitor 2017, https://hub.kpmg.de/dsm-2017 (accessed on 26 July 2021).

Miao, C. (2020), "Immigrant self-employment and local unemployment in Sweden", The Manchester School, Vol. 88/3, http://dx.doi.org/10.1111/manc.12315.

OECD (2020), Inclusive Entrepreneurship Policies: Country Assessment Notes, https://www.oecd.org/cfe/smes/inclusive-entrepreneurship-policies-country-assessmentnotes.htm (accessed on 6 June 2021). 
OECD (2019), "Policy brief on refugee entrepreneurship", OECD SME and Entrepreneurship

Papers, No. 14, OECD Publishing, Paris, https://dx.doi.org/10.1787/70571d6f-en.

OECD/EU (2019), Policy brief on business incubators and accelerators that support inclusive entrepreneurship, OECD, Paris.

OECD/European Union (2014), The Missing Entrepreneurs 2014: Policies for Inclusive Entrepreneurship in Europe, OECD Publishing, Paris, https://dx.doi.org/10.1787/9789264213593-en.

OECD/The European Commission (2013), The Missing Entrepreneurs: Policies for Inclusive Entrepreneurship in Europe, OECD Publishing, Paris, https://dx.doi.org/10.1787/9789264188167-en.

Ostrovsky, Y. and G. Picot (2020), Innovation in Immigrant-owned Firms in Canada, Statistics Canada, https://www150.statcan.gc.ca/n1/daily-quotidien/200609/dq200609e-eng.htm (accessed on 27 September 2021).

SPF Economie (2019), Entrepreneuriat et diversité - Une étude sur l'origine des travailleurs indépendants en Belgique, SPF, Brussels, https://economie.fgov.be/fr/publications/entrepreneuriat-et-diversite (accessed on 26 July 2021).

Statistics Finland (2020), Persons born abroad (database), http://www.stat.fi/tup/maahanmuutto/maahanmuuttajat-vaestossa/ulkomaillasyntyneet en.html (accessed on 26 July 2021). 


\section{Youth self-employment and entrepreneurship activities}

Nearly half of young people indicate that they would prefer to be an entrepreneur relative to working as an employees and more than $40 \%$ of university students report that they plan to become entrepreneurs within five years of their graduation. Despite this high level of interest in entrepreneurship, very few young people are working on start-ups. This gap is due to a number of important barriers such as a lack of experience and skills, low levels of collateral and savings and under-developed professional networks. Nonetheless, start-up rates among youth are high in some countries such as Estonia and Latvia. This chapter presents data on selfemployment and entrepreneurship activities by youth, including selfemployment rates, the proportion involved in starting a business and the characteristics of these activities. Data are presented for European Union Member States and OECD countries along with the averages for the European Union and the OECD. 


\section{Key messages}

- The data presented in this chapter are based on Eurostat Labour Force Survey data covering the self-employed and Global Entrepreneurship Monitor data on pre start-up and early-stage business activities. These data are complemented with country-specific statistics to provide additional insights on youth entrepreneurship.

- Estimates suggest that about $40 \%$ to $45 \%$ of young people have an interest in pursuing entrepreneurship but few youth are self-employed or activity working on a business start-up. This suggests that there continues to be untapped entrepreneurial potential among youth. If young people (18-30 years old) were as active as core-age men (30-49 years old), there would be an additional 1 million youth entrepreneurs in the European Union (EU). Youth account for $11 \%$ of the "missing" entrepreneurs in the EU.

- Youth (20-29 years old) self-employment rates have been stable in the EU for the past 20 years at about $7 \%$, but there have been some changes in the characteristics of these activities. One of the most significant trends has been a steady decline by 4 percentage points in the share of self-employed youth who employ others since 2004. In addition, after a steady increase in the share of self-employed youth with a tertiary education, the proportion has stabilised at 35\% since 2018.

- Fewer than $5 \%$ of youth (18-30 years old) in the EU are involved in early-stage entrepreneurship. Nearly $5 \%$ of youth (18-30 years old) were actively working on setting up a business between 2016 and 2020 compared to $4 \%$ of the overall population. Youth in OECD countries were slightly more active in business creation over this period $(8 \%)$, likely due higher levels of business churn in North America and greater levels of informal entrepreneurship in countries such as Chile, Colombia and Mexico.

- Youth face a number of key barriers to business creation, including a lack of entrepreneurship skills. Youth (18-30 years old) in the EU were slightly less likely than adults to self-report that they had the knowledge and skills for entrepreneurship over the 2016-20 period ( $38 \%$ vs. $44 \%$ for adults). A similar result was found in OECD economies over the same period ( $44 \%$ vs. $49 \%$ for adults).

- Those who are successful in starting a business are optimistic about their job creation potential. About $11 \%$ of early-stage youth entrepreneurs in the EU during the period 2016-20 expected to create at least 19 jobs over the next three years, which was slightly above the overall rate $(9 \%)$. These rates were below the proportion of early-stage entrepreneurs reporting high-growth expectations in OECD countries $-15 \%$ for youth and $14 \%$ overall. This job creation is likely driven by a greater likelihood of pursuing growth-oriented strategies such as exporting - $56 \%$ of early-stage youth entrepreneurs in the EU reported having customers in other countries relative to $47 \%$ of all early-stage entrepreneurs - but young people are also more likely to be overly optimistic about growth potential due to a lack of experience.

- Youth unemployment has increased rapidly during the COVID-19 pandemic and entrepreneurship policy can be part of the policy response. Youth entrepreneurship schemes were boosted following the financial crisis in 2008-09 and governments across the EU and OECD membership have strengthened investments in entrepreneurship schemes for youth. Within the EU, Member States can access greater amounts of financial support for youth entrepreneurship schemes through renewed investments in the Youth Employment Initiative. 


\section{Policy context}

\section{COVID-19 has made entry into the labour market even more difficult for young people}

The COVID-19 pandemic has had a negative impact on many young people since they have had difficulties getting the best out of their education and finding jobs in a labour market with increasing unemployment. Youth unemployment has increased more rapidly during the onset of the pandemic than unemployment overall, and many young people withdrew from the labour force or extended their studies since there are few job opportunities. About $19 \%$ of youth were unemployed in the European Union (EU) in 2021Q1 but this share was as high as 38\% in Spain. Addressing youth unemployment has therefore become a policy priority much like it did following the financial crisis of 2008-09 when the youth unemployment rate reached more than 50\% in Spain (55\%) and Greece (53\%) in 2012 and more than $30 \%$ in Croatia (42\%), Portugal (38\%), Italy (35\%), Slovak Republic (34\%) and Ireland (31\%) (Eurostat, 2021[1]). Youth entrepreneurship policies and programmes have demonstrated that they can facilitate access to work for many young people and therefore should be part of the policy response to this unemployment challenge.

Furthermore, young people who are already entrepreneurs faced disproportionate challenges during the pandemic since they operate less established businesses and tend to have more difficulty accessing resources than older entrepreneurs. Older entrepreneurs are more likely than youth entrepreneurs to have experience managing their businesses during downturns and have larger networks and collateral that can be used to access additional financial resources (see Chapter 1 for further discussion of the impact on COVID-19 pandemic on youth entrepreneurship).

\section{The EU's "missing" million youth entrepreneurs}

There is an abundance of evidence to suggest that youth are very interested in entrepreneurship, yet few young people are actively involved in entrepreneurship. Recent data from the Global University Entrepreneurial Spirit Students' Survey (GUESSS) of 208000 students across 54 countries found that $9 \%$ would like to become an entrepreneur immediately after their studies while another $35 \%$ plan to be an entrepreneur within the first five years after their studies (Sieger et al., 2018[2]). This is consistent with slightly older data from the Flash Eurobarometer survey, which shows that $45 \%$ of those surveyed between 15 and 24 years old indicated a preference for self-employment over working as an employee (European Commission, 2012[3]). However, very few people under 30 years old are creating businesses. This chapter shows that fewer than $7 \%$ of people aged 18 to 29 years old in the EU and $13 \%$ in OECD countries were involved in early-stage entrepreneurship, i.e. involved in creating a new business or managing one that is less than 42 months old. These rates are about equal to the overall average in EU and OECD countries. Nonetheless, these early-stage entrepreneurship rates are below those of core-age males (30-49 years old). If youth were as active core-age males in early-stage entrepreneurship, there would be an additional 1 million youth entrepreneurs in the EU. Those $18-30$ years old account for $11 \%$ of the "missing" entrepreneurs in the EU.

\section{Youth entrepreneurship policy has strengthened over the past decade}

Public policy support for youth entrepreneurship in the EU has developed considerably over the past decade following the financial crisis in 2008-09. EU Member States responded to this youth unemployment crisis with a large range of youth employment measures, including the Youth Guarantee that ensures that all young people under the age of 30 receive a good quality offer of employment, continued education, apprenticeship or traineeship within four months of becoming unemployed or leaving education. This commitment was reinforced in a Council Recommendation of October 2020 (European Commission, 2021 [4] $)$. The European Commission provides financial support to Member States and regions 
through the Youth Employment Initiative, which is one of the main EU financial resources to support the implementation of Youth Guarantee schemes until 2023. The EU launched it in 2012 to provide support to young people living in regions where youth unemployment was higher than $25 \%$. This financial resource was boosted for 2021-23 along with European Social Fund resources to help young people affected by the COVID-19 pandemic through the additional funding available under the Recovery Assistance for Cohesion and the Territories of Europe (REACT-EU) initiative.

Youth entrepreneurship policy is quite advanced relative to entrepreneurship support for other inclusive entrepreneurship target groups (e.g. seniors, immigrants) given this investment in youth policies over the past decade. An OECD assessment of inclusive entrepreneurship policies across EU Member States examined approaches to promoting and supporting inclusive entrepreneurship, including youth entrepreneurship (see Reader's Guide). Only one EU Member State reports that they do not have a clear youth entrepreneurship policy at the national level and nearly two-thirds of Member States have a specific youth entrepreneurship strategy (Figure 4.1). However, only about half of youth entrepreneurship strategies have set clear targets and objectives. There is also strong engagement at the regional level, due in part to the regional management and disbursement of EU Structural Funds as well as the strong linkages with entrepreneurship education, which is often implemented by sub-national governments.

One clear area for strengthening youth entrepreneurship policies in the EU is to make greater use of monitoring and evaluation tools. Only about one-third of EU Member States routinely assess youth entrepreneurship policies and schemes despite the strong role of EU Structural Funds in supporting youth entrepreneurship schemes.

\section{Figure 4.1. Youth entrepreneurship policy benefited from investments following the financial crisis}

Share of EU Member States, 2020

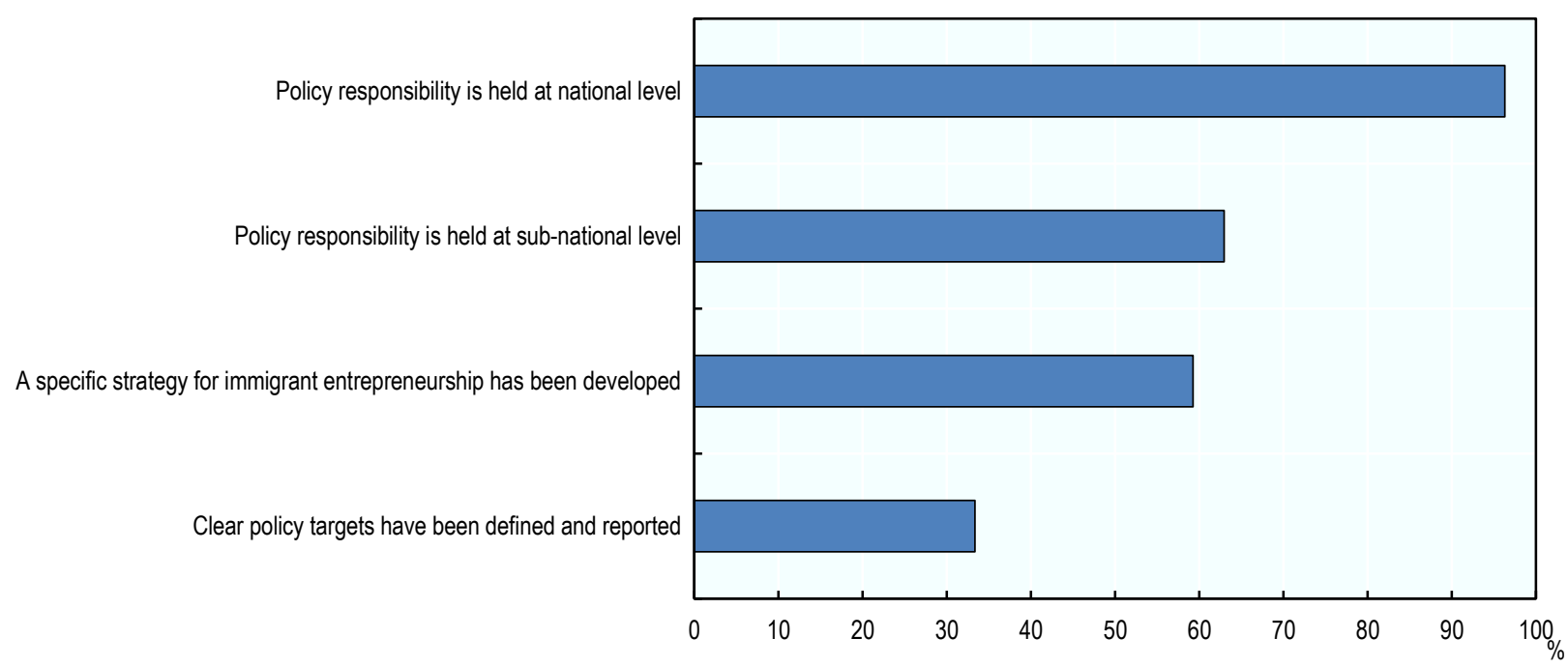

Note: It is possible for countries to have clear policy responsibility at both the national and sub-national levels; these are not mutually exclusive. Source: (OECD, 2020[5]) 


\section{Youth entrepreneurship schemes use a wide range of instruments to support business creation}

A wide range of schemes are offered for youth entrepreneurs in the EU, covering the main areas of entrepreneurship policy intervention. The OECD inclusive entrepreneurship policy assessments across the EU found that youth entrepreneurship schemes use various instruments to build motivations for entrepreneurship, develop entrepreneurship skills, improve access to finance, expand networks and provide incentives and supports through regulatory instruments. Using the OECD's 9-point assessment criteria (see Reader's Guide), schemes to support youth entrepreneurs appear to be, on average, more comprehensive in terms of the types of instruments used and better integrated into a system of support (Figure 4.2).

\section{Figure 4.2. Youth entrepreneurship schemes widely available and use a range of instruments}

Average OECD assessment scores for inclusive entrepreneurship schemes across EU Member States, 2020

a. Entrepreneurship skills

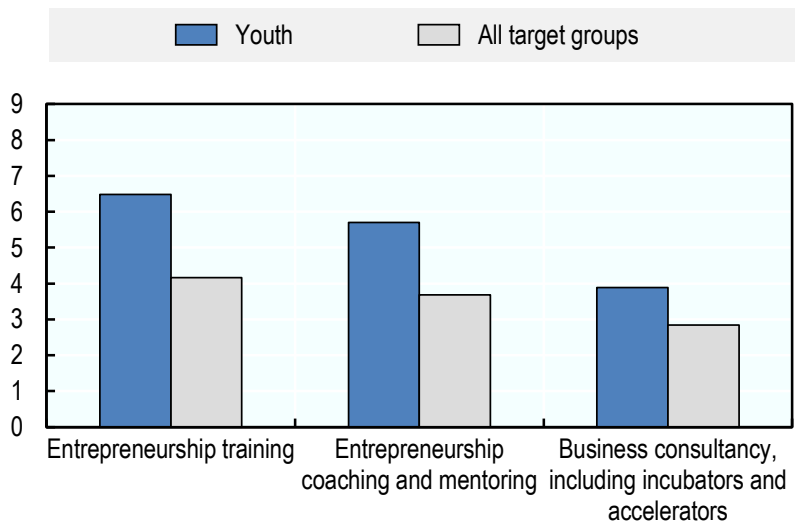

accelerators b. Entrepreneurship finance

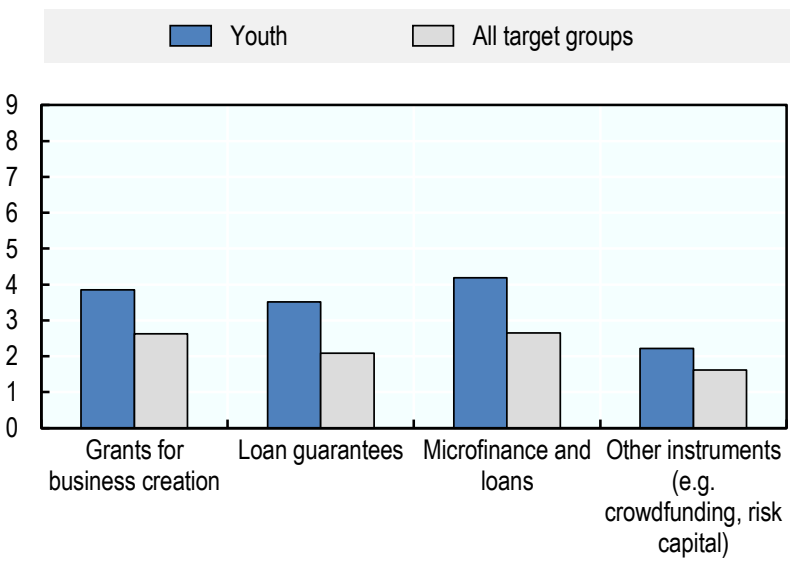

c. Entrepreneurship culture and social capital

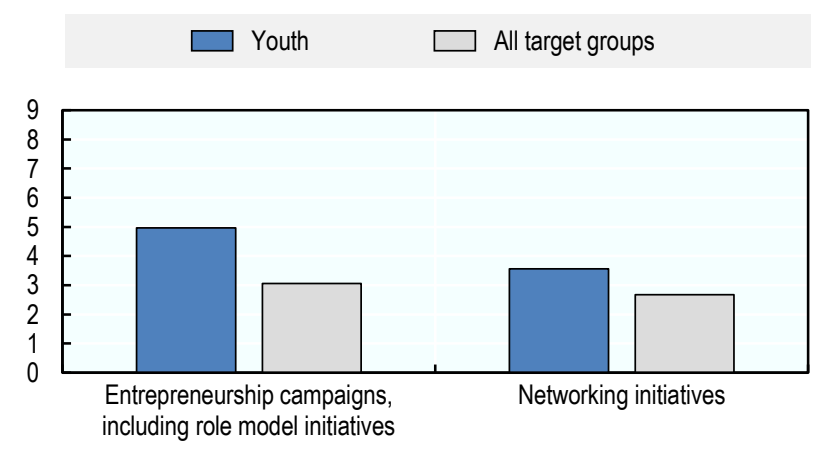

d. Regulatory tools

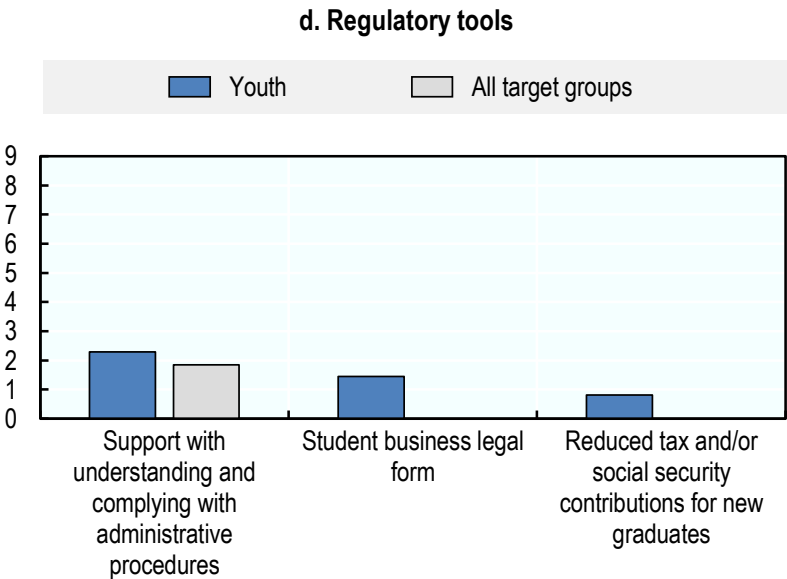

Note: The panels in this figure present an unweighted average of policy assessment scores for EU Member States. Each policy instrument (e.g. Entrepreneurship training) is assessed a scored out of 9 as described in the Reader's Guide. The figure shows the average score for schemes for immigrant entrepreneurs relative to the score for all inclusive entrepreneurship groups combined (i.e. women, immigrants, youth, seniors and the unemployed). Some of the policy instruments in panel $d$ are designed specifically for immigrant entrepreneurs so there is no comparative policy assessment score for all inclusive entrepreneurship target groups.

Source: (OECD, 2020[5]) 


\section{Building entrepreneurship skills}

Entrepreneurship training, coaching and mentoring schemes are one of the primary methods used by governments to help youth build entrepreneurship skills. Tailored schemes for young entrepreneurs are available in essentially all Member States, and they typically use dedicated delivery channels (i.e. schemes for youth only), including partnerships with non-government actors who deliver entrepreneurship training and coaching on behalf of governments. Take-up is often very high in youth entrepreneurship training and coaching schemes when investments are made in outreach, and about half of EU Member States indicate that the scale of support offered is appropriate. While the quality of support is highly variable across regions and countries, there is a growing body of evidence that youth entrepreneurship training and coaching schemes can be effective at not only supporting business creation by young people but also help them move into employment (OECD/European Commission, 2020[6]). An area where many schemes could be improved is to take further steps to engage young entrepreneurs and youth entrepreneurship organisations and networks in the design of support. This will help to ensure that support is relevant for the barriers that young people face in business creation and that the format of support is attractive and appropriate for youth.

Tailored business consultancy, including incubator and accelerator programmes, is less frequently offered than entrepreneurship training and coaching in EU Member States but about half of countries report having dedicated schemes for young entrepreneurs. The lower availability of consultancy schemes for youth entrepreneurs is not surprising since they are designed for young entrepreneurs who are already operating a business, which is a small subset of youth who indicate an interest in entrepreneurship. When consultancy for young entrepreneurs is offered, many Member States indicate that take-up is high and that the scale of support offered is suitable for demand.

\section{Facilitating access to start-up finance}

Microfinance and grants are the most common type of finance scheme offered for youth entrepreneurs. These types of financial supports for youth entrepreneurs are quite commonly offered together with entrepreneurship training and coaching, which can help increase the chances of the youth entrepreneurs in making effective use of the finance. There are both advantages and disadvantages to using both microfinance and grants to support young entrepreneurs. Grants tend to involve much smaller amounts of money so the main drawback is that grants may not provide sufficient resources to fully develop ideas and plans into sustainable businesses. In addition, grants are not repayable so governments do not recoup these investments and entrepreneurs may be given strong incentives to succeed unless they come with a condition that they must be repaid if the business is not operating for at least a period of time (e.g. two years). Microfinance schemes can have a greater impact since they provide access to larger sums of money and governments can achieve a multiplier effect with funds that are lent, i.e. money that is repaid can be lent to other entrepreneurs. However, these types of schemes are more difficult to setup and manage in practice since they often require private sector partners to manage the loans and select supported projects.

\section{Expanding entrepreneurship culture and networks}

Entrepreneurship is widely promoted to youth, including through entrepreneurship education programmes that are increasingly being introduced in formal education systems in the EU. A common method used to promote entrepreneurship outside of education is to use entrepreneurship role models to inspire youth and inform them about the role of entrepreneurs. While it is difficult to measure the effectiveness of such actions (e.g. entrepreneurship speakers at community events, entrepreneurship festivals), they are usually low-cost interventions that leverage volunteer mentors and role models. About two-thirds of EU Member States have actions that promote entrepreneurship to youth outside of education. 
Tailored networking actions, either as stand-along schemes or embedded into integrated packages, are an underused type of support in the EU. Youth often have less access to resources due to their age and lack of collateral (OECD/European Commission, 2020[6]), so entrepreneurship networks can be a way of bridging these deficiencies. However, only about half of Member States have invested in supporting the development of entrepreneurship networks for youth entrepreneurs and take-up does not appear to be strong overall. This suggests that governments could do more to educate young entrepreneurs about the benefits of building entrepreneurship networks.

\section{Supporting youth entrepreneurs with regulatory tools}

Regulatory tools such as temporary tax reductions and relief from social security contributions can also be used to support to youth entrepreneurs, but few EU Member States do so. Only about a handful of EU governments use these types of financial supports, but those that do tend to follow good practice approaches where support is phased-out over a short time period. For example, young entrepreneurs may not be required to make social security contributions during their first year of operation, but half of their contribution in the second year and the full amount starting in their third year of operation. While these types of interventions can provide some financial relief to young entrepreneurs, there are almost no evaluation reports that assess the overall impacts of such measures.

Another tool that about one-quarter of EU Member States use is a special legal form for businesses operated by youth entrepreneurs. These include, for example, "student entrepreneur" businesses or "trial" companies that offer advantages to the entrepreneur (e.g. no or very little tax on revenue) provided that the businesses operates within defined revenue thresholds. If the youth entrepreneur exceeds defined thresholds, they must convert the form of their business. These business forms can provide a valuable learning opportunity for youth entrepreneurs since they can gain some experience operating a business without taking on the full risk that is assumed by a typical business start-up.

\section{Recent developments in youth entrepreneurship policy}

As noted at the outset of this chapter, there has been a strong renewal of the commitment to strengthen youth employment and entrepreneurship policy in the wake of the COVID-19 pandemic. This includes renewed employment policies and action plans in many EU Member States, including for example the Spanish Youth Employment Action Plan 2019-21 ("plan de choque para el empleo joven"). It includes 50 measures, including entrepreneurship promotion, with an estimated cost of EUR 667 million for 2020.

Many Member States are working to improve the business conditions for young entrepreneurs. Some Member States such as Lithuania are adjusting the tax environment to support young entrepreneurs. This includes, for example, an amendment to the Law No I-442 on Corporate Tax initiated by the Ministry of Economy and Innovation provides greater incentives and flexibility for investments in new start-ups. The corporate tax relief now applies to venture capital and private equity entities that invest in both shares and convertible bonds. Until now, only venture capital and private equity entities that invested $70 \%$ of the capital value in equity securities (shares) have benefited from the corporate tax relief. Under the newly adopted legislative amendment, the $70 \%$ limit applies to both equity securities and convertible bonds together or if the investment portfolio is formed by only one of these investments. This amendment is expected to encourage increased investment by private and venture capital funds in early-stage start-ups. From the inclusive entrepreneurship perspective, this will mainly influence youth entrepreneurs, who often choose start-up form.

Governments have continued to invest in entrepreneurship education over the past decade. For example, the Austrian national action plan for entrepreneurship education was launched in 2020 ("Map of Entrepreneurship Education"), which includes three action areas to strengthen entrepreneurship education at all levels of education. It was developed through a co-operation between the Federal Ministry for Digital 
and Economic Affairs (BMDW), Federal Ministry of Education, Science and Research (BMBWF), several other ministries such as Federal Ministry of Labour, Family and Youth (BMAFJ), Federal Ministry of Finance (BMF) and the Federal Chancellery. About 65 other stakeholders also had a strong role in developing the plan. Germany is another country that continues to strengthen entrepreneurship education. The main programme to support student entrepreneurs in higher education is EXIST, which is operated by the Federal Ministry for Economic Affairs and Energy (BMWi) with co-funding from the European Social Fund. The new programme EXIST-potentials was launched in 2020 to increase the start-up potential of female students and scientists through role models. It will run until 2024.

As with most areas of policy delivery, youth entrepreneurship schemes have adjusted to the challenges presented by the COVID-19 pandemic by moving online. In Italy, for example, the "Yes, I start up" project was transformed from an in-person scheme to a fully online scheme. Launched in 2018 as part of the suite of Youth Guarantee actions, it offers entrepreneurship training and start-up grants to youth who are not in employment, education or training (i.e. NEETs). A new online platform was created in 2020 in response to COVID-19 containment measures that prohibited classroom training and in-person business support. The new platform facilitated remote training, which ensured continuity for those already in the programme and also improved access to supports for those in rural and remote locations. The platform also had some unforeseen benefits, notably improved monitoring of programme participants and the ability to use the platform to facilitate access to emergency support measures for existing entrepreneurs.

\section{Trends in self-employment by youth}

\section{Youth are about half as likely as all adults to be self-employed}

The self-employment rate for youth in the EU has been relatively stable over the past decade at about half the rate for the overall population. In 2020, there were about 2 million self-employed youth (20-29 years old) in the EU. This accounted for $7 \%$ of working youth (20-29 years old), which was half of the overall share of working people (15-64 years old) that were self-employed (Figure 4.3). Despite a stable self-employment rate, the absolute number of self-employed youth declined from 2.6 million in 2002 . This decline is due partly to demographics since many self-employed youth would have grown out of this age category over this period and there are fewer young people in subsequent generations. 
Figure 4.3. About $7 \%$ of working youth in the EU are self-employed

Self-employment as a percentage of employment in the EU

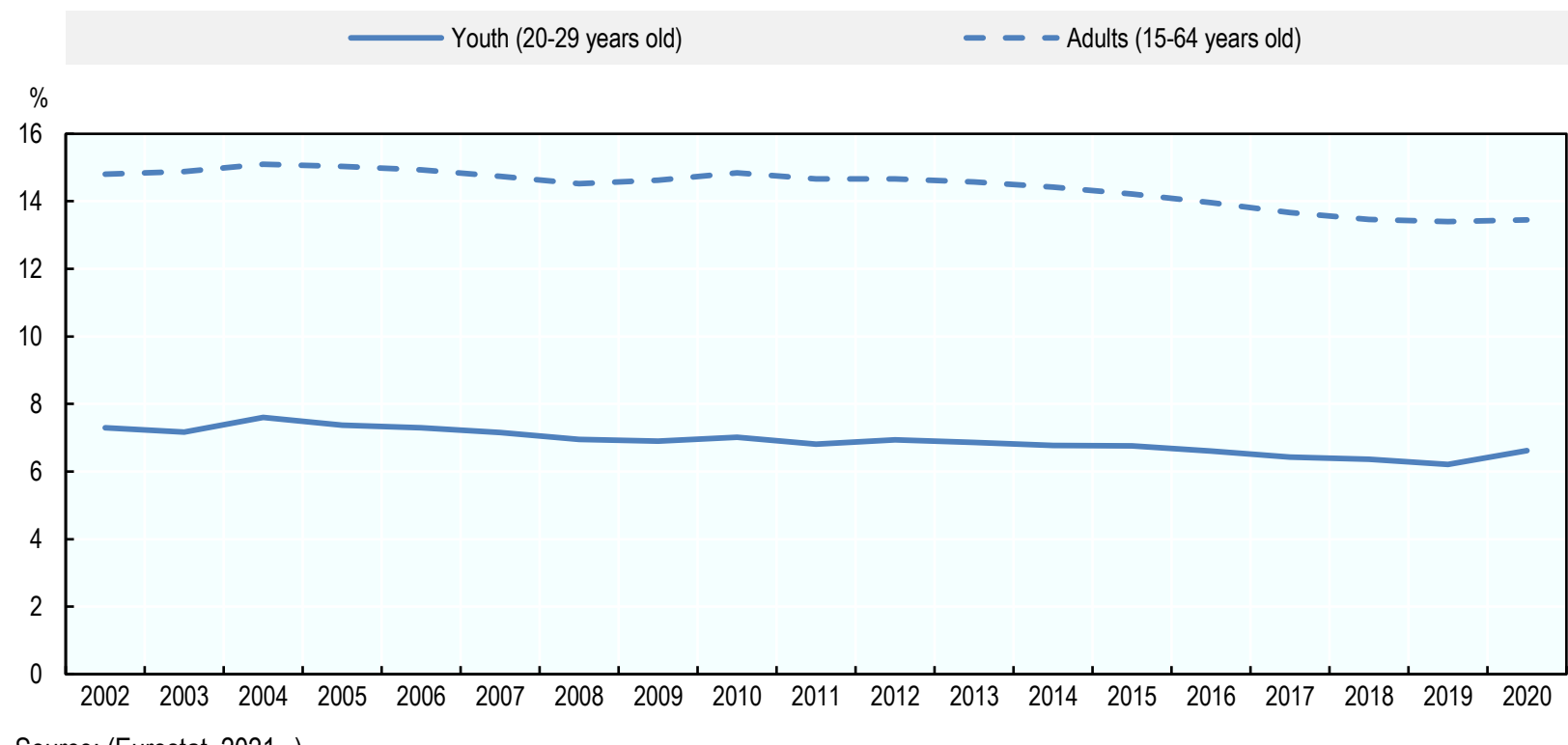

Source: (Eurostat, $\left.2021_{[1]}\right)$

StatLink त्ता Th https://doi.org/10.1787/888934280403

Among EU Member States, the share of youth who are self-employed ranged from about $2 \%$ in Germany to $13 \%$ in Greece. At least one-in-ten working youth (20-29 years old) was self-employed in six Member States - Romania (10\%), Poland (10\%), Czech Republic (11\%), Italy (12\%) and Greece (13\%) (Figure 4.4). Conversely, very few youth were self-employed in Germany (2\%), Austria (3\%) and Denmark (3\%). These differences across countries are driven by many factors. First, there is a strong positive correlation (0.8) between the youth self-employment rate and the overall self-employment. Factors that influence self-employment levels include notably labour market conditions for young people entering the labour market and social attitudes towards entrepreneurship and risk. Countries such as Greece and Italy that have had high youth unemployment since the financial crisis (2008-09) also have a youth selfemployment rate that is well-above the EU average. For further discussion on the role of youth unemployment influencing youth self-employment in the EU, please see Box 4.1. Conversely, countries such as Austria, France and Germany with strong mechanisms to support school to employment transitions (e.g. internships, work-study contracts) can result in lower levels of interest in business creation since employment is generally preferred (OECD, 2020 $[5])$. 
Figure 4.4. Youth self-employment rates tend to be correlated with overall self-employment rates Self-employment as a percentage of employment, 2020

- Youth (20-29 years old) $\quad \diamond$ Total (15 to 64 years old)

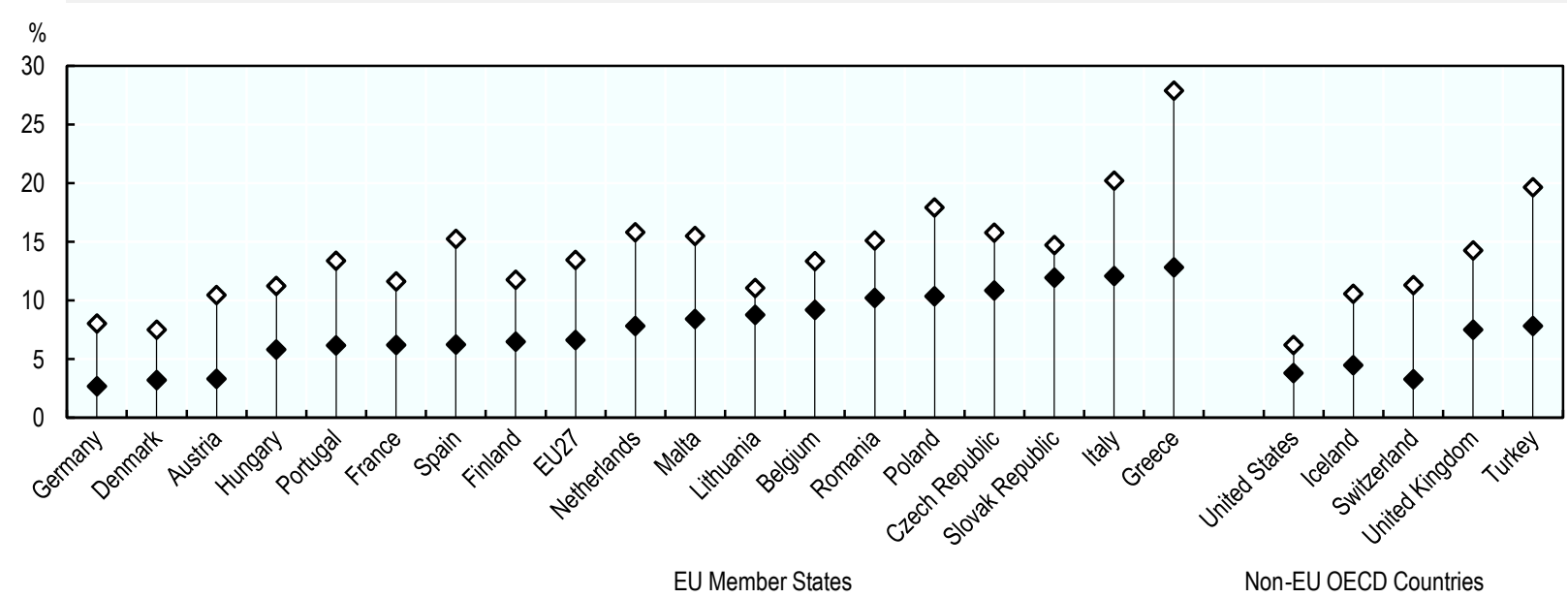

Note: Data for the United States only cover unincorporated self-employment activities and youth are considered to be 25 to 34 years old. Source: (Eurostat, 2021 [1]; US Bureau of Labor Statistics, 2021 $\left.{ }_{[7]}\right)$

StatLink त्ञाज https://doi.org/10.1787/888934280422 


\section{Box 4.1. The relationship between youth unemployment and self-employment in the EU}

A new study used a linear multiple regression to identify EU Member States with a strong relationship between youth unemployment and youth self-employment (Remeikienè et al., 2020[8]). It also sought to determine if this relationship is driven by "push" factors or "pull" factors.

Among EU Member States, a statistically significant relationships between youth unemployment and youth self-employment was found in only seven countries (Table 4.1). In four countries, a mediumstrong positive correlation was identified. Thus, the youth unemployment rate in the Czech Republic, Germany, Malta and Sweden tends to increase as the youth self-employment rate increase, suggesting that young people are often "pulled" into self-employment. Conversely, a negative correlation was found in Cyprus, Greece and Italy which suggests that youth are more likely to be "pushed" into selfemployment.

The push and pull theories help to identify motivations to become self-employed and can be useful for policy makers in designing and targeting youth entrepreneurship interventions. For instance, the results in Cyprus suggest that a targeted self-employment measure among youth would reduce unemployment, but this is not necessarily the case in other countries where a targeted support measure would not have an effect on the unemployment rate. Push and pull theories are useful tools in analysing existing relationships and adapting policies to address the most relevant issue for reducing youth unemployment considering specific situational factors.

\section{Table 4.1. Unemployment has both positive and negative influences on youth self-employment}

\begin{tabular}{|c|c|c|c|c|}
\hline \multirow[b]{2}{*}{ Country } & \multicolumn{2}{|c|}{ Pull into self-employment } & \multicolumn{2}{|c|}{ Push into self-employment } \\
\hline & rs value & $p$ value & rs value & $p$ value \\
\hline Czech Republic & 0.724 & 0.012 & & \\
\hline Germany & 0.627 & 0.039 & & \\
\hline Malta & 0.695 & 0.018 & & \\
\hline Sweden & 0.706 & 0.015 & & \\
\hline Cyprus & & & -0.772 & 0.050 \\
\hline Greece & & & -0.609 & 0.047 \\
\hline Italy & & & -0.618 & 0.043 \\
\hline
\end{tabular}

Source: (Remeikienè et al., 2020[8])

\section{Characteristics of self-employed youth and their activities}

\section{Self-employed youth are half as likely to employ others}

The share of self-employed youth who employ others is declining and at a slightly faster rate than among the total self-employed population. About $16 \%$ of self-employed youth (20-29 years old) in the EU had at least one employee in 2020, which has about half of the share of the total self-employed population (18-64 years old) (Figure 4.5). Both of these proportions have declined since 2004 - the share of self-employed youth who were employers declined from $20 \%$ and the overall share from $32 \%$. This decline is likely explained by the changing nature of self-employment, including an increase in part-time self-employment which is nearly always undertaken by those without employees. 
Figure 4.5. One-in-six self-employed youth employ others

Percentage of self-employed in the European Union

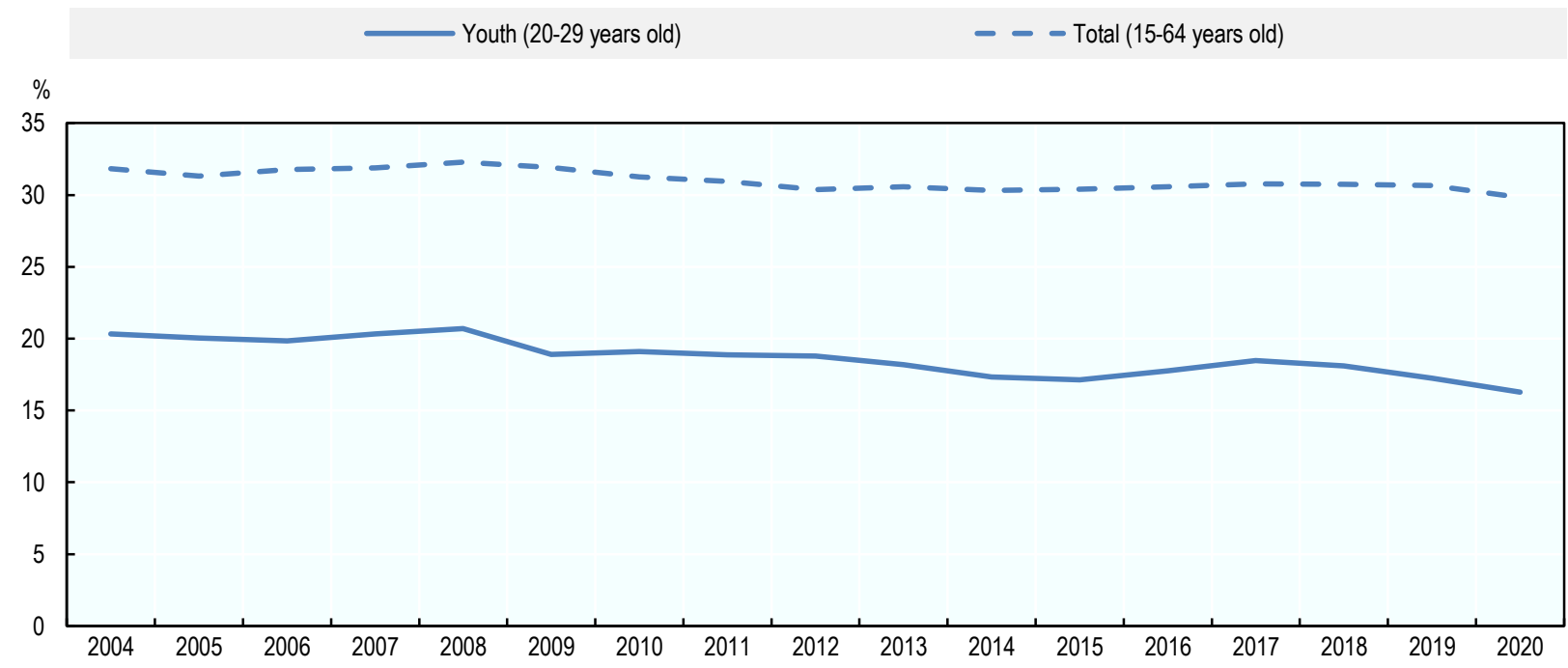

Source: (Eurostat, 2021 $\left.{ }_{[1]}\right)$

StatLink 게 sh https://doi.org/10.1787/888934280441

There was a substantial variation in the share of self-employed youth who had employees across EU Member States in 2020. The share of self-employed youth (20-29 years old) who were employers range from $7 \%$ in the Czech Republic to $28 \%$ in Hungary (Figure 4.6). Differences across countries can be explained by several factors, notably the sector and occupation of the self-employment activity.

Figure 4.6. Less than one-fifth of self-employed youth have employees in nearly all EU Member States

Percentage of self-employed, 2020

- Youth (20-29 years old)

$\diamond$ Total (15-64 years old)

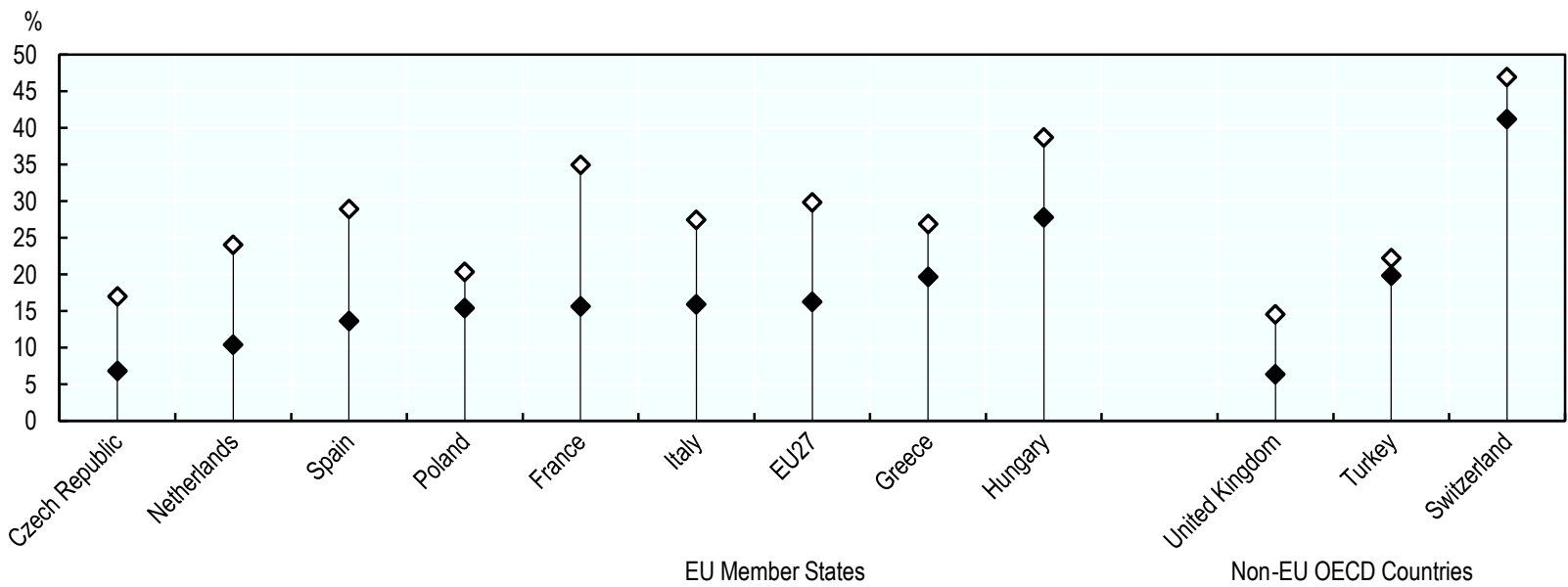

Source: (Eurostat, 2021 $\left.{ }_{[1]}\right)$

StatLink 제 S1 https://doi.org/10.1787/888934280460 


\section{Self-employed youth are most likely to operate in sectors with low levels of capital intensity...}

Youth entrepreneurs tend to have lower levels of resources relative to older people, which often results in a disproportionate share of self-employment activities in sectors that have low barriers to entry. The self-employment rate for youth (20-29 years old) was the highest in the Agriculture sector ( $26 \%$ for youth vs. $50 \%$ overall) and Other service activities (19\% vs. $29 \%$ ), which includes personal services (e.g. hairdressing and beauty services), computer repair and more (Figure 4.7). Both of these sectors are characterised by a high share of workers who are self-employed and do not always require substantial investments in equipment unless the self-employed person is undertaking large-scale activities. Youth were less likely than adults to be self-employed in all sectors except for household activities (e.g. babysitters, gardeners, tutors) where they were slightly more likely to be self-employed ( $9 \%$ vs. $4 \%$ ).

Variations across countries are difficult to report due to the limits of the Labour Force Survey but national research often points to differences in economic structure and education systems. For example, countries with strong vocational systems such as Austria and Germany tend to have a greater concentration of youth self-employment in professional and technical sectors. Other countries with strong agricultural sectors such as France and Italy tend to have higher rates of youth self-employment in agriculture. Moreover, several eastern EU Member States have had a rapid growth in technology sectors due to education investments and low living costs that attract multinational IT companies. In Romania, for example, young entrepreneurs and self-employed people have been moving into technology sectors due to a growing preference for flexible work in technology fields (Davidescu and Ghinararu, 2015[9]) and new types of business forms such as authorised licensed individual professionals ("persoana fizica autorizata") (Ghinararu, Pasnicu and Ciobanu, 2020[10]).

\section{Figure 4.7. Youth are more likely than adults to be self-employed in household activities}

Self-employment as a percentage of employment in the EU, 2020

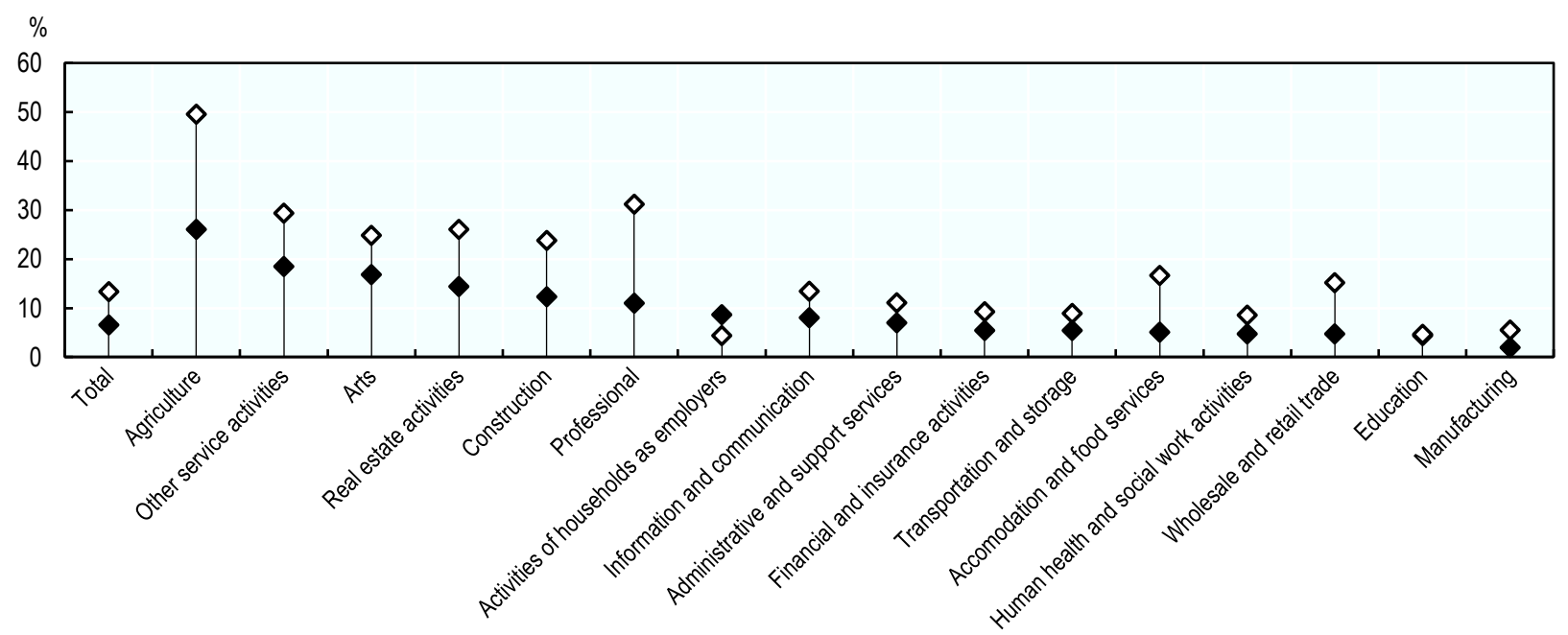

Note: The water supply and sewerage sector and electricity sector not presented in the figure due to the low self-employment rate in these sectors.

Source: (Eurostat, 2021 $\left.{ }_{[1]}\right)$ 


\section{....and were more likely to be working as professionals and sales and service workers}

Self-employed youth were concentrated in occupations that are consistent with the higher likelihood of being self-employed in sectors with low levels of capitalisation. In the EU, selfemployed youth were most heavily concentrated in professional occupations such as IT workers, teaching professionals and business consultants (24\%) and service and sales workers (17\%) in 2020 (Figure 4.8). Both of these shares were similar to the proportions for all self-employed workers $(22 \%$ and $16 \%)$ but slightly different than the distribution of youth working as employees (19\% and $21 \%)$. The greatest gap between self-employed youth and the overall distribution of the self-employed was in the share working as managers. Only $7 \%$ of self-employed youth were managers relative to $11 \%$ overall, which is not surprising because management occupations typically require a substantial amount of work experience.

The distribution of youth varies across EU Member States, reflecting differences in economic structure and education systems. For example, self-employed youth in Germany are more likely to work as Technicians and associate professionals which is consistent with having a strong vocational training system (OECD, 2020[5]).

\section{Figure 4.8. Nearly one-quarter of self-employed youth are working in professional occupations}

Distribution of workers by occupation in the EU, 2020
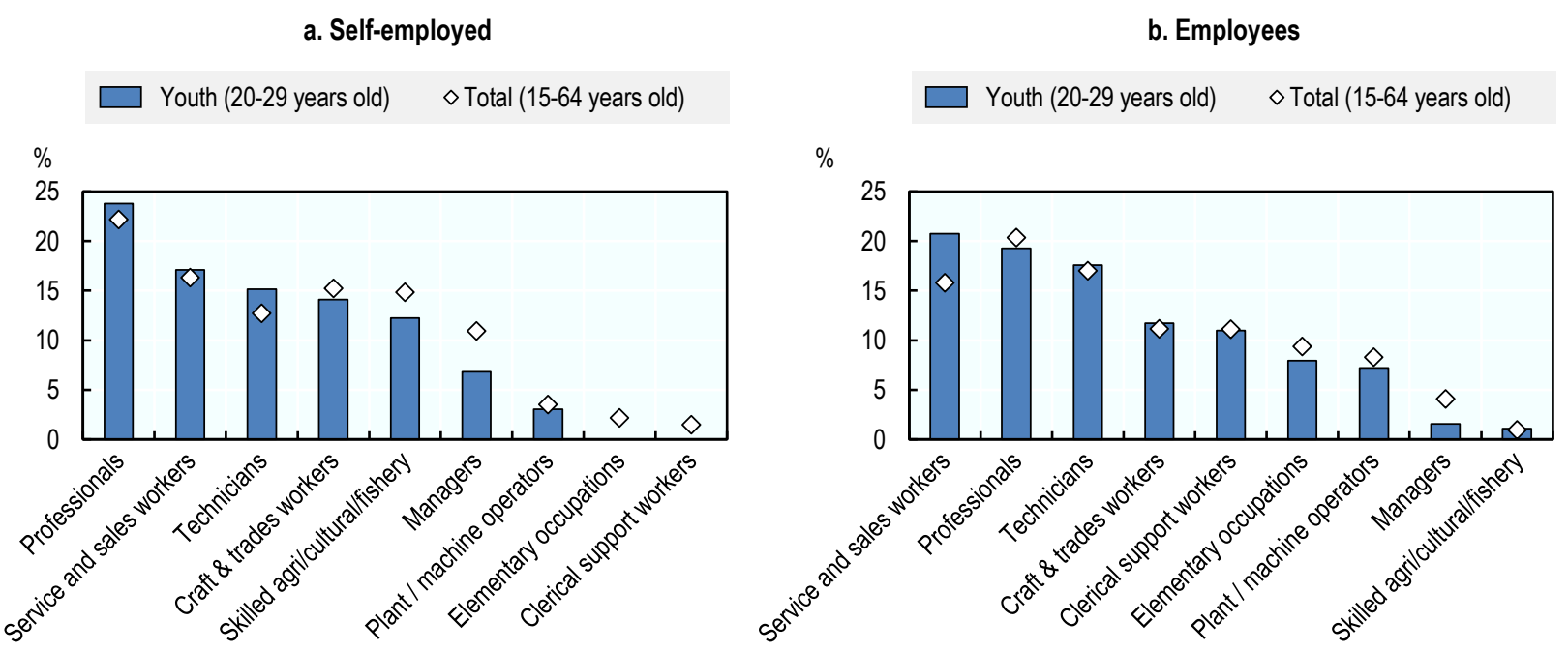

Source: (Eurostat, 2021 [1])

StatLink 제개 https://doi.org/10.1787/888934280498

\section{One-third of self-employed youth have a tertiary education}

Growth in the share of self-employed youth in the EU with a tertiary education has stalled over the past three years, halting a long-term increase. In 2020 , about $35 \%$ of self-employed youth (20-29 years old) had a tertiary education, which is unchanged since 2016 and 2017 when the proportion was $33 \%$ (Figure 4.9). Nonetheless, the share of self-employed youth with a tertiary education has increased significantly over the past decade, due partly to a growth in the number of people completing tertiary education as well as growing investments by higher education systems in supporting entrepreneurship (Box 4.2). This growth in the share of self-employed youth with a tertiary education has been offset by a decline in the share who have less than an upper secondary education. Most self-employed youth have an upper secondary or post-secondary non-tertiary education $(52 \%)$ and this proportion has been 
essentially constant over the past decade. The distribution of self-employed youth by education level is similar to the distribution of youth working as employees.

Figure 4.9. The share of self-employed in the EU with a tertiary education has plateaued in recent years

Distribution of self-employment in the EU by education level

a. Self-employed youth (20-29 years old)

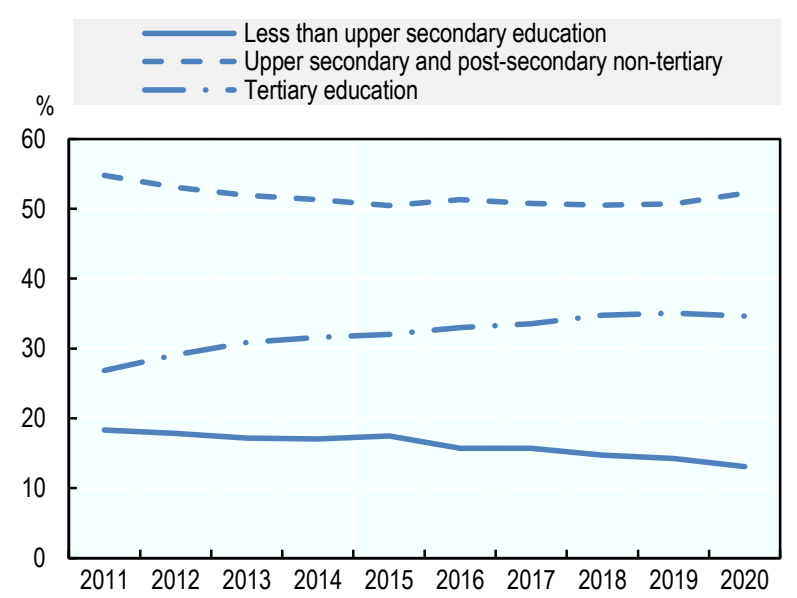

c. Total self-employed (15-64 years old)

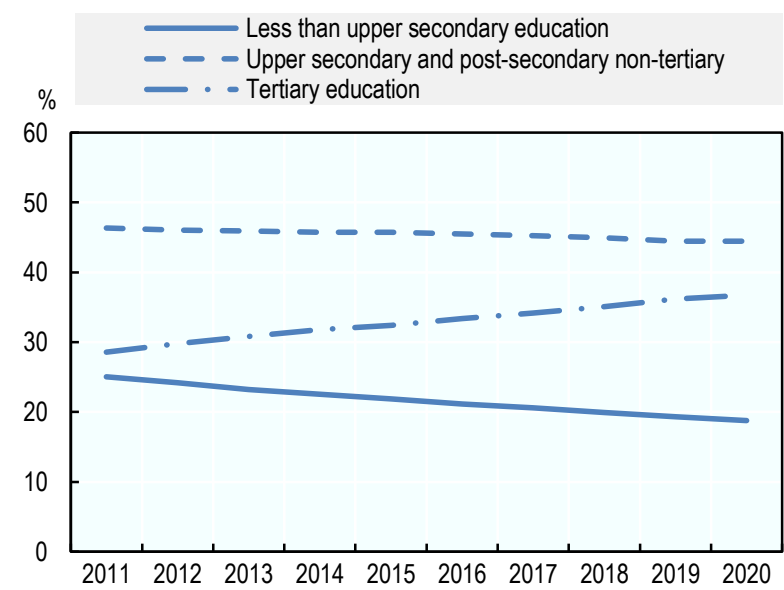

Source: (Eurostat, 2021 [1]) b. Youth employees (20-29 years old)
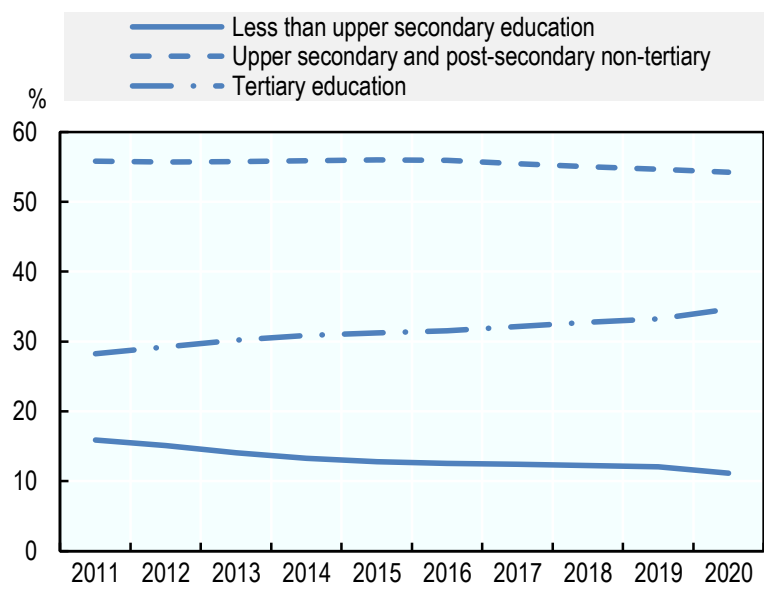

d. Total employees (15-64 years old)

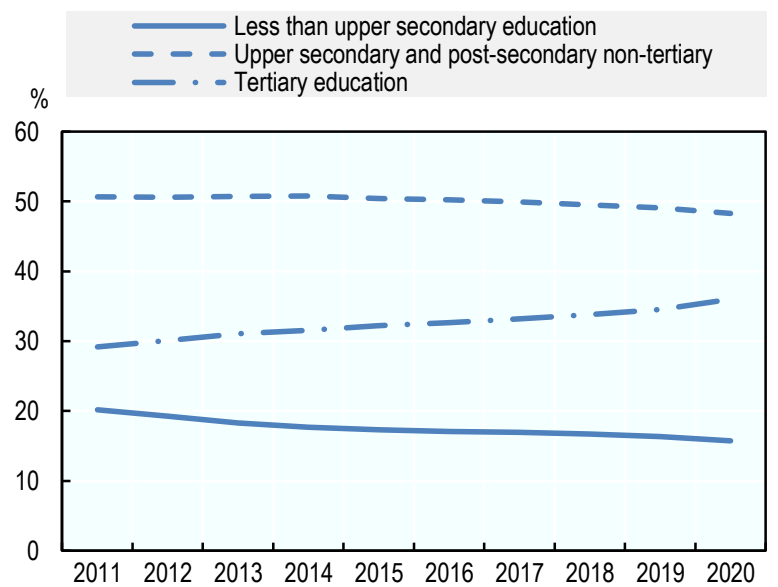

StatLink 제 जम https://doi.org/10.1787/888934280517 


\section{Box 4.2. Supporting the development of entrepreneurship skills through the OECD EECOLE} network

Entrepreneurs are not born, they are made. Over the past decades, a number of education and training programmes have focussed on entrepreneurship to promote spin-offs and start-ups, and to provide individuals with a bundle of skills that can help them vis-à-vis the future of work and society. Within this context, the OECD has developed programmes such as HEInnovate (in co-operation with the European Commission) and the Geography of Higher Education to identify good practices and generate data. Capitalising on these initiatives, the OECD recently launched a new network called EECOLE to strengthen evidence on entrepreneurship education, facilitate the sharing of good practices and offer a platform for policy dialogue on entrepreneurship education and university-business collaboration. The network is built around higher education institutions but also includes national and subnational authorities, private sector businesses, banks, venture capitalists and business angles, non-government actors and foundations.

A core priority for the network is to support youth in a post COVID-19 economy. This includes strengthening connections between HEls and their students, the business community, and policy makers to identify innovative approaches to internships and career guidance services. EECOLE also focuses on mainstreaming entrepreneurship education and supporting start-ups and spin-offs as means to promote jobs and innovation in all regions.

EECOLE will work through task-and-finish groups. TFGs will work on defining entrepreneurship and measuring the effects of entrepreneurship education on individuals, and on the "geography of higher education" to assess the way in which HEls' resources can be mobilised to promote entrepreneurship ecosystems. Another TFG will focus on SDGs and in particular on the role HEls can play helping communities to de-carbonise (evidence-based policy making).

For more information, please see: http://www.oecd.org/cfe/smes/geo-higher-education.htm.

\section{Activities by youth over the entrepreneurship life-cycle}

Entrepreneurship activities can also be estimated through household surveys that ask about activities related to business creation and business management. The Global Entrepreneurship Monitor (GEM) is one of the most well-known international surveys on entrepreneurship. The GEM survey asks people about their involvement in entrepreneurship activities and the characteristics of these activities. It is administered by a network of researchers and research institutes. For more information on GEM, please refer to the Reader's Guide at the beginning of this report.

\section{Youth are more active in early-stage entrepreneurship than adults...}

Youth (18-30 years old) in the EU were slightly more active in nascent entrepreneurship than the overall adult population (18-64 years old) between 2016 and 2020 . Across the EU, nearly $5 \%$ of youth were actively involved in setting up a business they will own or co-own relative to less than $4 \%$ of the overall population (Figure 4.10). Both proportions were higher in OECD countries during this period $-8 \%$ of youth and $7 \%$ of adults, due to high levels of business creation in non-EU G7 countries such as the United States and Canada as well as high levels of informal entrepreneurship in some OECD countries such as Chile, Colombia and Mexico. To be considered a nascent entrepreneur, the business start-up must not have paid salaries, wages or any other payments to the owners for more than three months. 
Nascent entrepreneurship rates for youth varied across EU Member States by a factor of ten over the 2016-20 period. The share of youth involved in setting up a business ranged from about $2 \%$ in Italy and Spain to $19 \%$ in Estonia. These differences are explained by a range of factors including social attitudes towards entrepreneurship and risk, strength of entrepreneurship policies, market dynamics, relative size of the public sector, economic structure and more.

However, there was no gap between youth and adults when it came to new business ownership in the EU over the 2016-20 period. Just under $3 \%$ of youth in the EU were new business owners during this period, which was essentially the same proportion as the overall population (Figure 4.10). Consistent with the nascent entrepreneurship rate, the new business ownership rate was slightly higher in OECD countries (5\%) than in EU Member States (4\%).

The new business ownership rate varied less across EU Member States than the nascent entrepreneurship rate during this period. The share of new business owners among youth ranged from about $2 \%$ in France and Italy to $9 \%$ in the Netherlands. One of the main drivers of the new business ownership rate is the nascent entrepreneurship rate. The correlation rate between the nascent entrepreneurship rate and the new business ownership rate is 0.7 in EU Member States, indicating a strong positive correlation, i.e. those countries with a high nascent entrepreneurship rate are typically those with high new business ownership rates. There are several country-specific factors that influence the likelihood of a nascent entrepreneur succeeding in moving into becoming a new business owner, including sufficient access to finance to sustain the activity during the early stages of development, adequate entrepreneurship skills to identify opportunities, the level of competition and more. The high rates of new business ownership among youth in the Netherlands is largely on account of the increased number of young self-employed workers - notably those under 25 years of age. This may be partly due to the government's focus on driving economic growth through knowledge-based sectors and their efforts to foster entrepreneurial skills within the Dutch education system and training programmes.

There is a substantial drop-off between the nascent entrepreneurship and new business stages in several EU Member States, notably Estonia, Hungary and the Slovak Republic. This drop-off (pre COVID-19) was often explained by perceptions related to the economic conditions. For example, less than one-third of early-stage entrepreneurs in the Slovak Republic indicated that they saw new opportunities for their business to pursue which suggests that many businesses do not go beyond the nascent stage (Bosma et al., 2021[11]). However, other factors also have an influence. Framework conditions and market receptivity may also explain gaps in nascent entrepreneurship and new business ownership. 
Figure 4.10. Youth in the EU are slightly more likely than adults to be involved in early-stage entrepreneurship

Percent of the population, 2016-20

a. Nascent entrepreneurship rate

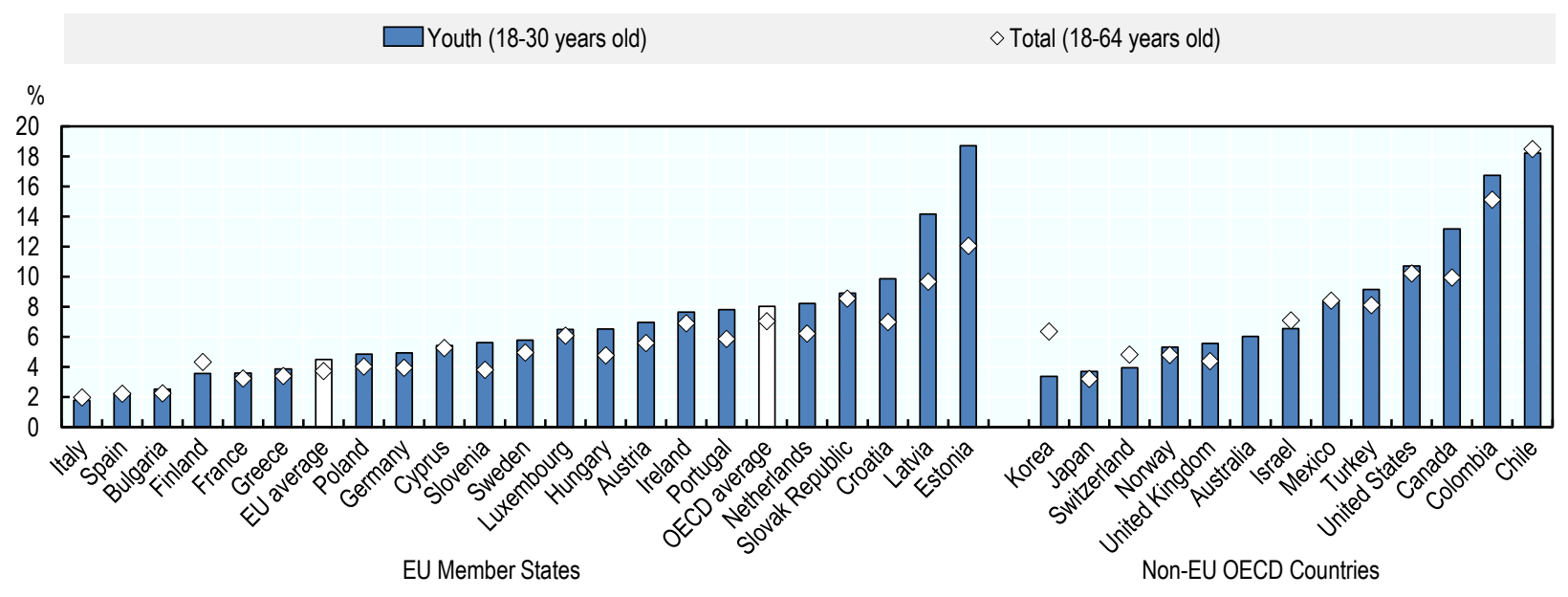

b. New business ownership rate

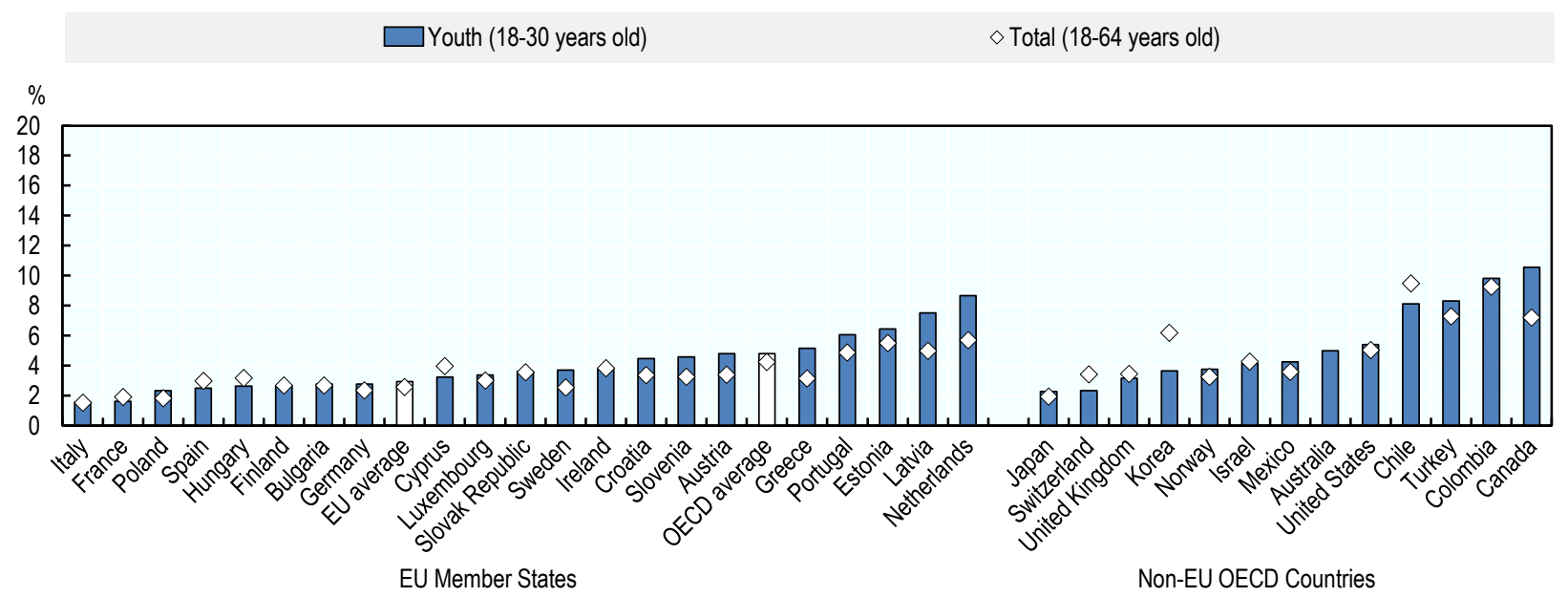

Note: All EU Member States participated in the GEM survey between 2016 and 2020 except for Belgium, Czech Republic, Denmark, Lithuania, Malta and Romania. However, the following countries did not participate in the survey in every year (years of participation indicated): Austria (2016, 2018, 2020), Bulgaria (2016-18), Estonia (2016-17), Finland (2016), France (2016-18), Hungary (2016), Ireland (2016-19), Latvia (2016$17,2019-20)$ and Portugal $(2016,2019)$. Similarly, the following OECD countries did not participation in the GEM survey between 2016 and 2020: Belgium, Czech Republic, Denmark, Iceland, Lithuania and New Zealand. The following countries did not participate in the survey in every year (years of participation indicated): Australia (2016-17, 2019), Austria (2016, 2018, 2020), Estonia (2016-17), Finland (2016), France (201618), Hungary (2016), Ireland (2016-19), Japan (2017-19), Latvia (2016-17, 2018-19), Mexico (2016-17, 2019), Norway (2019-20), Portugal (2016, 2019) and Turkey $(2016,2018)$.

Source: (Global Entrepreneurship Monitor (GEM), 2021[12])

StatLink त्गाज् https://doi.org/10.1787/888934280536 


\section{...but they are less likely to be motivated by "push" factors}

The motivation for becoming an entrepreneur is often considered according to "push" and "pull" factors. This includes, for example positive motivations such as generating income or having the freedom to make decisions about how one spends their time (i.e. pull factors) and negative motivations such as difficulty finding a job (i.e. push factors). While such a framework can help to understand factors that influence individual decision making and the impact that these business activities may have. Two caveats are needed. First, motivations can change over time. For example, someone may start a business because they could not find a job, but the business could be highly successful, potentially increasing the motivation of the entrepreneur to invest in its sustainability and growth. Conversely, pursuing a promising market opportunity does not ensure success and continued motivation from the entrepreneur. Second, the pushpull framework is overly simplistic in that there are only two possible motivations. This does not sufficiently capture the range of potential motivations that a person may have, including making a positive contribution to their community, creating a flexible lifestyle business that allows for the pursuit of other non-career objectives (e.g. travel, family care), and more.

Youth entrepreneurs (18-30 years old) in the EU were slightly less likely to start their business out of "necessity" relative to the overall population (18-64 years old) in the period 2016-20. About $16 \%$ of early-stage youth entrepreneurs in the EU reported that they started their business because they had difficulty finding a job (Figure 4.11), which was slightly below the share of early-stage entrepreneurs overall $(18 \%)$. The proportion of youth in the EU who started their business out of "necessity" were similar to the share of youth in OECD countries (15\%).

The rate of necessity entrepreneurship among youth varied across EU Member States, reflecting several factors such as labour market conditions, cultural attitudes towards entrepreneurship and levels of informal work. Among EU Member States, youth were most likely to be involved in necessity entrepreneurship in the Slovak Republic and Latvia (27\% of early-stage youth entrepreneurs) and least likely in the Netherlands (9\%), Estonia, Poland and Sweden (10\% each) (Figure 4.11). Country-level research helps to explain some of these differences across countries. In Sweden, for example, youth entrepreneurs are the most likely to indicate that they started their business out of "necessity" but this is among the lowest necessity rates for youth among EU Member States. This low level of necessity entrepreneurship is explained by the high proportion of new entrepreneurs who indicate becoming entrepreneurs due to "personal development and realisation of ideas" and "independence" (Tillvaxtverket, 2021 [13]). Moreover, Sweden's strong social security system also contributes to a low level of necessity entrepreneurship. Similarly, the social security system in Finland clearly distinguishes between selfemployment and waged employment with access to the latter being clearer and more straight-forward (Saikkonen, 2019 [14] $)$. Finnish youth are less likely to have established an employment history which limits access to the strong welfare support available to those who have. These conditions make it more likely that youth will be pushed into employment out of necessity. 
Figure 4.11. Youth are less likely to be motivated by necessity across nearly all EU Member States

Proportion of early-stage entrepreneurs, 2016-20

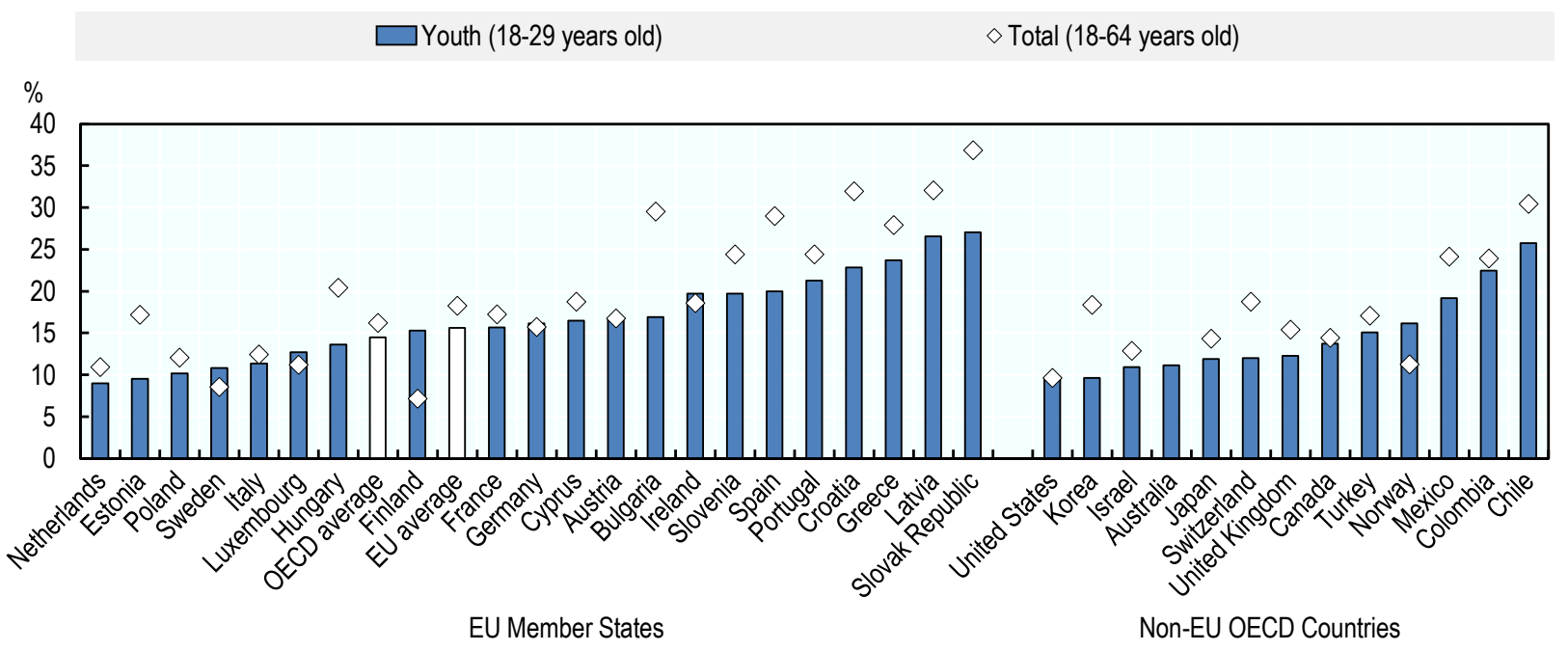

Note: All EU Member States participated in the GEM survey between 2016 and 2020 except for Belgium, Czech Republic, Denmark, Lithuania, Malta and Romania. However, the following countries did not participate in the survey in every year (years of participation indicated): Austria (2016, 2018, 2020), Bulgaria (2016-18), Estonia (2016-17), Finland (2016), France (2016-18), Hungary (2016), Ireland (2016-19), Latvia (2016$17,2019-20)$ and Portugal $(2016,2019)$. Similarly, the following OECD countries did not participation in the GEM survey between 2016 and 2020: Belgium, Czech Republic, Denmark, Iceland, Lithuania and New Zealand. The following countries did not participate in the survey in every year (years of participation indicated): Australia (2016-17, 2019), Austria (2016, 2018, 2020), Estonia (2016-17), Finland (2016), France (201618), Hungary (2016), Ireland (2016-19), Japan (2017-19), Latvia (2016-17, 2018-19), Mexico (2016-17, 2019), Norway (2019-20), Portugal (2016, 2019) and Turkey $(2016,2018)$.

Source: (Global Entrepreneurship Monitor (GEM), 2021[12])

StatLink 제 sh https://doi.org/10.1787/888934280555

\section{Youth entrepreneurs are more likely to start a business in teams than adults}

Youth (18-30 years old) were much more likely than adults (18-64 years old) to be involved in nascent entrepreneurship in teams of three or more between 2016 and 2020. Within the EU, nearly one-quarter of nascent entrepreneurs (23\%) were working on their start-up in a team of three or more relative to one-fifth of all nascent entrepreneurs (Figure 4.12). The proportions of youth and adults starting businesses in teams in the EU were about the same in OECD countries.

The share of team-driven nascent entrepreneurship among youth varied ten-fold across EU Member States between 2016 and 2020. The proportion of nascent entrepreneurship by youth that was team-driven ranged from about $4 \%$ in Poland to $42 \%$ in Finland, which was significantly higher than the proportion for adults (24\%). Only three EU Member States had a share of team-driven nascent entrepreneurship by youth during this period that was lower than the share for adults - Poland ( $4 \%$ vs. $6 \%)$, the Netherlands ( $12 \%$ vs. $16 \%)$ and Cyprus (21\% vs. $25 \%)$. 


\section{Figure 4.12. One-fifth of youth nascent entrepreneurs start their business in teams}

Proportion of nascent entrepreneurs starting their business in teams of three or more, 2016-20

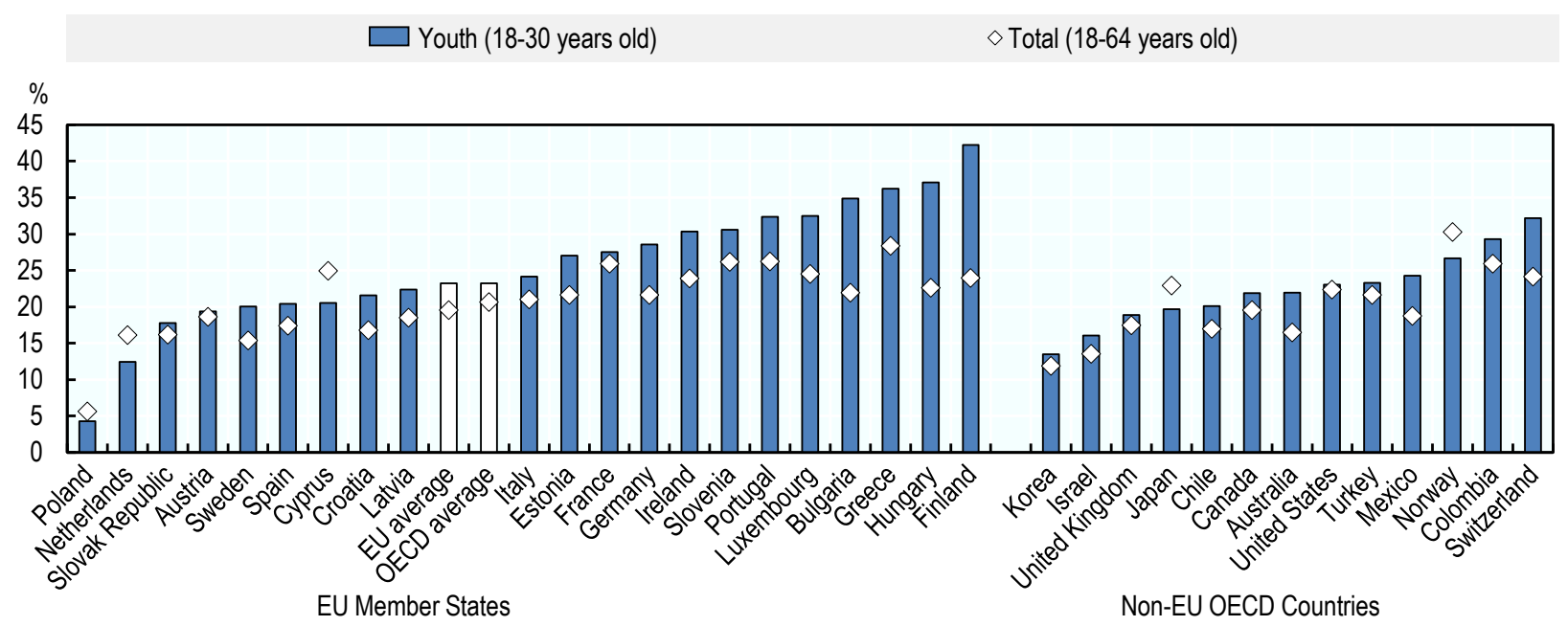

Note: All EU Member States participated in the GEM survey between 2016 and 2020 except for Belgium, Czech Republic, Denmark, Lithuania, Malta and Romania. However, the following countries did not participate in the survey in every year (years of participation indicated): Austria (2016, 2018, 2020), Bulgaria (2016-18), Estonia (2016-17), Finland (2016), France (2016-18), Hungary (2016), Ireland (2016-19), Latvia (2016$17,2019-20)$ and Portugal $(2016,2019)$. Similarly, the following OECD countries did not participation in the GEM survey between 2016 and 2020: Belgium, Czech Republic, Denmark, Iceland, Lithuania and New Zealand. The following countries did not participate in the survey in every year (years of participation indicated): Australia (2016-17, 2019), Austria (2016, 2018, 2020), Estonia (2016-17), Finland (2016), France (201618), Hungary (2016), Ireland (2016-19), Japan (2017-19), Latvia (2016-17, 2018-19), Mexico (2016-17, 2019), Norway (2019-20), Portugal (2016, 2019) and Turkey $(2016,2018)$.

Source: (Global Entrepreneurship Monitor (GEM), 2021[12])

StatLink त्ञाs https://doi.org/10.1787/888934280574

\section{Youth are less likely than adults to operate established businesses}

About $2 \%$ of youth (18-30 years old) in the EU operated an established business between 2016 and 2020 relative to nearly $4 \%$ of adults (18-64 years old). This measures the share of youth who are the owner-manager of an established business that has paid salaries, wages or any other payments to the owners for more than 42 months. The proportion of youth who were established business owners was about the same in EU Member States as in OECD countries. In both EU Member States and OECD countries, this proportion is lower than the new business ownership rate for youth (3\%), reflecting that many businesses exit the market before they reach 42 months old.

As with the new business ownership rate, there was a large variation in the established business rate for youth across EU Member States. The shares of youth who were established business owners over the period 2016-20 range from about 1\% in France and Spain to about $5 \%$ in Latvia and $9 \%$ in Greece (Figure 4.13). These rates are driven largely by the shares of youth who are active in early-stage entrepreneurs, as well as the market conditions that influence business survival rates such as access to finance, competition and access to markets. 
Figure 4.13. Only $2 \%$ of youth in the EU own an established business

Proportion of the population, 2016-20

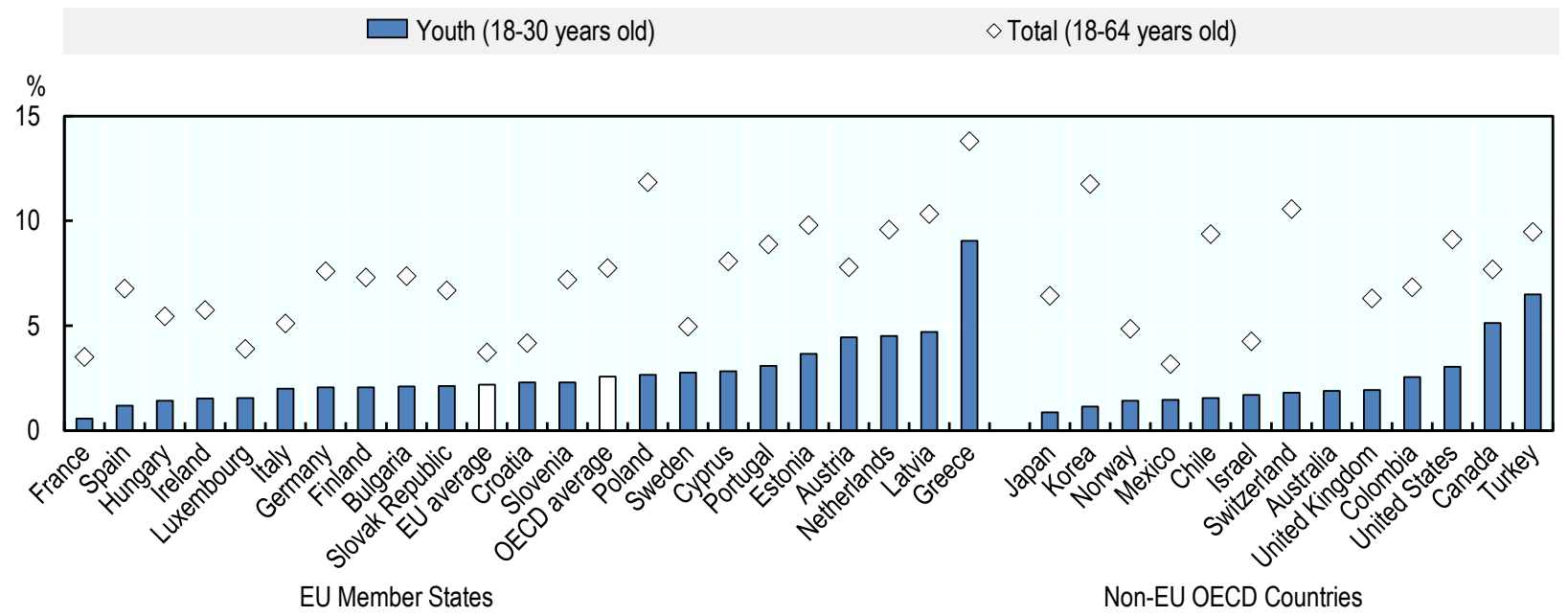

Note: All EU Member States participated in the GEM survey between 2016 and 2020 except for Belgium, Czech Republic, Denmark, Lithuania, Malta and Romania. However, the following countries did not participate in the survey in every year (years of participation indicated): Austria (2016, 2018, 2020), Bulgaria (2016-18), Estonia (2016-17), Finland (2016), France (2016-18), Hungary (2016), Ireland (2016-19), Latvia (201617, 2019-20) and Portugal (2016, 2019). Similarly, the following OECD countries did not participation in the GEM survey between 2016 and 2020: Belgium, Czech Republic, Denmark, Iceland, Lithuania and New Zealand. The following countries did not participate in the survey in every year (years of participation indicated): Australia (2016-17, 2019), Austria (2016, 2018, 2020), Estonia (2016-17), Finland (2016), France (201618), Hungary (2016), Ireland (2016-19), Japan (2017-19), Latvia (2016-17, 2018-19), Mexico (2016-17, 2019), Norway (2019-20), Portugal (2016, 2019) and Turkey $(2016,2018)$.

Source: (Global Entrepreneurship Monitor (GEM), 2021[12])

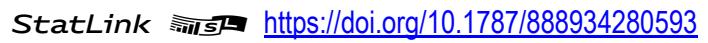

\section{The most common reason that youth stop operating their business is a lack of profits}

Youth entrepreneurs in the EU most frequently cite a lack of business profitability as the main reason for stopping their business activity. During the period 2016-20, more than one-fifth of youth entrepreneurs (18-30 years old) cited this as the reason for business exit, which was nearly three times more than adults (16-64 years old) $(21 \%$ vs. $8 \%$ ) (Figure 4.14$)$. This was similar to the share of youth entrepreneurs in OECD countries who reported exiting due to a lack of profitability. However, the overall share of entrepreneurs in the EU who cited a lack of profitability as the reason for exit was well below the share who cited this in OECD countries. This difference appears to be offset by the proportion who cited "an incident", which suggests that those in the EU are more likely to point to a specific decision or time period as the reason for exiting the business.

Youth entrepreneurs in the EU were also more likely than the overall population of entrepreneurs to cite a positive factor for exiting the business. For example, youth entrepreneurs were more likely to report that they had pursued another job or entrepreneurship opportunity (13\% for youth vs. $6 \%$ for all entrepreneurs) and that they had an opportunity to sell the business ( $9 \%$ vs. $4 \%)$. In addition, youth entrepreneurs who exited were more likely than the overall population to report that they have difficulties securing finance ( $11 \%$ vs. $4 \%$ ). Unsurprisingly, they were also much less likely to cite retirement as the reason for the business exit. 


\section{Figure 4.14. Youth entrepreneurs are most likely to exit due to a lack of profitability}

Proportion of entrepreneurs who exited their business in the past 12 months, 2016-20

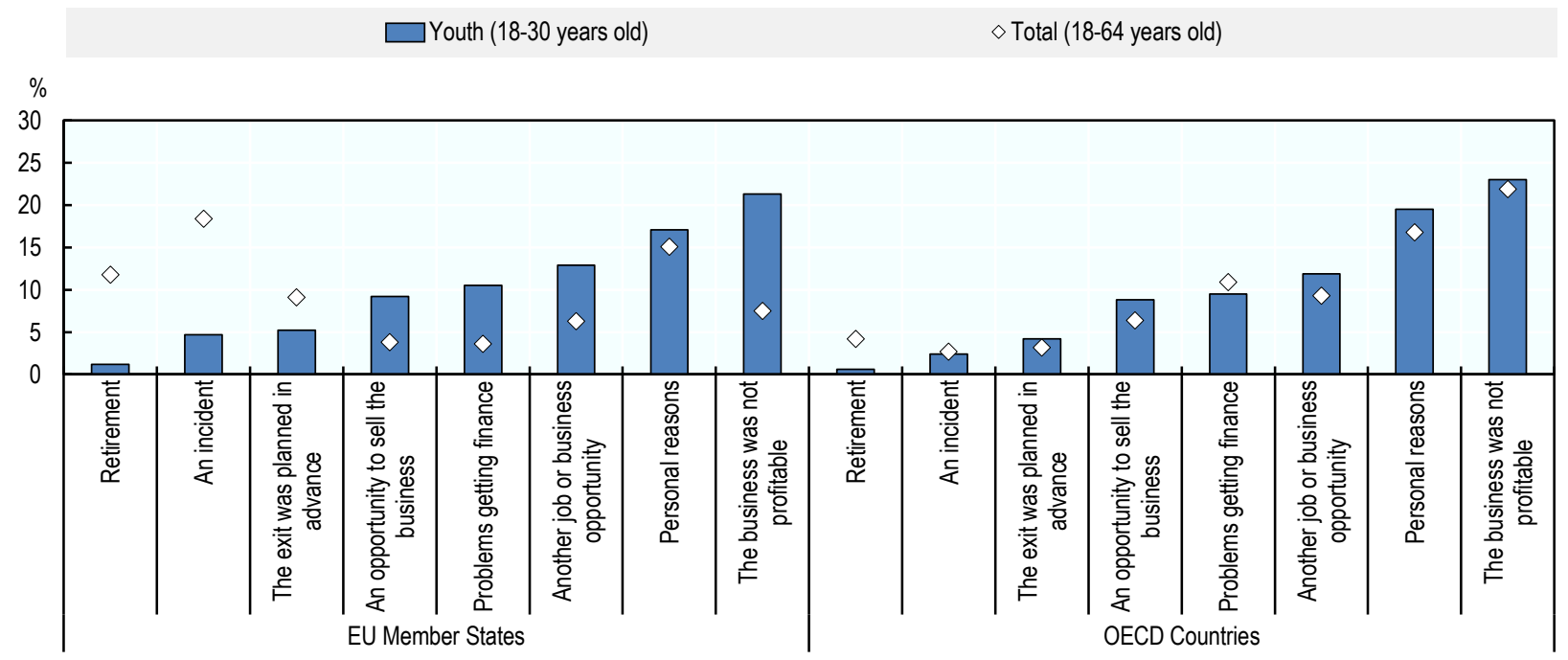

Note: All EU Member States participated in the GEM survey between 2016 and 2020 except for Belgium, Czech Republic, Denmark, Lithuania, Malta and Romania. However, the following countries did not participate in the survey in every year (years of participation indicated): Austria (2016, 2018, 2020), Bulgaria (2016-18), Estonia (2016-17), Finland (2016), France (2016-18), Hungary (2016), Ireland (2016-19), Latvia (2016$17,2019-20)$ and Portugal $(2016,2019)$. Similarly, the following OECD countries did not participation in the GEM survey between 2016 and 2020: Belgium, Czech Republic, Denmark, Iceland, Lithuania and New Zealand. The following countries did not participate in the survey in every year (years of participation indicated): Australia (2016-17, 2019), Austria (2016, 2018, 2020), Estonia (2016-17), Finland (2016), France (201618), Hungary (2016), Ireland (2016-19), Japan (2017-19), Latvia (2016-17, 2018-19), Mexico (2016-17, 2019), Norway (2019-20), Portugal (2016, 2019) and Turkey $(2016,2018)$.

Source: (Global Entrepreneurship Monitor (GEM), 2021 [12])

StatLink त्ता Th https://doi.org/10.1787/888934280612

\section{Barriers to business creation by youth}

\section{Youth are less likely to report "fear of failure" as a barrier to business creation...}

About four-in-ten youth (18-30 years old) in the EU reported during the period 2016-20 that a "fear of failure" was a barrier to business creation. Overall, fear of failure is one of the most frequently cited barriers to successful business creation, but in the EU, youth were slightly less likely than the overall average to cite this barrier (39\% vs. 44\%) (Figure 4.15). In OECD countries, the proportion of youth who cited fear of failure during this period was about the same as the share in the EU.

Despite the relatively lower share of youth citing "fear of failure" as a barrier to business creation, there were five EU Member States where at least half of youth reported this barrier. The highest shares of youth reporting this barrier over this period were in Cyprus $(50 \%)$, Portugal $(51 \%)$, Luxembourg $(52 \%)$, Spain $(53 \%)$ and Greece $(61 \%)$. However, many of these countries have very high rates earlystage entrepreneurship. For example, Greece was among the top five EU Member States for new business ownership rates for youth despite having the highest share of youth who identified fear of failure as a barrier to business creation. Some researchers explain this paradox by suggesting the "fear of failure" barrier is more about prevailing social attitudes towards risk and failure rather than their individual views of being more or less afraid of a business failure (Tubadji et al., 2021 [15]). 
Figure 4.15. About 4 in 10 youth report that "fear of failure" is a barrier to business creation

"Does a fear of failure prevent you from starting a business?"

Percentage of population who responded "yes", 2016-20

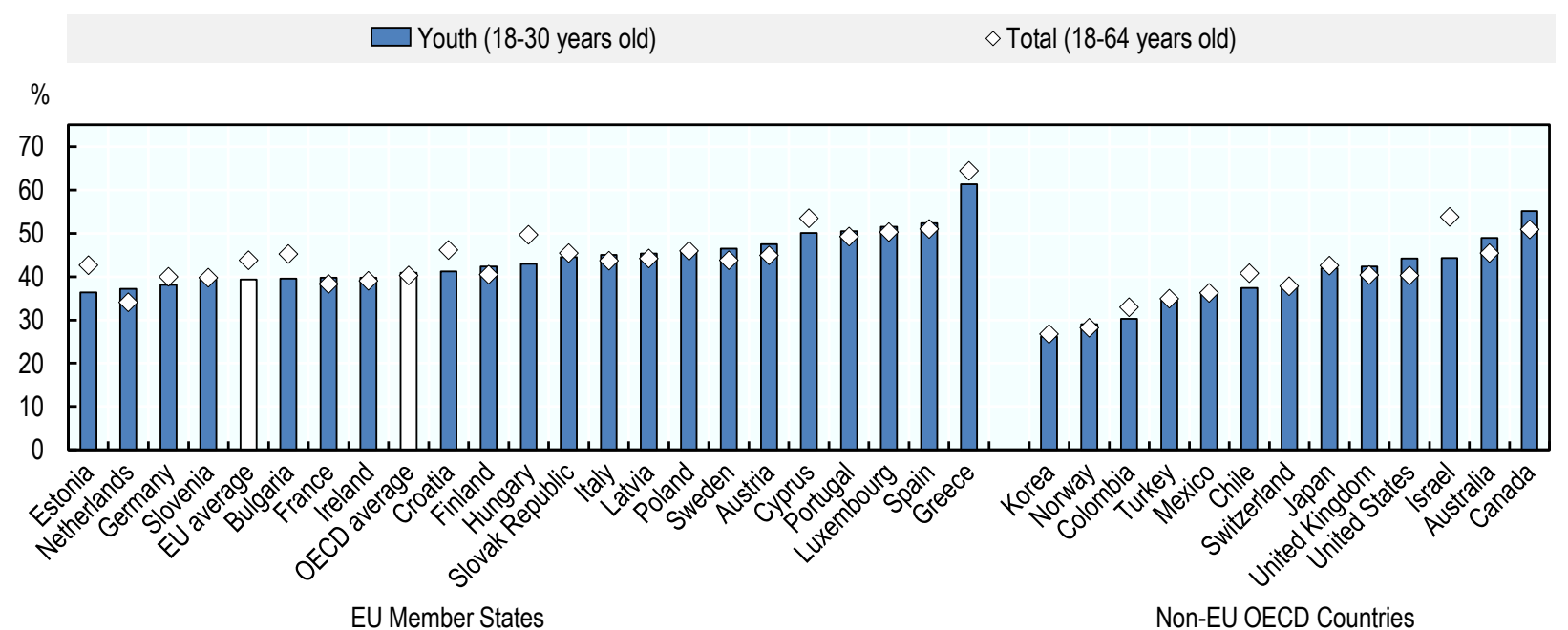

Note: All EU Member States participated in the GEM survey between 2016 and 2020 except for Belgium, Czech Republic, Denmark, Lithuania, Malta and Romania. However, the following countries did not participate in the survey in every year (years of participation indicated): Austria (2016, 2018, 2020), Bulgaria (2016-18), Estonia (2016-17), Finland (2016), France (2016-18), Hungary (2016), Ireland (2016-19), Latvia (201617, 2019-20) and Portugal $(2016,2019)$. Similarly, the following OECD countries did not participation in the GEM survey between 2016 and 2020: Belgium, Czech Republic, Denmark, Iceland, Lithuania and New Zealand. The following countries did not participate in the survey in every year (years of participation indicated): Australia (2016-17, 2019), Austria (2016, 2018, 2020), Estonia (2016-17), Finland (2016), France (201618), Hungary (2016), Ireland (2016-19), Japan (2017-19), Latvia (2016-17, 2018-19), Mexico (2016-17, 2019), Norway (2019-20), Portugal (2016, 2019) and Turkey $(2016,2018)$.

Source: (Global Entrepreneurship Monitor (GEM), 2021 [12])

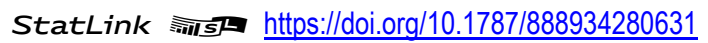

\section{....and are also more confident in their levels of entrepreneurship skills}

A lack of entrepreneurship skills is another frequently cited barrier to business creation, but youth are, on average, more confident in their entrepreneurship skills than adults. In the period 2016-20, $38 \%$ of youth (18-30 years old) in the EU reported that they had the skills and knowledge to start a business, which was below the overall proportion (44\%) (Figure 4.16). These shares were slightly below those reported in OECD countries over this period $-44 \%$ for youth and $49 \%$ overall - suggesting that the EU may lag slightly behind in developing entrepreneurship in the population. However, caution is needed with such a conclusion because this indicator measures the self-perception of entrepreneurship skills, which also picks up other factors such as self-confidence and cultural attitudes towards entrepreneurship.

More than half of youth reported having entrepreneurship skills needed to start a business in several EU Member States. Over the period 2016-20, the EU Member States with the greatest share of youth who reported having sufficient entrepreneurship skills to start a business were Croatia (57\%), Latvia $(53 \%)$ and Slovenia (52\%). The shares were the lowest in Hungary (29\%) and Finland (30\%). These results are generally consistent with the shares of university students reporting that they have taken entrepreneurship courses (Figure 4.17). Differences across countries can be explained by many factors, including as already noted self-confidence and social attitudes towards entrepreneurship. For example, many of the EU Member States that are below the EU average have low levels of early-stage entrepreneurship and self-employment, reflecting an overall preference for employment. In addition, 
different levels of investment in entrepreneurship education can also influence the share of youth who selfreport having entrepreneurship skills with stronger effects often observed among older students (Box 4.3).

\section{Figure 4.16. Youth are less likely than adults to self-report having entrepreneurship skills}

"Do you have the knowledge and skills to start a business?"

Percentage of population who responded "yes", 2016-20

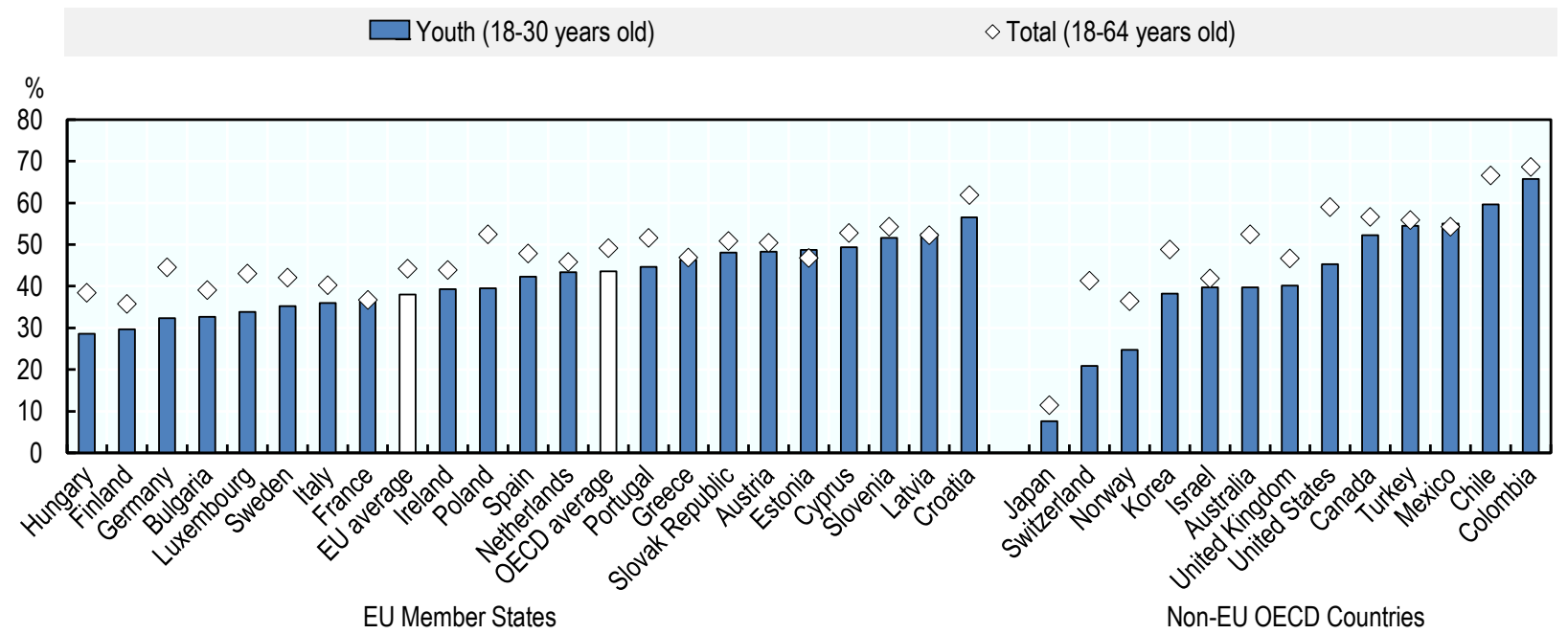

Note: All EU Member States participated in the GEM survey between 2016 and 2020 except for Belgium, Czech Republic, Denmark, Lithuania, Malta and Romania. However, the following countries did not participate in the survey in every year (years of participation indicated): Austria (2016, 2018, 2020), Bulgaria (2016-18), Estonia (2016-17), Finland (2016), France (2016-18), Hungary (2016), Ireland (2016-19), Latvia (201617, 2019-20) and Portugal $(2016,2019)$. Similarly, the following OECD countries did not participation in the GEM survey between 2016 and 2020: Belgium, Czech Republic, Denmark, Iceland, Lithuania and New Zealand. The following countries did not participate in the survey in every year (years of participation indicated): Australia (2016-17, 2019), Austria (2016, 2018, 2020), Estonia (2016-17), Finland (2016), France (201618), Hungary (2016), Ireland (2016-19), Japan (2017-19), Latvia (2016-17, 2018-19), Mexico (2016-17, 2019), Norway (2019-20), Portugal (2016, 2019) and Turkey $(2016,2018)$.

Source: (Global Entrepreneurship Monitor (GEM), 2021[12])

StatLink 제 Sh https://doi.org/10.1787/888934280650 
Figure 4.17. More than half the students surveyed in EU and OECD countries had received entrepreneurship education during their studies

Percentage of students who have attended any entrepreneurship-related course, 2018

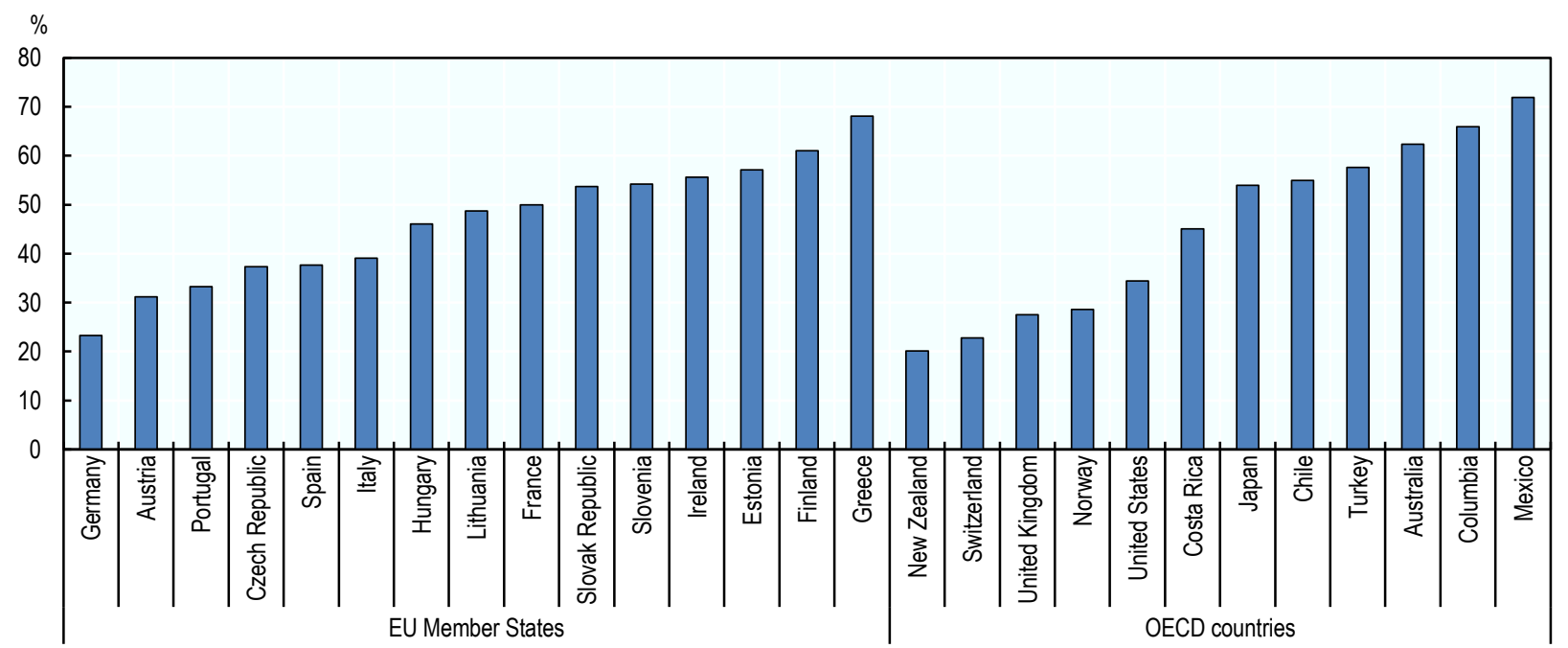

Note: Data reported for the United Kingdom refer to England.

Source: (Sieger et al., 2018[2])

StatLink त्ञाs https://doi.org/10.1787/888934280669 


\section{Box 4.3. Country spotlight - effectiveness of entrepreneurship education for youth, Korea}

A new study evaluates youth entrepreneurship education (EE) programmes through two large-scale quasi-experimental studies at the middle and high school level. Two EE programmes - "Entship School" and "Hero School" - were implemented across the provinces of Seoul, Gyeonggi, Gwangju, Busan and Jeju, reaching 1924 students. The Hero School offered the same programme for both middle school and high school students, which comprised of ten 2-hour classes. The Entship School had two different programmes, providing middle school students with a one-day workshop lasting 3-hours and high school students with six 2-hour sessions.

Six key indicators for EE outcomes were selected to assess the EE programmes' effectiveness. The analysis compared pre-test and post-test scores of the control and experimental groups on the six variables: opportunity discovery, opportunity exploitation, entrepreneurial orientation, creativity capacity, social problem solving and entrepreneurial intention.

An ANCOVA analysis found that the two programmes had varying effects across age cohorts. The results of the Entship programme show that among high school students, the post-test scores of the experimental group were higher than the control group for all variables (Table 4.2.). This was also seen in the Hero programme with the exception of entrepreneurial orientation outcome where the two groups scored the same. However, the programmes' impact among middle school students differed greatly. The Hero programme was more successful as the experimental group had higher post-test scores in all variables while middle school students in the Entship programme had scores that were almost equal to or even lower than those in the control groups, suggesting the impact of EE programmes depend on the age of the youth. Moreover, the ANCOVA results show that the Entship programme had statistically significant relationships for all variables while the Hero programme had significant relationships for five of the six variables for high school students. Regarding middle school students, the analysis revealed no significant differences in the post-test scores for all variables for the Entship programme but did find significant relationships for all variables in the Hero programme. Overall, this study is helpful in understanding entrepreneurship education and adapting EE programmes to fit the needs and goals of certain age groups.

\section{Table 4.2. Entrepreneurship education in Korea appears to be more effective among older students}

\begin{tabular}{|c|c|c|c|c|}
\hline \multirow[b]{2}{*}{ Outcome } & \multicolumn{2}{|c|}{ Middle School Programme Results } & \multicolumn{2}{|c|}{ High School Programme Results } \\
\hline & Entship & Hero School & Entship & Hero School \\
\hline Opportunity Discovery & 0.14 & $21.2^{\star \star \star}$ & $89.3^{\star \star \star}$ & $46.3^{\star \star *}$ \\
\hline Opportunity Exploitation & 1.51 & $15.8^{* * *}$ & $55.0^{* * *}$ & $39.2^{* * *}$ \\
\hline Entrepreneurial Orientation & 1.09 & $60.7^{* * *}$ & $44.6^{* * *}$ & - \\
\hline Creativity Capacity & - & $17.3^{\star \star \star}$ & $54.5^{\star \star *}$ & $55.2^{* * *}$ \\
\hline Social Problem Solving & - & $20.9^{* * *}$ & $30.1^{* * *}$ & $20.5^{* * *}$ \\
\hline${ }^{*}$ Entrepreneurial Intention & 0.02 & $12.4^{\star * *}$ & $23.6^{* \star *}$ & $12.9^{* * *}$ \\
\hline
\end{tabular}

Note: ${ }^{* * *} p<0.001$

Source: (Kim et al., 2020[16]) 


\section{Characteristics of youth entrepreneurship}

\section{Youth entrepreneurs are slightly more likely to introduce new products and services}

The introduction of new products and services is one potential way a business can achieve growth and youth entrepreneurs in the EU are slightly more likely than the overall average to introduce new products and services. About $35 \%$ of early-stage youth entrepreneurs (18-30 years old) in the EU self-reported that they introduced a new product or service for their customers between 2016 and 2002, which was slightly above the overall proportion for early-stage entrepreneurs (31\%) (Figure 4.18). This proportion for youth entrepreneurs was the same as in OECD countries over this period (35\%), but the rate for youth was the same as it was for all entrepreneurs (34\%). Across EU Member States, the shares of early-stage youth entrepreneurs reporting the introduction of new products and services ranged from about $20 \%$ in Bulgaria to more than $60 \%$ in Luxembourg.

\section{Figure 4.18. About one-third of youth entrepreneurs introduced new products and services}

Proportion of early-stage entrepreneurs, 2016-20

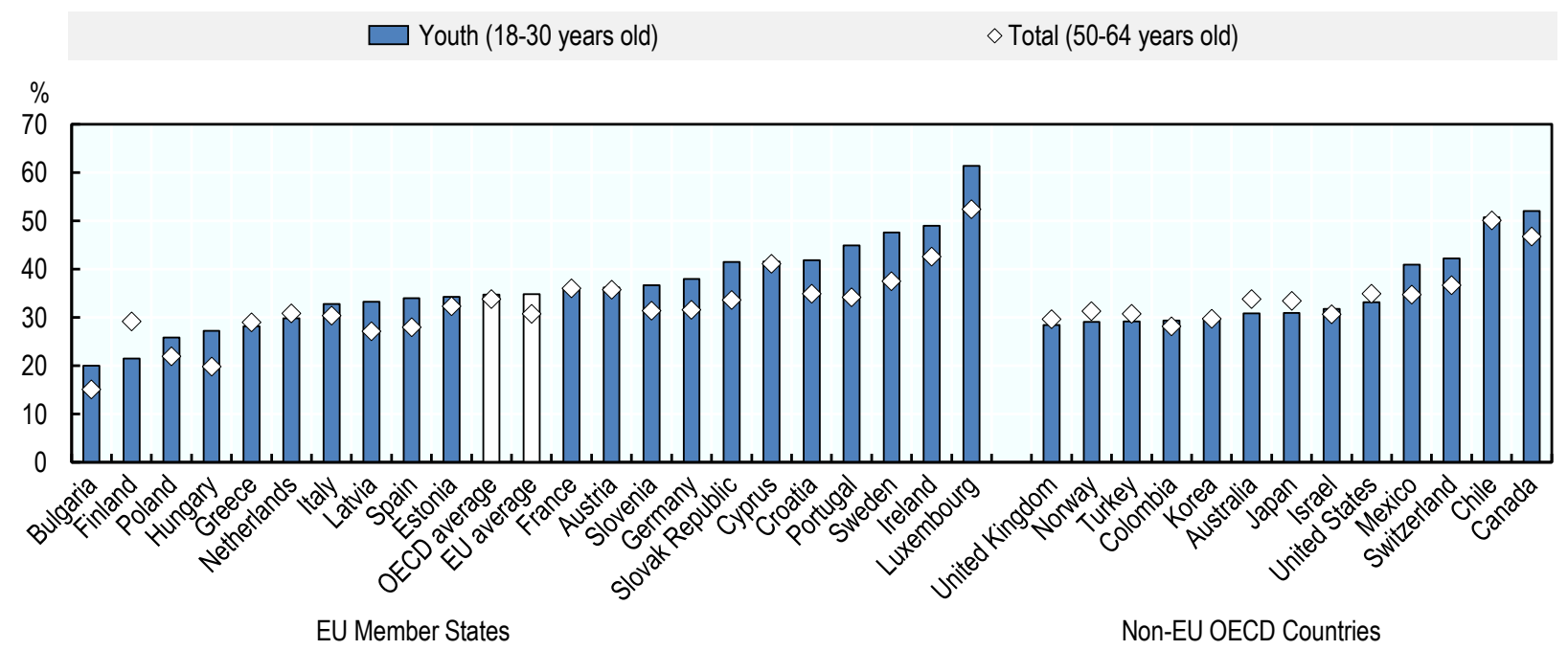

Note: All EU Member States participated in the GEM survey between 2016 and 2020 except for Belgium, Czech Republic, Denmark, Lithuania, Malta and Romania. However, the following countries did not participate in the survey in every year (years of participation indicated): Austria (2016, 2018, 2020), Bulgaria (2016-18), Estonia (2016-17), Finland (2016), France (2016-18), Hungary (2016), Ireland (2016-19), Latvia (201617, 2019-20) and Portugal $(2016,2019)$. Similarly, the following OECD countries did not participation in the GEM survey between 2016 and 2020: Belgium, Czech Republic, Denmark, Iceland, Lithuania and New Zealand. The following countries did not participate in the survey in every year (years of participation indicated): Australia (2016-17, 2019), Austria (2016, 2018, 2020), Estonia (2016-17), Finland (2016), France (201618), Hungary (2016), Ireland (2016-19), Japan (2017-19), Latvia (2016-17, 2018-19), Mexico (2016-17, 2019), Norway (2019-20), Portugal (2016, 2019) and Turkey $(2016,2018)$.

Source: (Global Entrepreneurship Monitor (GEM), 2021 [12])

StatLink त्गाड़ https://doi.org/10.1787/888934280688

\section{...but were slightly more likely to sell to customers in other countries...}

Early-stage youth entrepreneurs in the EU were more likely than adults to report exporting their products and services, which is another important avenue for achieving business growth. Between 2016 and 2020, about 56\% of early-stage youth entrepreneurs (18-30 years old) self-reported than they exported during that period relative to $47 \%$ of all early-stage entrepreneurs (Figure 4.19). These proportions were higher than those found in OECD countries ( $47 \%$ for youth and $43 \%$ for all early-stage 
entrepreneurs), which is not surprising given that the EU is a single market. This removes many of the trade barriers that are found in other parts of the world.

The share of youth entrepreneurs who exported was very high in several EU Member States. More than two-thirds of early-stage youth entrepreneurs reported selling to foreign customers in Ireland $(70 \%)$, France $(70 \%)$, Austria (71\%), Luxembourg $(72 \%)$ and Hungary $(81 \%)$. These differences across countries are likely explained by differences in export intensities across countries.

\section{Figure 4.19. About $56 \%$ of youth entrepreneurs in the EU export their products and services}

Proportion of early-stage entrepreneurs, 2016-20

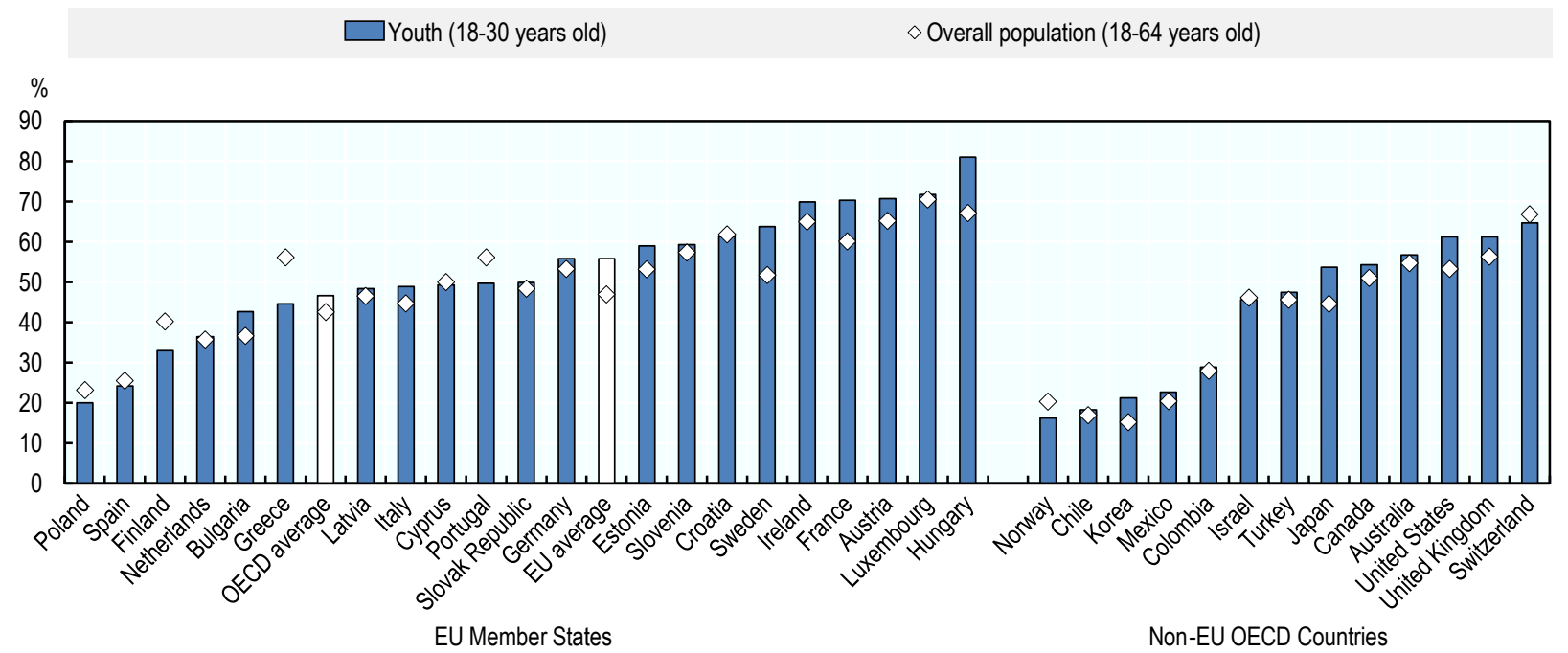

Note: All EU Member States participated in the GEM survey between 2016 and 2020 except for Belgium, Czech Republic, Denmark, Lithuania, Malta and Romania. However, the following countries did not participate in the survey in every year (years of participation indicated): Austria (2016, 2018, 2020), Bulgaria (2016-18), Estonia (2016-17), Finland (2016), France (2016-18), Hungary (2016), Ireland (2016-19), Latvia (2016$17,2019-20)$ and Portugal $(2016,2019)$. Similarly, the following OECD countries did not participation in the GEM survey between 2016 and 2020: Belgium, Czech Republic, Denmark, Iceland, Lithuania and New Zealand. The following countries did not participate in the survey in every year (years of participation indicated): Australia (2016-17, 2019), Austria (2016, 2018, 2020), Estonia (2016-17), Finland (2016), France (201618), Hungary (2016), Ireland (2016-19), Japan (2017-19), Latvia (2016-17, 2018-19), Mexico (2016-17, 2019), Norway (2019-20), Portugal (2016, 2019) and Turkey $(2016,2018)$.

Source: (Global Entrepreneurship Monitor (GEM), 2021[12])

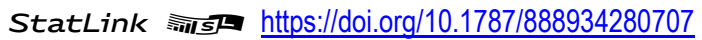

\section{....and had higher growth expectations}

Youth entrepreneurs in the EU are slightly more likely than the overall population of early-stage entrepreneurs to expect to achieve high levels of employment growth, which is consistent with higher shares who introduce new products and services and export. Between 2016 and 2020, about $11 \%$ of early-stage youth entrepreneurs reported an expectation of creating at least 19 jobs over the next five years, which was slightly above the overall rate (9\%) (Figure 4.20). These rates were below the proportion of early-stage entrepreneurs reporting high-growth expectations in OECD countries - 15\% for youth and $14 \%$ overall. It should be noted that expected job creation does not necessarily translate into actual jobs created. Youth entrepreneurs likely overestimate their business management abilities while underestimating various challenges that they will likely encounter.

There appears to be a positive correlation between the share of youth entrepreneurs who export and those who expect high levels of employment growth. Across EU Member States, the share of 
early-stage entrepreneurs who expected to create at least 19 jobs over the next five years ranged from about $2 \%$ in Bulgaria to $23 \%$ in Ireland. Growth expectations among youth entrepreneurs tended to be higher in Member States where there was an above-average proportion of youth entrepreneurs reporting that they export their goods and services. The correlation between the beyond high-growth expectations and exporting was 0.6 for the $2016-20$ period.

\section{Figure 4.20. About $11 \%$ of youth entrepreneurs expect to achieve high growth}

Proportion of early-stage entrepreneurs who expect to create at least 19 jobs over the next five years, 2016-20

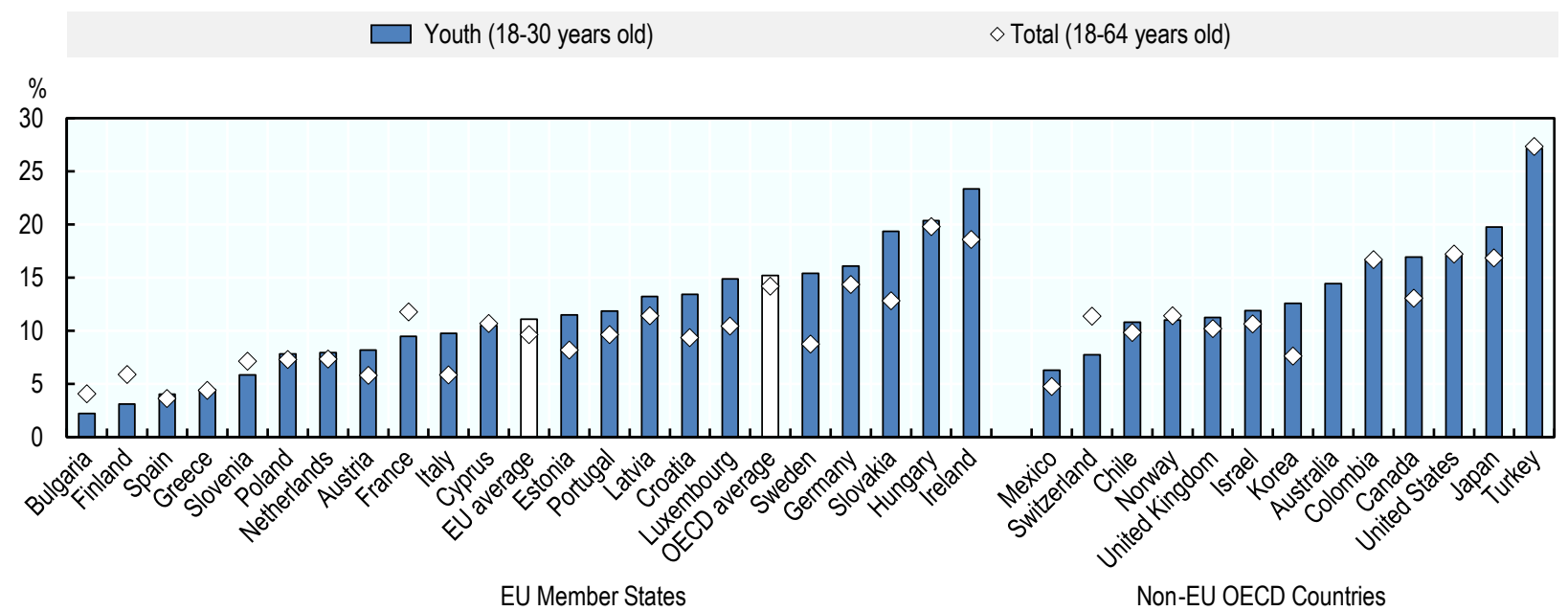

Note: All EU Member States participated in the GEM survey between 2016 and 2020 except for Belgium, Czech Republic, Denmark, Lithuania, Malta and Romania. However, the following countries did not participate in the survey in every year (years of participation indicated): Austria (2016, 2018, 2020), Bulgaria (2016-18), Estonia (2016-17), Finland (2016), France (2016-18), Hungary (2016), Ireland (2016-19), Latvia (2016$17,2019-20)$ and Portugal $(2016,2019)$. Similarly, the following OECD countries did not participation in the GEM survey between 2016 and 2020: Belgium, Czech Republic, Denmark, Iceland, Lithuania and New Zealand. The following countries did not participate in the survey in every year (years of participation indicated): Australia (2016-17, 2019), Austria (2016, 2018, 2020), Estonia (2016-17), Finland (2016), France (201618), Hungary (2016), Ireland (2016-19), Japan (2017-19), Latvia (2016-17, 2018-19), Mexico (2016-17, 2019), Norway (2019-20), Portugal (2016, 2019) and Turkey $(2016,2018)$.

Source: (Global Entrepreneurship Monitor (GEM), 2021 ${ }_{[12]}$ )

StatLink त्ञाs https://doi.org/10.1787/888934280726

\section{Conclusions}

The number of youth who are active in self-employment and business creation has been relatively stable over recent years, but there are a number of changes in the characteristics of these activities. About $7 \%$ of youth (20-29 years old) were self-employed in the EU in 2020 , which is essentially unchanged over the past 20 years. Many of these youth are working in professional occupations or as sales and service workers, and most are concentrated in the following sectors: Agriculture, Services, Arts, Real estate activities and Construction. While the nature of self-employment activities has not changed much in recent years, there has been a marked decline in the proportion of self-employed youth who employ others. The driver of this shift is not known. It could be due to a greater incidence of part-time selfemployment that occurs alongside education or working as an employee, or a change in preferences for more flexible and modular work such as freelancing. This requires further investigation because it may require policy makers to rethink the type of entrepreneurship support that is offered. If more young people are starting freelance activities, youth entrepreneurship schemes may wish to reframe how business 
development and growth are supported. This may also require a greater emphasis on building motivations to develop a business in policy interventions.

Governments have boosted their investment in youth entrepreneurship support schemes since the financial crisis in 2008-09. Relative to other inclusive entrepreneurship target groups, youth entrepreneurship support is more developed. A wide range of policy instruments are used to stimulate and support youth entrepreneurship in the EU, including entrepreneurship training and coaching, various financial instruments and building entrepreneurship networks, and these have been strengthened with large investments by national and regional governments, often supported by the European Union. However, the quality of youth entrepreneurship schemes is highly variable, and there continues to be little knowledge exchange across regions and countries about "what works".

Governments have renewed their commitment to support youth given the strong impacts faced during the COVID-19 pandemic, including increased attention on youth entrepreneurship policy. Evaluation evidence suggests that youth entrepreneurship schemes can have a role as part of governments' policy response to growing youth unemployment during an economic crisis. However, it is less clear where governments should focus their efforts. Recent research suggests that financial supports tend to have a greater impact on the sustainability of the business, but evaluations note that training, coaching and mentoring are often more valued by youth entrepreneurs. Priority actions for government include:

- Address the finance gap faced by young entrepreneurs; and

- Improve the appeal of support initiatives by better capturing youth perspectives in the design of initiatives.

For further policy discussion on youth entrepreneurship and related policy actions, please refer to (OECD/European Commission, 2020[6]). Examples of recent policy actions to support youth entrepreneurs are highlighted in several country profiles in Part III of this report.

\section{References}

Bosma, N. et al. (2021), Global Entrepreneurship Monitor 2020/2021 Global Report, Global Entrepreneurship Research Association, https://www.gemconsortium.org/file/open?fileld=50691 (accessed on 31 May 2021).

Davidescu, A. and C. Ghinararu (2015), "The hare and the tortoise' How older generations are replaced by young one on the labour market. Signals and insights form the relationship between the shadow economy and active ageing", Economia Seria Management, Vol. 18/1, pp. 163-171.

European Commission (2021), Youth Employment Initiative, https://ec.europa.eu/social/main.jsp?catld=1176 (accessed on 7 September 2021).

European Commission (2012), Flash Eurobarometer 354: Entrepreneurship in the EU and beyond, https://ec.europa.eu/commfrontoffice/publicopinion/flash/fl 354 en.pdf.

Eurostat (2021), Labour Force Survey, https://ec.europa.eu/eurostat/web/lfs (accessed on 6 May 2021).

Ghinararu, C., D. Pasnicu and G. Ciobanu (2020), Estimarea efectelor schimbarilor structurale din economie asupra ocuparii fortei de munca [Estimating the effects of structural changes in the economy on employment], UNIVERSITARA publishing house, Bucharest. 
Global Entrepreneurship Monitor (GEM) (2021), Special tabulations for the OECD of the Global Entrepreneurship Monitor (GEM) adult population survey for the years 2016 to 2020.

Kim, G. et al. (2020), "The Effect of Youth Entrepreneurship Education Programs: Two LargeScale Experimental Studies", SAGE Open, Vol. 10/3, http://dx.doi.org/10.1177/2158244020956976.

OECD (2020), Inclusive Entrepreneurship Policies: Country Assessment Notes, https://www.oecd.org/cfe/smes/inclusive-entrepreneurship-policies-country-assessmentnotes.htm (accessed on 6 June 2021).

OECD/European Commission (2020), "Policy brief on recent developments in youth entrepreneurship", OECD SME and Entrepreneurship Papers, No. 19, OECD Publishing, Paris, https://dx.doi.org/10.1787/5f5c9b4e-en.

Remeikienè, R. et al. (2020), Youth unemployment and self-employment: trends and perspectives, Technická univerzita v Liberci, http://hdl.handle.net/11025/39778 (accessed on 22 June 2021).

Saikkonen, P. (2019), "Palkkatyön, sosiaaliturvan ja yrittäjyyden yhteensovittamisen nykytila [A current situation of reconciling wage work, social security and entrepreneurship]", in Kananen, J. (ed.), Social security during the transformation of work - wage work, entrepreneurship and income related risks, Publications of the Government's analysis, assessment and research activities 2019:22,, https://julkaisut.valtioneuvosto.fi/bitstream/handle/10024/161479/VNTEAS 201922 Sosiaali turva tyon murroksessa.pdf (accessed on 26 July 2021).

Sieger, P. et al. (2018), Global Student Entrepreneurship 2018: Insights From 54 Countries, Global University Entrepreneurial Spirit Student's Survey, https://www.guesssurvey.org/resources/PDF InterReports/GUESSS Global 2018.pdf (accessed on 20 July 2021).

Tillvaxtverket (2021), Entreprenörskapsbarometern 2016, https://tillvaxtverket.se/statistik/varaundersokningar/entreprenorskapsbarometern.html (accessed on 26 July 2021).

Tubadji, A. et al. (2021), "Fear-of-failure and cultural persistence in youth entrepreneurship", Journal of Small Business \& Entrepreneurship, Vol. 33/5, http://dx.doi.org/10.1080/08276331.2019.1692999.

US Bureau of Labor Statistics (2021), "Labour Force Statistics from the Current Population Survey, https://www.bls.gov/cps/ (accessed on 9 September 2021). 


\section{Seniors' self-employment and entrepreneurship activities}

Overall, self-employment rates increase with age. About $18 \%$ of working people aged 50 to 64 years old are self-employed, about 4 percentage points above the overall average. This share increases to $39 \%$ for those 65-69 years old and 52\% for those $70-74$ years old. Moreover, about onethird of these businesses employ others. This chapter presents data and trends on self-employment and entrepreneurship activities by seniors for European Union Member States and OECD countries. It also discusses barriers to entrepreneurship and policy approaches used to support seniors in business creation and self-employment. 


\section{Key messages}

- The data presented in this chapter are based on Eurostat Labour Force Survey data covering the self-employed and Global Entrepreneurship Monitor data on pre start-up and early-stage business activities. These data are complemented with country-specific statistics to provide additional insights on senior entrepreneurship.

- Seniors are active in self-employment and the proportion of working seniors who are self-employed increases with age. In 2020, seniors (50-64 years old) were more likely to be self-employed than the overall adult population (15-64 years old) in the EU (18\% vs. $14 \%$ for adults). The share of working seniors who are self-employed increases to $39 \%$ for $65-69$ years old and $52 \%$ for $70-74$ years old (in 2020).

- Self-employed seniors are slightly more likely to have employees than the overall average. In the European Union (EU), one-third of self-employed seniors had at least one employee in 2020 , relative to $29 \%$ of all self-employed people. In some countries such as Germany, about half of self-employed seniors had employees. It will be important for policy makers to look for ways to sustain these businesses and jobs as these seniors look to retire.

- Despite high levels of self-employment activities, seniors are less active in creating new businesses. In the EU, only $2 \%$ of seniors (50-64 years old) were engaged in starting a business over the $2016-20$ period relative to $4 \%$ of the overall population (18-64 years old). The OECD average for seniors for the same period was $5 \%$.

- However, seniors were more likely to report starting their business out of "necessity". About one-quarter of new senior entrepreneurs in the EU started their business between 2016 and 2020 because they could not secure employment, relative to about $18 \%$ of the total population (18-64 years old). While some seniors start businesses due to insufficient savings, research also shows that many seek to remain active and to maintain social connections.

- Barriers to entrepreneurship for seniors often include health issues, the opportunity cost of time and the shorter timeline to grow a sustainable business are greater barriers for seniors than younger entrepreneurs. Neither a "fear of failure" nor a perceived lack of entrepreneurship skills appears to be disproportionate barriers to business creation for seniors.

- Once operating, businesses operated by new senior entrepreneurs follow many of the same business strategies as younger entrepreneurs. For example, they were as likely to report introducing new products and services, as well as exporting, between 2016 and 2020.

- Entrepreneurship can play a role in active ageing policy. There is a growing population of healthy older people with the skills, financial resources and time available to contribute to economic activity through extending their working lives, including through entrepreneurship. Research shows that entrepreneurship can increase the health and well-being of seniors relative to inactivity. Policy makers can do more to leverage this pool of potential entrepreneurs by increasing awareness about business creation and self-employment, providing training to fill knowledge and skills gaps, and ensuring that tax and social security systems do not contain disincentives to entrepreneurship for older people, including investment in other businesses.

- Overall, senior entrepreneurship policies and programmes are under-developed in the EU. Relative to other inclusive entrepreneurship target groups, there are few tailored entrepreneurship programmes for seniors. Most schemes in the EU are small-scale and are operated by local governments or non-government organisations. 


\section{Policy context}

\section{Extending careers through entrepreneurship}

The populations of European Union (EU) Member States and OECD countries are aging. The proportion of the EU population over the age of 65 years old will increase from $21 \%$ in 2020 to nearly $30 \%$ in 2050 (Eurostat, 2019[1]). Consequently, the dependency ratio (i.e. the ratio of people over 65 years old - when people are generally economically inactive - to the projected number of people between 15 and 64 years old) is expected reach $52 \%$ in 2050 , up from $32 \%$ in 2020 (Eurostat, $2021_{[2]}$ ). This aging of the population is due to a long-term decline in fertility rates, which means that each generation is relatively smaller than the previous.

Population aging has several significant impacts on labour markets and economies. Social security systems, including public pension and healthcare systems, will face increasing pressures because the larger population of older people will draw more heavily on them, and contribute less, as they retire. Moreover, the pattern of ageing is not constant across countries and regions, and the exit of the "baby boom generation" from the labour force may result in labour mismatches in certain regions and sectors where the skills and experience needed to replace those retiring are not available in younger generations. There may also be an issue related to business succession as younger people may not take over all businesses run by older people, which could have significant consequences, not only for employees of those firms, but also for the owners who may rely on the sale of their business for retirement income.

Entrepreneurship policy will also be affected by demographic shifts because the policy target groups are changing and a new target group is emerging. The promotion of entrepreneurship among those nearing the end of their careers is a potential policy option to prolong the working lives of older people, reduce older-age unemployment and enhance the social inclusion of older individuals. Older people are now living longer than previous generations and have different decisions to make about their career and lifestyle. Research shows that many older people may wish to remain economically active in order to maintain a lifestyle or choose self-employment as a flexible alternative to organisational employment. For example, surveys in Germany show that the majority of people would like to remain economically active after retirement and one in five people between the age of 50 and 75 would be interested in starting a business after retirement (Körber Stiftung, 2018[3]) (see also Box 5.1).

Despite an interest in remaining economically active through entrepreneurship, this chapter shows that few older people are working on creating businesses. Between 2016 and 2021, only about $7 \%$ of seniors were involved in early-stage entrepreneurship in the EU, i.e. involved in creating a new business or managing one that is less than 42 months old. If seniors were as active as core age men (30-49 years old) there would be an additional 4.8 million senior entrepreneurs in the EU, accounting for about half of the "missing" entrepreneurs in the EU.

Self-employment can positively improve senior's mental and physical well-being. Several recent studies from around the EU found positive non-monetary benefits of self-employment among seniors. In a longitudinal study of Italian self-employed workers, self-employed people were shown to live significantly longer than the rest of the population and that self-employment may have positive mental and physical health benefits (Lallo and Raitano, 2018[4] $)$. A UK study also finds self-employment to be a viable option and positive experience which increases general life satisfaction and personal growth among individuals who have been redundant by the age of 50 years old (Stirzaker and Galloway, 2017 ${ }_{[5]}$ ). 


\section{Box 5.1. "Unretirement" and retirement transitions among seniors in the EU}

Unretirement has become increasingly more common among seniors across the EU. While transitions to and from retirement have greatly changed in recent years due in part to the modifications to pension systems, the prolongation of retirement ages, and the increase life and health expectancies in many countries, a recent report investigates unretirement and the likelihood of seniors to return to the labour force through self-employment. Unretirement does not appear to be primarily driven by financial needs since those returning to the labour force are often those who are wealthy, healthy and well-educated. Retirees chose to return at varying rates across EU and OECD countries. For example, $14 \%$ of retirees in Sweden will unretire compared to $17 \%$ in Germany, $25 \%$ in the UK and $26 \%$ in the US (Lassen and Vrangbæk, $\left.2021_{[6]}\right)$. A recent study in the UK found the likelihood of unretirement changes by gender, education level and time spent in retirement. British men are $25 \%$ more likely to unretire than women while those with post-secondary qualifications are $50 \%$ more likely to unretire than those with no qualifications (Platts et al., 2019 $9_{[7]}$ ). Moreover, the same study finds unretirement occurs the most frequently among individuals who recently left the labour force.

Self-employment offers a bridge back into work for retired pensioners. Another recent study used register data from Sweden for retired seniors (56 years old and over) in the period 1994-2007 to investigate how retirees chose to re-enter the labour market. Overall, 13.9\% of Swedish pensioners unretired at least once during the period. More than a quarter of whom unretired as self-employed workers (Table 5.1). Having previous self-employment experience greatly increased the likelihood that a retiree would return to self-employment - approximately $90 \%$. However, about $9 \%$ of former employees unretired as self-employed workers, resulting in an uptick in self-employment from $21 \%$ of workers in the sample prior to retirement to about $26 \%$ in unretirement (Pettersson, $2014{ }_{[8]}$ ).

\section{Table 5.1. More than one-quarter of unretiring people in Sweden become self-employed}

\begin{tabular}{l|c|c}
\hline \multicolumn{1}{|c|}{ Type of work before retirement } & Unretired as an employee & Unretired as self-employed \\
\hline Employees (\%) & $7777(91 \%)$ & $761(9 \%)$ \\
\hline Self-employed $(\%)$ & $230(10 \%)$ & $2034(90 \%)$ \\
\hline Total $(\%)$ & $8007(74 \%)$ & $2795(26 \%)$ \\
\hline
\end{tabular}

Source: Adapted from (Pettersson, 2014[8])

Seniors become self-employed for various reasons. Evidence shows that more self-employed people continue to work after reaching retirement age (over 65 years old) relative to those working as employees. However, the reason for this remains unclear. Some studies suggest that it could be due to less access to pension schemes or personal preferences such as having a different concept of work or personally identifying with their company (Wahrendorf et al., 2017[9]). For example, a German study on self-employed people, who are not retirement age, finds that self-employed workers often do not save sufficiently for their pensions (Fachinger and Frankus, n.d.[10]). Other studies suggest that seniors continue to work because they can (physically and mentally) and because no one is telling them not to continue (Lassen and Moreira, $\left.2014_{[11]}\right)$. Research in France shows that necessity entrepreneurship among seniors can be driven by a lack of retirement savings and new financial pressures that arise from children attending post-secondary education or second families that have been started by people who have remarried (Malek, Adnane and Imen, 2011[12]).

Policy actions in the EU to encourage and support senior entrepreneurship are typically led by national governments. An OECD assessment of inclusive entrepreneurship policies across EU Member 
States examined approaches to promoting and supporting inclusive entrepreneurship, including senior entrepreneurship (see Reader's Guide). Policy responsibility is clearly defined at the national level in nearly two-thirds of EU Member States (Figure 5.1), which is a slightly lower level than for other target groups such as women, immigrants and youth. Given the clear demographic challenges that are coming over the next two-to-three decades, it is somewhat surprising that less than one-third of EU Member States have clear objectives related to entrepreneurship policy. Business creation and self-employment can be part of the solution to extend people careers and keep them active and engaged in society.

Entrepreneurship policies and schemes need to recognise that there are some factors in the decision to start a business that cannot be changed. This includes, for example, the age of a person, their health or an individual's preference for leisure over work. Therefore, policy should focus on the contextual factors that influence an older person's decision to enter into self-employment.

\section{Figure 5.1. Few EU governments use entrepreneurship as part of their active aging policies}

Share of EU Member States, 2020

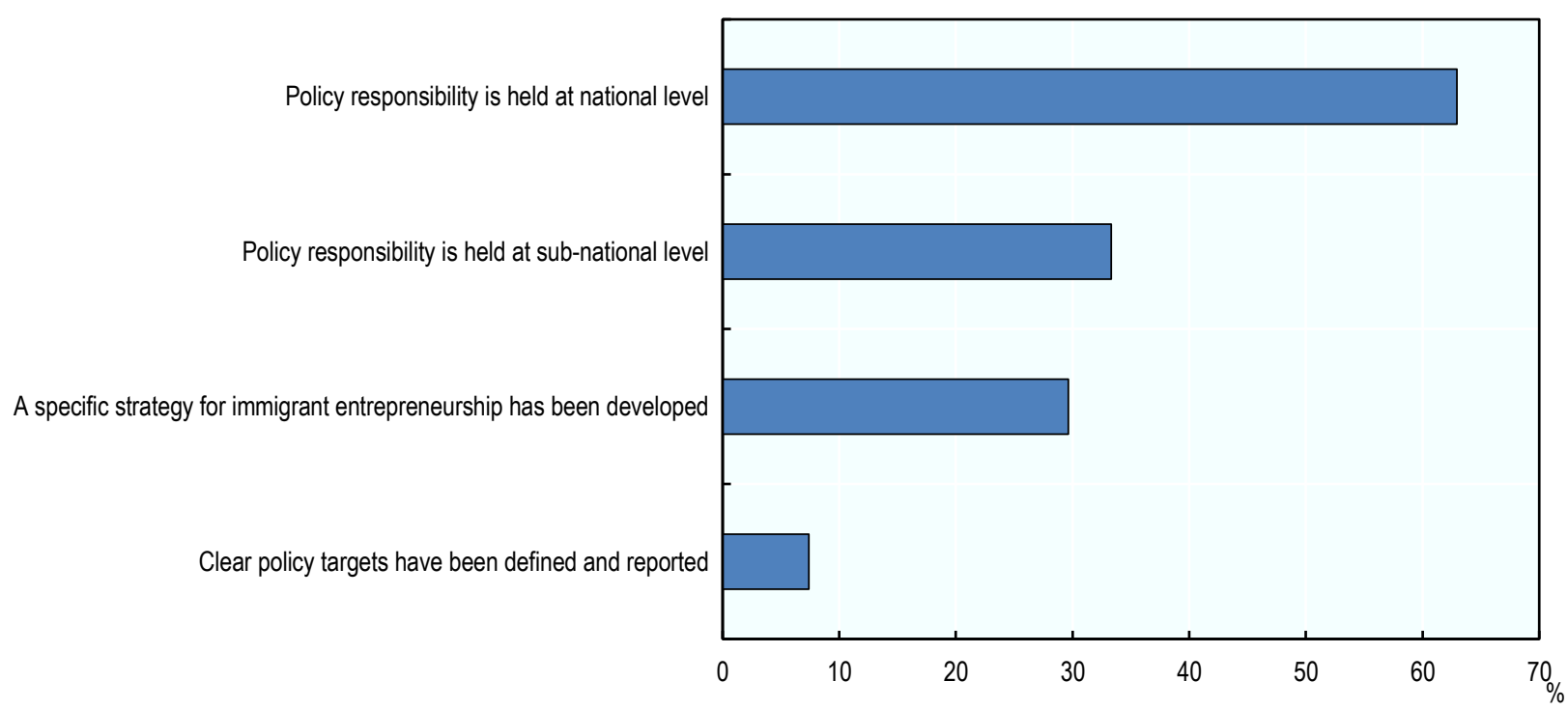

Note: It is possible for countries to have clear policy responsibility at both the national and sub-national levels; these are not mutually exclusive. Source: (OECD, 2020[13])

\section{Entrepreneurship schemes for seniors are under-developed in the EU}

There are a small number of entrepreneurship initiatives and schemes designed specifically to support older people in business start-up activities. The OECD inclusive entrepreneurship policy assessments across the EU found that senior entrepreneurship schemes tend to be very small-scale (e.g. 10 participants) and operate for a short period (e.g. two years). Using the OECD's 9-point assessment criteria (see Reader's Guide), entrepreneurship schemes for seniors are, on average, less likely to follow good practice principles for inclusive entrepreneurship policy (Figure 5.2). For example, they typically do not use a consultation process while they are being developed, outreach practices are limited and very few use monitoring and evaluation tools to report on their impact or to strengthen their design and delivery. 
Figure 5.2. Senior entrepreneurs have less access to tailored support than other target groups

Average OECD assessment scores for inclusive entrepreneurship schemes across EU Member States, 2020

a. Entrepreneurship skills

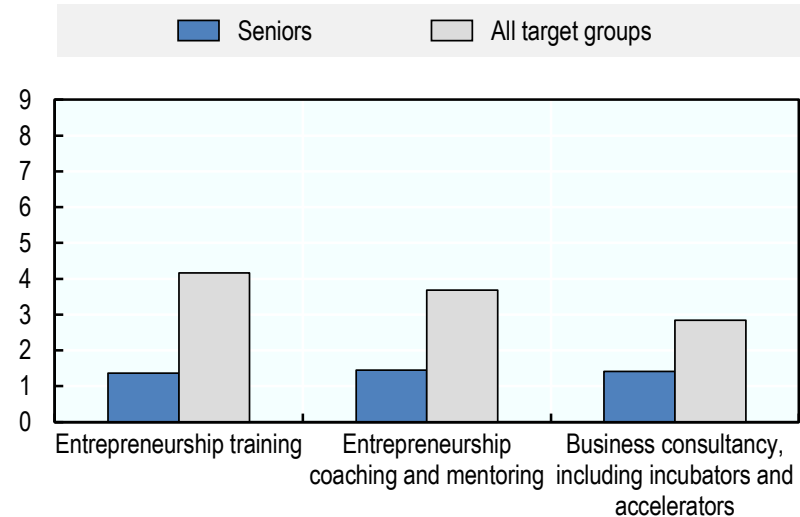

c. Entrepreneurship culture and social capital

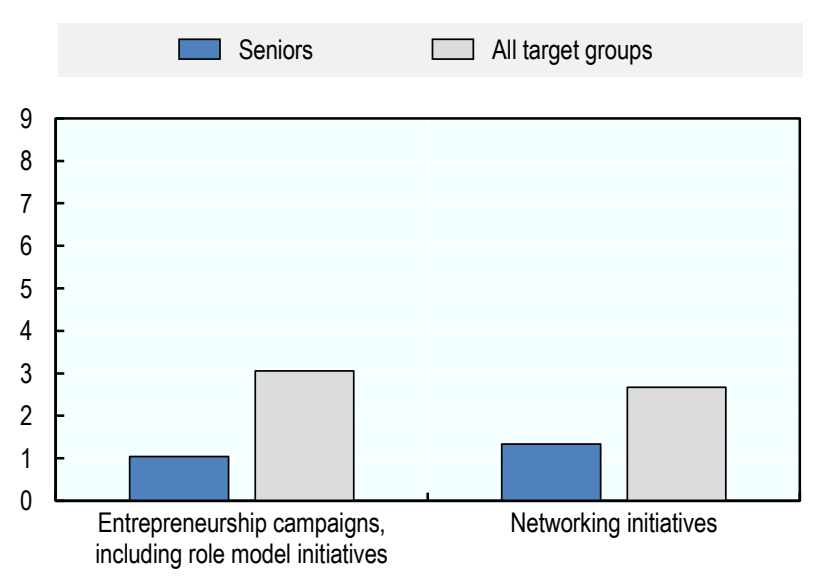

b. Entrepreneurship finance

Seniors All target groups

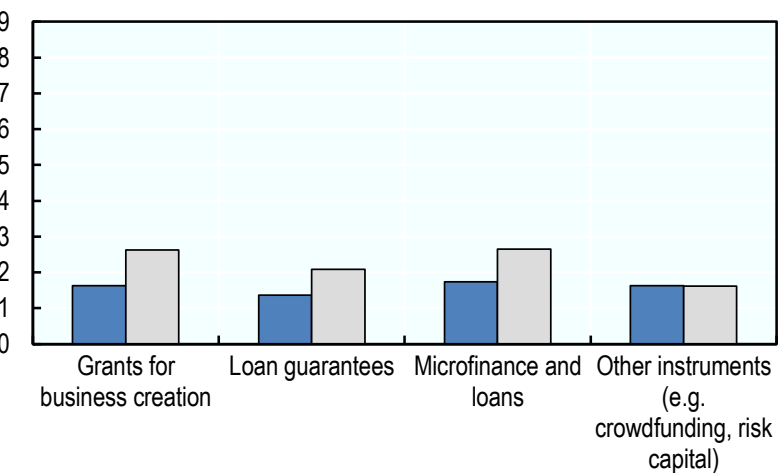

d. Regulatory tools

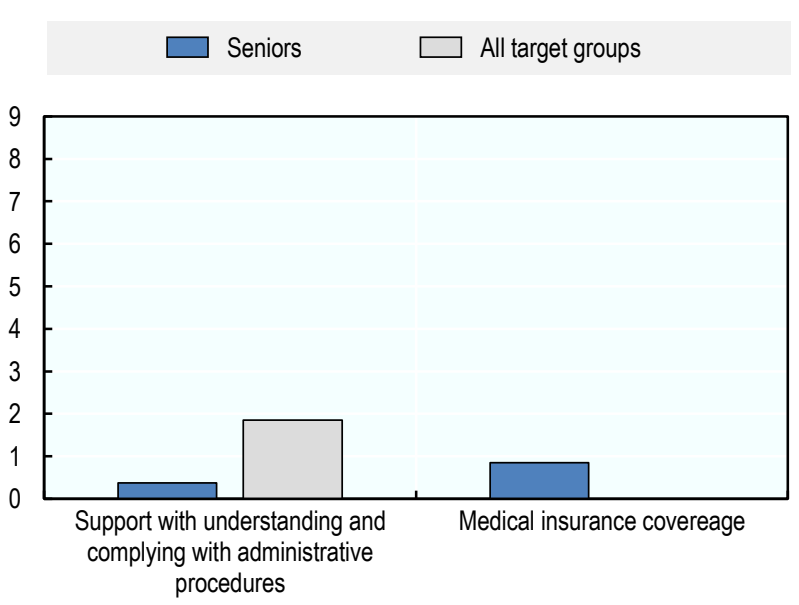

Note: The panels in this figure present an unweighted average of policy assessment scores for EU Member States. Each policy instrument (e.g. Entrepreneurship training) is assessed a scored out of 9 as described in the Reader's Guide. The figure shows the average score for schemes for immigrant entrepreneurs relative to the score for all inclusive entrepreneurship groups combined (i.e. women, immigrants, youth, seniors and the unemployed). Some of the policy instruments in panel $d$ are designed specifically for immigrant entrepreneurs so there is no comparative policy assessment score for all inclusive entrepreneurship target groups.

Source: (OECD, 2020[13])

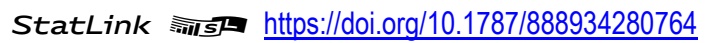

\section{Building entrepreneurship skills}

Older people that are interested in starting a business or becoming self-employed may have spent their entire careers working as employees, which gives them a lot of experience but they may need additional skills to be successful in entrepreneurship and self-employment. Entrepreneurship and self-employment require a broader set of skills that includes opportunity recognition as well as a broad set of business management skills. Governments have a range of schemes in place to support seniors in acquiring these entrepreneurship skills, including training programmes, coaching and mentoring and business consultancy. 
Tailored entrepreneurship training programmes for seniors are not commonly offered in EU Member States. While entrepreneurship training programmes for seniors often focus on developing a business plan, they are also generally quite strong at directing participants to sources of financing and more intensive support offers. Many of these schemes are integrated with other types of entrepreneurship support, notably small amounts of financial support and coaching. However, assessing the impact of these schemes is not often done.

Similarly, entrepreneurship coaching for seniors is not widely available for older people interested in receiving individual support during the start-up and early development phases. However, a small amount of coaching is almost always offered as part of integrated support packages, i.e. when training and start-up finance such as small grants or loans are offered together. Schemes can also do more to utilise the experience and expertise of senior entrepreneurs as coaches and mentors to support younger entrepreneurs.

Business consultancy schemes for senior entrepreneurship are extremely rare in the EU. However, it is not clear if there is a strong demand for senior entrepreneurs for this type of support. Moreover, senior entrepreneurs can access general business consultancy programmes.

\section{Facilitating access to start-up finance}

Access to finance is a commonly cited challenge for all entrepreneurs and even though seniors may have been able to accumulate savings over their career, many have difficulties securing sufficient funds to start a business. This is particularly true for those older people that start a business out of retirement, who are less likely to have extra savings that can be invested in a new start-up. Common approaches to facilitating access to finance for senior entrepreneurs include small grants and microfinance. However, few of these schemes are designed specifically for the needs for senior entrepreneurs since age alone would not be expected to be a barrier for accessing finance. However, the length of the period to repay debt is likely shorter than it would be for younger entrepreneurs, which may reduce the amount of debt offered. Nonetheless, there have been a small number of start-up finance schemes in the EU over the past decade that have used tailored outreach products to attract potential older entrepreneurs.

\section{Expanding entrepreneurship networks}

Networks are critical for entrepreneurs because they are a source of resources, ideas, feedback, clients, suppliers and more. Seniors who are still working often have extensive professional networks in their occupation and industry but the value of these networks can diminish quickly once a person stops working (e.g. retirement or unemployment). Governments can help senior entrepreneurs (re-)establish by connecting entrepreneurs to existing entrepreneurship networks, or using mentoring schemes. Most networking schemes for seniors in the EU tend to be offered as part of integrated support packages, supporting the development of both formal and informal networks.

\section{Supporting senior entrepreneurs with regulatory tools}

While there is always a temptation for governments to design new initiatives and schemes, the best approach can be to improve existing mechanisms. Removing disincentives to entrepreneurship for seniors within existing social support systems could be a significant step to make entrepreneurship more attractive for older people. This could include, for example, ensuring that income tax and social security systems do not discourage labour market activities and entrepreneurship by reducing benefits when income is earned. One issue that many countries are introducing is medical insurance for self-employed people because fears about becoming sick and not being able to meet business payments is a barrier for some older entrepreneurs. Although these types of schemes do not target older workers specifically, they stand to benefit from this type of social protection. Different countries have different schemes with different levels of coverage, including both mandatory and optional schemes. 


\section{Recent developments in senior entrepreneurship policy}

Policy support in the EU for senior entrepreneurship has changed little over the past decade despite the European Year of Active Ageing and Solidarity between Generations in 2012 that sought to draw attention to the needs of seniors. A small number of countries recently embedded senior entrepreneurship in active aging strategies including Lithuania. These relatively new Strategy for the Demographic, Migration and Integration Policy for 2018-30 outlines a plan to address the challenges of demographic change, including improving the quality of life of seniors. The Strategy implementation plan for 2019-21 outlines relevant measures from other strategic documents and also includes new measures on employment and entrepreneurship for seniors and immigrants. It also proposes measures on providing the financial support to NGOs to encourage social entrepreneurship (OECD, 2020[13]). However, this example is the exception rather than a representation of similar actions across the EU.

A small number of schemes have been implemented to support senior entrepreneurs at the national and regional levels. This includes the initiative Gründen mit Erfahrung ("Founding with Experience") in Germany which was launched in 2019 by the German Centre for Productivity and Innovation (RKW Kompetenzzentrum) to establish a discussion around business creation by "baby boomers" and to raise awareness about the potential benefits of entrepreneurship by seniors. This initiative is funded by the Federal Ministry for Economic Affairs and Energy (BMWi) as part of their initiatives to mitigate the effects of demographic change (OECD, 2020[13]).

There is also a very small number of examples where policies for senior entrepreneurship have been adjusted to respond to the COVID-19 crisis. This includes the scheme Intergenerational Pairs for Business Creation and Takeover (Tandem InterGénérationnel pour la création et la Reprise d'Entreprise, TIGcRE) in France, which supports entrepreneurship projects led by teams of senior and youth entrepreneurs. The scheme was designed around in-person workshops but this was not possible during the COVID-19 pandemic due to restrictions on in-person meetings. As a result, programme managers adjusted the delivery of support from two-day workshops to online workshops that are organised over a four-week period. In addition, online networking events were added to the scheme to help strengthen connections between participants and with other business support organisations (OECD, 2020[13]).

\section{Trends in self-employment by seniors}

\section{The self-employment rate for seniors is declining}

The share of working seniors who are self-employed in the EU has declined by five percentage points since 2002. In 2020 , about $17 \%$ of people aged $50-64$ years old were self-employed, representing 12.5 million people. This proportion was above the overall share in the working population (15-64 years old) $(13 \%)$ but below the share in 2002 (22\%) (Figure 5.3).

The self-employment rate among seniors increases with age. In 2020 , the majority of the working population between 70 and 75 years old in the EU were self-employed $(52 \%)$ relative to $37 \%$ of those 65 69 years old and $20 \%$ of those 60-64 years old. Only about two-in-ten workers aged 50 to 59 years old were self-employed in 2020 . Several key factors likely explain these relatively high self-employment rates among older age cohorts. First, many of these workers have likely been self-employed for most or all of their career and therefore do not have a pension plan that would allow them to retire. Second, some seniors use self-employment as a bridge to retirement, allowing them to reduce their workload and control the activities that they work on. This is particularly common in Luxembourg and the Netherlands (OECD, $2020_{[13]}$ ). Third, the incidence of part-time self-employment increases with age (Eurostat, 2021 [14]), so it appears that some self-employed seniors start a small business activity to remain professionally and socially active without working full-time. In 2017, Finland changed its pension scheme in an effort to 
encourage those aged 63 to 67 years old to continue working, which led to a substantial decrease in inactivity among this age cohort (OECD, 2020[13]).

\section{Figure 5.3. Self-employment for seniors increases with age but has declined over time}

Self-employment in the EU as a percentage of employment
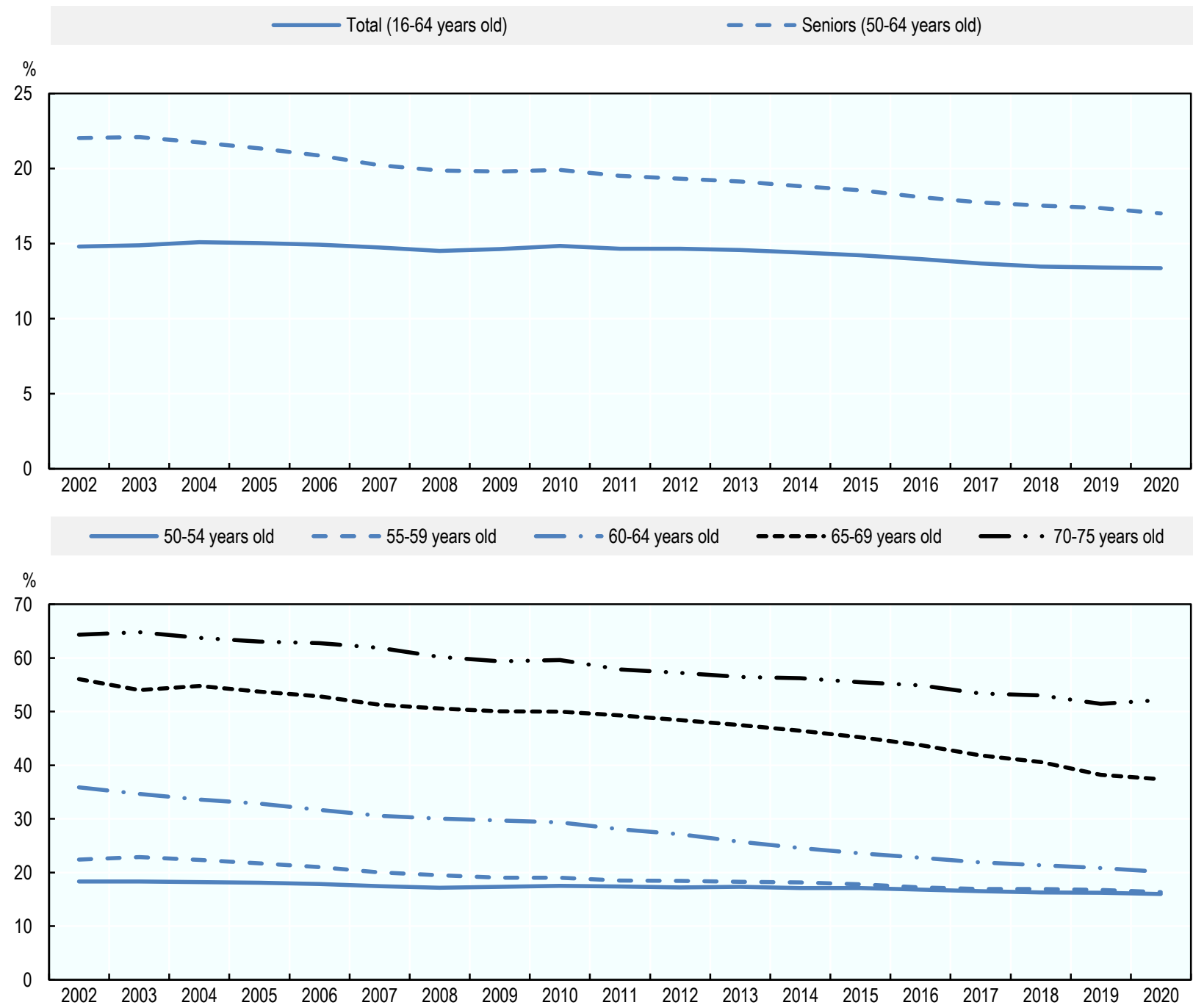

Source: (Eurostat, 2021 [14])

Self-employment rates for seniors vary substantially across countries but are often higher in EU Member States with lower labour market participation rates among old age cohorts. The selfemployment rate for those aged 50-64 years old was highest in Greece in 2020 (39\%), well above other EU Member States (Figure 5.4). The second highest rate was in Italy $(23 \%)$, followed by Poland (22\%). There was a moderate negative correlation rate $(-0.5)$ between the self-employment rate and labour market participation rates for seniors over the period 2002-20. A recent study on age discrimination in Europe identifies both Poland and Greece as countries with higher levels of discrimination by age, which could explain the reason that many older workers prefer self-employment to employment (Bratt et al., 2018[15]). Greece also had significant changes to their pension system, which affects labour market decisions of 
older people. Pension and social protection schemes were modified during the bailout period (2010-18), extending the working life of many older low-skilled workers. Following the crisis, senior workers experienced high unemployment rates and many were unable to find new jobs in the challenging labour market. Many jobs were temporary or part-time at minimum wage making it difficult for older workers to save for retirement. Evidence indicates many chose self-employment because of the lack of alternative employment opportunities but do not seek to grow, which leads to stagnation (OECD, 2020[16]).

Figure 5.4. Self-employment rates for seniors vary by country

Self-employment as a percentage of employment, 2020

- Seniors (50-64 years old)

OAdults (15-64 years old)

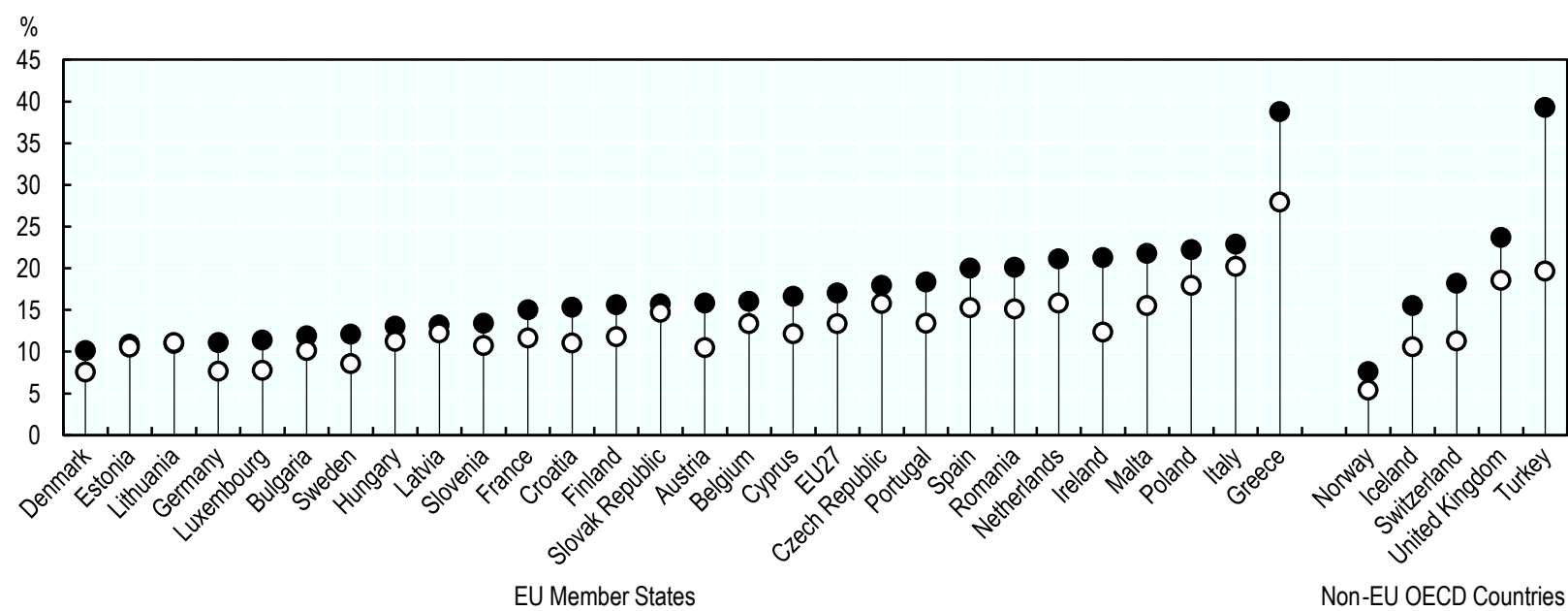

Note: Data for the United Kingdom are for 2019.

Source: (Eurostat, 2021 [14])

StatLink त्ञाज ht htps://doi.org/10.1787/888934280802 


\section{Box 5.2. Country spotlight - Bridging to retirement through self-employment, United States}

As workers become eligible for Social Security or pension schemes, they often transition to retirement. A recent study using data from the Health and Retirement Study (HRS) in the United States investigates the impact of eligibility for Social Security on work transitions. The report examines three age cohorts from 1999 to 2013: (i) 1965 birth cohort (34 to 48 years old during period of observation), (ii) 1945 birth cohort (54 to 68 years old) and (iii) 140 birth cohort (59 to 73 years old).

Social Security acts as a marker for beginning the retirement process. The report finds becoming eligible for Social Security often leads to transitions by wage-earners to self-employment for a variety of reasons. The added financial liquidity provided by Social Security creates the ability for some wageearners to pursue a business opportunity, while others begin to reduce hours at work and begin pursuing hobbies which in some cases may lead to self-employment. Across all three age cohorts, $4 \%$ of wage-earners transitioned to self-employment after 4 years - up from $2 \%$ after 2 years (Table 5.2).

Table 5.2. About $4 \%$ of older employees in the US transition to self-employment before retirement

\begin{tabular}{l|r|r|r|r|r|r}
\hline & \multicolumn{3}{c}{ Transition probabilities $\mathrm{t}+2$} & \multicolumn{3}{c}{ Transition probabilities $\mathrm{t}+4$} \\
\hline & Not working & Wage earner & Self-employed & Not working & Wage earner & Self-employed \\
\hline Not working & 0.92 & 0.05 & 0.02 & 0.91 & 0.06 & 0.03 \\
\hline Wage earner & 0.16 & 0.81 & 0.02 & 0.27 & 0.69 & 0.04 \\
\hline Self-employed & 0.16 & 0.07 & 0.77 & 0.25 & 0.10 & 0.65 \\
\hline
\end{tabular}

Source: (Ramnath, Shoven and Slavov, 2021[17])

\section{Characteristics of self-employed seniors and their activities}

\section{Self-employed seniors are more likely to have employees}

About one-third of self-employed seniors in the EU had a least one employee in 2020, which was slightly above the overall proportion of self-employed people. In $2020,33 \%$ of self-employed seniors in the EU (50-64 years old) employed relative to just under $30 \%$ of all self-employed people (Figure 5.5).

Among self-employed employed seniors, the likelihood of having employees decreases with age. About $34 \%$ of those between 50 and 54 years old had at least one employee relative to $33 \%$ of those 55 to 59 years old and $30 \%$ of those 60 to 64 years old. Those over 65 years old were slightly less likely to have employees $-28 \%$ of those 65 to 69 years old and $25 \%$ of those 70 to 74 years old. Although the proportion of self-employed people between the ages of 50 and 64 years old who employ others has been relatively stable since 2002 , the proportion of those over 65 years old employing others has increased. This is largely explained by the aging of self-employed seniors who already had employees (under 65 years old) rather than a growth in the number of older self-employed people hiring new employees. 
Figure 5.5. The share of seniors with employees increased most among those over 65 years old Percentage of self-employed in the EU
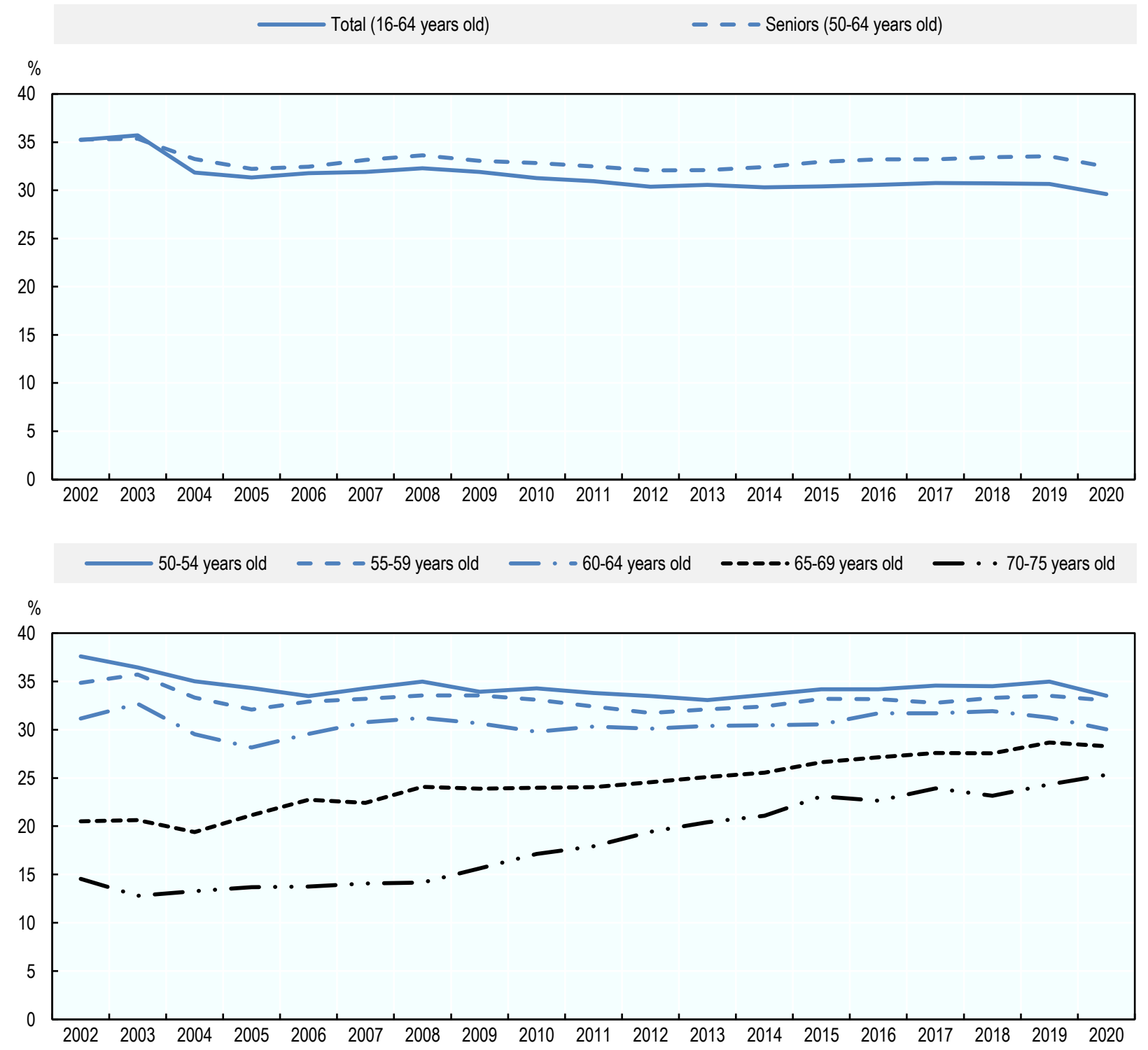

Source: (Eurostat, 2021 ${ }_{[14]}$ )

StatLink 제프 https://doi.org/10.1787/888934280821

Nearly half of self-employed seniors employed others in some EU Member States such as Austria and Germany. In 2020, the proportion of self-employed seniors (50-64 years old) who employed others ranged from about $6 \%$ in Romania to $48 \%$ in Germany (Figure 5.6). The share of self-employed seniors who were employers in 2020 was nearly perfectly correlated with the overall share of self-employed who were employers. Self-employed seniors were less likely to be employers than the overall rate in only six EU Member States - Croatia ( $44 \%$ vs. $47 \%$ ), Estonia ( $41 \%$ vs. $46 \%$ ), Greece ( $26 \%$ vs. $27 \%$ ), Latvia ( $36 \%$ vs. $38 \%$ ), Romania ( $6 \%$ vs. $8 \%$ ) and Sweden (37\% vs. $39 \%)$ - but the gap was very small in each country. 


\section{Figure 5.6. The share of self-employed seniors varied across EU Member States}

Percentage of the self-employed, 2020

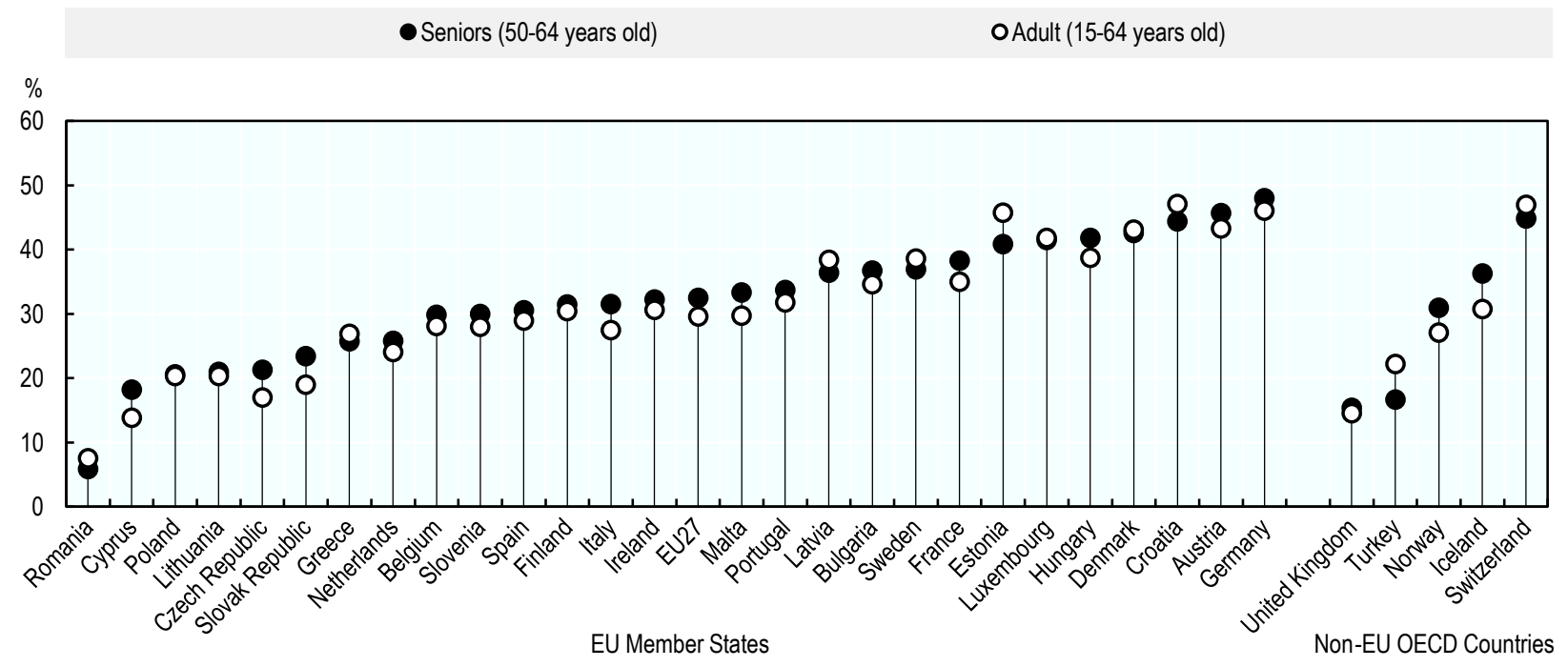

Source: (Eurostat, 2021[14])

StatLink त्गा Th https://doi.org/10.1787/888934280840

Seniors have higher self-employment rates than the total population across all sectors...

In 2020, the share of seniors who were self-employed was greater than the self-employment rate in all sectors of the economy. Seniors (50-64 years old) in the EU working in Agriculture, forestry and fishing were the most likely to be self-employed $(60 \%)$, followed by professional, scientific, technical activities (44\%) and other service activities (32\%), which includes personal services (e.g. hairdressing and beauty services), computer repair and more (Figure 5.7). These proportions generally follow the overall self-employment rates by sector but the rates for seniors were above the self-employment rates for the overall population (15-64 years old). However, the gap in self-employment rates between seniors and the overall population was large in professional, scientific, technical activities (12 percentage points, p.p.), accommodation and food services (11 p.p.) and agriculture, forestry and fishing (11 p.p.). This gap can be partially explained by the nature of the work in these sectors (e.g. some sectors have less physically demanding work than others) as well as different regulations across sectors (e.g. social security contributions and insurance requirements). 
Figure 5.7. More than $60 \%$ of seniors working in Agriculture, forestry and fishing in the EU are selfemployed

Self-employment as a percentage of employment in the EU, 2020

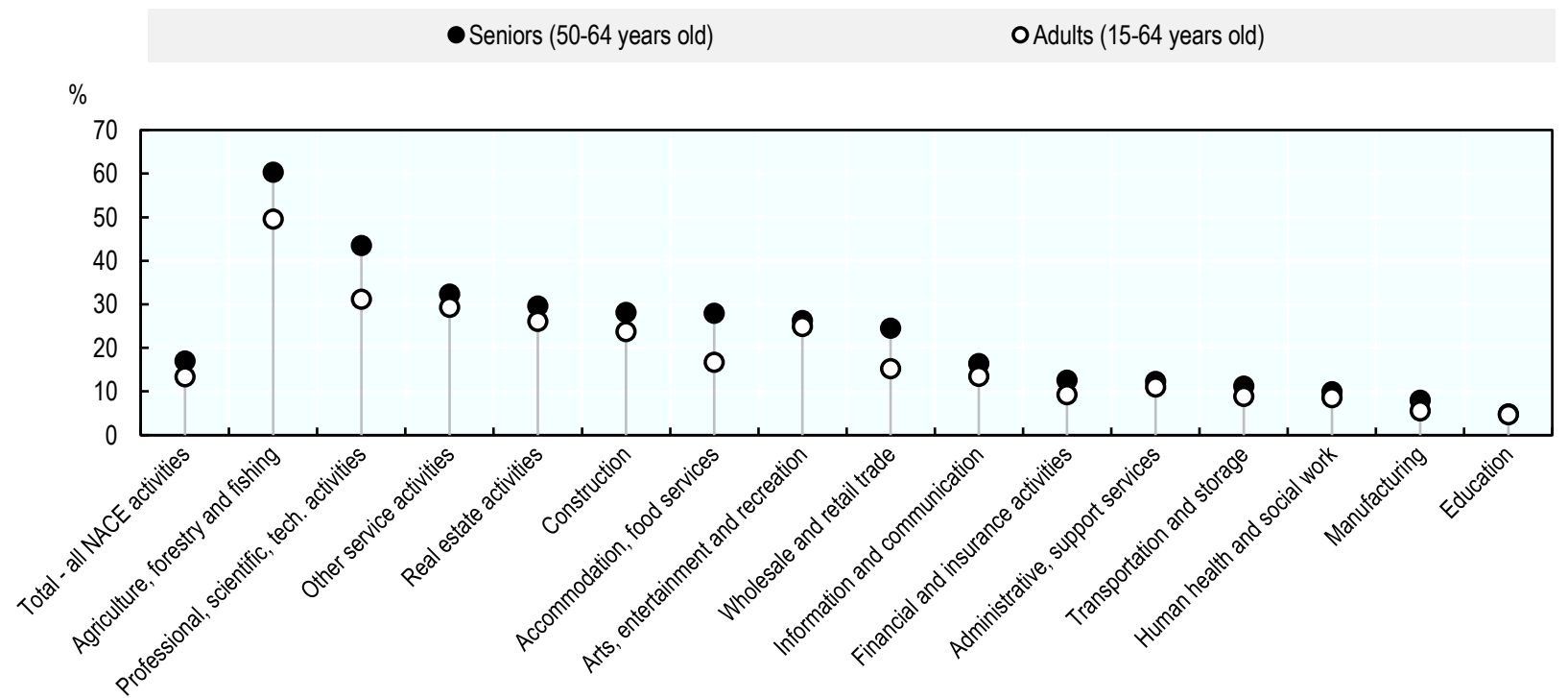

Note: The following sectors were excluded because the self-employment rate was less than $1 \%$ or the data were could not be reported due to a low reliability of the estimate: Public administration and defence, compulsory social security; Mining and quarrying; and Electricity, gas, steam and air conditioning supply.

Source: (Eurostat, 2021 [14])

StatLink त्ञाज https://doi.org/10.1787/888934280859

\section{....and the majority of self-employed seniors are professionals}

The distribution of self-employed seniors in the EU by occupation is essentially the same as the overall distribution of self-employed workers by sector. About one-fifth of self-employed seniors in the EU were in professional occupations in 2020 (e.g. business and administration professionals, ICT professionals), while $16 \%$ were service and sales workers and $14 \%$ were craft and trade workers (Figure 5.8). Conversely, self-employed seniors were least likely to be working as clerical support workers $(2 \%)$ or elementary occupations $(2 \%)$. However, self-employed seniors with employees had a higher concentration in managerial occupations $(29 \%)$, which was the same share for the overall population (1564 years old). 


\section{Figure 5.8. One-fifth of self-employed seniors are professionals}

Distribution of workers by sector in the EU, 2020

a. Self-employed

Seniors $(50-64$ years old $)$

$\diamond$ Adults $(15-64$ years old $)$

$\%$

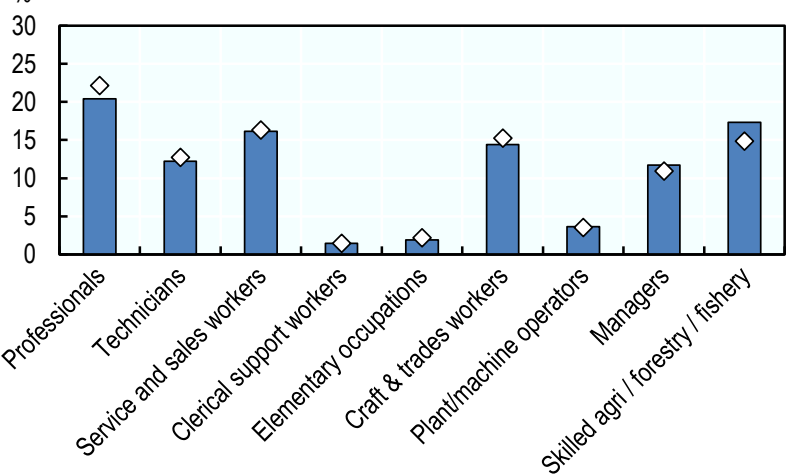

c. Self-employed with employees

$\square$ Seniors (50-64 years old) $\quad \diamond$ Adults (15-64 years old)

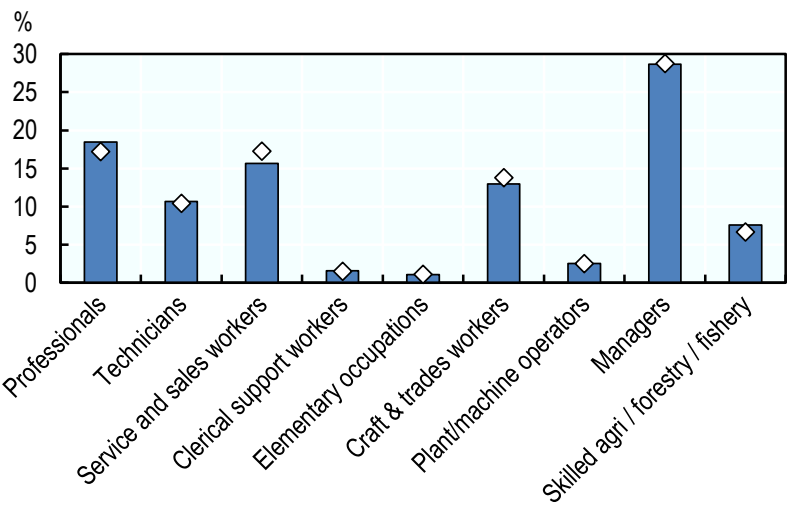

Source: (Eurostat, 2021 [14]) b. Employees

Seniors $(50-64$ years old $)$

$\diamond$ Adults $(15-64$ years old $)$
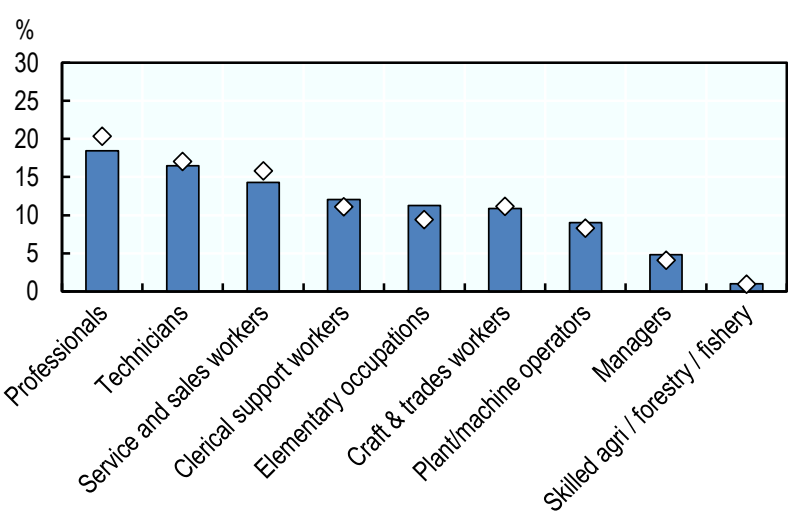

d. Self-employed without employees

Seniors (50-64 years old) $\quad \diamond$ Adults $(15-64$ years old

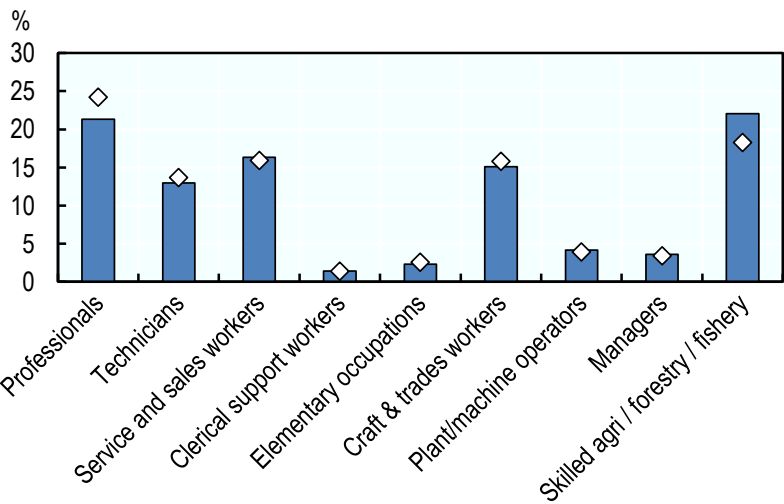

StatLink 겜 https://doi.org/10.1787/888934280878

\section{Self-employed seniors are more likely to have a tertiary education than those working as employees}

The share of self-employed seniors in the EU with a tertiary education increased over the last two decades, following the overall trend for self-employed adults. In 2002 , about $19 \%$ of self-employed seniors (50-64 years old) in the EU had a tertiary education and share increased to $33 \%$ in 2020 (Figure 5.9). Similarly, the share with an upper second and non-tertiary education increased $33 \%$ to $44 \%$ over this period. These increases were offset by a decrease in the share who had less than an upper secondary education, which declined from $49 \%$ to $23 \%$. The increase in the share of self-employed seniors with a tertiary education mirrored the overall increase in the population and is explained by increasing the growing share of the population obtaining a tertiary education and the aging of this population. Selfemployed seniors were slightly more likely to have a tertiary education than seniors working as employees but also more likely to have less than an upper secondary education. 
Figure 5.9. Self-employed seniors with employees are more likely to have a tertiary education than those without employees

Distribution of the self-employed and employees in the EU by educational attainment
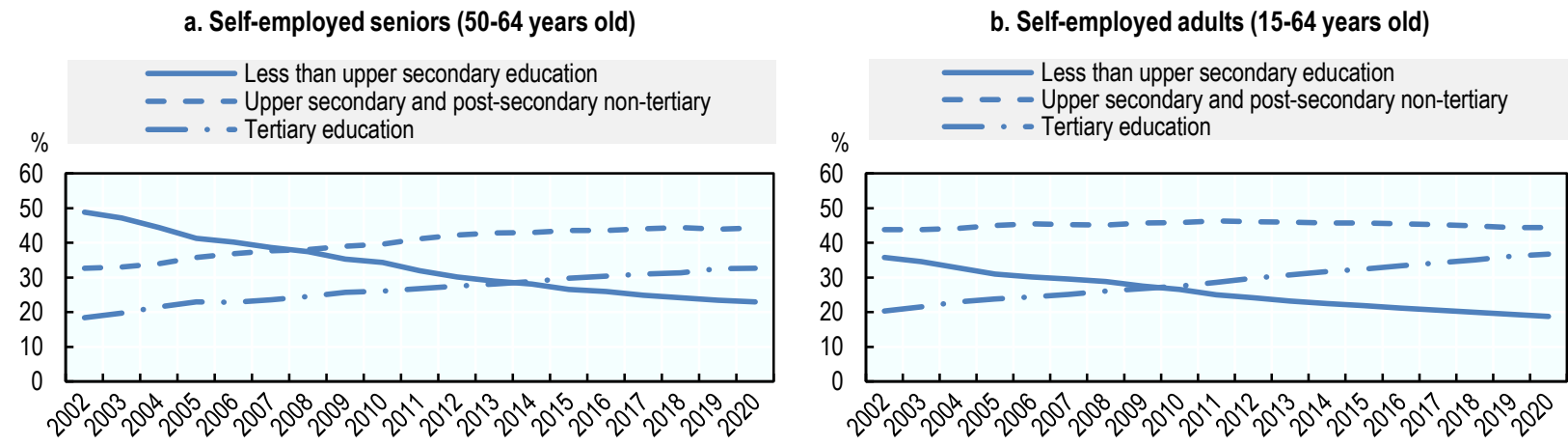

c. Seniors employees (50-64 years old)
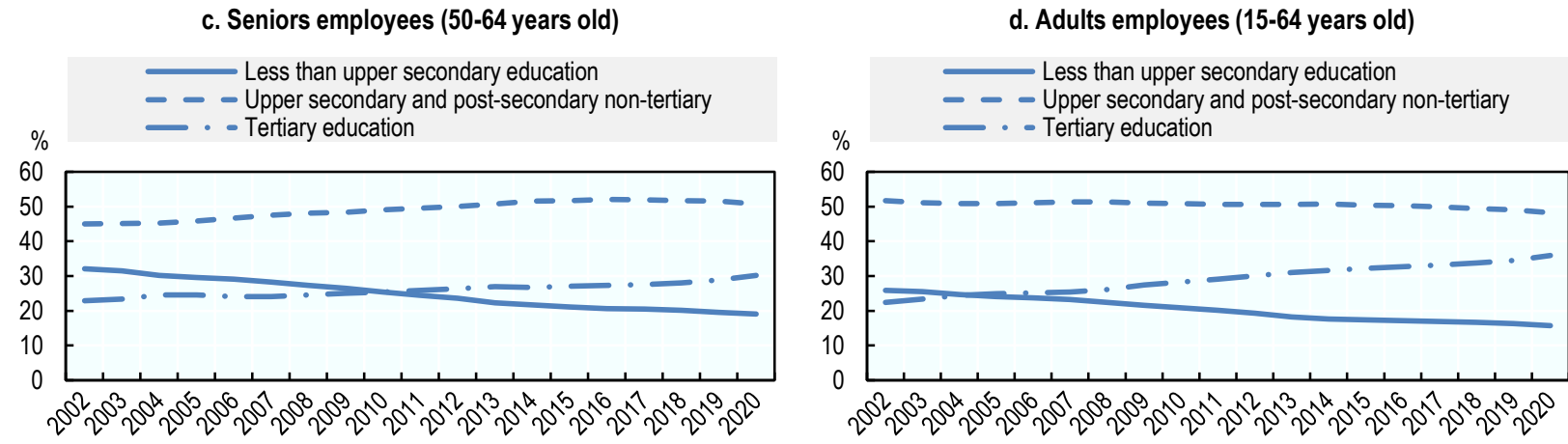

e. Self-employed seniors with employees (50-64 years old)

f. Self-employed adults with employees (15-64 years old)
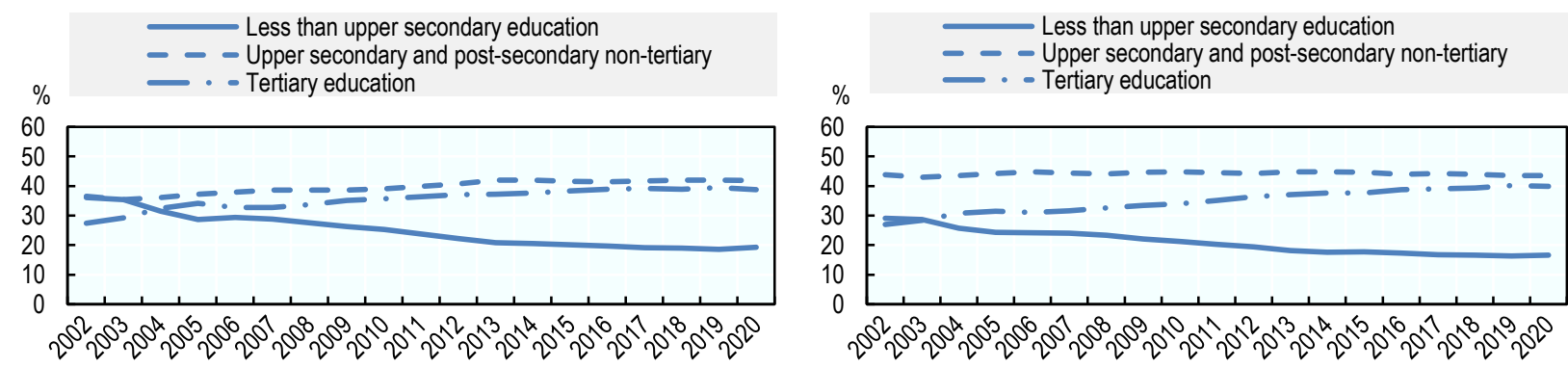

g. Self-employed seniors without employees (50-64 years old)

h. Self-employed adults without employees (15-64 years old)
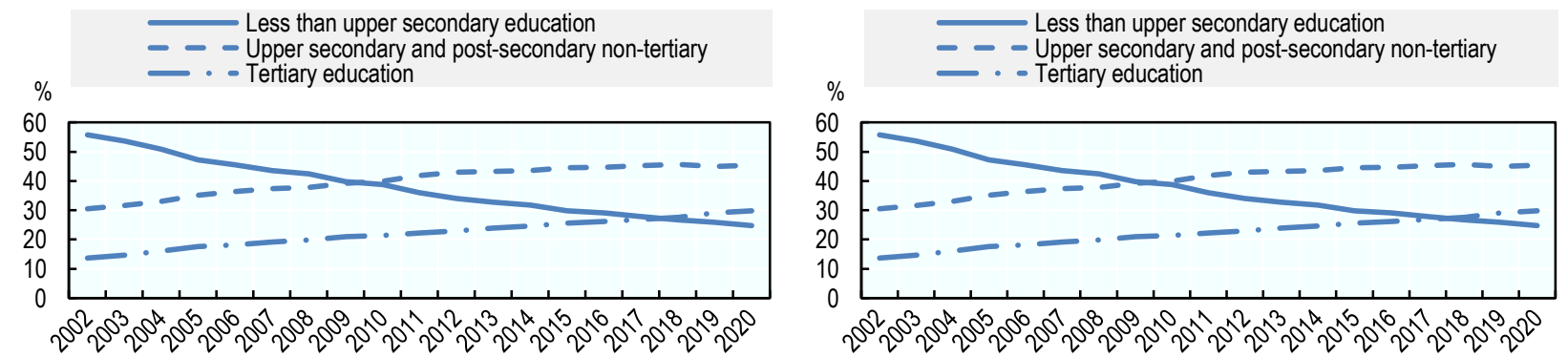

Source: (Eurostat, 2021 [14])

StatLink ज्ञाज https://doi.org/10.1787/888934280897 


\section{Activities by seniors over the entrepreneurship life-cycle}

Entrepreneurship activities by seniors can also be estimated through household surveys. The Global Entrepreneurship Monitor (GEM) is one of the most well-known annual international population surveys on entrepreneurship, asking about people's involvement in business creation and management. GEM is a network composed of researchers and research institutes that manage these annual household surveys. For more information on GEM, please refer to the Reader's Guide at the beginning of this report.

\section{Few seniors are involved in early-stage entrepreneurship...}

Seniors were almost half as likely as the overall population in the EU to be actively working on creating a new business between 2016 and 2020. About $2 \%$ of people between 50 and 64 years old were involved in nascent entrepreneurship activities in the EU over this period, which estimates the share of the population who were actively working towards the creating a new business that has not paid salaries or wages for more than three months (Figure 5.10). This is below the overall share of the population involved in nascent entrepreneurship (4\%). However, the share of seniors involved in nascent entrepreneurship was higher in OECD countries (5\%), which is consistent with a higher overall nascent entrepreneurship rate for this period. Several factors explain low levels of business creation among seniors, including a high proportion are already engaged in self-employment and many prefer to retire.

The nascent entrepreneurship rate for seniors varied somewhat across EU Member States over the 2016-20 period, ranging from about $1 \%$ in Bulgaria and Italy to $6 \%$ in the Slovak Republic and Ireland. The difference across countries can be largely explained by differences in entrepreneurship rates across countries and also differences in age structures of the population. However, there are also some country-specific factors that influence labour market decisions made by people near the end of their career. In the Netherlands, for example, the retirement age will increase to 67 years old beginning in 2024 and this is expected to increase entrepreneurship activities among seniors as a growing share of people look to business creation as a mechanism for transitioning into retirement (CBS, 2020[18]).

The share of seniors involved in new business ownership in the EU was also lower than the share for the overall population over the period 2016-20. Less than $2 \%$ of new business owners - those who own a business that is less than 42 months old - were $50-64$ years old relative to about $3 \%$ of the overall population. Consistent with the nascent entrepreneurship rate, the new business ownership rate for seniors was higher in OECD than in EU countries (more than 4\%).

New business ownership rates among seniors did not vary substantially across EU Member States. Seniors were the most likely to be new business owners in Portugal, Ireland and the Netherlands where about 3\% of those 50-64 years old owned a new business (Figure 5.10). The new business ownership rate also tended to be low in countries where the nascent entrepreneurship rate was low. Less than $1 \%$ of seniors in Poland and Italy had the lowest level of new business ownership in the EU. 
Figure 5.10. Early-stage entrepreneurship varies by country

Percent of the population (18-64 years old), 2016-20

a. Nascent entrepreneurship rate

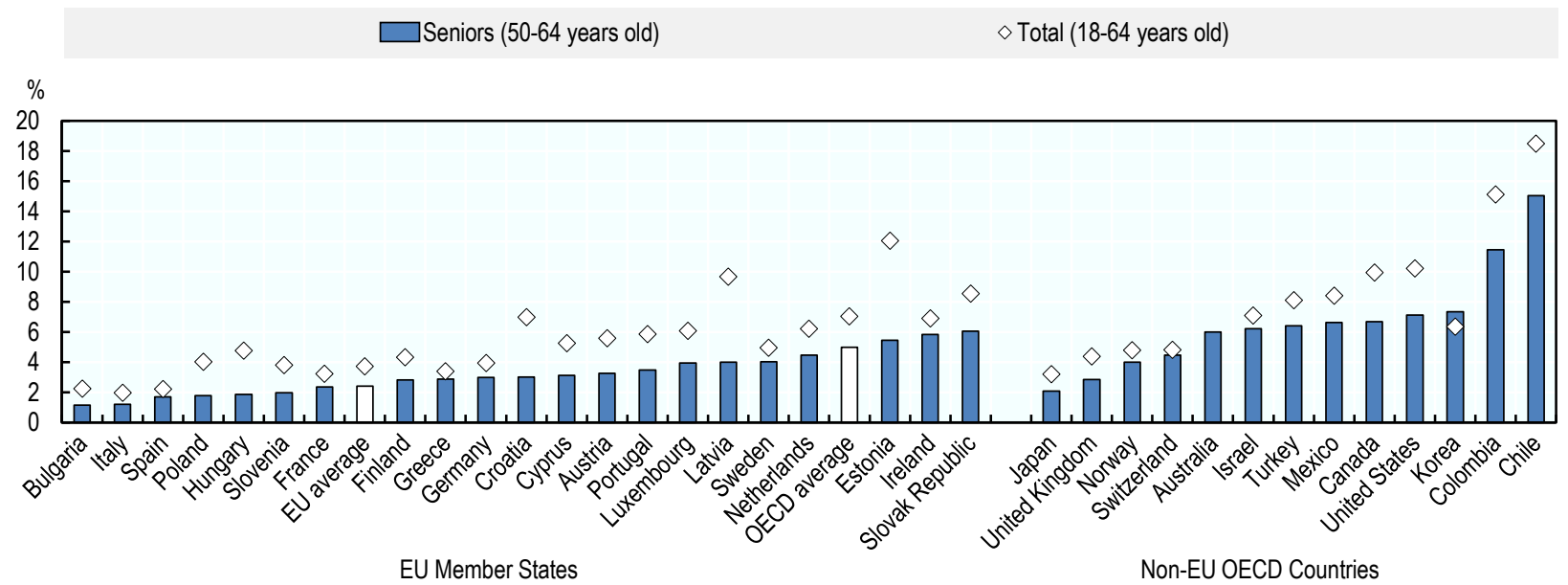

b. New business ownership rate

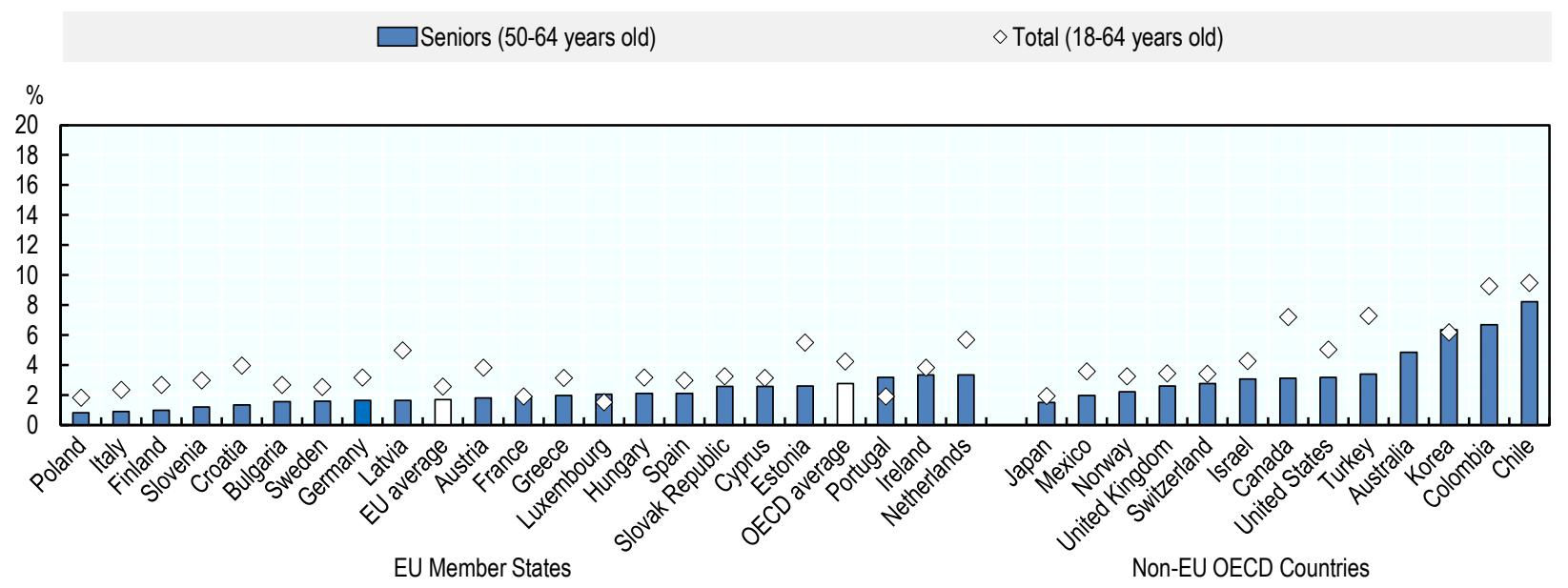

Note: Nascent entrepreneurship rate is the proportion of the population that is actively involved in setting up a business they will own or co-own; this business has not paid salaries, wages or any other payments to the owners for more than three months. New business ownership is the proportion of the population that is currently an owner-manager of a new business that has paid salaries, wages or any other payments to the owners for more than three months, but not more than 42 months. All EU Member States participated in the GEM survey between 2016 and 2020 except for Belgium, Czech Republic, Denmark, Lithuania, Malta and Romania. Furthermore, the following countries did not participate in the survey in every year over this period (years of participation are indicated): Austria (2016, 2018, 2020), Bulgaria (2016-18), Estonia (201617), Finland (2016), France (2016-18), Hungary (2016), Ireland (2016-19), Latvia (2016-17, 2019-20) and Portugal (2016, 2019). Similarly, the following OECD countries did not participate in the GEM survey between 2016 and 2020: Belgium, Czech Republic, Denmark, Iceland, Lithuania and New Zealand. The following countries did not participate in the survey in every year (years of participation are indicated): Australia (201617, 2019), Austria (2016, 2018, 2020), Estonia (2016-17), Finland (2016), France (2016-18), Hungary (2016), Ireland (2016-19), Japan (201719), Latvia (2016-17, 2018-19), Mexico (2016-17, 2019), Norway (2019-20), Portugal (2016, 2019) and Turkey $(2016,2018)$.

Source: (Global Entrepreneurship Monitor (GEM), 2021[19]) 


\section{....and were more likely than adults to have started their business out of necessity}

The GEM survey shows that seniors in the EU were more likely to start their early-stage business activity between 2016 and 2020 because they could not find suitable employment. Nearly onequarter of new entrepreneurs between 50 and 64 years old started their business out of "necessity" relative to the overall average (15-64 years old) of $18 \%$ (Figure 5.11). These shares were higher than those reported in OECD countries where about $20 \%$ of new early-stage senior entrepreneurs launched their business out of necessity. While it is not uncommon for people to start a business to earn income because they cannot find a job, there are some factors that are more likely to affect those who are at the end of their career. For example, research in France shows that necessity entrepreneurship among seniors can be driven by a lack of retirement savings and new financial pressures that arise from children attending postsecondary education or second families that have been started by people who have remarried (Malek, Adnane and Imen, 2011[12]).

At the country level, there was often but not always a strong correlation between the overall rate of necessity entrepreneurship and the share of seniors who were "necessity" entrepreneurs. Half of early-stage senior entrepreneurs in Croatia reported that they started their business out of necessity, followed by Hungary (48\%) and Latvia (46\%) (Figure 5.11). These necessity rates were well above those for the overall population - 32\% in Croatia and Latvia and $20 \%$ in Hungary. On the other hand, the necessity rate tended to be lower Member States with strong public pension systems such as Luxembourg, Netherlands and Sweden. Research from the Netherlands shows that seniors who pursue entrepreneurship at the end of their career are people who have had successful careers and who have better access to resources (e.g. networks, finance) (Lassen and Vrangbæk, 2021[6]).

\section{Figure 5.11. Nearly one-quarter of seniors started businesses out of necessity in the EU}

Percent of early-stage entrepreneurs, 2016-20

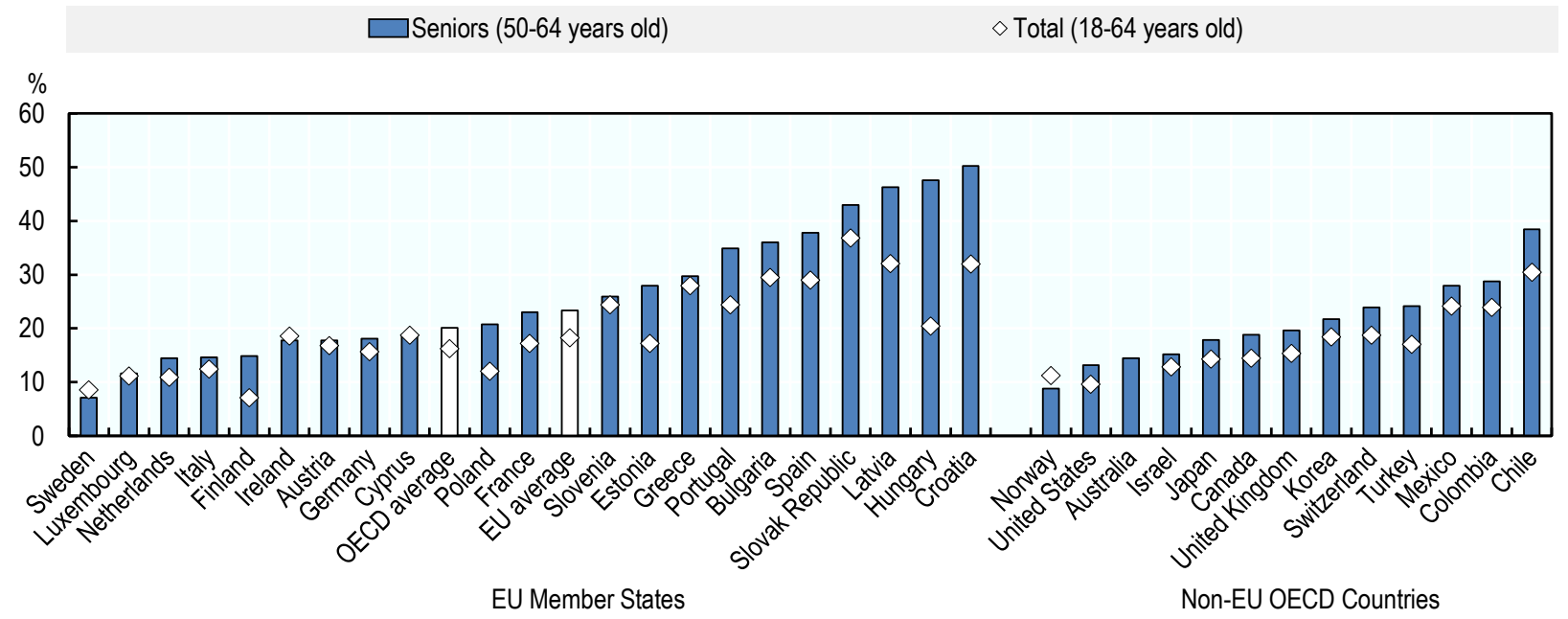

Note: Necessity entrepreneurship rate is the proportion of early-stage entrepreneurs (i.e. nascent entrepreneurs and new business owners) who launched their business due to a lack of other opportunities in the labour market. All EU Member States participated in the GEM survey between 2016 and 2020 except for Belgium, Czech Republic, Denmark, Lithuania, Malta and Romania. Furthermore, the following countries did not participate in the survey in every year over this period (years of participation are indicated): Austria (2016, 2018, 2020), Bulgaria (2016-18), Estonia (2016-17), Finland (2016), France (2016-18), Hungary (2016), Ireland (2016-19), Latvia (2016-17, 2019-20) and Portugal (2016, 2019). Similarly, the following OECD countries did not participate in the GEM survey between 2016 and 2020: Belgium, Czech Republic, Denmark, Iceland, Lithuania and New Zealand. The following countries did not participate in the survey in every year (years of participation are indicated): Australia (2016-17, 2019), Austria (2016, 2018, 2020), Estonia (2016-17), Finland (2016), France (2016-18), Hungary (2016), Ireland (2016-19), Japan (2017-19), Latvia (2016-17, 2018-19), Mexico (2016-17, 2019), Norway (2019-20), Portugal (2016, 2019) and Turkey (2016, 2018). Source: (Global Entrepreneurship Monitor (GEM), 2021 [19]) 


\section{New senior entrepreneurs were as likely as all adults to start a business in a team}

One-in-five nascent entrepreneurship projects in the EU are started by teams of three or more, and seniors were no exception. Between 2016 and 2020, $20 \%$ of nascent entrepreneurship activities by those 50 to 64 years old were undertaken by teams of three or more people (Figure 5.12). The share of nascent senior entrepreneurs in the EU operating in teams was about the same as the OECD average for this period ( $21 \%$ for both seniors and the whole population).

The share of senior entrepreneurs working in teams varied little across EU Member States, with the exception of a few countries where it was really common or not common. Team entrepreneurship was the most common among seniors in Slovenia over this period where more than one-third of nascent senior entrepreneurs (36\%) reported working in teams relative to $26 \%$ of all nascent entrepreneurship activities. On the other hand, relatively few senior entrepreneurs were working in teams in Poland $(11 \%)$ and Sweden (10\%).

\section{Figure 5.12. Around one-fifth of seniors started a business in a team}

Percent of nascent entrepreneurs, 2016-20

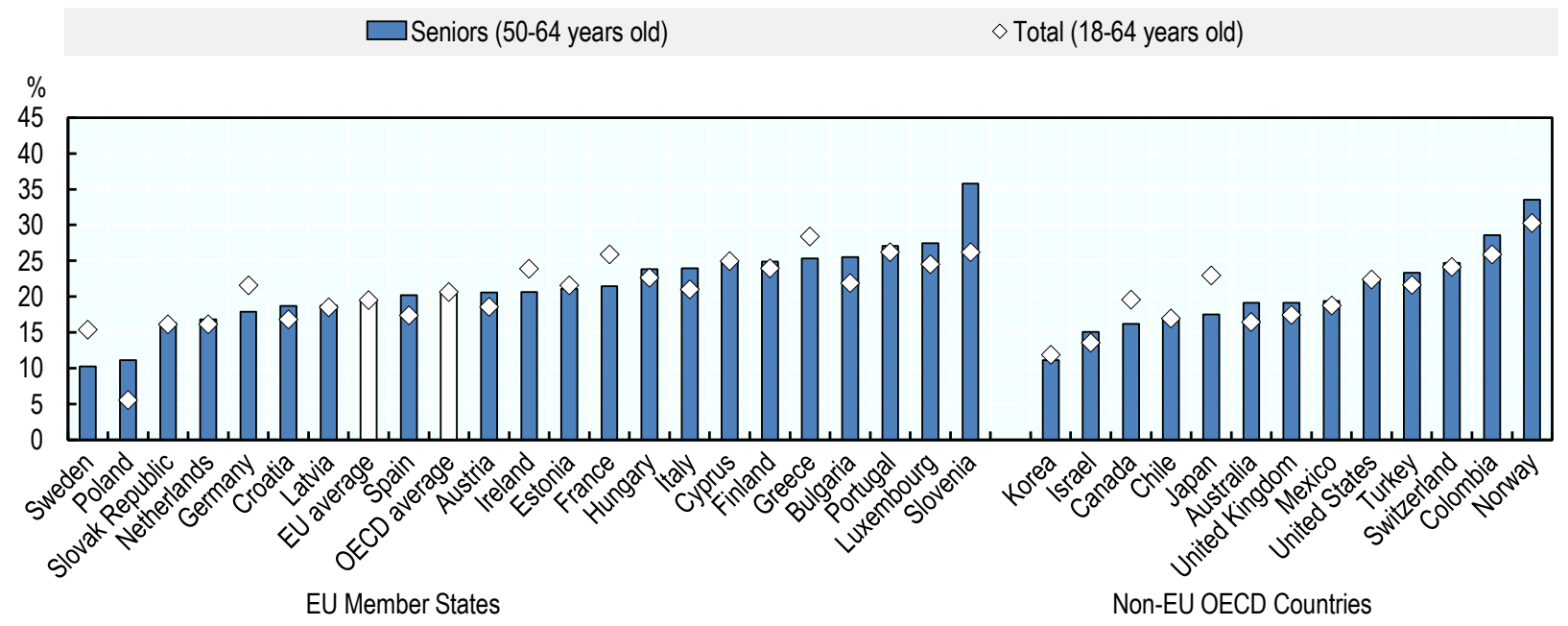

Note: Nascent entrepreneurship rate is the proportion of the population that is actively involved in setting up a business they will own or co-own; this business has not paid salaries, wages or any other payments to the owners for more than three months. All EU Member States participated in the GEM survey between 2016 and 2020 except for Belgium, Czech Republic, Denmark, Lithuania, Malta and Romania. Furthermore, the following countries did not participate in the survey in every year over this period (years of participation are indicated): Austria (2016, 2018, 2020), Bulgaria (2016-18), Estonia (2016-17), Finland (2016), France (2016-18), Hungary (2016), Ireland (2016-19), Latvia (2016-17, 2019-20) and Portugal $(2016,2019)$. Similarly, the following OECD countries did not participate in the GEM survey between 2016 and 2020: Belgium, Czech Republic, Denmark, Iceland, Lithuania and New Zealand. The following countries did not participate in the survey in every year (years of participation are indicated): Australia (2016-17, 2019), Austria (2016, 2018, 2020), Estonia (2016-17), Finland (2016), France (2016-18), Hungary (2016), Ireland (2016-19), Japan (2017-19), Latvia (2016-17, 2018-19), Mexico (2016-17, 2019), Norway (2019-20), Portugal (2016, 2019) and Turkey $(2016,2018)$.

Source: (Global Entrepreneurship Monitor (GEM), 2021[19]) 


\section{Seniors are twice as likely as all adults to be established business owners}

Contrary to the measures of early-stage entrepreneurship - nascent entrepreneurship activities and new business ownership - the share of seniors who are established business owners is greater than the overall share in the population. Nearly $9 \%$ of seniors (50-64 years old) in the EU were owners of an established business, i.e. on that has paid salaries, wages or any other payments to the owners for more than 42 months. This share is higher than the nascent entrepreneurship and new business ownership rates because this measure picks up the stock of business owners in the economy rather than the flow of people into entrepreneurship. It is not surprising that younger people are more likely to be new entrepreneurs because most of the older people who want to be entrepreneurs already are. A similar picture emerges in OECD countries, but a slightly greater proportion of seniors in OECD countries are established business owners (11\%), which is consistent with higher rates of early-stage entrepreneurship.

The share of seniors who were established business owners between 2016 and 2020 varied across EU Member States, ranging from $4 \%$ in Luxembourg to $14 \%$ in Greece. The level of established business ownership among seniors is influenced by a large range of factors - much like self-employment rates - including labour market conditions, access to finance, competition and market factors, regulatory burden and more.

\section{Figure 5.13. Nearly $9 \%$ of seniors in the EU are owners of an established business}

Percent of the population (18-64 years old), 2016-20

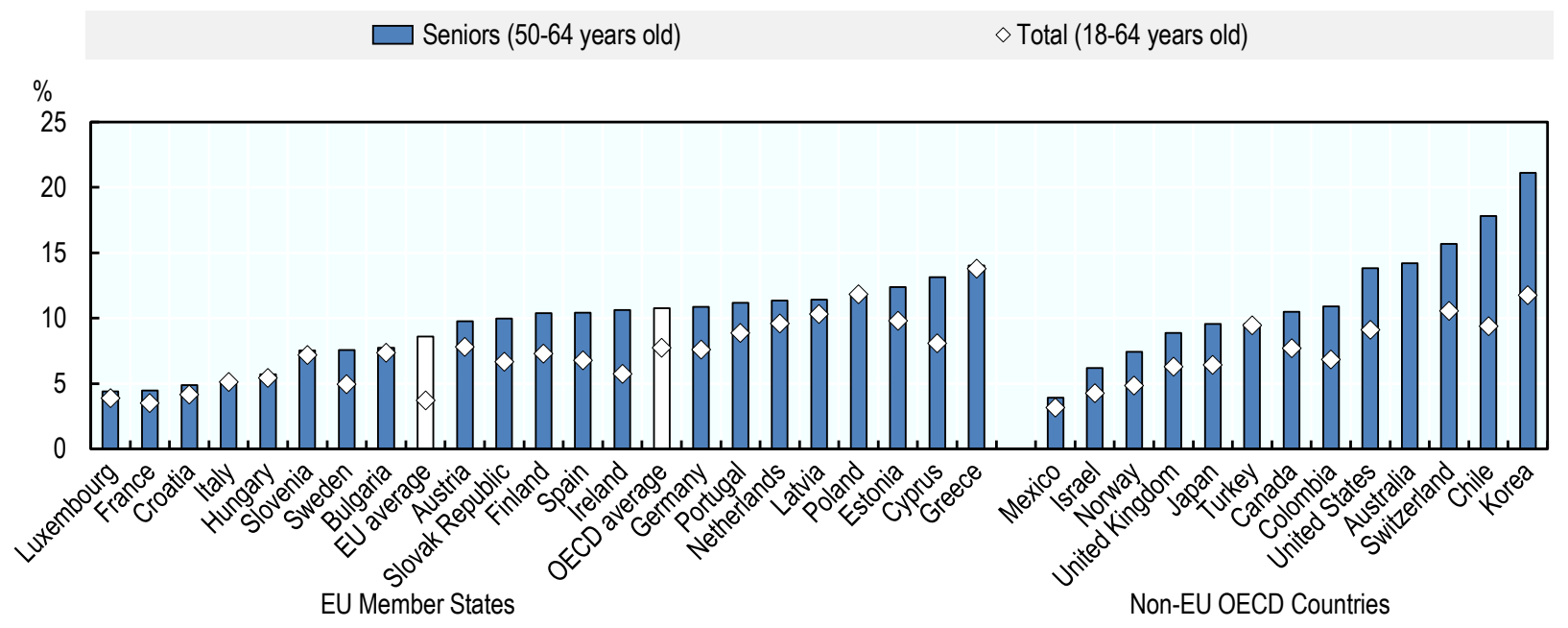

Note: Established business ownership rate is the proportion of the adult population that are currently owner-managers of an established business that has paid salaries, wages or any other payments to the owners for more than 42 months. All EU Member States participated in the GEM survey between 2016 and 2020 except for Belgium, Czech Republic, Denmark, Lithuania, Malta and Romania. Furthermore, the following countries did not participate in the survey in every year over this period (years of participation are indicated): Austria (2016, 2018, 2020), Bulgaria (2016-18), Estonia (2016-17), Finland (2016), France (2016-18), Hungary (2016), Ireland (2016-19), Latvia (2016-17, 2019-20) and Portugal (2016, 2019). Similarly, the following OECD countries did not participate in the GEM survey between 2016 and 2020: Belgium, Czech Republic, Denmark, Iceland, Lithuania and New Zealand. The following countries did not participate in the survey in every year (years of participation are indicated): Australia (2016-17, 2019), Austria (2016, 2018, 2020), Estonia (2016-17), Finland (2016), France (2016-18), Hungary (2016), Ireland (2016-19), Japan (2017-19), Latvia (2016-17, 2018-19), Mexico (2016-17, 2019), Norway (2019-20), Portugal (2016, 2019) and Turkey (2016, 2018).

Source: (Global Entrepreneurship Monitor (GEM), 2021 $\left.{ }_{[19]}\right)$ 


\section{Most seniors stopped operating their business because it was not profitable}

About $40 \%$ of seniors who stopped their business during the previous year reported that they were motivated by retirement or that their business was not profitable. Between 2016 and 2020, (50-64 years old) were three times more likely than all entrepreneurs who closed a business during the previous year to report that their main motivation was that it was not profitable ( $24 \%$ vs. $8 \%$ ) (Figure 5.14$)$. Few senior entrepreneurs reported that they exited their business because they had an opportunity to sell it $(6 \%)$. This could point to a need for greater policy actions to support business transfers for entrepreneurs who seek to sell their business to fund their retirement.

\section{Figure 5.14. One-quarter of seniors who stopped their business were more likely to cite lack of profit over retirement}

"What was the most important reason for quitting this business?"

Share of entrepreneurs that exited in the past 12 months, 2016-20

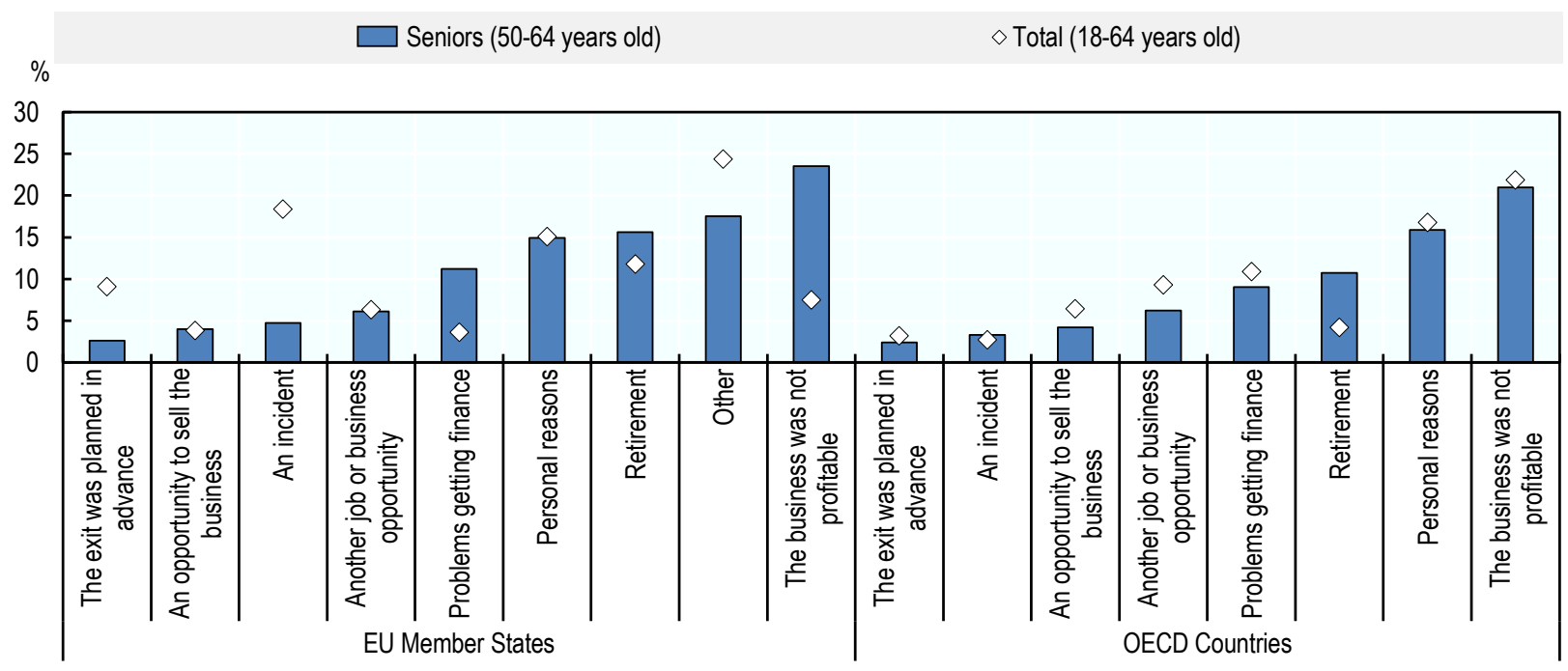

Note: All EU Member States participated in the GEM survey between 2016 and 2020 except for Belgium, Czech Republic, Denmark, Lithuania, Malta and Romania. Furthermore, the following countries did not participate in the survey in every year over this period (years of participation are indicated): Austria (2016, 2018, 2020), Bulgaria (2016-18), Estonia (2016-17), Finland (2016), France (2016-18), Hungary (2016), Ireland (2016-19), Latvia $(2016-17,2019-20)$ and Portugal $(2016,2019)$. Similarly, the following OECD countries did not participate in the GEM survey between 2016 and 2020: Belgium, Czech Republic, Denmark, Iceland, Lithuania and New Zealand. The following countries did not participate in the survey in every year (years of participation are indicated): Australia (2016-17, 2019), Austria (2016, 2018, 2020), Estonia (2016-17), Finland (2016), France (2016-18), Hungary (2016), Ireland (2016-19), Japan (2017-19), Latvia (2016-17, 2018-19), Mexico (2016-17, 2019), Norway (2019-20), Portugal $(2016,2019)$ and Turkey $(2016,2018)$.

Source: (Global Entrepreneurship Monitor (GEM), 2021[19])

StatLink 케프 https://doi.org/10.1787/888934280992

\section{Barriers to business creation by seniors}

\section{Seniors reported that fear of failure was a barrier to business creation as often as younger people}

"Fear of failure" does not appear to be a disproportionate barrier to business creation for seniors. While $44 \%$ of seniors (50-64 years old) in the EU reported that a "fear of failure" was an obstacle to 
business creation over the period 2016-20, this was not different than the share in the overall population (Figure 5.15). The share of seniors reporting that fear of failure was a barrier to business creation was slightly higher in the EU than in OECD countries over this period $(38 \%)$. This suggests that there are differences in social attitudes towards risk in EU and non-EU OECD countries and is consistent with higher early-stage entrepreneurship rates in non-EU OECD countries.

The share of seniors reporting that fear of failure varied greatly across EU Member States. Between 2016 and 2020, the proportion of seniors (50-64 years old) reporting this barrier ranged from $29 \%$ in the Netherlands to $69 \%$ in Greece.

\section{Figure 5.15. Nearly $45 \%$ of seniors report a fear of failure as a barrier to business creation}

"Does a fear of failure prevent you from starting a business?"

Percentage of population (18-64 years old) who responded "yes", 2016-20

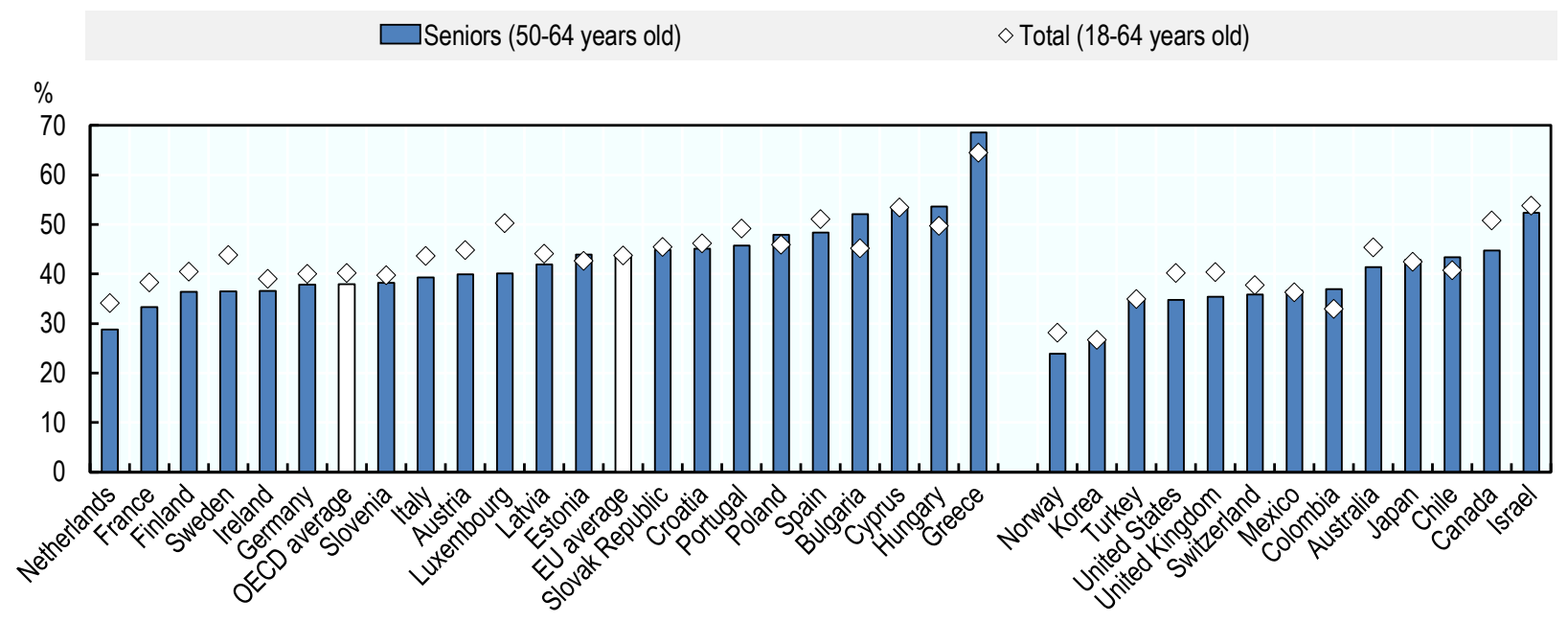

EU Member States

Non-EU OECD Countries

Note: All EU Member States participated in the GEM survey between 2016 and 2020 except for Belgium, Czech Republic, Denmark, Lithuania, Malta and Romania. Furthermore, the following countries did not participate in the survey in every year over this period (years of participation are indicated): Austria (2016, 2018, 2020), Bulgaria (2016-18), Estonia (2016-17), Finland (2016), France (2016-18), Hungary (2016), Ireland (2016-19), Latvia (2016-17, 2019-20) and Portugal (2016, 2019). Similarly, the following OECD countries did not participate in the GEM survey between 2016 and 2020: Belgium, Czech Republic, Denmark, Iceland, Lithuania and New Zealand. The following countries did not participate in the survey in every year (years of participation are indicated): Australia (2016-17, 2019), Austria (2016, 2018, 2020), Estonia (2016-17), Finland (2016), France (2016-18), Hungary (2016), Ireland (2016-19), Japan (2017-19), Latvia (2016-17, 2018-19), Mexico (2016-17, 2019), Norway (2019-20), Portugal $(2016,2019)$ and Turkey $(2016,2018)$.

Source: (Global Entrepreneurship Monitor (GEM), 2021[19])

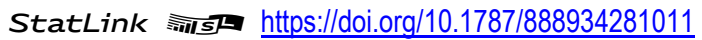

\section{Seniors are as likely as the overall population to report having entrepreneurship skills}

Older people, on average, do not appear to be disadvantaged in business due to a lack of perceived entrepreneurship skills. The real or perceived lack of entrepreneurship skills and knowledge can also be a strong barrier to business creation, but about $45 \%$ of seniors (50-64 years old) in the EU reported having the skills needed to start a business over the period 2016-20 (Figure 5.16). This was the same as the overall share of the population who reported having entrepreneurship skills. However, this proportion of seniors was about five percentage points below the share of seniors in OECD countries, which is consistent with the overall gap in entrepreneurship skills between EU and OECD countries. 
The share of seniors reporting that they had sufficient entrepreneurship skills to start a business did not vary substantially across EU Member States. In the vast majority of countries, the proportion ranged from $42 \%$ to $49 \%$. Outliers included France $(32 \%)$, Bulgaria $(34 \%)$, Hungary $(37 \%)$ and Finland (39\%), and Austria (50\%), Poland (52\%) and Croatia (56\%). Differences across countries illustrate a number of factors, including differences in perceived skills but also differences in self-confidence, social attitudes towards entrepreneurship and more.

\section{Figure 5.16. Seniors in the EU are as likely as the overall average to report having the skills to start} a business

"Do you have the knowledge and skills to start a business?"

Percentage of population who responded "yes", 2016-20

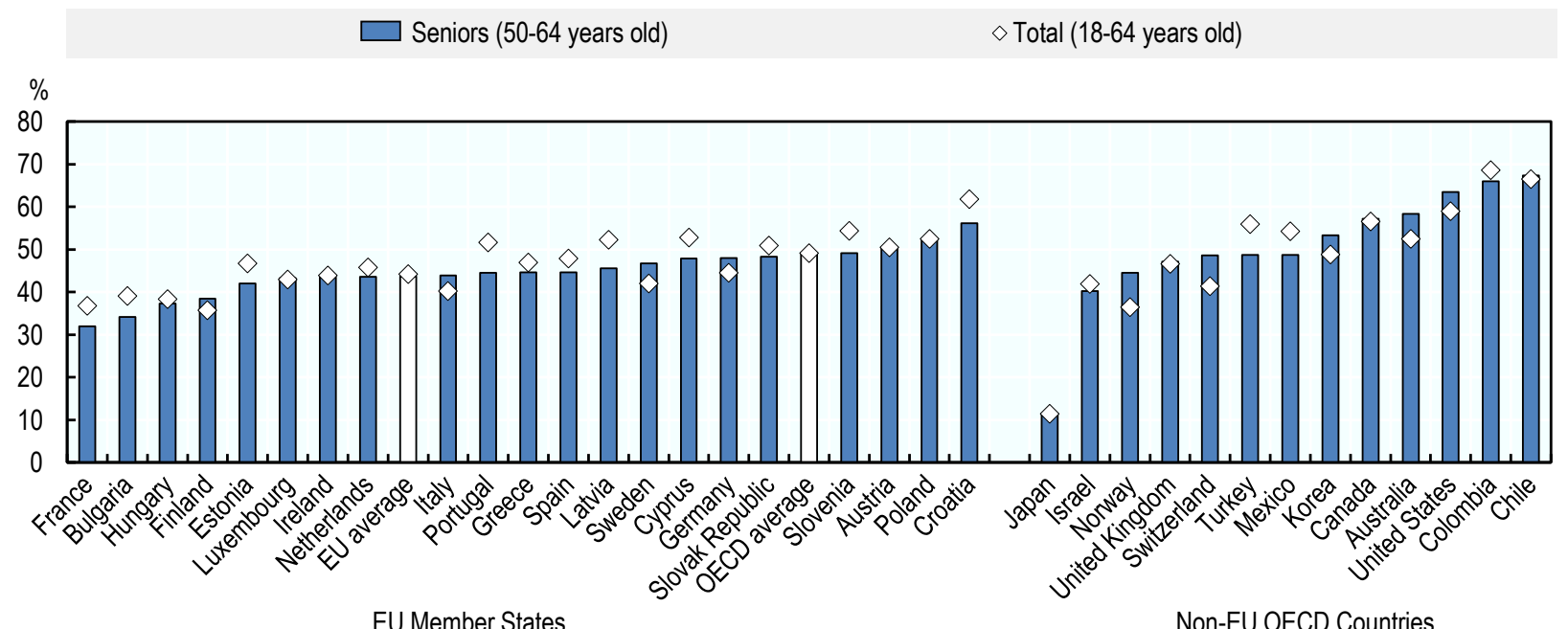

Note: All EU Member States participated in the GEM survey between 2016 and 2020 except for Belgium, Czech Republic, Denmark, Lithuania, Malta and Romania. Furthermore, the following countries did not participate in the survey in every year over this period (years of participation are indicated): Austria (2016, 2018, 2020), Bulgaria (2016-18), Estonia (2016-17), Finland (2016), France (2016-18), Hungary (2016), Ireland (2016-19), Latvia $(2016-17,2019-20)$ and Portugal $(2016,2019)$. Similarly, the following OECD countries did not participate in the GEM survey between 2016 and 2020: Belgium, Czech Republic, Denmark, Iceland, Lithuania and New Zealand. The following countries did not participate in the survey in every year (years of participation are indicated): Australia (2016-17, 2019), Austria (2016, 2018, 2020), Estonia (2016-17), Finland (2016), France (2016-18), Hungary (2016), Ireland (2016-19), Japan (2017-19), Latvia (2016-17, 2018-19), Mexico (2016-17, 2019), Norway (2019-20), Portugal $(2016,2019)$ and Turkey $(2016,2018)$.

Source: (Global Entrepreneurship Monitor (GEM), 2021 [19])

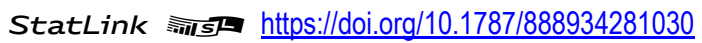

\section{Characteristics of senior entrepreneurship}

\section{Senior entrepreneurs are as likely to introduce new products and services...}

Nearly one-third of senior entrepreneurs in the EU introduced new products or services in the past year, which was about the same share as the overall population. A common method used by entrepreneurs to maintain and grow their market share is to introduce new products and services to attract customers. Across the EU, $29 \%$ of early-stage entrepreneurs (i.e. nascent entrepreneurs and new business owners) who were between 50 and 64 years old reported offering new products and/or services in the past year to potential customers in the period 2016-20 (Figure 5.17). This was slightly below the 
overall share of early-stage entrepreneurs (18 to 64 years old) who reported offering new products and/or services (31\%). The proportion of senior entrepreneurs offering new products and services in the EU was about the same as in OECD countries $(31 \%)$ during this period.

The share of senior entrepreneurs introducing new products and services over this period ranged from less than $10 \%$ to nearly half. Less than one-fifth of early-stage senior entrepreneurs (50-64 years old) introduced a new product or service in Hungary (9\%), Bulgaria (17\%) and Latvia (19\%) but more than four-fifths did in Ireland (40\%) and Luxembourg (44\%). In general, the share of early-stage senior entrepreneurs (50-64 years old) who introduced new products and services closely followed the overall proportion of early-stage entrepreneurs. The only exceptions were in Finland and Poland where they were more likely, and Croatia, Hungary, Latvia and Sweden where they were less likely.

\section{Figure 5.17. Nearly a third of early-stage senior entrepreneurs offered new products or services}

Proportion of early-stage entrepreneurs, 2016-20

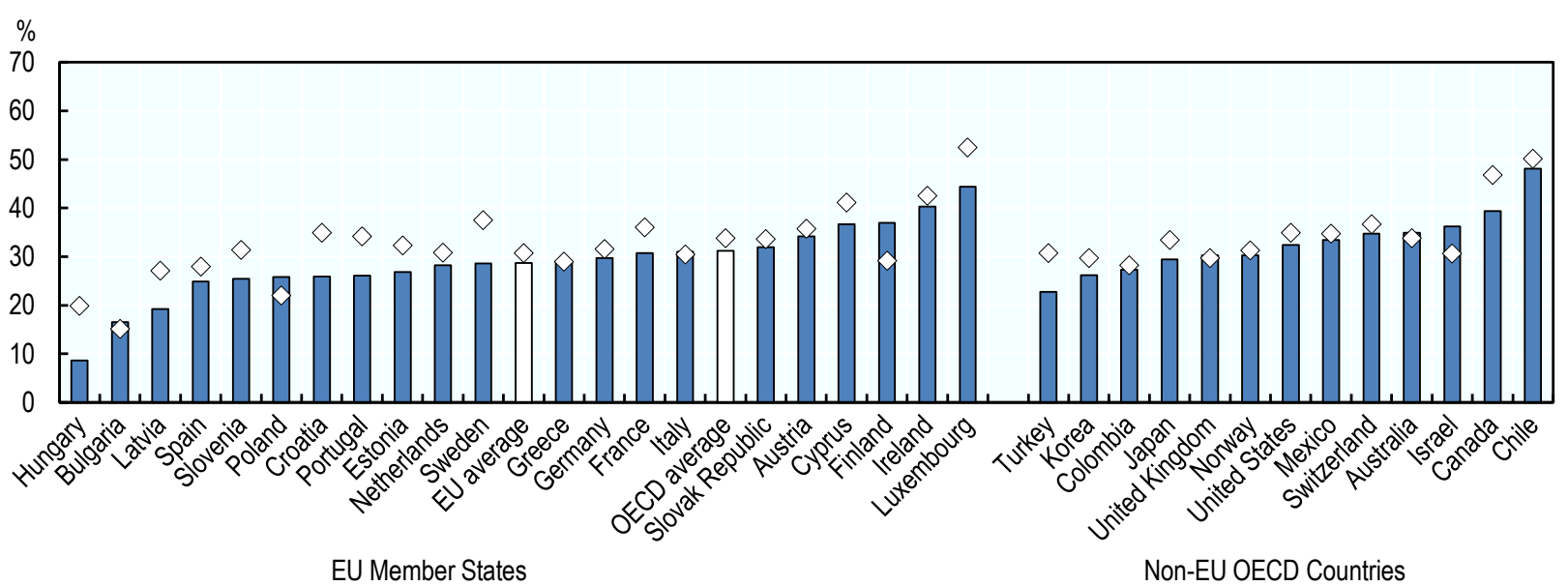

Note: All EU Member States participated in the GEM survey between 2016 and 2020 except for Belgium, Czech Republic, Denmark, Lithuania, Malta and Romania. Furthermore, the following countries did not participate in the survey in every year over this period (years of participation are indicated): Austria (2016, 2018, 2020), Bulgaria (2016-18), Estonia (2016-17), Finland (2016), France (2016-18), Hungary (2016), Ireland (2016-19), Latvia (2016-17, 2019-20) and Portugal $(2016,2019)$. Similarly, the following OECD countries did not participate in the GEM survey between 2016 and 2020: Belgium, Czech Republic, Denmark, Iceland, Lithuania and New Zealand. The following countries did not participate in the survey in every year (years of participation are indicated): Australia (2016-17, 2019), Austria (2016, 2018, 2020), Estonia (2016-17), Finland (2016), France (2016-18), Hungary (2016), Ireland (2016-19), Japan (2017-19), Latvia (2016-17, 2018-19), Mexico (2016-17, 2019), Norway (2019-20), Portugal $(2016,2019)$ and Turkey $(2016,2018)$.

Source: (Global Entrepreneurship Monitor (GEM), 2021 [19])

StatLink त्ञाs https://doi.org/10.1787/888934281049

\section{....and as likely to have internationally-oriented businesses...}

Early-stage senior entrepreneurs in the EU were about as likely as the overall population of earlystage entrepreneurs to report having customers in other countries between 2016 and 2020. Nearly half of early-stage senior entrepreneurs (50-64 years old) in the EU reported selling to customers in other countries (46\%), which was the share proportion among all early-stage entrepreneurs (47\%) (Figure 5.18). These proportions were slightly above the OECD averages for this period $-38 \%$ for seniors and $43 \%$ for all early-stage entrepreneurs - which is consistent with the EU operating as a single market. Barriers to 
exporting are very low in the EU so the share of entrepreneurs exporting would be expected to be higher in the EU than in other regions of the world where there are no free trade agreements.

More than $60 \%$ of early-stage senior entrepreneurs sold to foreign customers in five EU Member States. The countries with the greatest proportion of early-stage senior entrepreneurs (50-64 years old) who exported during the period 2016-20 were Ireland, Croatia and Slovenia (61\% each), as well as Greece $(62 \%)$ and Luxembourg (75\%) (Figure 5.18). Conversely, the EU Member States where early-stage senior entrepreneurs were least likely to report having customers in foreign countries were Spain (26\%), Bulgaria $(29 \%)$ and Poland (30\%). In several Member States, the proportion of early-stage seniors was substantially greater than the share among all early-stage entrepreneurs -7 percentage points (p.p.) in Poland and the Slovak Republic and 6 p.p. in Finland and Greece. Conversely, early-stage senior entrepreneurs were much less likely than the overall average to export in Hungary (29 p.p.) and Sweden (10 p.p.).

\section{Figure 5.18. Nearly half of early-stage senior entrepreneurs sold to foreign customers}

Proportion of early-stage entrepreneurs, 2016-20

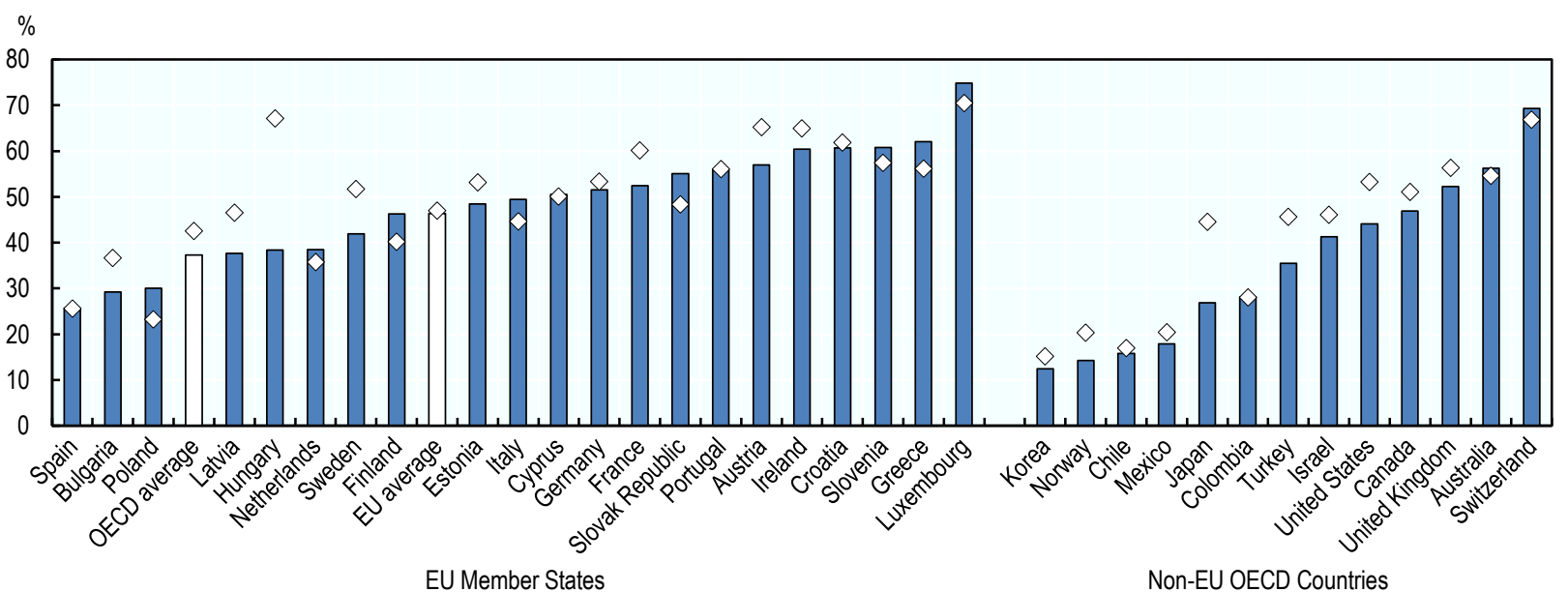

Note: All EU Member States participated in the GEM survey between 2016 and 2020 except for Belgium, Czech Republic, Denmark, Lithuania, Malta and Romania. Furthermore, the following countries did not participate in the survey in every year over this period (years of participation are indicated): Austria (2016, 2018, 2020), Bulgaria (2016-18), Estonia (2016-17), Finland (2016), France (2016-18), Hungary (2016), Ireland (2016-19), Latvia (2016-17, 2019-20) and Portugal $(2016,2019)$. Similarly, the following OECD countries did not participate in the GEM survey between 2016 and 2020: Belgium, Czech Republic, Denmark, Iceland, Lithuania and New Zealand. The following countries did not participate in the survey in every year (years of participation are indicated): Australia (2016-17, 2019), Austria (2016, 2018, 2020), Estonia (2016-17), Finland (2016), France (2016-18), Hungary (2016), Ireland (2016-19), Japan (2017-19), Latvia (2016-17, 2018-19), Mexico (2016-17, 2019), Norway (2019-20), Portugal $(2016,2019)$ and Turkey $(2016,2018)$.

Source: (Global Entrepreneurship Monitor (GEM), 2021 [19])

StatLink त्गाज् https://doi.org/10.1787/888934281068

\section{... and as likely to expect high growth over the next three years}

Early-stage senior entrepreneurs in the EU were about as likely to expect to create at least 19 new jobs over the next three years as the overall population of early-stage entrepreneurs. In the EU, $9 \%$ of early-stage entrepreneurs (50-64 years old) reported during the period 2016-20 that they expected this level of job creation relative to $10 \%$ of all early-stage entrepreneurs (Figure 5.19). This result is consistent with similarities in the proportions of early-stage entrepreneurs reporting that they are introducing new products and services, as well as exporting, i.e. growth-oriented business strategies. However, the 
proportion of early-stage senior entrepreneurs expecting high-growth was slightly higher in OECD countries $(12 \%)$ over this period.

The share of early-stage senior entrepreneurs reporting a high-growth expectation generally typically ranged from 5\% to 10\% across EU Member States between 2016 and 2020 . The countries were the greatest share of early-stage seniors expecting high-growth were Ireland (13\%), Germany (12\%), Cyprus and Luxembourg ( $11 \%$ each). On the other hand, fewer than $5 \%$ of early-stage senior entrepreneurs expected this level of job creation in Sweden (2\%) and Spain (4\%). There was only one Member State where seniors were substantially more likely to expect a high level of employment creation - Bulgaria, where $9 \%$ of early-stage seniors had high-growth expectations relative to $4 \%$ of all early-stage entrepreneurs.

\section{Figure 5.19. Nearly $10 \%$ of early-stage senior entrepreneurs expected to create 19 or more jobs in} the next five years

Proportion of early-stage entrepreneurs, 2016-20

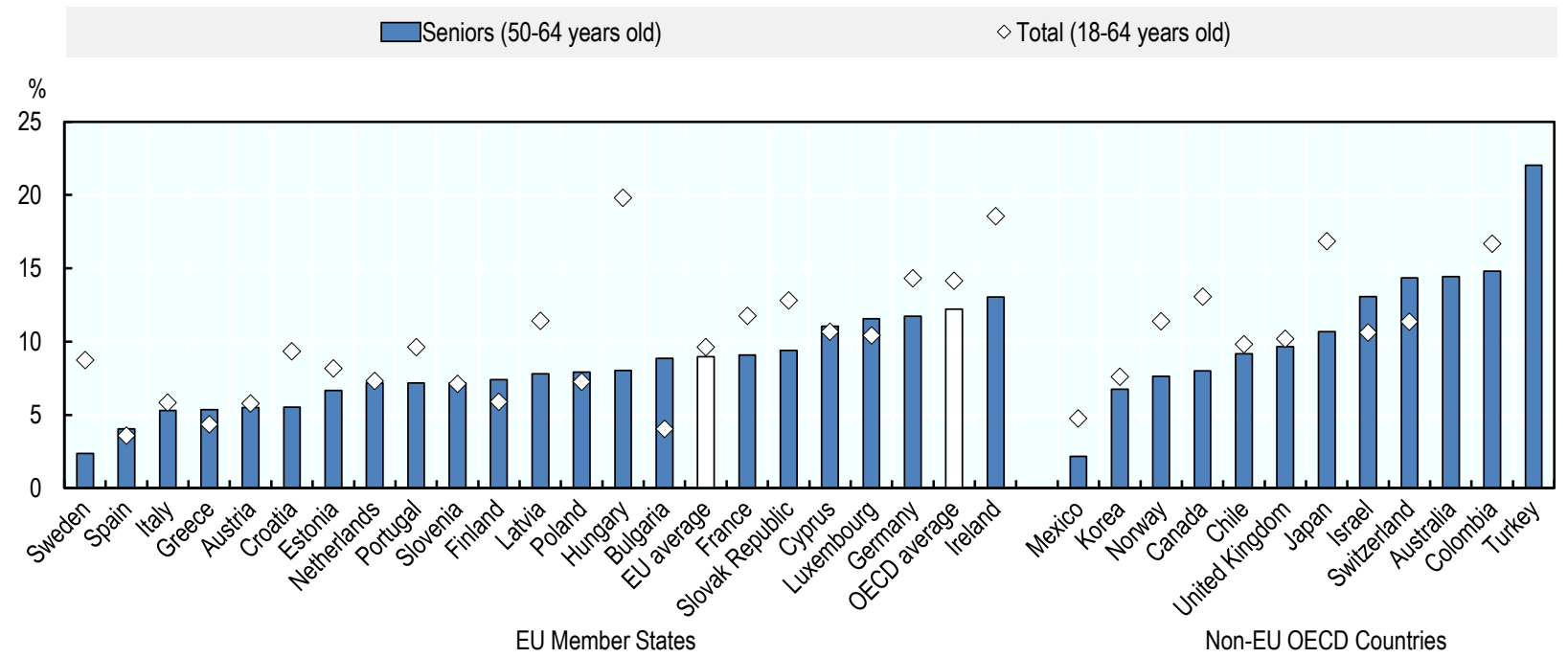

Note: All EU Member States participated in the GEM survey between 2016 and 2020 except for Belgium, Czech Republic, Denmark, Lithuania, Malta and Romania. Furthermore, the following countries did not participate in the survey in every year over this period (years of participation are indicated): Austria (2016, 2018, 2020), Bulgaria (2016-18), Estonia (2016-17), Finland (2016), France (2016-18), Hungary (2016), Ireland (2016-19), Latvia (2016-17, 2019-20) and Portugal (2016, 2019). Similarly, the following OECD countries did not participate in the GEM survey between 2016 and 2020: Belgium, Czech Republic, Denmark, Iceland, Lithuania and New Zealand. The following countries did not participate in the survey in every year (years of participation are indicated): Australia (2016-17, 2019), Austria (2016, 2018, 2020), Estonia (2016-17), Finland (2016), France (2016-18), Hungary (2016), Ireland (2016-19), Japan (2017-19), Latvia (2016-17, 2018-19), Mexico (2016-17, 2019), Norway (2019-20), Portugal $(2016,2019)$ and Turkey $(2016,2018)$.

Source: (Global Entrepreneurship Monitor (GEM), 2021[19])

StatLink त्ता Th https://doi.org/10.1787/888934281087

\section{Conclusions}

Seniors are more active than the adult population in self-employment and self-employed seniors are an extremely diverse group. They include people who have spent their entire career in selfemployment, those transitioning into retirement by starting a part-time business and those who start a business from retirement to boost retirement income or to remain active. Accordingly, the challenges faced by this group are diverse. Some lack entrepreneurship skills, while others lack financial resources and many will have small or outdated business networks. Public policy can play a role in addressing these 
barriers by offering entrepreneurship training, improving access to start-up financing and supporting the development of entrepreneurship networks.

Entrepreneurship holds potential for providing a way for seniors to remain active beyond the typical retirement age for those who wish to do so. Surveys suggest that many seniors wish to remain economically and socially active beyond 65 years old and there are many potential benefits to doing so, including improved physical and mental health, maintaining social connections, and creating economic value. Governments can do more to support people who wish to extend their careers through business creation, including the following actions:

- Create a positive awareness of entrepreneurship as a late-career option through promotional activities aimed at different stakeholder groups (e.g. business support organisations, financiers) to remove negative age bias as a potential barrier to senior entrepreneurship;

- Offer digital training and financial literacy training to potential senior entrepreneurs; and

- Ensure that enterprise support officials receive sensitivity training so that they can offer support to older people in an appropriate way (e.g. avoid jargon).

In addition, there is also untapped potential to leverage the experience of older entrepreneurs in supporting younger entrepreneurs. Encouraging experienced older individuals can support other business start-ups through mentoring, coaching and providing financial assistance. Their support is appreciated by (potential) entrepreneurs across all age groups, but especially by older entrepreneurs who require mentors at least of their own age who not only have the business experience but also empathy to the situation the older entrepreneur faces.

For more information and policy discussion on senior entrepreneurship activities, please refer to (OECD/EC, 2012[20]). Examples of recent policy action to support senior entrepreneurs are contained in the country profiles in Part III of this report.

\section{References}

Bratt, C. et al. (2018), "Perceived age discrimination across age in Europe: From an ageing society to a society for all ages.", Developmental Psychology, Vol. 54/1, http://dx.doi.org/10.1037/dev0000398.

CBS (2020), Krapte op de arbeidsmarkt neemt weer toe in vierde kwartaal, https://www.cbs.nl/nlnl/nieuws/2020/07/krapte-op-de-arbeidsmarkt-neemt-weer-toe-in-vierde-kwartaal (accessed on 2 July 2021).

Eurostat (2021), Labour Force Survey, https://ec.europa.eu/eurostat/web/lfs (accessed on 6 May 2021).

Eurostat (2021), Projected old-age dependency ratio, https://ec.europa.eu/eurostat/web/population-demography/population-projections/database (accessed on 30 July 2021).

Eurostat (2019), Population on 1st January by age, sex and type of projection, https://ec.europa.eu/eurostat/web/population-demography/population-projections/database (accessed on 30 July 2021).

Fachinger, U. and A. Frankus (n.d.), "Self-employed people and pension: is old age poverty the inevitable dark side of an entrepreneurial society?", in Exploring the Entrepreneurial Society, Edward Elgar Publishing, http://dx.doi.org/10.4337/9781783472666.00029. 
Global Entrepreneurship Monitor (GEM) (2021), Special tabulations for the OECD of the Global Entrepreneurship Monitor (GEM) adult population survey for the years 2016 to 2020.

Körber Stiftung (2018), Aufbruch: Gründergeist und soziale Verantwortung, Ergebnisse einer forsa-Umfrage im Auftrag der Körber-Stiftung zum gesellschaftlichen Potenzial der 50- bis 75Jährigen.

Lallo, C. and M. Raitano (2018), "Life expectancy inequalities in the elderly by socioeconomic status: evidence from Italy", Population Health Metrics, Vol. 16/1, http://dx.doi.org/10.1186/s12963-018-0163-7.

Lassen, A. and T. Moreira (2014), "Unmaking old age: Political and cognitive formats of active ageing", Journal of Aging Studies, Vol. 30, http://dx.doi.org/10.1016/j.jaging.2014.03.004.

Lassen, A. and K. Vrangbæk (2021), "Retirement transitions in the 21st century: A scoping review of the changing nature of retirement in Europe", International Journal of Ageing and Later Life, http://dx.doi.org/10.3384/ijal.1652-8670.1501.

Malek, B., M. Adnane and S. Imen (2011), ““Entrepreneurial intention among seniors: An application to French entrepreneurs", Proceedings of the 2011 Annual Conference of the International Council for Small Business.

OECD (2020), Inclusive Entrepreneurship Policies: Country Assessment Notes, https://www.oecd.org/cfe/smes/inclusive-entrepreneurship-policies-country-assessmentnotes.htm (accessed on 6 June 2021).

OECD (2020), "Rejuvenating Greece's labour market to generate more and higher-quality jobs", Economics Department Working Paper, No. 1622, OECD Publishing, Paris.

OECD/EC (2012), “Entrepreneurial Activities in Europe - Senior Entrepreneurship”, OECD Employment Policy Papers, No. 2, OECD, http://dx.doi.org/10.1787/5jxrcml7/hxq-en.

Pettersson, J. (2014), "Instead of bowling alone? Unretirement of pensioners in Sweden", International Journal of Manpower, Vol. 35/7, pp. 1016-1037.

Platts, L. et al. (2019), "Returns to work after retirement: a prospective study of unretirement in the United Kingdom", Ageing and Society, Vol. 39/3, http://dx.doi.org/10.1017/S0144686X17000885.

Ramnath, S., J. Shoven and S. Slavov (2021), "Pathways to retirement through selfemployment", Journal of Pension Economics and Finance, Vol. 20/2, http://dx.doi.org/10.1017/S1474747220000062.

Stirzaker, R. and L. Galloway (2017), "Ageing and redundancy and the silver lining of entrepreneurship", The International Journal of Entrepreneurship and Innovation, Vol. 18/2, http://dx.doi.org/10.1177/1465750317706441.

Wahrendorf, M. et al. (2017), "Who in Europe Works beyond the State Pension Age and under which Conditions? Results from SHARE", Journal of Population Ageing, Vol. 10/3, http://dx.doi.org/10.1007/s12062-016-9160-4. 



\section{Self-employment and entrepreneurship by the unemployed}

Governments have long-supported business creation schemes for the unemployed as a route back into work and many of these schemes were expanded in the wake of the COVID-19 pandemic. There are examples of large and successful schemes but only a small proportion of unemployed people in the European Union seek to return to work through self-employment. This chapter presents data on the proportion of unemployed people who seek to return to work through self-employment, as well as the proportion that are successful at transitioning from unemployment to self-employment. Data on the unemployed are presented at both the European Union (EU) and EU Member State levels. Selected OECD countries are covered to the extent possible. 


\section{Key messages}

- The data presented in this chapter are largely based on Eurostat Labour Force Survey data covering the self-employed. These data are complemented with country-specific statistics to provide additional insights.

- Unemployment increased rapidly following the onset of the COVID-19 pandemic. The seasonally adjusted monthly unemployment rate in the European Union (EU) increased from $6.6 \%$ in January 2020 to $7.7 \%$ in August 2020, before falling to $6.8 \%$ in August 2020 . Inactivity also increased as many workers feared infection, faced reduced working hours and had higher demands at home due to the lockdowns and closures (e.g. home schooling) enacted as a part of the public health strategy against COVID-19.

- Overall, few unemployed people in the EU self-report that they would prefer to move back to work via self-employment. In 2020, there were 14.9 million unemployed people in EU countries and only 358000 (less than $3 \%$ ) were seeking to return to work as a self-employed person.

- In recent years, however, more unemployed people became self-employed than the number who reported that they would to return to work via self-employment. In 2020 , 415000 people in the EU became self-employed after being unemployed in 2019, representing $3 \%$ of the unemployed. This is about 57000 more people than the number of unemployed people (in 2019) who reported that they were seeking to become self-employed. Unemployed men appear to be about 1.5 times more likely to move into self-employment than unemployed women.

- The likelihood of seeking to return to work via self-employment was lower among women and appears to increase slightly with age. Less than $2 \%$ of unemployed women in 2020 were trying to return to work via self-employment relative to about $3 \%$ of men. In 2020 , unemployed seniors (50-64 years old) were the most likely age group to seek to return to work via selfemployment (3\%) while unemployed youth (20-29 years old) were the least likely $(2 \%)$. However, this estimate for youth does not consider those starting a business from inactivity (e.g. transitioning from education to work).

- Those who have been unemployed for only a short duration are the most likely to report that they would like to become self-employed. More than $3 \%$ of those who have been unemployed for less than three months indicated they are interested in self-employment compared to less than $2 \%$ of those who have been unemployed for more than 24 months in 2020. This suggests that self-employment and start-up initiatives for the unemployed should try to reach and support those with entrepreneurial ambitions quickly.

- Many countries launched new business creation schemes - or extended existing ones to provide incentives and support to the unemployed as a policy response to the COVID19 crisis. About one-fifth of countries surveyed in a joint OECD-European Commission questionnaire on labour market policy responses to COVID-19 reported that start-up incentive programmes for the unemployed and other disadvantaged groups were expanded in 2020.

- Even before COVID-19, governments in EU and OECD countries commonly used initiatives and programmes to support self-employment among the unemployed. Common interventions include training and workshops, financial support for start-up activities and reductions in social security contributions. Evaluations tend to show that the survival rates of the businesses started through these programmes are close to unsupported businesses. 


\section{Policy context}

\section{Unemployment increased following the onset of the COVID-19 crisis}

There were 14.9 million unemployed people (15-64 years old) in 2020, increasing from the previous year for the first time since 2013. This growth in unemployment was uneven across countries and regions, reflecting differences in economic structure and policy responses to the COVID-19 pandemic. Those countries with greater concentrations of workers in sectors that were impacted by social distancing and lock-down measures tended to have greater increases in unemployment. Governments were able to mitigate some of these effects with various measures ranging from wage subsidies to a moratorium on layoffs. Among European Union (EU) Member States, unemployment rates increased strongly in Lithuania and Spain over the course of 2020 - 3 percentage points (p.p.) and 2.3 p.p., respectively (OECD, $2021_{[1]}$ ). At the same time, the share of the population that was active in the labour market (15-64 years old) in the EU also declined by about 1 p.p. in 2020 after continuous growth over the last decade (Eurostat, 2021[2]).

Unemployment among youth surged at the beginning of the COVID-19 crisis. As is often the case in recessions, youth are among the most impacted as they are usually the most recently hired, least experienced and more likely to work in heavily impacted sectors. Following both the financial crisis of 200809 and the COVID-19 crisis, the increase in the unemployment rate for those 20-24 years old was more than double the increase in the overall unemployment rate, while slightly older and potentially more experienced youth (25-29 years old) fared slightly better (Figure 6.1). For additional discussion on the impacts on COVID-19 on unemployment, please see Chapter 1. The OECD Employment Outlook 2021 (OECD, 2021 $\left.{ }_{[1]}\right)$ and the OECD policy brief on designing active labour market policies for the recovery (OECD, 2021 [3]) also contain more in-depth discussion.

\section{Figure 6.1. Unemployment among youth rose sharply after financial crises}

Share of people in the labour force who are unemployed in the EU

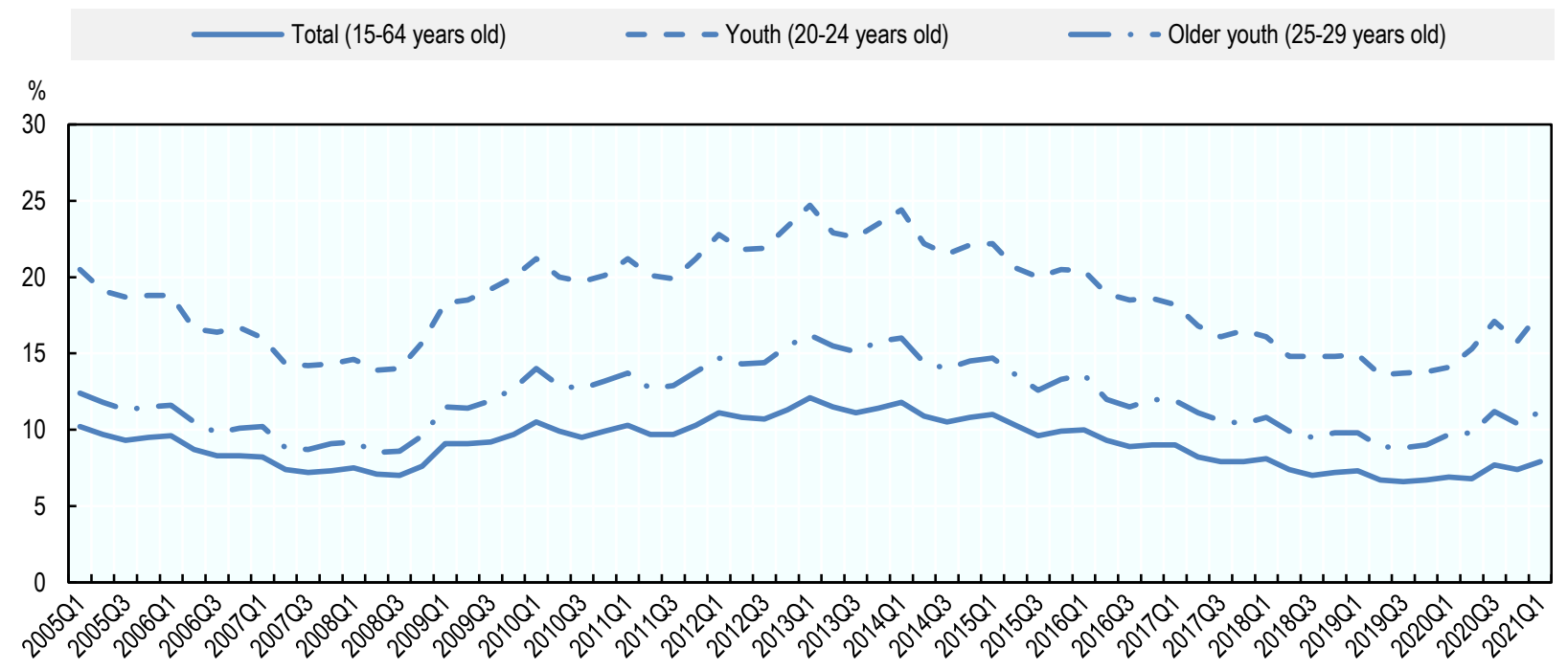

Source: (Eurostat, 2021[2]) 


\section{Policy support for business creation out of unemployment}

Support for business creation is a common element of active labour market measures across EU Member States and OECD countries. The rationale for such support is to provide an alternative pathway back into work for the unemployment. Moreover, moving into self-employment can help people avoid skills attrition and the erosion of their professional networks. Creating a business activity can also help boost an individual's self-esteem since they have an opportunity to generate income for themselves, be an active and contributing member of society, and reduce their chances of falling into poverty. This is particularly important for young people where unemployment spells can negatively impact their career trajectory and life path (OECD/European Commission, 2020[4] ). The opportunity cost of not supporting groups such as youth who are not in employment, education or training (i.e. NEETs) is extraordinarily high, particularly during times of high unemployment. For example, following the 2008-09 financial crisis, it was estimated that the direct economic cost of NEETs to the EU economy in 2011 was EUR 153 billion (Eurofound, $\left.2013_{[5]}\right)$. This cost would be expected to grow an individual's lifetime since people typically become more productive with experience, and this does not include social costs.

While it is possible for people to create highly impactful businesses from unemployment, most aim to create a sustainable self-employment activity without high-growth expectations. In general, selfemployed individuals that enter from unemployment have lower growth and chances of survival of their business than those that enter from employment (OECD/European Union, 2014[6]). However, some people may gain new skills and expand their networks through a business creation programme but ultimately return to paid employment. These outcomes should also be viewed as successes.

There is some evidence that self-employment can be a "bridge" to paid employment. The decision to become self-employed is not fixed and many transition to another work status at some point in their careers (Daly, $\left.2015_{[7]}\right)$. A recent studying comparing self-employment transitions in Italy, United Kingdom and the United States shows that individuals leaving solo self-employment are more likely to continue selfemployment as an employer or find paid employment than become unemployed (Box 6.1). The results also show that flexibility was a main driver in job satisfaction among the self-employed but that this could lead to under-employment for some. In addition, many of the respondents agreed with a need for stronger social protection due to income insecurity and fewer non-wage benefits. Similarly, evidence from Canada over the period $2002-13$ shows that $45 \%$ of formerly self-employed workers transition to paid employment (Grekou and Liu, 2018[8]). There is also some evidence showing that those who transition from unemployment to working as an employee through self-employment earn more than those who went directly to employment. Norwegian entrepreneurs who have returned to paid employment have been found to earn, on average, $19 \%$ more than employees who transitioned to another paid employment position in the period 2006-12 (Luzzi and Sasson, 2016[9]). 


\section{Box 6.1. Self-employment and alternative work arrangement trends: Italy, United Kingdom and United States}

A new study examines the changing nature of self-employment in Italy, the United Kingdom and the United States over the period 2000-17. Using OECD macro-level data and three online surveys (LSECEP Survey of Alternative Work Arrangements in the UK from February 2018 covering 20000 individuals; Princeton Self-Employment Survey in the US from April 2017 covering 10000 individuals; fRDB Survey of Independent Workers in Italy from May 2018 covering 15000 individuals), the study examines several policy issues including:

- Under-employment among the self-employed;

- Transitions in and out of self-employment;

- Social protection

The survey found flexibility to be a main driver in the job satisfaction among the self-employed; however, uncertainly and flexibility in hours worked leads to under-employment for some. The study found about $30 \%$ of solo self-employed workers and about $23 \%$ of self-employed employers would prefer to work more hours per week but face constraints due to the unavailability of additional work. Moreover, $18 \%$ of British and American and $12 \%$ of Italian solo self-employed workers were part-time because they cannot find more work.

The cross-country study also found some common patterns in transitions in and out of self-employment. Unemployed workers are more likely to become solo self-employed than those working as employees. Between 2016 and 2017, almost 6\% of unemployed workers in the UK became solo self-employed compared to only $2 \%$ of employees. Unemployed people were also more likely to move into solo selfemployment between these two years in the US (4\% of unemployed vs. $2 \%$ of employees) and Italy ( $3 \%$ vs. less than $1 \%$ ). Conversely, the self-employed in the three countries were less likely to become unemployed than employees.

There appears to be a strong demand for stronger social protection among self-employed workers due to greater income insecurity and fewer non-wage benefits. In the UK and US surveys, $80 \%$ of selfemployed workers indicated support for the creation of a fund designed to help self-employed workers obtain work-related benefits (i.e. retirement savings and health insurance). When asked to rank the desirability of potential benefits, self-employed workers reported the top choice as retirement savings in Italy (42\% among solo self-employed workers and $34 \%$ for self-employed employers) and the UK ( $40 \%$ and $45 \%$ respectively), while those in the US preferred health insurance $(52 \%$ for solo selfemployed workers and $44 \%$ for self-employed employers). The report also highlights the many challenges associated with designing a social protection scheme for self-employed workers, such as who is responsible for the employers' contributions.

Source: (Boeri et al., 2020[10]) 
EU Member States often support business creation for the unemployed at both the national and sub-national levels. Support is commonly offered as part of the suite of active labour market measures and schemes are implemented at national, regional and local levels (Figure 6.2). About half of Member States explicitly note in employment strategies that there are specific actions to support the transition from unemployment to self-employment. However, these types of strategies tend to be quite general and are not likely to have clearly defined policy objectives and targets relative to other target groups such as women or youth. Clearly the policy priority is to minimise unemployment and to improve transitions back into work. Self-employment is one potential route back into work so governments should seek to open that possibility without pushing people to pursue it unless the individual wishes to.

\section{Figure 6.2. Governments in the EU commonly offer schemes to support the unemployed in business creation}

Share of EU Member States, 2020

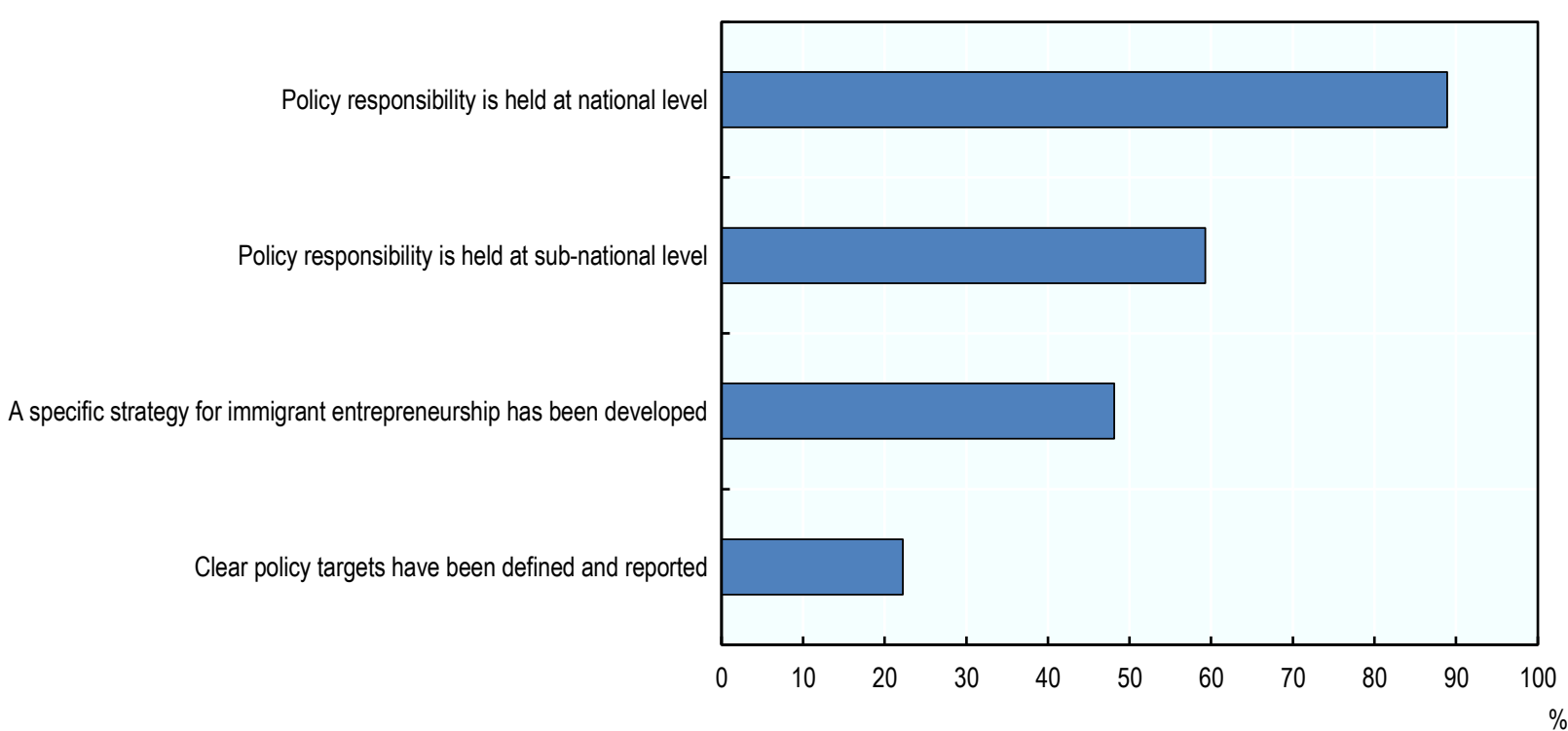

Note: It is possible for countries to have clear policy responsibility at both the national and sub-national levels; these are not mutually exclusive. Source: (OECD, 2020[11])

StatLink त्ञाs https://doi.org/10.1787/888934281125

\section{Schemes to support the unemployed in business creation can improve labour market outcomes for some}

Schemes that support the unemployed in business creation are widespread in the EU. The OECD inclusive entrepreneurship policy assessments across the EU found that schemes to support the unemployed in business creation often include at least two of the following actions: i) increasing awareness about possibilities of entrepreneurship, ii) facilitating the acquisition of entrepreneurship skills, iii) financial supports for business start-up, iv) financial support following business start-up, v) the provision of business development services, and vi) broad regulatory changes. Using the OECD's 9-point assessment criteria (see Reader's Guide), many activities are of higher quality than the average inclusive entrepreneurship scheme (Figure 6.3). A common success factor is that the different actions are typically combined into comprehensive packages that addresses the complementary and multiplicative nature of the barriers faced in business creation. 
Overall, the accumulated evidence suggests that well-targeted programmes have the potential to improve the labour market outcomes for the unemployed. Successful schemes have been found to have two critical success factors - a strong focus on training paired with well-designed financial incentives (OECD/European Union, 2014[6]; OECD/European Union, 2017 ${ }_{[12]}$ ). Training addresses the depreciation of human and social capital that can occur during unemployment as well as the lack of business experience, while the financial incentives such as start-up subsidies help to remove barriers faced by entrepreneurs transitioning from unemployment in acquiring the financial capital needed during the founding period (Caliendo, 2016[13]).

Comparatively speaking, there is some evidence showing that business start-up supports can be more cost-effective than other labour market supports for the unemployed (Caliendo, 2016 $\left.{ }_{[13]}\right)$. This is particularly true when additional job creation and innovation are considered. For example, a recent study found a German start-up subsidy scheme cost, on average, around EUR 4900 per participant considerably lower than other active labour market policies such as a public employment scheme at EUR 8200 per participant in 2009 (Caliendo, Künn and Weissenberger, 2020[14]). In addition, businesses started with support from this scheme created one full-time job per participant is created, on average, after 40 months. A similar scheme in the Czech Republic show similar results (Dvouletý, 2017[15]). In the period 2012-15, the average cost of the start-up initiative for the unemployed increased as did the average unemployment support (for a six-month period). In 2012, the average cost per self-employed worker was CZK 26430 (approximately EUR 980), which was lower than the average unemployment support provided over six months - CZK 35352 (approximately EUR 1310 ). Although in subsequent years the costs associated with supporting programme participants increased, the direct costs were not significantly more than the average unemployment support. In 2015, for example, the average costs per participant was CZK 45815 (approximately EUR 1 700) compared to CZK 37026 (approximately EUR 1370), on average, in unemployment support for six months. One possible explanation for these outcomes is that applicants to start-up support schemes are typically required to submit a business proposal that is reviewed, which could lead to a selection bias. 


\section{Figure 6.3. Entrepreneurship schemes for the unemployed focus on building skills and offering} finance

Average OECD assessment scores for inclusive entrepreneurship schemes across EU Member States, 2020

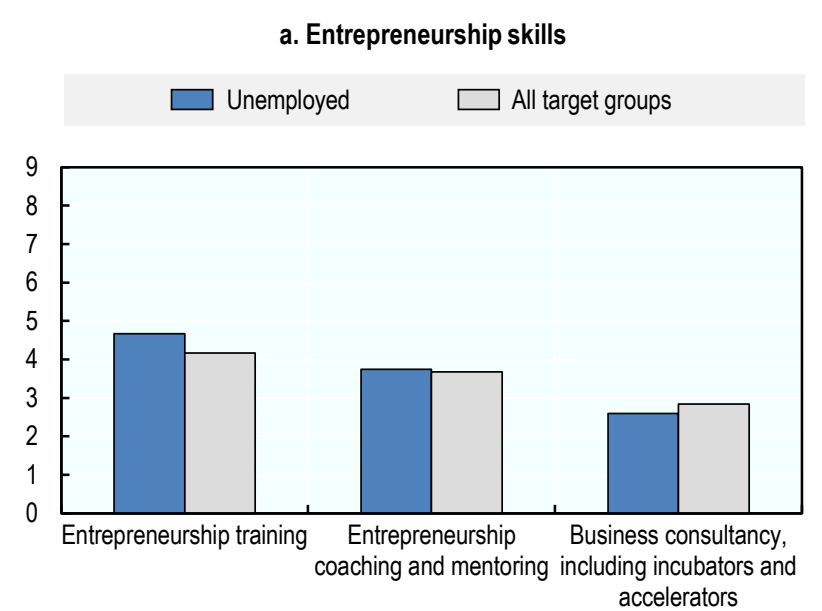

c. Entrepreneurship culture and social capital
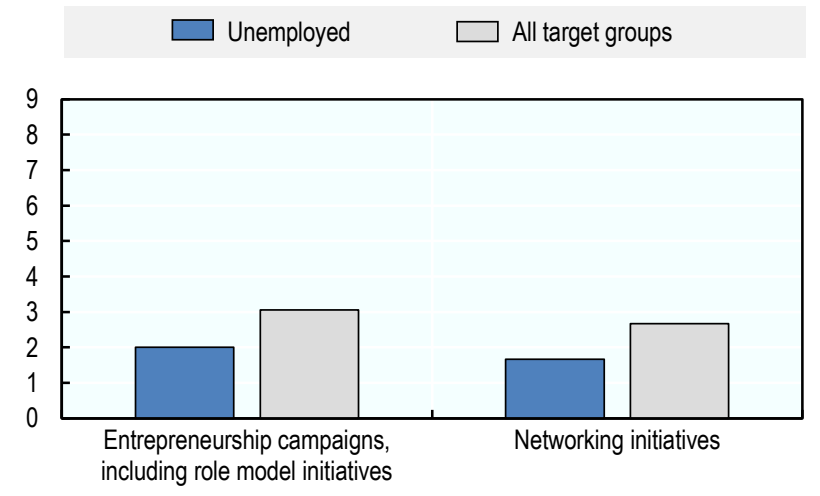

b. Entrepreneurship finance

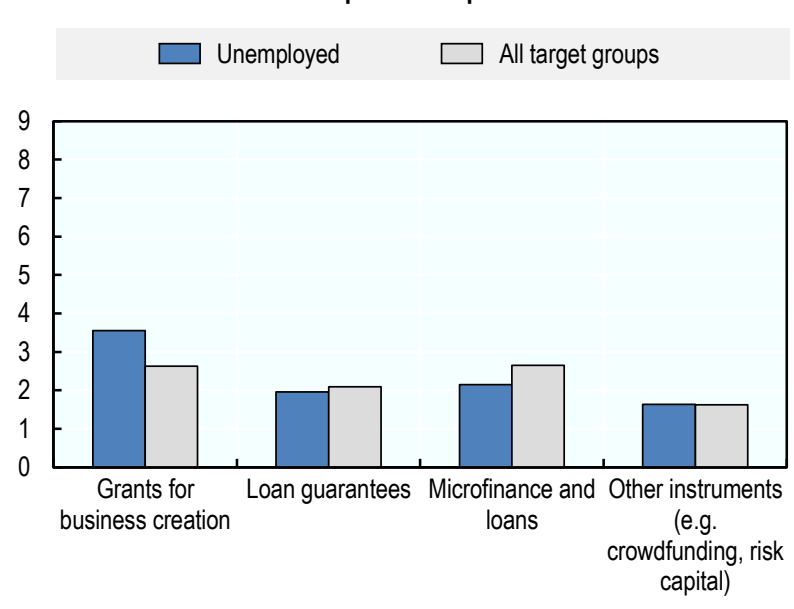

d. Regulatory tools

Unemployed $\square$ All target groups

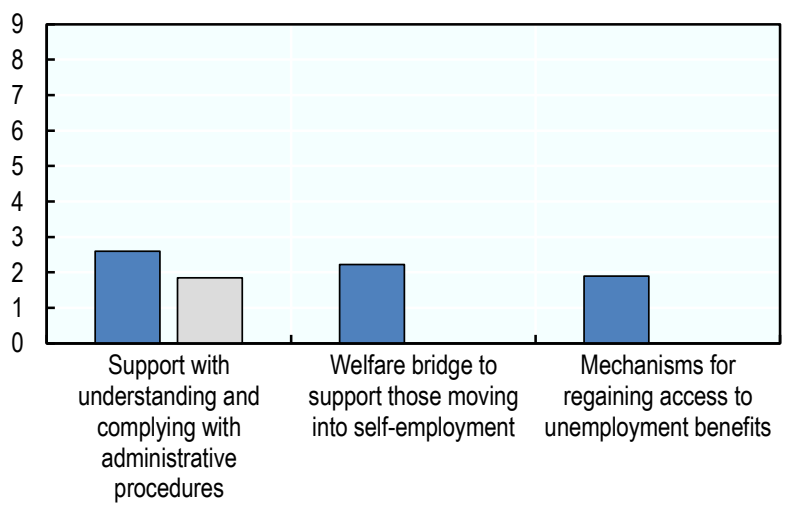

Note: The panels in this figure present an unweighted average of policy assessment scores for EU Member States. Each policy instrument (e.g. Entrepreneurship training) is assessed a scored out of 9 as described in the Reader's Guide. The figure shows the average score for schemes for immigrant entrepreneurs relative to the score for all inclusive entrepreneurship groups combined (i.e. women, immigrants, youth, seniors and the unemployed). Some of the policy instruments in panel $d$ are designed specifically for immigrant entrepreneurs so there is no comparative policy assessment score for all inclusive entrepreneurship target groups.

Source: (OECD, 2020[11])

StatLink 제에 https://doi.org/10.1787/888934281144

Governments face a risk that some of the subsidised individuals might have started a business even without public support. Therefore, a central question to gauge the effectiveness of policy schemes supporting business creation for people in unemployment is the relative size of the "deadweight" loss (i.e. the supported person would have started a business without any support, therefore the expenditure is a loss), as well as "displacement" effects (i.e. the new business does not have a positive net impact, it simply substitutes for another by capturing its market). Evaluations find wide ranging estimates of deadweight loss, according to the country and the characteristics of the programme. For example, deadweight costs are often reported to be between $20 \%$ and $70 \%$ of programme costs (OECD/European Union, $2014_{[6]}$ ). These figures suggest that deadweight costs might be substantial and policy evaluations cannot merely 
look at number of firms created as a measure of programme success. However, studies in Germany show overall that deadweight effects for start-up subsidies occur at a much lower scale than expected (Caliendo, Künn and Weissenberger, 2020[14]; Caliendo, 2016[13]; Caliendo and Kritikos, 2007[16]). When the impact on business survival during the first six months is not considered, the share of subsidised businesses that may be affected by deadweight effects dropped from $49 \%$ to $21 \%$ and when a narrower definition for unemployed people was applied, the effects fell from 23\% to 9\% (Caliendo, 2016 ${ }_{[13]}$ ). Moreover, the deadweight costs of entrepreneurship supports are not higher than other active labour market policies and are substantially lower than direct employment creation measures (e.g. public sector jobs) (Carling and Gustafson, 1999 $[17])$. Displacement effects are seldom investigated in evaluations but need to be considered, especially for large programmes and/or programmes that are maintained during periods of low unemployment.

\section{Building entrepreneurship skills}

About two-thirds of EU Member States offer tailored entrepreneurship training for the unemployed. Entrepreneurship training programmes for the unemployment typically have three objectives. First, they seek to develop more positive attitudes towards self-employment and business creation since many may not have previously considered self-employment as a potential labour market activity. Second, they seek to provide the basic skills needed to start and manage a small business activity. This often includes for example, basic business and financial planning, accounting and identifying opportunities. Third, entrepreneurship training programmes tend to support broader skills development since many participants will find paid employment rather that starting a business. For example, this could include basic computer skills, which can be applied to both self-employment and wage employment.

The quality of entrepreneurship training is highly variable across EU Member States. There are some very high quality examples such as the training that is packaged with financial support in the welfare bridge schemes in Germany, which have been able to close nearly all of the gaps (e.g. survival rates, employment creation) between those supported out of unemployment relative to unsupported entrepreneurs (Caliendo et al., 2015[18]; Caliendo and Künn, 2011 [19]). However, there are also very small schemes that appear to have very little impact. In general, entrepreneurship training programmes tend to have high take-up levels and are linked to other types of support such as coaching and financial support.

Tailored entrepreneurship coaching and mentoring is also very commonly offered across the EU. However, it is quite rare to find stand-alone coaching schemes for people starting businesses out of unemployment. Instead, coaching tends to be embedded into packages of support. It is often a critical element in support packages because coaches can help new entrepreneurs implement skills learned in training programmes and can also be important driver of expanding professional networks (OECD/European Union, 2014[6]).

Business consultancy is also used to support the unemployed in about one-third of EU Member States. Evaluations of business consultancy typically show that treatment groups have higher survival rates and business growth, including for those starting businesses out of unemployment. For example, an evaluation of "guided preparation" for self-employment in North Jutland, Denmark found that the scheme improved survival rates and also appeared to be cost-effective (Rotger, Gørtz and Storey, 2012[20]). The evaluation also found that the scheme was effective for those starting from unemployment.

\section{Facilitating access to start-up finance}

The most common instrument used to support business creation by the unemployed is grants for business creation. About three-quarters of Member States offer specific grants for business creation for the unemployed. Loan guarantees and microfinance are less frequently offered. Fewer than half of Member States offer tailored microfinance and only about one-third offer loan guarantees. It is difficult to understand the effectiveness of schemes that facilitate access to finance for people starting businesses from 
unemployment since few schemes are evaluated. Older evaluations indicate that fixed-period income support programmes are more effective than other labour market training efforts (Carling and Gustafson, $\left.1999_{[17]}\right)$. (See also Welfare Bridge schemes under regulatory supports on the next page).

\section{Promoting self-employment and expanding entrepreneurship networks}

Business creation is promoted less frequently to unemployed people than other target groups. Governments typically promote self-employment directly to unemployed people through information packages provided by public employment services rather than through public campaigns. In addition, there are examples of targeted efforts to promote business creation when large numbers of employees are made redundant, particularly where the majority of workers are highly skilled. For example, when Nokia launched the Bridge Programme in partnership with the governments and public employment services while it was restructuring its Finnish operations in 2011-14 (OECD/European Union, 2017[12]). The Bridge Programme aimed to mobilise as much of the internal expertise of Nokia as possible and the entrepreneurship track was seen as being tailored for start-ups mostly in the technology and financial sectors. Those who became entrepreneurs through the Bridge Programme could arrange agreements with Nokia for technology licensing or idea releases (Autio et al., 2014[21]). Once participants were ready to launch their business, they could apply for a start-up grant of up to EUR 25000 . Those working in teams of up to four people could receive up to EUR 100 000. Overall, the average grant provided was approximately EUR 27000 , and it is estimated that Nokia provided a total of nearly EUR 10 million in Bridge Programme grants (Autio et al., 2014[21]]). Other financial supports were also available, including a loan guarantee programme where Nokia backed credit accounts. Support was also provided to help participants access public entrepreneurship programmes, including the Start-up Grant. Approximately $90 \%$ of the companies that were started through the Bridge Programme were still operating in 2014 or operations continue in another company, or in a new company that was set up to replace the Bridge start-up (Autio et al., 2014[21]).

Networking support is often included as part of bundled support packages. However, governments typically take a different approach when supporting the expansion of professional networks for those moving from unemployment to self-employment relative to other target groups such as women or youth. Entrepreneurship networks for women, youth and other groups tend to facilitate networking within groups but support for the unemployed place a greater emphasis on building linkages with business support organisations and other entrepreneurs.

\section{Supporting business creation from unemployment with regulatory tools}

Regulations have a strong role in influencing incentives and disincentives for entrepreneurship, especially for those moving from unemployment to self-employment. Regulatory changes to improve conditions for entrepreneurship can increase rates of firm formation, firm survival and growth. Positive effects of improving general conditions for entrepreneurship are well-documented, especially factors such as lowering tax rates for entrepreneurs, decreasing administrative costs and regulations.

Welfare bridges are a long-standing tool for supporting job seekers in business creation. Welfare bridge schemes allow an individual to keep receiving unemployment insurance payments for a fixed period of time (e.g. six months) - or an allowance instead of unemployment insurance payments - while they setup their own enterprise. It is also common for these types of schemes to include training, coaching and other types of financial support such as small grants. These types of schemes are used in countries such as Belgium, Denmark, France, Germany, Hungary, Italy, Poland and Spain. Some of these schemes are well-evaluated and evidence often shows that participants were less likely to return to unemployment than non-participants, and that their businesses often have survival rates and job creation rates that are on-par with non-supported start-ups (OECD/European Union, 2014[6]).

Another approach to supporting entrepreneurs in the context of business start-up is to provide exemptions to payroll taxes. This approach is commonly used in conjunction with a welfare bridge 
schemes but evaluations tend to find mixed results. Some evaluations from France find that these tax exemptions can improve five-year business survival rates (Cabannes and Fougere, 2012[22]), while others find lower survival rates than unsupported firms (Vari-Lavoisier, 2011[23]). Both of these evaluations note the role of eligibility criteria. Strong selection criteria increase survival rates since only higher quality businesses can make use of the benefit and weaker selection criteria lead to lower survival rates but are more consistent with the overall policy objective of supporting those who need assistance.

\section{Recent developments}

Schemes to support business creation by the unemployed have a long history in the EU and major innovations are rare. However, small adjustments to schemes and measures are made frequently, notably adjustments to eligibility criteria and amounts of financial support offered. An OECD-EU survey of 46 countries and regions on active labour market policy responses to the COVID-19 pandemic indicates that nearly-one quarter of governments had expanded start-up incentive programmes targeted at unemployed and other disadvantaged groups (OECD, 2021[24]). This includes, for example, an amendment to Law No XII-2470 in Lithuania in April 2020 to lower the age at which unemployed people can access additional financial support for business creation from 50 years old to 45 years old (OECD, 2020[11]). It anticipated that this change will lead to business creations by more than 100 additional unemployed people. Moreover, other countries such as Finland extended the timelines of financial support to jobseekers who are creating a business - the maximum duration of the start-up grant moved from 12 months to 18 months for any Finnish start-up beginning operations in 2020 (Ministry of Economic Affairs and Employment (Finland), 2021[25]). Such actions are consistent with the EU Recommendation on Effective Active Support to Employment following the COVID-19 crisis (EASE) in March 2021, which outlined three components for Member States policy packages for the post COVID-19 recovery. The first component outlined the importance of hiring incentives and entrepreneurial support, including suggestions for start-up grants, loans and equity as well as support services to promote entrepreneurship especially among youth, women and social entrepreneurs in the EU.

There are also examples of more substantial regulatory changes over the past five years. In Slovenia, the Employment Service of Slovenia ended the subsidy that it offered to unemployed people who were interested in creating a business in 2014. A noticeable drop-off in business creation from unemployment was observed. However, this trend has reversed with the creation of new business forms that facilitate short-term contract work and favourable tax treatment for sole proprietors which was enacted in 2015 (Širok, 2019[26]).

Countries are also giving greater visibility to entrepreneurship support in their employment strategies, particularly in the context of rising unemployment due to the COVID-19 pandemic. For example, the Spanish public employment service (under the Ministry of Labour and Social Economy) launched the Plan Reincorpora-T for the period 2019-21 on 5 April 2019. It seeks to prevent and reduce long-term unemployment through 63 measures that include a focus on promoting and supporting business creation. The total cost of these measures in 2020 was estimated to be nearly EUR 1.5 billion (OECD, $\left.2020_{[11]}\right)$.

\section{Seeking self-employment from unemployment}

\section{Less than $3 \%$ of the unemployed want to return to work through self-employment}

Very few unemployed people in the EU prefer to return to work as a self-employed person. Of the 14.9 million unemployed people in 2020 , only 358000 were seeking to return to work as a self-employed person. This represented about $2.5 \%$ of the total number of unemployed people (Figure 6.4). This proportion could be expected to increase in the short-term given the spike in unemployment due to the 
COVID-19 pandemic. With the increase in unemployment and few job opportunities, it is likely that a greater share of the unemployed will consider self-employment as a viable option to return to work. During the previous unemployment crisis in 2008-09, the number and share of unemployed people who sought to become unemployed increased by about $30 \%$ in the first year of the crisis.

Figure 6.4. Few unemployed people seek self-employment

Proportion seeking to return to work as self-employed in the EU (15-64 years old unless stated otherwise)
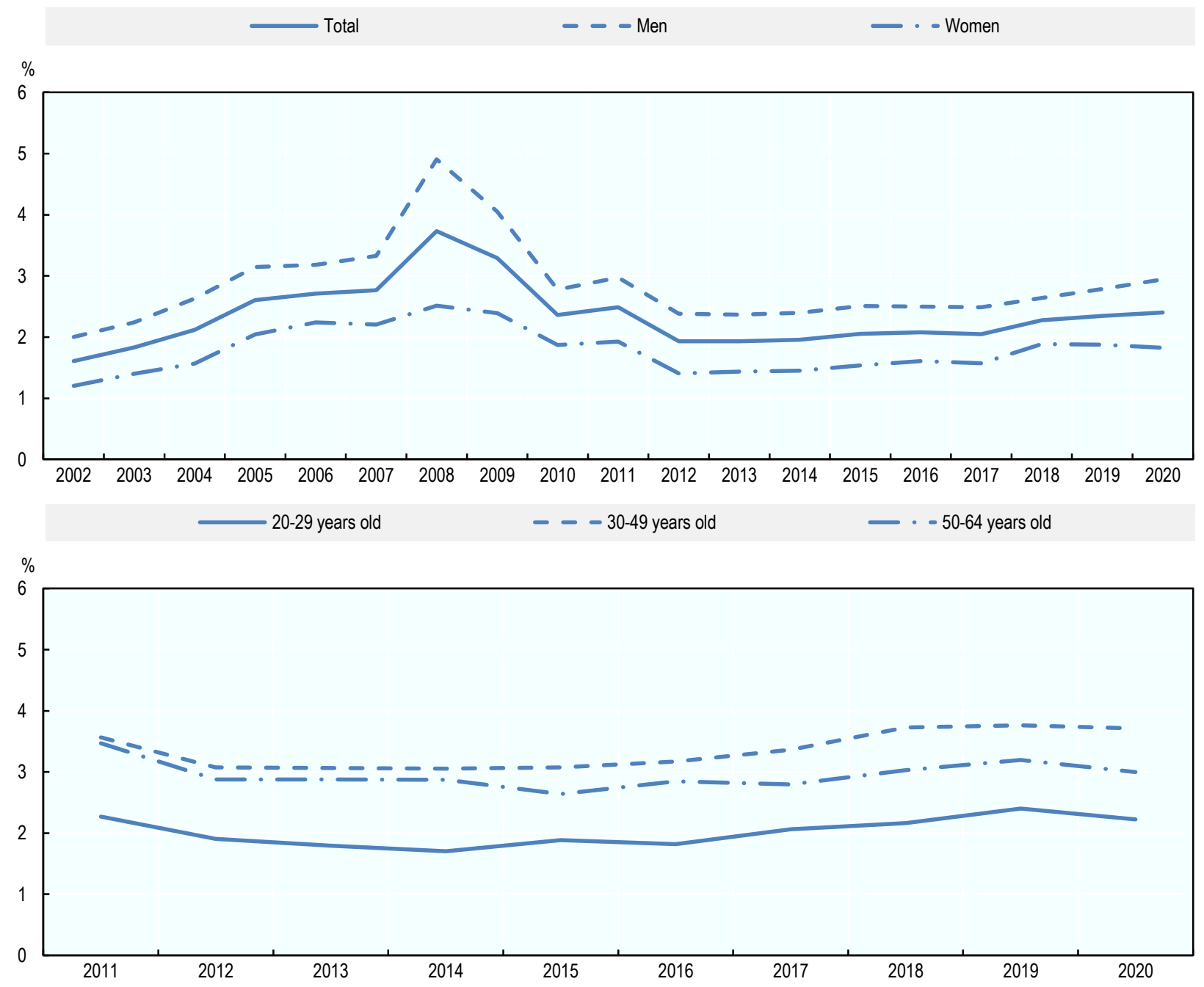

Source: (Eurostat, 2021 $[2]$ ) 
Unemployed men are more likely than unemployed women to try to return to work as selfemployed. In 2020, about $3 \%$ of unemployed men reported that they were trying to become self-employed relative to less than $2 \%$ of unemployed women. Over the past decade, this gender gap in the share of unemployed people seeking to become self-employed remained relatively constant. However, this gap may be expected to grow as a result of the COVID-19 pandemic for two reasons. First, as discussed in Chapter 1 , women were more likely to have lost employment and self-employment during 2020. Second, during the previous unemployment crisis in 2008-09, the share of unemployed women seeking to become self-employed did not increase to the extent that it did for men.

Interest in returning to work through self-employment also varies by age. Young unemployed people (20-29 years old) are the least likely target group to seek self-employment with slightly more than $2 \%$ seeking to start a business activity in 2020. This was below the overall average for all ages. However, core-age people (30-49 years old) and seniors (50-64 years old) are more likely than the overall average to seek self-employment. In 2020 , nearly $4 \%$ of core age people indicated that they were trying to start a business activity and about $3 \%$ of seniors did. The share for all ages has trended upwards for all age groups since 2015, but it is unclear how the COVID-19 pandemic will impact interest in self-employment by age.

The proportion of unemployed people that sought to become self-employed varied considerably across EU Member States. The share of unemployed people seeking to become self-employed ranged from about $1 \%$ to $11 \%$ in 2020 (Figure 6.5). The proportion was highest in Luxembourg (11\%), which has a high self-employment rate relative to other EU Member States, while the proportion is low in countries that tend to have high unemployment rates. This includes, for example, Greece, Spain and Italy where the share was less than $2 \%$. Self-employment as a way to leave unemployment was also low in countries such as Finland and Sweden (about 2\% in each country) where the cultural norm is to prefer salaried employment to self-employed. The low proportion of unemployed people seeking self-employment in Sweden can also be partly explained by the strong social security system, which secures living conditions for all.

\section{Figure 6.5. Unemployed seeking self-employment varies by EU Member State}

Proportion of unemployed (15-64 years old) seeking self-employment, 2020

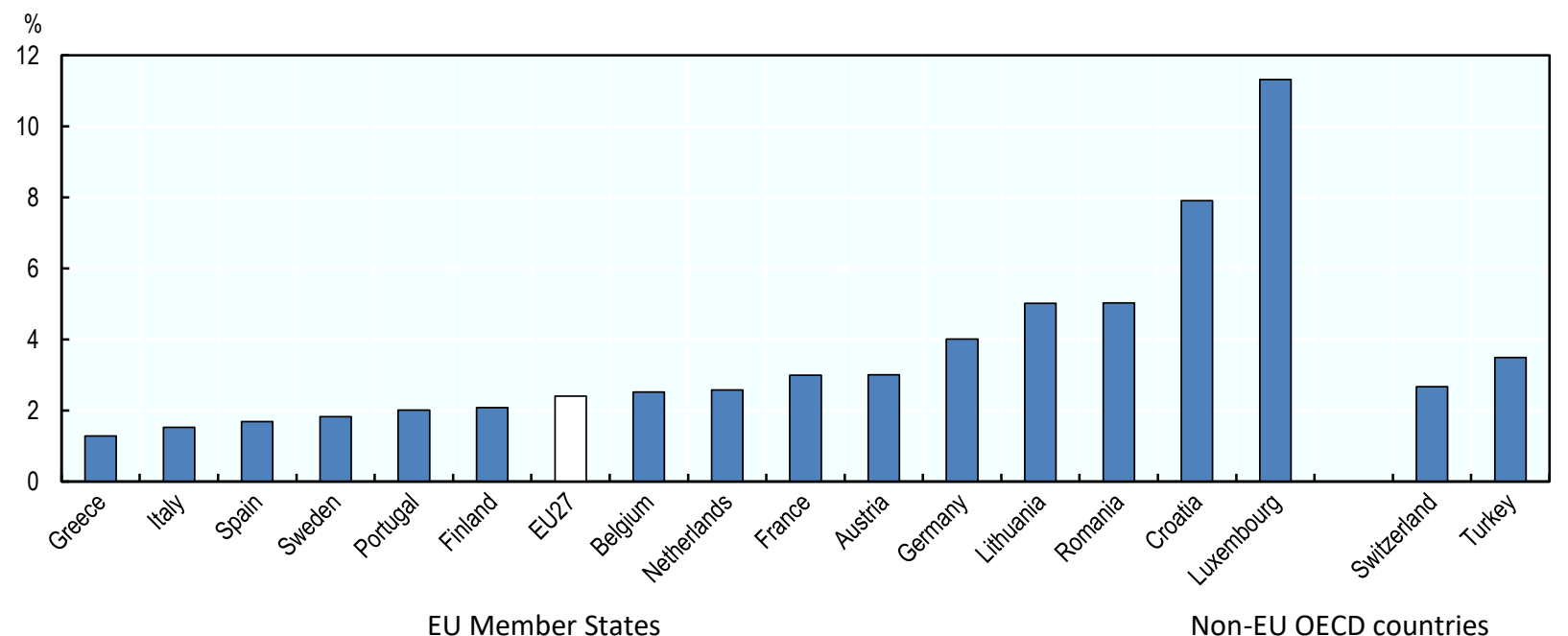

Note: Data are not available for the Czech Republic, Ireland, Latvia, Poland and the Slovak Republic.

Source: (Eurostat, 2021 [2]) 


\section{Entering self-employment from unemployment}

\section{Likelihood of seeking self-employment decreases with duration of unemployment...}

The interest of unemployed people seeking self-employment declines as the duration of unemployment increases. More than $3 \%$ of those who have been unemployed for less than three months indicated they are interested in self-employment compared to less than $2 \%$ of those who have been unemployed for more than 24 months in 2020 (Figure 6.6). This gap is likely due to a greater likelihood of short-term unemployed participating in active labour market programmes and higher levels of motivation (Helbling, 2019 ${ }_{[27]}$; Bejaković and Mrnjavac, 2018 ${ }_{[28]}$ ), as well deteriorating professional networks and skills attrition. The shares have been quite stable over the past decade overall, with the exception of the share of those unemployed for less than three months which has trended slightly upwards since 2012.

\section{Figure 6.6. Recently unemployed people are most likely to try to become self-employed}

Proportion of unemployed (15-64 years old) seeking self-employment in the EU by duration of unemployment

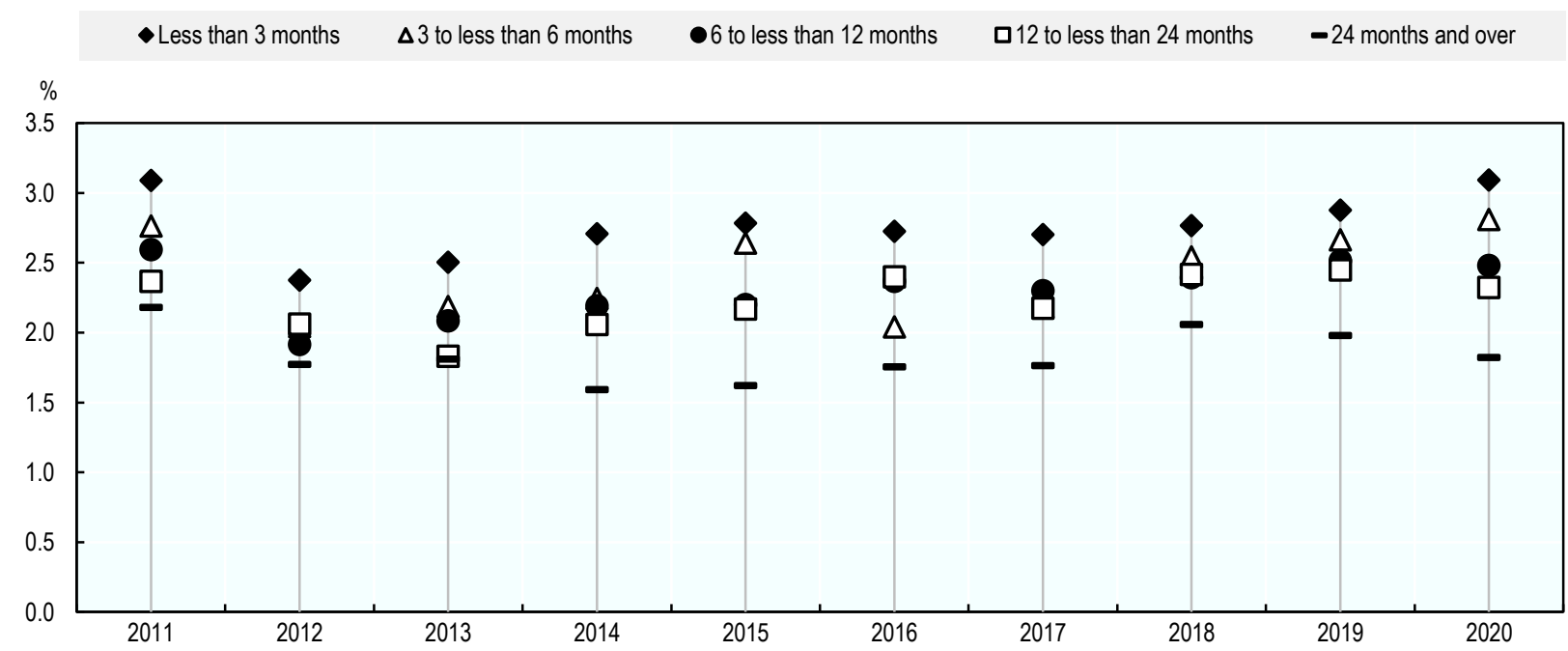

Source: (Eurostat, 2021[2])

\section{....and more unemployed people become self-employed than those reportedly seeking it}

Approximately 415000 people in the EU became self-employed in 2020 after being unemployed in 2019, representing about $2 \%$ of the unemployed (in 2019) who indicated that they were seeking to become selfemployed (Figure 6.7). However, only 358000 unemployed people in the EU reported that they were seeking to return to work through self-employment, indicating that slightly more people move into selfemployment from unemployment than those who seek it. This is likely due to the inability to find salaried employment that met their expectations (e.g. skills, experience, working conditions, wages), and they consequently became self-employed. It is also possible that an unemployed person identified a potential entrepreneurial activity and decided to pursue the business opportunity without it being initially sought out.

Consistent with intentions, unemployed men appear to be slightly more likely than unemployed women to become self-employed. While data are limited due to the quality of estimates, unemployed men were about 1.5 times more likely than unemployed women to move into self-employment between 2011 and 2020. 


\section{Figure 6.7. More unemployed people become self-employed than those seeking it}

Percentage of unemployed men and women (15-64 years old) moving into self-employment in the EU

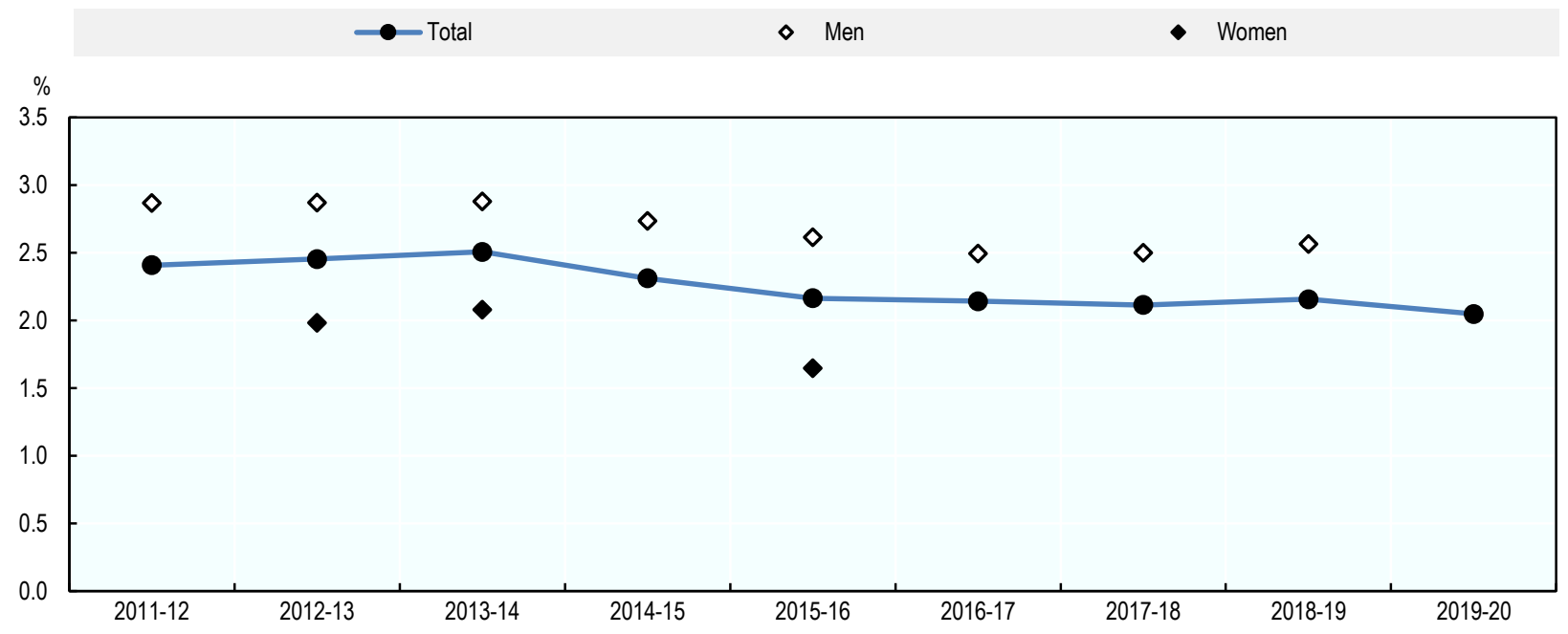

Note: The estimate of the share of unemployed people who moved into self-employment between 2019 and 2020 has a low reliability. Similarly, all estimates for women have a low reliability as do those for men from 2011-13 and 2016-19.

Source: (Eurostat, 2021 [2])

StatLink 제 Sh https://doi.org/10.1787/888934281220

\section{Conclusions}

The main policy rationale for supporting job seekers in self-employment is to provide an alternative to working as an employee. This additional route to work may help people return to work more quickly, which is often a policy objective during times of high or growing unemployment such as the current COVID19 pandemic. This is particularly important for young people who have been impacted disproportionately by the pandemic. Unemployment spells faced early in careers can increase the likelihood of unemployment throughout careers and also reduce lifetime earnings.

Although few job seekers return to work as a self-employed person, there is a body of evidence that shows that those who become self-employed can be successful. The accumulated evidence suggests that well-targeted programmes with considerable training content have the potential to improve the labour market outcomes of those targeted, including by moving some back into working as an employee. There is some evidence showing that these types of schemes are more effective during economic downturns, supporting the decision of governments to increase support for business creation among job seekers during the economic recovery following the COVID-19 pandemic. Comparatively speaking, business start-up supports can be more cost-effective than other labour market supports for the unemployed. However, a central question to gauge the effectiveness of schemes supporting business creation for job seekers is the relative "deadweight effects" and "displacement effects" of schemes. Evaluations have obtained wide-ranging estimates of deadweight, according to the country and the characteristics of the programme but indicate that deadweight costs might be substantial and policy evaluations should not only look at number of firms created as a measure of programme success. Displacement effects are much more seldom investigated in evaluations but needs to be considered, especially for large programmes and/or programmes that are maintained during periods of low unemployment rates. 
Moreover, entrepreneurship programmes for job seekers can have broader benefits such as supporting the acquisition of skills and experience, as well as expanding professional networks. These can all increase the employability of people and can help them move back into work, which is the primary policy objective. Moreover, some studies show that even when those who moved into selfemployment go on to find employment, they are better off than those who went straight from unemployment into employment.

The data in this chapter suggest several lessons for policy makers designing self-employment supports for job seekers. First, unemployed people with shorter durations of unemployment appear more interested in becoming self-employed so governments should seek to move these people into support programmes quickly while they are motivated. Second, there is a gender gap among job seekers who are interested in self-employment. This suggests that greater attention is needed to gender issues when designing support measures. Overall, entrepreneurship support schemes for women tend to be more successful at attracting participants when they are women-only. Therefore, this could be considered also among job seekers when there is sufficient demand for schemes. Priority actions for governments in strengthening business creation support for the unemployed include:

- Use of strong selection criteria to target support on those with high motivation levels and a reasonable chance of success; and

- Scale-up support during times of rapidly increasingly unemployment.

Additional examples of recent policy actions to support the unemployed in business creation - particularly in the COVID-19 context - are contained in the country profiles in Part III of this report.

\section{References}

Autio, E. et al. (2014), "Analyses on the Finnish High-Growth Entrepreneurship Ecosystem", Aalto University publication series BUSINESS + ECONOMY, No. 1/2014, https://aaltodoc.aalto.fi/handle/123456789/12444 (accessed on 23 July 2021).

Bejaković, P. and Ž. Mrnjavac (2018), "The danger of long-term unemployment and measures for its reduction: the case of Croatia*”, Economic Research-Ekonomska Istraživanja, Vol. 31/1, pp. 1837-1850, http://dx.doi.org/10.1080/1331677x.2018.1521295.

Boeri, T. et al. (2020), "Solo Self-Employment and Alternative Work Arrangements: A CrossCountry Perspective on the Changing Composition of Jobs", Journal of Economic Perspectives, Vol. 34/1, http://dx.doi.org/10.1257/jep.34.1.170.

Cabannes, P. and D. Fougere (2012), Une évaluation de l'effet de l'ACCRE sur la durée de vie des entreprises, Rapport pour la chaire "Sécurisation des parcours professionnels".

Caliendo, M. (2016), "Start-up subsidies for the unemployed: Opportunities and limitations", IZA World of Labor, http://dx.doi.org/10.15185/izawol.200.

Caliendo, M. et al. (2015), "Subsidized start-ups out of unemployment: a comparison to regular business start-ups", Small Business Economics, Vol. 45, pp. 165-190, http://dx.doi.org/10.1007/s11187-015-9646-0.

Caliendo, M. and A. Kritikos (2007), "Start-Ups by the Unemployed: Characteristics, Survival and Direct Employment Effects”, Discussion Paper, No. 3220, IZA, http://ftp.iza.org/dp3220.pdf (accessed on 3 August 2021). 
Caliendo, M. and S. Künn (2011), "Start-up subsidies for the unemployed: Long-term evidence and effect heterogeneity", Journal of Public Economics, Vol. 95/3-4, pp. 311-331.

Caliendo, M., S. Künn and M. Weissenberger (2020), "Catching up or Lagging Behind? The Long-Term Business and Innovation Potential of Subsidized Start-Ups out of Unemployment", Research Policy, Vol. 49/10, pp. 1-14.

Carling, K. and L. Gustafson (1999), "Self-employment grants vs. subsidized employment: Is there a difference in the re-unemployment risk?", IFAU, Office of Labor Market Policy Evaluation, https://www.researchgate.net/publication/5095695 Selfemployment grants vs subsidized employment is there a difference in the reunemployment risk (accessed on 23 July 2021).

Daly, M. (2015), "The long term returns of attempting self-employment with regular employment as a fall back option", Labour Economics, Vol. 35, pp. 26-52.

Dvouletý, O. (2017), "Does the Self-employment Policy Reduce Unemployment and Increase Employment? Empirical Evidence from the Czech Regions", Central European Journal of Public Policy, Vol. 11/2, http://dx.doi.org/10.1515/cejpp-2016-0032.

Eurofound (2013), NEETs Young people not in employment, education or training: Characteristics, costs and policy responses in Europe, https://www.eurofound.europa.eu/sites/default/files/ef files/pubdocs/2012/54/en/1/EF1254EN .pdf (accessed on 22 July 2021).

Eurostat (2021), Labour Force Survey, https://ec.europa.eu/eurostat/web/lfs (accessed on 6 May 2021).

Grekou, D. and H. Liu (2018), The Entry into and Exit out of Self-employment and Business Ownership in Canada, Statistics Canada, Ottawa, https://www150.statcan.gc.ca/n1/pub/11f0019m/11f0019m2018407-eng.htm (accessed on 3 August 2021).

Helbling, L. (2019), "Comparing long-term scarring effects of unemployment across countries: the impact of graduating during an economic downturn", in Negotiating Early Job Insecurity, Edward Elgar Publishing, http://dx.doi.org/10.4337/9781788118798.00011.

Luzzi, A. and A. Sasson (2016), "Individual Entrepreneurial Exit and Earnings in Subsequent Paid Employment", Entrepreneurship Theory and Practice, Vol. 40/2, http://dx.doi.org/10.1111/etap.12225.

Ministry of Economic Affairs and Employment (Finland) (2021), A startup grant supports a new entrepreneur, https://www.te-palvelut.fi/en/employers/for-entrepreneurs/services-newentrepreneurs/startup-grant (accessed on 3 August 2021).

OECD (2021), Active labour market policy measures to mitigate the rise in (long-term) unemployment: A summary of country responses to the OECD-EC questionnaire, OECD Publishing, Paris, https://www.oecd.org/els/emp/almpmeasurescovid19.pdf (accessed on 3 August 2021).

OECD (2021), "Designing active labour market policies for the recovery", OECD Policy Responses to Coronavirus (COVID-19), OECD Publishing, Paris, https://www.oecd.org/coronavirus/policy-responses/designing-active-labour-market-policiesfor-the-recovery-79c833cf/ (accessed on 23 July 2021). 
OECD (2021), OECD Employment Outlook 2021: Navigating the COVID-19 Crisis and Recovery, OECD Publishing, Paris, https://dx.doi.org/10.1787/5a700c4b-en.

OECD (2020), Inclusive Entrepreneurship Policies: Country Assessment Notes, https://www.oecd.org/cfe/smes/inclusive-entrepreneurship-policies-country-assessmentnotes.htm (accessed on 6 June 2021).

OECD/European Commission (2020), "Policy brief on recent developments in youth entrepreneurship", OECD SME and Entrepreneurship Papers, No. 19, OECD Publishing, Paris, https://dx.doi.org/10.1787/5f5c9b4e-en.

OECD/European Union (2017), The Missing Entrepreneurs 2017: Policies for Inclusive Entrepreneurship, OECD Publishing, Paris, https://dx.doi.org/10.1787/9789264283602-en.

OECD/European Union (2014), The Missing Entrepreneurs 2014: Policies for Inclusive Entrepreneurship in Europe, OECD Publishing, Paris, https://dx.doi.org/10.1787/9789264213593-en.

Rotger, G., M. Gørtz and D. Storey (2012), "Assessing the effectiveness of guided preparation for new venture creation and performance: Theory and practice", Journal of Business Venturing, Vol. 27/4, http://dx.doi.org/10.1016/j.jbusvent.2012.01.003.

Širok, K. (2019), "Slovenia: The precarious nature of self-employed professionals", in Semenza, R. and F. Pichault (eds.), The Challenges of Self-Employment in Europe: Status, Social Protection and Collective Representation, Edward Elgar.

Vari-Lavoisier, I. (2011), "Heurs et malheurs des chômeurs créateurs d'entreprises", Terrains \& [23] travaux, Vol. n 19/2, http://dx.doi.org/10.3917/tt.019.0121. 


\section{Part II Policies for inclusive entrepreneurship}




\section{Designing effective microfinance schemes for inclusive entrepreneurship}

Microfinance has grown rapidly as a tool to help entrepreneurs from underrepresented and disadvantaged groups access start-up financing. The largest target client group of microfinance is women, followed by youth, seniors, the unemployed and immigrants. Estimates suggest that the global market is about EUR 124-137 billion and this is expected to more than double by 2027 . However, the supply of microfinance has not been able to keep up with demand and annual unmet demand for microfinance is about EUR 14 billion. This chapter discusses how governments can address this gap. It also covers other debates in microfinance such as the extent to which digitalisation should be embraced and how microfinance can be used to support the green transition. The chapter provides policy advice that is illustrated with case study examples. 


\section{Key messages}

- Microfinance is an important tool for inclusive entrepreneurship because it provides access to start-up capital to people that cannot access mainstream financial markets. It is typically offered by Microfinance institutions (MFIs) that are dedicated to serving specific target client groups, but it can also be offered by financial institutions, governments and other actors.

- The development of microfinance has been rapid. Worldwide, more than 130 million people have used microfinance for both business and personal reasons and the total loan portfolio will reach approximately EUR 124 billion in 2021. Microfinance markets are the most developed in developing countries. Combined, Africa, Latin America, South Asia, East Asia and the Pacific regions account for about $80 \%$ of the global market. In the European Union (EU), the sector has experienced significant growth in the last decade, with financial and technical support from the European Investment Bank (EIB) Group and the European Commission. This experience has shown that microfinance has promoted financial inclusion of the poor, supported their entrepreneurial ambitions and generated employment. The sector is less developed in North America where financial markets are tightly regulated and an abundance of alternative debt instruments are available to entrepreneurs.

- Further, there is progressive consolidation of a micro-finance ecosystem in the EU. This is supported by micro-finance networks that spread good practice in the provision of finance to people in vulnerable situations (European Code of Good Conduct for Micro-finance provision).

- There is significant unmet demand for microfinance in many markets including in the EU. Estimates suggest that there is currently a gap of about EUR 14 billion per year in the EU (excluding informal businesses).

- The COVID-19 pandemic had a strong impact on both MFIs and their clients, which threatens to increase unmet demand in the market. Many MFIs reported operational challenges during the pandemic, including difficulties disbursing funds since the containment measures (e.g. lockdowns, curfews) caused a dramatic reduction in beneficiaries' income as well as difficulties collecting reimbursements and meeting with clients to provide business development services and monitor their activities.

- Governments need to inject more liquidity into the microfinance market, especially in the EU to address the current liquidity crisis. In addition, governments can offer greater technical support to MFIs to boost the quality of "soft" support that accompanies loans and improve the alignment of products and services with the needs of entrepreneurs from under-represented and disadvantaged groups.

- Governments can do more to assess the particular needs of countries and regions. This will ensure that microfinance schemes are relevant for the specific financial and social inclusion needs of the area and more broadly, will support further development of the micro-finance ecosystem in the EU.

- Governments can use economic recovery packages to address long-term issues faced by MFIs such as the slow adoption of digital tools. While MFIs should not seek to be fully digital since their business model relies on intensive interaction with clients, there is room to better use digital tools to reach and serve clients.

- Microfinance can also play a role in supporting the green transition. This includes supporting entrepreneurs in becoming greener through targeted funds and greater incentives to MFIs for funding green projects (e.g. greater guarantees, interest rate subsidies). 


\section{The growing demand for microfinance}

\section{Microfinance is an important tool to support inclusive entrepreneurship...}

Microfinance plays a critical role in supporting inclusive entrepreneurship through the offering of small loans, financial services and business development services to entrepreneurs. The primary target clients are people who face financial exclusion (see Box 7.1). Many people from these groups lack personal capital, credit history, collateral and guarantees so they are often perceived as too risky for many lenders in mainstream financial markets. Women are the most frequently targeted population group, accounting for nearly $60 \%$ of borrowers in Europe (Figure 7.1). People living in rural areas are also an important target groups with $46 \%$ of MFIs specifically seeking to address their needs.

The growth of microfinance over the past $\mathbf{3 0}$ years has been remarkable. Since the launch of the Grameen Bank in 1977 by Nobel Prize laureate Muhammad Yunus, this model of lending has supported more than 130 million people. There are now more than 10000 MFIs worldwide. While most MFIs are located in developing countries, they have a strong presence in the EU, especially in Eastern Member States (World Bank, 2019 ${ }_{[1]}$ ). The total global loan portfolio is currently estimated to be about USD 145-160 billion (approximately EUR 124-137 billion) (MEDICI, 2021[2]; ReportLinker Consulting, 2021 ${ }_{[3]}$ ) and this could grow to reach about USD 400 billion (approximately EUR 342 billion) by 2027 (ReportLinker Consulting, 2021[3]).

The European Union encourages the development of initiatives such as microfinance schemes focused on financial and social inclusion, job creation and economic growth in general. For example, in many European countries, microfinance is gradually being consolidated as an essential social policy tool for the promotion of self-employment, microenterprise support, and the fight against social and financial exclusion. The EU market is expected to reach about USD 90 billion (approximately EUR 77 billion) by 2027, accounting for about $23 \%$ of the global market (ReportLinker Consulting, 2021 [3]). Although this growth is below some of the leading markets such as China, growth is expected to be strong in some EU Member States such as Germany.

\section{Figure 7.1. Women and rural populations are the most frequently served client groups}

Distribution of MFIs in Europe by primary target client group, 2018-19

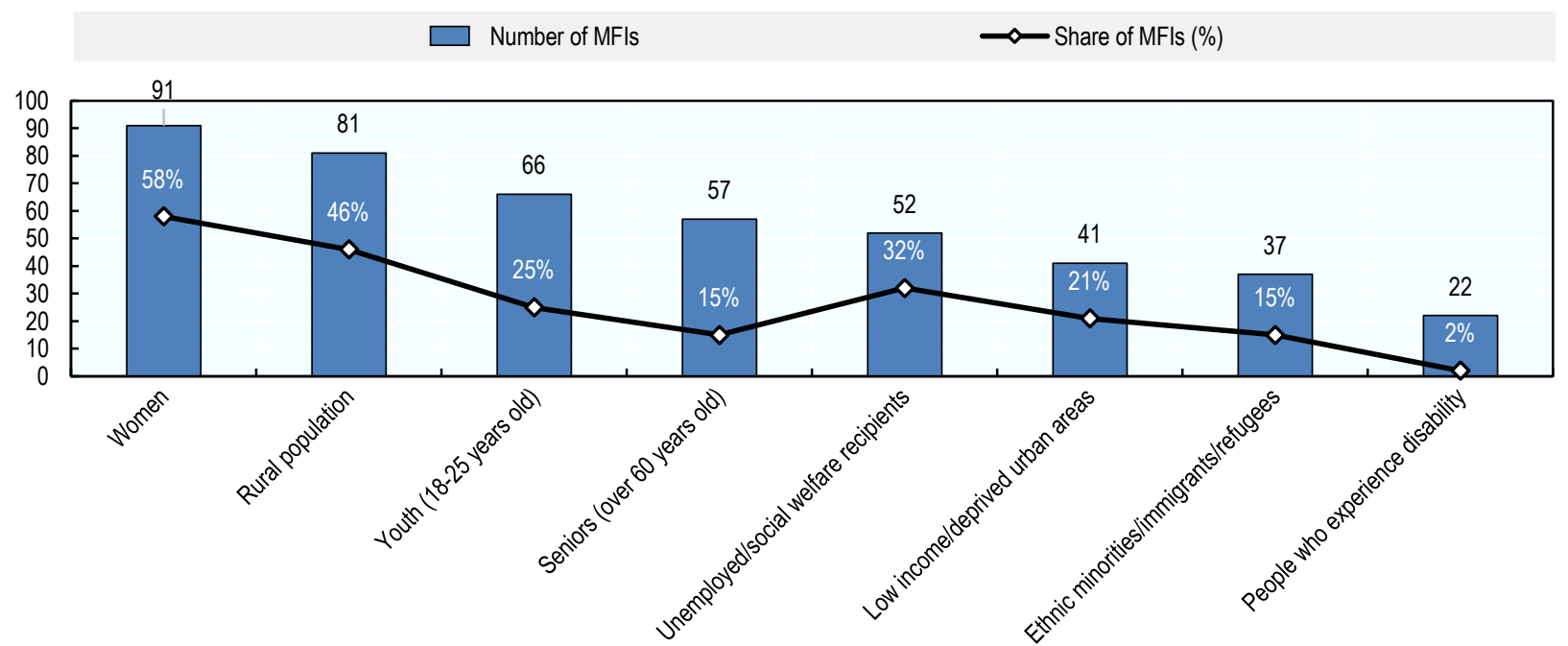

Note: Data were tabulated from the European Microfinance Network Survey 2018-19, which covered 156 MFIs. It is possible for MFls to have more than one target client group.

Source: (Corsi, 2021 [4]) 


\section{Box 7.1. What is microfinance?}

Microfinance depends on microcredit, a collateral-free loan that is targeted at people who are generally excluded from traditional banking services. This financial exclusion typically stems from low income and unstable income source(s), a lack of adequate collateral and credit history, as well as high administrative costs of small-scale lending and the high costs of enforcing contracts (Hermes and Lensink, 2007 $7_{[5]}$; KONO and TAKAHASHI, 2010[6]; Rosenberg, Gonzalez and Narain, 2009 $9_{[7]}$; Rosenberg, Gonzalez and Narain, $\left.2009_{[8]}\right)$. Within the European Union (EU), microcredit is generally considered to be loans up to EUR 25000 but some offers can be as much as EUR 50000 . These small loans - particularly when they are used by entrepreneurs - are often bundled with other support services such as entrepreneurship and financial literacy training, coaching and mentoring. Once packaged together with business development services, microcredit becomes known as microfinance.

Many types of financial institutions can deliver microfinance. This includes, for example, traditional and co-operative banks, business development banks and other types of financial institutions. However, microfinance for entrepreneurship is most often delivered through specialised microfinance institutions (MFIs). In the EU, MFIs often offer loans at interest rates that are below commercial bank rates due to public subsidies and guarantees (Drexler et al., 2020 ${ }_{[9]}$ ). In developing countries, however, microfinance is often offered at above market rates since MFIs typically assume the full risk of these uncollateralised loans (i.e. an absence of government guarantees), the value of the loans are smaller and more expensive to service, and capital is generally less available. MFIs in both developed and developing countries commonly offer flexible repayment options.

Businesses or personal microloans are the most common microfinance products provided by MFIs. However, microfinance offered by European MFIs looks different than that offered by MFIs in developing countries. In general, European MFIs offer individual microcredit rather than the collective type of microcredit that prevails in developing countries. MFIs can also offer other financial products and services alongside microfinance, including microinsurance. However, the development of microfinancial services remains limited, both in developed and developing countries.

Microfinance has an important role to play in supporting inclusive entrepreneurship because it can address several market failures. Market failures can create a mismatch between (potential) demand for small loans by entrepreneurs and the supply from MFls. These gaps typically stem from the following market inefficiencies (Drexler et al., 2020[9]):

- Information asymmetry: Lenders have less information about the capacity to repay a loan than the loan applicant. This information gap can be greater when the applicant has little or no financial history, making it difficult for the lender to assess its level of risk. This could result in adverse selection (i.e. risky loans that eventually put upward pressure on interest rates to cover losses) and moral hazard (i.e. overfunding and/or shifting risk from borrowers to lenders).

- Capacity gaps: A lack of knowledge, skills, tools and staff in borrowing companies or MFIs can hinder the completion and assessment of loan applications. This can result in incomplete or poor quality applications, as well as inaccurate appraisals that lead to rejections for the wrong reason (resulting in unmet demand).

- Absence of markets: There can be insufficient credit provision when certain other systems such as property rights are not fully functional or when assets are difficult to value since these may result in insecure collateral. Lenders may not lend against collateral that has some risk attached to it. This is particularly challenging in the agriculture sector and for informal businesses. 
- Imperfect competition: A concentration of market power with a small number of microfinance providers could result in upward price pressure and/or insufficient supply of credit. This is most likely to arise in immature markets or countries with limited possibilities for MFIs (e.g. Germany).

- Public policy: Government actions can influence microfinance markets in both positive and negative ways, including through the establishment of property rights, regulatory frameworks and offers of guarantees, small loans, insurance, etc. Market distortions can occur when governments operate directly in microfinance markets since many very small MFIs cannot compete against subsidised lending schemes.

- Country-specific risks: Several local factors can also influence microfinance markets by influencing the attractiveness of lending conditions. These factors include political stability, trust in the banking system, currency risks, etc.

The main advantage of microfinance relative to other debt products is that it is designed to address the obstacles faced in the credit market. However, it can also help entrepreneurs (and individuals) build a credit history to improve access to mainstream financial products. On the downside, MFls are unlikely to become self-sustainable because of the higher risk profile of the entrepreneurs they target and require significant policy support. The degree of subsidisation is stronger as the target group becomes harder to reach. In addition, there is also a risk that microfinance could further marginalise these borrowers into a segmented credit market due to social stigma attributed to microcredit clients by mainstream lending institutions.

\section{... and there is a significant unmet demand}

While microfinance has established itself as an important tool for entrepreneurs, especially those from under-represented and disadvantaged groups, there is significant unmet demand. Recent estimates based on microfinance applications that were turned down suggest that the total volume of annual unmet demand for microfinance within the EU is EUR 14.1 billion (EUR 42.3 billion when informal businesses are also considered) (Drexler et al., 2020[9]). At the Member State-level, the highest estimated value of unmet demand is for Italy (EUR 2.1 billion), followed by France (EUR 1.9 billion), Germany, Poland (both EUR 1.3 billon), and Romania and Spain (EUR 1.1 billion each). In principle, however, some of this unmet demand could be served by the banking sector as well as non-bank lenders such as peer-to-peer (P2P) platforms. This gap in unmet demand expected to grow to between EUR 15.0 billion and EUR 16.7 billion by 2027 (Drexler et al., 2020[9]). This clearly suggests a need to increase the supply for microfinance and related products.

Furthermore, there also appears to be a gap in the non-financial services provided by MFIs. The study (Drexler et al., 2020[9]) estimated the gap in non-financial services using the proportion of MFI activities dedicated to these services and unmet demand for loans. Excluding informal businesses, it is estimated that about 1.2 million clients in the EU are not receiving non-financial services that they would like to access. 
Figure 7.2. There is substantial unmet demand for microfinance in the EU

Estimated size of market gaps as of 2020
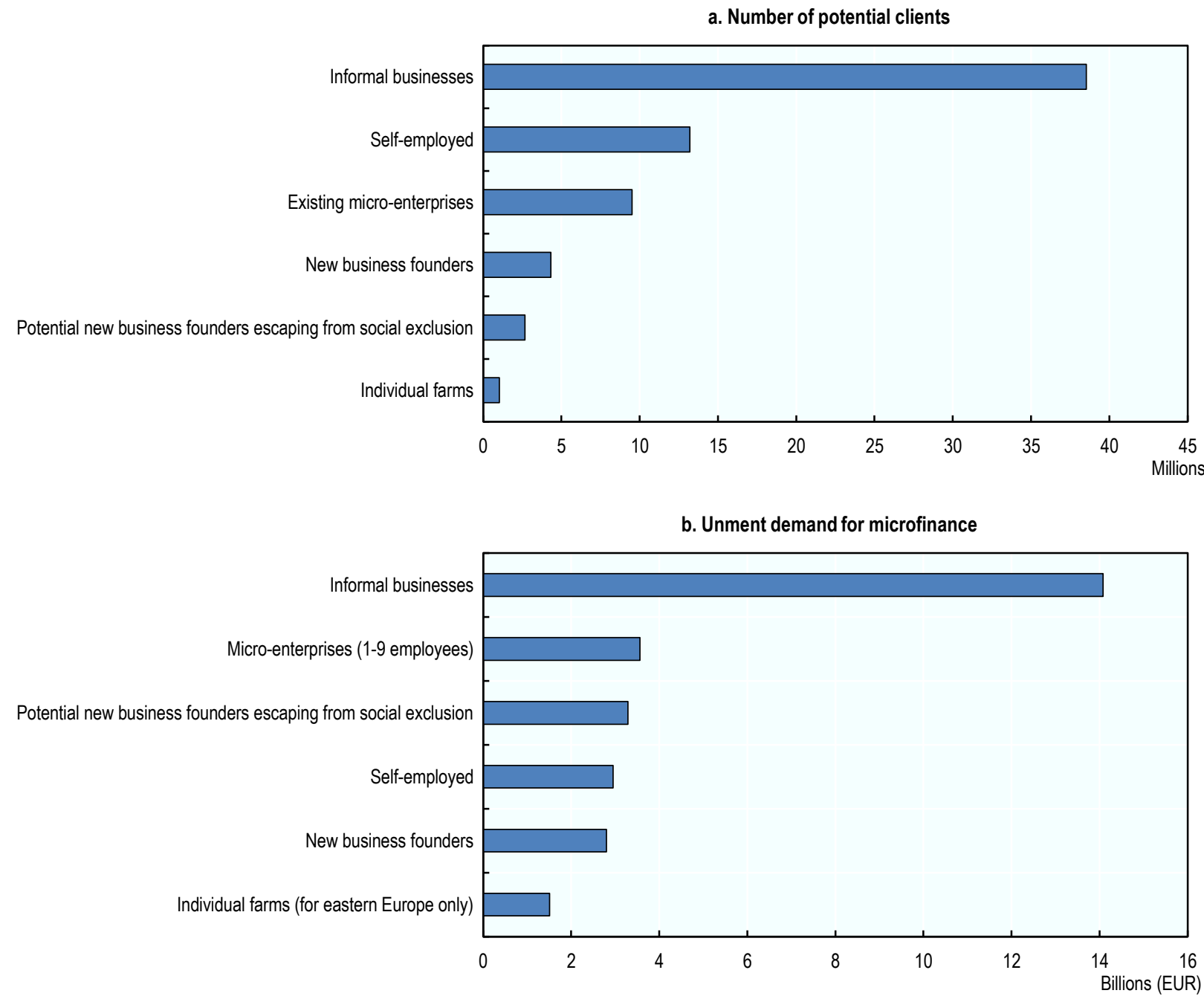

Source: (Drexler et al., 2020[9])

StatLink 제대 https://doi.org/10.1787/888934281258

\section{Microfinance in the European Union and beyond}

\section{Microfinance providers in the EU are extremely diverse in size, offerings and objectives...}

The microfinance sector is reaching maturity in the EU after more than $\mathbf{3 0}$ years, yet the sector is diverse and fragmented. Microfinance services are delivered by various types of institutions operating under different regulatory regimes. Some microfinance providers are entirely dedicated to providing small loans to low-income people. For the others, microfinance constitutes only a small fraction of the entity's financial services. Yet, other institutions engaged in microfinance do not disburse loans themselves but facilitate access to microfinance by supporting the client in the loan application and repayment process or provide guarantees in addition to other non-financial services supporting micro-entrepreneurs. 
Microfinance providers come in all shapes and sizes. Nearly $90 \%$ of MFls operate under the legal status of non-governmental organisation (NGO), non-bank financial institution (NBFI), credit union or financial co-operative, while the remaining are other legal forms such as banks, and governmental bodies (Diriker, Landoni and Benaglio, 2018[10]). The majority of microloans are offered by credit unions. Altogether, the European Microfinance Network (EMN) identifies 456 MFIs, predominantly operating as NGOs and NBFIs (Diriker, Landoni and Benaglio, 2018[10]). A profile of the typical MFI in the EU is described in Box 7.2. Certainly, all banks have micro-entrepreneurs as their clients, but the scale of lending to micro-enterprises is not known.

MFIs provide a variety of financial and non-financial products and services. In EU Member States, micro-enterprise loans are the most popular product for about $80 \%$ of MFls, followed by personal loans (64\%) (Diriker, Landoni and Benaglio, 2018[10]). Altogether, 52\% of MFIs provide both business (micro, SME or agricultural loans) and personal or housing loans. Non-financial services in addition to the financial ones are more commonly delivered by MFls in Western European countries where $79 \%$ of the MFIs engage in this type of support (Diriker, Landoni and Benaglio, 2018[10]).

Many MFIs orient microfinance services to specific target population groups, such as women entrepreneurs. There are several strong rationale for supporting female entrepreneurs with microfinance, such as: gender bias in financial markets, poverty reduction since women are assumed to contribute more to family welfare, and efficiency since women entrepreneurs tend to be more risk averse and are more likely to repay debt. However, women-oriented MFIs differ from other MFIs across key characteristics (Table 7.1). MFls with a higher proportion of women borrowers are slightly more mature, consistent with previous evidence on European microfinance.

Table 7.1. Women-oriented MFIs are smaller and less profit-driven than other MFIs

\begin{tabular}{|c|c|c|}
\hline & Women-oriented MFIs (\%) & Other MFIs (\%) \\
\hline Age (years, mean) & 12.3 & 10.9 \\
\hline \multicolumn{3}{|l|}{ Institutional type } \\
\hline Banks & 14.3 & 19.4 \\
\hline Government body & 6.2 & 8.6 \\
\hline NBFI & 37.3 & 28.2 \\
\hline NGO & 40.8 & 41.8 \\
\hline Others & 1.4 & 2.1 \\
\hline \multicolumn{3}{|l|}{ Business orientation } \\
\hline $\begin{array}{l}\text { Commercialised (profit-oriented and/or mission on job creation, micro-enterprise and } \\
\text { SME promotion) }\end{array}$ & 30.5 & 43.2 \\
\hline $\begin{array}{l}\text { Non commercialised (non-profit and/or social inclusion and poverty reduction, and } \\
\text { financial inclusion objectives }\end{array}$ & 45.1 & 41.9 \\
\hline $\mathrm{N} / \mathrm{A}$ & 24.3 & 14.9 \\
\hline \multicolumn{3}{|l|}{ Depth of outreach } \\
\hline Average loan per borrower/GNI p.c. & 35.0 & 68.7 \\
\hline \multicolumn{3}{|l|}{ Geographical area } \\
\hline Western Europe & 63.5 & 61.8 \\
\hline Eastern Europe & 36.5 & 38.2 \\
\hline \multicolumn{3}{|l|}{ Staff } \\
\hline Total number (mean)* & 22.5 & 50.8 \\
\hline Share of women & 68.9 & 58.1 \\
\hline
\end{tabular}

Note: * Data available only for the years 2006-11.

Source: EMN Survey Panel Dataset 2006-15. 


\section{Box 7.2. A profile of the "average" European MFI}

At least 450 institutions offer or facilitate the disbursement of microloans in Europe. One third of them responded to a biannual industrywide survey financed by the EU in 2017 . The surveyed institutions serve just under one million clients, with an outstanding gross microloan portfolio of EUR 3.2 billion. They also provide non-financial support services to 443825 clients. ${ }^{1}$

Overall, the median MFI in Europe has total assets of EUR 1.71 million, 246 active borrowers, and is about nine years old. It employs five workers, the majority of whom are women (60\%). The median loan was for EUR 8000 to repay in 36 months at an interest rate of $8 \%$.

Women-oriented MFIs are, on average, markedly smaller - the staff size is less than half of their counterparts. They are also more likely to operate as Non-Bank Financial Institutions (NBFIs) and tend to be less profit-driven. These MFls also appear to have a stronger emphasis on social inclusion, poverty reduction and financial inclusion. Women-oriented MFIs seem to target more disadvantaged categories of clients, as their depth of outreach indicator is half that of other institutions. It is clear that among the surveyed MFIs, those with a higher percentage of women employees translated into more gender-sensitive portfolios. This is consistent with other evidence on the impact of involving more women on the supply-side of financial decision making.

One-fifth of MFIs in the EU specialise in financial services only, with the provision of additional services such as entrepreneurship training or business consultancy being delivered through partnerships with other organisations. Moreover, $46.4 \%$ of MFIs report that their main activity is microlending (i.e. accounting for $75 \%$ to $100 \%$ of their activities), while $19.7 \%$ are more oriented to non-financial services (i.e. microlending activities account for less than $5 \%$ of their activities). Only $5.2 \%$ of MFIs use solidarity groups as their primary lending method. About one-third of MFIs (36\%) serve their customers primarily on a local basis while internationalisation is a core activity for only $3 \%$ of MFIs.

The median Return on Assets (ROA) as reported by the MFIs is $3 \%$ while the Portfolio at Risk (PaR30) is $7.25 \%$. The yield on the loan portfolio is $14.16 \%$.

Note: This figures cited are based on panel data constructed from biennial EMN survey covering 444 MFIs in 34 countries - including MFIs in Eastern European countries that are members of the Microfinance Centre (MFC) - over the period 2006-15.

Source: (Botti, Corsi and Zacchia, 2018[11])

The size of the microfinance sector in other parts of the world varies greatly according to the macroeconomic conditions and regulatory environment. In general, microfinance has a stronger presence in countries where the formal financial system is less developed. Thus, the microfinance sectors in Southeast Asia, Africa and Latin American are much more active than in the EU and North America. In developing countries, microfinance often takes the form of group loans where group members act as guarantors for each other, whereas microfinance in the EU and North America tends to be based on individual loans. Even among developing countries, the regulatory environments vary greatly which has a strong impact on the development of the microfinance sector. See Box 7.3 for further discussion of approaches in selected non-EU countries. 


\section{Box 7.3. Microfinance in non-EU OECD countries}

\section{United States}

The total microfinance portfolio is estimated to be USD 21 million (approximately EUR 18 million) (About Microfinance, 2021 [12]). This accounts for only a fraction of a percentage point of the global market. This tiny share is due to the tighter financial regulations and an abundance of alternative financing mechanisms. Nonetheless there is evidence that many MFIs are having encouraging impacts on their clients. This includes, for example, high rates of business operation, reduced material hardship and improved credit scores in the 7-12 month period following a microloan (Schaberg et al., 2019[13]).

\section{Mexico}

Similarly, the microfinance market in Mexico is generally considered to be under-developed - especially relative to other Latin American economies. Nonetheless, regulatory changes in the financial sector over the last 10-15 years have led to a rapid growth in credit providers for low-income individuals. The microfinance market has become increasingly competitive, but also more concentrated. In 2015 , the ten largest MFIs accounted for $81 \%$ of the total market and about 1500 MFls shared the remaining $19 \%$ of the market (Antón Díaz, 2017 ${ }_{[14]}$ ). This concentration means that new MFIs need to quickly acquire a sizable healthy portfolio to achieve longer-term sustainability.

There are several unique features of the microfinance market in Mexico. First, the "village banking" model continues to be the dominant approach to microlending. This involves a type of group lending where borrowers act as each other's guarantor rather than the more common model based on individual loans (Women's World Banking, 2014[15]). Second, the vast majority of new loan applicants $(74 \%)$ already have active loans and many (44\%) are already in arrears at their time of application (Graham, Ericksen and Ericksen, 2014[16]) (MFTransparency, 2015[17]).

There are several challenges to the further development of microfinance in Mexico. One of the challenges is that there are many MFls in densely populated areas. New entrants are increasingly turning to rural areas for customers, but this increases the costs of servicing the loans (Antón Díaz, 2017[14]). Second, consumer credit has acted as a substitute for micro-enterprise lending. Third, there are regulatory disincentives for large financial institutions to enter the microfinance market (Women's World Banking, 2014 $[15])$. There are also some demand-side factors, including low levels of financial literacy and high levels of over-indebtedness (Women's World Banking, 2014[15]).

\section{Colombia}

The microfinance sector in Colombia is the largest in Latin America, both in terms of the number of total active borrowers and in outstanding loans. Lenders include commercial banks, commercial finance companies, financial co-operatives, loans and savings co-operatives and NGOs. The sector has developed rapidly since its inception in the early 1980s. This scaling-up has been driven by strong partnerships between key governmental, non-governmental and private sector actors (MFTransparency, 2015[17]).

The regulatory and supervisory framework is built around deposit taking and non-deposit taking MFIs. The Financial Superintendence of Colombia (SFC) is the main regulatory body that oversees deposit taking microfinance service providers. MFIs that are co-operatives and saving and loans associations are overseen by the Economia Solidaria Superintendency. However, the majority of NGO MFIs do not fall under any regulatory body. In addition, a legal framework on consumer protection for the financial sector was implemented in 2009 (Law 1328). It aims to promote transparency but again, this does not cover the vast majority of unregulated NGO MFIs (MFTransparency, 2015 ${ }_{[17]}$ ). 
...and regulatory frameworks vary greatly across EU Member States...

Non-bank financial institutions are the most common legal form of MFIs in the EU, and also globally. In general, legislation on microcredit activities in the EU seeks to formalise the operations of nonbank actors that are not obligated to comply with full banking regulations. Nevertheless, the regulatory framework for microcredit activities varies across countries according to contextual factors related to history, economy and financial system development. There is no EU-wide legislative framework for microfinance provision but the European Code of Conduct for Microcredit Provision provides a selfregulatory framework (Box 7.4). Instead, national legislation provides the conditions under which microfinance can be provided.

\section{Box 7.4. European Code of Good Conduct for Microcredit Provision}

The European Code of Good Conduct for Microcredit Provision was established in October 2011. It defines a set of standards for the microfinance sector in Europe and serves as a self-regulation tool and quality label for MFIs. It targets MFIs that provide business loans of up to EUR 25000 to microentrepreneurs or self-employed persons. Signing up to or endorsing the Code is a pre-condition for accessing EU funding for microfinance under the EU Programme for Employment and Social Innovation (EaSI) and InvestEU.

The Code was developed based on recognised best practices in the sector in close consultation with stakeholders and updated through a consultation process in 2019. The updated Code was formally adopted in October 2019 and came into force on 1 January 2021.

The objective of the update was to fine-tune the existing clauses in the Code, taking account of the changes intervened since its first establishment. This includes some amendments to reflect changes in the market and to better reflect the diversity of European MFIs in terms of size, legal structures and national regulatory frameworks.

Source: (European Commission, 2020[18]; European Commisison, 2021 [19])

There are three main scenarios of regulatory and legislative frameworks for non-bank financial MFIs in the EU (Figure 7.3). One approach is to use specific microcredit legislation in the national law with a distinct category for microcredit providers. Several EU Member States and EU candidate countries use this approach: the earliest in France (2001), Bosnia and Herzegovina (2006), Kosovo (2008), Romania (2009), Italy and Portugal (both 2010), Montenegro (2017) and Greece (2020). Microcredit activity is restricted to commercial entities in Portugal, Romania and Montenegro, and to not-for-profit organisations in France. A mixed approach has been followed in the remaining countries. The supervision of non-banking MFls is entrusted to national central banks in all the noted legislations. Microcredit regulation in France, Italy, Kosovo, Bosnia and Herzegovina and Portugal introduces a distinct category for non-bank MFIs. In the first three countries, the regulation is part of banking law. Interestingly, in Romania and Montenegro, microcredit is regulated in the NBFI law, as one of the financial products potentially offered by them. Two contrasting approaches to microcredit regulation are presented in Box 7.5. 
Figure 7.3. Regulatory approaches in Europe, including EU accession countries

1. Specific microcredit
regulation
- France (since 2001)
- Bosnia and Herzegovina
(2006)
- Kosovo (2008)
- Romania (2009)
- Italy (2010)
- Portugal (2010
- Montenegro (2017)
- Greece (2020)
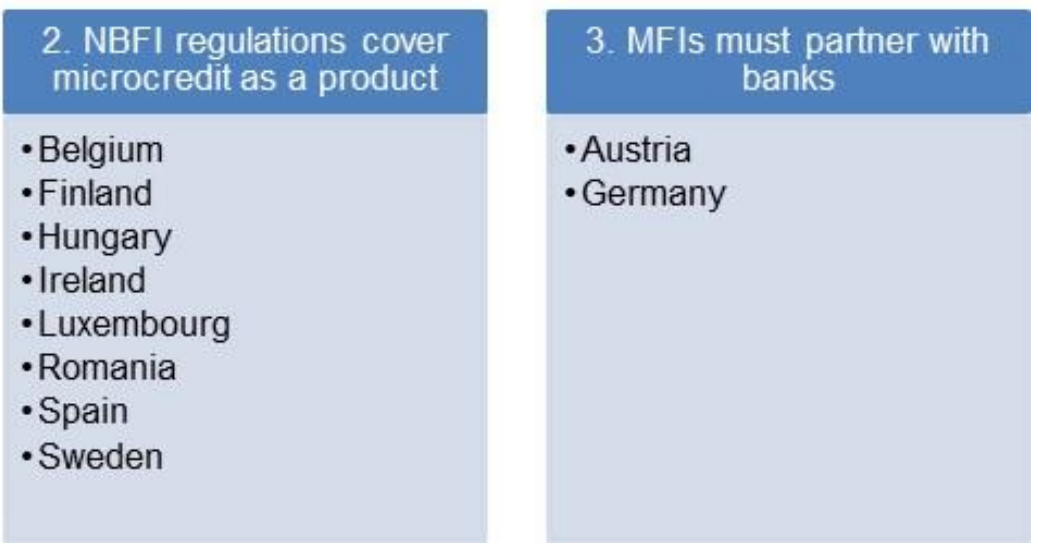

Source: (Ruesta and Benaglio, 2021 [20])

\section{Box 7.5. Examples of approaches to microcredit legislation in the EU}

Italy

The Italian banking law reform in 2014 introduced the definition of microcredit activities and created a register of MFIs managed by the Bank of Italy. MFIs are allowed to operate as specialised microcredit operators if complying with additional conditions, namely the lack of real guarantees, the provision of non-financial services and monitoring of clients (Art. 111). The Italian legal framework enables a broad array of legal types to provide microcredit: non-profit organisations (e.g. associations, foundations, mutual aid societies, local and governmental agencies, social co-operatives, non-profit co-operatives), banks, non-bank financial institutions (for-profit organisations regulated under Article 106 of the banking law) and mutual financial operators (co-operatives with specific by-law conditions) provided that they adhere to the criteria of Art. 111.

The Italian law formally differentiates between business and personal microloans in terms of maximum amount (EUR 40000 for personal microloans with a possible additional EUR 10000 for the first business microloan cycle) and microloan term (7-10 years for personal loans and five years for businesses). Both products must be accompanied by non-financial services. The interest rate cap is set according to Italian anti-usury legislation.

Advantages of this approach:

- Distinguishing between business and personal microloans concerning terms, conditions and formal purposes allows for a more tailored approach to different target groups.

- Recognising specific categories of non-bank legal forms that operate in the sector can encourage their direct participation without any forced partnership with banks and increases the supply of microfinance.

Disadvantage of this approach:

- Conservative and restrictive regulation on non-bank actors may impede access to the sector. 


\section{Romania}

The current law on non-bank financial institutions (Law on Non-Bank Financial Institutions no. 93/2009) regulates all non-bank financial activities, including MFIs as well as leasing companies, mortgage companies, credit unions, consumer lenders. The National Bank of Romania is responsible for regulations, supervision and registration of all non-bank financial institutions. MFls do not have any distinct legal status compared to other non-bank financial institutions. There are no limits for business or personal microloans size. Only for-profit organisations are allowed for microcredit provision and credit unions are authorised to disburse only personal loans to their members.

\section{Advantage of this approach:}

- The lack of limits for microloan size and interest rate ceilings can enhance the possibility of attaining financial sustainability for MFIs.

\section{Disadvantages of this approach:}

- Only credit unions are authorised to collect savings as an alternative source of funding, which reduces the range of microfinancial services that MFIs can offer.

- The inclusion of microcredit in a broad range of financial products that NBFls can offer implies the lack of a distinct status for MFIs and of a formal definition of microcredit.

A second approach to regulating microcredit is to use regulations for NBFls to cover microcredit as one of the regulated products. Non-bank microlenders can disburse loans even with the lack of a proper microcredit legislation in Belgium, Ireland, Luxembourg, Spain, and Sweden, where non-bank lenders operate under the national consumer law. In Ireland, only one non-bank provider operates in the absence of general regulation of microcredit activities due to a specific mandate from the government to lend to micro-enterprises. In Finland, the law on crowdfunding allows non-bank MFIs to operate. In Hungary, an exemption in the banking law allows non-profit, semi-public entities to disburse microloans under a national programme on microcredit.

The third approach to regulating the provision of microcredit is to require non-bank actors to partner with a regulated bank, which is found in Austria and Germany. In Austria, the banking law formally forbids NBFIs from offering credit while lending activities in Germany are restricted to banks, forcing non-bank actors to act as agents. In Germany, restrictive requirements set by the banking law for non-bank lenders make it impossible for them operate in the market.

The fragmented nature of the regulatory environment for microcredit provision across Europe can lead to a variety of microcredit lending practices. Regardless of the regulatory approach, minimum capital requirements differ substantially from one country to another. In France and Italy, such a limit is not provided for not-for-profit organisations in the main regulation. Restrictive regulations in the form of constraining minimum capital requirements or interest rate ceilings may result in legislative barriers to the operational viability of non-bank microlenders. The crucial role of minimum capital requirements as a potential barrier to NBFI access to a regulated microcredit sector is emphasised by the Portuguese case: the threshold set by the law is so substantial (EUR 1 million) that only commercial lenders are involved in the national microcredit sector. This shows the potential undesirable effect of a restrictive regulation in which microloans end up being disbursed only by banks in partnership with social purpose organisations.

\section{... and the $E U$ is increasing investments in the sector}

The EU has supported the development of the microfinance sector dating back to the $1990 \mathrm{~s}$. However, it was not until the 2007-13 programming period when its use became more widespread as part of the EU policy toolkit for the realisation of the "Lisbon Strategy for growth and jobs" and the promotion of social inclusion (European Commission, $2007_{[21]}$ ). The foundation for current instruments was laid during 
this period, notably through three programmes: JASMINE (Joint Action to Support Microfinance Institutions in Europe), JEREMIE (Joint European Resources for Micro to Medium Enterprises) and European Progress Microfinance Facility (EPMF). ${ }^{2}$ During this period, expenditure on supporting microfinance schemes accounted for approximately $5 \%$ of the total European Regional Fund resources and this increased in subsequent programming periods (European Commission, 2020[22]). Support was further strengthened in the 2014-20 period under the framework of the Europe 2020 strategy for growth and jobs. The EU Programme for Employment and Social Innovation (EaSI) has become one of the main programmes to support microfinance with a budget of EUR 919 million for 2014-20. Its main objectives are to increase access to, and the availability of microfinance for vulnerable persons and micro-enterprises in both start-up and development phase, build up the institutional capacity of microcredit providers and support the development of the social investment market and facilitate access to finance for social enterprises. It has three axes, including one on Microfinance and Social Entrepreneurship, which supports: i) microcredit and microloans for vulnerable groups and micro-enterprises, and ii) social entrepreneurship. ${ }^{3}$

The new programming period 2021-27 will bring some major changes to the way that microfinance is structured and supported. The InvestEU programme will replace the European Fund for Strategic Investments (EFSI) and also bring together 12 other EU financial instruments, including EaSI. The size of the relative EU budgetary guarantee to support investment and access to finance across the EU is EUR 38 billion, of which EUR 4 billion will target the policy area Social investment and Skills, including a budgetary guarantee for microfinance, whereas the ESF+ will cover grants and advisory support for microfinance. InvestEU is expected to achieve EUR 650 billion of investments by attracting additional public and private investments. InvestEU will also be flexible in terms of adjustments to market and policy priorities changes over time.

\section{Box 7.6. Micro-finance under InvestEU 2021-27}

"The Social Investment and Skills window will support microfinance and social enterprises. In the case of microfinance, a microloan (or microcredit) means a loan of up to EUR 50000 . The provision of investment amounts of up to EUR 500000 for social enterprises will in particular be encouraged, while larger amounts of up to EUR 2000000 will also be targeted to foster their expansion and scaling up".

"As regards microfinance, the policy objective is to promote quality, sustainable employment and social inclusion by supporting job creation and income-generating activities, in particular for persons in vulnerable situations who wish to start up or develop a micro-enterprise, including on a self-employed basis.

In addition, financial intermediaries active in the microfinance space must ensure the provision, directly or indirectly, of non-financial services such as business development services (mentoring, coaching and training), which are an integral part of microfinance. Conditions such as the cost of borrowing (including the lending rate) and collateral requirements for microfinance directly or indirectly supported in the framework of InvestEU must reflect the benefit derived from the support and must be justifiable with regard to underlying risks and the actual cost of funding related to a credit.

As a pre-condition for InvestEU Fund support, financial intermediaries providing microfinance must sign up to (in the case of non-banks) or endorse (in the case of banks) the 'European code of good conduct for microcredit provision' to ensure high ethical lending standards in terms of, among others, governance, management and customer protection. Financial intermediaries shall seek to prevent individuals and undertakings from becoming over-indebted by, among others, taking into account their repayment capacity and ensuring an affordable cost of borrowing".

Source: (European Union, 2021 [23]) 


\section{Challenges faced in the wake of the COVID-19}

\section{The COVID-19 pandemic heavily disrupted MFI's financial and non-financial activities...}

The COVID-19 pandemic has created several immediate challenges for MFIs with simultaneous disruptions on both the demand (i.e. client) and supply (i.e. capital) sides of the market. These major disruptions threaten to reduce the important role in providing liquidity to micro-entrepreneurs, especially those from groups that are under-represented and disadvantaged in entrepreneurship. It is also important to recognise that the client group has been disproportionately impacted by the virus in terms of personal health (Horton, 2020[24]).

Many MFIs reported operational challenges during the pandemic. They include difficulties disbursing funds since the containment measures (e.g. lockdowns, curfews) caused a dramatic reduction in beneficiaries' income, difficulties collecting reimbursements since clients were generating much less revenue, and difficulties meeting with clients to provide business development services and monitor their activities. Underlying all of these operational challenges are two issues. First, MFIs themselves have been impacted by containment measures that have restricted business activities. Second, MFIs continue to rely heavily on face-to-face interactions with clients. For example, loan officers require personal meetings with beneficiaries, both to make loans and to collect repayments, and most of all to support them and to define sustainable relief strategies to overcome financial, economic, and social difficulties that are vital in times of crisis. MFIs, more than other financial institutions, rely on "social capital" or "organisational capital" that implies trust between institutions and customers, transparency in communication, and the prioritisation of beneficiaries' needs.

There was an immediate impact on portfolio and risk management. Globally, the quality of the loan portfolio of MFIs started to decrease at the beginning 2020 Q2. According to the CGAP interactive dashboard, ${ }^{4}$ the PAR- $30^{5}$ (i.e. loans in arrears for over 30 days) of responding MFIs increased on average from $8.8 \%$ before COVID-19 to $12.5 \%$ in December 2020 . The rise in portfolio at risk in the pandemic is even higher for small MFIs and for those that target female entrepreneurs - PAR-30 in December 2020 was $17.6 \%$ for small MFIs and $14.0 \%$ for those that targeted women entrepreneurs.

Within the EU, the impact of the COVID-19 pandemic on MFIs was uneven. It appears that MFIs based in Western EU Member States suffered a higher deterioration of portfolio quality (as measured by PAR30) than those in Eastern Member States (Dąbrowska, Koryński and Pytkowska, 2020[25]). This result can be explained by the greater focus on small early-stage businesses and start-ups by the MFIs in the West, which have a lower probability of surviving the crisis. However, the survey also found that MFIs in Eastern EU Member States demonstrated a greater readiness for dealing with the pandemic and resilience in their internal operational and governance structures (Dąbrowska, Koryński and Pytkowska, 2020[25]).

The difficulties experienced by MFI clients have made it more difficult for MFIs to repay their own investors and funders, and to cover their ongoing operational expenses since they have had difficulties generating revenue. The employees of MFIs have also been negatively impacted because some loan officers have performance-related pay. This type of pay is typically viewed as an incentive that rewards them for new loan disbursements and the repayment of existing loans. However, this has introduced a new stress since the difficulties faced by clients due to the COVID-19 pandemic is reducing employee earnings. This has created difficulties for many MFIs that have established policies that create a moratorium on loan repayment to assist their clients.

MFIs have responded to the COVID-19 pandemic by adjusting their products and the way that services are delivered. This includes delivering business support services (e.g. training, coaching and mentoring) through online platforms and the introduction of new products that are designed to provide liquidity during the crisis and/or support the pivoting of business activities to post-crisis opportunities (Box 7.7). Many of these new products have been supported by funding from national and local 
governments. This includes, for example, actions by the Italian Government to mitigate the impact of the COVID-19 pandemic on the microcredit sector by introducing a moratorium on loan repayments, a guarantee of up to $80 \%$ of the loan amount and an increase in the maximum amount for business microcredit from EUR 25000 to EUR 40000.

\section{... and reduced the ability of borrowers to repay loans...}

The COVID-19 pandemic has had a strong impact on entrepreneurs. One of the consequences has been an increase in demand for credit within microfinance markets, in terms of both the number of borrowers and the loan amounts (Brickell et al., 2020[26]). However, many MFIs began to avoid issuing new loans and additional credit for existing clients to preserve their own liquidity. A similar, but less severe strategy was to orient microloans to clients in sectors that were less impacted by the pandemic. Thus, there has been a credit crunch for microfinance borrowers and this has led to an increase in financial and social exclusion of the most marginalised groups.

\section{Box 7.7. Examples of MFls adapting their activities during the COVID-19 pandemic}

\section{Deferring repayments: MicroStart, Belgium}

MicroStart created a three-stage recovery plan for loans and deployed six specific measures in March 2020 to help entrepreneurs with the crisis. From April 2020 to May 2020, the first stage ("mS Express") offered emergency microcredit loans in collaboration with Funds for Good. This included a loan of EUR 2000 with an additional EUR 1000 unsecured, interest-free loan and the option of deferring capital repayment for up to three months. All clients were given the option to defer repayment deadlines until July 2020. From June 2020 to September 2020, the second stage ("mS Business") increased the value of loans offered to EUR 12000 with an additional EUR 3000 unsecured, interest-free loan with a possible 24-month deferred payment period. Clients also received online access to coaching services, webinars, and trainings. This programme was used by over 600 entrepreneurs. The third stage ("mS Scale-up) began in October 2020 and continued until June 2021 covering loans of up to EUR 20000 automatically supplemented by an unsecured, interest-free loan with a maximum amount of EUR 5000 and a possible 24-month deferred payment period. MicroStart also offered a three-month intensive individual coaching programme in addition to the loans in this programme which was used by over 1000 entrepreneurs. Overall, in 2020, MicroStart granted 583 microcredits in Belgium for a total amount of EUR 4.12 million. More than 400 of these microcredits benefited from the COVID adapted loans with $0 \%$ interest. Additionally, $50 \%$ of clients benefited from a moratorium as a result of the specific COVID19 measures.

\section{New loan products: Microfinance Ireland}

Microfinance Ireland launched a COVID-19 Business Loan Scheme ("COVID19-2") offering eligible small businesses loans from EUR 5000 to EUR 25000 with $0 \%$ interest and zero repayments for the first six months. Following the initial six months, reduced interest rates of $4.5 \%$ (annual percentage rate) or 5.5\% (annual percentage rate), depending on certain conditions, applied for the rest of the loan term. Borrowers received a government rebate of the equivalent of six months interest in Month 13 of the loan period as long as all conditions had been met. Current borrowers of Microfinance Ireland could apply for up to EUR 25000 in additional loans which were subject to a maximum credit exposure of EUR 50000 and subject to a maximum exposure under COVID19-2 of EUR 25000 . Loans from COVID19-2 could be used for working capital or required changes due to COVID-19 management and 
could be repaid in advanced without penalty. Loan application volumes increased $101 \%$ with 1229 loan approvals in 2020 . $67 \%$ of the total value of EUR 27 million were through the COVID19-2 scheme.

Reduced interest rates and administrative fees: Microlux, Luxembourg

Microlux adapted interest rates and fees to help micro-entrepreneurs negatively impacted by COVID19. From 15 June 2020, Microlux offered loans of up to EUR 25000 with conditions including a guarantor for $1 / 3$ of the loan amount. Borrowers received a lower annual interest rate of $4 \%$ in lieu of the standard $9 \%$ with an extended deffered payment period of up to six months instead of the traditional three months. Administrative fees dropped from $5 \%$ to $3 \%$ with a minimum of EUR 150 and a maximum of EUR 500. Under the COVID-19 Exceptional Conditions, the repayment period for a loan was set up to 36 months, and loans could be paid back early without penalty.

\section{... and also reignited debates about the dual mission of microfinance}

The COVID-19 crisis has reignited debates around the potential trade-offs in achieving the dual mission of microfinance: fighting against financial exclusion (i.e. social performance) and financial sustainability (i.e. financial performance). The most rigorous and comprehensive studies globally suggest that there is a trade-off between sustainability and outreach (Cull, Demirguc-Kunt and Morduch, 2009 ${ }_{[27] ;}$ Hermes, Lensink and Meesters, $2011_{[28]}$ ) and this is also confirmed in the EU context (Botti, Corsi and Zacchia, 2018[11]). These studies find a trade-off between the MFIs profitability and clients' poverty level - those MFIs serving the poorest clients and a significant share of women clients - are typically less cost-efficient and are often not able to earn enough profit to attract investors or transform into commercial institutions. For example, a study of MFIs over the period 2006-15 found that a growing share of MFIs had a mission that focused on poverty reduction and a decline in the share that focus on the empowerment of women and ethnic minority groups. Over the same period, there was an overall improvement of portfolio quality (i.e. declining PAR-30 and write-off ratio) and cost-efficiency (i.e. decreasing operating expense ratio) (Table 7.2). The Operational self-sufficiency ratio over the period also indicates a high level of operational sustainability. However, the data also show a worsening in profitability measures (i.e. return on equity and return on investment ratios) and the capacity to generate revenues from microloan portfolios (i.e. portfolio yield). This suggests that many MFIs will face a liquidity crunch in the wake of the COVID-19 pandemic. With growing inactivity and unemployment, there will likely be a greater priority placed on social performance within the microfinance sector. However, the experience following the financial crisis in 200809 suggests that the sector will have a declining financial performance if a greater social mission is followed. 
Table 7.2. Financial sustainability and social impact for European MFls after the 2007-08 financial crisis

\begin{tabular}{|c|c|c|c|c|}
\hline & & $2010-11$ & $2012-13$ & $2014-15$ \\
\hline \multirow[t]{9}{*}{ Social performance } & \multicolumn{4}{|c|}{ Target groups - \% of the total number of active borrowers } \\
\hline & Women & $25 \%$ & $32 \%$ & $39 \%$ \\
\hline & Ethnic minorities/immigrants & $18 \%$ & $17 \%$ & $18 \%$ \\
\hline & People with disabilities & $1 \%$ & $5 \%$ & $6 \%$ \\
\hline & Financially excluded & $34 \%$ & $40 \%$ & $33 \%$ \\
\hline & \multicolumn{4}{|c|}{ Mission statements } \\
\hline & Poverty reduction & $40 \%$ & $57 \%$ & $62 \%$ \\
\hline & Women empowerment & $36 \%$ & $29 \%$ & $32 \%$ \\
\hline & Minority empowerment & $31 \%$ & $20 \%$ & $20 \%$ \\
\hline \multirow[t]{8}{*}{ Financial performance } & PAR30 & $11.4 \%$ & $11.0 \%$ & $10.5 \%$ \\
\hline & Write-off ratio & $5.5 \%$ & $2.1 \%$ & $5.0 \%$ \\
\hline & Portfolio yield & $16.4 \%$ & $14.8 \%$ & $14.3 \%$ \\
\hline & Debt to equity ratio & $67.0 \%$ & $63.2 \%$ & $191.1 \%$ \\
\hline & Operating expense ratio & $25.5 \%$ & $22.2 \%$ & $16.4 \%$ \\
\hline & Return on equity & $12.0 \%$ & n.a. & $4.5 \%$ \\
\hline & Return on assets & $6.7 \%$ & $9.2 \%$ & $3.1 \%$ \\
\hline & Operational self-sufficiency ratio & n.a. & $96.4 \%$ & $91.8 \%$ \\
\hline
\end{tabular}

Note: * Data available only for the years 2006-11.

Source: EMN Survey Panel Dataset 2006-15.

\section{Policy actions to prepare the microfinance sector for the future}

Governments can play a role in addressing gaps in the microfinance market, including injecting capital into the market to increase supply and supporting MFIs in addressing unmet demand for new microfinancial products and services. While public involvement in microfinance markets risks crowding-out private sector actors, the size of market gaps calls for public intervention (Drexler et al., 2020[9]) Governments have several instruments that they can use to try to increase the supply of microfinance, including directly setting up schemes, offering grants and/or guarantees to MFIs or offering other incentives such as tax reductions to induce new entrants into the microfinance market (Box 7.8). Governments can also support the sector in many other ways, including the provision of technical assistance to address growing gaps between the products demanded and the products offered and to improve the quality of non-financial services offered. 


\section{Box 7.8. Setting up a microfinance scheme}

Policy makers are faced with several important choices when setting up a microfinance scheme. One concerns the Fund operator, which can either be selected through a public call for tender or be chosen without any tender among existing public institutions with experience in Fund management. The first option has the advantage of drawing on the most cost-effective solution to the government. The second option will ensure better coherence between the Fund's operations and the government's strategic objectives.

A second choice regards the financial intermediary organisation that will deliver the scheme, which can be an ad-hoc government body or be chosen among existing players in the credit market (e.g. commercial banks, non-bank financial institutions, credit unions, etc.), generally through a call for tender. The first option will have the main benefit of building an organisation tailored to its mission, but which will have high overhead costs, especially if the microfinance scheme is only temporary. The second will have the main advantage of leveraging on the expertise of players already active in the credit market, but who may not devote the same level of attention to microfinance than to their other activities.

Microfinance schemes require paying attention to distribution of costs among participants, namely government, providers and clients. There are several fixed costs involved in a microfinance scheme, including the loan capital, operating and refinancing costs, loan assessment and monitoring costs, etc. Additional services such as interest rebates, financial advice and education, and business development training also imply costs for microfinance providers.

Microfinance schemes are, therefore, unlikely to become fully self-sustainable, and policy makers should expect a strong element of subsidisation. This will be especially true for programmes for disadvantaged entrepreneurs who may need complementary services such as interest rebates and business training to be pulled in the scheme.

Source: (Marchese, 2014[29])

\section{Continue to address short-term liquidity pressures}

Government support for entrepreneurs during the COVID-19 pandemic was a much needed boost for the economy, but one of the consequences has been a liquidity shortage for MFIs. The COVID19 pandemic simultaneously disrupted both the demand- (clients' repayments) and supply-sides (access to capital and liquidity) of the global microfinance market. In response, governments have used a range of instruments to support lenders and borrowers in the microfinance sector, including repayment holidays, payment moratoria and credit restructuring. However, this has created liquidity shortages for MFIs and potentially hurt the long-term sustainability of the sector.

A number of actions are needed in the short term to ensure the survival of MFIs, notably including an injection of liquidity into the sector. Three main categories of liquidity support measures for the microfinance sector have been advanced especially in emerging markets. They include central bank liquidity windows available to banks, some with priority sector lending requirements attached, or their own targeted liquidity facilities aimed at MSME or microfinance clients; liquidity facilities managed by multilateral development banks and other investors; and credit guarantee schemes (Michaels, Bansal and El-Zoghbi, 2020 [30]). Within the EU, one notable recovery scheme was launched by the EIF and the European Commission through the new COVID-19 support measures under the EaSI Guarantee Instrument (EaSI) 
to enhance access to finance for micro-borrowers, micro- and social enterprises (Box 7.9). However, more is likely needed to help MFIs restructure their debt (Meagher, 2020[31]).

In addition, there is a need to increase the supply of guaranteed and funded debt instruments that are targeted at micro-entrepreneurs, especially the target groups of inclusive entrepreneurship. This is particularly true in the EU Member States with most need and the highest expected growth in demand for microfinance (southern and Eastern Europe). In addition to increasing the supply, it also seems necessary to speed up the implementation of the funding instruments in the short-term (Drexler et al., 2020[9]).

Governments could also consider providing funds for microfinance with softer conditions to target groups of inclusive entrepreneurship. At the financial intermediary level, it appears that not all types of MFIs get access to funding or guarantees and the result is that there is insufficient targeting to clients from vulnerable groups, which are riskier (Drexler et al., 2020[9]). This is primarily due to the difficulty of entering into transactions with innovative providers and the difficulties that smaller providers have with managing appraisal and due diligence procedures (Drexler et al., 2020[9]). The use of softer conditions can address these challenges and encourage financial intermediaries and MFIs to enter into these markets. Emergency liquidity facilities and recapitalisation could be considered by regulatory authorities and central banks to help stabilise the microfinance sector through MFI forgiveness of non-performing loans and prepare for the provision of liquidity management products. The case for strengthening prudential regulation and extending stabilising initiatives to microcredit segments of the financial markets by central banks is even stronger if microfinance is primarily a tool for managing liquidity for their clients.

Governments may also consider providing some relief to MFIs by deferring non-critical supervisory processes (Meagher, 2020[31]). Additional regulation and supervision, also fostered by uncertainty over the microfinance sector prospects, may lead to increasing operating costs for MFIs with unintended consequences over their capacity to serve the most vulnerable categories of clients (Cull, Demirguc-Kunt and Morduch, 2009[27]). 


\section{Box 7.9. COVID-19 support measures under the EaSI Guarantee Instrument}

As part of the policy response to address the economic disruption caused by COVID-19, the European Investment Fund (EIF) and the European Commission have introduced specific support measures to support micro- and social enterprises for a COVID-19 support period April 2020 - December 2021. The aim of the COVID-19 support measures is to incentivise financial intermediaries to provide microloans to small businesses, mitigating the increase in perceived risk triggered by the coronavirus pandemic, and alleviating working capital and liquidity constraints of final beneficiaries targeted by the EaSI programme.

The new features will be accessible to financial intermediaries selected after an application under a call for expression of interest followed by a due diligence process, that can benefit from guarantees under the EaSI Guarantee Instrument. Financial intermediaries with existing EIF agreements under the EaSI Guarantee will be able to access the new terms of the guarantees upon their request. Micro-borrowers and micro- and social enterprises will be able to apply directly to their local banks and lenders participating in the scheme.

Losses covered by the Guarantee may include interest amounts (excluding late payment or default interest, fees and other costs and expenses) accrued, deferred or capitalised for a maximum period of 360 days. Guarantee coverage will be extended by 12 months, i.e. up to 7 years for microfinance operations and up to 11 years for social entrepreneurship operations. The EaSI Guarantee shall cover losses incurred by the selected financial intermediary at a guarantee rate of up to $80 \%$ or up to $90 \%$ for COVID-19 involved transactions.

\section{Lessons learned:}

- Quick response to mitigate the consequences of the COVID-19 pandemic, through enhanced terms of an existing instrument.

- Due to budgetary constraints, new COVID-19 support measures will primarily serve financial intermediaries who have already entered into a guarantee contract with the EIF and to intermediaries that have been already selected.

\section{Better align microfinance and micro-financial services to changing market needs}

Although microfinance markets in the EU are maturing, they continue to evolve to the changing needs of businesses. One of the central elements of microfinance is the provision of non-financial services, which aim to improve the performance of the business to ensure that the microloans can be repaid. Offers vary across MFIs, but often include pre training programmes to help ensure that the client entrepreneur has a basic set of entrepreneurship skills, training modules focussed on specific themes that can be taken after the loans have been issued, individual coaching and business consultancy. In addition, loan officers often have regular check-ins with clients to monitor the performance of the business and the repayment schedule. For an example of how these are implemented in practice, please see Box 7.10 for a description of the non-financial services offered by the Microfinance and Development Onlus Association in Italy.

Overall, there is a need to increase the number of MFls offering non-financial supports and also improve the quality of supports. About $80 \%$ of MFIs in the EU provide supplemental support services such as training, coaching and consultancy, but significantly fewer MFIs in Eastern Member States offer such supports (Diriker, Landoni and Benaglio, 2018 ${ }_{[10]}$ ). This clearly calls for an increase in the supply of non-financial services, especially since evaluations typically show that the packaging of microloans and complementary support services increases the chances of business sustainability and repayment of the 
Ioan (OECD/The European Commission, 2013[32]). There is also a need to increase the quality of the supports since many offers are relatively basic modules (Drexler et al., 2020[9]).

\section{Box 7.10. Example of MFI non-financial services, Microfinance and Development Onlus Association, Italy}

Target group: Immigrant entrepreneurs

Intervention type: Micro-credit, training programmes and support services

Description: The Microfinance and Development Onlus Association (Associazione Microfinanza e Sviluppo Onlus, "Microfinanza") is a non-profit association, which aims to provide financial education to vulnerable populations and to support entrepreneurial activities through microfinance, with offices in Vicenza and Milan (Italy). Microfinanza offers financial education training to financially vulnerable population groups, notably those with migrant experience. Other support services include entrepreneurship toolkits - StarToolkit and QEF. The StarToolkit aims to predict and monitor the economic sustainability of social enterprises and guides entrepreneurs through essential steps (i.e. creating a business plan, generating business ideas, forecasting, monitoring framework). QEF is a financial education toolkit aimed at enhancing entrepreneurs' financial capabilities and social capital through training modules. These modules range from exercises and games to practical tools for planning expenses and savings management (i.e. an account book). Online training modules are also available, covering subjects such as monitoring cash flows, expense planning, savings and debt management, accessing finance, entrepreneurship and financial negotiations. Microfinanza has been involved with numerous entrepreneurship projects including the recent PIANI project, targeting potential entrepreneurs who have migrant backgrounds in the Turin region. PIANI consisted of four training courses where trainees worked with mentors (i.e. local entrepreneurs) to collaborate and outline new strategies for their own shops as well as how to adapt to their new environment.

Results achieved: The PIANI programme aimed to encourage long-lasting, inclusive and sustainable economic growth (Sustainable Development Goal 8) and ran from 2018 to 2019. Overall, five microsmall entrepreneurs and 20 immigrant entrepreneurs participated.

Source: (Microfinance and Development Onlus Association, 2021 ${ }_{[33]}$ )

Governments can have a role in strengthening support services through the offers of technical support, including by adding conditions on MFls utilising public guarantees and subsidies. MFls can access a range of technical supports, including through EU Structural Funds, which can help them better understand client needs and tailor supports to these needs. It is also possible for governments to require MFIs drawing on public supports to offer a range of non-financial supports as a condition of utilising public support. Finally, governments can help facilitate collaborations between MFIs and specialist entrepreneurship trainers, coaches and consultants. There are many examples of such collaborations where financial support is provided through one organisation and non-financial support is provided through a partner organisation. This can also be facilitated through calls that require partnerships.

In addition, governments can provide technical assistance to MFls to help them understand untapped market demand for financial and non-financial products. Among the financial services that are not currently widely offered, MFIs are increasingly recognising the potential of microinsurance products and services. Innovative insurance products tailored to the needs of micro-enterprises are emerging and, slowly, the supply is growing, and some innovative products and distribution models are developing, provided, or facilitated by MFIs that co-operate with commercial insurers. This includes for example the microinsurance offered to women entrepreneurs by Compartamos Banco in Mexico in Box 7.11. Moreover, 
micro-entrepreneurs, in particular the more vulnerable, often suffer from a lack of knowledge on how insurance works, or what risks they should seek insurance coverage for, requiring also tailored financial literacy training in order to better understand their specific needs and risks.

\section{Box 7.11. Microinsurance, Compartamos Banco, Mexico}

Target group: Women entrepreneurs

Intervention type: Microcredit and microinsurance schemes

Description: Compartamos Banco is a Mexican microfinance institution. Since opening in 1990, Compartamos has since expanded to Guatemala and Peru and offers group and individual microfinance credits and microinsurance. Many of their services are targeted towards women and $90 \%$ of their 2.2 million clients are women. If offers three microfinance credit schemes (below) that can be packaged with microinsurance:

- Women's Microcredit programme is a group credit given to at least 10 women aged 18 to 98 years old;

- Merchant Microcredit programme is a group credit for a minimum of 5 individuals, women or men, aged 20 to 98 years old;

- Individual Microcredit scheme is an individual credit offered to a business owner with a minimum of six months experience and aged 20 to 79 years old.

Compartamos currently offers four primary insurance schemes to those enrolled in one of the above microcredit schemes. The Basic Life insurance is a free insurance benefit to clients who renew their microcredit loans to protect them against unexpected situations which may adversely affect their family, while the Let's Share Protection is a voluntary insurance to protect against unexpected health expenses. The other two programmes are the Theft insurance scheme and the Magenta insurance, which provides insurance for motor vehicles and offers a digital platform to store digital data on the vehicle. In addition to offering insurance products, Compartamos has invested educating its clients about insurance since financial literacy levels are often very low.

Results achieved: Since 2016, insurance product uptake has fluctuated, decreasing from the initial 12.4 million policies sold in 2016 (4.9 million active) to 11.8 policies sold (4.2 million active) in 2018 . Insurance coverage continued to rise in 2019 with 18.3 million policies sold and 7.2 million active policies but the COVID-19 crisis reversed some of the progress made. In 2020, there was an $18.6 \%$ decrease in policies sold (16.7 million) and an $8.5 \%$ decrease in active insurance policies (5.9 million).

Source: (Compartamos Banco, 2021[34]) 


\section{Leverage the benefits of digitalisation}

The COVID-19 pandemic has strengthened calls for digitalisation within the microfinance sector. Most MFIs suffered great disruptions to their operations during the past two years due to a heavy reliance on delivering services to clients through face-to-face interactions, some of which could have been avoided if digital practices were more prevalent. Governments have encouraged the use of digital payments through measures to facilitate the use of digital payments during lockdown (e.g. reduction or removal of fees, relaxed know your customer procedures, increased transaction limits) and to provide longer-term support for fintech players and financial innovation (Boakye-Adjei, 2020[35]).

Increasing the level of digitalisation of MFIs' products and processes can have many benefits, especially for non-bank MFIs. First, digitalisation can be used to broaden outreach to unbanked entrepreneurs to expand the customer base. Second, there is potential to reduce operating costs by implementing cost-efficient management solutions such as the use of electronic signatures (Box 7.12). Third, it can diversify the products and services offered by MFIs so that they can better compete with fintech companies that are increasingly operating in the same markets. However, only a limited number of MFIs within the EU have implemented digital solutions and these have been focused on making the lending process more efficient and building interfaces to interact with clients (Pytkowska and Korynski, 2017[36]).

This renewed push for digitalisation creates both opportunities and challenges for MFIs. Many MFIs view the current context as an opportunity to explore new ways of working. This includes, for example, using big data for monitoring the beneficiaries, adopting new communication methods with clients, exploring new outreach approaches to new clients, piloting digital disbursement of loans, innovating with digital savings products, and improving remote customer service (e.g. delivering business advice and financial education). About one-third of MFls have expanded call-centre operations or digital channels during the pandemic, and slightly less than one-third have implemented new digital channels (Zetterli, $2020_{[37]}$ ). Moreover, about $40 \%$ of MFls are reported to be doing "at least some" transactions over digital channels, although just one in seven are conducting at least $30 \%$ of transactions digitally, and a sizeable one-quarter are not doing any digital transactions at all. This is consistent with another international study of MFIs that found that MFIs across 47 countries are using technology to face the crisis (ADA, Inpulse and Grameen Crédit Agricole Foundation, 2020[38]). About half (48\%) of MFIs interviewed indicated that they are using existing digital solutions and $31 \%$ have implemented new technological solutions for communication with customers and the management of financial products and services. The use of digital solutions to maintain communication and work activities with employees is also relevant. $82 \%$ of MFIs interviewed use online meeting solutions and $57 \%$ use an online document sharing solution (mainly MENA and LAC partners).

While this increased use of basic digital technologies may signal an openness to further adopt digital practices, products and services, there are a number of risks for MFls. First, the low-income and underserved clients that utilise MFIs are likely to have low levels of digital skills and access to mobile devices. Therefore, the digitalisation of MFIs may lead to market skimming that further exacerbates inequalities. This would go against the primary function of MFIs in addressing financial exclusion. Second, these new models of fintech that ensure faster, easier, and more cost-effective lending could lead to an over-indebtedness of more fragile micro-entrepreneurs. Third, the digital transformation of MFIs may lead them into more direct competition with fintech and tech companies that are increasingly moving into microfinance markets.

To fully implement the benefits of automation and digitalisation and address increasing competition from new providers, governments may need to provide support to both MFIs and their clients. The transformation of MFIs will require investment in technologies and tools, as well as in boosting the skills of their staff. Governments can support this upskilling with short training programmes and technical assistance for MFIs. In parallel, capacity building programmes that increase digital literacy for entrepreneurship among interested people from MFI target client groups is needed. 


\section{Box 7.12. Adie's e-Signature for better delivery of microfinance services, France}

Target group: Adie is a non-governmental organisation supporting access to entrepreneurship and employment for individuals who cannot access credit from mainstream sources (e.g. rural populations, urban populations, the unemployed, women, ethnic minorities, immigrants, youth). It provides financial services (i.e. business microloans, personal microloans, insurance), while also providing non-financial services (i.e. entrepreneurship training, mentoring, e-learning courses).

Intervention type: Introduction of a simple electronic signature or "e-signature".

Description: The purpose of an e-signature is to demonstrate to a third party that a document has been approved by the client. It is a reliable mechanism and Adie's experience suggests that MFI clients do not typically encounter difficulties using the platform. The main motivation for introducing e-signatures was to improve the efficiency of the loan process, but it also reduces paper waste. The system also helped to ensure business continuity during the COVID-19 pandemic when face-to-face meetings were not possible.

The system implemented by Adie was developed by an external provider, which was selected based on several criteria such as ease of implementation, user experience and document storage processes. The costs associated with this platform are based on the number of contracts digitally underwritten and pricing is often digressive, starting at about EUR 1 per signature. An external provider was selected over the development of an internal system due to the short-term resources and capacities needed, and to ensure compliance with the relevant national and EU regulations. The implementation of this esignature system was accompanied by a training programme for loan officers who manage the loan contracts with clients.

Results achieved: Adie's e-signature was used for over 40000 documents (e.g. contracts, microinsurance contracts, guarantor's agreement) in 2020. While client feedback has been positive, both digital and manual signature options will be maintained. Efforts to make e-signatures legal for guarantee acts and other types of contracts are underway as are initiatives to increase security through ID verification steps, one-time passwords and timestamping.

Source: (European Microfinance Network, 2021[39]) 


\section{Use microfinance to support green entrepreneurship}

Many governments have embedded environmental policy objectives in their economic recovery packages and microfinance can play a role in achieving these objectives by directing more funding to green entrepreneurs. Numerous policy actions continue to push for greater investment in sustainable activities, including economic recovery plans (OECD, 2021 [40]) and green action plans such as the European Green Deal (European Commission, 2021 ${ }_{[41]}$ ) that outline steps towards reducing greenhouse gas emissions and decoupling economic growth from resource constraints. Such broad policy agendas are relevant for microfinance because the transition to renewable energy and decarbonisation processes also affects economic activities of micro-enterprises and vulnerable groups that will need support for the implementation of sustainable ways of doing business.

Surveys suggest that there is a large interest among MFls in the EU in providing green products and services. Green loans are offered by $21 \%$ of MFIs and are specifically designed either for financing energy efficiency, renewable energies and/or for environmentally friendly activities (European Investment Fund, 2020[42]). MFIs can provide loans to entrepreneurs to develop green products and services, developing new green business models and adapting solutions (e.g. irrigation systems, energy efficiency), as well as loans to consumers that will benefit green entrepreneurs. This includes, for example, loan programmes to help homeowners upgrade their homes with energy efficient solutions (Box 7.13). Moreover, environmentally friendly activities or technologies are supported even without specific green microloans.

Governments can support MFls in contributing to the green agenda in several ways. Principally, governments can encourage more MFls to offer more green products and to invest in green projects by offering a range of incentives. These could include, for example, a greater guarantee for risky green projects, and the use of greater interest rate subsidies for projects that meet a "green" criteria. Financial service provision should also be accompanied by non-financial service supply in order to foster adaptation to the "new normal" (Mendelson et al., 2019 ${ }_{[43]}$ ). 


\section{Box 7.13. Green and Sustainable Development Microcredits, Belgium}

Target group: Green entrepreneurs

Intervention type: Direct and indirect microfinance credit for green and sustainable entrepreneurship

Description: The Crédal cooperative (Crédal l'argent solidaire) was created in 1984 to provide an alternative and professional financial institution to the French-speaking areas of Belgium. In recent years, Crédal has focused on providing microcredit directly and indirectly to green and sustainable entrepreneurs who are developing sustainable projects that will socially and environmentally benefit the local community, notably through the Sustainable Development Microcredit scheme (available in both Wallonia and Brussels regions). Eligibility requirements for this programme include that the individual be an early-stage entrepreneur, a self-employed worker (either primary or secondary occupation), be involved in a pre-existing collaborative project or currently participating in a start-up incubator programme. The project must be focused on sustainable development, require up to EUR 100000 in funding and be ready to implement once funding is secured. Priority is given to entrepreneurs who face difficulty in accessing finance from traditional institutions. The programme offers three sustainable microcredits. Depending on the entrepreneurs' situation, it is possible to combine an investment loan, a working capital loan or a cash loan (maximum of EUR 25000 in total) as well as to combine any microcredit loan with a traditional bank loan. The first microcredit is the Sustainable Development Microcredit which finances up to EUR 25000 with repayment in six years (maximum) with an interest rate of $6 \%$ (excluding administration fees). The Sustainable Working Capital Development Microcredit has a disbursement period of six months (maximum), a capital repayment period of up to 24 months with an $8 \%$ interest rate, while the Sustainable Treasury Development Microcredit has a repayment period of 18 months (maximum) and an interest rate of $8 \%$ of the outstanding amount of the loan.

In the Brussels region, Crédal offers an additional microcredit programme the Brussels Green Loan (Prêt vert bruxellois) through a partnership with Housing Fund (a non-profit organisation subsidised by the Brussels-Capital Region to support tenants and owners). The Brussels Green Loan offers financial support to homeowners to make home energy improvements in three primary areas: insulation and ventilation, efficient heating and renewable energies. While green entrepreneurs do not directly apply for this microfinance support, they indirectly benefit as a stipulation for receiving this individual loan is that all the work must be carried out by an entrepreneur registered with the Banque Carrefour des Entreprises (BCE). The programme, therefore, is offering indirect support to green entrepreneurs in the Brussels region by providing work arrangements.

Results achieved: In 2020, Crédal provided microcredit to 53 entrepreneurs and 48 social entrepreneurs, totalling to EUR 550759 and EUR 1.5 million respectively. As expected, entrepreneurs were heavily impacted due to the COVID-19 pandemic, leading to a decline in the number of entrepreneurs who received microfinancing $(-33 \%)$. Moreover, the profile of these entrepreneurs changed. They were more likely to be young, have higher levels of education and to be men. While social and sustainable entrepreneurship remained relatively stable in terms of accepted applications in 2020 compared to 2019 (46 vs. 48), the amount of the loan decreased from EUR 47759 to EUR 30 659. Crédal provided EUR 4.4 million in microcredits to 636 individuals in 2020. The Brussels Green Loan accounted for $31 \%$ of all individual microfinancing (197 green microfinance loans), resulting in work opportunities for Brussel-based entrepreneurs.

Source: (Crédal, 2021 [44]; Philippe, 2020[45]) 


\section{Conclusions}

Microfinance is particularly relevant to support inclusive entrepreneurship and those who are excluded from access to traditional banking and related services, such as the unemployed, migrants, women, people with disabilities and students. The sector has developed rapidly in the EU, with European networks of micro-finance providers spreading good practice and continued support from EU Institutions (European Commission, European Investment Fund) but there is evidence of market failures in different geographies and excess demand (Drexler et al., 2020[9]). The progress achieved over the last ten years should be consolidated by means of dedicated financial instruments such as the recently established InvestEU Programme (Social Investments and Skills Window). Evidence also suggests that government efforts to build the sector could be scaled-up, as microfinance has proved to be an effective tool for promoting social inclusion, opening up opportunities for vulnerable people.

Governments face twin priorities in supporting the microfinance sector. First, more actions are needed to support short-term pressures resulting from the COVID-19 pandemic. Priority policy actions could include:

- Scaling-up the available funds, including through the creation of guarantee and revenue-based instruments.

In addition, governments can consider the use economic recovery packages as a way to shape the microfinance sector for the future. This includes:

- Expanding financial support to MFIs through guarantee and debt instruments applying softer conditions for providers targeting vulnerable clients, with these incentives taking the form of longer microloan terms and below market interest rates.

- Increasing the quality of support services offered, including by strengthening linkages between microfinance institutions and partner organisations that deliver "soft" supports for inclusive entrepreneurship.

- Assessing particular needs in different EU geographical areas, examining different characteristics (e.g. urban vs rural areas, availability of digital financial tools, types of financial intermediaries) to ensure that targeted interventions aimed at financial and social inclusion, access to credit and development of the micro-finance eco-system are appropriate for local conditions.

- Expanding funding to meet low-carbon and energy-efficiency of microenterprises served by MFIs.

- Making greater use of the InvestEU Advisory Hub technical support for adjusting microfinance business models (e.g. digitalisation) and increasing the offer of digital training among target client groups.

- Strengthening evaluation practices for microfinance for inclusive entrepreneurship.

\section{References}

About Microfinance (2021), About Microfinance: North America, https://www.aboutmicrofinance.com/latin-america-caribbean/north-america (accessed on 25 March 2021).

ADA, Inpulse and Grameen Crédit Agricole Foundation (2020), Beyond the difficulties posed by the COVID-19 crisis, new opportunities are emerging for microfinance institutions (MFIs), https://www.inpulse.coop/wordpress/wp-content/uploads/2020/06/COVID-19-Newopportunities-are-emerging-for-MFIs EN.pdf (accessed on 25 March 2021). 
Antón Díaz, P. (2017), Growing Concerns about Overindebtedness in Mexico's Microfinance Sector, Centre for Financial Inclusion, https://www.centerforfinancialinclusion.org/growingconcerns-about-overindebtedness-in-mexicos-microfinance-sector (accessed on 25 March 2021).

Boakye-Adjei, N. (2020), "Covid-19: Boon and bane for digital payments and financial inclusion", FSI briefs, No. 9, Bank for International Settlements, https://www.bis.org/fsi/fsibriefs9.htm (accessed on 23 March 2021).

Botti, F., M. Corsi and G. Zacchia (2018), "A New European Microfinance Panel Data Set: The European Microfinance Network Survey 2006-2015”, EMN Working Papers, European Microfinance Network, Brussels.

Brickell, K. et al. (2020), "Compounding crises of social reproduction: Microfinance, overindebtedness and the COVID-19 pandemic", World Development, Vol. 136, http://dx.doi.org/10.1016/i.worlddev.2020.105087.

Compartamos Banco (2021), Products, https://www.compartamos.com.mx/compartamos (accessed on 24 September 2021).

Corsi, M. (2021), European Microfinance Survey 2018-2019.

Crédal (2021), Credit, https://www.credal.be/credit (accessed on 24 September 2021).

Cull, R., A. Demirguc-Kunt and J. Morduch (2009), Microfinance Tradeoffs : Regulation, Competition, And Financing, The World Bank, http://dx.doi.org/10.1596/1813-9450-5086.

Dąbrowska, K., P. Koryński and J. Pytkowska (2020), Impact of COVID-19 Pandemic on the Microfinance Sector in Europe: Field Analysis and Policy Recommendations, Microfinance Cenre.

Diriker, D., P. Landoni and N. Benaglio (2018), Microfinance in Europe: Survey Report 20162017, European Microfinance Network / Microfinance Centre.

Drexler, B. et al. (2020), Microfinance in the European Union: Market analysis and recommendations for delivery options in 2021-2027, Publications Office of the European Union, Luxembourg.

European Commisison (2021), European Code of Good Conduct for Microcredit Provision, https://ec.europa.eu/social/main.jsp?catld=738\&langld=en\&publd=8312\&furtherPubs=yes (accessed on 29 September 2021).

European Commission (2021), A European Green Deal, https://ec.europa.eu/info/strategy/priorities-2019-2024/european-green-deal en (accessed on 6 October 2021).

European Commission (2020), Microfinance in the European Union: Market analysis and recommendations for delivery options in 2021-2027, Publications Office of the European Union, Luxembourg.

European Commission (2020), The updated European Code of Good Conduct for Microcredit Provision has been published, Employment, Social Affairs \& Inclusion, https://ec.europa.eu/social/main.jsp?langld=en\&catld=89\&newsld=9726\&furtherNews=yes\#n avltem-2 (accessed on 25 March 2021). 
European Commission (2007), A European initiative for the development of micro-credit in support of growth and employment, $\operatorname{COM(2007)} 708$ final, https://eurlex.europa.eu/LexUriServ/LexUriServ.do?uri=COM:2007:0708:FIN:en:PDF.

European Investment Fund (2020), "European Small Business Finance Outlook 2020: The impact of COVID-19 on SME Financing markets", EIF Working Paper 2020, No. 67, https://www.eif.org/news centre/publications/EIF Working Paper 2020 67.htm (accessed on 23 March 2021).

European Microfinance Network (2021), Adie's e-Signature for better delivery of microfinance services, https://www.european-microfinance.org/publication/adies-e-signature-betterdelivery-microfinance-services (accessed on 22 September 2021).

European Union (2021), Commission Delegated Regulation (EU) 2021/1078 of 14 April 2021 supplementing Regulation (EU) 2021/523 of the European Parliament and of the Council by setting out the investment guidelines for the InvestEU Fund, Official Journal of the European Union, https://eur-lex.europa.eu/legalcontent/EN/TXT/HTML/?uri=CELEX:32021R1078\&from=EN (accessed on 27 October 2021).

Graham, S., J. Ericksen and E. Ericksen (2014), Over-Indebtedness in Mexico: Its Effect on Borrowers, Microfinance CEO Working Group, https://www.finca.org/files/2014/05/OverIndebtedness-in-Mexico-Its-Effect-on-Borrowers.pdf (accessed on 25 March 2021).

Hermes, N. and R. Lensink (2007), "The Empirics of Microfinance: What Do we know?", The Economic Journal, Vol. 117/517, http://dx.doi.org/10.1111/j.1468-0297.2007.02013.x.

Hermes, N., R. Lensink and A. Meesters (2011), "Outreach and Efficiency of Microfinance Institutions", World Development, Vol. 39/6, http://dx.doi.org/10.1016/..worlddev.2009.10.018.

Horton, R. (2020), "Offline: COVID-19 is not a pandemic", The Lancet, Vol. 396/10255, http://dx.doi.org/10.1016/S0140-6736(20)32000-6.

KONO, H. and K. TAKAHASHI (2010), "MICROFINANCE REVOLUTION: ITS EFFECTS, INNOVATIONS, AND CHALLENGES", The Developing Economies, Vol. 48/1, http://dx.doi.org/10.1111/j.1746-1049.2010.00098.x.

Kuhn, H. et al. (2015), Interim evaluation of the European progress microfinance facility, Publications Office of the European Union, Luxembourg.

Marchese, M. (2014), "Entrepreneurial Activities in Europe - Finance for Inclusive Entrepreneurship”, OECD Employment Policy Papers, No. 5, OECD Publishing, Paris, https://dx.doi.org/10.1787/5jxrcmkgkzzs-en.

Meagher, P. (2020), "Microfinance in the COVID-19 Crisis: A Framework for Regulatory Responses", Consultative Group to Assist the Poor, Washington DC, https://www.cgap.org/research/covid-19-briefing/microfinance-and-covid-19-frameworkregulatory-response (accessed on 24 March 2021).

MEDICI (2021), Understanding the Microlending Landscape: Slow but steady growth, https://gomedici.com/understanding-microlending-landscape-slow-steady-growth (accessed on 23 March 2021). 
Mendelson, S. et al. (2019), Adapting to a New Normal. Strengthening Resilience to Climate Change: Best Practices from the European Microfinance Award 2019ctices from the European Microfinance Award 2019, European Microfinance Platform, http://www.emfp.eu/resources/adapting-new-normal-strengthening-resilience-climate-change-bestpractices-european (accessed on 23 March 2021).

MFTransparency (2015), Transparent Pricing In Colombia, https://www.mftransparency.org/microfinancepricing/colombia/\#: : text=The $\% 20$ Colombian\%20microfinance $\% 20$ sector $\% 20$ is, and $\% 20$ outst anding $\% 20$ gross $\% 20$ loans $\% 20$ disbursed.\&text=The $\% 20$ Financial $\% 20$ Superintendence $\% 20$ of \%20Colombia, deposit\%20taking\%20microfinance\%20service\%20providers. (accessed on 25 March 2021).

Michaels, L., H. Bansal and M. El-Zoghbi (2020), Preserving Liquidity: Policymaker Responses to COVID-19 and the Impact on Low-Income Customers, Center for Financial Inclusion, https://www.centerforfinancialinclusion.org/preserving-liquidity-policymaker-responses-tocovid-19-and-the-impact-on-low-income-customers (accessed on 23 March 2021).

Microfinance and Development Onlus Association (2021), What We Do, https://www.microfinanzaesviluppo.it/cosa-facciamo/ (accessed on 24 September 2021).

OECD (2021), "No Net Zero without SMEs: Exploring the key issues for Greening SMEs and Green Entrepreneurship".

OECD/The European Commission (2013), The Missing Entrepreneurs: Policies for Inclusive Entrepreneurship in Europe, OECD Publishing, Paris, https://dx.doi.org/10.1787/9789264188167-en.

Philippe, I. (2020), Crédal Rapport d'activité, Einstein Business Center, Mont-Saint-Guibert, https://www.credal.be/medias/files/publication/CredalRapport2020.pdf (accessed on 24 September 2021).

Pytkowska, J. and P. Korynski (2017), Digitalizing Microfinance in Europe, Microfinance Centre, https://www.european-microfinance.org/publication/digitalizing-microfinance-europe (accessed on 23 March 2021).

ReportLinker Consulting (2021), Global Microfinance Industry, https://www.reportlinker.com/p05799111/Global-MicrofinanceIndustry.html?utm source=GNW (accessed on 22 September 2021).

Rosenberg, R., A. Gonzalez and S. Narain (2009), "Are Microcredit Interest Rates Excessive?", Consultative Group to Assist the Poor, Washington DC, https://www.cgap.org/sites/default/files/CGAP-Brief-Are-Microcredit-Interest-Rates-ExcessiveFeb-2009.pdf (accessed on 23 March 2021).

Rosenberg, R., A. Gonzalez and S. Narain (2009), "The New Moneylenders: Are the Poor Being Exploited by High Microcredit Interest Rates?", Consultative Group to Assist the Poor, Washington DC, https://www.cgap.org/sites/default/files/CGAP-Occasional-Paper-The-NewMoneylenders-Are-the-Poor-Being-Exploited-by-High-Microcredit-Interest-Rates-Feb2009.pdf (accessed on 23 March 2021).

Ruesta, C. and N. Benaglio (2021), Microcredit regulation in Europe: An overview, European Microfinance Network. 
Schaberg, K. et al. (2019), Microfinance in the United States Early Impacts of the Grameen America Program, MDRC, New York, https://www.mdrc.org/sites/default/files/Grameen Report final-web.pdf (accessed on 25 March 2021).

Women's World Banking (2014), Why Mexico Can't Make Microfinance Work (And Why It Needs to), https://www.womensworldbanking.org/insights-and-impact/individual-lendingmicroenterprises-mexico-constraints-opportunities/ (accessed on 25 March 2021).

World Bank (2019), World Bank Data Catalog, https://datacatalog.worldbank.org/dataset/mixmarket.

Zetterli, P. (2020), Four Ways Microfinance Institutions Are Responding to COVID-19, CGAP, https://www.cgap.org/blog/four-ways-microfinance-institutions-are-responding-covid-19 (accessed on 25 March 2021).

\section{Notes}

${ }^{1}$ Microfinance in the European Union: Market analysis and recommendations for delivery options in 20212027, Final Report (May 2020)

2 JASMINE (Joint Action to Support Microfinance Institutions in Europe), which was aimed at providing EU technical assistance to non-bank financial institutions in the 2007-13 programming period;

JEREMIE (Joint European Resources for Micro to Medium Enterprises), which is a joint initiative of European Commission (Directorate General for Regional Policy) and the EIB Group (mainly through the European Investment Fund) to facilitate the use of EU Structural Funds to finance SMEs and entrepreneurs in a more efficient and sustainable way;

European Progress Microfinance Facility (EPMF), which was established by the Commission and the EIB to provide financial instruments such as loans and guarantees to support MFIs complying with the "European Code of Good Conduct for Microcredit Provision". EPMF was aimed at increasing access to finance for micro enterprises and creating jobs for vulnerable groups and it gained relevance in the aftermath of the 2008-09 financial crisis. By December 2013, more than 20000 entrepreneurs had benefited from loans and guarantees under the facility, worth a total of EUR 182 million (Kuhn et al., 2015[46]).

${ }^{3}$ Some of the EASI instruments for microfinance are managed and implemented by the European Investment Fund on behalf of the European Commission:

- EaSI Guarantee Instrument (EUR 430 million) to sustain microcredit providers in serving risky beneficiaries excluded from mainstream financial markets. It sustains also social finance providers in serving social enterprises. The EaSI Guarantee benefitted from EUR 130 million from EaSI and EUR 300 million from the European Fund for Strategic Investments (EFSI);

- EaSI Capacity Building Investments Window (EUR 45 million) to support mostly with subordinated loans the growth process of selected MFIs and social finance providers. 
- EaSI Funded Instrument is a partnership between the EIF, the EIB and the EU to manage a loan fund of EUR 200 million; $70 \%$ of the fund size will be dedicated to provide microloans (up to EUR 25000 ) to vulnerable micro-borrowers and micro-enterprises .

- EaSI BDS Pilot for refugees and migrants provide partial coverage for business development services (coaching, mentoring, or training) costs incurred by existing EIF financial intermediaries serving migrants and refugees demand seeking to establish a micro-enterprise.

- The EaSI Technical Assistance is managed directly by the DG Employment, Social Affairs and Inclusion of the European Commission to provide non-financial advisory services to public and private financial intermediaries active in the microfinance sector in Europe and for the implementation of the European Code of Good Conduct for Microcredit Provision.

${ }^{4}$ CGAP is a global partnership of more than 30 leading development organisations that works to advance the lives of poor people through financial inclusion. The interactive dashboard was launched on 1 June 2020 to report results of the CGAP Pulse Survey of Microfinance Institutions, which examines the impacts of the COVID-19 pandemic on microfinance sector at the global, national and regional levels.

${ }^{5}$ PAR-30 is the most common indicator for credit risk that accounts for loans in arrears for over 30 days. 



\section{Leveraging immigrant entrepreneurship for job creation and growth}

Immigrant entrepreneurship is diverse, ranging from small self-employment activities to businesses that operate in multiple countries. Traditionally policy support for immigrant entrepreneurship has focussed on supporting labour market integration through self-employment. However, the increasing skills levels of immigrants create an opportunity for governments to do more to attract and support immigrant entrepreneurs that have the potential to make significant impacts on the economy. This chapter discusses a range of emerging policy approaches such as start-up visa programmes, dedicated business incubation and accelerator programmes, as well as outreach and incentive programmes to attract high-potential immigrant entrepreneurs. Policy advice is provided for national, regional and local governments and is illustrated with good practice examples from European Union (EU) Member States and non-EU OECD countries. 


\section{Key messages}

- Immigrant entrepreneurs are a diverse group of business owners. Businesses operate across all sectors and range from small solo self-employed activities to large multinational corporations.

- Immigrant entrepreneurship has an important function in economies because it can facilitate the transfer innovation between countries and create jobs. In addition, selfemployment offers immigrants an alternative to paid employment since many encounter barriers to work such as credential recognition.

- The picture of immigrant entrepreneurship is changing. The number of immigrant entrepreneurs and business owners has nearly doubled over the past decade in the European Union (EU) and a similar picture emerges in non-EU OECD countries. This growth is largely driven by an increase in migration flows.

- In addition, the nature of immigrant entrepreneurship activities is changing. There have been slight increases in the share of self-employed immigrants working in education and service sectors over the past decade while the shares in agriculture and accommodation and food services have declined. While the skills levels of immigrants overall are increasing, the evidence on skills levels among immigrant entrepreneurs is mixed across EU Member States and OECD countries. However, there has been strong growth in the number of international students who become entrepreneurs.

- The COVID-19 pandemic was difficult for many entrepreneurs and immigrant business owners appear to have been strongly impacted. Most evidence indicates strong sector effects and also confirms that immigrant entrepreneurs, on average, have poor access to resources.

- Even pre-COVID, immigrant entrepreneurs faced additional disincentives and challenges to business creation relative to native-born entrepreneurs. The barriers to business creation are often similar to those that all entrepreneurs face, including challenges accessing finance, low levels of entrepreneurship skills and small entrepreneurship networks. However, a lack of language skills compounds all of these challenges.

- Support for existing immigrant business owners has an important role in improving business quality, but the scale of support has not grown with the increase in immigrant entrepreneurship. Entrepreneurship training, coaching and access to finance schemes need to be scaled-up. More can also be done to engage the relevant communities in the design and delivery of support initiatives to ensure that they are relevant and attractive to potential participants.

- Governments can also do more to harness the job creation potential of skilled immigrants with various incentives such as start-up visas, incubator and accelerator programmes and finance. However, many of these schemes are quite new and do not support a large number of entrepreneurs. When using such measures, governments should seek to ensure strong connections between the immigrant entrepreneurs and local entrepreneurship ecosystems. 


\section{The changing nature of immigrant entrepreneurship}

\section{The relative scale of immigrant entrepreneurship increased over the past decade...}

The number of immigrant entrepreneurs has nearly doubled over the past decade. Chapter 3 shows that approximately 2.8 million out of 25.8 million self-employed people in the European Union (EU) in 2020 were born in another country. This accounts for $11 \%$ of all self-employed people in the EU, which was up from $6 \%$ in 2011 . Slightly more than $60 \%$ of these self-employed immigrants were born outside of the EU. This picture is very similar to that of immigrants who worked as employees; $13 \%$ of those working as employees in the EU in 2020 were born in another country and about $60 \%$ of foreign-born employees were born in non-EU countries. The growth in employees who were foreign-born also increased by about the same rate over the past decade. These data only include first-generation immigrants; subsequent generations of immigrants who become entrepreneurs would likely be considered "ethnic minority" entrepreneurs (Box 8.1).

A similar picture emerges in many OECD countries. For example, the share of immigrants among the self-employed in the United States grew from 13\% in 2000 to $21 \%$ in 2014 (Lofstrom and Wang, 2019 ${ }_{[1]}$ ). This was greater than the increase in the share of immigrants among the labour force overall $-13 \%$ in 2000 to $17 \%$ in 2014 . This growth is consistent with data from the American Community Survey over the 2005-17 period that shows a significant increase in self-employment among Mexican immigrants (AmuedoDorantes, Lofstrom and Wang, 2020[2] $)$. Immigrant self-employment in Canada increased substantially in the 1980s and 1990s, then declined in the early 2000s before returning to an upward trend. The growth in immigrant self-employment in Canada is due to several factors, including the aging of the labour force, technological changes and government policies seeking to boost immigrant entrepreneurship (Hou and Wang, 2017[3]).

\section{Box 8.1. Ethnic minority entrepreneurship}

The terms immigrant entrepreneurship and ethnic minority entrepreneurship are often used interchangeably but these concepts are distinct. An immigrant is a person who lives in a country in which they were not born. Thus, an immigrant entrepreneur is an entrepreneur who lives in a country in which they were not born.

A person from an ethnic minority group is someone that shares "a set of connections and regular patterns of interaction among people sharing common national background or migration experiences" (Waldinger, Aldrich and Ward, 1990[4] $)$. This individual characteristic is independent from where the person was born. Therefore, an ethnic minority entrepreneur is an entrepreneur that has high levels of involvement in their ethnic community (Chaganti and Greene, 2002[5]). It is important to recognise that a person may identify as belonging to a specific ethnic group from a country that is different to the one in which they were born (e.g. a person born in Germany of Turkish heritage).

The role of ethnicity can have a strong role in entrepreneurship since each culture is unique, diverse and has a profound influence on an ethnic group's values and overt behaviour (Spencer-Oatey and Franklin, 2009[6]). For example, a study of the Tunisian community living in Paris, which is the smallest North African immigrant group residing in that city, found that their strong sense of ethnic identity played a key role in fostering their business enterprises (Carter and Jones-Evans, 2012[7]).

The economic contributions by ethnic businesses include the revival of declining places, the enhancement or development of new conduits for transnational trading links, and social adaptation and integration of new migrants in their local economies and communities (Carter et al., 2015[8]). 
The increased scale of immigrant entrepreneurship is largely due to increased migration flows. The number of international migrants reached 272 million people in 2019, up from 221 million from 2010 - an increase of about $23 \%$ (United Nations, 2020[9]). Just over 4 million immigrants arrived in EU Member States in 2020 and about 8 million arrived in OECD countries. The growth in immigration to the EU and OECD countries increased about $50 \%$ over the past decade, which is about double the worldwide average. The distribution across EU Member State and OECD countries varies greatly. Overall, about two-thirds of immigrants move to one of 20 countries (United Nations, 2020[9]). In absolute numbers, the top five countries for immigration are the United States (1 million permanent immigrants in 2019), Germany (612 000), Spain (409 000), United Kingdom (346 000) and Canada (341 000) (OECD, 2020[10]). However, the picture looks quite different in relative terms since many small countries receive relatively more immigrants. For example, the number of immigrants moving to Luxembourg in 2019 was equivalent to nearly $4 \%$ of the population.

\section{... and the nature of immigrant entrepreneurship is evolving}

Immigrant entrepreneurship activities are often associated with urban and economic adversity where entrepreneurship or self-employment is the only means of earning a living. This suggests that many self-employed workers have started their activity because they could not find a job (Barrett, Jones and McEvoy, $\left.1996_{[11]}\right)$, or because they were seeking to move out of low-wage employment or faced discrimination (OECD, 2011 $\left.{ }_{[12]}\right)$. As a result, immigrants who start businesses are often more likely to enter markets with low barriers to entry and over-supply of firms, which are characterised by labour-intensive production and low profits (Kloosterman, 2010[13]; Waldinger, Aldrich and Ward, 1990[4]). This is some recent evidence to support this perspective. For example, Canadian evidence shows that nearly half of self-employment activities by immigrants are part-time activities to earn supplemental income (Green et al., $\left.2016_{[14]}\right)$. The implication that is often drawn by this perspective is that many of these activities focus on serving small ethnic markets within a specific geographic area and that they therefore have a limited economic impact (Clark and Drinkwater, 2000[15]; Basu and Altinay, 2002[16]; Dalhammar, 2004[17]). Typical examples include small shops providing speciality food or beauty services.

This picture is starting to change as the skills levels of immigrants to EU Member States and OECD countries are increasing. The share of immigrants with a tertiary education has increased in nearly all EU Member States and OECD countries between 2006-07 and 2017 (OECD/European Union, 2018[18]). On average, the share increased by 7 percentage points over this period and immigrants are now more likely than non-immigrants to have a tertiary education in nearly half of EU Member States. These findings are consistent with country-specific studies, including in France which found that the share of immigrants with a tertiary education more than doubled between 1990 and 2010 (Mitaritonna, Orefice and Peri, 2017[19]). Similarly, educational attainment levels among immigrants in the United States increased during the period 2011-19 (U.S. Census Bureau, 2019[20]).

However, the evidence is mixed on whether these overall increases in skills levels among immigrants are also found among self-employed immigrants and immigrant business owners. Within the EU, there is a small amount of evidence that these skills gaps persist. Recent research in Sweden found that $33 \%$ of native-born male entrepreneurs had a tertiary education relative to $28 \%$ of immigrant male entrepreneurs (Neuman, 2021[21]). However, no gap was found among women entrepreneurs (about $31 \%$ regardless of place of birth). Similarly, the growth in self-employment between 2000 and 2017 was driven largely by highly skilled US-born people and low-skilled immigrants (Lofstrom and Wang, 2019 $\left.9_{[1]}\right)$. On the contrary, the share of immigrant business owners in Canada with a tertiary education has increased slightly since 2001 (Green et al., 2016[14]; Ostrovsky and Picot, 2020[22]). Furthermore, immigrant business owners in Canada are twice as likely to be educated in STEM fields and three times more likely to be educated in engineering or computer science compared to Canadian-born business owners (Ostrovsky and Picot, 2020[22]). However, a gap in proportion who have at tertiary 
education has been identified between self-employed immigrants with unincorporated businesses (31\%) and those who operate incorporated businesses (46\%) (Picot and Ostrovsky, 2021 [23]).

Despite this mixed picture on skills levels among immigrant entrepreneurs, it is clear that more international students are becoming entrepreneurs. Globally, the number of international students increased from about 3.9 million in 2011 to nearly 4.9 million in 2016 and more than half were studying in six countries: the United States of America, the United Kingdom, Australia, France, Germany and the Russian Federation (Migration Data Portal, 2020[24]). This growth in international students would be expected to have a positive effect on entrepreneurship levels since higher education students have a high level of interest in entrepreneurship - 9\% would like to become an entrepreneur immediately after their studies while another $35 \%$ plan to be an entrepreneur within the first five years after their studies (Sieger et al., 2018[25]). Furthermore, there is some evidence suggesting that international university students are more likely to start a business than native students. For example, nearly $60 \%$ of graduate start-ups in the United Kingdom have at least one international student on the founding team, which is three times greater than their share among the student population (Lewin, 2020[26]). There is also evidence from the United States that international graduates are an important source of venture capital-backed entrepreneurship. The majority of ventured capital-backed immigrant-owned business owners in the United States originally came to undertake post-secondary studies. It is estimated that $42 \%$ came for undergraduate studies and $37 \%$ for post-graduate studies, while the remaining $22 \%$ came for employment (Amornsiripanitch et al., 2021[27]).

The types of businesses being started by immigrants are also changing in several ways, notably the sector of operation. Within the EU, the distribution of foreign-born self-employed workers across sectors has shifted slightly over the past decade. Among self-employed immigrants born outside of the $\mathrm{EU}$, there has been a slight increase of two percentage points over the past five years in the share who are working in service sectors, followed by a slight increase in the share working in education. These were offset with decreases in the share working in agriculture and accommodation and food services. While it is difficult to read too much into these shifts across sectors, some of these changes are consistent with increasing skills levels.

The growing literature on international entrepreneurship also suggests that immigrant entrepreneurship activities are becoming more diverse, some of which is enabled by technology. Academic and policy literature is increasingly categorising and discussing different forms of immigrant entrepreneurship and greater attention is being placed on business activities that span several countries because these activities appear to be effective at transferring innovation between countries. This includes transnational entrepreneurship that leverages knowledge and networks of multiple locations to seek new opportunities in different markets, as well as business activities that use technology to operate independent of a location (e.g. "digital nomads") (Box 8.2).

The COVID-19 pandemic has given a boost, at least temporarily, to a growing number of return migrants going back to their home country. While international travel and migration was essentially halted during the first half of 2020 due to lock-down measures and border closures, there was a sharp increase in the number of people returning to their home country from abroad. Globally, it is estimated that several million people returned to their country of origin during the early stage of the COVID-19 pandemic. Within the EU, these return migration flows have been concentrated in eastern Member States such as Bulgaria, where more than 200000 Bulgarians returned from abroad in March 2020 alone (Georgiev, $2020_{[28]}$ ). Return migration can have important impacts on economies, including strengthened political institutions, stronger trade linkages and increased investment flows (Batista, Mclndoe-Calder and Vicente, 2017 ${ }_{[29]}$ ). Moreover, the return migrant typically brings accumulated savings and skills with them (Wahba, $\left.2015_{[30]}\right)$. There is a growing body of evidence showing that return migrants are more likely to be employers or self-employed rather than wage workers (Wahba, 2015[30]), and that they are more likely than nonmigrants to be business owners (Mahé, 2021[31]; Vlase and Croitoru, 2019[32]). 


\section{Box 8.2. Forms of immigrant entrepreneurship}

\section{Self-employment and small business owners}

Many immigrant entrepreneurs operate small businesses on their own. Often these businesses operate in highly competitive sectors that have low barriers to entry (e.g. restaurants). While solo selfemployment is an important activity for many because it provides an opportunity to earn an income to support themselves and their family, evidence suggests that it is not likely to be an effective tool of upward economic mobility among low-skilled immigrants (Lofstrom and Wang, 2019 $9_{[1]}$ ).

\section{International entrepreneurship}

International entrepreneurs are entrepreneurs that conduct a business venture across national borders. This often includes sales in foreign markets, but could also include parts of the supply chain located in another country. These entrepreneurs tend to have a capacity for innovative, proactive and risk-seeking behaviours, and a subset of these immigrants seek to create firms that are "born-global."

\section{Transnational entrepreneurship}

A transnational entrepreneur is an entrepreneur that exploits business opportunities between their country of origin and their adopted country (Drori, Honig and Wright, 2009[33]). By engaging in two or more socially embedded transnational environments, transnational entrepreneurs create, develop and deploy resources to exploit comparative advantages in both their country of residence and their country of origin (Thieme, 2008[34]). The affiliations to both country of residence and country of origin put transnational entrepreneurs in a uniquely advantageous position compared to single market entrepreneurs (Drori, Honig and Wright, 2009[33]).

\section{Lifestyle entrepreneurship and digital nomads}

A lifestyle entrepreneur is an individual who is motivated to develop businesses as part of a lifestyle decisions. This includes, for example, digital nomads who utilise mobile technologies to work independently of a location. This type of work blurs the line between tourism and migration (Hannonen, $2020_{[35]}$ ). It also includes those who have activities that are connected with more balanced and sustainable living, e.g. rural tourism sector (Cunha, Kastenholz and Carneiro, 2020[36]).

\section{Expat-preneurs}

These immigrant entrepreneurs are those who transitioned from working with multi-national firms or organisations to pursuing entrepreneurship (Vance et al., 2017[37]). Many of these entrepreneurs have high levels of education, financial resources and strong networks.

\section{Diaspora entrepreneurship}

Another form of immigrant entrepreneurship is undertaken by those entrepreneurs who were active abroad but have returned to their country of origin to continue business activities (Zhou and Hsu, 2011[38]; Saxenian and Sabel, 2009[39]). This type of entrepreneurship has been stimulated by the implementation of economic liberalisation policies and lowering of trade barriers that facilitate foreign direct investment, as well as the immense technology advances in communication and transportation that have occurred over the past decade. 


\section{The potential benefits of immigrant entrepreneurship}

\section{There is a growing recognition of the contributions to innovation ....}

A critical question about policy support for immigrant entrepreneurship is the extent to which immigrant entrepreneurs contribute to innovation and job creation. While the evidence base on both their contributions to innovation and job creation is thin, it would be expected that contributions should increase as the skills levels of immigrants increase. There is some evidence from Germany suggesting that skilled immigrants can potentially increase a country's capacity for innovation and productivity growth. A recent study in Germany found higher rates of inventions by immigrant and local inventors in the period 2001-10 due to an increase in Polish immigrants (Candel-Haug, Cuntz and Falck, 2018[40]). A 10\% increase in Polish immigration was associated with a $0.29 \%$ increase in the number of Polish inventors immigrating to Germany, which led to a $0.31 \%$ increase of German inventors. Immigration created positive spill-over effects on innovative activities and local economies. However, the spill-over effects from Polish inventors to German inventors was found to be slightly higher than their direct contribution. An earlier German study also found immigrant entrepreneurs to be more innovative than German entrepreneurs and noted that immigrants were more likely to start businesses in teams, which are typically more innovative (Metzger, $\left.2016_{[41]}\right)$. A second hypothesis suggested was that, on average, immigrant entrepreneurs were slightly younger when they started their firm and had a slightly higher risk tolerance than German-born entrepreneurs (Metzger, 2016 $\left.6_{[11]}\right)$.

This is consistent with evidence from North America that shows that immigrant business owners and entrepreneurs are more innovative relative to the native-born populations. Statistics Canada shows that immigrant-owned businesses are more likely to introduce an innovative product or processes compared to Canadian-born SME owners (Ostrovsky and Picot, 2020[22]). Similarly, research from the United States typically shows that skilled immigrants (i.e. immigrants with a university degree) outperform their native-born counterparts in terms of wages, patenting, commercialising and licensing patents, and publishing (Hunt, 2010[42]). More recent research found that immigrants who came to the United States in the period $1972-2012$ accounted for $16 \%$ of all US-based inventors, $23 \%$ of all patents and were responsible for $25 \%$ of the aggregate economic value created by patents in publicly traded companies (Bernstein et al., 2018[43]). This study also found that the innovation impacts by immigrants were not concentrated in any specific sector $-25 \%$ in Computers and communications, Drugs and medical, Electronics and Chemical sectors and 15\% in Metal working, Transportation, and Engines sectors.

\section{...and job creation...}

Overall, self-employed immigrants are nearly as likely as non-immigrant self-employed workers to employ others. Chapter 3 shows that, overall, self-employed immigrants in the EU are about as likely to employ others than non-immigrant self-employed workers. In $2020,32 \%$ of self-employed immigrants that were born outside of the EU had employees, which was essentially the same proportion as those selfemployed who were born in the reporting country (30\%). However, a slightly lower proportion of selfemployed immigrants that were born in another Member State had employees (28\%). As with the selfemployment rate, the proportion of the self-employed with employees varied greatly across countries. For example, the share of self-employed people born outside of the EU with employees in 2020 ranged from $22 \%$ in the Netherlands to about half in Austria (52\%).

Recent evidence on the job creation potential of immigrant entrepreneurs in North America is mixed. Data from the United States shows that immigrant-owned firms are less likely to create jobs than those by native-born entrepreneurs (Kerr and Kerr, 2020[44]). Additional research notes that many of the jobs created have lower pay and fewer benefits than those created by non-immigrants (Lofstrom and Wang, 2019 $\left.{ }_{[1]}\right)$. However, a recent analysis in Canada found that immigrant-owned firms were more likely than firms with Canadian-born owners to be job creators (Picot and Rollin, 2019[45]). On average, 
immigrant-owned firms accounted for one-quarter of net job creation between 2003 and 2013, while accounting for $17 \%$ of the firms. This was primarily because immigrant-owned firms were younger. Among all firms, young firms (i.e. those less than five years old) accounted for $41 \%$ of gross job creation and only $17 \%$ of job losses. Among immigrant-owned firms, those under five years old accounted for $63 \%$ of gross job creation but $33 \%$ of job losses. This positive finding is likely due to the overall success of the immigration system in integrating immigrants into the labour market. Canada admits the largest number of skilled labour migrants in the OECD and has a carefully designed and longest-standing skilled migration system in the OECD (OECD, 2019[46]).

\section{...however most research finds a slightly lower business survival rates for immigrant- owned businesses}

There is a substantial body of evidence from EU and OECD countries that highlights a small gap in business survival rates between those operated by immigrants and those operated by nonimmigrants. As with all businesses, the survival rates of businesses operated by immigrant entrepreneurs varies greatly across sectors and countries. Over the period 1998-08, a small gap in the sustainability of businesses started by immigrants and those started by non-immigrants is observed across nearly all EU and OECD countries. Overall, the average gap within OECD countries in the EU was about three p.p. (OECD, 2011 ${ }_{[12]}$ ). More recently, some recent research in France shows that among innovative companies, those operated by immigrants had a three-year survival rate of $58 \%$ over the period $2006-14$ relative to $68 \%$ for those operated by French nationals (European Migration Network, 2019[47]). However, businesses operated by immigrants in Canada have survival rates that are about the same as those operated by Canadian-born people (Ostrovsky and Picot, 2018[48]). Two-year business survival rates were found to be about $80 \%$ and nearly $60 \%$ continued to operate after seven years regardless of where they were born. The Canadian research also found that businesses operated by immigrants who had been in Canada for longer were more likely to have higher business survival rates than those operated by new immigrants. In addition to length of time in the country, several other factors were found to influence business survival rates in Canada including immigrants age, source country and sector (Ostrovsky and Picot, 2018[48]).

The fragility of many immigrant-owned businesses was highlighted during the COVID-19 pandemic. There is some evidence illustrating the relatively high impact levels on immigrant-owned businesses, often due to their over-representation in sectors that have most heavily impacted by containment measures such as the hospitality sector. For example, immigrants account for more than $40 \%$ of self-employment in the hospitality sector in several EU Member States such as Denmark, Germany, Luxembourg and Sweden and non-EU OECD countries such as Canada and Norway (OECD, 2020[49]). Evidence from the United States shows that despite some recovery in May 2020, there was an $18 \%$ decline in the number of immigrant-owned businesses between February and June 2020 relative to a decline of $8 \%$ overall (Fairlie, 2020 [50]). There appears to have been a recovery in the second half of 2020 because the decline in immigrant-owned businesses was only 16\% between February and December 2020 (Fairlie, 2021 [51]). A comparable decline was also observed in Canada, where the number of immigrant-owned businesses dropped by $16.1 \%$ between February and May 2020 compared with $12.6 \%$ for Canada as a whole (Beland, Fakorede and Mikola, 2020[52]). This disproportionate impact is often explained by sector, geographical location, education levels, gender and occupation (Price, 2020[53]). In addition, immigrant-owned businesses often have a limited ability to absorb negative economic shocks due to weak entrepreneurship networks and low levels of capital. 


\section{Challenges faced by immigrant entrepreneurs}

All entrepreneurs face obstacles in the process of creating a business and developing it through the early stages of its life cycle. Commonly cited barriers include access to finance, a lack of entrepreneurship skills, negative social attitudes, regulatory burden and small professional networks (OECD/The European Commission, 2013 ${ }_{[54]}$ ). On average, three barriers tend to be greater for immigrant entrepreneurs than for non-immigrant entrepreneurs: access to start-up finance, access to networks in the new country, barriers to accessing local entrepreneurship ecosystems. Across these three barriers, language difficulties can amplify the magnitude of the obstacles faced.

\section{Access to finance appears to be a disproportionate barrier to business creation for immigrant entrepreneurs in some but not all countries...}

Immigrant entrepreneurship is often characterised by a lack of start-up capital. This is typically caused by several factors including low levels of savings, low-income levels and a lack of collateral, However, some may also have difficulties demonstrating a credit history, which is a barrier to accessing debt (Basu and Altinay, 2002[16]). Financial institutions also report that immigrants can have lower levels of financial literacy skills (European Commission, 2016 $\left.{ }_{[55]}\right)$. This presents a range of obstacles, including difficulty identifying potential sources of start-up financing, understanding how to apply for financing and pitching their ideas and financial plans to lenders and investors. Therefore, it appears to be relatively common for immigrant entrepreneurs to use informal networks to secure financing, notably through family and personal connections. This is confirmed by research in several countries such as Germany (David, Schäfer and Terstriep, 2021 [56]; Metzger, 2016[41]), the Netherlands (De Lange, Berntsen and Hanoeman, 2019[57]), Sweden (Aldén and Hammarstedt, 2016 $6_{[58]}$ ) and the United States (Lee and Black, 2017[59]). The Swedish research found that non-EU immigrant entrepreneurs had higher rejection rates and were charged, on average, an interest rate that was 1.4 percent points higher than non-immigrants. In the Netherlands, specific challenges were identified as client identity requirements under anti-terrorism laws and anti-money laundering policies. In addition, there are some restrictions related to nationality and having a temporary residency status. Research from the United States identified key obstacles to accessing finance as a lack of knowledge and skills.

However, evidence from other countries indicates that access to start-up financing is not necessarily a stronger barrier of immigrant entrepreneurs. In Canada, immigrant and non-immigrant entrepreneurs use similar sources of funding and tend to rely heavily on personal financing (Ostrovsky and Picot, 2018[48]). Immigrant and Canadian-born entrepreneurs also seem to use similar sources of start-up financing with personal financing being the most commonly used source. Overall, recent immigrants are less likely to turn to a formal financial institution such as a bank for start-up financing. Research in other countries such as Australia (Njaramba, Chigeza and Whitehouse, 2018[60]) and Italy (Campanella and Serino, 2019[61]; Magri, 2008[62]) also finds a heavy reliance on own-funding among immigrant entrepreneurs, which makes it difficult to assess the extent to which access to finance is a barrier to business creation.

\section{...which can be further hampered by less access to social capital and networks}

One of the main challenges for immigrant entrepreneurs is developing networks and relationships with entrepreneurs and business support actors who are outside of their community. Immigrant networks often build on relationships based on socio-cultural components like family, community, education religion, ethnicity, social class, economic class and age (Egbert, 2009[63]). The availability of these resources allows an immigrant entrepreneur to build trust and expand personal networks, thereby contributing to a business venture's success by helping to gain a competitive advantage over competitors (Bhagavatula et al., 2010[64]). While country of origin cultural predispositions can be important facilitating 
factors for immigrant entrepreneurship, they can also reduce the ability of immigrant entrepreneurs to operate beyond their own enclave environment (Neuman, 2016[65]; Liu et al., 2020[66]).

\section{A lack of language skills can increase the significance of barriers ...}

A low level of language skills (in the language spoken in the new country) remains one of the most significant barriers to business creation for immigrant entrepreneurs. Language barriers can impact all aspects of setting up and running a business, including registering a business, completing administrative forms such as licences applications and paying taxes (Italian Ministry of Economic Development, 2020[67]; Slovak Business Agency, 2019[68]). Moreover, language barriers can hinder communications with other entrepreneurs (e.g. suppliers, partners) and potential customers and create difficulties in building entrepreneurship networks (Parker, 2009 [69]; Fregetto, 2004 [70]).

\section{...including difficulties accessing the local entrepreneurship institutions}

Barriers to enterprise success can also occur through institutional structures. Immigrant entrepreneurs typically have a low propensity to use mainstream business support agencies, often relying instead on self-help and informal sources of assistance (Cooney and Flynn, 2008[71]). The main barriers to accessing support included: a lack of commitment of agencies to reach out to marginalised groups; the inappropriateness of agency product and service-orientated approaches; doubts over the relevance of what is offered; and a lack of trust and confidence in those delivering the support. These barriers can arise from the person (e.g. lack of language skills, self-confidence), from local society (e.g. attitudes towards immigration) and from institutional agencies (e.g. accessibility and flexibility of support schemes).

Another barrier is complexity of the governing structure, which often includes many institutions, organisations and procedures that require knowledge of regulations and laws. This can be challenging for immigrants since starting a business often requires interacting with several institutions (e.g. finding and renting a business space, registering the business with the Chamber of Commerce, applying for municipal permits, opening a professional bank account). These difficulties can be compounded by language barriers (De Lange, Berntsen and Hanoeman, 2019 [57]). A further consequence is that immigrant entrepreneurs may miss out on public support schemes. For example, research in the Netherlands finds that despite the presences of a European Guarantee Fund exists to help vulnerable populations including immigrant entrepreneurs to gain access to grants and credit, the fund remains underutilised by immigrants due to difficulties accessing information (De Lange, Berntsen and Hanoeman, 2019[57]).

\section{Policies to unlock the potential of immigrant entrepreneurship}

Governments have an interest in boosting the quality of immigrant entrepreneurship given the numerous potential benefits such as job creation, innovation, attracting investments and openingup trade opportunities. In general, two types of approaches are used by governments. First, there is a range of schemes that seeks to increase the chances of success for immigrant-owned businesses, notably the self-employed. These include schemes that offer entrepreneurship training, coaching and mentoring and a suite of financial supports. While many of these approaches have demonstrated a positive impact, the scale of support has not increased to meet the growth in the relative and absolute number of immigrant entrepreneurs. Second, a growing number of countries are using start-up visas and financial incentives to attract immigrant entrepreneurs. The majority of these schemes lead to only a small number of new firms created by immigrants so governments need to temper their expectations about the potential impacts of such instruments. 


\section{Scale-up and strengthen traditional supports to increase the chances of sustainability}

Current support offers for immigrant business owners and self-employed immigrants include entrepreneurship training, coaching and mentoring, start-up finance and strengthening entrepreneurship networks. Such support schemes seek to improve the chances of success for these businesses but there is also some evidence that self-employment can positively affect labour market integration. Evidence from the United States suggests that this effect is stronger among low-skilled immigrants (Lofstrom and Wang, 2019 $\left.{ }_{[1]}\right)$. These types of supports can be scaled-up to reflect the growth in the absolute and relative number of immigrant entrepreneurs. In addition, whenever possible, efforts are needed to help steer these immigrant entrepreneurs away from sectors that are already characterised by an over-supply of firms.

\section{Entrepreneurship training}

One of the most commonly used approaches to boost entrepreneurship skills for immigrants is through tailored training schemes (European Commission, 2016[55]). These group training sessions typically cover all of the phases of entrepreneurship, ranging from pre start-up activities (e.g. idea development, identification of markets, financial literacy) to business creation (e.g. business registration, securing premises) to the early stages of development (e.g. business management, opportunity recognition) (Zhan, Bolwijn and Farinelli, 2018[72]). It is important for training schemes to also include some contextual information on the national and local business environments, particularly on regulatory institutions and administrative requirements such as business registration, obtaining permits, filling taxes since the entrepreneur likely has no experience with these processes in the new country (Solano, Wolffhardt and Xhani, 2019 ${ }_{[73]}$ ). Immigrant entrepreneurs may also need support in navigating immigration regulations concerning, for example, permit renewals and status changes. The EU-funded Migrants Empowerment for Change (ME4Change) project offers for example guidance to immigrant entrepreneurs on legal and procedural aspects of starting a business, both related to their status in the host country as well as the rules to start and manage a business (Solano, Wolffhardt and Xhani, 2019[73]).

The success factors for designing an effective entrepreneurship training scheme for immigrants are to develop a high-quality course that can be delivered consistently to many cohorts, yet have enough flexibility for the content to be tailored to the needs of the specific group on the course. Content should focus on delivering practical skills such as the development of business ideas, mobilising resources, financial literacy and access to funding, planning and management, coping with uncertainty and risk, and legal and administrative aspects of managing a business. Often this can be best achieved when training is offered as part of an integrated package of support, as done by the Ester Foundation in Sweden (Box 8.3). Support structures should be attuned to the specific needs and interests of immigrant entrepreneurs in different stages of business development (Berntsen et al., 2021[74]). The training schedule and location also need to be appropriate for the group, which may mean organising courses in the evenings or weekends. Training programmes will be more attractive to immigrant populations if the training is offered in the relevant language and trainers come from similar backgrounds. Some entrepreneurship programmes include basic language training so that participants can learn key terms and phrases that are relevant to their business activity. 


\section{Box 8.3. Support measures for immigrant entrepreneurs, Sweden}

Target group: Potential immigrant women entrepreneurs

Intervention type: Training, coaching, mentoring and financial support

Description: The Ester Foundation in Sweden offers training to unemployed immigrant women entrepreneurs in a multi-month programme consisting of three six-month modules. The first module aims to introduce participants to life, culture and business culture in Sweden. The second module focuses on supporting these entrepreneurs in registering their business, while the third module offers advice in the early stages of the business, including support in applying for public grants. A mentoring service also matches participating entrepreneurs with volunteer mentors in later stages of the programme. Additionally, these entrepreneurs receive financial assistance for the duration of the programme to ensure living expenses are covered and entrepreneurs can focus on developing their project. Lastly, the Ester Foundation offers a microcredit programme in partnership with Swedbank (a Swedish financial institution in the Stockholm region), in which the Foundation guarantees $80 \%$ of each loan. These loans range from SEK 20000 to SEK 30000 (EUR 2140 to EUR 32 120) and have a repayment period of three years or under.

Results achieved: In the period 2012-16, the programme supported 21 immigrant women entrepreneurs, leading to the creation of 11 businesses. In 2016, 10 of these businesses were still in operation and 4 had part-time or full-time employees. Despite the COVID-19 crisis, the programme welcomed a cohort of 10 women entrepreneurs and adapted to a virtual format in April 2020.

\section{Coaching and mentoring}

A more individualised approach to developing entrepreneurship skills is through coaching and mentoring. These one-to-one relationships are designed to address the needs of entrepreneurs and their businesses. Coaching and mentoring is typically offered to entrepreneurs after the business is operating and can be delivered as part of integrated packages that include finance.

Evaluation evidence points to a set of characteristics that successful coaching and mentoring schemes for immigrant entrepreneurs tends to share, notably a high-quality match between the entrepreneur and their coach or mentor (European Commission, 2016[55]). A prerequisite for successful schemes is building a pool of potential coaches and mentors (Solano, Wolffhardt and Xhani, 2019 ${ }_{[73]}$ ), who can be either business professionals or experienced entrepreneurs who volunteer to support others. Goodpractice matching mechanisms consider a range of factors in assigning coaches and mentors, including business activity, interests, personality, motivations, language, location and background. Schemes should provide a framework for the relationships and tools that coaches and mentors can work with. Successful schemes set up relationships that last about six months and ensure that entrepreneurs and their coaches and mentors work towards objectives that are set at the outset (OECD/European Union, 2014[75]). For immigrant entrepreneurs, coaching and mentoring can be very valuable in providing support beyond entrepreneurship, including support with family integration (e.g. registering children for school). There are many examples of coaching and mentoring schemes across the EU including MEnt, an EU-level project which includes a mentoring programme for migrant and refugee entrepreneurs as well as incubation services (Box 8.4). 


\section{Box 8.4. Migrant Entrepreneurs Team-Up with Mentors (MEnt), EU}

Target group: Immigrant and refugee entrepreneurs

Intervention type: Incubation and mentoring programme

Description: The MEnt programme is an EU-level entrepreneurial project financed by the EU Asylum, Migration and Integration Fund. MEnt aims to facilitate and foster economic and social integration of immigrants interested in developing a business or joining a team of entrepreneurs. The programme has been adapted to the needs of immigrant entrepreneurs and consists of short training sessions focussed on early-stage development of the business followed by incubation. This includes two workshops aimed to provide knowledge and aid in the creation of a business model as well as facilitate access to markets, resources and key partners in the local community. One of the core tenants of MEnt is the matching of immigrant entrepreneurs to a mentor. Matching helps to foster business relationships and networking in the local community and allows immigrant entrepreneurs to gain valuable insights of the business sector and national context.

Results achieved: The first cycle of the programme ran between 2017 and 2018 with local teams in Austria, Belgium, France, Germany and Italy. In total, there were 81 participants and 46 projects. Participants came from over 23 different countries and many were asylum seekers. The average participant in the programme is an adult male, aged between 26 and 35 years old.

Source: (MEnt Project, 2021 176$]$ )

\section{Access to finance}

Government schemes that seek to improve access to finance for immigrant entrepreneurs often focus on the provision of small grants or facilitating access to loans (European Commission, $\left.2016_{[55]}\right)$. In general, these types of supports are effective and considered helpful by immigrant entrepreneurs (European Commission, 2016 $\left[{ }_{[5]}\right)$. However, a greater emphasis is needed on complementary support such as the provision of information and financial literacy training (Zhan, Bolwijn and Farinelli, 2018[72]).

Microfinance is an important tool to support immigrant entrepreneurs. Estimates suggest that about $15 \%$ of microfinance institutions in the EU offer tailored products and services for immigrant and ethnic minority business owners. However, there continues to be unmet demand for microfinance in the EU (Drexler et al., $2020_{[77]}$ ) so there is scope to scale-up the use of microfinance to support immigrant entrepreneurship. Furthermore, governments can do more to improve the quality of non-financial supports that are typically packaged together with microfinance. This includes, for example, entrepreneurship training and coaching. An approach that appears to be successful with immigrant entrepreneurs is to partner with specialised organisations that have a history of working with immigrant communities. This can improve the relevance of support offered and leverage a pre-existing level of trust to increase the efficacy of the support delivered (OECD/The European Commission, 2013 ${ }_{[54]}$ ). For additional discussion on access to finance for immigrant entrepreneurs as well as entrepreneurs from other under-represented population groups, please see Chapter 7, which discusses microfinance for inclusive entrepreneurship. 


\section{Entrepreneurship networks}

The most common approach for public policy is to bring entrepreneurs and business service professionals with a common background together to build connections among themselves. Given their common backgrounds, the participants easily identify with each other and trust builds quickly. In addition to building these connections, public policy needs to pay attention to building bridges to entrepreneurs, business service providers and other stakeholders from other communities (Scandura and Bolzani, 2020[78]; Solano, Wolffhardt and Xhani, 2019 [73]; Zhan, Bolwijn and Farinelli, 2018[72]). One of the most important success factors for policy intervention is that network members have ownership of the supported networks. This can be achieved through the use of existing community structures and the involvement of network participants in the management of the network (Haandrikman and Webster, 2020 [79]).

Public policy can also create networks of entrepreneurs around other policy interventions such as training or other business development services. This has the advantages for programme delivery of generating economies of scale and ensuring that targeted entrepreneurs are reached as well as having added benefits from the creation of networks among the participants. However, this approach excludes entrepreneurs who are not participating in the policy intervention. Moreover, these networks are not always sustainable when the binding factor is receipt of the training or business service.

Online networks also hold potential for entrepreneurship. They eliminate physical distances between entrepreneurs and offer some of the key characteristics of traditional networks including connections with other entrepreneurs that are built on trust and reciprocal relationships. The effectiveness of online networks is unknown but they offer a potentially important opportunity for policy because of their low-cost structures. However, policy makers must recognise that online networking initiatives likely need to be complemented with face-to-face interactions.

\section{Attract skilled immigrant entrepreneurs}

\section{Promote the attractiveness of local economies to potential foreign entrepreneurs}

Many governments use information packages and websites to promote themselves to entrepreneurs abroad. This can be done by local, regional and national governments, and often leverages a brand that was created to help "sell" the local economy. These types of information products tend to highlight "pull" factors that attract new entrepreneurs. While it is critical to highlight the attractiveness of the local economy and the entrepreneurship ecosystem, it is also important to include other factors that impact quality of life such as socioeconomic factors (e.g. cost of living), as well as cultural and lifestyle considerations (European Migration Network, 2019[47]). There are examples, such as Canada's province of Prince Edward Island that have created information products that are targeted to specific profiles of entrepreneurs (Box 8.5).

In addition to making materials available online, governments can also partner with community organisations to help disseminate the information to the targeted group. These organisations can help reach out through local events and association and to potentially disseminate the information abroad (European Commission, 2016[55]). This type of collaboration can increase the reach of communication activities and also achieves an increased level of credibility. The involvement of highly visible community leaders can be a key success factor for this type of approach.

The evidence to support such activities is very thin because it is difficult to link a promotional action to a business created by an immigrant. It is therefore difficult to know how much governments should invest in this activity. An additional challenge is that there is no assurance that the immigrant will remain in the location where they first arrived. In the case of Prince Edward Island (Canada), for example, an immigrant may move to another province after receiving the visa. 
Box 8.5. Information Packages to Attract Immigrant Entrepreneurs to Prince Edward Island, Canada

Target group: Potential immigrant entrepreneurs

Intervention type: Promotional materials

Description: The Réseau de développement économique et d'employabilité (RDÉE) [Economic Development and Employability Network] is a francophone economic development group from Prince Edward Island (Canada). It aims to contribute to entrepreneurial and community economic development within the Acadian and francophone community of Prince Edward Island (PEI). RDÉE created a kit of eight bilingual booklets with funding from the LIENS Project (with the Immigration, Refugees and Citizenship Canada and the P.E.I. Office of Immigration) to provide pertinent information about PEl's economic and francophone landscape. The main booklet, "Opportunity Awaits: Attracting Francophone immigrants to Prince Edward Island" targets French-speaking immigrant entrepreneurs and highlights their role in the province's culture and economy. It provides information on available services and possible administrative avenues to achieve working status. One such example is the Work Permit Stream of the Prince Edward Island Provincial Nominee Program (PEI PNP) which helps eligible entrepreneurs achieve permanent residency.

Results achieved: In 2019, RDÉE and LIENS provided support services for 33 job seekers and hosted two entrepreneurial networking events with 43 participants. 100 participants attended a multicultural night as part of the francophone immigration week and a welcome event was held for 15 new arrivals.

\section{Attract immigrant entrepreneurs with start-up visas}

An emerging approach that governments are using to attract immigrant entrepreneurs is through start-up visa programmes. These visas are offered by a growing number of countries and seek to streamline visa admission procedures to attract more immigrant entrepreneurs. Immigrant entrepreneurs receiving start-up visas can usually access a range of support services, including financial support, business incubation and more. Applicants are typically immigrant entrepreneurs who have a successful track record as business managers; they are not immigrants who will be self-employed or operate lowimpact businesses. While these schemes do not necessarily have a sector focus, they tend to be disproportionately used by IT start-ups (OECD, 2021[80]).

Despite the growing use of start-up visa programmes, there remains little evidence on their impact (Lofstrom and Wang, 2019 $\left.{ }_{[1]}\right)$. One challenge is that many start-up visa programmes are relatively new so evaluating impacts can be difficult or misleading if they have only been operating for a few years. Therefore, research tends to focus on how processes could be improved rather than programmes' impacts. Most studies of schemes in the EU recommend simplifying procedures or broadening the scope of the visa to cover employees in new start-ups (European Migration Network, 2019[47]). Deeper insights can be gleaned from studies of some of the long-standing programmes. A recent survey of start-up visa recipients in Italy found that about $16 \%$ of those who successfully started their business considered themselves to be a scale-up (Italian Ministry of Economic Development, 2020[67]). However, nearly one-fifth of those receiving a visa did not move to Italy or moved but did not start a business. Moreover, the process was often found to be difficult and two-thirds of those surveyed indicated that they endured a problem throughout the process. An older evaluation of the Start-up Visa pilot programme in Canada found that there were fewer applications than expected and also fewer entrepreneurs admitted than under previous programmes (Immigration Refugee and Citizenship Canada, 2016[81]). Nonetheless, the evaluation found that the visa appears to be successful at attracting human capital to Canada and it was considered to be a success overall. 
Governments face a number of challenges in setting up start-up visa programmes. First, government studies point to the critical role that outreach and communication have in attracting entrepreneurs. However, as in the Italian case, communication efforts do not always sufficiently involve innovation actors (e.g. incubators and accelerators) and other support providers (e.g. investors) to fully inform potential entrepreneurs about the benefits of the visa programme (Italian Ministry of Economic Development, 2020[67]). Second, it can be difficult and burdensome to verify the creation of the business once the new entrepreneur has arrived. Only about half of EU Member States conduct any follow-up on visa recipients to see if the proposed business was created (European Migration Network, 2019 [47]). This is clearly an area where greater resources are needed. Finally, there is often a challenge in retaining the start-ups and entrepreneurs due to long application process for renewing start-up permits, language difficulties and a lack of growth financing, local skills and tax incentives (European Migration Network, 2019[47]).

Going beyond start-up visas, some governments are experimenting with mechanisms that allow entrepreneurs and businesses to operate as domestic firms from abroad. For example, Estonia has created a new status for entrepreneurs called "e-entrepreneurs" through its e-residency scheme (Box 8.6). This status allows for entrepreneurs to be registered in Estonia even if they do not have a physical presence. While this type of activity may create opportunities for other Estonian businesses through supply chains and partnerships, it also creates some regulatory challenges including taxation and the application and enforcement of Estonia laws and regulations.

\section{Box 8.6. E-entrepreneurs, Estonia}

Target group: Entrepreneurs abroad who wish to operate a business in Estonia

Intervention type: E-residency that allows for the operation of a domestic business

Description: E-residency was launched in 2014 to support entrepreneurs, digital nomads, freelancers, consultants, and business owners. It aims to provide access to the EU market, help grow business remotely and efficiently, and reduce bureaucracy. Estonia's Digital Nation offers e-residents the ability to establish and manage a paperless EU-based company $100 \%$ online through a five-step programme. E-residents apply online, pay a state fee, and choose a pick-up location for their digital ID (EUR 100 EUR 120). The next step requires a service provider through obtaining an Estonian contact person and legal address from their market place (EUR 30 - EUR 150 monthly average). The company structure is registered online at the e-Business Registry which requires a state fee (EUR 190). The application review process ranges from 3 to 8 weeks. Business banking needs can be handled through the Marketplace and an active role in the Digital Nation is suggested to help grow the network and the ebusiness.

Results achieved: Estonia has the most start-ups per capita in the EU including 12000 established companies through the Digital Nation.

Another emerging policy area is related to "digital nomads". As noted earlier in the chapter, this form of lifestyle entrepreneurship has increased as technology developments allow for remote working and some surveys suggest that this type of work has increased due to the COVID-19 pandemic. In response to this trend, a small number of countries have introduced digital nomad visas, including Croatia and Iceland, and a draft law is being debated in Spain. This draft law seeks to create new tax measures that apply to "digital nomads" (los nómadas digitales) and other types of teleworkers, and also proposes to lower the requirement of not being a tax resident in Spain from 10 years to 5 years and prolonging the period of eligibility from 5 years to 10 years. Moreover, the draft law also discusses the creation of a specific visa for people working in Spain for a foreign company. 
Governments need to be aware of several policy challenges related to digital nomads when designing these types of visas, notably work documentation and taxation. The main issue is the legal right to work when an individual has not acquired any type of work visa and many individuals may not be aware of requirements across jurisdictions. A special visa could overcome these challenges but this requires a high level of awareness among digital entrepreneurs otherwise they will work without the proper documentation. A related issue is taxation and collecting taxation across multiple jurisdictions. Finally, digital nomads have also been found to have direct consequences on local economies. In popular digital nomad destinations, some local communities have been negatively impacted as digital nomads have reshaped local economies with their large economic buying power (e.g. driving-up prices, buying up commercial and residential real estate) and the establishment of new societal structures which often exclude local communities.

\section{Offer financial incentives to attract immigrant entrepreneurs}

Another approach used to attract skilled immigrant entrepreneurs is to offer financial incentives to business creation. This could include, for example, various forms of financial awards, and access to incubator and accelerator programmes that can facilitate access to investors. While financial incentives can be effective at attracting high-potential immigrant entrepreneurs, the long-term success of the entrepreneur will depend on the effectiveness of accessing resources and developing strong entrepreneurship networks. This is well-illustrated by the Poland Prize, which offers a financial incentive for immigrant entrepreneurs as well as a range of dedicated services that includes match-making with investors and networking events (Box 8.7).

\section{Box 8.7. Poland Prize}

Target group: Immigrant entrepreneurs

Intervention type: Programme and support services for foreign start-ups

Description: The Poland Prize is a programme for foreign start-ups which offers services and assistance for starting business activities in Poland and is co-sponsored by the Polish Agency for Enterprise Development. The primary objective is to establish Poland as an attractive country for immigrant entrepreneurs. The Poland Prize aims to effectively introduce foreign mid-stage start-ups into the Polish start-up ecosystem by offering grants up to PLN 200000 (approximately EUR 43 500), services up to PLN 50000 (approximately EUR 10 900) (i.e. legal, consulting and mentoring services), a dedicated visa pathway, a concierge service for official banking and settlement-related needs, specialised technology consulting, and mentoring and networking. There are six specific operators specialised in different start-up sectors that provide start-up incubation and acceleration. Depending on the specialised operator, participants are selected through eligible partner countries including Canada, Estonia, Finland, France, Germany, Israel, Spain, Ukraine, the United Kingdom, and the United States. Selected teams receive cash and services to deliver up to 50 prototypes with Poland Prize taking $0 \%$ equity. 


\section{Support growth-oriented immigrant entrepreneurs with business incubator and accelerator programmes}

Business incubators and business accelerators are types of business development support programmes that provide a range of support services to entrepreneurs in business creation and during the early stages of the business life-cycle. Both types of support programmes typically offer a package of services, including training seminars, workshops, business coaching and mentoring, business advice, networking opportunities and access to financing. In addition, business incubators have traditionally offered premises for the business to operate. These types of programmes are very common in non-EU OECD countries such as Canada and the United States, and are increasingly appearing in the EU (OECD/EU, 2019[82]). Overall, evidence suggests that business incubators and business accelerators can be effective supports for new and growing businesses. For example, businesses that receive support in incubators tend to have higher survival rates, create more jobs, and generate more revenue (OECD/EU, 2019[82]).

While there are relatively few examples of business incubators and accelerators that are fully dedicated to supporting immigrant entrepreneurs, there is a small body of evidence that shows similarly positive results. For example, the iStart programme in Norway for highly skilled immigrants has supported the creation of more than 60 start-ups since 2014 (Box 8.8). Similarly, a dedicated incubator at the University of Montreal, supported by the Government of Quebec (Canada), has supported about 20 new start-ups per year since 2015-16 (HEC Montreal, 2021[83]). A key success factor for this incubator is that it helps entrepreneurs build relationships with Quebecois entrepreneurs to expand professional networks and facilitate settlement into a new community. A greater number of incubators that serve immigrant entrepreneurs are expected in the EU with a boost in support from the European Commission through the LIAISE project, which will inject funding into dedicated business development services for entrepreneurs from under-represented and disadvantaged groups.

\section{Box 8.8. iStart, Norway}

Target group: Growth-oriented immigrant entrepreneurs

Intervention type: Entrepreneurial guidance and start-up programmes

Description: iStart is a programme offered by the Norwegian Center for Multicultural Value Creation (NSFV) specifically designed for immigrant entrepreneurs to help mobilise, empower and guide innovation and new businesses locally, nationally, and internationally. Participants should be living in Norway and fluent in Norwegian (orally and written). Additional selection criteria include education level (higher education required), business experience (domestic or international), clear business idea with market potential, high drive and ambition to complete programme and subsequently establish a business. iStart provides professional development, mentorship, networking, government grants and funding, and an interdisciplinary team of experienced consultants to further develop participants' ideas and business strategy. The programme has an open-door policy which allows participants to continue individual follow-up appointments and mentorship after completing the programme.

Results achieved: Since the launch of iStart in 2014, there have been four cohorts of around 12 participants each. $74 \%$ of iStart participants have established businesses across various industries.

\section{Offer incentives for diaspora entrepreneurship}

Governments are beginning to consider diaspora entrepreneurs as a source of innovation. Return migrants have higher rates of business ownership and many have experience running a business while 
they were abroad. Research tends to suggest that many of these returning migrants have relatively high levels of capital and skills (Wassink and Hagan, 2018[84]) but may have weaker networks in their home country (Wahba and Zenou, 2012[85]). Government schemes, therefore, tend to focus on building and updating professional networks, as well as developing and growing businesses with the objective of stimulating job creation since many diaspora entrepreneurs have potential for upward mobility (Wassink and Hagan, 2018[84]). For example, the Back for Business scheme in Ireland supports early-stage entrepreneurs who are returning emigrants with group coaching and network building (Box 8.9). Most participants enter the scheme in the pre start-up phase and nearly two-thirds of participants are operating a business by the end of the six-month scheme. Another option for governments to consider is to offer financial incentives such as tax incentives or low or no-interest rate loans (Georgiev, 2020[28]). Such measures could be offered by local, regional or national governments. One important consideration for governments is to set-up a mechanism to ensure that the recipients of financial support utilise the funds as intended.

\section{Box 8.9. Back for Business, Ireland}

Target group: Irish entrepreneurs abroad who seek to come back Ireland

Intervention type: Development programme for returned emigrant entrepreneurs

Description: Back to Business is a free six-month development programme that fosters entrepreneurial activity among returned Irish emigrants. It aims to assist entrepreneurs in starting and developing a business by addressing challenges faced by early-stage entrepreneurs. It is based on peer support and offers the applied learning model through a series of round table interactive sessions conducted by Lead Entrepreneurs. External organisations and development agencies also offer workshops for participants. At the end of the programme, participants of Back for Business ( $4^{\text {th }}$ cohort) will receive a free one-year membership to the Irish International Business Network (IIBN) and have produced a SMART Action Plan, a six-month roadmap, to facilitate business growth.

Results achieved: Of the 34 participants who participated in the Back to Business $3^{\text {rd }}$ cohort, $55 \%$ were pre-revenue at the start of the cycle and $64 \%$ were operating a business by the end of the cycle. The combined turnover of the group increased threefold. Due to the international experience of the participants, 6 participants had some export sales before beginning the programme while an additional 9 participants became first time exporters throughout the programme. The majority of the cohort expects to have customers in export markets within three years.

\section{Conclusions}

Business creation is an important pathway into work for many immigrants since many face challenges entering the labour market, particularly those with low skill levels. However, many of these businesses operate in highly competitive sectors and have little growth potential. Governments can consider doing more to improve the sustainability of these businesses by attracting more self-employed immigrants into support schemes and increasing the scale of support offered when demand is sufficient. To strengthen support for immigrant entrepreneurship, governments could consider:

- Improving access to tailored supports when there are a sufficient number of immigrant entrepreneurs by conducting outreach, and offering some entrepreneurship support services, in various languages.

- Scaling-up schemes (e.g. training, coaching, microfinance) that have demonstrated success in parallel with launching new small-scale schemes. 
- Providing training to support providers so that they are sensitive to cultural differences.

- Recruiting entrepreneurship support providers from various immigrant communities to leverage trust with different communities, making offers more relevant and attractive.

- Embedding basic language training in integrated entrepreneurship support schemes for immigrants.

One of the most significant trends in inclusive entrepreneurship has been the growth - both absolute and relative - of immigrant entrepreneurship. There is a growing recognition of the contributions made to innovation and job creation by immigrant entrepreneurs, yet policy has been slow to adjust to the changing context. This calls for greater investments to supporting high-potential immigrant entrepreneurs, including greater use of outreach and incentives to attract them. To expand and strengthen support for high potential immigrant entrepreneurs, governments could consider:

- Strengthening linkages between start-up visa programmes and business development service providers (e.g. incubators and accelerators).

- Improving the integration of immigrant entrepreneurs into local ecosystems with matchmaking services and vouchers for business development services.

\section{References}

A Brother Abroad (2021), 63 Surprising Digital Nomad Statistics in 2021,

https://abrotherabroad.com/digital-nomad-statistics/ (accessed on 27 September 2021).

Aldén, L. and M. Hammarstedt (2016), "Discrimination in the Credit Market? Access to Financial

Capital among Self-employed Immigrants”, Kyklos, Vol. 69/1, pp. 3-31,

http://dx.doi.org/10.1111/kykl.12101.

Amornsiripanitch, N. et al. (2021), Getting Schooled: The Role of Universities in Attracting Immigrant Entrepreneurs, National Bureau of Economic Research, Cambridge, MA, http://dx.doi.org/10.3386/w28773.

Amuedo-Dorantes, C., M. Lofstrom and C. Wang (2020), "Immigration Policy and the Rise of Self-Employment among Mexican Immigrants", IZA Discussion Papers, No. 13930, IZA, https://ftp.iza.org/dp13930.pdf (accessed on 1 October 2021).

Bambra, C. et al. (2020), "The COVID-19 pandemic and health inequalities", Journal of Epidemiology and Community Health, http://dx.doi.org/10.1136/jech-2020-214401.

Barrett, G., T. Jones and D. McEvoy (1996), "Ethnic Minority Business: Theoretical Discourse in Britain and North America", Urban Studies, Vol. 33/4-5, http://dx.doi.org/10.1080/00420989650011825.

Basu, A. and E. Altinay (2002), "The Interaction between Culture and Entrepreneurship in London's Immigrant Businesses", International Small Business Journal: Researching Entrepreneurship, Vol. 20/4, http://dx.doi.org/10.1177/0266242602204001.

Batista, C., T. Mclndoe-Calder and P. Vicente (2017), "Return Migration, Self-selection and Entrepreneurship", Oxford Bulletin of Economics and Statistics, Vol. 79/5, pp. 797-821, http://dx.doi.org/10.1111/obes.12176. 
Beland, L., O. Fakorede and D. Mikola (2020), "Short-Term Effect of COVID-19 on Self-

Employed Workers in Canada", Canadian Public Policy, Vol. 46/s1, http://dx.doi.org/10.3138/cpp.2020-076.

Bernstein, S. et al. (2018), "The contribution of high-skilled immigrants to innovation in the United States”, Standford Graduate School of Business Working Paper, No. 3748.

Berntsen, L. et al. (2021), “Migrant Entrepreneurship Enablers: From Chance Encounters to Community Development", Work, Employment and Society, p. 095001702110314, http://dx.doi.org/10.1177/09500170211031441.

Bhagavatula, S. et al. (2010), "How social and human capital influence opportunity recognition and resource mobilization in India's handloom industry", Journal of Business Venturing, Vol. 25/3, http://dx.doi.org/10.1016/j.jbusvent.2008.10.006.

Brieger, S. and M. Gielnik (2021), "Understanding the gender gap in immigrant entrepreneurship: a multi-country study of immigrants' embeddedness in economic, social, and institutional contexts", Small Business Economics, Vol. 56/3, http://dx.doi.org/10.1007/s11187-019-00314$\underline{x}$.

Campanella, F. and L. Serino (2019), "Gender and Financial Constraints: An Empirical Investigation in Italy", International Journal of Financial Research, Vol. 10/2, p. 109, http://dx.doi.org/10.5430/ijfr.v10n2p109.

Candel-Haug, K., A. Cuntz and O. Falck (2018), "Polish immigrants stimulate innovation in Germany", LSE Business Review, http://i. http://eprints.Ise.ac.uk/89794/1/businessreview2018-05-10-polish-immigrants-stimulate-innovation-in.pdf (accessed on 4 August 2021).

Carbonell, J., J. Hernandez and F. García (2014), "Business creation by immigrant entrepreneurs in the valencian community. The influence of education", International Entrepreneurship and Management Journal, Vol. 10/2, http://dx.doi.org/10.1007/s11365-011$\underline{0211-2 .}$

Carter, S. and D. Jones-Evans (2012), Enterprise and Small Business, Pearson, London.

Carter, S. et al. (2015), "Barriers to ethnic minority and women's enterprise: Existing evidence, policy tensions and unsettled questions", International Small Business Journal: Researching Entrepreneurship, Vol. 33/1, http://dx.doi.org/10.1177/0266242614556823.

Chaganti, R. and P. Greene (2002), "Who Are Ethnic Entrepreneurs? A Study of Entrepreneursapos; Ethnic Involvement and Business Characteristics", Journal of Small Business Management, Vol. 40/2, http://dx.doi.org/10.1111/1540-627X.00045.

Clark, K. and S. Drinkwater (2000), "Pushed out or pulled in? Self-employment among ethnic minorities in England and Wales", Labour Economics, Vol. 7/5, http://dx.doi.org/10.1016/S0927-5371(00)00015-4.

Coduras M. A., C. Martínez and J. Saiz-Alvarez (2013), "Immigrant Entrepreneurship: an international comparison", Revista de Economía Mundial, Vol. 35, pp. 137-149.

Conway, S. and O. Jones (2012), Enterprise and Small Business: Principles, Practice and Policy, Pearson Education. 
Cooney, T. and A. Flynn (2008), A mapping of ethnic entrepreneurship in Ireland, Institute for Minority Entrepreneurship, Dublin Institute of Technology.

Cunha, C., E. Kastenholz and M. Carneiro (2020), "Entrepreneurs in rural tourism: Do lifestyle motivations contribute to management practices that enhance sustainable entrepreneurial ecosystems?", Journal of Hospitality and Tourism Management, Vol. 44, http://dx.doi.org/10.1016/j.jhtm.2020.06.007.

D'Ambrosio, A. et al. (2019), "Migration, communities on the move and international innovation networks: an empirical analysis of Spanish regions", Regional Studies, Vol. 53/1, http://dx.doi.org/10.1080/00343404.2018.1426850.

Dalhammar, T. (2004), Voices of entrepreneurship and small business: Immigrant enterprises in Kista, Stockholm.

David, A., S. Schäfer and J. Terstriep (2021), "Characteristics of migrant entrepreneurs: Asset in times of crisis?", Forschung Aktuell, No. 01/2021, Institut Arbeit und Technik (IAT), Gelsenkirchen, https://www.econstor.eu/handle/10419/231383 (accessed on 24 September 2021).

De Lange, T., L. Berntsen and R. Hanoeman (2019), Wat werkt voor ondernemende migranten? Een studie naar ervaren mechanismen van in- en uitsluiting in recht en praktijk, https://www.researchgate.net/publication/338448908 Wat werkt voor ondernemende migra nten Een studie naar ervaren mechanismen van in- en uitsluiting in recht en praktijk (accessed on 26 July 2021).

Desiderio, M. (2014), Policies To Support Immigrant Entrepreneurship, Migration Policy Institute, Washington, https://www.migrationpolicy.org/research/policies-support-immigrantentrepreneurship.

Djajic, S. and M. Michael (2013), "Guest worker programs: A theoretical analysis of welfare of the host and source countries", International Trade and Economic Development, Vol. 22/3.

Drexler, B. et al. (2020), Microfinance in the European Union: Market analysis and recommendations for delivery options in 2021-2027, Publications Office of the European Union, Luxembourg.

Drori, I., B. Honig and M. Wright (2009), "Transnational Entrepreneurship: An Emergent Field of Study”, Entrepreneurship Theory and Practice, Vol. 33/5, http://dx.doi.org/10.1111/1.15406520.2009.00332.x.

Egbert, H. (2009), "Business Success Through Social Networks? A Comment on Social Networks and Business Success", American Journal of Economics and Sociology, Vol. 68/3, http://dx.doi.org/10.1111/j.1536-7150.2009.00643.x.

European Commission (2016), Evaluation and Analysis of Good Practices in Promoting and Supporting Migrant Entrepreneurship Guide book, European Commission, Brussels.

European Migration Network (2019), Migratory Pathways for Start-Ups and Innovative Entrepreneurs in the European Union EMN Synthesis Report for the EMN Study 2019, European Migration Network, Brussels, https://ec.europa.eu/homeaffairs/sites/default/files/00 eu startups entrepreneurs synthesis report 2019 en.pdf (accessed on 31 March 2021). 
Eurostat (2021), Immigration, Population (Demographic and Migration) Statistics.

Eurostat (2020), Labour Force Survey, https://ec.europa.eu/eurostat/web/lfs.

Eurostat (2019), Labour Force Survey, https://ec.europa.eu/eurostat/web/lfs/data/database.

Eurostat (2018), Labour Force Survey, https://ec.europa.eu/eurostat/web/lfs/data/database (accessed on 1 December 2018).

Fairlie, R. (2021), Update on data presented in: The impact of COVID-19 on small business owners: Evidence from the first three months after widespread social-distancing restrictions.

Fairlie, R. (2020), "The impact of COVID-19 on small business owners: Evidence from the first three months after widespread social-distancing restrictions", Journal of Economics \& Management Strategy, Vol. 29/4, http://dx.doi.org/10.1111/jems.12400.

Fairlie, R. (2012), Immigrant Entrepreneurs and Small Business Owners, and their Access to Financial Capital, SBA Office of Advocacy, Washington DC.

Fregetto, E. (2004), “Immigrant and Ethnic Entrepreneurship", in Entrepreneurship, Routledge, http://dx.doi.org/10.4324/9780203356821.ch18.

Georgiev, O. (2020), Western Europe Is Losing Its Immigrants.

Gobierno de España (2020), Anteproyecto de Ley de fomento del ecosistema de las empresas emergentes, https://www.lamoncloa.gob.es/consejodeministros/Paginas/enlaces/060721enlace-startups.aspx (accessed on 28 September 2021).

Gold, S. and I. Light (2000), "Ethnic economies and social policy", in Leitz, L. (ed.), Research in social movements, conflicts and change, Emerald Group Publishing Limited, http://dx.doi.org/10.1016/S0163-786X(00)80039-7.

Green, D., H. Liu and Y. Ostrovsky (2016), "Business Ownership and Employment in Immigrantowned Firms in Canada", Analytical Studies Branch Research Papers Series, No. 375, Statistics Canada.

Green, D. et al. (2016), Immigration, Business Ownership and Employment in Canada, Statistics Canada, Ottawa, https://www150.statcan.gc.ca/n1/pub/11f0019m/11f0019m2016375-eng.htm (accessed on 26 September 2021).

Gurău, C., L. Dana and I. Light (2020), "Overcoming the Liability of Foreignness: A Typology and Model of Immigrant Entrepreneurs", European Management Review, Vol. 17/3, http://dx.doi.org/10.1111/emre.12392.

Haandrikman, K. and N. Webster (2020), Migrant, woman and business owner: A heterogeneous group with diverse needs, Stockholm University, Department of Human Geography, https://www.researchgate.net/publication/346601337 Migrant woman and business owner A heterogeneous group with diverse needs (accessed on 7 October 2021).

Habiyakare, E. et al. (2009), Characterising African immigrant entrepreneurship in Finland.

Hannonen, O. (2020), "In search of a digital nomad: defining the phenomenon", Information Technology \& Tourism, Vol. 22/3, pp. 335-353, http://dx.doi.org/10.1007/s40558-020-00177-z. 
HEC Montreal (2021), EntrePrism: L'inclusion par l'entrepreneuriat, https://entreprism.hec.cal (accessed on 7 April 2021).

Hjerm, M. (2004), "Immigrant Entrepreneurship in the Swedish Welfare State", Sociology, Vol. 38/4, pp. 739-756, http://dx.doi.org/10.1177/0038038504045862.

Hopp, C. and J. Martin (2017), "Does entrepreneurship pay for women and immigrants? A 30 year assessment of the socio-economic impact of entrepreneurial activity in Germany", Entrepreneurship \& Regional Development, Vol. 29/5-6, http://dx.doi.org/10.1080/08985626.2017.1299224.

Hou, F. and S. Wang (2017), Immigrants in self-employment, Statistics Canada, https://www150.statcan.gc.ca/n1/pub/75-001-x/2011003/article/11500-eng.htm (accessed on 28 September 2021).

Hunt, J. (2010), "Skilled immigrants' contribution to innovation and entrepreneurship in the United States", in Open for Business: Migrant Entrepreneurship in OECD Countries, OECD Publishing, Paris, https://dx.doi.org/10.1787/9789264095830-13-en.

Immigration Refugee and Citizenship Canada (2016), Evaluation of the Start-Up Visa (SUV) pilot, https://www.canada.ca/content/dam/ircc/migration/ircc/english/pdf/pub/e5-2015-suvexecsumm-eng.pdf (accessed on 28 September 2021).

Italian Ministry of Economic Development (2020), \#ISV Survey2019: Italia Startup Visa Report, https://www.mise.gov.it/images/stories/documenti/Rapporto ISV Survey ENG.PDF (accessed on 28 September 2021).

Kerr, W. and S. Kerr (2020), "Immigration Policy Levers for U.S. Innovation and Startups", Harvard Business School Working Paper, No. No. 20-105, Harvard.

Kloosterman, R. (2010), "Matching opportunities with resources: A framework for analysing (migrant) entrepreneurship from a mixed embeddedness perspective", Entrepreneurship \& Regional Development, Vol. 22/1, http://dx.doi.org/10.1080/08985620903220488.

Kloosterman, R. and J. Rath (2001), "Immigrant entrepreneurs in advanced economies: Mixed embeddedness further explored”, Journal of Ethnic and Migration Studies, Vol. 27/2, http://dx.doi.org/10.1080/13691830020041561.

Kloosterman, R., J. Van Der Leun and J. Rath (1999), "Mixed embeddedness:(in) formal [101] economic activities and immigrant businesses in the Netherlands", International journal of urban and regional research, Vol. 23/2, pp. 252-266.

Krol, R. (2021), "The Effects of Immigration on Entrepreneurship and Innovation", Mercatus Working Paper, George Mason University, https://www.mercatus.org/system/files/krol working paper what do we know about the impact of immigration on entrepreneurship innovation an d the labor market - v1.pdf (accessed on 28 October 2021).

Lange, T. (2016), Wezenlijk Nederlands Belang: De toelating tot Nederland van ondernemers van buiten de EU, Wolf Legal Publishers.

Lee, W. and S. Black (2017), "Small business development: immigrants' access to loan capital", Journal of Small Business \& Entrepreneurship, Vol. 29/3, pp. 193-209, http://dx.doi.org/10.1080/08276331.2017.1297106. 
Lewin, A. (2020), Today's students want to become startup founders, https://sifted.eu/articles/student-startup-founders-data/ (accessed on 27 October 2021).

Liu, Y. et al. (2020), “Entrepreneurs' transnational networks channelling exports: diasporas from Central \&amp; South America, Sub-Sahara Africa, Middle East \&amp; North Africa, Asia, and the European culture region", Journal of Ethnic and Migration Studies, Vol. 46/10, http://dx.doi.org/10.1080/1369183X.2018.1560002.

Lofstrom, M. and C. Wang (2019), "Immigrants and entrepreneurship", IZA World of Labor, http://dx.doi.org/10.15185/izawol.85.v2.

Magri, S. (2008), "The financing of small entrepreneurs in Italy", Annals of Finance, Vol. 5/3-4, pp. 397-419, http://dx.doi.org/10.1007/s10436-008-0109-3.

Mahé, C. (2021), "Return migration and self-employment: is there a 'jack-of-all-trades' effect?", Oxford Economic Papers, http://dx.doi.org/10.1093/oep/gpab013.

Mathies, C. and H. Karhunen (2021), "Do they stay or go? Analysis of international students in Finland", Globalisation, Societies and Education, Vol. 19/3, http://dx.doi.org/10.1080/14767724.2020.1816926.

McDougall, P. and B. Oviatt (2000), "INTERNATIONAL ENTREPRENEURSHIP: THE INTERSECTION OF TWO RESEARCH PATHS.", Academy of Management Journal, Vol. 43/5, http://dx.doi.org/10.2307/1556418.

MEnt Project (2021), About MEnt Project, https://mentproject.eu/\#about (accessed on 29 October 2021).

Metzger, G. (2016), "Migranten überdurchschnittlich gründungsaktiv - Arbeitsmarkt spielt eine große Rolle”, Fokus Volkswirtschaft, No. 115, KfW Research.

Migration Data Portal (2020), International students, https://www.migrationdataportal.org/themes/international-students (accessed on 26 September 2021).

Mitaritonna, C., G. Orefice and G. Peri (2017), "Immigrants and firms' outcomes: Evidence from France", European Economic Review, Vol. 96, pp. 62-82, http://dx.doi.org/10.1016/i.euroecorev.2017.05.001.

Nash, E., M. Jarrahi and W. Sutherland (2021), "Nomadic work and location independence: The role of space in shaping the work of digital nomads", Human Behavior and Emerging Technologies, Vol. 3/2, http://dx.doi.org/10.1002/hbe2.234.

Nazareno, J., M. Zhou and T. You (2019), "Global dynamics of immigrant entrepreneurship", International Journal of Entrepreneurial Behavior \& Research, Vol. 25/5, http://dx.doi.org/10.1108/IJEBR-03-2018-0141.

Neuman, E. (2021), "Performance and job creation among self-employed immigrants and natives in Sweden", Small Business Economics, Vol. 56/1, http://dx.doi.org/10.1007/s11187-01900223-z.

Neuman, E. (2016), "Ethnic concentration and economic outcomes of natives and secondgeneration immigrants", International Journal of Manpower, Vol. 37/1, http://dx.doi.org/10.1108/IJM-06-2014-0136. 
OECD (2021), International Migration Outlook 2021, OECD Publishing, Paris, https://dx.doi.org/10.1787/29f23e9d-en.

OECD (2020), International Migration Outlook 2020, OECD Publishing, Paris, https://dx.doi.org/10.1787/ec98f531-en.

OECD (2020), What is the impact of the COVID-19 pandemic on immigrants and their children?, http://www.oecd.org/coronavirus/policy-responses/what-is-the-impact-of-the-covid-19pandemic-on-immigrants-and-their-children-e7cbb7de/ (accessed on 6 April 2021).

OECD (2019), "Policy brief on refugee entrepreneurship", OECD SME and Entrepreneurship Papers, No. 14, OECD Publishing, Paris, https://dx.doi.org/10.1787/70571d6f-en.

OECD (2019), Recruiting Immigrant Workers: Canada 2019, Recruiting Immigrant Workers, OECD Publishing, Paris, https://dx.doi.org/10.1787/4abab00d-en.

OECD (2017), Entrepreneurship at a Glance 2017, OECD Publishing, Paris, https://dx.doi.org/10.1787/entrepreneur aag-2017-en.

OECD (2014), Is migration good for the economy?, OECD Publishing, Paris.

OECD (2011), International Migration Outlook 2011, OECD Publishing, Paris, https://dx.doi.org/10.1787/migr outlook-2011-en.

OECD/EU (2019), Policy brief on business incubators and accelerators that support inclusive entrepreneurship, OECD, Paris.

OECD/European Union (2018), Settling In 2018: Indicators of Immigrant Integration, OECD Publishing, Paris/European Union, Brussels, https://dx.doi.org/10.1787/9789264307216-en.

OECD/European Union (2014), The Missing Entrepreneurs 2014: Policies for Inclusive Entrepreneurship in Europe, OECD Publishing, Paris, https://dx.doi.org/10.1787/9789264213593-en.

OECD/The European Commission (2013), The Missing Entrepreneurs: Policies for Inclusive Entrepreneurship in Europe, OECD Publishing, Paris, https://dx.doi.org/10.1787/9789264188167-en.

Office for National Statistics (2018), Survey of Graduating International Students, UK, https://www.ons.gov.uk/peoplepopulationandcommunity/populationandmigration/international migration/datasets/surveyofgraduatinginternationalstudentsuk (accessed on 28 September 2021).

Ostrovsky, Y. and G. Picot (2020), Innovation in Immigrant-owned Firms in Canada, Statistics Canada, https://www150.statcan.gc.ca/n1/daily-quotidien/200609/dq200609e-eng.htm (accessed on 27 September 2021).

Ostrovsky, Y. and G. Picot (2018), Research Blog: Immigrant entrepreneurs in Canada, https://www.statcan.gc.ca/eng/blog/cs/immigrant-entrepreneurs (accessed on 26 September 2021).

Parker, S. (2009), The economics of self-employment and entrepreneurship, Cambridge University Press, Cambridge. 
Peroni, C., C. Riillo and F. Sarracino (2016), "Entrepreneurship and immigration: evidence from GEM Luxembourg", Small Business Economics, Vol. 46/4, http://dx.doi.org/10.1007/s11187016-9708-y.

Picot, G. and Y. Ostrovsky (2021), Immigrant and second-generation entrepreneurs in Canada: An intergenerational comparison of business ownership, Statistics Canada, Ottawa, https://www150.statcan.gc.ca/n1/pub/36-28-0001/2021009/article/00003-eng.htm (accessed on 28 September 2021).

Picot, G. and A. Rollin (2019), "Immigrant Entrepreneurs as Job Creators: The Case of Canadian Private Incorporated Companies", Analytical Studies Branch Research Paper Series, No. 423, Statisitics Canada, Ottawa, https://www150.statcan.gc.ca/n1/en/pub/11f0019m/11f0019m2019011-eng.pdf?st=g5OILrhR.

Price, G. (2020), "Introduction to the Special Issue: COVID-19 and Its Impact on Racial/Ethnic Groups", Journal of Economics, Race, and Policy, Vol. 3, pp. 221-222, https://link.springer.com/article/10.1007/s41996-020-00074-x (accessed on 6 April 2021).

Rath, J. (2011), Promoting ethnic entrepreneurship in European cities, Publications Office of the European Union, Luxembourg, https://www.eurofound.europa.eu/sites/default/files/ef publication/field ef document/ef1138e n.pdf.

Riddle, L., G. Hrivnak and T. Nielsen (2010), "Transnational diaspora entrepreneurship in emerging markets: Bridging institutional divides", Journal of International Management, Vol. 16/4, http://dx.doi.org/10.1016/j.intman.2010.09.009.

Saxenian, A. and C. Sabel (2009), "Roepke Lecture in Economic Geography Venture Capital in the "Periphery": The New Argonauts, Global Search, and Local Institution Building", Economic Geography, Vol. 84/4, http://dx.doi.org/10.1111/j.1944-8287.2008.00001.x.

Scandura, A. and D. Bolzani (2020), "The role of collaboration networks for innovation in immigrant-owned new technology-based firms", LEI\&BRICK Working Paper, https://www.est.unito.it/do/home.pl/View?doc=WP Lei Brick.html (accessed on 7 October 2021).

Scannell Bryan, M. et al. (2021), "Coronavirus disease 2019 (COVID-19) mortality and neighborhood characteristics in Chicago", Annals of Epidemiology, Vol. 56, http://dx.doi.org/10.1016/j.annepidem.2020.10.011.

Schüller, S. (2015), "Parental ethnic identity and educational attainment of second-generation immigrants", Journal of Population Economics, Vol. 28/4, pp. 965-1004, http://dx.doi.org/10.1007/s00148-015-0559-7.

Sieger, P. et al. (2018), Global Student Entrepreneurship 2018: Insights From 54 Countries, Global University Entrepreneurial Spirit Student's Survey, https://www.guesssurvey.org/resources/PDF InterReports/GUESSS Global 2018.pdf (accessed on 20 July 2021).

Slovak Business Agency (2019), Analysis of Conditions for Doing Business and Employing Foreigners in Slovakia, http://www.sbagency.sk/sites/default/files/analyza podmienok podnikania a zamestnavania cudzincov na slovensku.pdf (accessed on 27 September 2021). 
Solano, G., A. Wolffhardt and A. Xhani (2019), "Measures to support early-stage migrant entrepreneurs", in MEGA Handbook.

Spencer-Oatey, H. and P. Franklin (2009), Intercultural interaction: A multidisciplinary approach to intercultural communication, Springer.

Thieme, S. (2008), "Sustaining Livelihoods in Multi-local Settings: Possible Theoretical Linkages Between Transnational Migration and Livelihood Studies", Mobilities, Vol. 3/1, http://dx.doi.org/10.1080/17450100701797315.

Tvaronavičienè, M. (ed.) (2018), "Barriers and challenges experienced by migrant African [60] women entrepreneurs in North Queensland, Australia", Entrepreneurship and Sustainability Issues, Vol. 5/4, pp. 1054-1068, http://dx.doi.org/10.9770/jesi.2018.5.4(25).

U.S. Census Bureau (2019), American Community Survey 2011-2019, https://www.census.gov/programs-surveys/acs (accessed on 27 October 2021).

United Nations (2021), Migration, https://www.un.org/en/sections/issuesdepth/migration/index.html\#: :text=The\%20UN\%20Migration\%20Agency\%20(IOM,the\%20ca uses $\% 20$ for $\% 20$ the $\% 20$ movement.

United Nations (2020), International Migration 2019, United Nations, New York.

Vance, C. et al. (2017), "A field exploration of the "expat-preneur" phenomenon", Global Business and Organizational Excellence, Vol. 36/6, http://dx.doi.org/10.1002/joe.21812.

Vandor, P. and N. Franke (2018), "Immigrant Entrepreneurship: Drivers, Economic Effects, and Policy Implications", in Clemens, J. (ed.), Demographics and Entrepreneurship: Mitigating the Effects of an Aging Population, Fraser Institute.

Vlase, I. and A. Croitoru (2019), "Nesting self-employment in education, work and family trajectories of Romanian migrant returnees", Current Sociology, Vol. 67/5, pp. 778-797, http://dx.doi.org/10.1177/0011392119842205.

Vlase, I. and A. Croitoru (2019), "Nesting self-employment in education, work and family trajectories of Romanian migrant returnees", Current Sociology, Vol. 67/5, http://dx.doi.org/10.1177/0011392119842205.

Volery, T. (2002), "An Entrepreneur Commercialises Conservation: The Case of Earth Sanctuaries Ltd,", Greener Management International, Vol. 38, pp. 109-116.

Wahba, J. (2015), "Selection, selection, selection: the impact of return migration", Journal of Population Economics, Vol. 28/3, pp. 535-563, http://dx.doi.org/10.1007/s00148-015-0541-4.

Wahba, J. and Y. Zenou (2012), "Out of sight, out of mind: Migration, entrepreneurship and social capital”, Regional Science and Urban Economics, Vol. 42/5, pp. 890-903, http://dx.doi.org/10.1016/j.regsciurbeco.2012.04.007.

Waldinger, R., H. Aldrich and R. Ward (1990), Immigrant Entrepreneurs: Immigrant and Ethnic Business in Western Industrial Societies, Sage, Beverly Hills.

Wang, Z. (2021), "The incidence of overeducation among international students upon graduation in Ireland: the effects of social capital and job searching methods", Irish Educational Studies, Vol. 40/1, http://dx.doi.org/10.1080/03323315.2020.1779109. 
Wassink, J. and J. Hagan (2018), "A Dynamic Model of Self-Employment and Socioeconomic Mobility Among Return Migrants: The Case of Urban Mexico", Social Forces, Vol. 96/3, pp. 1069-1096, http://dx.doi.org/10.1093/sf/sox095.

Wassink, J. and J. Hagan (2018), "A Dynamic Model of Self-Employment and Socioeconomic Mobility Among Return Migrants: The Case of Urban Mexico", Social Forces, Vol. 96/3, http://dx.doi.org/10.1093/sf/sox095.

Zhan, J., R. Bolwijn and F. Farinelli (2018), Policy guide on entrepreneurship for migrants and refugees, United Nations Conference on Trade and Development, https://unctad.org/system/files/official-document/diae2018d2 en.pdf (accessed on 7 October 2021).

Zhou, Y. and J. Hsu (2011), "Divergent engagements: roles and strategies of Taiwanese and mainland Chinese returnee entrepreneurs in the IT industry", Global Networks, Vol. 11/3, http://dx.doi.org/10.1111/j.1471-0374.2010.00302.x. 

Part III Country profiles: Key inclusive entrepreneurship trends, issues and recent policy actions 


\section{Reader's guide for the country profiles}

Inclusive entrepreneurship trends and policies vary greatly across countries. This section presents a short overview of inclusive entrepreneurship trends, issues and recent policy developments in each of the 27 European Union Member States. Each profile includes a set of key indicators that benchmark self-employment and entrepreneurship activity rates and barriers in each country relative to the European Union average for men, women, youth and seniors. 


\section{Overview}

This section of the book provides a short overview of inclusive entrepreneurship trends and recent policy actions in each European Union Member State. Each Country Profile presents recent trends for key inclusive entrepreneurship indicators, focusing on self-employment and entrepreneurship activity rates, motivations for business creation and growth aspirations for women, immigrant, youth and senior entrepreneurs. In addition, the Country Profiles highlight recent policy developments related to inclusive entrepreneurship, notably actions to mitigate the impact of the COVID-19 pandemic on women, immigrant, senior and youth entrepreneurs.

\section{Description of indicators}

The Country Profiles include a common set of country-specific data that benchmark key inclusive entrepreneurship indicators against the European Union average. Data are presented for men, women, youth, seniors and the overall population. These data help to show the scale of the challenge and its recent evolution. Each profile contains six figures:

- Panel a: Conditions for entrepreneurship, 2020. This figure presents four indicators to provide an overview of the conditions for business creation in each country:

- Administrative burden is defined as the simple average of the scores for four component indicators for starting a business - procedure (number), time (days), cost (\% of income per capita) and paid-in minimum capital requirement (current as of 1 May 2019) (World Bank, 2020[1]).

- Entrepreneurship skills is defined as the percentage of the adult population (18-64 years old) - excluding individuals involved in any stage of entrepreneurial activity - who believe that they have the required skills and knowledge to start a business. This indicator covers the period 2016 to 2020 (Global Entrepreneurship Monitor (GEM), 2021 [2]).

- SME lending is defined as the share of SME loans to total outstanding business loans in 2020 (OECD, forthcoming $\left.{ }_{[3]}\right]$.

- Entrepreneurship expectation is defined as a percentage of the adult population (18-64 years old) - excluding individuals involved in any stage of entrepreneurial activity - who intend to start a business within the next three years. This indicator covers the period 2016 to 2020 (Global Entrepreneurship Monitor (GEM), 2021[2]).

- Panel b: Total Early-stage Entrepreneurship Activity (TEA) rate, 2016-20. This presents the proportion of the adult population (18-64 years old) that is actively involved in starting a business or who is the owner-operator of a business that is less than 42 months old. Data are presented for the overall population, men, women, youth (18-30 years old) and seniors (50-64 years old) for the period 2016 to 2020 (Global Entrepreneurship Monitor (GEM), 2021[2]).

- Panel c. Proportion of TEA that is necessity-based entrepreneurship, 2016-20. This presents the proportion of early-stage entrepreneurs (18-64 years old) who launched their business due to a lack of other opportunities in the labour market. Data are presented for the overall population, men, women, youth (18-30 years old) and seniors (50-64 years old) for the period 2016 to 2020 (Global Entrepreneurship Monitor (GEM), 2021[2]).

- Panel d: Proportion of early-stage entrepreneurs who expect to create more than 19 jobs in five years, 2016-20. This presents the proportion of early-stage entrepreneurs (18-64 years old) who anticipate the creation of at least 19 additional new jobs over the next five years. Data are presented for the overall population, men, women, youth (18-30 years old) and seniors (50-64 years old) for the period 2016 to 2020 (Global Entrepreneurship Monitor (GEM), 2021 [2]). 
- Panel e: Self-employment rate. This presents the proportion of those aged 15-64 years old in employment who are self-employed. Data are presented for the overall population, women, immigrants, youth (20-29 years old) and seniors (50-64 years old) for the period 2011 to 2020 (Eurostat, 2021 [4]).

- Panel f: Proportion of self-employed people that have employees. This presents the share of the self-employed (15-64 years old) that employ at least one other person. Data are presented for the overall population, women, immigrants, youth (20-29 years old) and seniors (50-64 years old) for the period 2011 to 2020 (Eurostat, 2021 [4]).

In Panel a, the data for the EU average refers to the median and excludes Belgium, Czech Republic, Denmark, Lithuania, Malta and Romania for the indicators entrepreneurship skills and entrepreneurship expectation. Furthermore, the data for SME lending excludes the following countries from the EU median: Austria, Bulgaria, Croatia, Cyprus, Denmark, Finland, Germany, Luxembourg, Malta, Romania and Sweden.

In Panels b-d, the data for the EU average refers to a population-weighted average and excludes Belgium, Czech Republic, Denmark, Lithuania, Malta and Romania since they did not participate in the GEM survey between 2016 and 2020. Furthermore, the following countries did not participate in the survey in every year over this period (years of participation are indicated): Austria $(2016,2018,2020)$, Bulgaria (2016-18), Estonia (2016-17), Finland (2016), France (2016-18), Hungary (2016), Ireland (2016-19), Latvia (2016-17, 2019-20) and Portugal (2016, 2019).

This set of Country Profiles draw on country-specific reports that are produced as part of the OECD and European Commission on inclusive entrepreneurship policies and programmes (OECD, 2020[5]). These reports are available at: https://www.oecd.org/cfe/smes/inclusive-entrepreneurshippolicies-countryassessment-notes.htm.

\section{References}

Eurostat (2021), Labour Force Survey, https://ec.europa.eu/eurostat/web/lfs (accessed on 6 May 2021).

Global Entrepreneurship Monitor (GEM) (2021), Special tabulations for the OECD of the Global Entrepreneurship Monitor (GEM) adult population survey for the years 2016 to 2020.

OECD (2020), Inclusive Entrepreneurship Policies: Country Assessment Notes, https://www.oecd.org/cfe/smes/inclusive-entrepreneurship-policies-country-assessmentnotes.htm (accessed on 6 June 2021).

OECD (forthcoming), Financing SMEs and Entrepreneurs 2022: An OECD Scoreboard, OECD Publishing, Paris.

World Bank (2020), Starting a Business Score, World Bank Doing Business 2020, https://www.doingbusiness.org/en/data (accessed on 21 July 2021). 


\section{Austria}

This country profile benchmarks recent trends in self-employment and entrepreneurship for women, youth, seniors and immigrants in Austria relative to the average for the European Union. It also describes recent policy actions and current issues related to inclusive entrepreneurship.

\section{Conditions for inclusive entrepreneurship}

The overall entrepreneurship conditions are similar to most of the European Union (EU) Member States. Most entrepreneurs cite access to finance as a major barrier to business creation, but other barriers include limited availability for broadband internet, the lack of a skilled-work force in rural areas and a "fear of failure", notably among women. A wide range of entrepreneurship policies and programmes are in place to support new and actual entrepreneurs. The majority of which focus on entrepreneurship skills and improving access to start-up finance; however, few are tailored to the needs of specific population groups.

\section{Recent trends}

Early-stage entrepreneurship rates for women (7\%), youth (12\%) and seniors (5\%) were all above the EU average (5\% for women, $7 \%$ for youth and $4 \%$ for seniors) for the period $2016-20$. Few started their business due to a lack of alternative options in the labour market but each of these groups continues to be under-represented in entrepreneurship. Eliminating all of the gaps in entrepreneurship activity rates across population groups (i.e. applying the early-stage entrepreneurship rate of men who are 30-49 years old to the whole population) would result in an additional 270000 entrepreneurs. About $70 \%$ of these "missing" entrepreneurs are female, $60 \%$ are over 50 years old and $45 \%$ are immigrants.

Overall, self-employment has been stable over the past decade but the share of women (8\%), youth (3\%), seniors $(16 \%)$ and immigrants $(8 \%)$ who are self-employed was below the EU average for each group ( $10 \%$ for women, $7 \%$ for youth, $17 \%$ for seniors and $12 \%$ for immigrants) in 2020 . However, the share of self-employed people who employ others has increased slightly over the past decade. Growth was strongest among self-employed immigrants, despite a decline in 2019-20.

\section{Hot policy issue}

In response to the COVID-19 crisis, several policy measures were introduced to support the self-employed, such as a June 2020 stimulus package as well as a hardship fund (Härtefallfonds) for micro-entrepreneurs and freelancers. The stimulus package included additional measures for entrepreneurs such as a credit moratorium, while the hardship fund offered grants of EUR 1000 of immediate aid (up to EUR 15000 in all over six months). This measure was prolonged with the last extension until 15 June 2021, granting EUR 2600 per month per applicant (up to EUR 39000 for the period) with an additional bonus of EUR 100 per month and allowing transfers to non-Austrian bank accounts. As of March 2021, the average monthly payment was EUR 1200 with a total of EUR 1.22 billion in grants being provided. 


\section{Inclusive entrepreneurship indicators}

Figure 10.1. Entrepreneurship and self-employment data for Austria

a. Conditions for entrepreneurship, 2020

Bottom 5 countries $\square$ Median $\square$ Top 5 countries $\bullet$ Austria

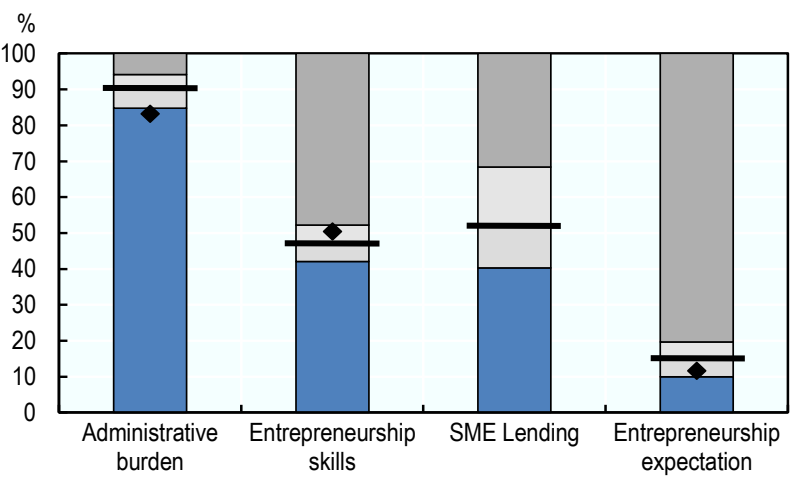

c. Share of TEA that is necessity-based, 2016-20

Austria

$\diamond \mathrm{EU}$

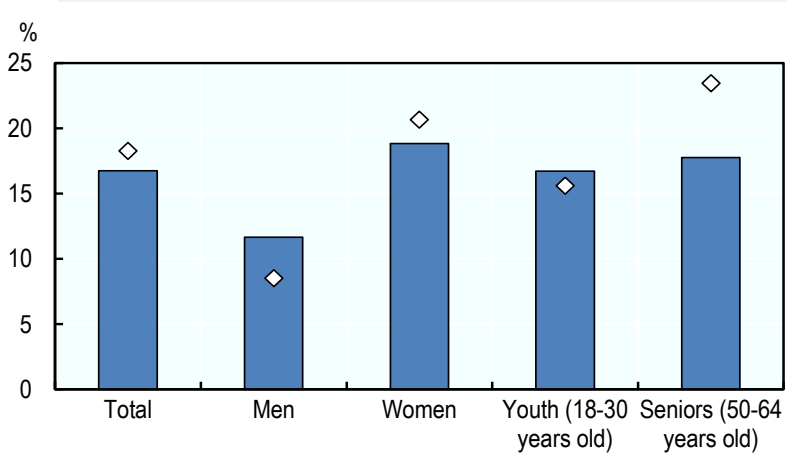

e. Self-employment rate

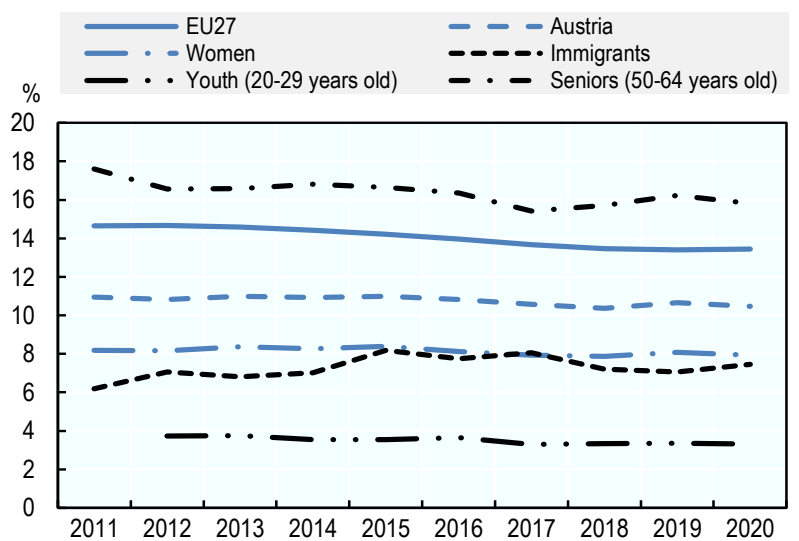

b. TEA rate, $2016-20$ $\diamond \mathrm{EU}$

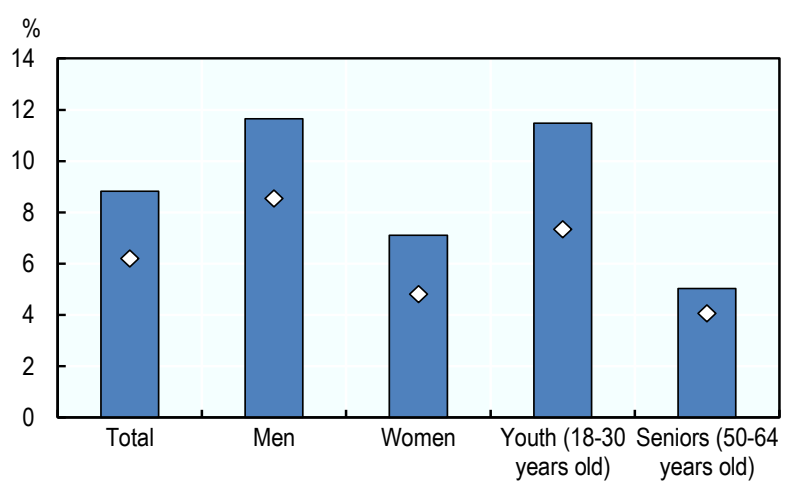

d. Share of TEA that expects to create at least 19 jobs over the next 5 years, 2016-20

$\square$ Austria $\diamond E U$

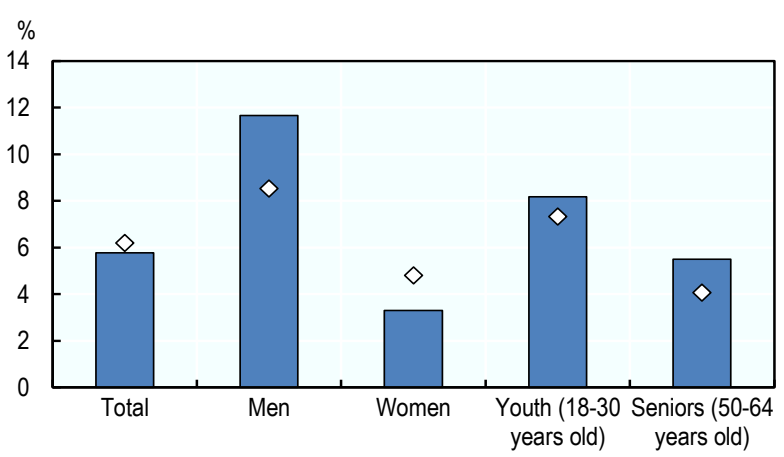

f. Share of self-employed with employees

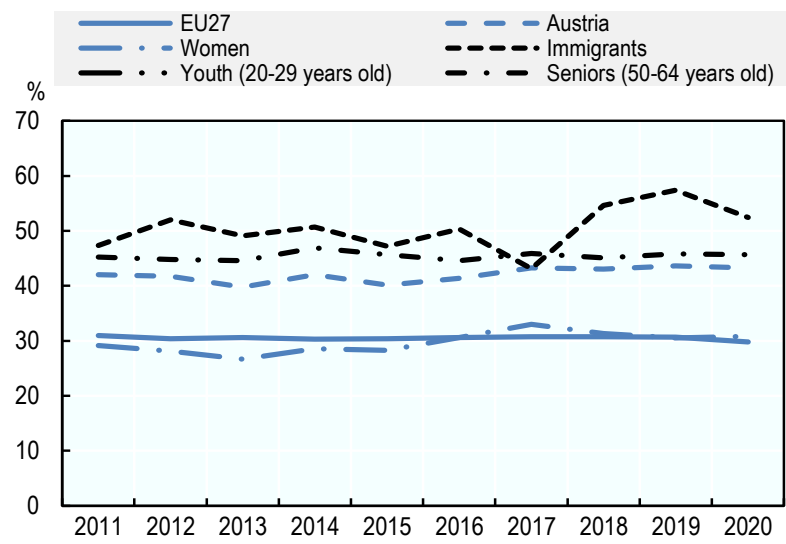

Note: The EU average in panels b-d excludes Belgium, Czech Republic, Denmark, Lithuania, Malta and Romania. Please see Chapter 9 for notes on the figures.

Source: Panel a: (World Bank, 2020[1]; Global Entrepreneurship Monitor (GEM), 2021 [2]; OECD, forthcoming[3]); Panels b-d: (Global Entrepreneurship Monitor (GEM), 2021[2]]; Panels e-f: (Eurostat, 2021[4]]). Please see Chapter 9 for the full citations. 


\section{Belgium}

This country profile presents self-employment and entrepreneurship data for women, youth, seniors and immigrants in Belgium relative to the average for the European Union. It also highlights recent developments in inclusive entrepreneurship policy, including the COVID-19 response.

\section{Conditions for inclusive entrepreneurship}

The Belgian context for entrepreneurship has strengths, but some areas could be improved. For example, the regulatory burden on new start-ups is heavier than the EU median. Entrepreneurship policies and programmes are designed and implemented by the federal government, regions and language Communities. This makes for a rich but fragmented support system. However, business start-up support is widely available across the three regions: Brussels, Flanders and Wallonia. This includes general entrepreneurship schemes, as well as a wide range of tailored schemes for different population groups. Youth entrepreneurship support has been prioritised across the three regions in recent years, but support for immigrant and women's entrepreneurship has also been strengthened.

\section{Recent trends}

The self-employment rate remained relatively stable over the past decade at about $13 \%$, nearly equalling the EU average in 2020 (14\%). However, the shares of women and youth who were self-employed increased since 2011. The share of women increased by 1 percentage point (p.p.), while the share of youth (20-29 years old) increased by nearly 3 p.p. over the last decade. The share of self-employed people with employees decreased slightly in the same period, notably among self-employed immigrants and seniors.

\section{Hot policy issue}

Regional and federal governments implemented COVID-19 relief measures for the self-employed. This included a temporary extension of Federal unemployment benefits and the "Corona Bridging Rights", which offered financial subsidies to impacted full and part-time self-employed workers. These subsidies ranged from EUR 1292 (for those without family responsibilities) to EUR 1614 (for those with family responsibilities) and were extended until March 2021. Further, the Brussels-Capital Region provided EUR 2000 to small companies with significant drops in revenues and EUR 4000 to those forced to temporarily close. The Flemish regional government provided EUR 3000 to full-time self-employed workers (EUR 1500 for self-employed as a secondary occupation) with substantial turnover loss and EUR 4000 to firms forced to temporarily close. This programme was extended in January 2021 for companies facing a turnover loss of at least $60 \%$. Other supports for the self-employed included temporary access to the Flemish Support Premium (Vlaamse Ondersteuningspremium, VOP). The Wallonia Region launched a support fund of EUR 350 million, of which EUR 223 million was designated for lump sum compensation to impacted businesses and self-employed workers experiencing cash flow difficulties. 


\section{Inclusive entrepreneurship indicators}

Figure 11.1. Entrepreneurship and self-employment data for Belgium

a. Conditions for entrepreneurship, 2020

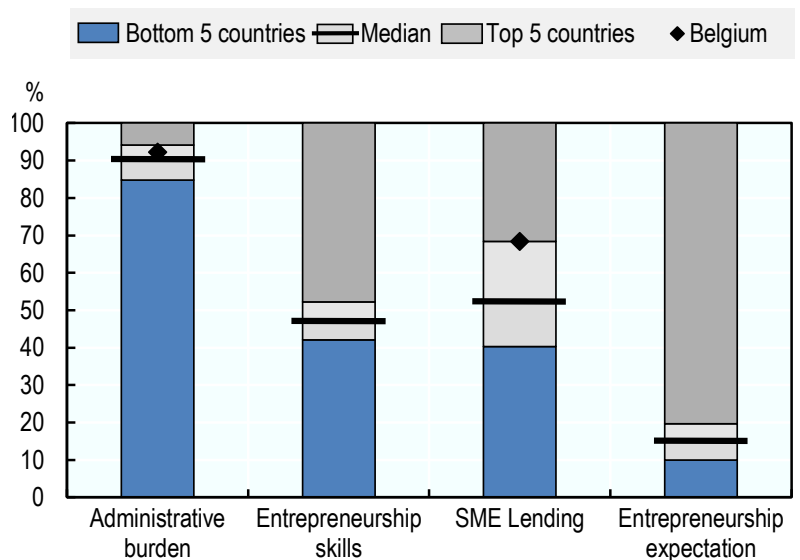

b. Self-employment rate

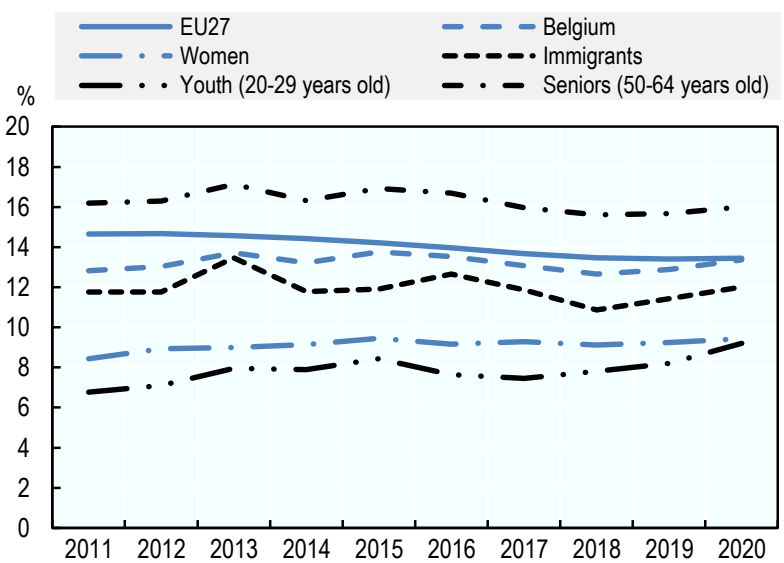

c. Share of self-employed with employees

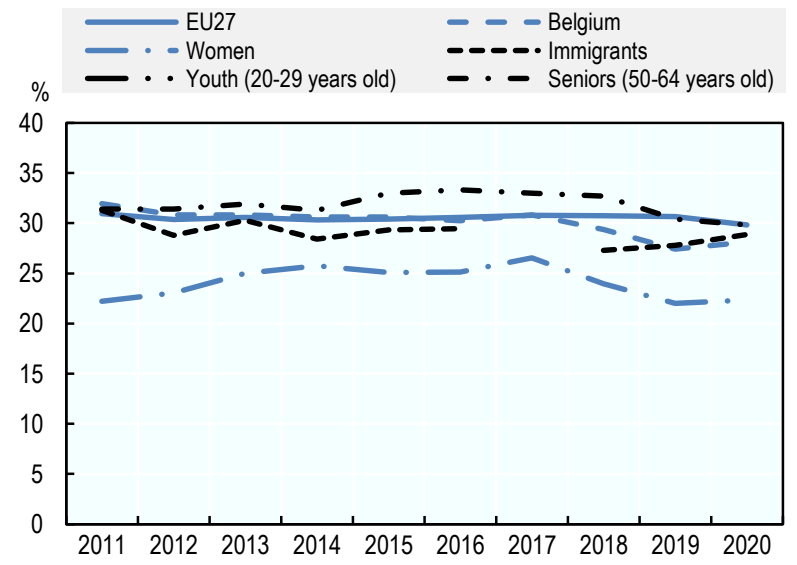

Note: Please see Chapter 9 for notes on the figures.

Source: Panel a: (World Bank, 2020[1]; Global Entrepreneurship Monitor (GEM), 2021 [2]; OECD, forthcoming[3]); Panels b-c: (Eurostat, 2021 [4]). Please see Chapter 9 for the full citations. 


\section{Bulgaria}

This country profile highlights recent policy actions related to supporting women, youth, seniors and immigrants in entrepreneurship. It also benchmarks recent self-employment and inclusive entrepreneurship indicators for Bulgaria against the average for the European Union.

\section{Conditions for inclusive entrepreneurship}

Overall entrepreneurship conditions remain challenging. New start-ups face above average levels of administrative burden due to lengthy processes and access to finance is challenging for entrepreneurs. While entrepreneurship support mainly consists of general financing and training schemes, a small number of tailored entrepreneurship support schemes are in place. European Structural and Investment Funds remain a critical support for policies and programmes in this area. There is a fairly comprehensive support system for young entrepreneurs. Tailored training and mentoring are also available for women entrepreneurs; however, the Strategy for Promoting Women Entrepreneurship is still under development.

\section{Recent trends}

The early-stage entrepreneurship rate was slightly below the EU average for the 2016-20. This gap was greatest among youth (5\% in Bulgaria vs. $7 \%$ in the EU). Moreover, a high proportion of these early-stage entrepreneurship activities were driven by a lack of other opportunities in the labour market, notably among seniors (36\%) and women (33\%). Eliminating all of the gaps in entrepreneurship activity rates across population groups (i.e. applying the early-stage entrepreneurship rate of men who are 30-49 years old to the whole population) would result in an additional 106000 entrepreneurs. About $60 \%$ of these "missing" entrepreneurs are female, nearly $60 \%$ are over 50 years old and another $15 \%$ are youth (20-29 years old).

Self-employment levels were below the EU average over the past decade. Women ( $7 \%)$ and seniors (12\%) were less likely to be self-employed than the respective EU average (10\% for women and $17 \%$ for seniors). However, the self-employed were more likely to employ others (35\% vs. $30 \%$ ), including a higher proportion of self-employed women relative to the EU average (30\% vs. $24 \%)$.

\section{Hot policy issue}

Nearly $80 \%$ of companies reported direct or indirect losses due to the COVID-19 crisis so several financial measures were implemented to support the self-employed and micro businesses. For example, the "60/40" programme provided subsidies ranging from BGN 3000 to BGN 10000 (EUR 1530 to EUR 5 110) to businesses experiencing turnover loss of at least $20 \%$ from the previous year. Due to high demand, the fund was increased by BGN 20 million (EUR 10.2 million). Freelance and independent artists could receive financial support of up to BGN 1000 per month (EUR 510). A range of other measures for SMEs was made available, including a special agricultural programme which provided BGN 70 million (EUR 35 million) in funding to around 30000 farmers from August to November 2020. 


\section{Inclusive entrepreneurship indicators}

Figure 12.1. Entrepreneurship and self-employment data for Bulgaria

a. Conditions for entrepreneurship, 2020

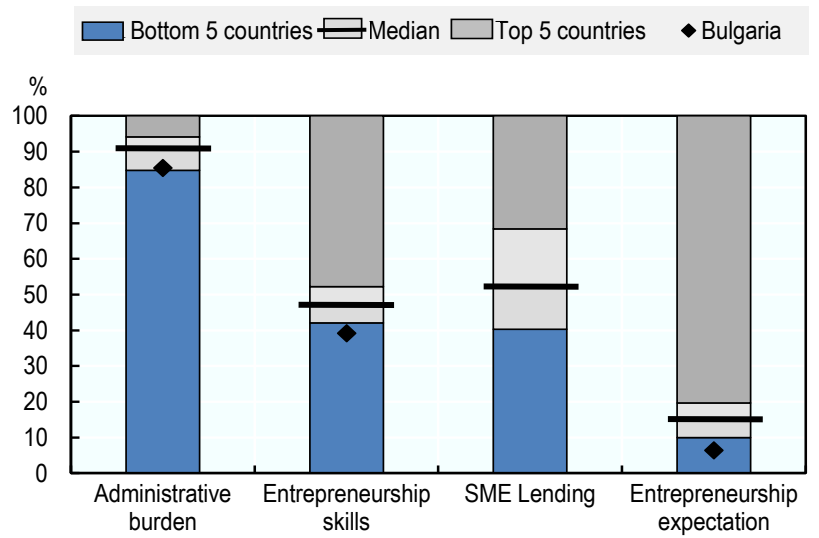

c. Share of TEA that is necessity-based, $2016-20$

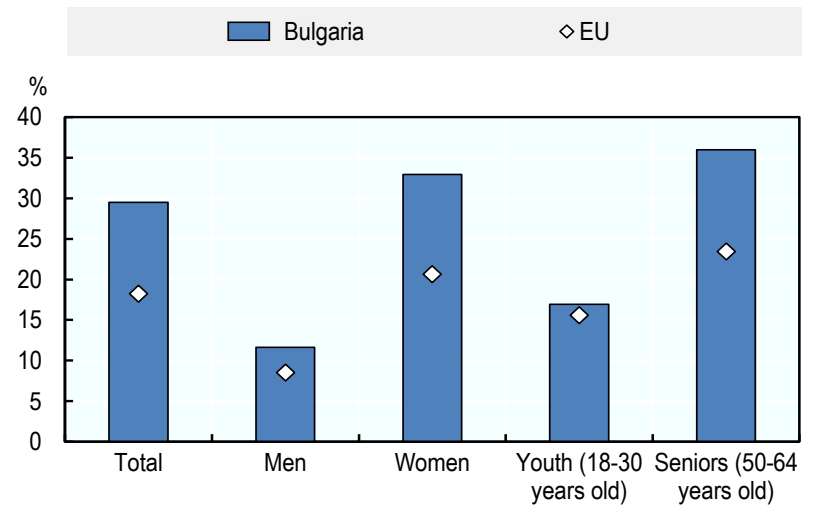

e. Self-employment rate

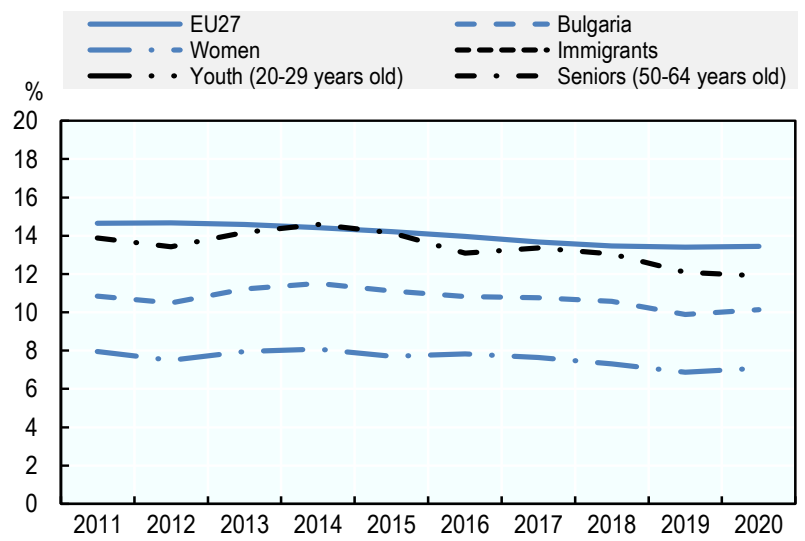

b. TEA rate, $2016-20$

$\square$ Bulgaria $\diamond \mathrm{EU}$

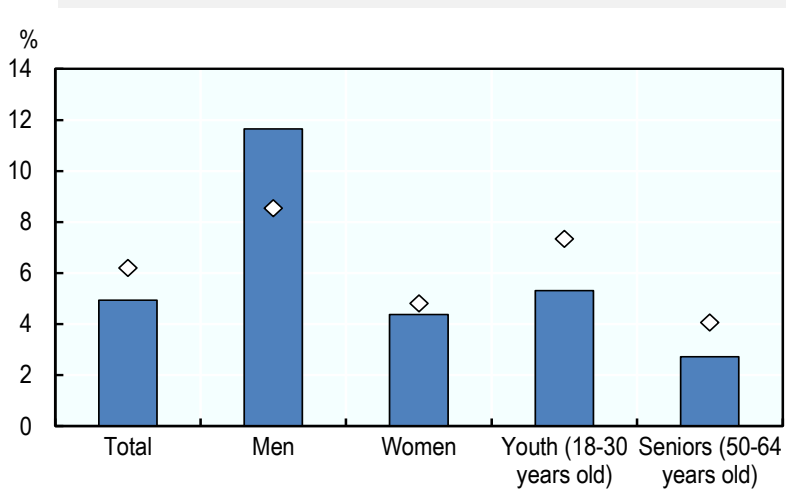

d. Share of TEA that expects to create at least 19 jobs over the next 5 years, 2016-20

$\square$ Bulgaria $\diamond E U$

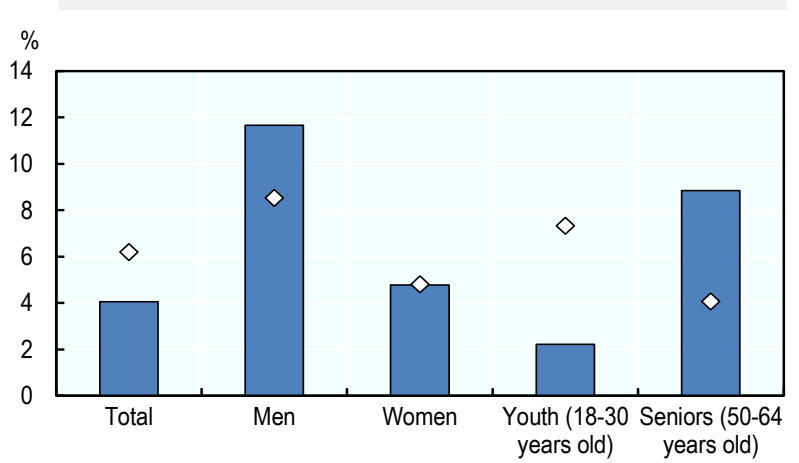

f. Share of self-employed with employees

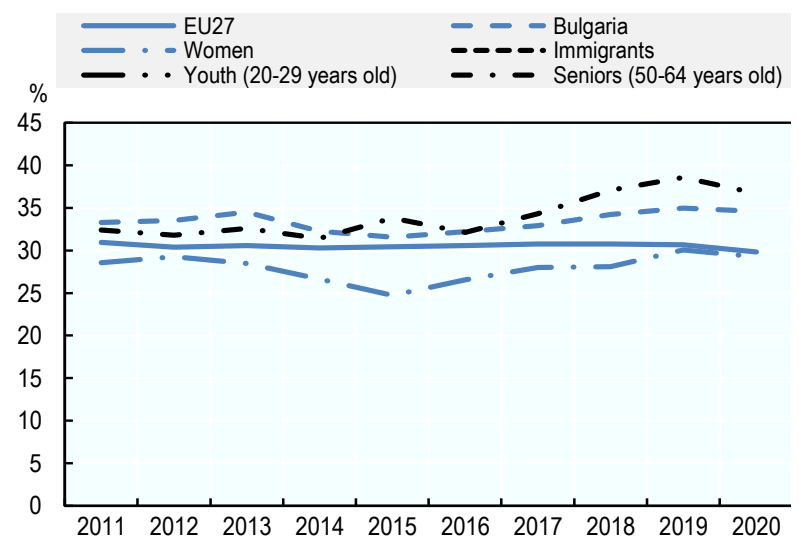

Note: The EU average in panels b-d excludes Belgium, Czech Republic, Denmark, Lithuania, Malta and Romania. Please see Chapter 9 for notes on the figures.

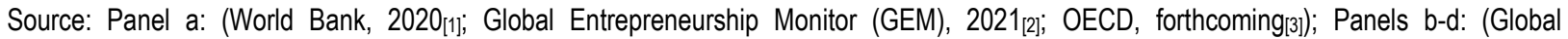
Entrepreneurship Monitor (GEM), 2021 [2]]); Panels e-f: (Eurostat, 2021 [4]]). Please see Chapter 9 for the full citations. 


\section{Croatia}

This country profile describes current inclusive entrepreneurship policy issues and recent developments in Croatia. It also benchmarks key self-employment and entrepreneurship indicators for women, youth, seniors and immigrants against the average for the European Union.

\section{Conditions for inclusive entrepreneurship}

The general framework conditions for entrepreneurship have improved over the past decade; however, some areas remain challenging, such as the regulatory environment and levels of administrative burden. Entrepreneurship support remains relatively high on the political agenda with several strategies calling for tailored support for women, youth, seniors, immigrants and the unemployed in the labour market, including through entrepreneurship. While not all actions outlined in these strategies have been implemented, tailored entrepreneurship support for women, youth and the unemployed is in place, particularly for developing entrepreneurship skills and accessing small grants and loans. Entrepreneurship support for the unemployed is also well-developed and has increased substantially in recent years.

\section{Recent trends}

The early-stage entrepreneurship rate was above the EU average between 2016 and 2020, notably among youth ( $14 \%$ vs. $7 \%)$ and women ( $8 \%$ vs. $5 \%$ ). Nearly one-third of activities were launched out of necessity compared to $18 \%$ across the EU - women ( $35 \%$ vs. $21 \%)$, youth ( $23 \%$ vs. $16 \%)$ and seniors ( $50 \%$ vs. $24 \%$ ) all had higher shares. However, each of these groups remain under-represented in entrepreneurship. Eliminating these gaps (i.e. applying the early-stage entrepreneurship rate of men who are 30-49 years old to the whole population) would result in an additional 155000 entrepreneurs. About $70 \%$ of these "missing" entrepreneurs are female, nearly $65 \%$ are over 50 years old and $20 \%$ are immigrants.

The self-employment rate remained around $11 \%$ over the last decade - about 3 percentage points lower than the EU average in 2020 . However, the self-employed were more likely to have employees compared to the EU on average ( $47 \%$ vs. $30 \%)$ in 2020 - notably women ( $41 \%$ vs. $24 \%$ ) and seniors ( $44 \%$ vs. $33 \%)$.

\section{Hot policy issue}

Several actions for entrepreneurs and SMEs were introduced in response to the COVID-19 crisis to preserve their financial liquidity, including a three-month moratorium on liabilities, loans, payroll subsidies and more. These measures have been strengthened over the past 18 months. Moreover, the Ministry of Culture provided payments for independent artists ranging from HRK 1625 (EUR 217) to HRK 3250 (EUR 433) from 15 March 2020 to 15 June 2020 before increasing the sum in October 2020 to HRK 4000 (EUR 533.33) per month for any person working independently in the cultural and creative sector. The local government of Zagreb provided an additional lump sum payment of HRK 5000 (EUR 667) in December 2020 to support young artists. 


\section{Inclusive entrepreneurship indicators}

Figure 13.1. Entrepreneurship and self-employment data for Croatia

a. Conditions for entrepreneurship, 2020

Bottom 5 countries $\Longrightarrow$ Median $\square$ Top 5 countries

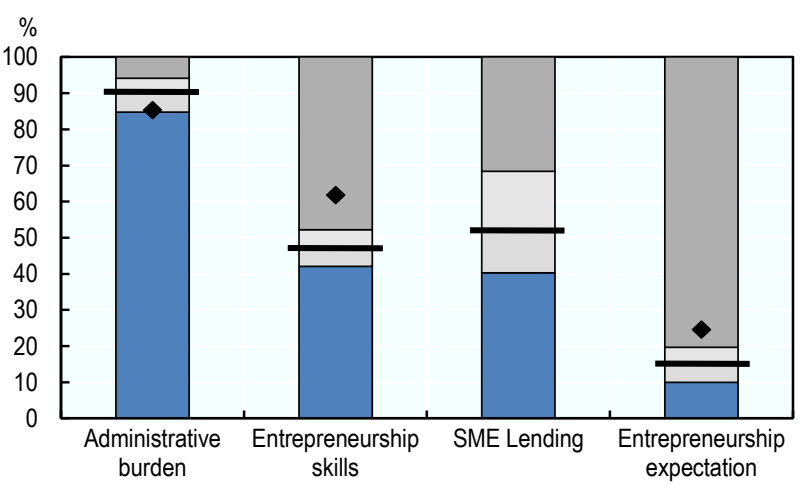

c. Share of TEA that is necessity-based, 2016-20

$\square$ Croatia

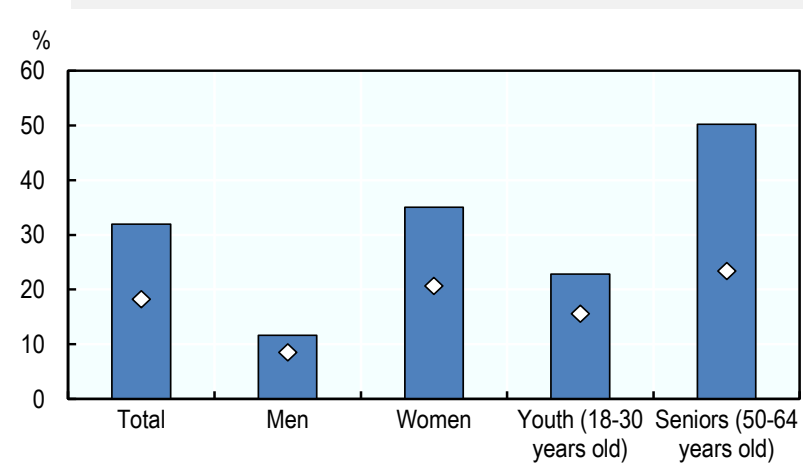

e. Self-employment rate

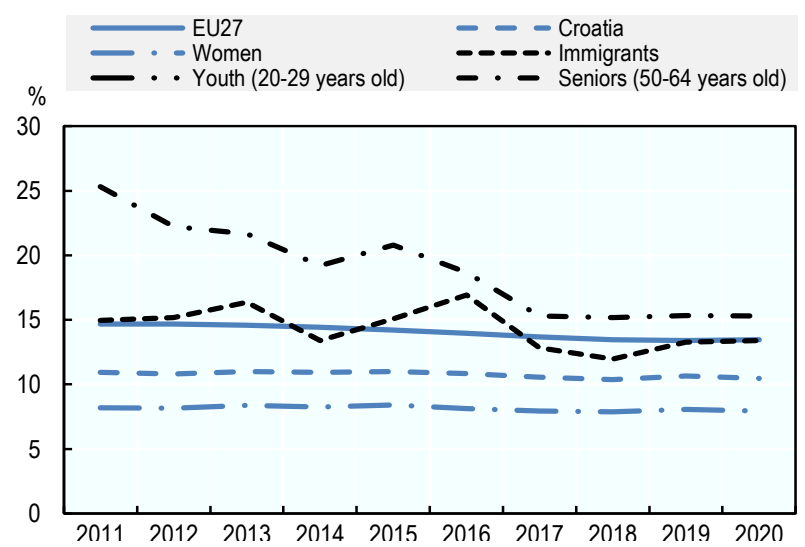

b. TEA rate, $2016-20$

$\square$ Croatia $\diamond E U$

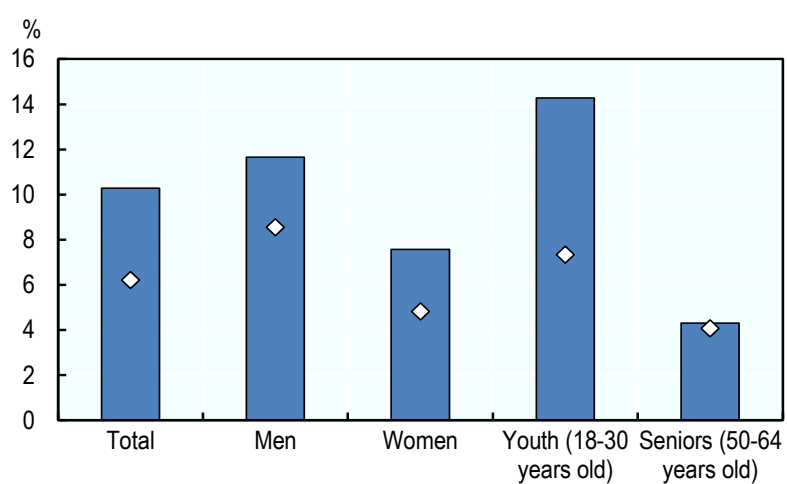

d. Share of TEA that expects to create at least 19 jobs over the next 5 years, 2016-20

$\square$ Croatia $\diamond \mathrm{EU}$

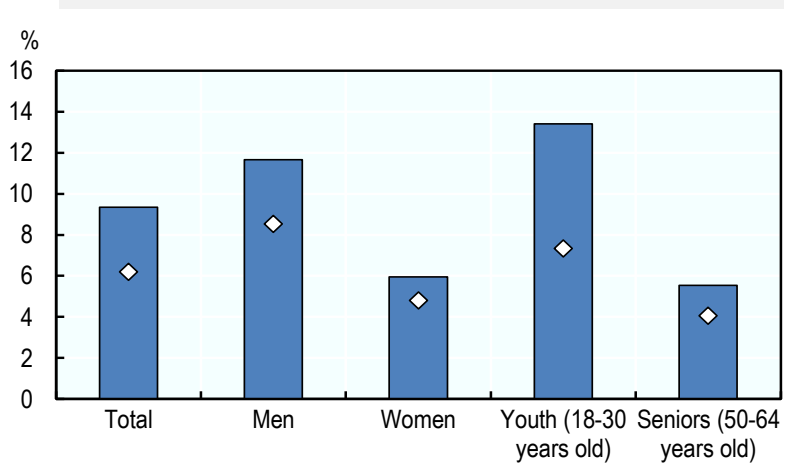

f. Share of self-employed with employees
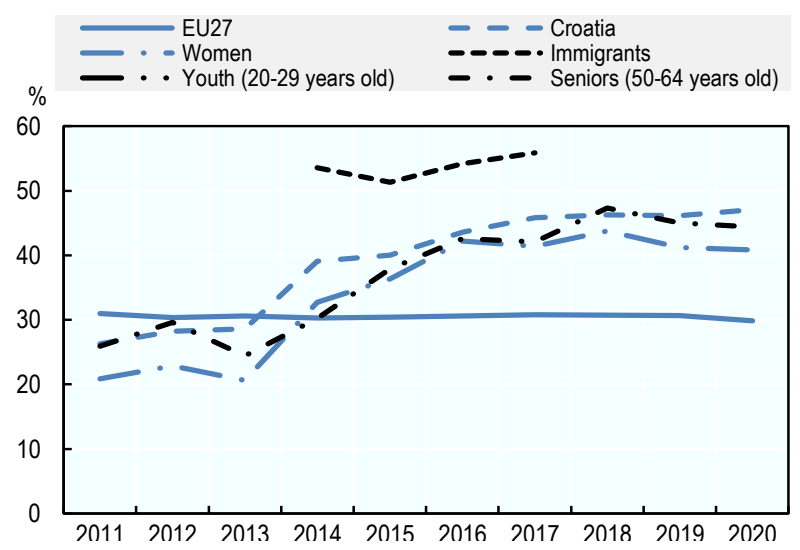

Note: The EU average in panels b-d excludes Belgium, Czech Republic, Denmark, Lithuania, Malta and Romania. Please see Chapter 9 for notes on the figures.

Source: Panel a: (World Bank, 2020[1]; Global Entrepreneurship Monitor (GEM), 2021 [2]; OECD, forthcoming[3]); Panels b-d: (Global Entrepreneurship Monitor (GEM), 2021[2]); Panels e-f: (Eurostat, 2021 [4]]). Please see Chapter 9 for the full citations. 


\section{Cyprus}

This country profile presents recent trends in entrepreneurship by women, youth and seniors, including indicators that benchmark data for Cyprus against the European Union average. It also highlights recent developments in inclusive entrepreneurship policy, including COVID-19 responses.

\section{Conditions for inclusive entrepreneurship}

The framework conditions for entrepreneurship are improving. The level of administrative burden on new start-ups ranks above the EU average and the proportion of people who report having entrepreneurship skills and entrepreneurial expectations are among the top 5 in the EU. There is limited tailored public support for under-represented and disadvantaged groups in entrepreneurship, which is expected given the size of the country.

\section{Recent trends}

Over the period 2016-20, the share of the population engaged in early-stage entrepreneurship rates were above the EU average. Women (9\%), youth (18-30 years old) $(9 \%)$ and seniors (50-64 years old) $(6 \%)$ were slightly more likely to be involved in starting and managing new businesses than the EU average (5\% for women, $7 \%$ for youth and $4 \%$ for seniors). However, many of these population groups remain underrepresented in entrepreneurship. Eliminating these gaps (i.e. applying the early-stage entrepreneurship rate of men who are 30-49 years old to the whole population) would result in an additional 34500 entrepreneurs. About $75 \%$ of these "missing" entrepreneurs are female, $40 \%$ are over 50 years old and $25 \%$ are youth (18-30 years old).

Self-employment rates have declined slightly over the past decade and remain below the EU average $(11 \%$ vs. $14 \%$ in 2020$)$. Moreover, the share of self-employed with employees decreased substantially over the past decade, most notably among women and seniors.

\section{Hot policy issue}

To combat the effects of the COVID-19 crisis, the Scheme for Self-Employed Workers was launched by the Ministry of Labour, Welfare and Social Insurance. It provided an allowance for up to 4-weeks of $60 \%$ of insured weekly earnings (typically EUR 300 to EUR 900) to those who had their work fully or partially suspended due to the pandemic. The Ministry of Labour also provided a lump sum subsidy to the selfemployed and very small enterprises to help cover rents, operational expenses and debts from 13 April to 12 May 2020. The amount of support ranged from EUR 1250 for an enterprise employing up to one person to EUR 6000 for those employing 10-50 people. In addition, youth entrepreneurs can receive various forms of support through the "ReCOVer20" Programme, operated by the Youth Board of Cyprus. It funds local support projects focussed on youth, and other vulnerable groups. 


\section{Inclusive entrepreneurship indicators}

Figure 14.1. Entrepreneurship and self-employment data for Cyprus

a. Conditions for entrepreneurship, 2020

Bottom 5 countries $\square$ Median $\square$ Top 5 countries $\bullet$ Cyprus

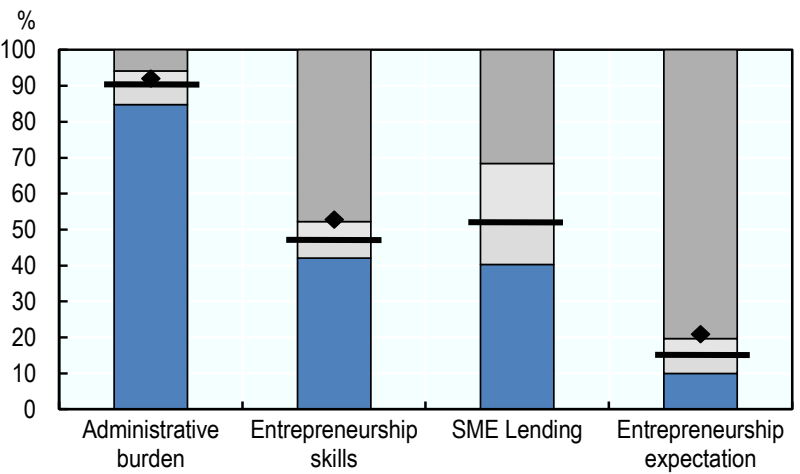

c. Share of TEA that is necessity-based, 2016-20

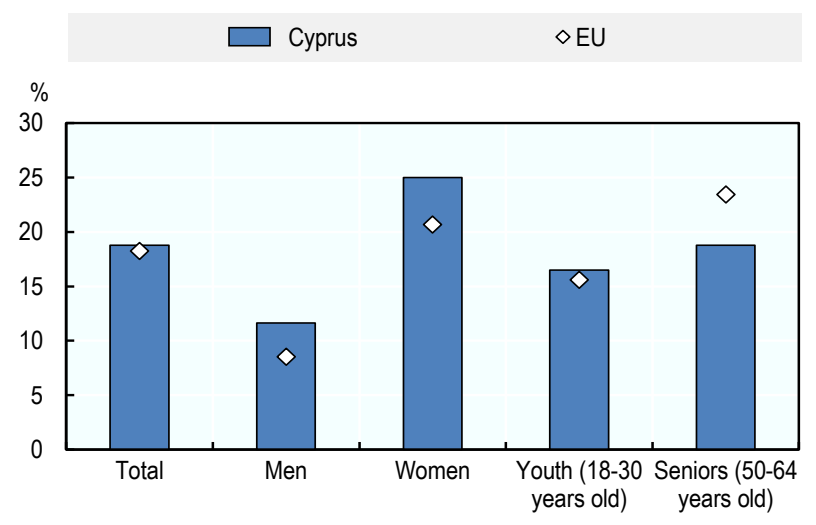

e. Self-employment rate

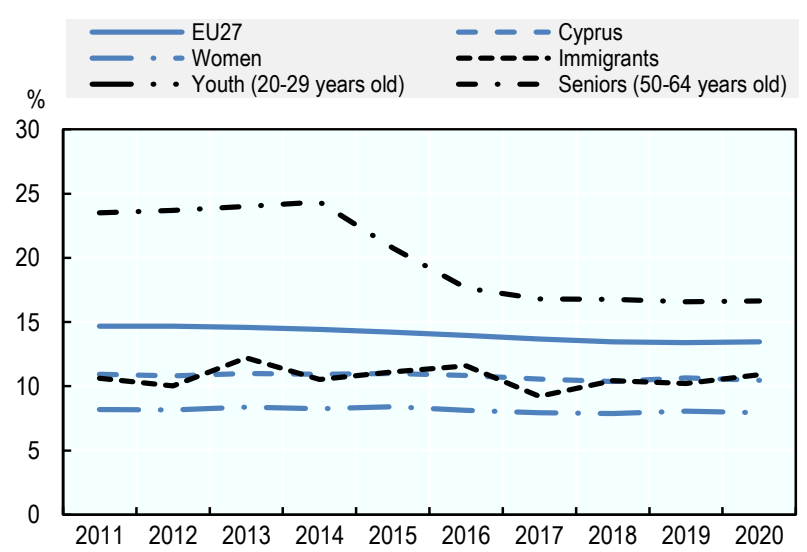

b. TEA rate, $2016-20$

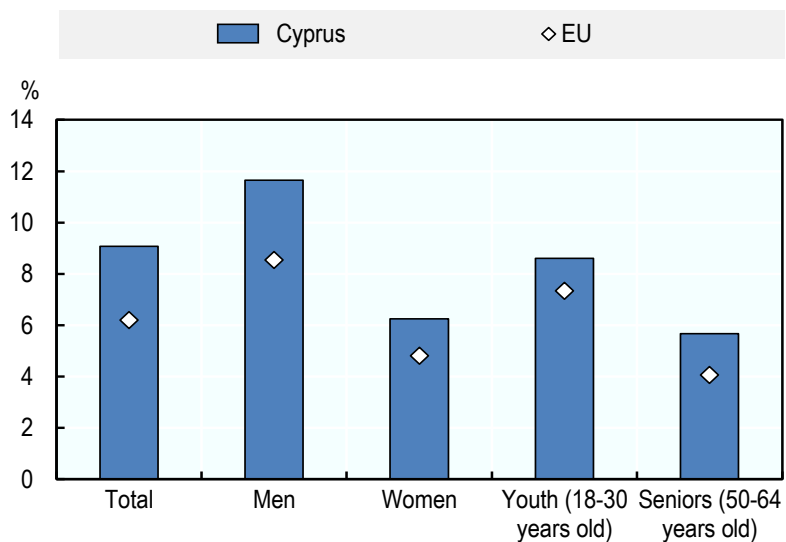

d. Share of TEA that expects to create at least 19 jobs over the next 5 years, 2016-20

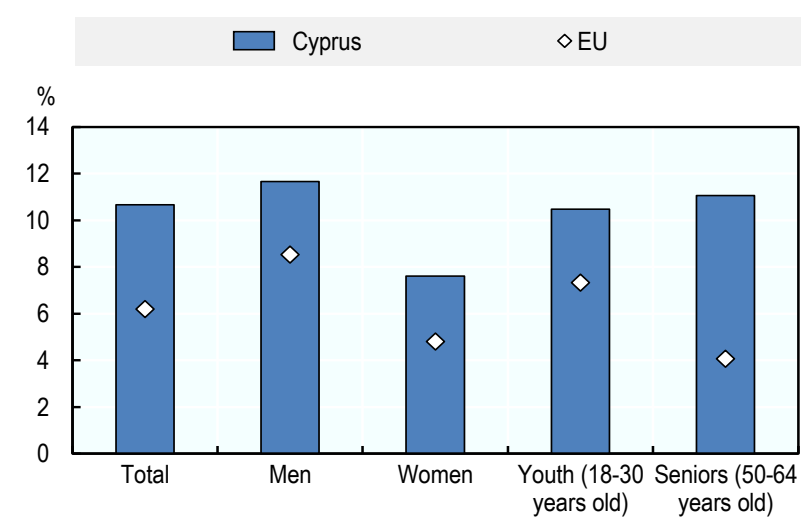

f. Share of self-employed with employees

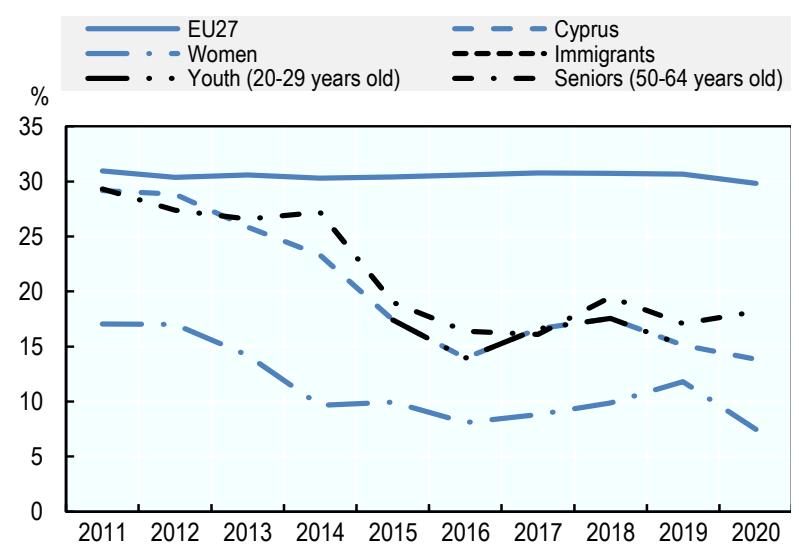

Note: The EU average in panels b-d excludes Belgium, Czech Republic, Denmark, Lithuania, Malta and Romania. Please see Chapter 9 for notes on the figures.

Source: Panel a: (World Bank, 2020[1]; Global Entrepreneurship Monitor (GEM), 2021[2]; OECD, forthcoming[3]); Panels b-d: (Global Entrepreneurship Monitor (GEM), 2021 $\left.1_{[2]}\right)$; Panels e-f: (Eurostat, 2021 $\left.{ }_{[4]}\right)$. Please see Chapter 9 for the full citations. 


\section{Czech Republic}

This country profile reports current inclusive entrepreneurship policy issues and recent developments in the Czech Republic, including the COVID-19 response. It also presents recent trends in self-employment for women, youth, seniors and immigrants relative to the average for the European Union.

\section{Conditions for inclusive entrepreneurship}

The framework conditions for entrepreneurship are generally favourable. However, the level of administrative burden on new start-ups remains high (bottom 5 countries in the European Union (EU)) and the cost of enforcing contracts is one of the highest among EU Member States. Moreover, as in many countries that moved to a market-based economy in 1989, social attitudes are, overall, less open to entrepreneurship than elsewhere in the EU. The government has a suite of actions to support the selfemployment and entrepreneurs; however, inclusive entrepreneurship actions remain relatively underdeveloped. A small number of projects offer tailored training and coaching to women, youth and senior entrepreneurs, but most are very small schemes with a limited impact.

\section{Recent trends}

The self-employment rate remained steady over the past decade at about $16 \%$, which was slightly above the EU average in 2020 (14\%). Above-average self-employment rates were observed across most population groups, notably among immigrants $(28 \%$ vs. $12 \%)$ and youth $(11 \%$ vs. $7 \%)$ but also women $(11 \%$ vs. $10 \%)$ and seniors (18\% vs. $17 \%)$. Nonetheless, each of these groups is under-represented in self-employment. Eliminating these gaps (i.e. applying the self-employment rate of men who are 30-49 years old to the whole population), would result in about 110000 additional entrepreneurs. These "missing" entrepreneurs are essentially all young females (aged 20-29 years old).

\section{Hot policy issue}

Several phases of COVID-19 support measures have been introduced to support entrepreneurs and the self-employed. These measures included financial support for rental costs, forgiveness of social insurance obligations (for employers), tax allowances, as well as monthly flat rate payments. Initial direct support measures (early 2020) offered the self-employed a daily compensation of CZK 500 (EUR 19) totalling to CZK 44500 (EUR 1 660). By February 2021, compensation bonuses to the self-employed had increased to CZK 500 - CZK 1000 (EUR 19 - EUR 28) per day. The third phase of support was significant as it introduced operating loans of up to CZK 45 million (EUR 1.7 million). As of March 2021, there have been 4204 accepted applications with a total of around CZK 28.4 billion (EUR 1.1 billion) granted. Some sectorspecific measures have also been introduced, including the COVID-Culture for the self-employed operating cultural and creative businesses (launched in August 2020), which was replaced by the COVID 2021 programme in April 2021. 


\section{Inclusive entrepreneurship indicators}

Figure 15.1. Entrepreneurship and self-employment data for the Czech Republic

a. Conditions for entrepreneurship, 2020

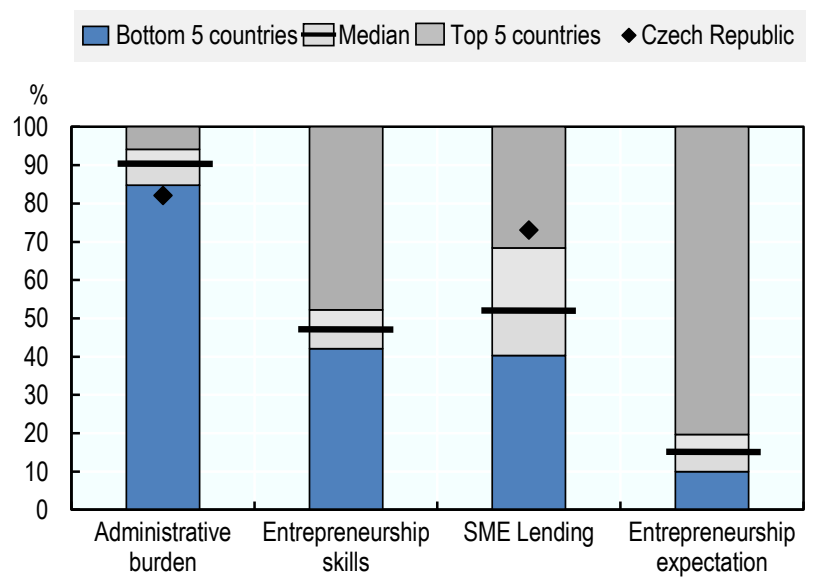

c. Share of self-employed with employees

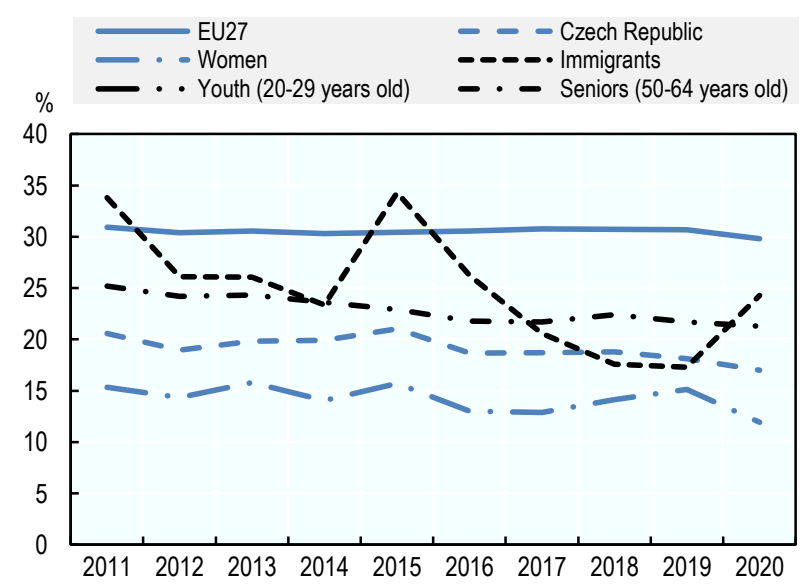

b. Self-employment rate

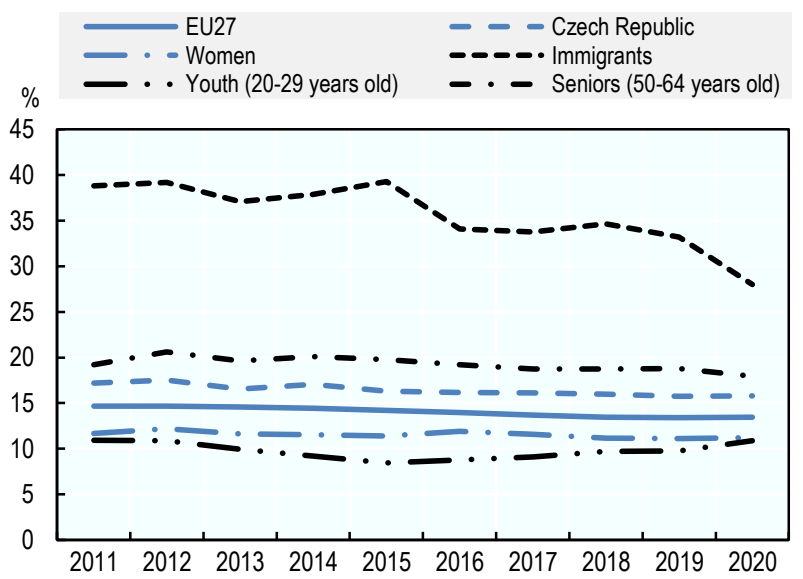

Note: Please see Chapter 9 for notes on the figures.

Source: Panel a: (World Bank, 2020[1]; Global Entrepreneurship Monitor (GEM), 2021[2]; OECD, forthcoming[3]); Panels b-c: (Eurostat, 2021[4]). Please see Chapter 9 for the full citations. 


\section{Denmark}

This country profile benchmarks recent self-employment trends for women, youth, seniors and immigrants against the average for the European Union. It also reports on entrepreneurship conditions and describes recent policy actions related to inclusive entrepreneurship, including the COVID-19 response.

\section{Conditions for inclusive entrepreneurship}

The framework conditions for entrepreneurship are strong with respect to regulations and administrative burden on entrepreneurs. However, access to finance and skills are less strong relative to other European Union (EU) Member States and the cost of registering a business remains among the highest in the EU. Entrepreneurship policy is focused on promoting innovation, growth and the digital economy. Consequently, entrepreneurship policies do not aim to address social inclusion and few initiatives support people from under-represented and disadvantaged groups in business creation and self-employment. However, entrepreneurship education and the support infrastructure for youth entrepreneurship is strong. Moreover, there are strong initiatives that support immigrant entrepreneurs, particularly at the local level.

\section{Recent trends}

Self-employment rates have been stable over the past decade at about $8 \%$, substantially below the EU average (14\% in 2020). These low rates are likely explained, in part, by a healthy labour market with low levels of unemployment and a very strong social security system. Moreover, the public sector employs a relatively high share of the labour force. The proportion of self-employed workers varies across population groups - seniors $(10 \%)$ were more likely to be self-employed than youth $(3 \%)$ or women $(5 \%)$ in 2020 . Closing the gaps in self-employment across the population groups (i.e. applying the self-employment rate of men who are 30-49 years old to the whole population) would result in another 52000 self-employed people. Virtually all of these "missing" entrepreneurs are women and two-thirds are under 30 years old.

Despite low self-employment rates, a higher proportion of self-employment activities have created employment for others. About $42 \%$ self-employed workers have employees, including $44 \%$ of selfemployed immigrants, $43 \%$ of self-employed seniors and $30 \%$ of self-employed women.

\section{Hot policy issue}

Several measures and programmes were introduced during the COVID-19 pandemic. All businesses, including the self-employed and freelance workers, could receive compensation to cover loss of turnover and fixed costs due to the COVID-19 pandemic. A support fund of DKK 100 million (EUR 13.3 million) was designed to strengthen recovery and innovation for impacted industries and enterprises. As of March 2021, the Danish Business Authority had approved over 150000 applications (businesses and people) and paid DKK 7232 million (EUR 985 million) in total compensation. The Innofounder programme for entrepreneurs also provided 12 monthly stipends, which was then extended by six months as was its programme period. 


\section{Inclusive entrepreneurship indicators}

Figure 16.1. Entrepreneurship and self-employment data for Denmark

a. Conditions for entrepreneurship, 2020

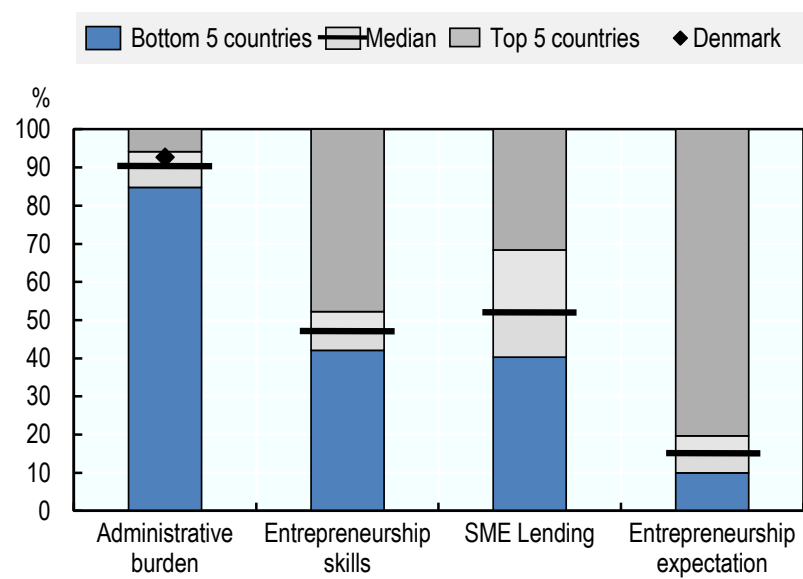

b. Self-employment rate

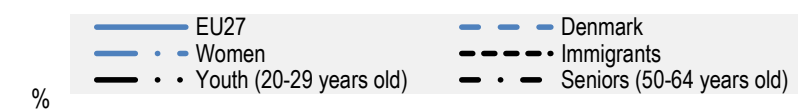

$\%$

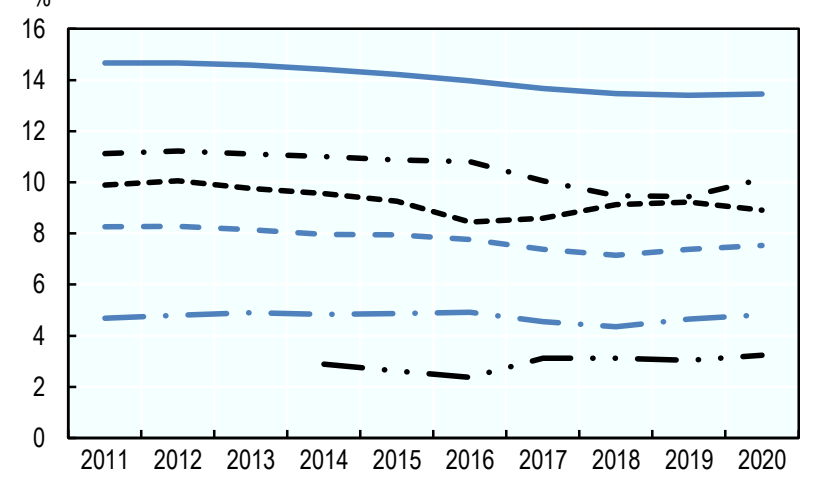

c. Share of self-employed with employees

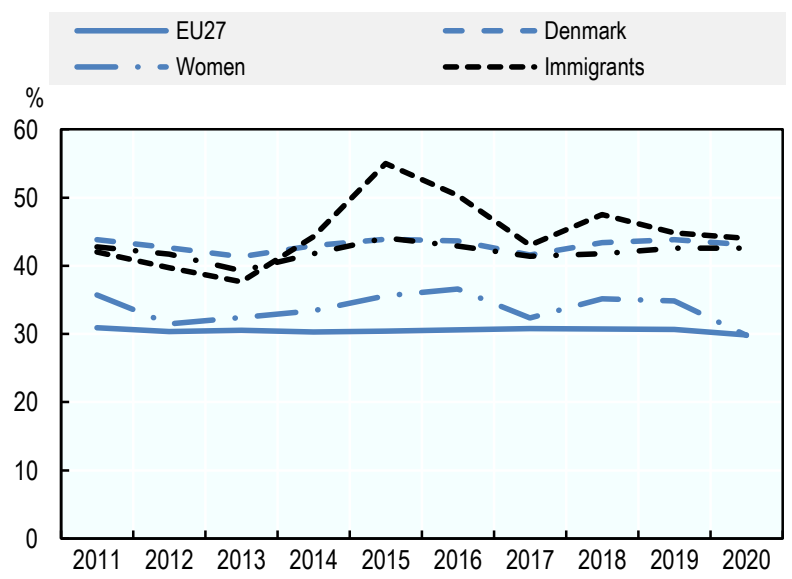

Note: Please see Chapter 9 for notes on the figures.

Source: Panel a: (World Bank, 2020[1]; Global Entrepreneurship Monitor (GEM), $202_{[2]}$; OECD, forthcoming[3]); Panels b-c: (Eurostat, 2021 [4]]). Please see Chapter 9 for the full citations. 


\section{Estonia}

This country profile highlights recent policy actions related to supporting women, youth, seniors and immigrants in entrepreneurship. It also reports on entrepreneurship conditions and benchmarks recent selfemployment and inclusive entrepreneurship indicators for Estonia against the European Union average.

\section{Conditions for inclusive entrepreneurship}

The conditions for entrepreneurship are generally considered favourable relative to other European Union (EU) countries. A high proportion of the population reports having entrepreneurship skills, as well as an expectation that they will start a business in the next three years. Moreover, Estonia ranked among the most favourable in the EU for regulatory environment due to the low start-up costs and ease of complying with taxes. Entrepreneurship policies are generally designed to increase innovation within SMEs and to support firm growth. There are few tailored and targeted policies and initiatives that seek to support specific social target groups in business creation, with the exception of several support measures developed for youth entrepreneurs and a very small number of initiatives to support the unemployed in business creation.

\section{Recent trends}

Over the period 2016-20, the proportion of people involved in starting or managing a new business was double the EU average (17\% vs. $6 \%)$. Similarly, rates were relatively high among population groups such as youth $(25 \%)$, women $(12 \%)$ and seniors $(8 \%)$ relative to the EU averages for each group ( $7 \%$ for youth, $5 \%$ for women and $4 \%$ for seniors). However, many of these groups remain under-represented in earlystage entrepreneurship. Closing these gaps (i.e. applying the early-stage entrepreneurship rate of men who are 30-49 years old to the whole population) would result in about 68400 additional entrepreneurs. Among these "missing" entrepreneurs, $75 \%$ are female and $60 \%$ over 50 years old.

The proportion of working people who were self-employed increased over the last decade from about $8 \%$ in 2011 to nearly $11 \%$ in 2020. However, this rate was still below the EU average in $2020(14 \%)$. A very high proportion of the self-employed employ other people ( $46 \%$ in $2020 \mathrm{vs.} 30 \%$ for the EU) but the gender gap - in terms of the self-employment rate and share who are employers - is greater than the EU average.

\section{Hot policy issue}

In response to the COVID-19 crisis, entrepreneurs who met the criteria for the general SME crisis support measures could apply for grants, loans and guarantees, as well as sector-specific supports. Only one policy was designed for the self-employed, which provided short-term social tax-relief by waving the advanced social tax contribution for 2Q2020. The Tax and Customs Board paid a total of EUR 800000 for the 1747 self-employed workers who had not paid and reimbursed the 5769 who had (total of EUR 2.5 million). Subsequent reforms expanded the unemployment insurance system to self-employed and business owners without employment contracts. 


\section{Inclusive entrepreneurship indicators}

Figure 17.1. Entrepreneurship and self-employment data for Estonia

a. Conditions for entrepreneurship, 2020

Bottom 5 countries $\rightleftarrows$ Median $\square$ Top 5 countries $\bullet$ Estonia

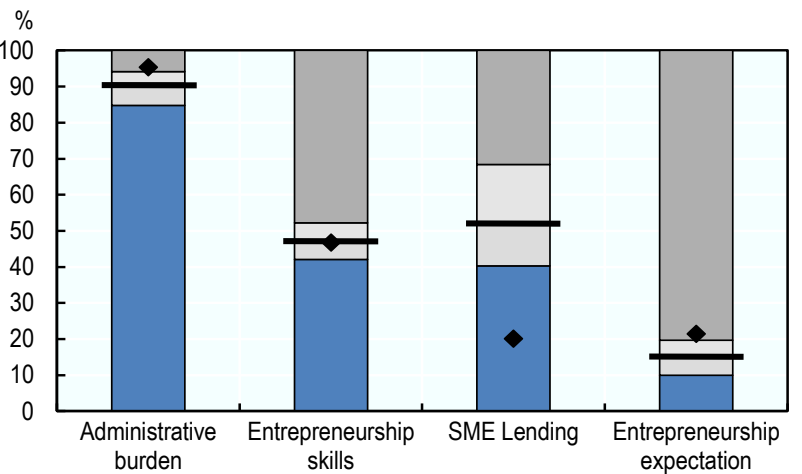

c. Share of TEA that is necessity-based, 2016-20

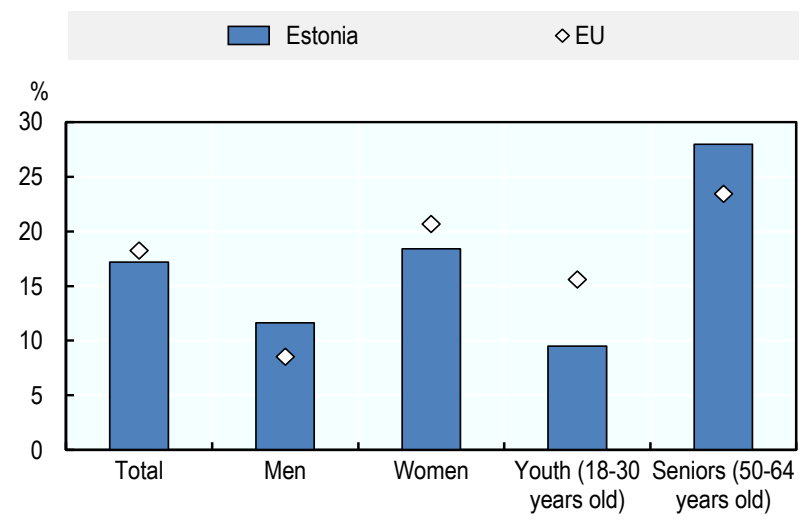

e. Self-employment rate

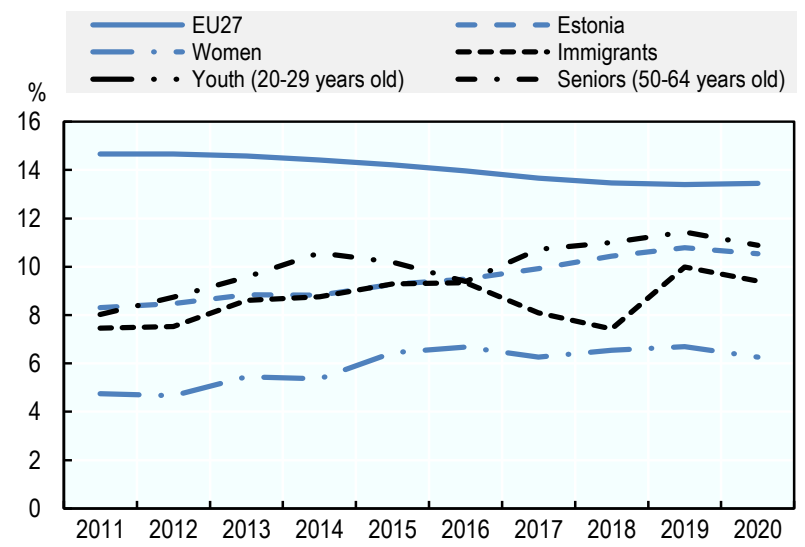

b. TEA rate, $2016-20$

Estonia $\diamond \mathrm{EU}$

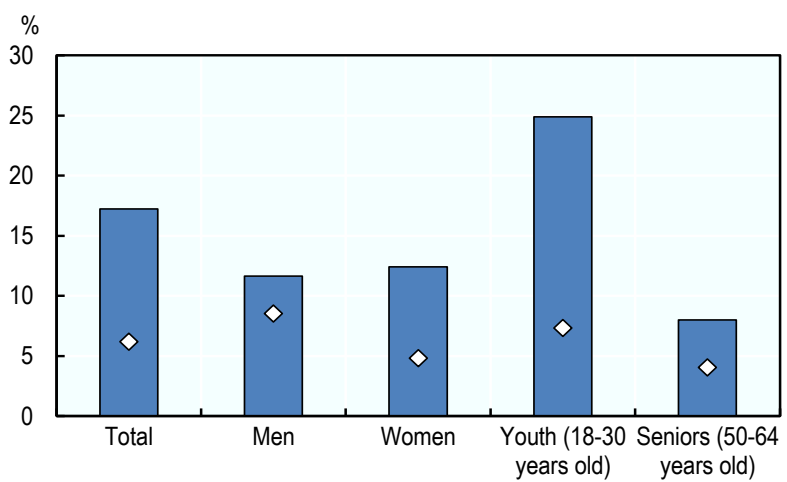

d. Share of TEA that expects to create at least 19 jobs over the next 5 years, 2016-20

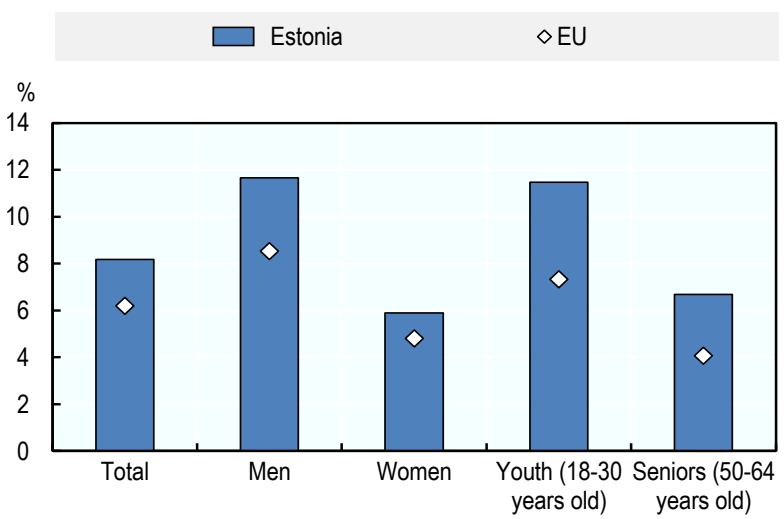

f. Share of self-employed with employees

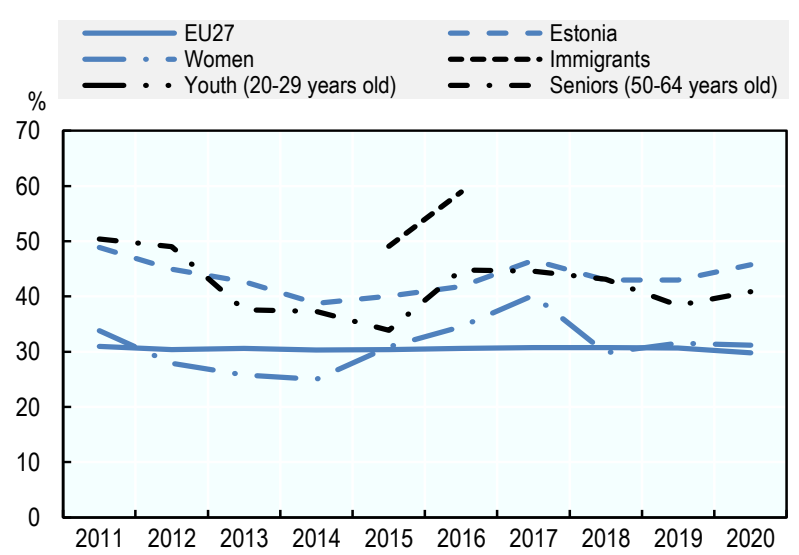

Note: The EU average in panels b-d excludes Belgium, Czech Republic, Denmark, Lithuania, Malta and Romania. Please see Chapter 9 for notes on the figures.

Source: Panel a: (World Bank, 2020[2]; Global Entrepreneurship Monitor (GEM), 2021[3]; OECD, forthcoming[4]); Panels b-d: (Global Entrepreneurship Monitor (GEM), 2021 [3]]); Panels e-f: (Eurostat, 2021 $\left.{ }_{[5]}\right)$. Please see Chapter 9 for the full citations. 


\section{Finland}

This country profile presents self-employment and entrepreneurship data for women, youth, seniors and immigrants relative to the average for the European Union. It also highlights current inclusive entrepreneurship policy actions and reports on entrepreneurship conditions.

\section{Conditions for inclusive entrepreneurship}

Finland offers a supportive environment for entrepreneurship. This includes low levels of administrative burden for start-ups and easy access to debt financing for new and small firms. However, self-reported levels of entrepreneurship skills are below the European Union (EU) median despite a highly skilled workforce, which could be due to a general preference for salaried employment. Overall, entrepreneurship policy is widely available and focuses on supporting innovative and growth-oriented entrepreneurship. While inclusive entrepreneurship is not a clear policy priority, increased attention to group-specific needs is foreseen in forthcoming entrepreneurship strategy. Some tailored actions are used to support specific population groups, e.g. entrepreneurial education for youth, labour market integration for immigrants.

\section{Recent trends}

About $7 \%$ of the population was involved in early-stage entrepreneurship between 2016 and 2020, which was about the same as the EU average. New entrepreneurs were also significantly less likely to start a business out of necessity relative the EU average (7\% vs. $18 \%$ ). However, women, youth and seniors remain under-represented in entrepreneurship. If all groups engaged in early-stage entrepreneurship at the same rate as core-age men, there would be 170000 more entrepreneurs. About two-thirds of these "missing" entrepreneurs would be women and nearly half would be entrepreneurs over 50 years old.

Self-employment levels were relatively stable over the last decade and only slightly lower than the EU average in 2020 (12\% vs. nearly 14\%). The share of immigrants who were self-employed increased from $11 \%$ in 2011 to $14 \%$ in 2020 . Moreover, the share with employees is about equal to the EU average (30\%).

\section{Hot policy issue}

Supporting businesses during the COVID-19 pandemic was a policy priority. This included a range of financial supports for entrepreneurs and the self-employed such as the allocation of EUR 250 million for financial aid for solo self-employed workers through a one-time grant of EUR 2000 to cover affected business activities between 16 March 2020 and 31 August 2020. By the end of the programme, 20000 self-employed workers had received grants. Additional financial supports are offered through the Bank of Finland, Finnvera Plc (state-owned risk finance company) and Enterprise Finland's Talousapu programme, which also included some business counselling. In addition, non-financial support was also offered to sole entrepreneurs through the Centres for Economic Development, Transport and the Environment (ELY Centres) and municipalities. 


\section{Inclusive entrepreneurship indicators}

Figure 18.1. Entrepreneurship and self-employment data for Finland

a. Conditions for entrepreneurship, 2020

$\square$ Bottom 5 countries $\square$ Median $\square$ Top 5 countries • Finland

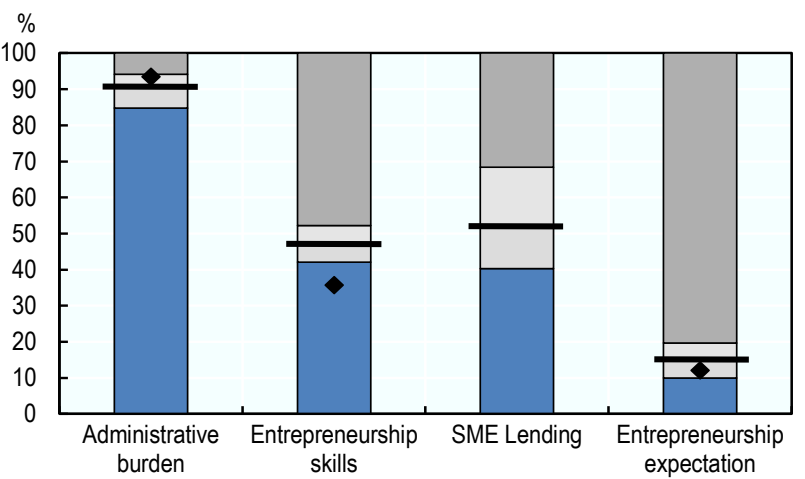

c. Share of TEA that is necessity-based, 2016-20

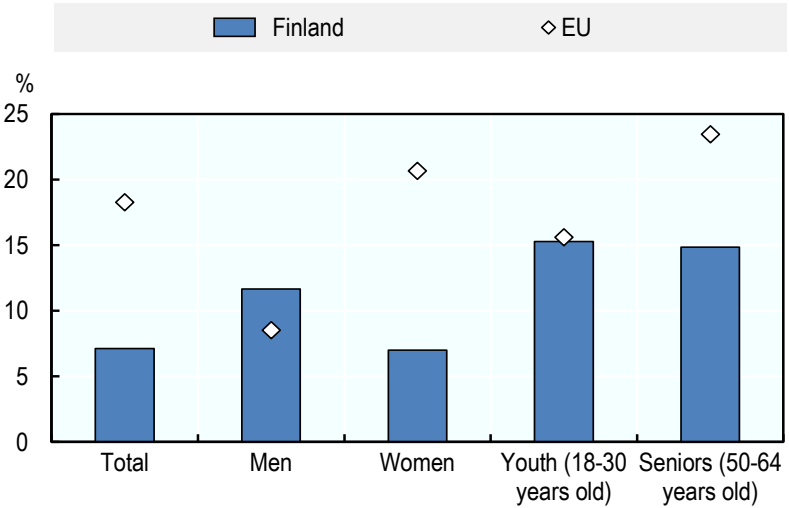

e. Self-employment rate

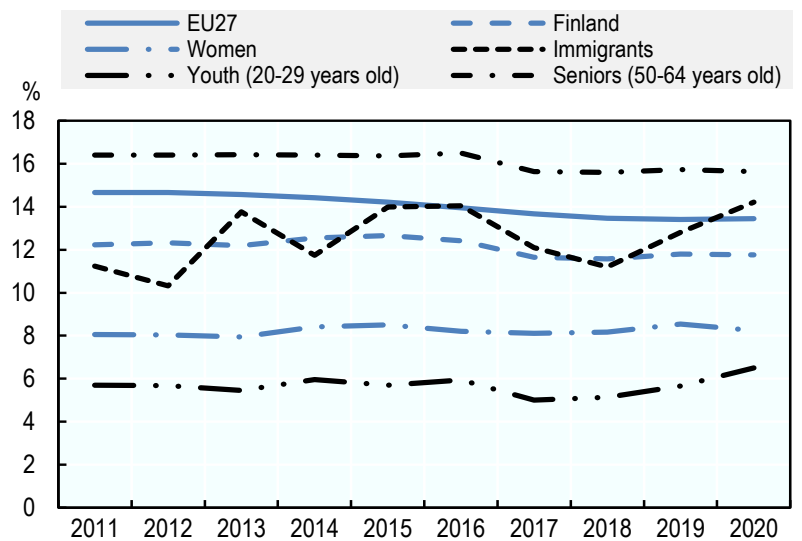

b. TEA rate, $2016-20$

Finland $\diamond \mathrm{EU}$

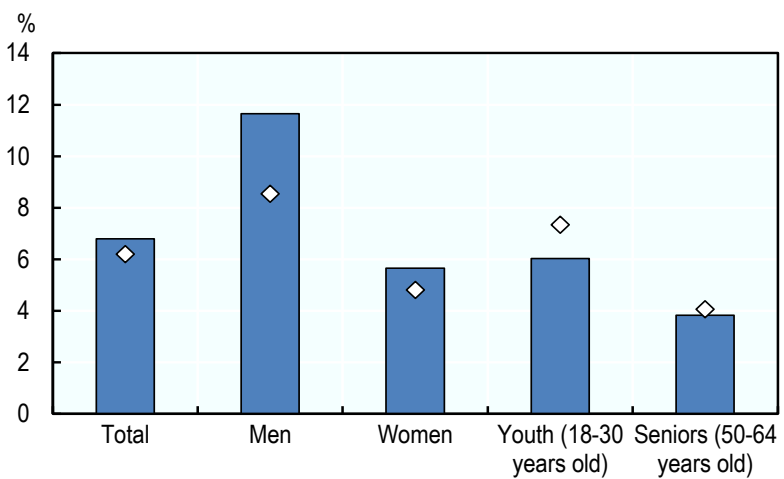

d. Share of TEA that expects to create at least 19 jobs over the next 5 years, 2016-20

$\square$ Finland $\diamond \mathrm{EU}$

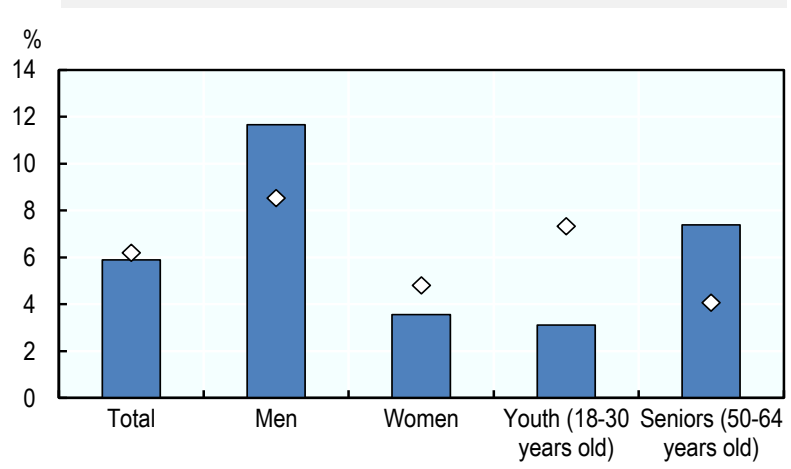

f. Share of self-employed with employees

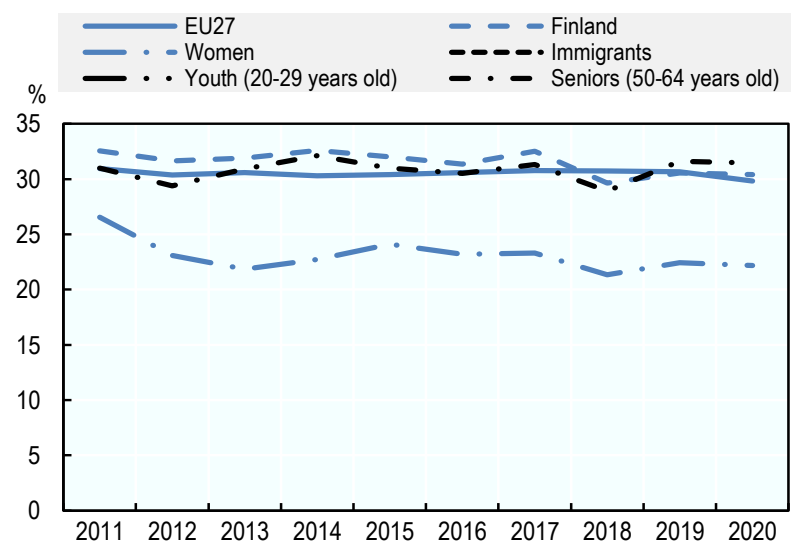

Note: The EU average in panels b-d excludes Belgium, Czech Republic, Denmark, Lithuania, Malta and Romania. Please see Chapter 9 for notes on the figures.

Source: Panel a: (World Bank, 2020[2]; Global Entrepreneurship Monitor (GEM), 2021 $1_{[3]}$; OECD, forthcoming[4]]); Panels b-d: (Global Entrepreneurship Monitor (GEM), 2021 [3]]); Panels e-f: (Eurostat, 2021 $\left.{ }_{[5]}\right)$. Please see Chapter 9 for the full citations. 


\section{France}

This country profile benchmarks self-employment and entrepreneurship indicators for women, youth, seniors and immigrants in France relative to the average for the European Union. It also highlights current inclusive entrepreneurship policy issues and recent developments, notably COVID-19 response measures.

\section{Conditions for inclusive entrepreneurship}

The overall entrepreneurship conditions remain below the European Union (EU) average for some important indicators (e.g. administrative burden and new SME lending), despite some areas of relative strength (e.g. high level of entrepreneurial expectation, low cost of business creation, low interest rate for SMEs). Efforts to improve the conditions have been made, notably by improving access to social benefits for the self-employed, simplifying the tax regime for micro-entrepreneurs and reducing corporate tax to $15 \%$ for SMEs in the 2018 Finance Bill (to be effective in 2022). Many policies and measures are in place to encourage business creation, including support for entrepreneurs from under-represented and disadvantaged groups. Tailored support is offered by various government agencies at national and local levels and many actors in the non-governmental and private sectors.

\section{Recent trends}

The share of people involved in starting and managing new businesses was slightly below the EU average for the period $2016-20$ (5\% vs. $6 \%$ ). This was also observed among women (4\% vs. $5 \%$ ) and youth (5\% vs. $7 \%$ ). If all groups engaged in early-stage entrepreneurship at the same rate as core-age men, there would be 935000 more entrepreneurs. Around $80 \%$ of these "missing" entrepreneurs would be women. Those over 50 years old would account for $45 \%$ and those under 30 years old would account for $15 \%$.

Self-employment increased with the introduction of the auto-entrepreneur regime in 2009 (called microentrepreneur as of 2014) as well as several new universal entrepreneurship and SMEs policies in the period 2013-19. By the end of 2019, 928000 micro-entrepreneurs were economically active. Despite an overall increase, the self-employment rate remained below the EU average in 2020 (12\% vs. nearly 14\%).

\section{Hot policy issue}

Several measures were designed to support entrepreneurs and SMEs following the COVID-19 pandemic, including a solidarity fund that allocated aid corresponding to turnover loss at or above EUR 1500 . Some very small companies, freelancers, micro-entrepreneurs and liberal professions with up to 10 employees (turnover under EUR 1 million) were eligible for support through this fund. On 2 March 2020, Bpifrance in partnership with the State extended credit guarantees to support loan restructuring (without management fees), a new state guaranteed loan device (PGE) to ease cash flow and a EUR 4 billion fund to support start-ups. Other actions targeted specific population groups such as increased support for entrepreneurs with a disability receiving aid from Agefiph (total cost of EUR 23 million). 


\section{Inclusive entrepreneurship indicators}

Figure 19.1. Entrepreneurship and self-employment data for France

a. Conditions for entrepreneurship, 2020

$\square$ Bottom 5 countries $\square$ Median $\square$ Top 5 countries

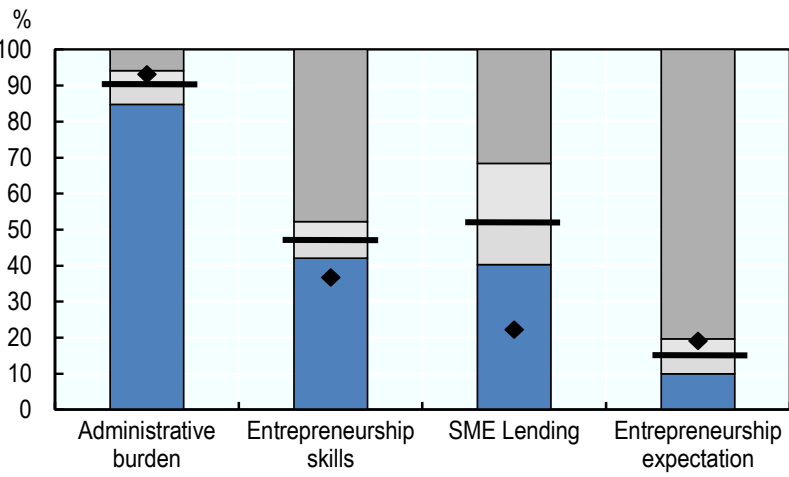

c. Share of TEA that is necessity-based, 2016-20

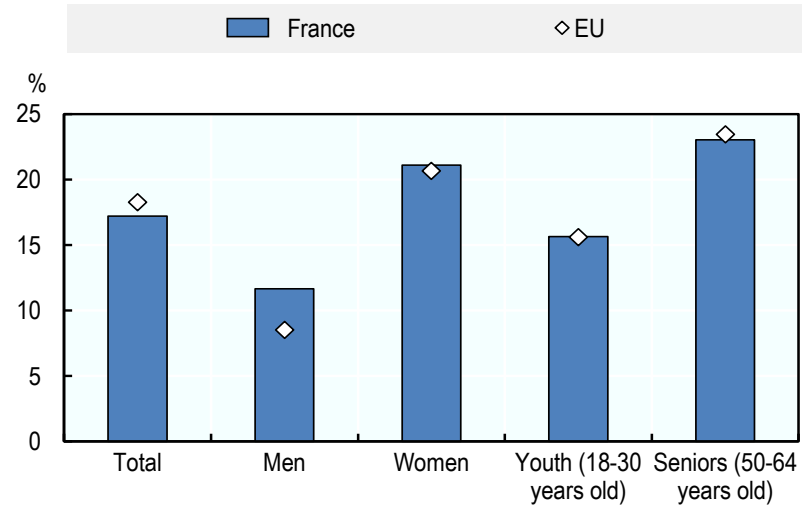

e. Self-employment rate

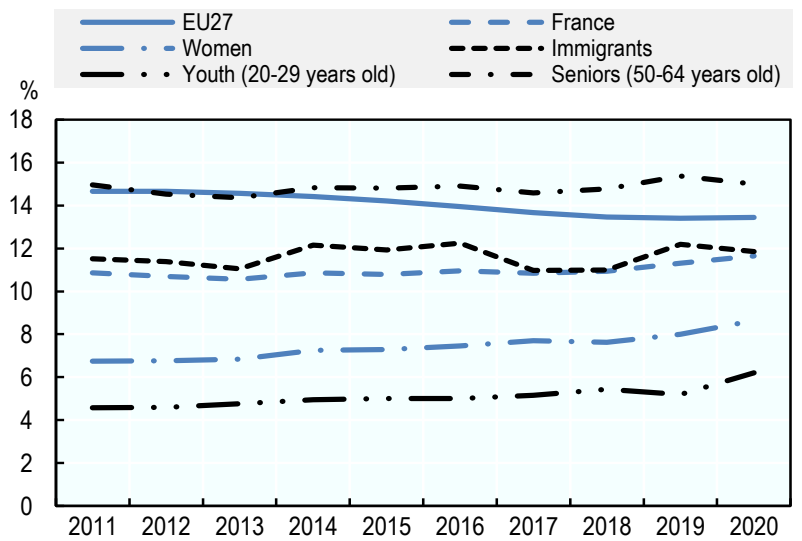

b. TEA rate, 2016-20 $\diamond \mathrm{EU}$

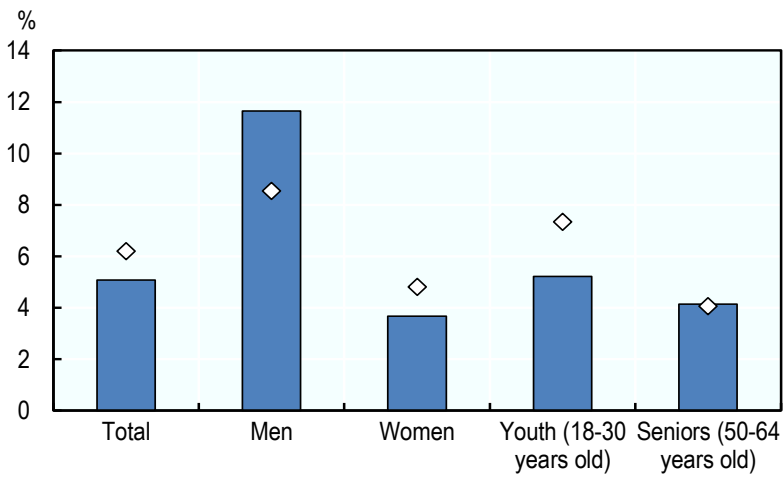

d. Share of TEA that expects to create at least 19 jobs over the next 5 years, 2016-20

$\square$ France $\diamond E U$

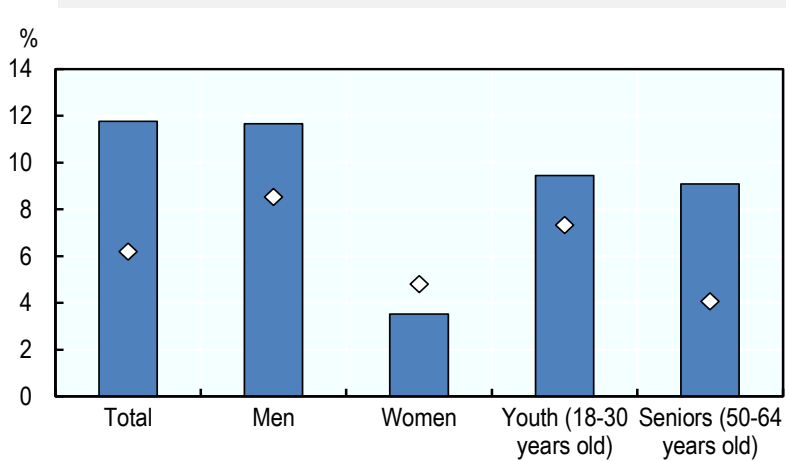

Note: The EU average in panels b-d excludes Belgium, Czech Republic, Denmark, Lithuania, Malta and Romania. Please see Chapter 9 for notes on the figures.

Source: Panel a: (World Bank, 2020[1]; Global Entrepreneurship Monitor (GEM), 2021[2]; OECD, forthcoming[3]); Panels b-d: (Global Entrepreneurship Monitor (GEM), 2021[2]); Panels e-f: (Eurostat, 2021 [4]]). Please see Chapter 9 for the full citations. 


\section{Germany}

This country profile reports entrepreneurship activity rates by women, youth and seniors relative to the European Union average. It also benchmarks the conditions for entrepreneurship against the EU Member States and reports highlights current inclusive entrepreneurship policy issues and recent developments.

\section{Conditions for inclusive entrepreneurship}

The framework conditions for entrepreneurship are comparable to most European Union (EU) Member States. The federal government continues to simplify the regulatory environment with actions such as strengthening e-government services. Entrepreneurship support policies have become an important and effective component of economic policies over recent decades. This includes actions to stimulate a more inclusive entrepreneurship culture (e.g. Start-up Campaign "GO!" [Gründungsoffensive "GO!"]), as well as a broad suite of schemes to support women, students and migrants in business creation.

\section{Recent trends}

The share of people involved in early-stage entrepreneurship was about equal to the EU average for the period $2016-20$ (6\%). Gaps across population groups were generally small relative to the EU average yet many of these groups remain under-represented in entrepreneurship. If all groups engaged in early-stage entrepreneurship at the same rate as core-age men, there would be an additional 1.3 million entrepreneurs. More than one million of these "missing" entrepreneurs are female and $55 \%$ are over 50 years old.

The self-employment rate steadily declined from $11 \%$ in 2011 to $8 \%$ in 2020 . This decline was observed across all target groups, notably among seniors (14\% to $11 \%)$ and women ( $7 \%$ to under $6 \%)$.

\section{Hot policy issue}

In response to the COVID-19 crisis, a multi-billion-euro assistance programme was established with the $\mathrm{KfW}$ group (state-owned investment bank) to provide liquidity to businesses, self-employed people and freelancers. Entrepreneurs (up to 5 employees) were eligible for a one-time payment of EUR 9000 for a three-month period while entrepreneurs with up to 10 employees received EUR 15000 . Around 426000 solo self-employed and micro-entrepreneurs received the grant in its first phase ending in June 2020, totalling EUR 4.5 billion. A successor programme (Überbrückungshilfe) launched in July 2020 to facilitate financial assistance for micro-entrepreneurs and freelancers. In a subsequent phase running from December 2020 to June 2021, applicants could receive grants of up to EUR 200000 per month (in special circumstance even up to EUR 500000 per month) and solo self-employed workers could receive a lump sum payment of up to EUR 7500 for the months of January 2021 until June 2021. On 30 April 2020, the government introduced an additional EUR 2 billion package aimed at start-ups and small enterprises with sustainable business models. There are also regional measures such as aid (EUR 1000 per month) for solo artists in Bavaria. 


\section{Inclusive entrepreneurship indicators}

Figure 20.1. Entrepreneurship and self-employment data for Germany

a. Conditions for entrepreneurship, 2020

Bottom 5 countries $\square$ Median $\square$ Top 5 countries $\bullet$ Germany

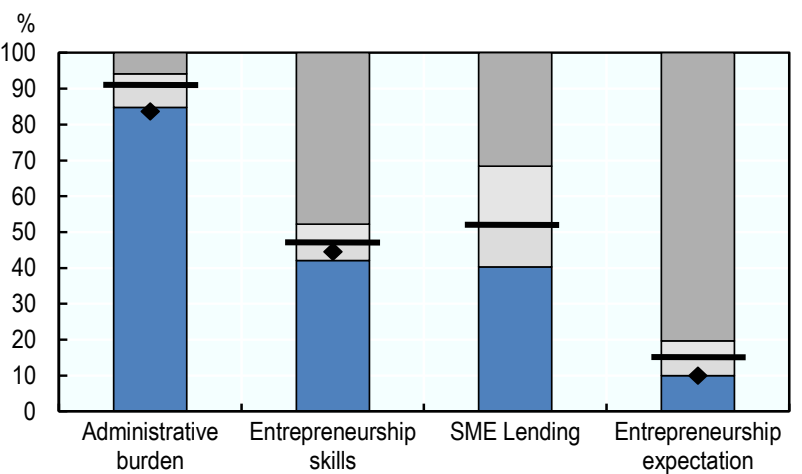

c. Share of TEA that is necessity-based, 2016-20

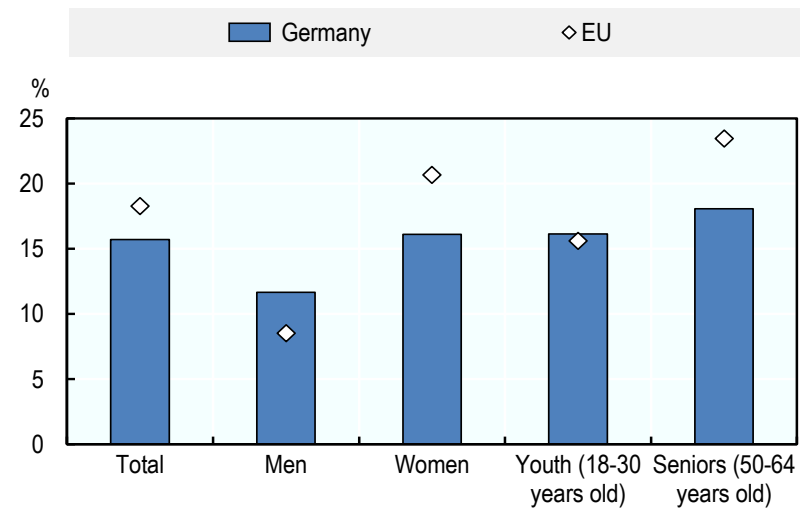

e. Self-employment rate

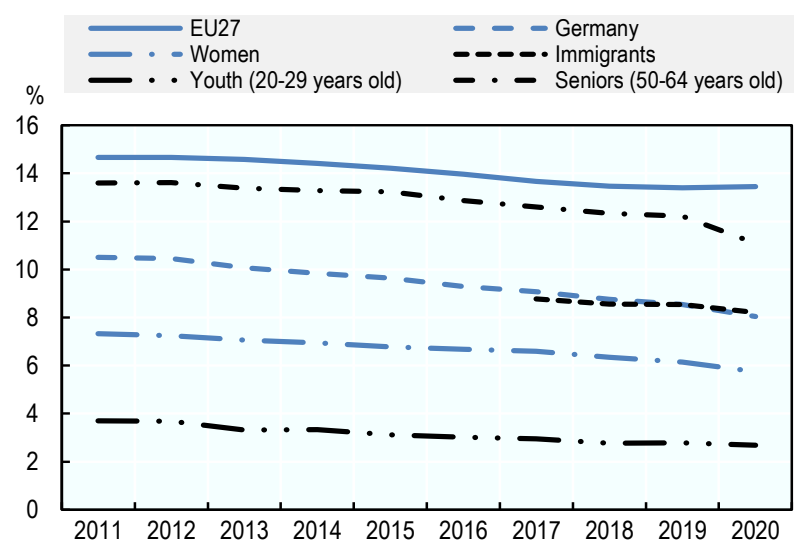

b. TEA rate, $2016-20$

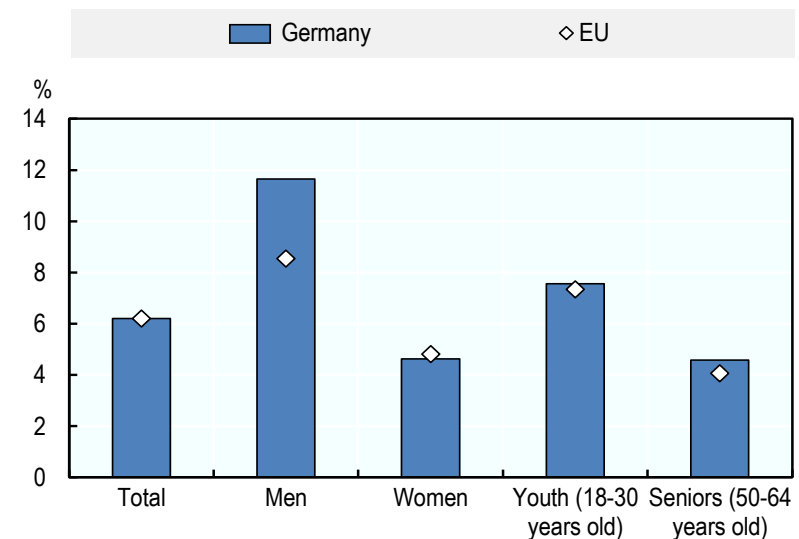

d. Share of TEA that expects to create at least 19 jobs over the next 5 years, 2016-20

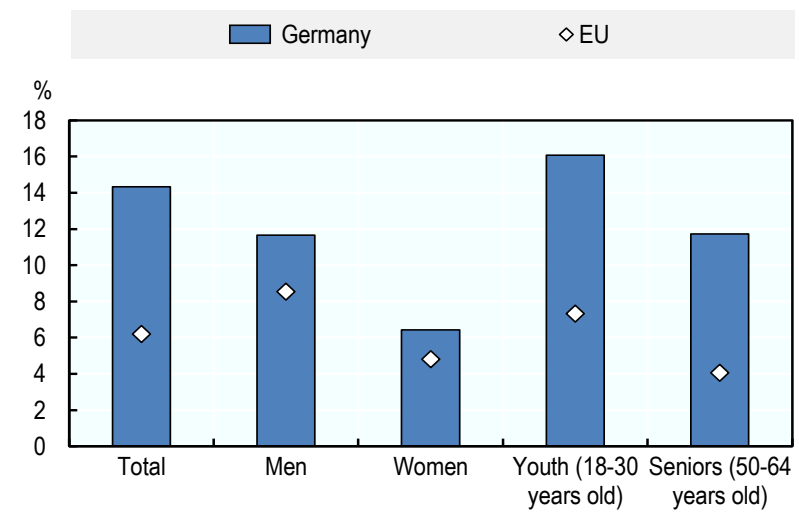

f. Share of self-employed with employees

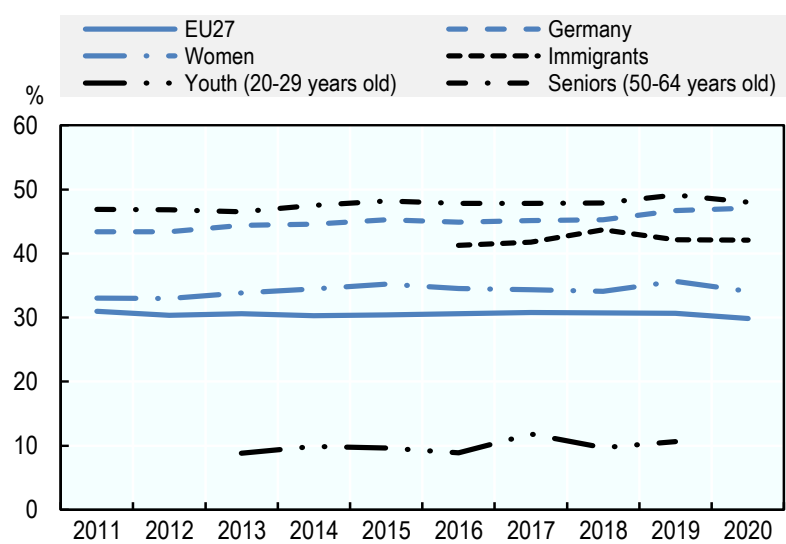

Note: The EU average in panels b-d excludes Belgium, Czech Republic, Denmark, Lithuania, Malta and Romania. Please see Chapter 9 for notes on the figures.

Source: Panel a: (World Bank, 2020[1]; Global Entrepreneurship Monitor (GEM), 2021[2]; OECD, forthcoming[3]); Panels b-d: (Global Entrepreneurship Monitor (GEM), 2021 [2]); Panels e-f: (Eurostat, 2021 [4]]). Please see Chapter 9 for the full citations.

StatLink त्ताज्य https://doi.org/10.1787/888934281467 


\section{Greece}

This country profile describes current inclusive entrepreneurship policy issues and recent developments in Greece, including policy responses to COVID-19. It also benchmarks self-employment and entrepreneurship indicators for women, youth, seniors and immigrants against the average for the European Union.

\section{Conditions for inclusive entrepreneurship}

Framework conditions for entrepreneurship are improving, notably due to efforts to streamline regulations and boost the access to finance for entrepreneurs and SMEs. Recent progress includes a general business registry one-stop shop (2018) which led to a 70\% reduction in registration costs. However, domestic market conditions remain challenging. Many inclusive entrepreneurship policies and programmes are operated at the national level by the employment agency and the majority of these public actions have been realised with support from European Union (EU) Structural Funds and international donors. Youth entrepreneurship is well-established with many actions being implemented through the Youth Employment Initiative.

\section{Recent trends}

Early-stage entrepreneurship rates were about equal to the EU average for the period 2016-20 (about 6\%). However, more than one-quarter of new entrepreneurs reported starting their business out of necessity significantly higher than the EU average ( $28 \%$ vs. $18 \%)$. Gaps in early-stage entrepreneurship rates across population groups were also quite pronounced. Removing these differences (i.e. applying the early-stage entrepreneurship rate of core-age men to the whole population) would result in an additional 68000 entrepreneurs. Most of these "missing" entrepreneurs are women and about half are over 50 years old.

The share of working people who are self-employed is very high in Greece. In 2020, the self-employment rate was double the EU average ( $28 \%$ vs. $14 \%)$. Seniors and youth, the most affected by the persisting effects of the financial crisis, have the highest self-employment rates.

\section{Hot issue}

A number of emergency measures were introduced to support entrepreneurs and the self-employed, including the suspension of tax and social security contributions (excluding VAT) for the self-employed and freelancers among others. Between 17 March and 30 April 2020, 480810 freelancers, self-employed and individual business owners (less than 20 employees) received a state benefit of EUR 800 and an additional 178538 beneficiaries received an exceptional financial support of EUR 300 or EUR 534 from 1 May to 31 May 2020. Additional financial aid was extended in December 2020, including the reimbursement of 2019 social security contributions to 158600 self-employed, freelancers and farmers (total of EUR 135 million). In March 2021, "GEFIRA II" or "Bridge" programme began offering subsides for 8-months. Training vouchers are offered widely to complement these financial measures. 


\section{Inclusive entrepreneurship indicators}

Figure 21.1. Entrepreneurship and self-employment data for Greece

a. Conditions for entrepreneurship, 2020

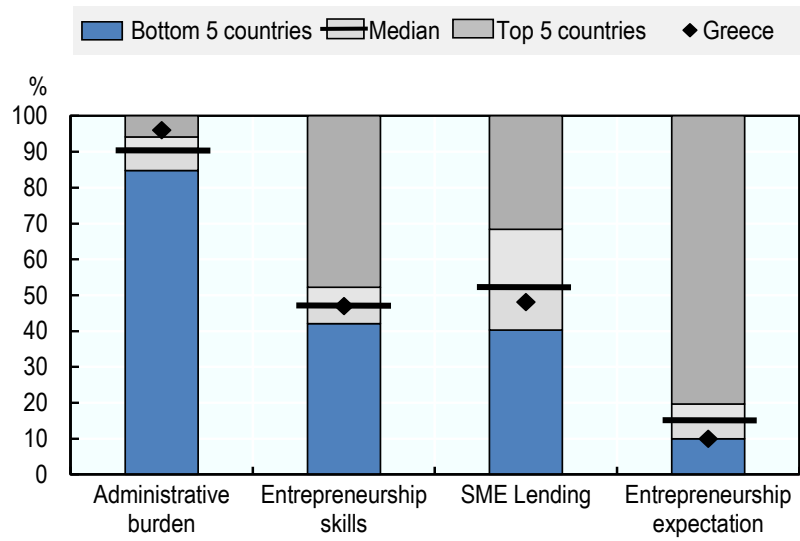

c. Share of TEA that is necessity-based, 2016-20

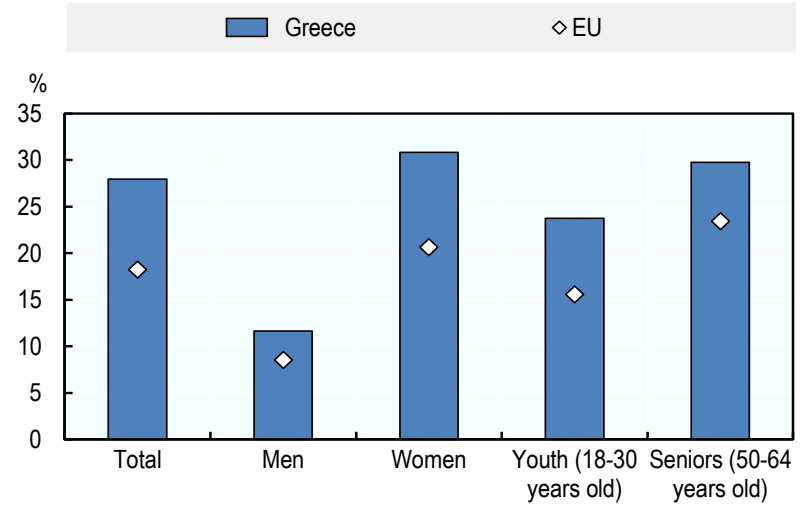

e. Self-employment rate

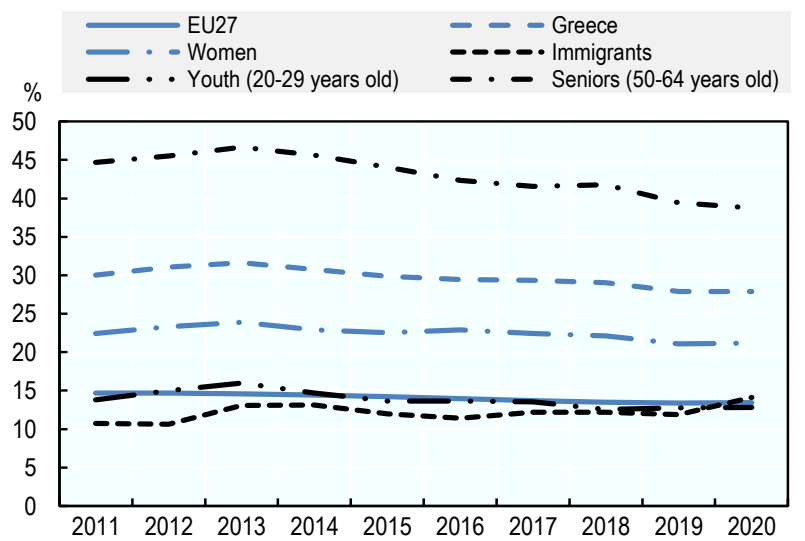

b. TEA rate, $2016-20$
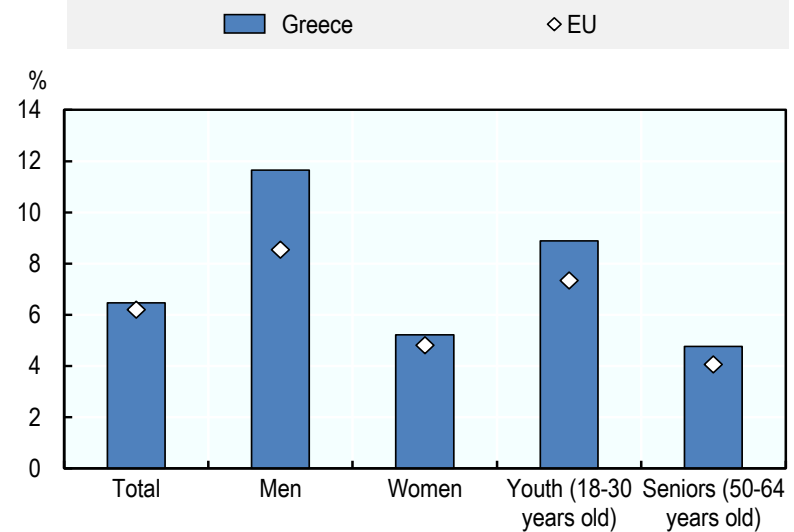

d. Share of TEA that expects to create at least 19 jobs over the next 5 years, 2016-20

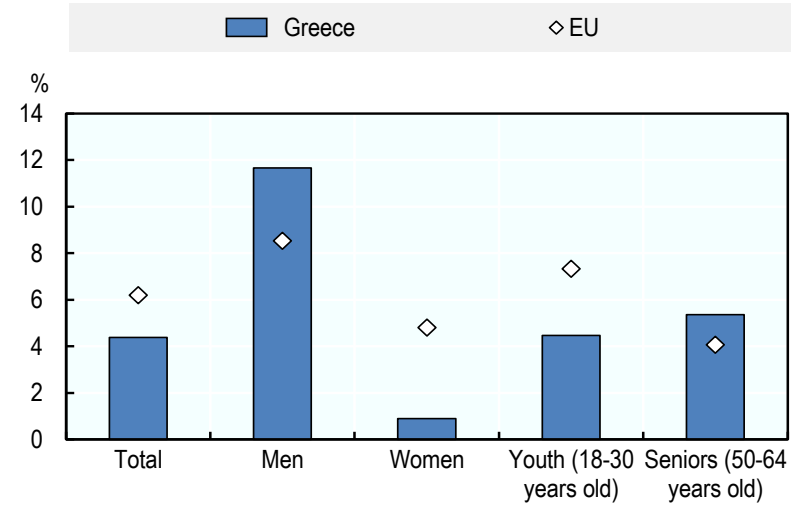

f. Share of self-employed with employees

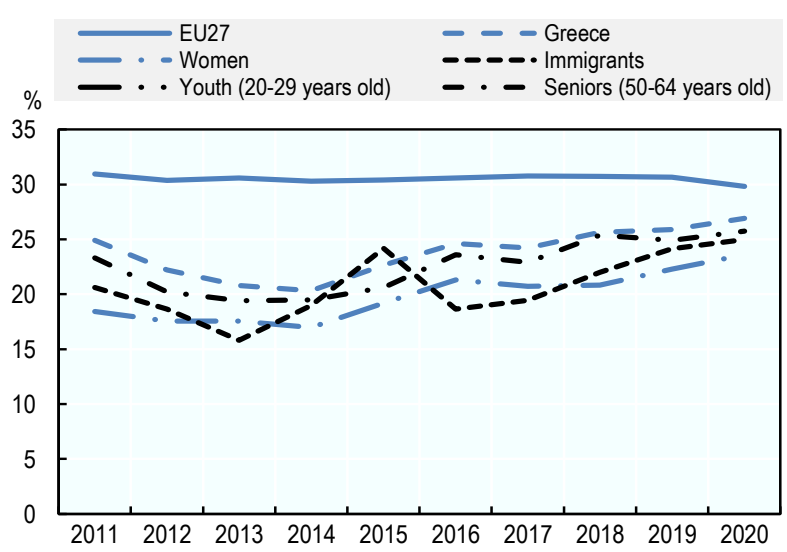

Note: The EU average in panels b-d excludes Belgium, Czech Republic, Denmark, Lithuania, Malta and Romania. Please see Chapter 9 for notes on the figures.

Source: Panel a: (World Bank, 2020[3]; Global Entrepreneurship Monitor (GEM), 2021 [4]; OECD, forthcoming[5]); Panels b-d: (Global Entrepreneurship Monitor (GEM), 2021 $\left.1_{[4]}\right)$; Panels e-f: (Eurostat, 2021 $\left.{ }_{[6]}\right)$. Please see Chapter 9 for the full citations. 


\section{Hungary}

This country profile presents self-employment and entrepreneurship data for women, youth, seniors and immigrants in Hungary relative to the average for the European Union. It also benchmarks the conditions for entrepreneurship and highlights current inclusive entrepreneurship policy issues and recent developments.

\section{Conditions for inclusive entrepreneurship}

Entrepreneurship conditions are generally less favourable than the European Union (EU) average. Despite ongoing efforts to reduce administrative burden, new start-ups still face greater administrative burden than on average in the EU. There are several ongoing initiatives that seek to improve these conditions such as the new Strategy on Small and Medium Enterprises for 2019-30 and self-employment is also to be supported by labour market measures planned for the 2020-30 period. Some tailored support measures for youth, women and the unemployed, are in place and focus on combining entrepreneurship training, mentoring, and financial assistance. Overall, dedicated support is strongest for youth entrepreneurs as several measures were introduced following the financial crisis in 2008-09 as part of the Youth Guarantee.

\section{Recent trends}

In the period 2016-20, the early-stage entrepreneurship rate was above the EU average (8\% vs. $6 \%$ ), due in part to a high share of young people in new start-ups ( $9 \%$ vs. $7 \%$ for the EU). Despite this above-average rate, youth - as well as women and seniors - continue to be under-represented in entrepreneurship. For example, women were half as likely as men to be involved in early-stage entrepreneurship. Eliminating the differences across all population groups (i.e. applying the early-stage entrepreneurship rate of men who are 30-49 years old to the whole population) would result in 300000 more entrepreneurs. Of these "missing" entrepreneurs, $75 \%$ are female and slightly more than half are 50-64 years old.

The self-employment rate remained stable yet below the EU average over the last decade $(11 \%$ vs. nearly $14 \%$ in 2020). Compared to the EU average, there were lower shares of immigrants ( $1 \%$ vs. $7 \%$ ), seniors ( $34 \%$ vs. $41 \%)$ and to a lesser extent, youth ( $6 \%$ vs. $7 \%)$. However, the self-employed were more likely to have employees relative to the EU average (39\% vs. 30\%), notably self-employed women and seniors.

\section{Hot policy issue}

In response to the COVID-19 crisis, the Economy Protection Action Plan 2020 (Gazdaságvédelmi Akcióterv) was introduced in March 2020. A dedicated webpage was launched for entrepreneurs with information on available supports and online training modules. A series of capital programmes were also offered to relaunch enterprises with a total budget of HUF 100 billion (EUR 277.8 million). The maximum amount of the loan was HUF 10 million (EUR 27780 ) with $0 \%$ annual interest for a maximum of 10 years and a 3-year grace period. More than 5000 businesses applied within the first four days after the launch with an average loan of HUF 9.2 million (EUR 26 289). Furthermore, a compensation scheme has been introduced for those self-employed who operate in sectors adversely affected by the COVID-19 related restrictions but who were not entitled to the sectoral wage subsidy 


\section{Inclusive entrepreneurship indicators}

Figure 22.1. Entrepreneurship and self-employment in Hungary

a. Conditions for entrepreneurship, 2020

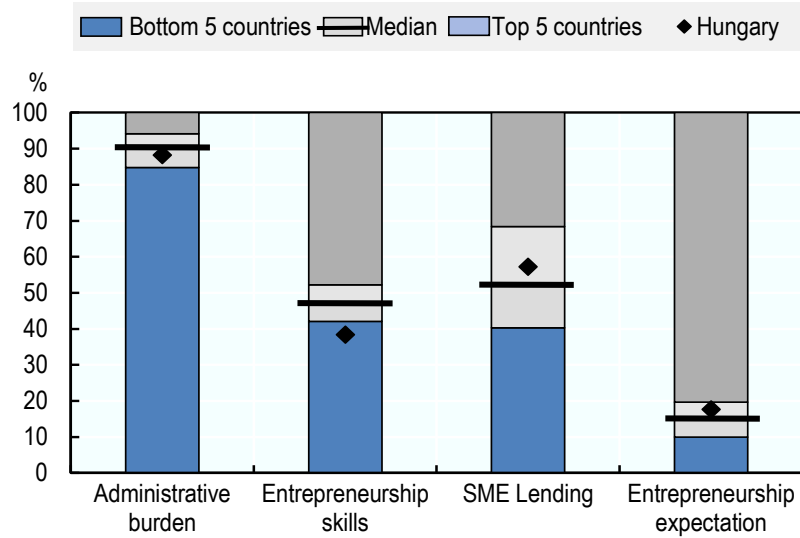

c. Share of TEA that is necessity-based, 2016-20

Hungary

$\diamond \mathrm{EU}$

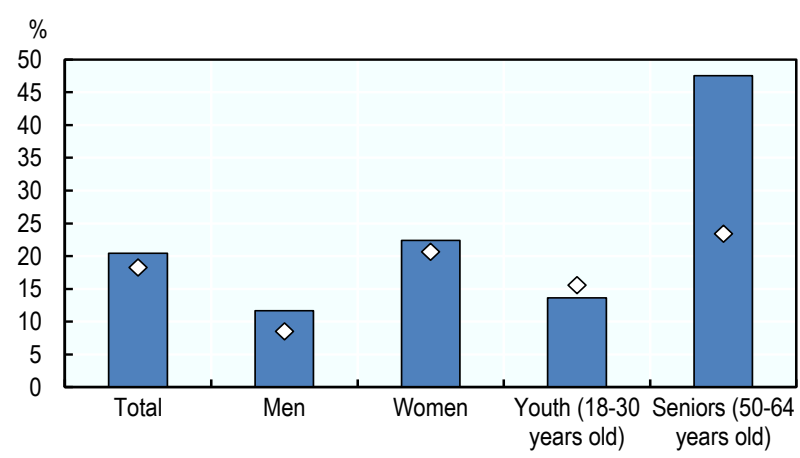

e. Self-employment rate

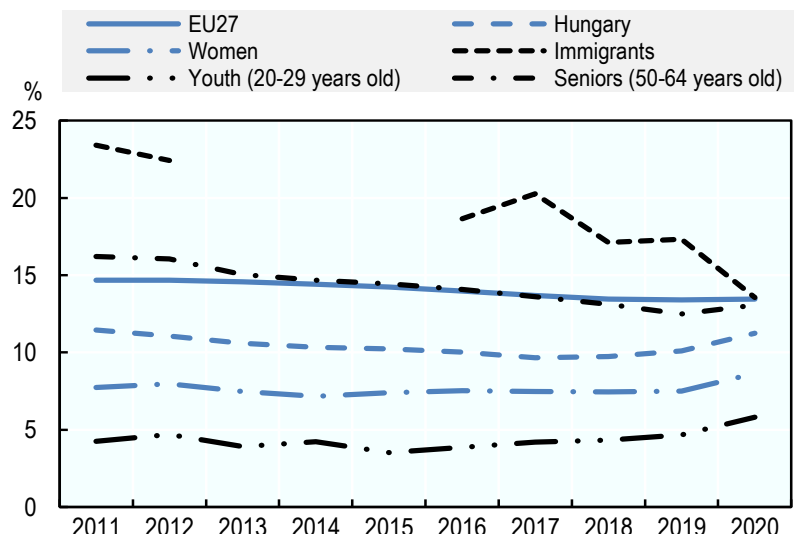

b. TEA rate, $2016-20$

Hungary $\diamond \mathrm{EU}$

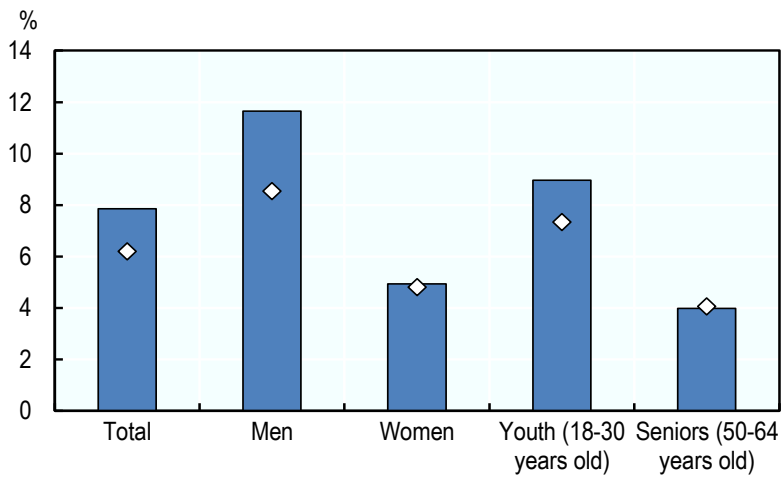

d. Share of TEA that expects to create at least 19 jobs over the next 5 years, 2016-20

$\square$ Hungary $\diamond \mathrm{EU}$

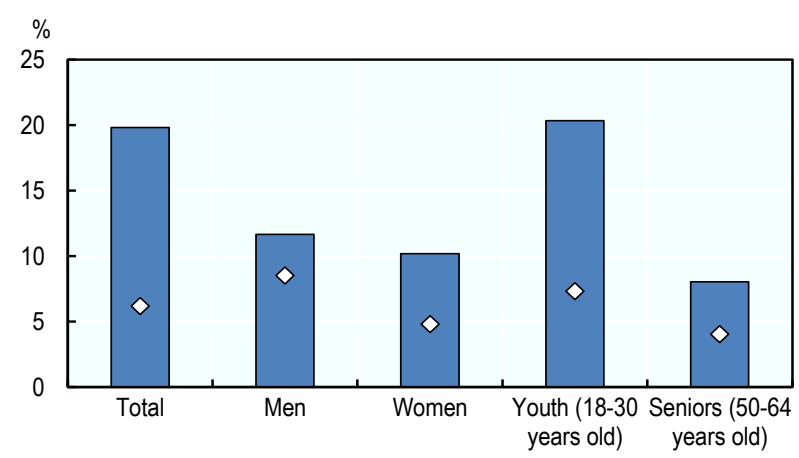

f. Share of self-employed with employees

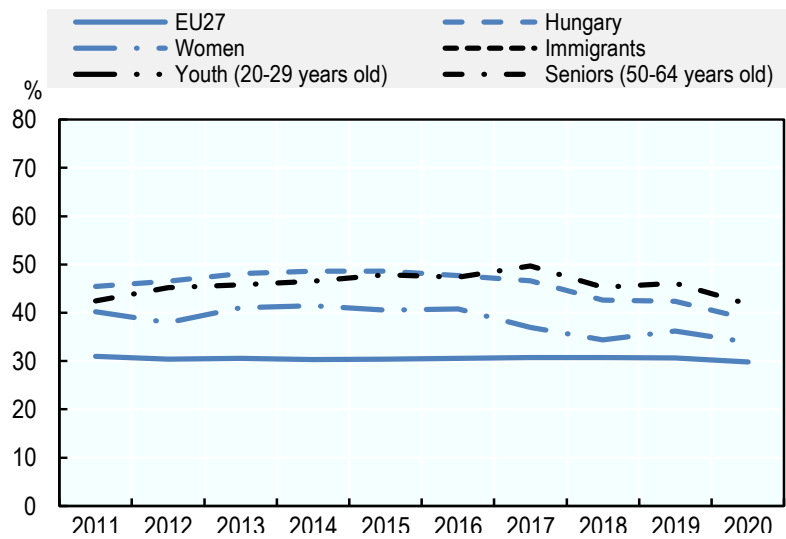

Note: The EU average in panels b-d excludes Belgium, Czech Republic, Denmark, Lithuania, Malta and Romania. Please see Chapter 9 for notes on the figures.

Source: Panel a: (World Bank, 2020[1]; Global Entrepreneurship Monitor (GEM), 2021[2]; OECD, forthcoming[3]); Panels b-d: (Global Entrepreneurship Monitor (GEM), 2021 $\left.1_{[2]}\right)$; Panels e-f: (Eurostat, 2021 $\left.{ }_{[4]}\right)$. Please see Chapter 9 for the full citations. 


\section{Ireland}

This country profile describes current inclusive entrepreneurship policy issues and recent developments in Ireland, including the COVID-19 response. It also benchmarks self-employment and entrepreneurship indicators for women, youth, seniors and immigrants against the average for the European Union.

\section{Conditions for inclusive entrepreneurship}

The overall entrepreneurship conditions are about average among European Union (EU) Member States. Areas of strength include low levels of administrative burden on new start-ups and investor protection, while SME lending was slightly below the EU median in 2020. Entrepreneurship policies overall are welldeveloped with a range of programmes for entrepreneurs from different population groups but there is not co-ordinated inclusive entrepreneurship policy. There is significant support for female entrepreneurs (e.g. Starting Strong, Going for Growth) and some support available for the unemployed. There are few targeted supports for youth, but they have been very successful (e.g. Ireland's Best Young Entrepreneur).

\section{Recent trends}

The share of people starting or managing a new business was nearly double the EU average between 2016 and 2020 ( $11 \%$ vs. $6 \%$ ). Women, youth and seniors also had early-stage entrepreneurship rates wellabove the EU average and a high proportion expected high levels of growth. Despite these positive findings, there are gaps in entrepreneurship activity rates across most population groups. Eliminating these gaps in entrepreneurship activity rates would result in an additional 115000 entrepreneurs. About $90 \%$ of these "missing" entrepreneurs are female, $33 \%$ are over 50 years old and $33 \%$ are immigrants.

The self-employment rate declined over the last decade (15\% in 2011 to $12 \%$ in 2020). The self-employed differ from the EU average as there is a greater share over 50 years old and a greater share of immigrants. Moreover, women were three times less likely to be self-employed than men despite having higher rates of tertiary education ( $64 \%$ vs. $35 \%$ ) - about 20 percentage points higher than the EU average.

\section{Hot policy issue}

Several supports for the self-employed were established during the COVID-19 pandemic, such as the COVID-19 Wage Subsidy Scheme (replaced after August 2020), the Employment Wage Subsidy Scheme and a COVID-19 Pandemic Unemployment Payment. Additionally, the Restart Grant provided grants (EUR 4000 to EUR 25000 ) to micro and small-enterprises to support re-opening following temporary closures. Financial measures were boosted in the 2021 Budget, including the Tax Debt Warehousing scheme, repayments of Temporary Wage Subsidy Scheme funds owed by employers and preliminary tax obligations for self-employed workers. Between January and June 2021, the COVID-19 Business Aid Scheme provided up to EUR 8000 to an estimated 7500 companies, self-employed workers and sole traders or partnerships who experienced significant turnover loss. 


\section{Inclusive entrepreneurship indicators}

Figure 23.1. Entrepreneurship and self-employment in Ireland

a. Conditions for entrepreneurship, 2020

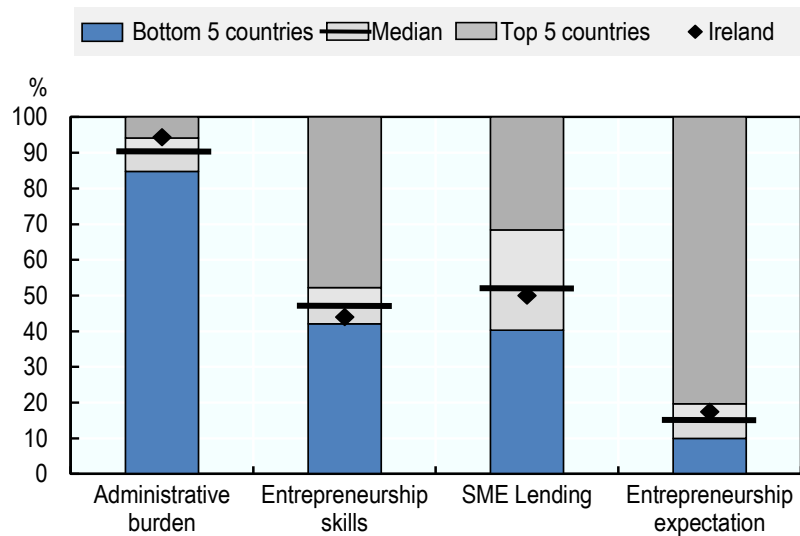

c. Share of TEA that is necessity-based, 2016-20

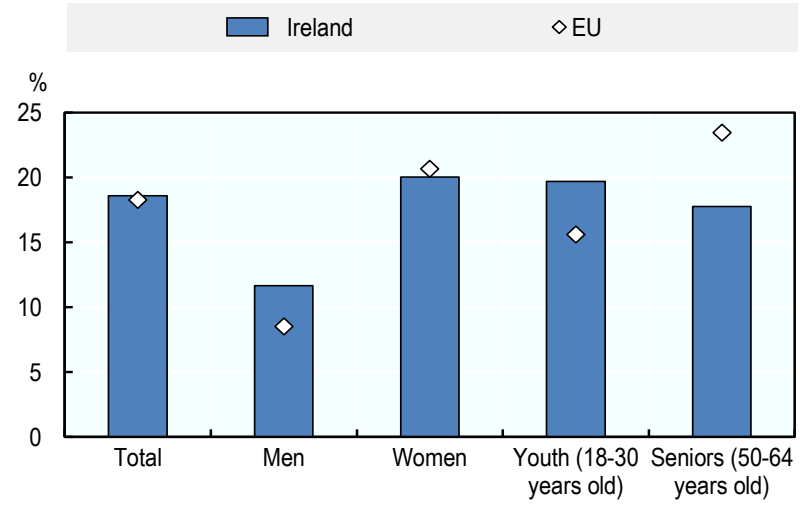

e. Self-employment rate

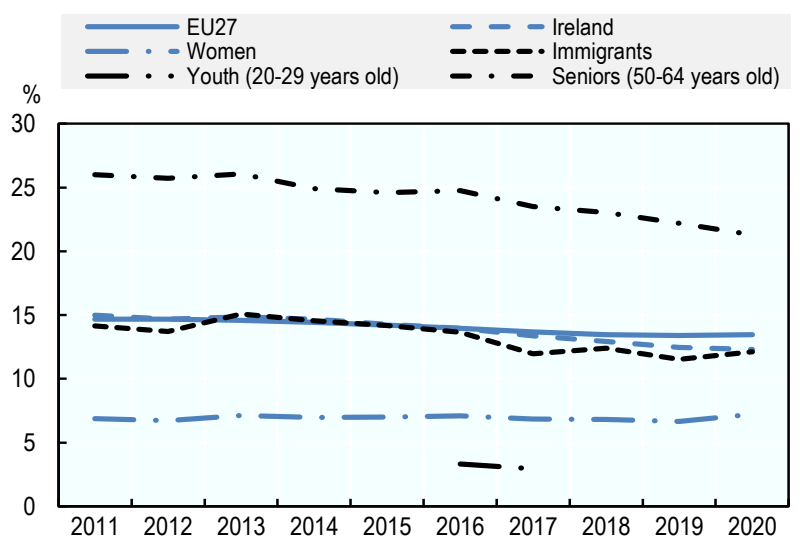

b. TEA rate, 2016-20

$\square$ Ireland $\diamond \mathrm{EU}$

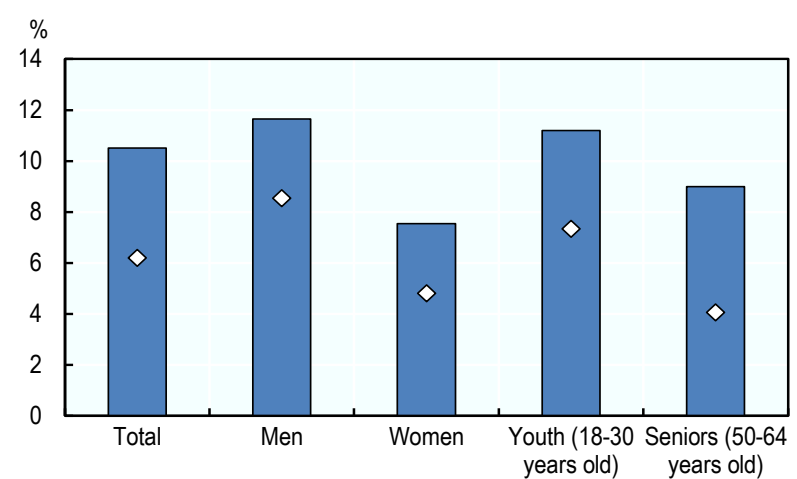

d. Share of TEA that expects to create at least 19 jobs over the next 5 years, 2016-20

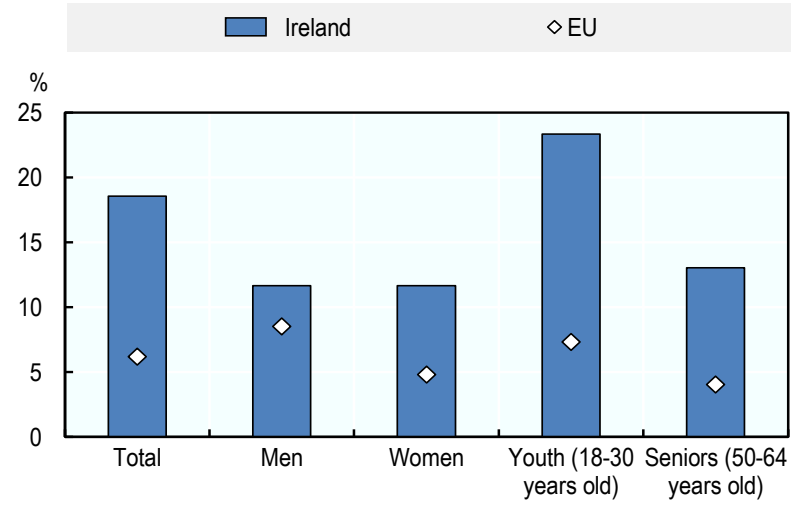

f. Share of self-employed with employees

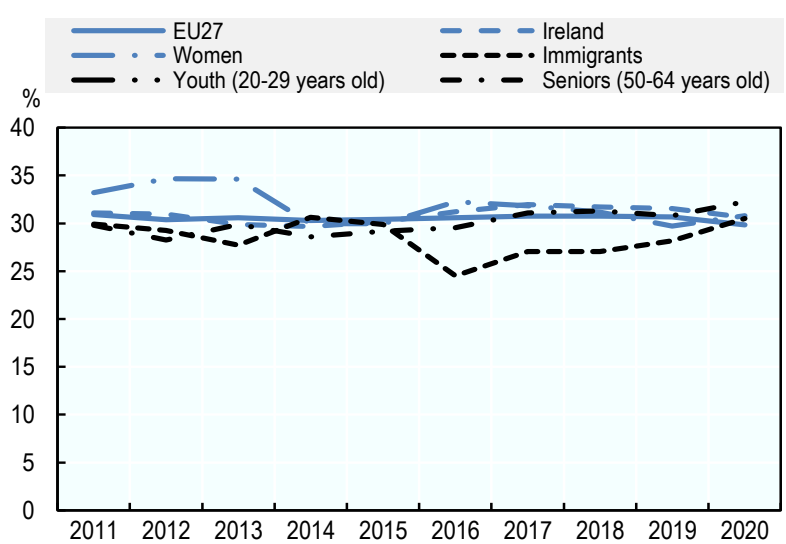

Note: The EU average in panels b-d excludes Belgium, Czech Republic, Denmark, Lithuania, Malta and Romania. Please see Chapter 9 for notes on the figures.

Source: Panel a: (World Bank, 2020[1]; Global Entrepreneurship Monitor (GEM), 2021[2]; OECD, forthcoming[3]); Panels b-d: (Global Entrepreneurship Monitor (GEM), 2021[2]); Panels e-f: (Eurostat, 2021 [4]]). Please see Chapter 9 for the full citations. 


\section{Italy}

This country profile highlights current inclusive entrepreneurship policy issues and recent developments in Italy. It also presents self-employment and entrepreneurship data for women, youth, seniors and immigrants relative to the average for the European Union and reports on the conditions for entreprenuership.

\section{Conditions for inclusive entrepreneurship}

Framework conditions that facilitate entrepreneurship are often rated as above average relative to other European Union (EU) Member States. However, access to finance can be a challenge for many entrepreneurs and some indicators suggest that this challenge is greater than in other EU countries. Recent inclusive entrepreneurship support has been mainly focused on supporting youth, often as part of the Youth Guarantee and the Youth Employment Initiative. There has also been public support for women's entrepreneurship, recently driven by the Committees for Female Entrepreneurship that were set-up by the Ministry for Economic Development and the Union of the Chambers of Commerce. However, little support is in place for some target groups such as immigrants and people who experience disabilities.

\section{Recent trends}

Relatively few people appear to be creating new businesses. The share of the population involved in starting and managing a new business was about half of the EU average over the period 2016-20 and early-stage entrepreneurship rates were particularly low among women and seniors. Eliminating the gaps in activity rates across population groups (i.e. applying the early-stage entrepreneurship rate of men who are 30-49 years old to the whole population) would result in nearly 1.2 million more entrepreneurs. About $70 \%$ of these "missing" entrepreneurs are female and nearly $50 \%$ are between 50 and 64 years old.

Despite the low rates of new business creation, the proportion of people who are self-employed is wellabove the EU average. However, this share is declining, likely due to combination of retirements and fewer young self-employed people - the share of working youth who are self-employed declined 2.5 percentage points over the past decade and the share of seniors declined 3.5 percentage points.

\section{Hot policy issue}

The Ministry of Labour and Social Policies introduced COVID-19 relief measures designed for the selfemployed. The fundamental policy measure provided an emergency income (reddito di emergenza) of EUR 400 to EUR 800 per month to those who could no longer work due to COVID-19 (as of July 2020). The Ministry of Equal Opportunities and the Family allocated an extra EUR 5 million to an existing fund for SMEs specifically dedicated to female entrepreneurship. Several regions further supplemented this income measure and provided supports aimed for female-led and youth-led firms (e.g. grants and the possibility of partial advance payments). Moreover, Invitalia offered a single payment contribution to compliant beneficiaries of the Resto al Sud programme to pay wages and avoid layoffs during the COVID-19 crisis. 


\section{Inclusive entrepreneurship indicators}

Figure 24.1. Entrepreneurship and self-employment in Italy

a. Conditions for entrepreneurship, 2020

Bottom 5 countries $\square$ Median $\square$ Top 5 countries

$\bullet$ Italy

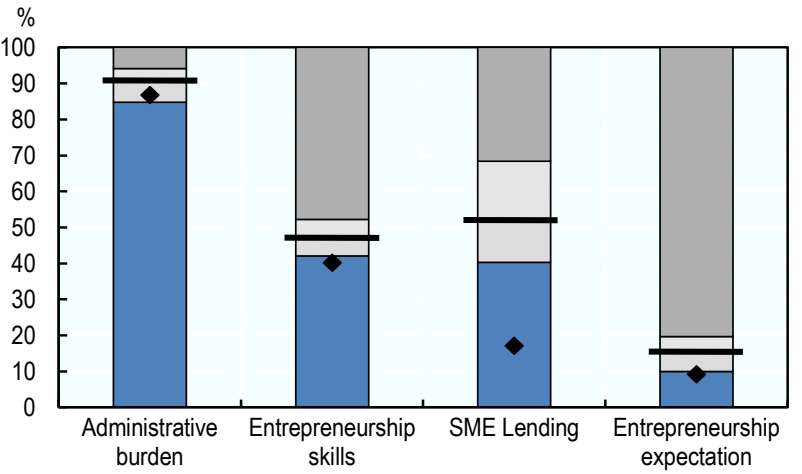

c. Share of TEA that is necessity-based, 2016-20

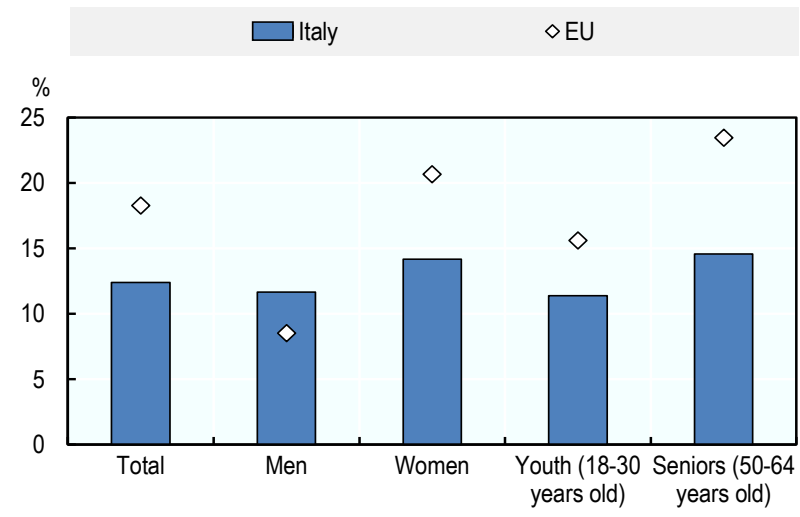

e. Self-employment rate

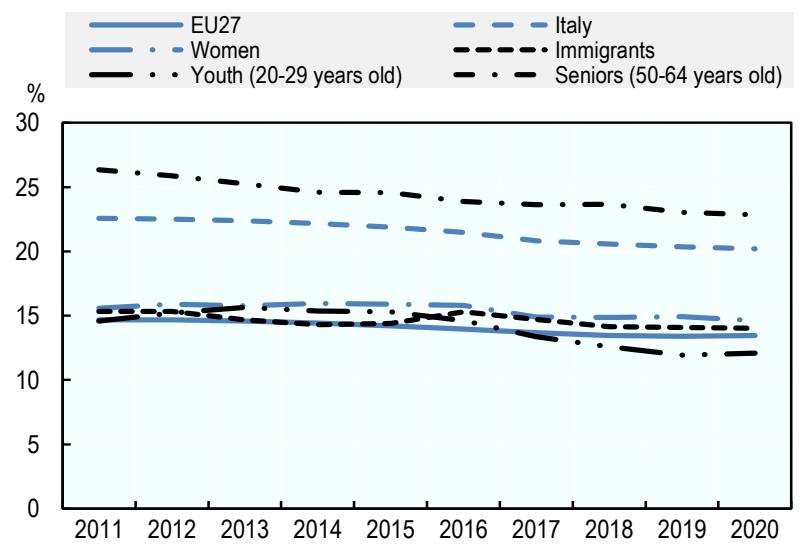

b. TEA rate, $2016-20$
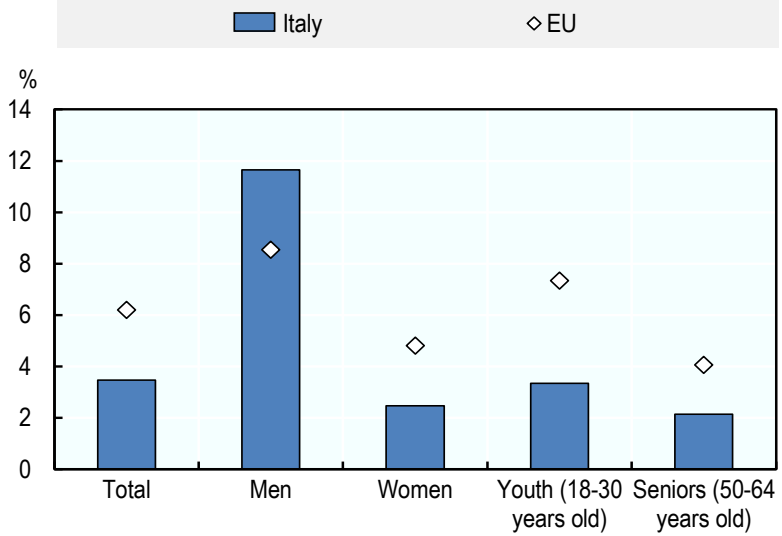

d. Share of TEA that expects to create at least 19 jobs over the next 5 years, 2016-20

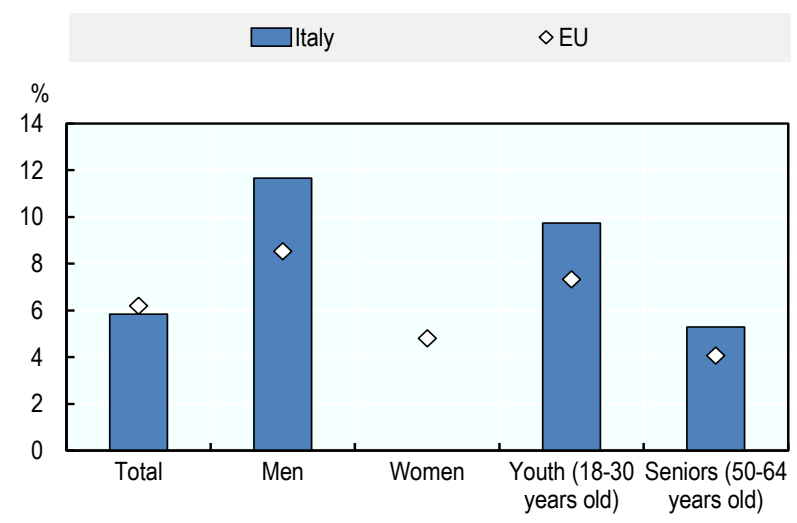

f. Share of self-employed with employees

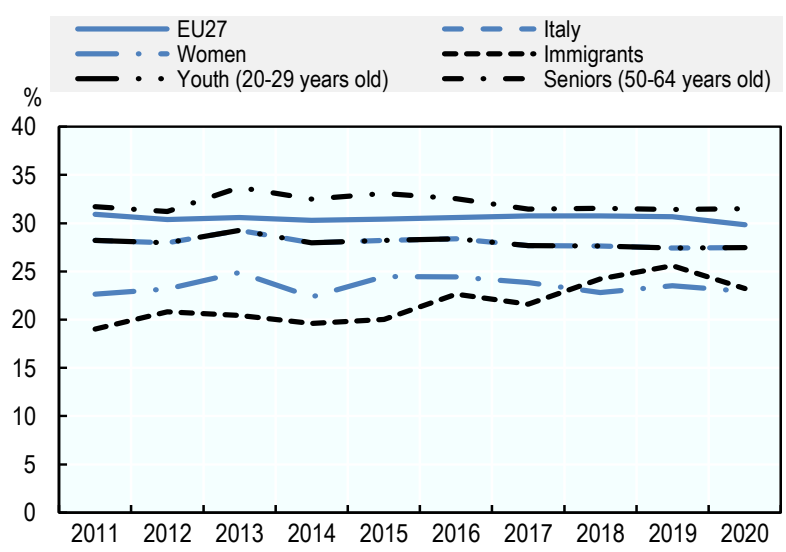

Note: The EU average in panels b-d excludes Belgium, Czech Republic, Denmark, Lithuania, Malta and Romania. Please see Chapter 9 for notes on the figures.

Source: Panel a: (World Bank, 2020[1]; Global Entrepreneurship Monitor (GEM), 2021[2]; OECD, forthcoming[3]); Panels b-d: (Global Entrepreneurship Monitor (GEM), 2021 $\left.1_{[2]}\right)$; Panels e-f: (Eurostat, 2021 $\left.{ }_{[4]}\right)$. Please see Chapter 9 for the full citations. 


\section{Latvia}

This country profile benchmarks key self-employment and entrepreneurship indicators for women, youth, seniors and immigrants in Latvia against the average for the European Union. It also reports on the conditions for entrepreneurship and describes recent inclusive entrepreneurship policy actions.

\section{Conditions for inclusive entrepreneurship}

Entrepreneurship framework conditions are generally favourable and rank among the highest European Union (EU) Member States for several key indicators. Efforts to build on these strengths are ongoing, including the new Business Environment Plan (2019-21) that streamlines online business registration and increases the availability of digital public services as well as several measures to improve access to financing (i.e. start-up and micro loans, portfolio guarantees, the strengthening of venture capital programmes). Strategies and objectives for supporting specific groups such as youth, women, migrants or seniors have not been developed and tailored support schemes are generally not available.

\section{Recent trends}

Over the period 2016-20, the proportion of the population involved in starting or managing a new business was about three times the EU average $(21 \%$ vs. $6 \%)$. However, nearly one-third of these entrepreneurs reported that they started their business due to a lack of opportunities in the labour market. Seniors (5064 years old) had the highest levels of necessity-driven entrepreneurship (46\% vs. $24 \%$ for the EU), followed by women ( $34 \%$ vs. $21 \%$ ) and youth (18-30 years old) $(27 \%$ vs. $16 \%)$. Gaps in activity rates can be observed across the population. If all groups engaged in early-stage entrepreneurship at the same rate as core-age men, there would be 84000 more entrepreneurs. About $80 \%$ of these "missing" entrepreneurs are female and $70 \%$ are over 50 years old. However, there are virtually no "missing" youth entrepreneurs

Self-employment increased over the previous decade, particularly among immigrants. The proportion of immigrants who were self-employed increased from $6.5 \%$ in 2011 to $14.6 \%$ in 2020 .

\section{Hot policy issue}

In the wake of the COVID-19 crisis, several measures were implemented for the self-employed such as deferring late tax payments up to three years or paying in instalments. As of March 2020, a monthly allowance for idle time covered $75 \%$ of the average gross monthly wage, ranging from EUR 180 to EUR 700 per worker with a monthly supplement of EUR 50 per dependent child. For those who did not qualify, another support provided EUR 180 per month (plus EUR 50 per dependent child). This allowance was re-launched in November 2020. Unemployment benefits were also extended to micro-entrepreneurs with a benefit of EUR 180 for a period of four months (extended until 31 December 2021). Moreover, ALTUM (a national finance institution) extended guarantees and loans to entrepreneurs, postponed payments and offered liquidity loans up to EUR 1 million. 


\section{Inclusive entrepreneurship indicators}

Figure 25.1. Entrepreneurship and self-employment in Latvia

a. Conditions for entrepreneurship, 2020

Bottom 5 countries $\rightleftharpoons$ Median $\square$ Top 5 countries $\bullet$ Latvia

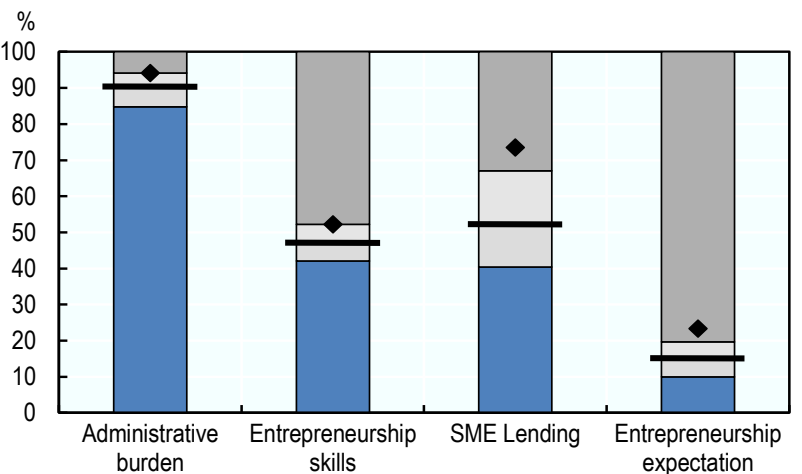

c. Share of TEA that is necessity-based, 2016-20

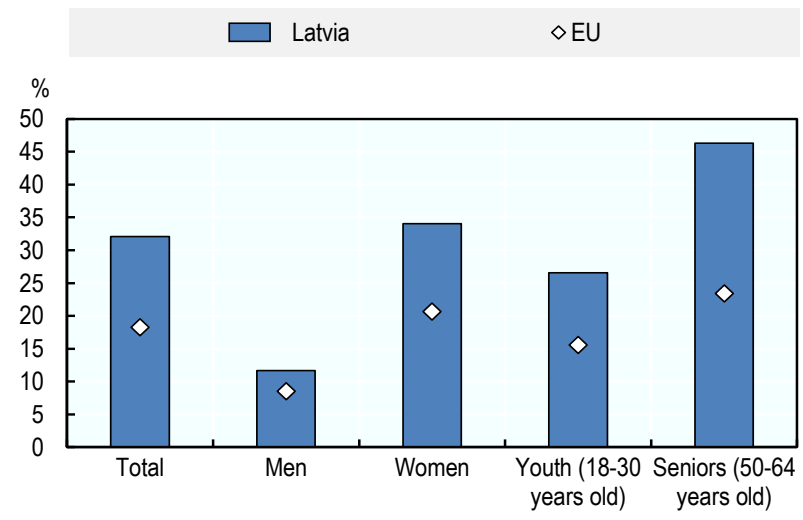

e. Self-employment rate

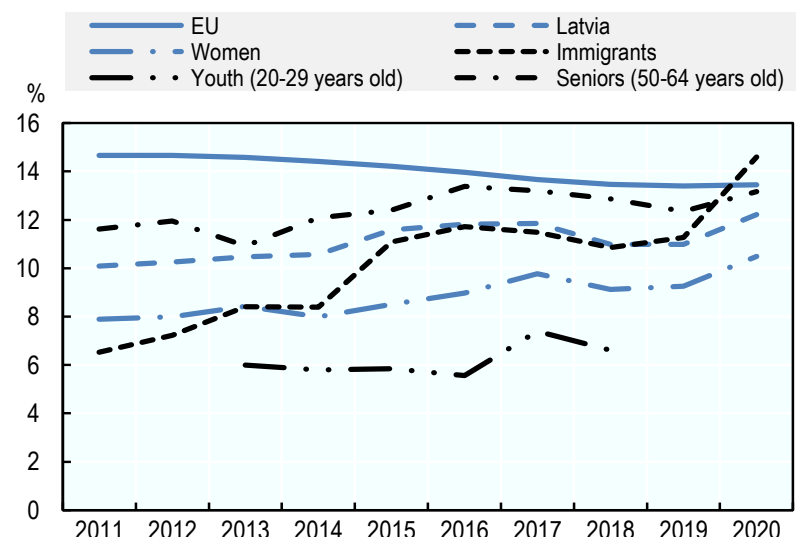

b. TEA rate, $2016-20$

Latvia $\diamond \mathrm{EU}$

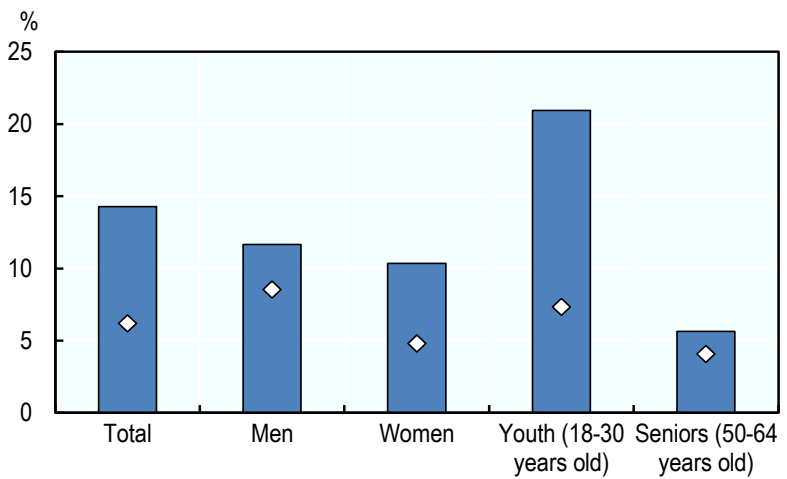

d. Share of TEA that expects to create at least 19 jobs over the next 5 years, 2016-20

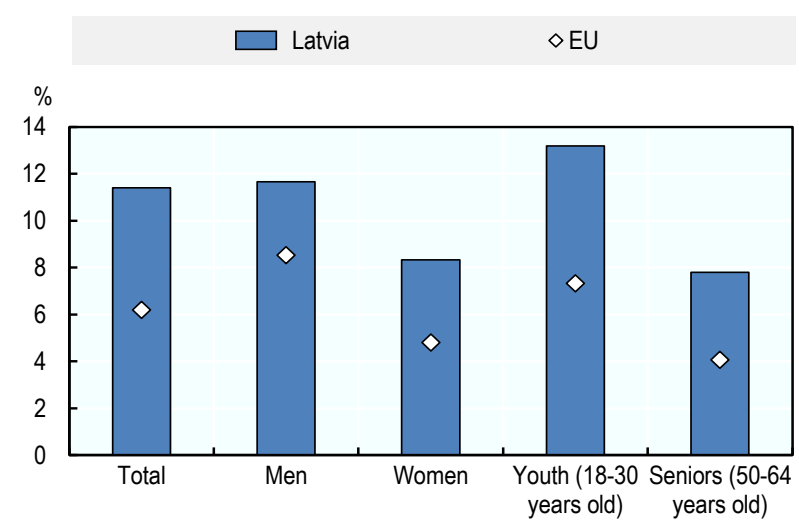

f. Share of self-employed with employees

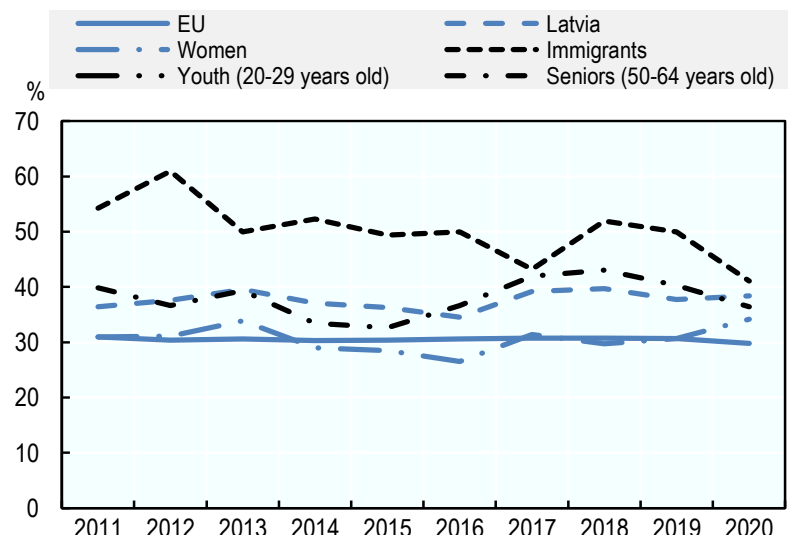

Note: The EU average in panels b-d excludes Belgium, Czech Republic, Denmark, Lithuania, Malta and Romania. Please see Chapter 9 for notes on the figures.

Source: Panel a: (World Bank, 2020[1]; Global Entrepreneurship Monitor (GEM), 2021[2]; OECD, forthcoming[3]); Panels b-d: (Global Entrepreneurship Monitor (GEM), 2021 $\left.1_{[2]}\right)$; Panels e-f: (Eurostat, 2021 $\left.{ }_{[4]}\right)$. Please see Chapter 9 for the full citations. 


\section{Lithuania}

This country profile presents recent trends in entrepreneurship by women, youth and seniors, including the self-employment rate. It also highlights current inclusive entrepreneurship policy issues and recent developments and reports on entrepreneurship conditions.

\section{Conditions for inclusive entrepreneurship}

Some of the framework conditions for entrepreneurship are fairly strong, notably the level of administrative burden on new start-ups. However, there are low levels of reported entrepreneurship skills and access to finance for new start-ups often ranks below the European Union (EU) median. Entrepreneurship policy and programmes mostly promote competitiveness and innovation. Some progress has been made in implementing an integrated approach to the development of the country's human resources and designing measures for individual target groups. Some tailored measures for business creation and self-employment exist for youth, and to a lesser extent, for the unemployed and people with disabilities.

\section{Recent trends}

Over the last decade, the self-employment rate remained below than the EU average $(11 \%$ vs. nearly $14 \%$ in 2020). The self-employed differ from the EU average in several ways, including higher shares of youth (20-29 years old) in self-employment ( $9 \%$ vs. $7 \%$ ), but lower shares of women, seniors and immigrants. Overall, these population groups were each under-represented in self-employment. Eliminating these gaps (i.e. applying the self-employment rate of men who are 30-49 years old to the whole population), would result in another 45000 self-employed people. These "missing" entrepreneurs are virtually all female while about one-third were between 20 and 30 years old and another one-third between 50 and 64 years old.

\section{Hot policy issue}

In response to the COVID-19 crisis, several policy measures were introduced including tax and state social security deferrals, subsidies for small entrepreneurs and the self-employed and supports to ensure business liquidity. The Lithuanian Employment Service offered a flat rate benefit of EUR 257 per month to self-employed persons who did not have an employment relationship and did not receive income from work. By 1 July 2020, 93049 self-employed workers had applied for the one-time grant, totalling to EUR 5.1 million. Qualifying self-employed workers also received a governmental subsidy for job creation of up to EUR 6 980. Moreover, marketplace vendors who had paid or committed to pay a market place fee received a EUR 300 compensation. Between July to September 2021, 5500 applicants received grants. The programme was renewed in December 2020 through June 2021 with a EUR 2 million budget and a total of 2600 applicants received aid from 5 March 2021 to 18 March 2021. In response to the continued crisis, the State Tax Inspectorate also provided lump sum payments to self-employed workers from March to June 2021. 


\section{Inclusive entrepreneurship indicators}

Figure 26.1. Entrepreneurship and self-employment in Lithuania

a. Conditions for entrepreneurship, 2020

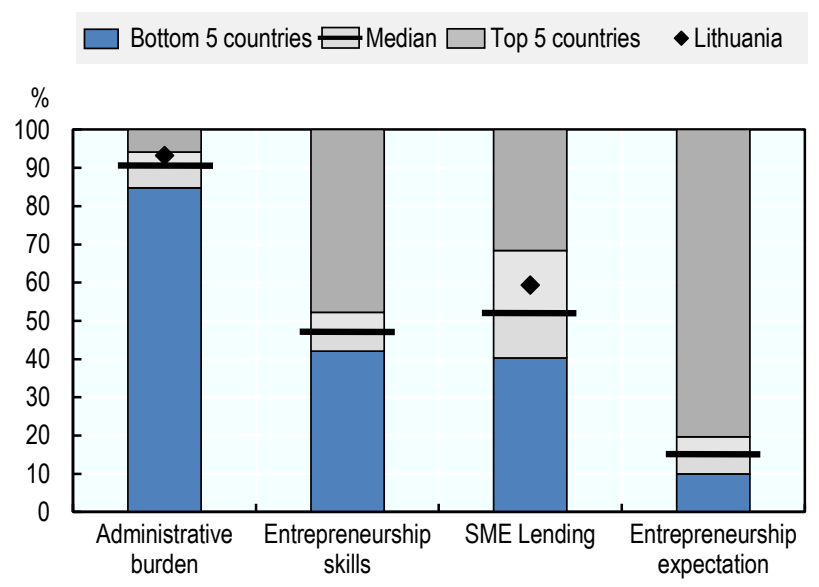

c. Share of self-employed with employees

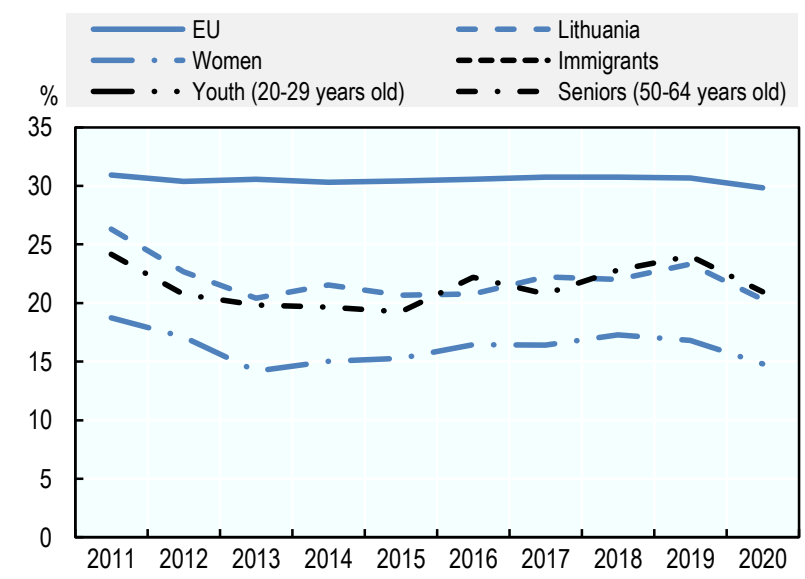

Note: Please see Chapter 9 for notes on the figures.

Source: Panel a: (World Bank, 2020[1]; Global Entrepreneurship Monitor (GEM), $2021_{[2]}$; OECD, forthcoming[3] ); Panels b-c: (Eurostat, 2021 [4]]). Please see Chapter 9 for the full citations. b. Self-employment rate

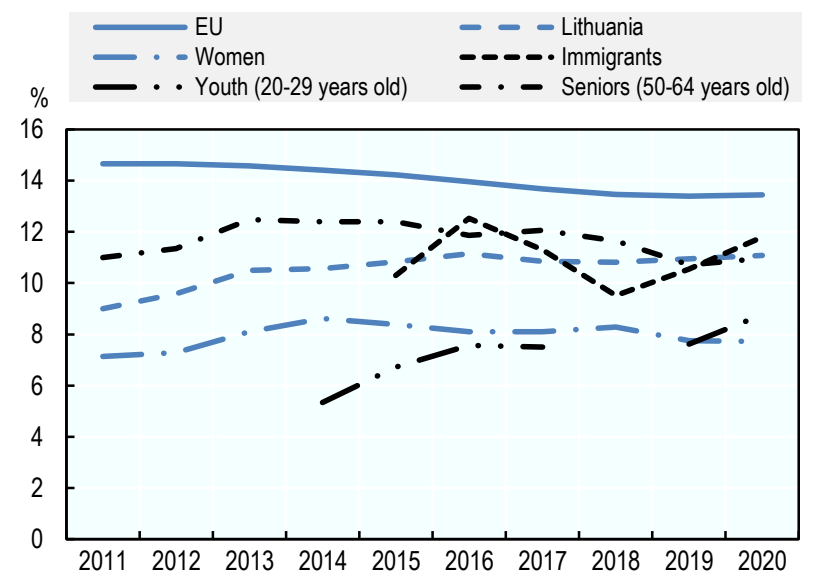




\section{Luxembourg}

This country profile highlights current inclusive entrepreneurship policy issues and recent developments in Luxembourg. It also presents self-employment and entrepreneurship data for women, youth, seniors and immigrants relative to the average for the European Union and reports on entrepreneurship conditions.

\section{Conditions for inclusive entrepreneurship}

The overall entrepreneurship conditions are similar to most of the European Union (EU) Member States. The business environment is characterised by low complexity procedures and low costs for enforcing contracts, yet administrative burden ranks slightly below average due partly to long bankruptcy procedures and notable barriers to entry in the service and network sectors. Policies are in place to address the regulatory environment, including a new simplified limited liability company form to facilitate business creation - la société à responsabilité limitée ("S.à r.I.-S") [“1-1-1 company" (1 person, 1 euro, in 1 day)].

\section{Recent trends}

Between 2016 and 2020, women, youth (18-30 years old) and seniors (50-64 years old) were more involved in early-stage entrepreneurship than on average in the EU. Moreover, many expect to create jobs in the next 5 years, especially youth (15\%) and seniors (12\%). Despite these positive findings, many population groups remain under-represented in entrepreneurship. If all groups engaged in early-stage entrepreneurship at the same rate as core-age men, there would be an additional 9500 entrepreneurs. Virtually all of these "missing" entrepreneurs are female, around two-thirds are over 50 years old.

Over the last decade, workers were almost half as likely to be self-employed compared to the EU average ( $6 \%$ vs. $14 \%$ ), yet self-employed workers were significantly more likely to employ others ( $42 \%$ vs. $30 \%)$. Among the self-employed, women (33\%) and seniors (42\%) were especially likely to have employees.

\section{Hot policy issue}

In response to the COVID-19 crisis, specific measures were introduced to support start-ups, micro enterprises and the self-employed among others, including tolerance for social security contributions and deferment of taxation requirements as well as amendments of taxation for cross-border commuters to facilitate teleworking and e-commerce. As of July 2020, EUR 82.4 million in government grants had been paid to the self-employed and SMEs. The Directorate for SMEs also provided loans of up to EUR 500000 to impacted businesses. By July 2020, 820 loan applications had been approved (EUR 43.7 million in total). Additionally, the self-employed employing less than 10 workers could receive one-time support grants of EUR 2 500, while impacted micro enterprises could also benefit from a one-time non-repayable EUR 5000 grant. As of 19 October 2020, 2547 self-employed workers received the allowance (EUR 6.4 million in total) and 6204 micro enterprises received grants (EUR 31 million in total). Additional measures were introduced to support young start-ups. 


\section{Inclusive entrepreneurship indicators}

Figure 27.1. Entrepreneurship and self-employment in Luxembourg

a. Conditions for entrepreneurship, 2020

$\square$ Bottom 5 countries $\square$ Median $\square$ Top 5 countries • Luxembourg

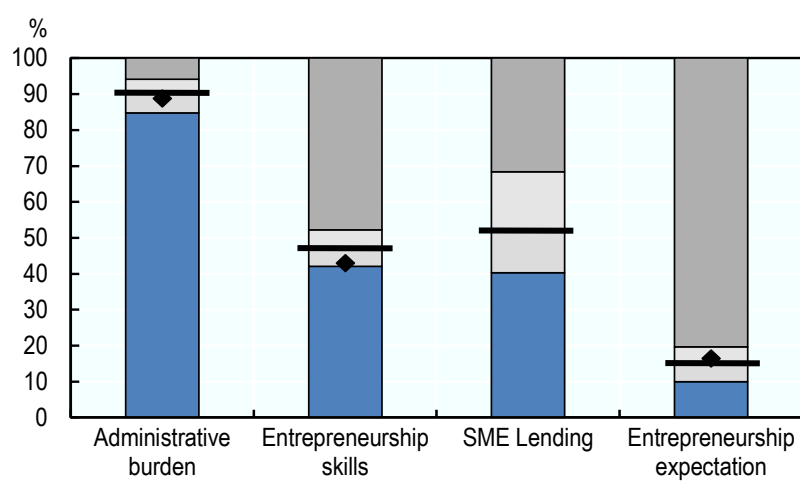

c. Share of TEA that is necessity-based, $2016-20$

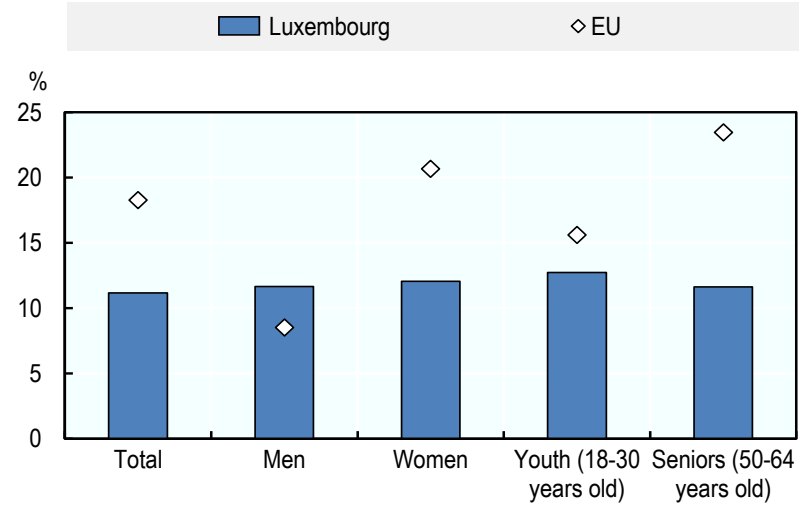

e. Self-employment rate

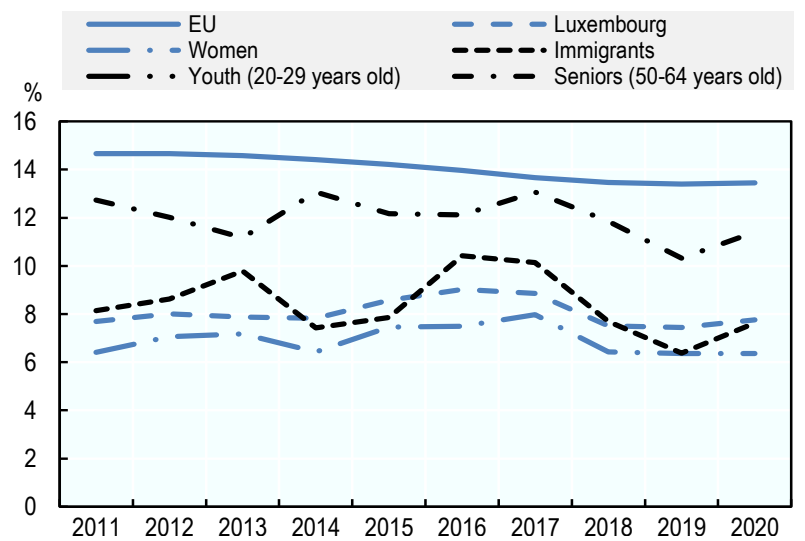

b. TEA rate, $2016-20$

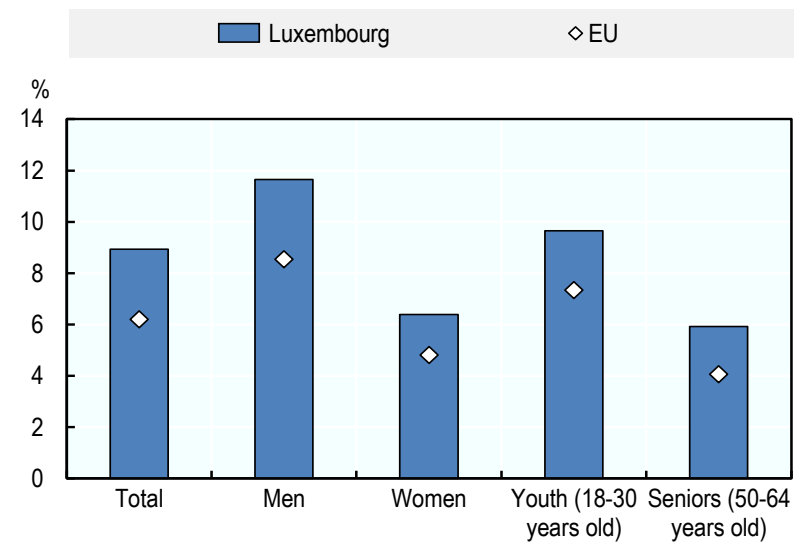

d. Share of TEA that expects to create at least 19 jobs over the next 5 years, 2016-20

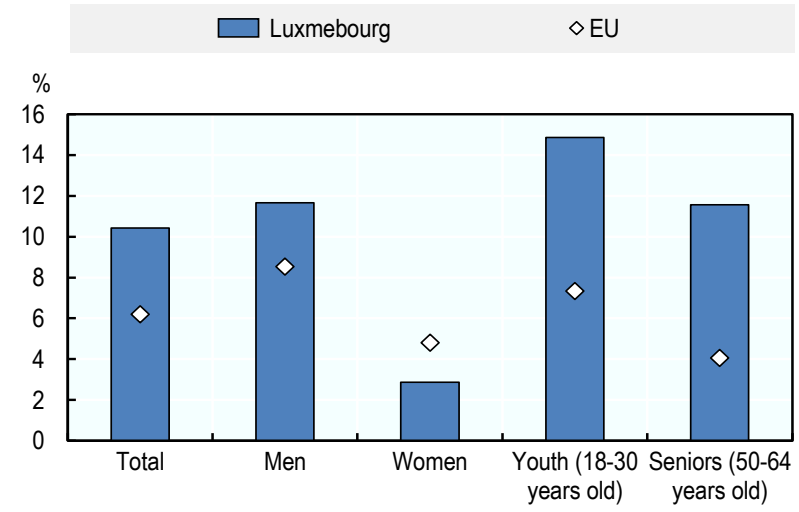

f. Share of self-employed with employees

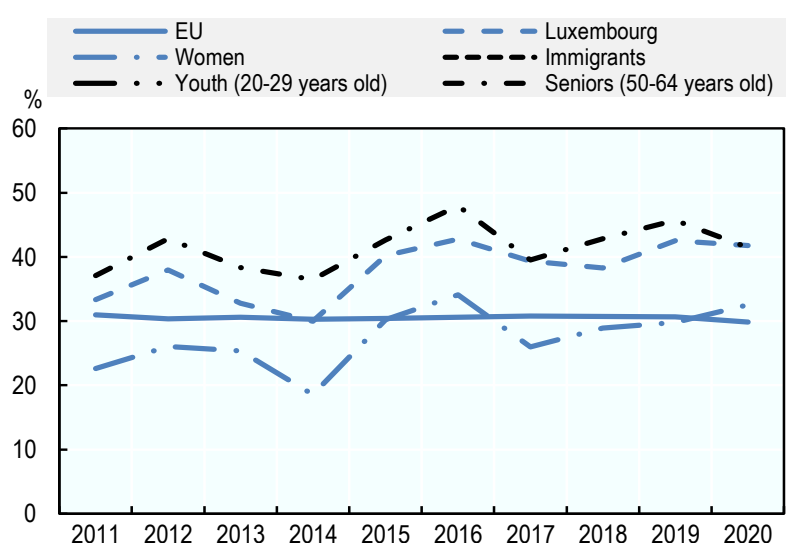

Note: The EU average in panels b-d excludes Belgium, Czech Republic, Denmark, Lithuania, Malta and Romania. Please see Chapter 9 for notes on the figures.

Source: Panel a: (World Bank, 2020[1]; Global Entrepreneurship Monitor (GEM), 2021[2]; OECD, forthcoming[3]); Panels b-d: (Global Entrepreneurship Monitor (GEM), 2021 [2]]); Panels e-f: (Eurostat, 2021 [4]] .Please see Chapter 9 for the full citations. 


\section{Matta}

This country profile describes current inclusive entrepreneurship policy issues and recent developments in Malta. It also benchmarks the self-employment rate and the proportion of self-employed workers who are employers against the European Union average for women, youth, seniors and immigrants.

\section{Conditions for inclusive entrepreneurship}

Overall entrepreneurship conditions improved over the last decade. Labour market indicators are generally positive with a growth rate more than triple the European Union (EU) average in 2018. While ranking among the top 50 innovative economies in the world according the Global Innovation Index (2019) and $4^{\text {th }}$ in new business density (2018 and 2019), administrative burden remains an issue for entrepreneurship, notably challenges such as resolving insolvency, accessing credit and registering property.

\section{Recent trends}

Self-employment gradually increased, converging with the EU average in 2017. In 2020, the selfemployment rate was 2 percentage points higher than the EU average (16\% vs. nearly $14 \%)$. The selfemployed differ from the EU average in several ways, such as seniors (50-64 years old) (33\%) and immigrants $(36 \%)$ employing others at higher rates than on average in the EU. Moreover, immigrants account for a quarter of self-employed - more than three times the EU average. The self-employed also tend to be younger than on average in the EU due to higher shares of youth (20-29 years old) (13\% vs. $7 \%$ ) and lower shares of seniors (50-64 years old) (30\% vs. $17 \%)$. A gender gap is also present as women account for only $25 \%$ of the self-employed relative to $33 \%$ on average in the EU. Eliminating all of the gaps in entrepreneurship activity rates across population groups (i.e. applying the early-stage entrepreneurship rate of core-age men to the whole population) would result in 5700 more entrepreneurs. Almost all of these "missing" entrepreneurs are young females between the ages of 20 and 29 years old.

\section{Hot policy issue}

Malta Enterprise introduced many policy measures during the COVID-19 pandemic. These included the Investment Aid for the Production of COVID-19 Relevant Products Scheme, which provided entrepreneurs with grants, and the Skill Development Scheme, which assisted businesses with fewer than 50 employees in up-skilling their workforce through a EUR 5 million fund. In addition, the Micro-Invest Cash Conversion Scheme permitted qualifying businesses to convert tax credits into grants (up to EUR 2 000) - female entrepreneurs, family-run enterprises and entrepreneurs located in Gozo (i.e. smaller sister island) received EUR 2 5000. Overall, SMEs have received around EUR 5 million in support. Sector specific assistance was also made available with the State Aide Temporary Framework in partnership with the European Commission (EUR 720000 in total). Bluefin tuna fishermen received grants of up to EUR 120000 to compensate for the drop in market price and to support the continuation of their activities. 


\section{Inclusive entrepreneurship indicators}

Figure 28.1. Entrepreneurship and self-employment in Malta

a. Conditions for entrepreneurship, 2020

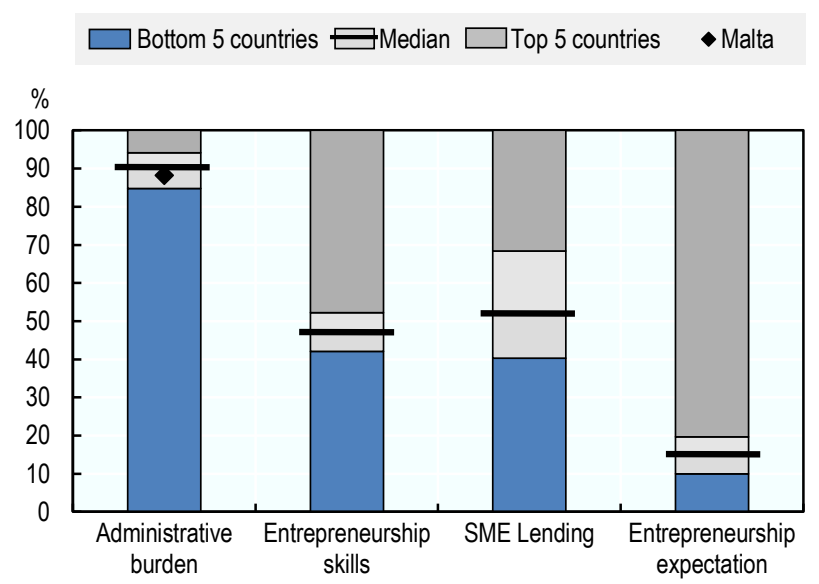

c. Share of self-employed with employees

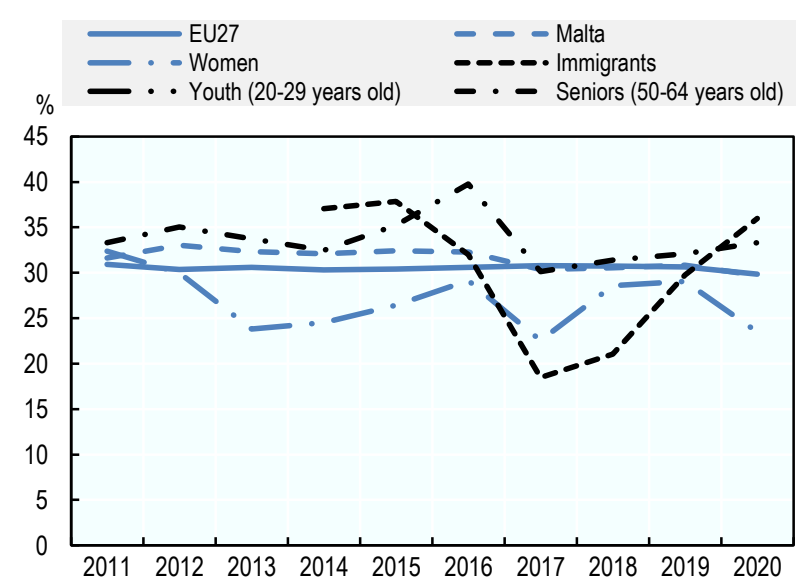

b. Self-employment rate

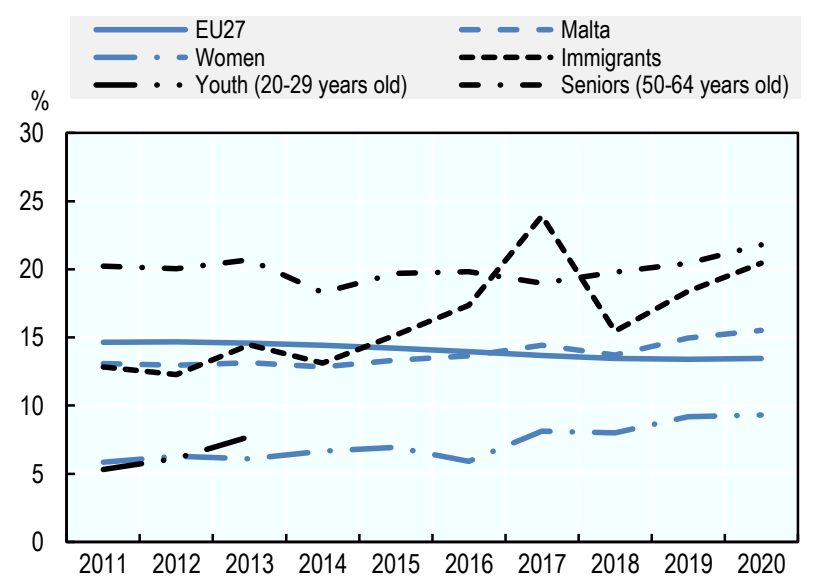

Note: Please see Chapter 9 for notes on the figures.

Source: Panel a: (World Bank, 2020[1]; Global Entrepreneurship Monitor (GEM), 2021 [2]]; OECD, forthcoming[3]); Panels b-C: (Eurostat, 2021[4]]). Please see Chapter 9 for the full citations. 


\section{Netherlands}

This country profile highlights benchmarks self-employment and entrepreneurship indicators for women, youth, seniors and immigrants in the Netherlands against the European Union average. It also reports on recent inclusive entrepreneurship policy actions, including the COVID-19 policy response.

\section{Conditions for inclusive entrepreneurship}

Entrepreneurship conditions are relatively similar to most of the European Union (EU) Member States. While the level of administrative burden and regulatory conditions rank in the top $5 \mathrm{EU}$ countries, the share of SME loans among outstanding business loans was one of the lowest. Public entrepreneurship support is generally provided through an individualised approach. National schemes are often delivered by local agencies and organisations and are complemented by a suite of initiatives from municipal governments and non-government organisations. Many of these initiatives are aimed at women, youth and migrants.

\section{Recent trends}

Between 2016 and 2020, early-stage entrepreneurship rates were higher than the EU average for women ( $10 \%$ vs. $5 \%$ ), youth (18-30 years old) $(17 \%$ vs. $7 \%)$ and seniors $(50-64$ years old) $(8 \%$ vs. $4 \%)$. However, women and seniors continue to be under-represented in entrepreneurship. If all population groups participated in early-stage entrepreneurship at the same rate as core-age men, there would be 300000 more entrepreneurs. About $95 \%$ of these "missing" entrepreneurs are female, $80 \%$ are over 50 years old.

Self-employment increased over the decade with around $90 \%$ of the growth stemming from an increase in own-account workers. All target population groups are more likely to be self-employed relative to the EU average. The self-employed tend to be older as around $22 \%$ are over 55 years old, following recent national labour force trends which will likely continue as the retirement age changes to 67 years old in 2024 .

\section{Hot policy issue}

In the wake of the COVID-19 crisis, an estimated 37 policy measures were introduced by the end of 2020, with a total expected expenditure of EUR 61 billion for 2020 and 2021 (Eurofound, 2020[1]). These measures have undergone several iterations since their introduction and it is estimated that almost half of companies made use of at least one of the measures. The main support for the self-employed (Tijdelijke Overbruggingsregelling Zelfstandige Ondernemers, TOZO) was introduced in March 2020. Nearly all of the one million self-employed who worked before the COVID-19 pandemic could access the five iterations of TOZO. TOZO offered a monthly grant of EUR 1500 per couple or EUR 1000 per individual. Monitoring data show that that TOZO 1 reached an estimated 375000 applicants; TOZO about 2125000 applicants, and TOZO 3 more than 100000 applicants. It is estimated that almost half of companies made use of at least one of the measures of the broader stimulus package (e.g. NOW, TVL) in the Netherlands. Most measures, including the TOZO, have been phased out as of October 2021. 


\section{Inclusive entrepreneurship indicators}

Figure 29.1. Entrepreneurship and self-employment in the Netherlands

a. Conditions for entrepreneurship, 2020

Bottom 5 countries $\succeq$ Median $\square$ Top 5 countries $\bullet$ Netherlands

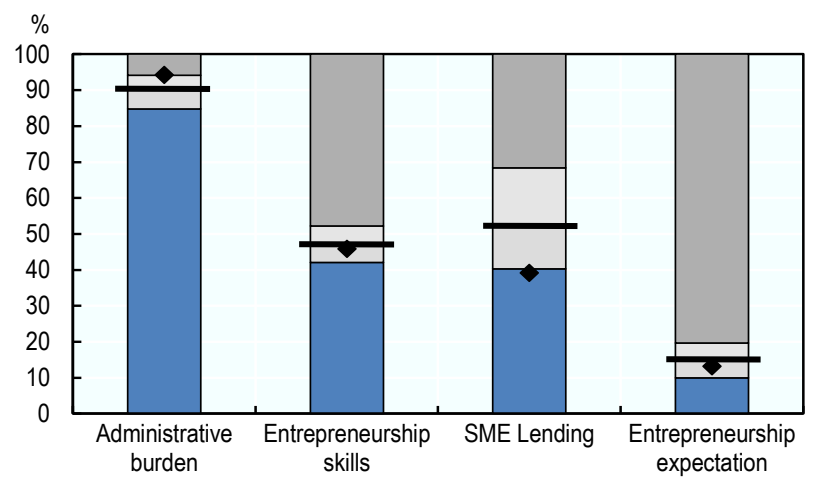

c. Share of TEA that is necessity-based, $2016-20$

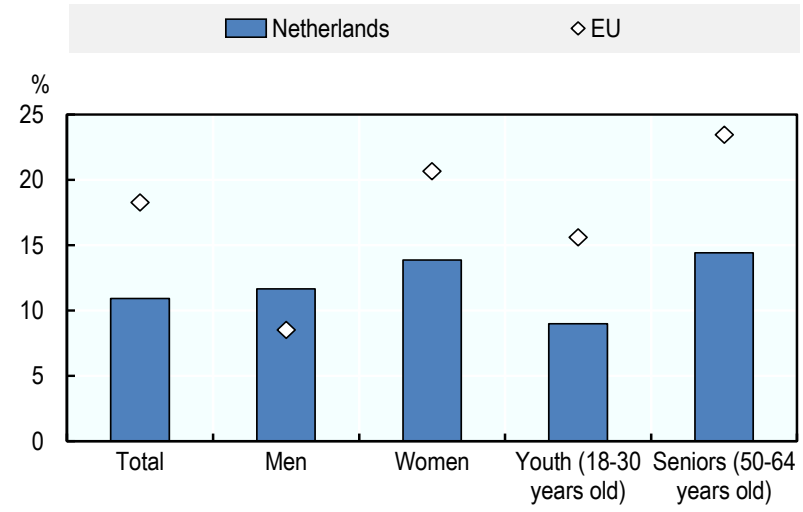

e. Self-employment rate

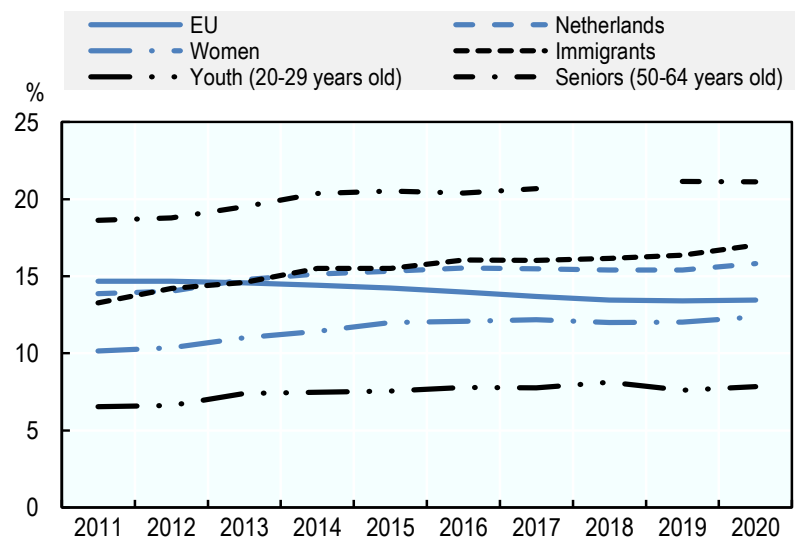

b. TEA rate, $2016-20$

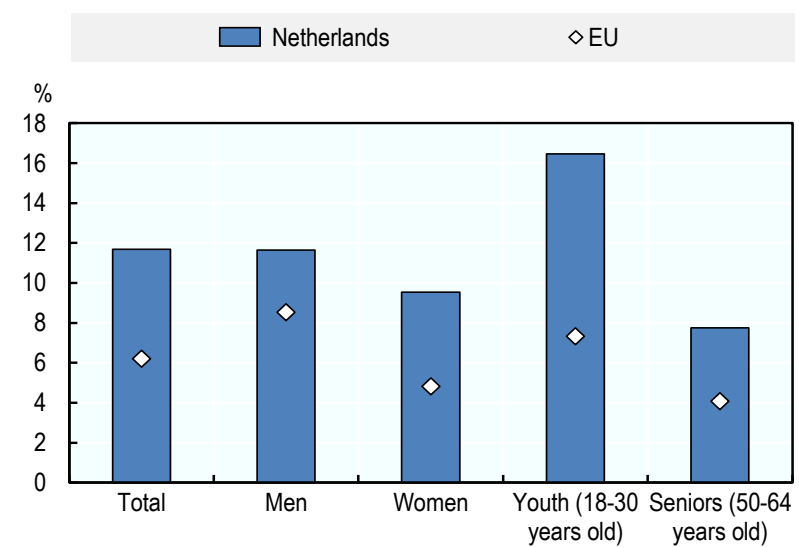

d. Share of TEA that expects to create at least 19 jobs over the next 5 years, 2016-20

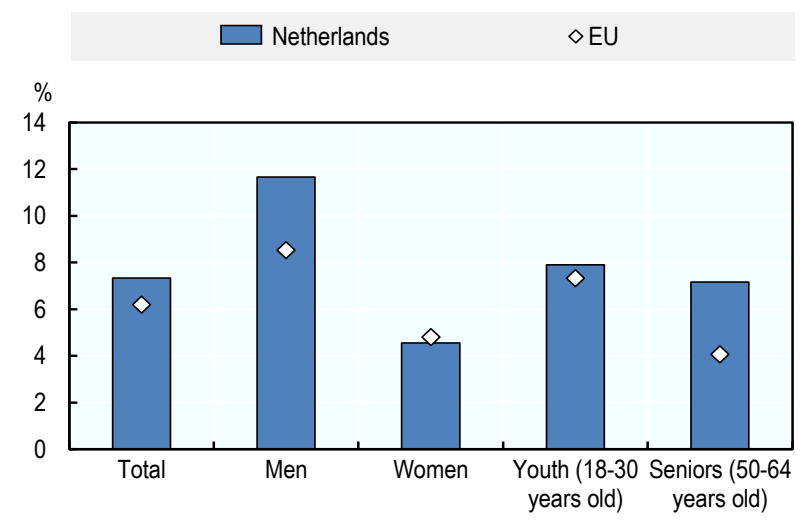

f. Share of self-employed with employees

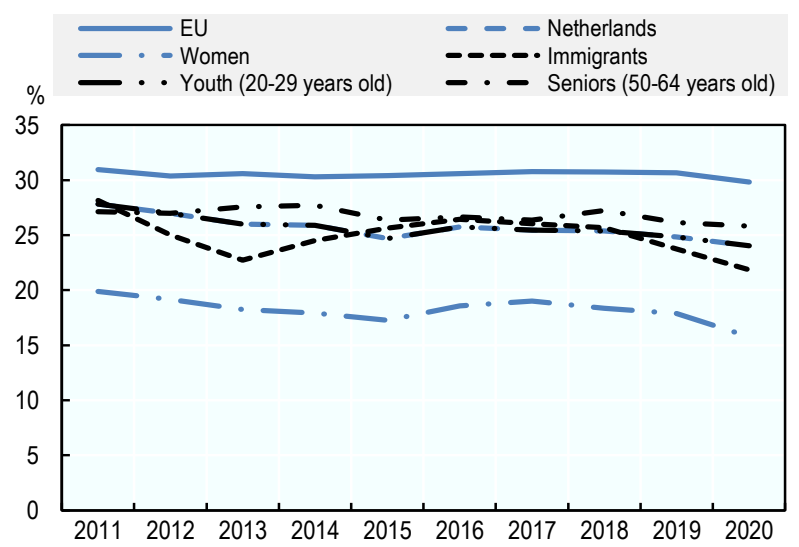

Note: The EU average in panels b-d excludes Belgium, Czech Republic, Denmark, Lithuania, Malta and Romania. Please see Chapter 9 for notes on the figures.

Source: Panel a: (World Bank, 2020[2]; Global Entrepreneurship Monitor (GEM), 2021[3]; OECD, forthcoming[4]); Panels b-d: (Global Entrepreneurship Monitor (GEM), 2021 $\left.{ }_{[3]}\right)$; Panels e-f: (Eurostat, 2021 $\left.{ }_{[5]}\right)$. Please see Chapter 9 for the full citations. 


\section{Poland}

This country profile benchmarks self-employment and entrepreneurship indicators for women, youth, seniors and immigrants in Poland against the average for the European Union. It also describes recent policy actions, notably the COVID-19 responses. It also reports on entrepreneurship conditions.

\section{Conditions for inclusive entrepreneurship}

Entrepreneurship conditions improved in recent years partly due the introduction of key policy measures. These include an increase in the annual income threshold for small taxpayers from EUR 1.2 million to EUR 2 million; an exemption from registration for micro firms with a turnover below $50 \%$ of the minimum wage; and, an exemption from social contributions for start-ups in the first six months followed by reduced social contributions for two years. Despite these improvements, administrative burden and entrepreneurship expectation remain among the lowest among European Union (EU) Member States. Entrepreneurship policies are relatively well developed. Tailored support is often available for youth at both the national and regional levels, while limited tailored support is offered for women and the unemployed. NGOs and local governments often offer small initiatives for immigrants, seniors and other groups.

\section{Recent trends}

The overall early-stage entrepreneurship rate was on par with the EU average for the period 2016-20. However, each target group remains under-represented in entrepreneurship. Eliminating these gaps (i.e. applying the early-stage entrepreneurship rate of men who are 30-49 years old to the whole population) would result in an additional 514000 entrepreneurs. About $85 \%$ of these "missing" entrepreneurs are between 50 and 64 years old, around $75 \%$ are female and only $3 \%$ are youth (20-29 years old).

Self-employment declined over the last decade yet remained above the EU average by 4 percentage points in 2020 . Women $(12 \%)$, youth (20-29 years old) $(10 \%)$ and seniors $(50-64$ years old) $(22 \%)$ were all more likely to be self-employed relative to the EU averages but were less likely to have employees.

\section{Hot policy issue}

Several policy measures were introduced to help the self-employed during the COVID-19 crisis, including a lump sum payment of PLN 1300 (EUR 290) in April 2020 as well as a PLN 100 billion (EUR 22 billion) financial scheme by the Polish Development Fund which made available three-year zero-interest loans to micro enterprises. The main support for the self-employed and freelancers was the "Anti-crisis Shield" programme. In its first iteration, self-employed workers received $80 \%$ of the minimum wage, while freelancers who reported income below $50 \%$ of the minimum wage could request financial aid to cover all of their lost income. In subsequent phases, eligibility criteria were adjusted to allow more self-employed workers to access financial support before being scaled back in September 2020 under "Anti-crisis Shield 5.0", limiting support to those working in tourism, stage performance and exhibition. 


\section{Inclusive entrepreneurship indicators}

Figure 30.1. Entrepreneurship and self-employment in Poland

a. Conditions for entrepreneurship, 2020

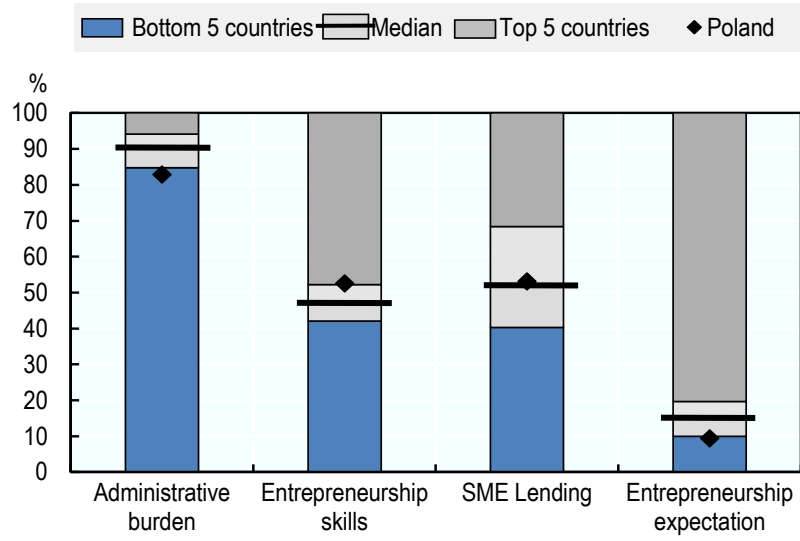

c. Share of TEA that is necessity-based, $2016-20$

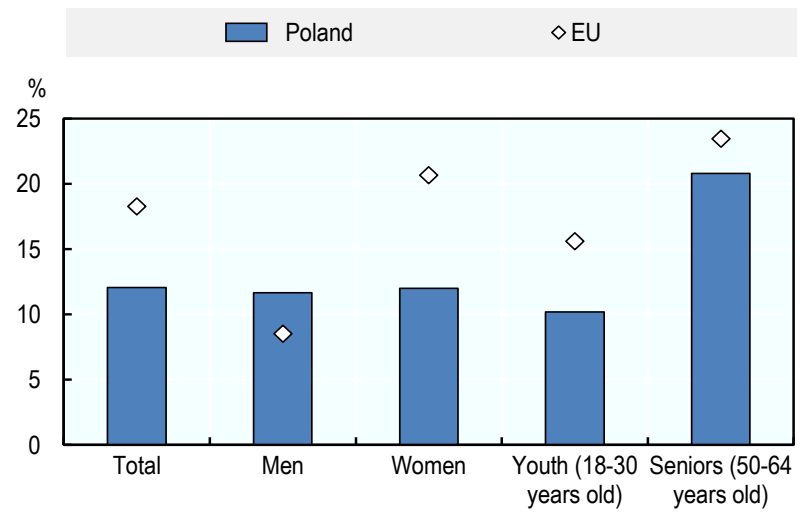

e. Self-employment rate

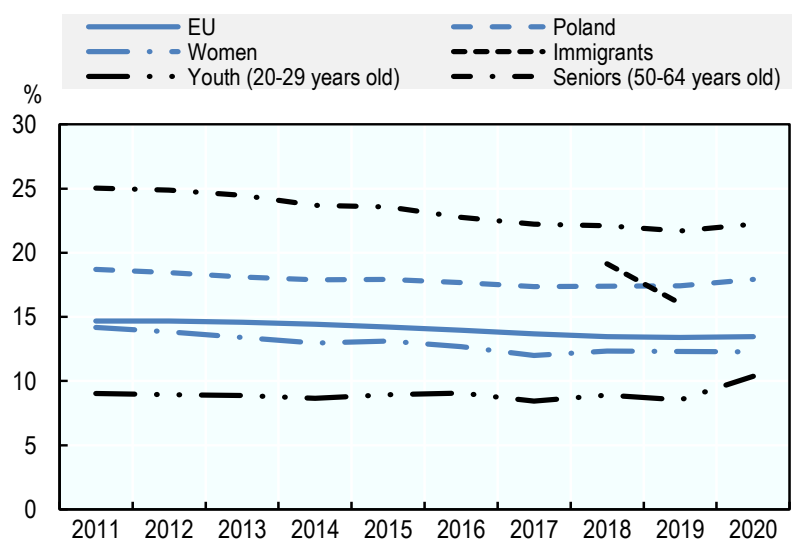

b. TEA rate, $2016-20$

Poland $\diamond \mathrm{EU}$

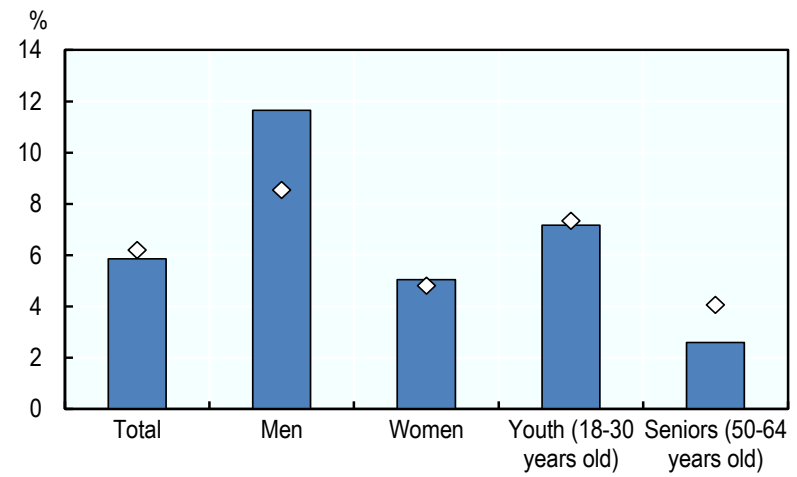

d. Share of TEA that expects to create at least 19 jobs over the next 5 years, 2016-20

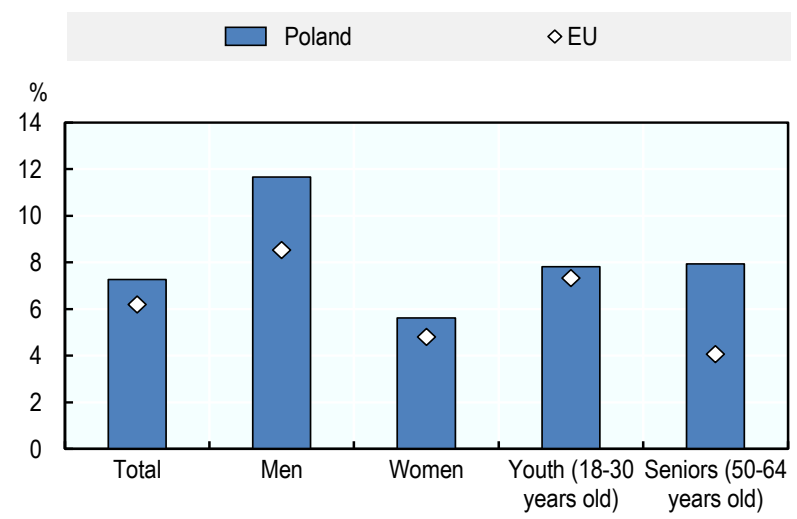

f. Share of self-employed with employees

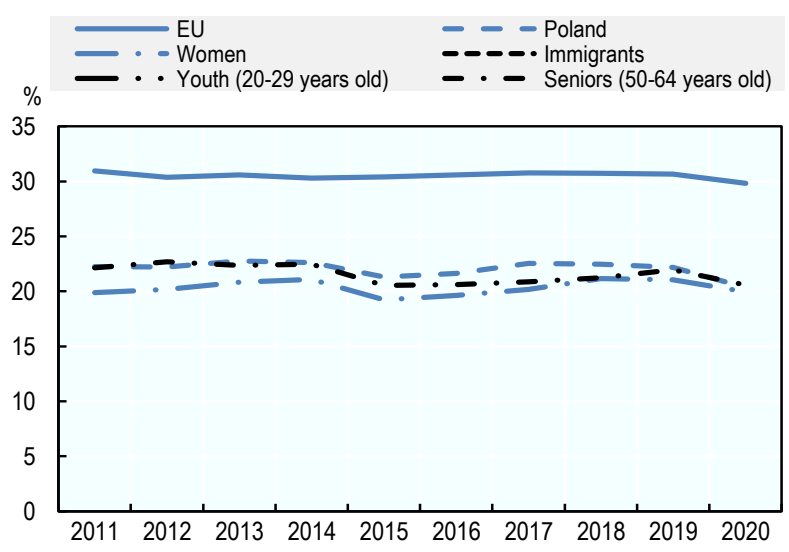

Note: The EU average in panels b-d excludes Belgium, Czech Republic, Denmark, Lithuania, Malta and Romania. Please see Chapter 9 for notes on the figures.

Source: Panel a: (World Bank, 2020[1]; Global Entrepreneurship Monitor (GEM), 2021[2]; OECD, forthcoming[3]); Panels b-d: (Global Entrepreneurship Monitor (GEM), 2021 [2]]); Panels e-f: (Eurostat, 2021 [4]]). Please see Chapter 9 for the full citations. 


\section{Portugal}

This country profile presents self-employment and entrepreneurship data for women, youth, seniors and immigrants in Portugal relative to the average for the European Union. It also reports on the conditions for entrepreneurship and highlights current inclusive entrepreneurship policy issues and recent developments.

\section{Conditions for inclusive entrepreneurship}

Entrepreneurship conditions are strong compared to most of the European Union (EU) Member States, ranking among the top $5 \mathrm{EU}$ countries for SME lending, entrepreneurship skills and entrepreneurship expectation. This is largely due to the simplification of administrative and licensing procedures over the past decade. Public policies to promote entrepreneurship have gained importance in recent years, notably through the StartUp Portugal Strategy. Tailored policies and programmes are used to support youth entrepreneurship through the Youth Guarantee. There is also some dedicated support for immigrants.

\section{Recent trends}

Early-stage entrepreneurship was over the EU average for the period 2016-20, notably youth (18-30 years old) who were about twice as likely as the EU average. Many new entrepreneurs started their business out of necessity - notably women (31\%) and seniors (35\%) - yet remain more optimistic about job creation in the next 5 years than the EU average. Closing the gaps in entrepreneurship (i.e. applying the early-stage entrepreneurship rate of core-age men to the whole population) would result in an additional 280000 entrepreneurs. About $85 \%$ of these "missing" entrepreneurs are female and $60 \%$ are over 50 years old.

The self-employment rate declined by 4 percentage points over the past decade, reflecting the overall downward trend in the EU. However, immigrants (17\%) and to a lesser extent women $(11 \%)$ were more likely to be self-employed relative to the EU averages (12\% for immigrants; $10 \%$ for women) in 2020 .

\section{Hot policy issue}

In response to the COVID-19 pandemic, a EUR 25 million five-prong start-up support initiative for entrepreneurs and the self-employed was introduced in April 2020 with: financial support (equivalent to the minimum wage of up to 10 employees per start-up); a 3-month extension of the Start-up Voucher Scheme (EUR 2075 per entrepreneurial job); an incubation service for new start-ups including a non-refundable incentive of EUR 1500 ; a measure converting loans into social capital and a favourable discount rate (average investment between EUR 50000 and EUR 100000 per start-up); and, an instrument for start-up investments beginning at EUR 50 000. In September 2020, MSMEs received support through the Programme ATIVAR.PT for non-residential leasing mostly through a non-repayable subsidy in the first half of 2021 (EUR 300 million in total). Some sector-specific support was also made available, including a EUR 25 million fiscal package in June 2020 to help an estimated 18000 cultural and creative self-employed workers. 


\section{Inclusive entrepreneurship indicators}

Figure 31.1. Entrepreneurship and self-employment in Portugal

a. Conditions for entrepreneurship, 2020

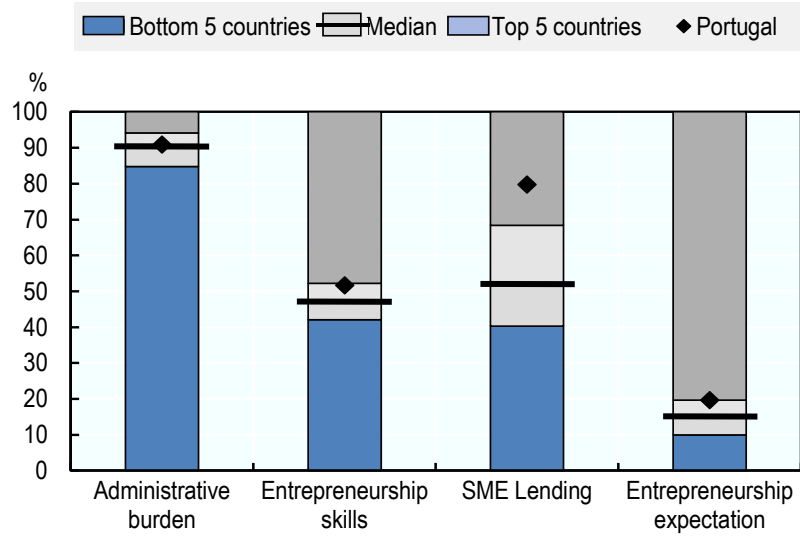

c. Share of TEA that is necessity-based, $2016-20$

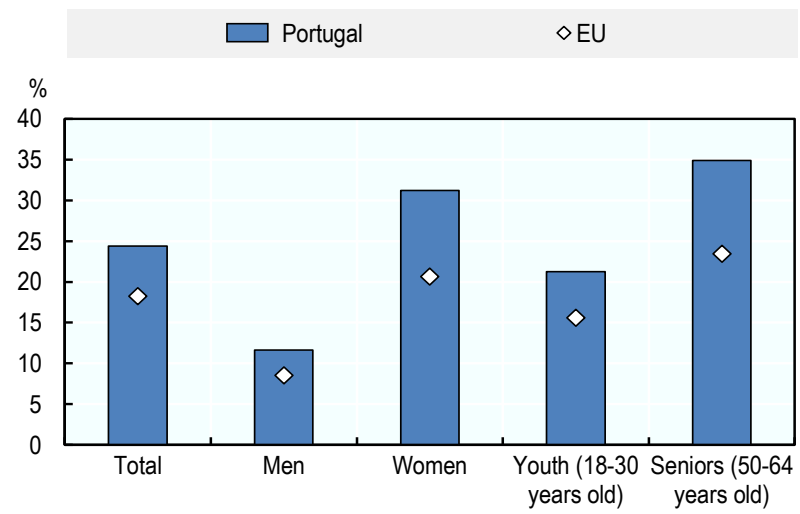

e. Self-employment rate

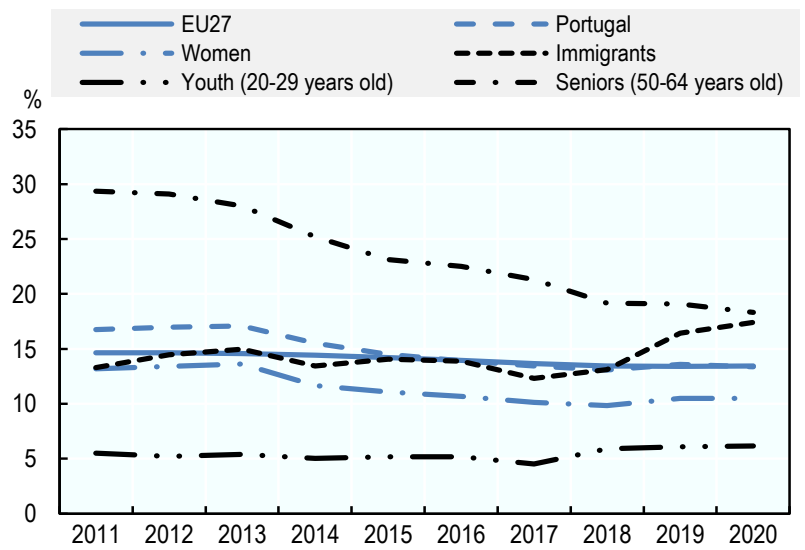

b. TEA rate, $2016-20$

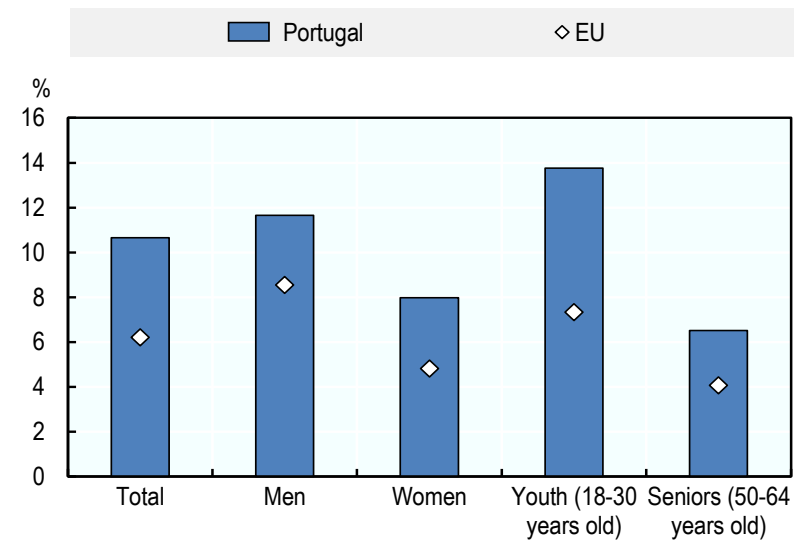

d. Share of TEA that expects to create at least 19 jobs over the next 5 years, 2016-20

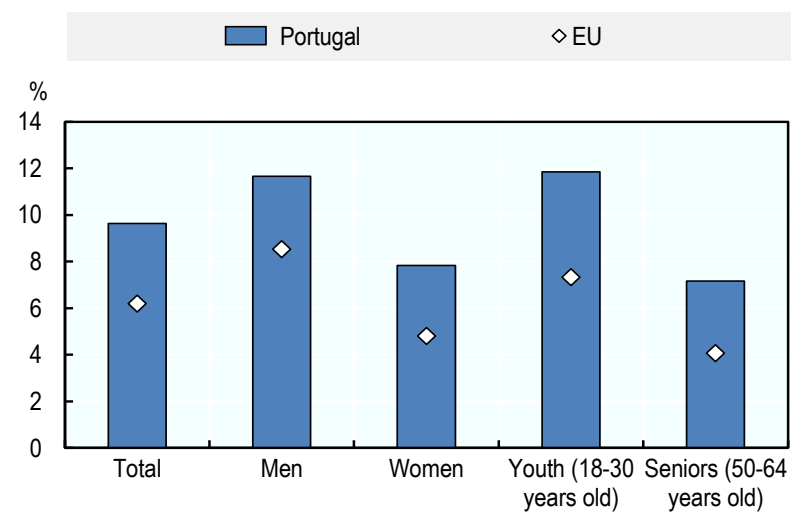

f. Share of self-employed with employees

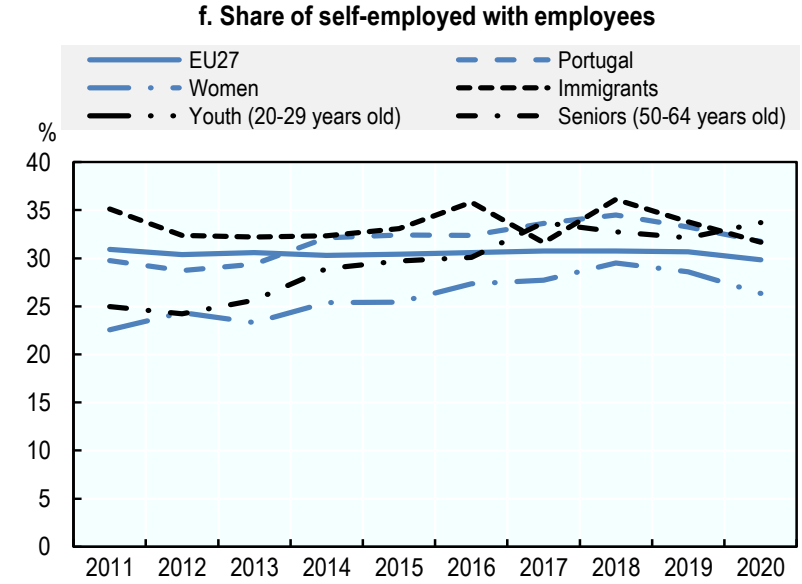

Note: The EU average in panels b-d excludes Belgium, Czech Republic, Denmark, Lithuania, Malta and Romania. Please see Chapter 9 for notes on the figures.

Source: Panel a: (World Bank, 2020[3]; Global Entrepreneurship Monitor (GEM), 2021[4]; OECD, forthcoming[5]); Panels b-d: (Global Entrepreneurship Monitor (GEM), 2021 [4] ); Panels e-f: (Eurostat, 2021 $\left.{ }_{[6]}\right)$. Please see Chapter 9 for the full citations. 


\section{Romania}

This country profile describes current inclusive entrepreneurship policy issues and recent developments in Romania. It also benchmarks self-employment indicators for women, youth, seniors and immigrants against the average for the European Union and reports on the conditions for entrepreneurship.

\section{Conditions for inclusive entrepreneurship}

The overall entrepreneurship conditions are less favourable than in most of the European Union (EU) Member States. Barriers to entrepreneurship are largely due to the challenging regulatory environment and heavy administrative burden on new start-ups. Entrepreneurship policy in recent years has been guided by an SME and entrepreneurship strategy for 2014-20. Policy has focussed on improving the business environment through innovation programmes, new incubator programmes and education measures targeting entrepreneurship and digital skills. Some support is offered to (potential) entrepreneurs from groups that are under-represented or disadvantaged in entrepreneurship (e.g. women, youth, people living in rural areas), notably through preferential access to general entrepreneurship programmes.

\section{Recent trends}

Overall, self-employment declined over the last decade yet remained slightly higher than the EU average (15\% vs. under $14 \%$ in 2020$)$. This is largely due to high levels of self-employment among seniors (50-64 years old) (20\%) and youth (20-29 years old) (10\%). Population aging and high levels of emigration largely explain the different age profile of the self-employed. There is also a notable gender gap among selfemployed workers as women only account for about one-quarter of the self-employed workforce compared to an EU average of $33 \%$. Eliminating the gaps in entrepreneurship activity rates as measured by selfemployment across population groups (i.e. applying the self-employment rate of men who are 30-49 years old to the whole population) would result in an additional 577000 entrepreneurs. 85\% of these "missing" entrepreneurs are female and $62 \%$ are between 50 and 65 years old.

\section{Hot policy issue}

Several measures and programmes designed to support the self-employed and SMEs during the COVID19 pandemic came into effect in March 2020 and were extended several times. These included liquidity support, loan and credit extension and deferring loan payments until 31 December 2020. For example, within the first three weeks of the SME Invest Romania programme, partner banks extended 451 loans totalling LEI 332 million (EUR 67 million) to support businesses address issues related to liquidity, working capital or investments. Another new guarantee scheme supported commercial credit by using regressive factoring tools (recourse), discount credit and guarantee-leasing products. Furthermore, the State supported workers unemployed due to suspended contracts with a financial benefit of at least $75 \%$ of the basic salary. 


\section{Inclusive entrepreneurship indicators}

Figure 32.1. Entrepreneurship and self-employment in Romania

a. Conditions for entrepreneurship, 2020

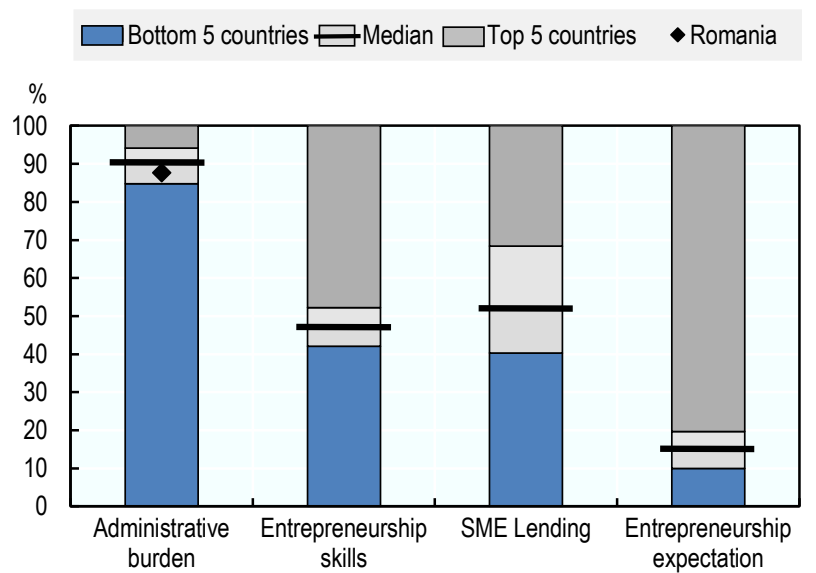

c. Share of self-employed with employees

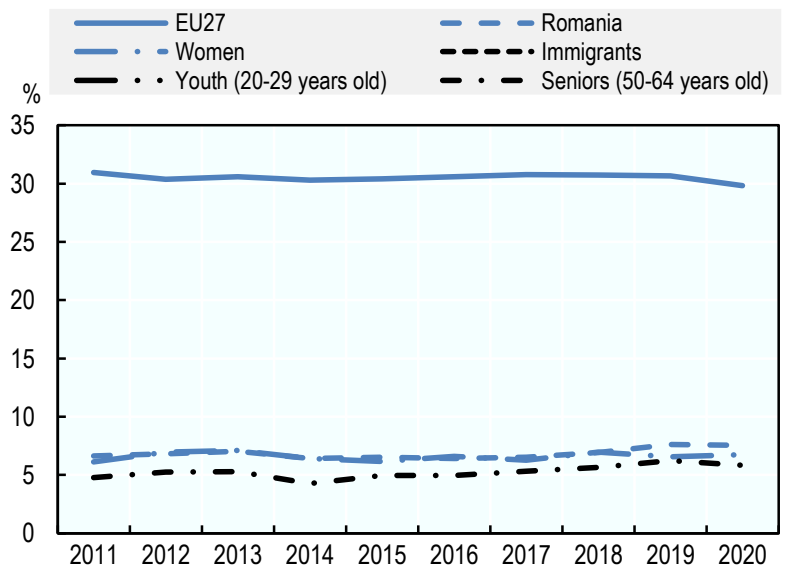

\section{b. Self-employment rate}
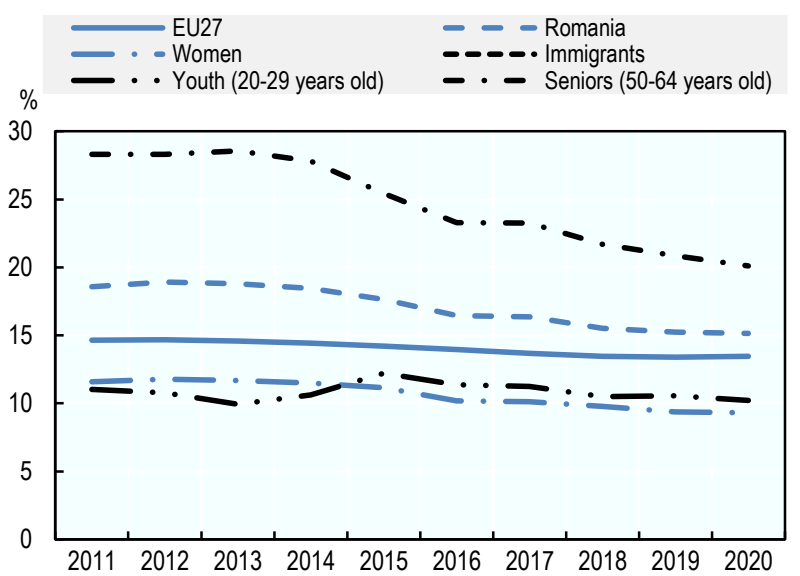

Note: Please see Chapter 9 for notes on the figures.

Source: Panel a: (World Bank, 2020[1]; Global Entrepreneurship Monitor (GEM), $2021_{[2]}$; OECD, forthcoming[3]); Panels b-c: (Eurostat, 2021 [4]]). Please see Chapter 9 for the full citations. 


\section{Slovak Republic}

This country profile presents recent trends in entrepreneurship by women, youth and seniors, including indicators that benchmark the Slovak Republic against the European Union average. It also reports on the conditions for entrepreneurship and highlights recent inclusive entrepreneurship policy developments.

\section{Conditions for inclusive entrepreneurship}

The overall entrepreneurship conditions are favourable compared to most of the European Union (EU) Member States. The share of the population with entrepreneurship skills and who intend on pursuing entrepreneurship are above average but the level of administrative burden on new start-ups remains an issue. Despite government action in addressing the regulatory environment through simplifying measures, improving the quality of laws and streamlining regulation, administrative burden still ranks in the bottom 5 EU countries in the period 2016-20. However, many policies and programmes aim to support SME's access to finance through providing loans and guarantees through specialised state banks as well as the Slovak Business Agency (SBA), which led to SME lending trending upwards as of 2012 as well as gradual improvement of credit conditions. As a result, the share of loans going to SMEs is high compared to other EU Member States, and conditions for SME lending rank in the top 5 EU countries.

\section{Recent trends}

Early-stage entrepreneurship rates for women (9\%), youth (18-30 years old) (12\%) and seniors ( $50-64$ years old) $(9 \%)$ were all above the EU average ( $5 \%$ for women, $7 \%$ for youth and $4 \%$ for seniors) for the period 2016-20. However, many of these new entrepreneurs started their businesses out of necessity - about twice as likely than the EU average across all population groups. Eliminating all of the gaps in entrepreneurship activity rates across population groups (i.e. applying the early-stage entrepreneurship rate of men who are 30-49 years old to the whole population) would result in an additional 200000 entrepreneurs. Of these "missing" entrepreneurs, about $75 \%$ are female, $45 \%$ seniors and $20 \%$ youth.

Overall, the self-employment rate slightly declined over the decade yet remained above the EU average (15\% vs. $14 \%$ in 2020$)$. The self-employed population is younger on average due to high levels of selfemployed youth $(12 \%)$ - nearly double the EU average $(7 \%)$.

\section{Hot policy issue}

Many measures were introduced in response to the COVID-19 crisis. Self-employed workers received compensation for up to $80 \%$ of lost wages and could defer social security contributions and tax payments. As the crisis continued scaled benefits were provided and the average monthly subsidy for a self-employed worker increased from EUR 435 (July 2020 to September 2020) to EUR 745 (January 2020). Low-interest, state-guaranteed loans for self-employed workers were introduced, allowing loan payments to be deferred for up to nine months and deadlines for tax duties to be extended to reduce administrative burden. 


\section{Inclusive entrepreneurship indicators}

Figure 33.1. Entrepreneurship and self-employment in the Slovak Republic

a. Conditions for entrepreneurship, 2020

$\square$ Bottom 5 countries $\boxminus$ Median $\square$ Top 5 countries • Slovak Republic

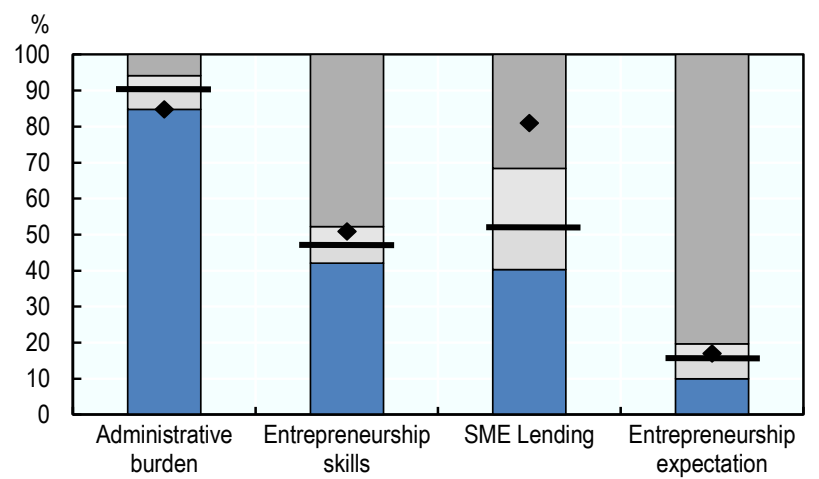

c. Share of TEA that is necessity-based, $2016-20$

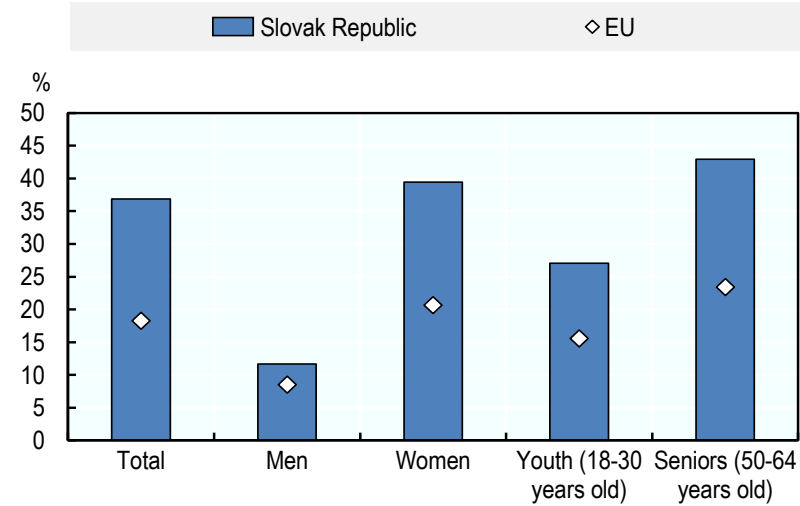

e. Self-employment rate

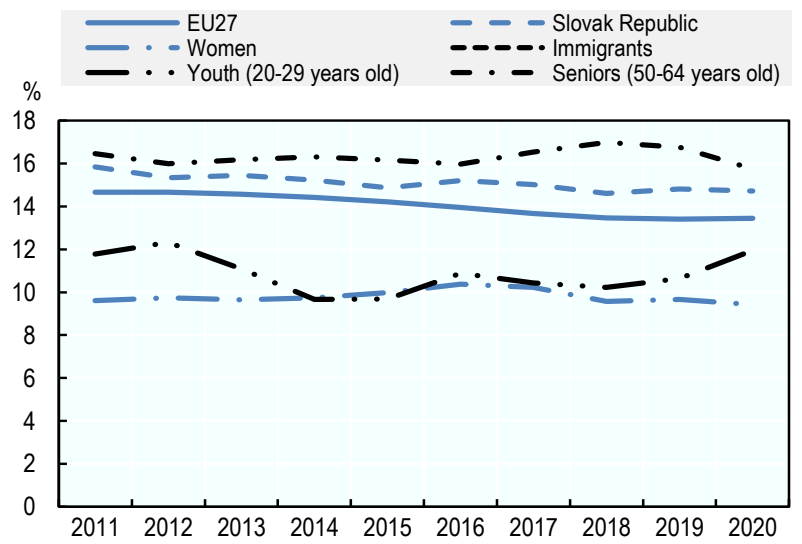

b. TEA rate, $2016-20$

Slovak Republic $\diamond \mathrm{EU}$

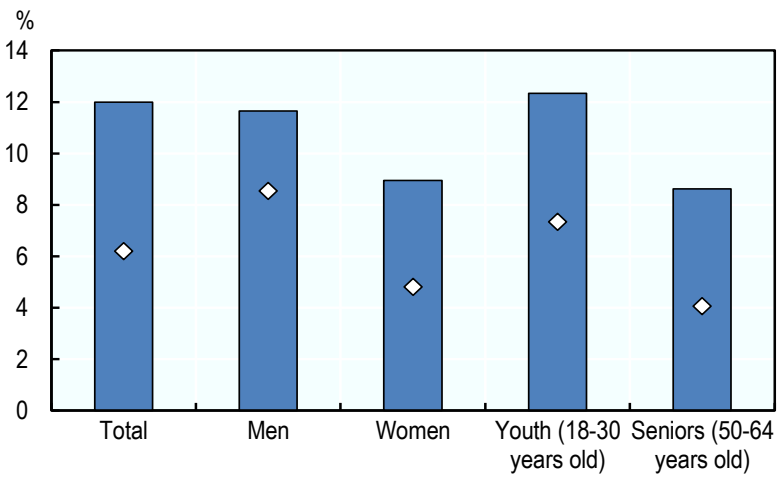

d. Share of TEA that expects to create at least 19 jobs over the next 5 years, 2016-20

$\square$ Slovak Republic $\quad \diamond$ EU

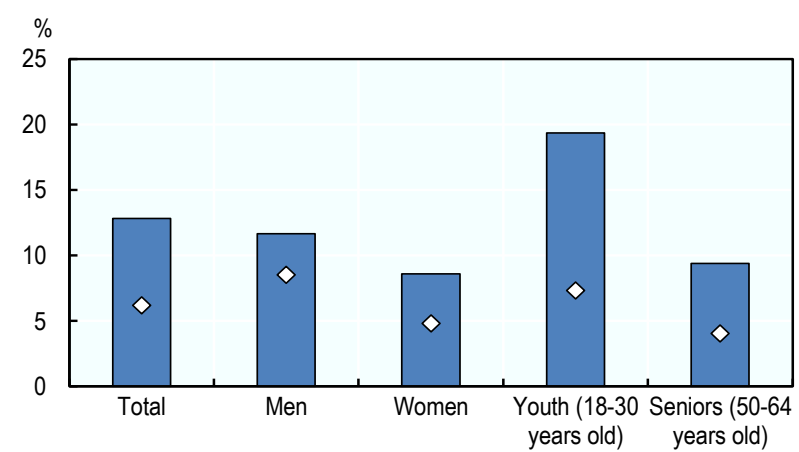

f. Share of self-employed with employees

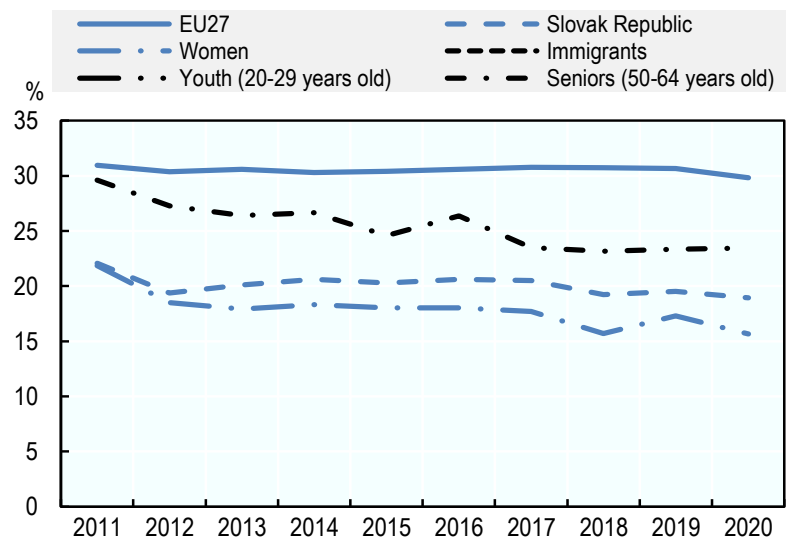

Note: The EU average in panels b-d excludes Belgium, Czech Republic, Denmark, Lithuania, Malta and Romania. Please see Chapter 9 for notes on the figures.

Source: Panel a: (World Bank, 2020[1]; Global Entrepreneurship Monitor (GEM), 2021[2]; OECD, forthcoming[3]); Panels b-d: (Global Entrepreneurship Monitor (GEM), 2021[2]); Panels e-f: (Eurostat, 2021 [4]]). Please see Chapter 9 for the full citations. 


\section{Slovenia}

This country profile highlights recent policy actions related to entrepreneurship by women, youth, seniors and immigrants. It also benchmarks key self-employment and inclusive entrepreneurship indicators for Slovenia against the average for the European Union and reports on entrepreneurship conditions.

\section{Conditions for inclusive entrepreneurship}

The overall conditions for entrepreneurship are similar to most of the European Union (EU) Member States. The share of the population with entrepreneurship skills and the level of administrative burden on new start-ups are well-above average, while the share of the population of who intend to start a business and SME lending levels are on par with EU average. These improvements may be the result of national level initiatives to foster the business environment, such as the national online business portal e-VEM which simplifies procedures and reduces costs related to starting a business. Much progress has been made in making entrepreneurship more inclusive over the past decade but this progress may erode in the coming years because some notable initiatives have ended, including the start-up subsidy for the unemployed.

\section{Recent trends}

The overall early-stage entrepreneurship rate (7\%) was slightly above the EU average (6\%) between 2016 and 2020 , largely due to higher activity rates among youth (18-30 years old) ( $10 \% \mathrm{vs.} 7 \%$ ). Almost a quarter of all new entrepreneurs reported starting their business out of necessity relative to $19 \%$ on average in the EU. This was true across all target population groups - women ( $32 \%$ vs. $21 \%)$, youth $(20 \%$ vs. $16 \%)$ and seniors (50-64 years old) (26\% vs. $26 \%$ ). However, more early-stage entrepreneurs ( $7 \%$ ) anticipated job creation than on average in the EU $(6 \%)$, notably senior entrepreneurs (7\%). Eliminating the gaps in entrepreneurship activity rates across population groups (i.e. applying the early-stage entrepreneurship rate of men who are 30-49 years old to the whole population) would result in 59000 more entrepreneurs. About $75 \%$ of these "missing" entrepreneurs are female and $60 \%$ are between 50 and 64 years old.

Self-employment rates remained stable at about $12 \%$ over the previous decade yet remained below the EU average (14\% in 2020). Among the self-employed, most are registered as private entrepreneurs followed by farmers and own-account workers. There is a noticeable gender gap among the self-employed as women are more than half as likely to be self-employed than men (32\% vs. $68 \%$ in 2020$)$.

\section{Hot policy issue}

The government announced a range of measures to support the self-employed and SMEs during the COVID-19 pandemic. This included the postponement of loan payments, unemployment aid and liquidity support for the self-employed and SMEs. Moreover, the SME Invest Romania programme offered loans to help enterprises maintain their liquidity, working capital and investments. This programme granted 451 loans totalling to LEI 332 million (EUR 67 million) within the first three weeks. 


\section{Inclusive entrepreneurship indicators}

Figure 34.1. Entrepreneurship and self-employment in Slovenia

a. Conditions for entrepreneurship, 2020

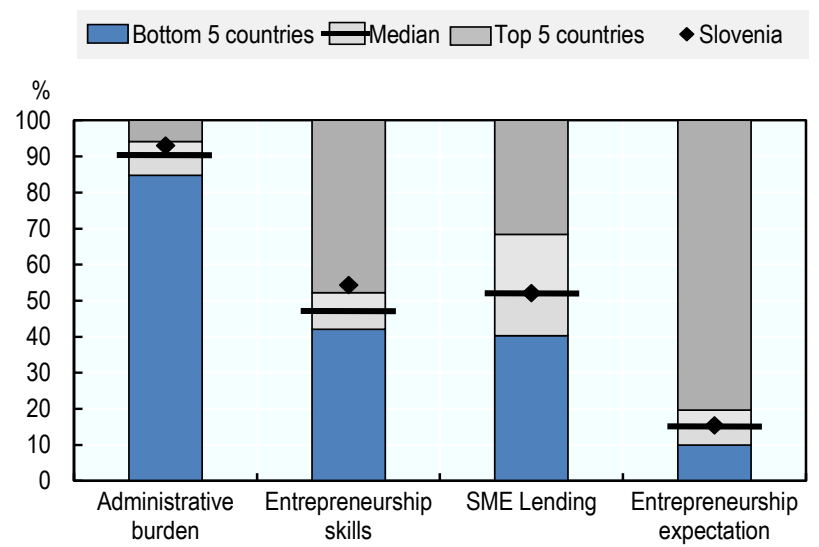

c. Share of TEA that is necessity-based, 2016-20

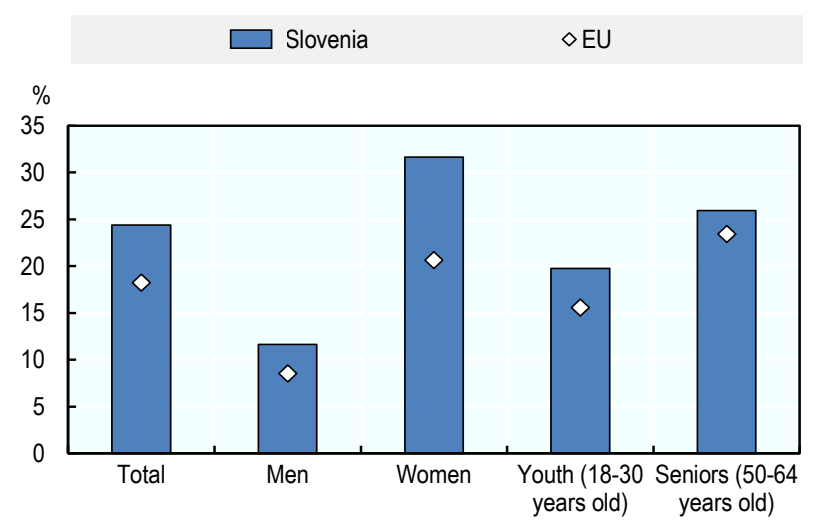

e. Self-employment rate

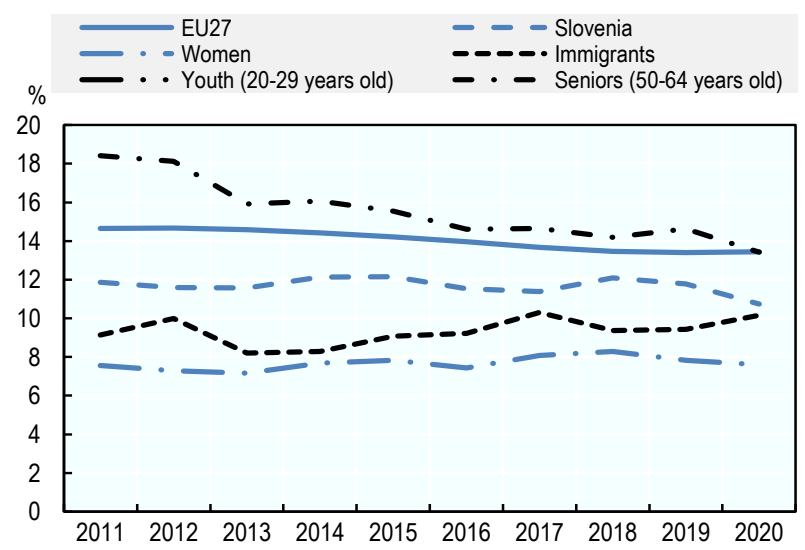

b. TEA rate, $2016-20$

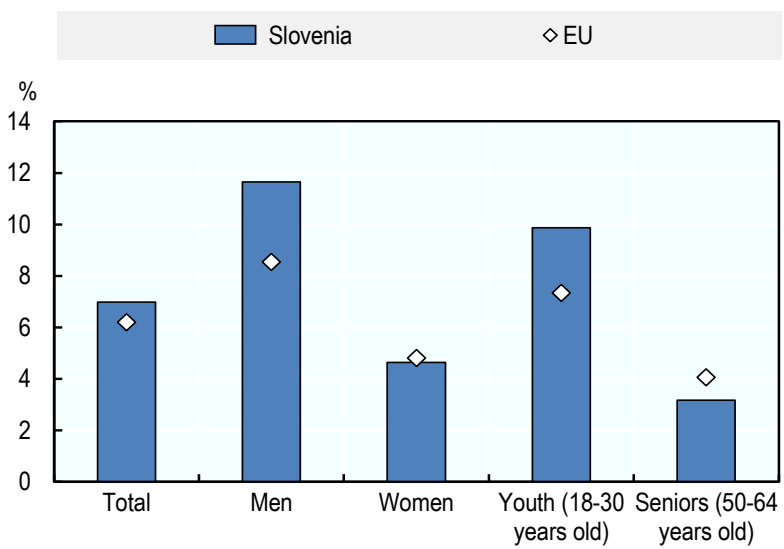

d. Share of TEA that expects to create at least 19 jobs over the next 5 years, 2016-20

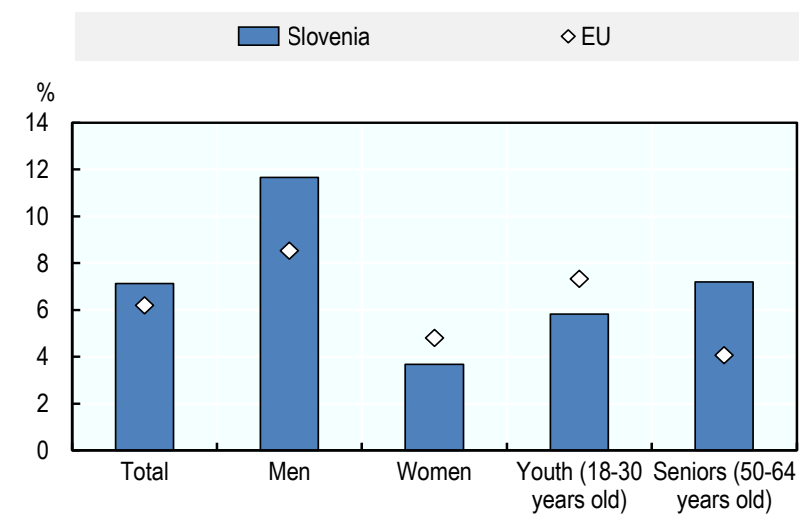

f. Share of self-employed with employees

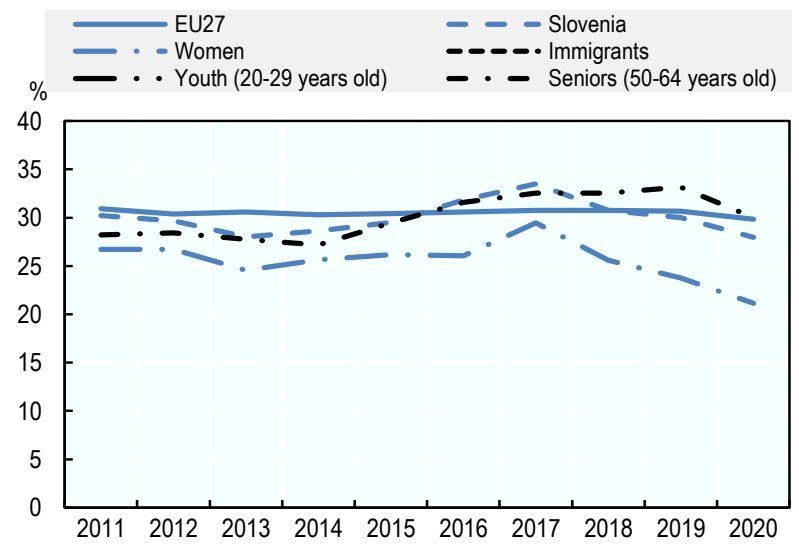

Note: The EU average in panels b-d excludes Belgium, Czech Republic, Denmark, Lithuania, Malta and Romania. Please see Chapter 9 for notes on the figures.

Source: Panel a: (World Bank, 2020[1]; Global Entrepreneurship Monitor (GEM), 2021 [2]; OECD, forthcoming[3]); Panels b-d: (Global Entrepreneurship Monitor (GEM), 2021[2]); Panels e-f: (Eurostat, 2021 [4]]). Please see Chapter 9 for the full citations. 


\section{$\underline{35}$ spain}

This country profile highlights current inclusive entrepreneurship policy issues and recent developments in Spain. It also presents self-employment and entrepreneurship data for women, youth, seniors and immigrants relative to the average for the European Union.

\section{Conditions for inclusive entrepreneurship}

Entrepreneurship conditions are on par with the European Union (EU) average. Administrative burdens for business are relatively low and SME lending is around the EU median and has been improving since 2014. Entrepreneurship support has expanded in recent years and is mostly offered through general entrepreneurship programmes. However, a number of measures are in place to facilitate entrepreneurship among under-represented and disadvantaged groups, especially for the unemployed, youth and women.

\section{Recent trends}

In the period 2016-20, the early-stage entrepreneurship rate increased (5\%) yet remained below the EU average (6\%), except among seniors (50-64 years old) (10\% vs. $4 \%)$. Necessity entrepreneurship played a larger role for entrepreneurial activities than on average across the EU, notably among seniors (38\% vs. $24 \%$ ) and women (33\% vs. $21 \%)$. If all groups engaged in early-stage entrepreneurship at the same rate as core-age men, there would be 608000 more entrepreneurs. About $60 \%$ of these "missing" entrepreneurs are female and $60 \%$ are over 50 years old. However, immigrants are over-represented.

Self-employment rates have been relatively stable over the last decade. While the women's selfemployment rate is nearly 2 percentage points higher than the EU average, women $(34 \%)$ remain significantly less likely to be self-employed relative to men $(66 \%)$.

\section{Hot policy issue}

In response to the COVID-19 crisis, national level support measures for the self-employed were introduced. These included a social security contribution exemption, a financial support equivalent to $70 \%$ of the amount due for a full cessation of activity and under certain conditions, self-employed workers and SMEs received backing for $80 \%$ of new loans, credit facilities and renewals of pre-existing agreements. Regional measures, for example, in Andalusia were also introduced. From 1 April 2020 to 31 March 2021, selfemployed workers and micro-enterprises benefitted from microcredits ranging from EUR 9000 to EUR 15000 guaranteed by Garántia (duration of 3-5 years). From September 2020 to 30 October 2021, the region provided two additional lines of subsidies for the self-employed with a total budget of EUR 14 million (EUR 9 million for the first line and EUR 5 million for the second). The first line aimed to help the general economic activity of self-employed workers with an individual subsidy of EUR 1200 while the second line specifically targeted economic activity related to night life and recreational establishments for children with a EUR 4000 subsidy. 


\section{Inclusive entrepreneurship indicators}

Figure 35.1. Entrepreneurship and self-employment in Spain

a. Conditions for entrepreneurship, 2020

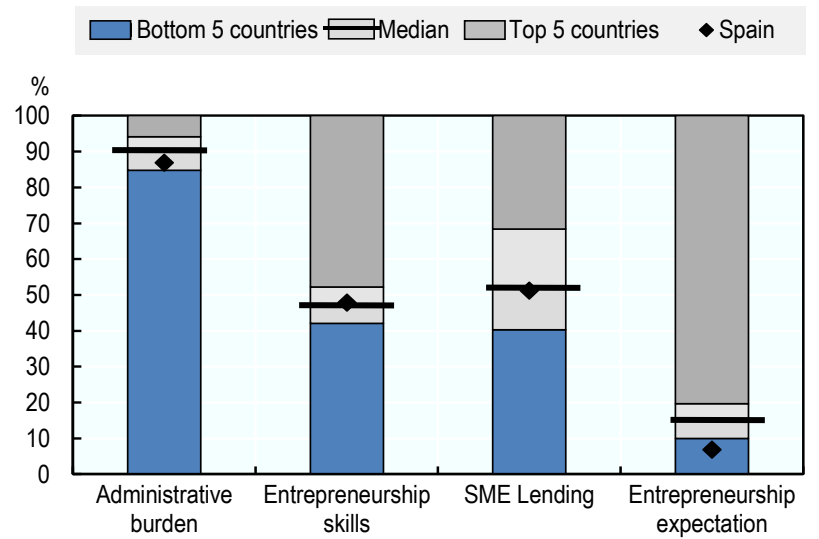

c. Share of TEA that is necessity-based, 2016-20

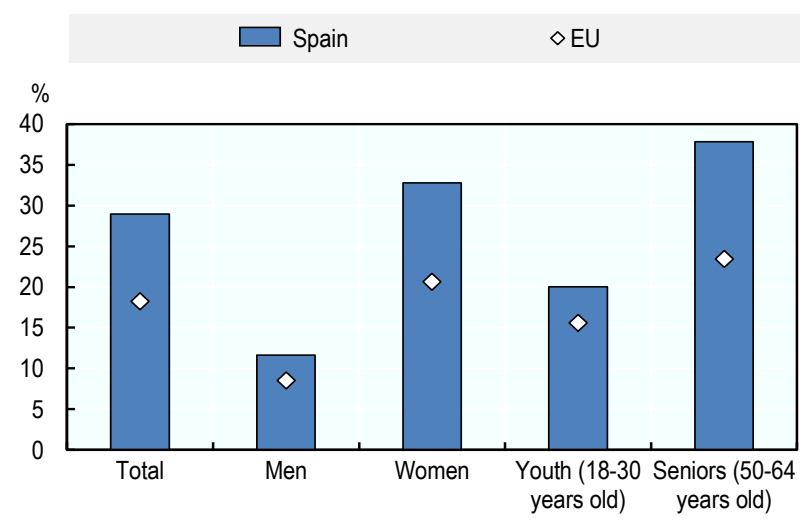

e. Self-employment rate

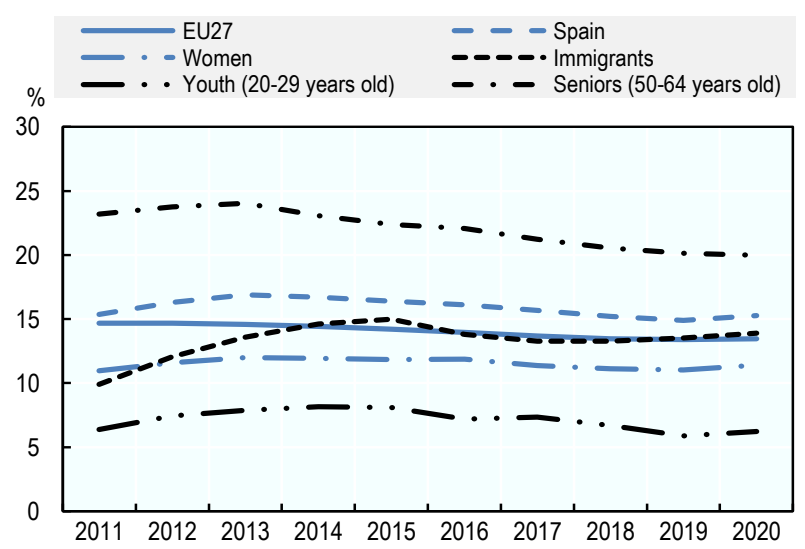

b. TEA rate, $2016-20$

$\square$ Spain $\diamond \mathrm{EU}$

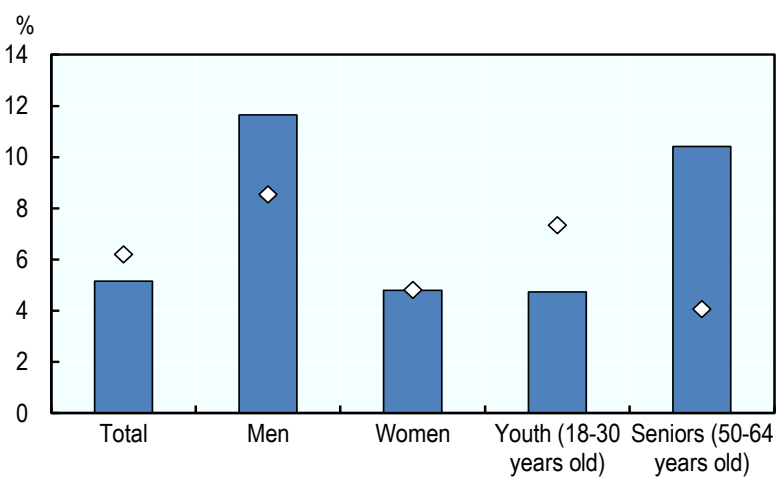

d. Share of TEA that expects to create at least 19 jobs over the next 5 years, 2016-20

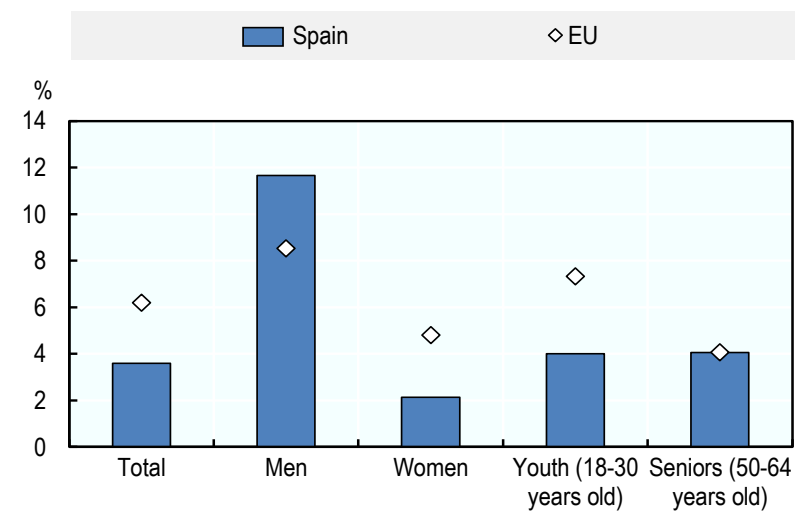

f. Share of self-employed with employees

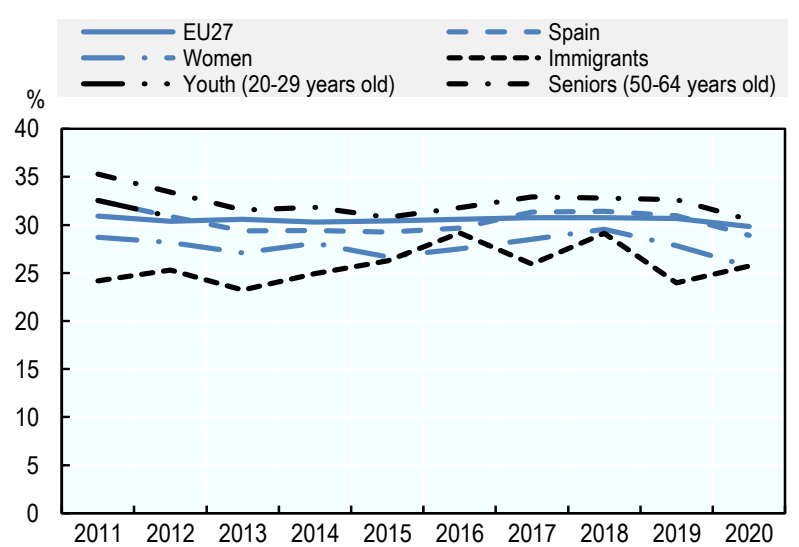

Note: The EU average in panels b-d excludes Belgium, Czech Republic, Denmark, Lithuania, Malta and Romania. Please see Chapter 9 for notes on the figures.

Source: Panel a: (World Bank, 2020[3]; Global Entrepreneurship Monitor (GEM), $2021_{[4]}$; OECD, forthcoming[5]); Panels b-d: (Global Entrepreneurship Monitor (GEM), 2021[4]]); Panels e-f: (Eurostat, 2021 [6]]). Please see Chapter 9 for the full citations. 


\section{Sweden}

This country profile benchmarks key self-employment and entrepreneurship indicators for women, youth, seniors and immigrants in Sweden against the average for the European Union. It also reports on the conditions for entrepreneurship and describes recent policy actions, including the COVID-19 response.

\section{Conditions for inclusive entrepreneurship}

The conditions for entrepreneurship are generally favourable relative to other European Union (EU) Member States, including low levels of administrative burden for start-ups and access to finance. However, a low share of people self-report having entrepreneurship skills despite high levels of educational attainment and digital literacy. Entrepreneurship policies are designed with a mainstream approach, aiming at increasing entrepreneurship and firm growth in general. Moreover, immigration flows have increased in recent years and a number of new employment programmes have been created, of which many are focused on women while others aim to promote and support entrepreneurship among immigrants.

\section{Recent trends}

The proportions of women (5\%), youth (18-30 years old) $(9 \%)$ and seniors (50-64 years old) $(6 \%)$ involved in starting and managing new businesses were all above the EU averages ( $5 \%$ for women, $7 \%$ for youth and $4 \%$ for seniors) in the period 2016-20. While necessity-driven entrepreneurship was around half the EU average, many groups continue to be under-represented in entrepreneurship. If all groups participated in early-stage entrepreneurship at the same rate as core-age men, there would be 157000 more entrepreneurs. About $90 \%$ of these "missing" entrepreneurs are female and half are over 50 years old.

Following the overall EU trend, Sweden's self-employment rate remained stable but in slow decline over the last decade - around 5 percentage points lower than the EU average in 2020 . While seniors (12\%), immigrants $(8 \%)$ and women $(5 \%)$ are less likely to be self-employed than on average in the EU $(17 \%$, $12 \%$ and $10 \%$ respectively), all are more likely to employ others relative to the EU average (women: $29 \%$ vs. $24 \%$, seniors: $37 \%$ vs. $33 \%$ and immigrants: $39 \%$ vs. $32 \%$ ).

\section{Hot policy issue}

Several support packages for the self-employed and SMEs were implemented in the wake of the COVID19 crisis. Temporary changes and extensions to unemployment insurance allowed 3000 self-employed workers, including some who partially continued operations, to claim unemployment insurance from 13 April 2020 to 25 August 2020. Moreover, the Government waved the rule blocking self-employed workers from receiving unemployment insurance in the next 5 years if claimed in 2020. SMEs could also receive a loan guarantee of $70 \%$ of new loans up to SEK 75 million (EUR 7.2 million), totalling to around SEK 100 billion (EUR 9.6 billion) in 2020. Further measures targeting small enterprises included tax cuts for sole proprietors of up to SEK 1 million (EUR 95600 ). 


\section{Inclusive entrepreneurship indicators}

Figure 36.1. Entrepreneurship and self-employment in Sweden

a. Conditions for entrepreneurship, 2020

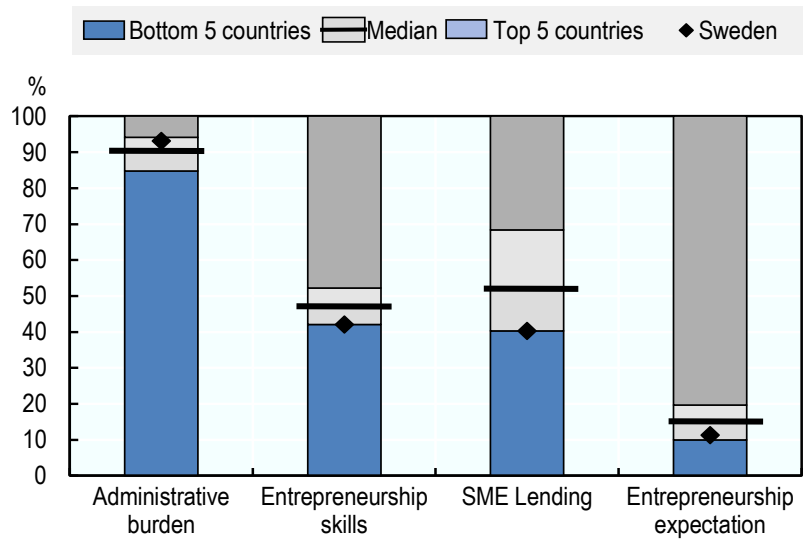

c. Share of TEA that is necessity-based, 2016-20

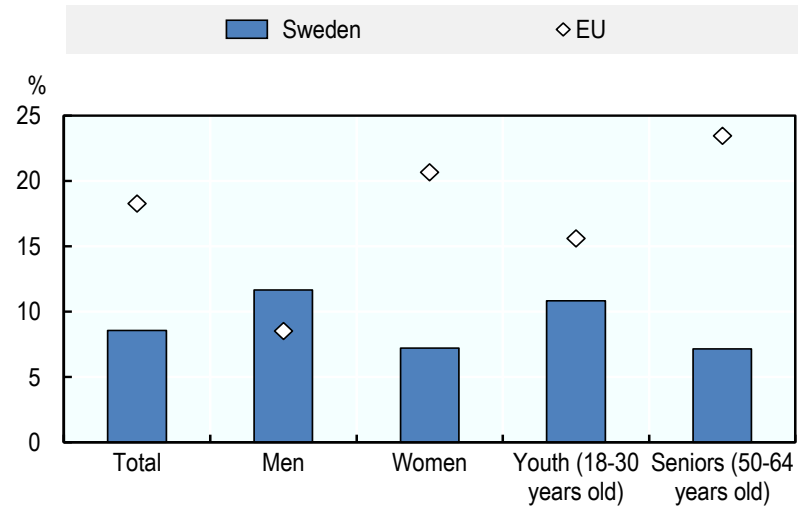

e. Self-employment rate

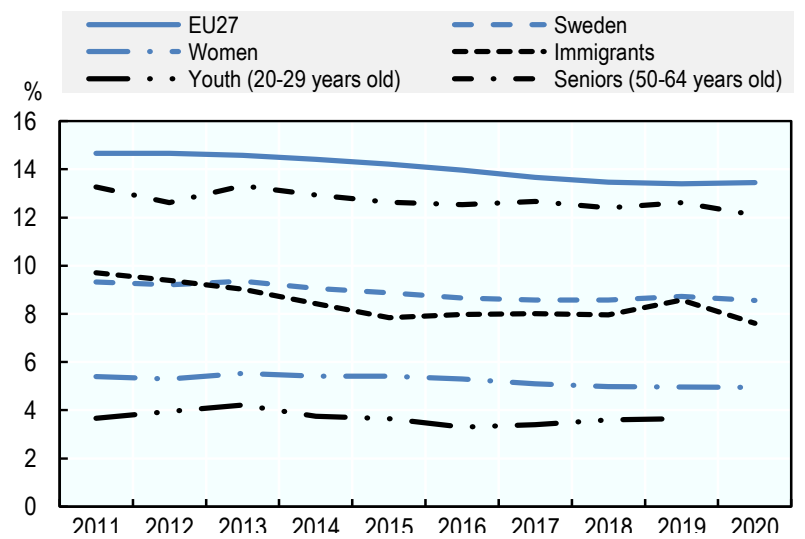

b. TEA rate, $2016-20$

Sweden $\diamond \mathrm{EU}$

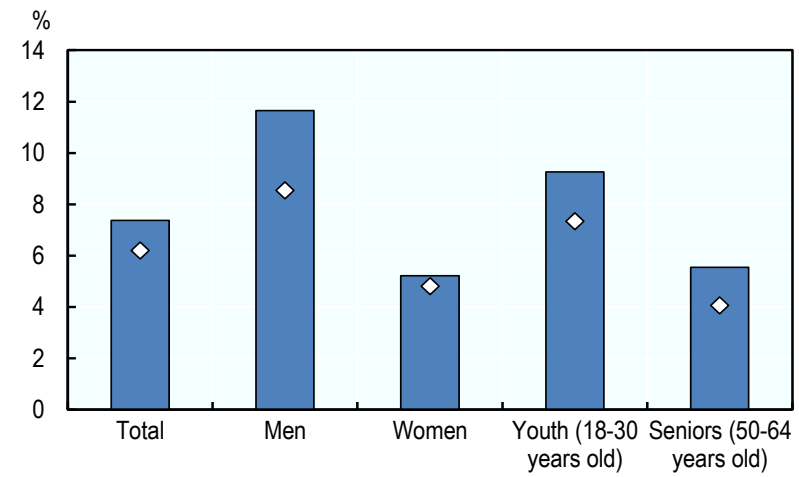

d. Share of TEA that expects to create at least 19 jobs over the next 5 years, 2016-20

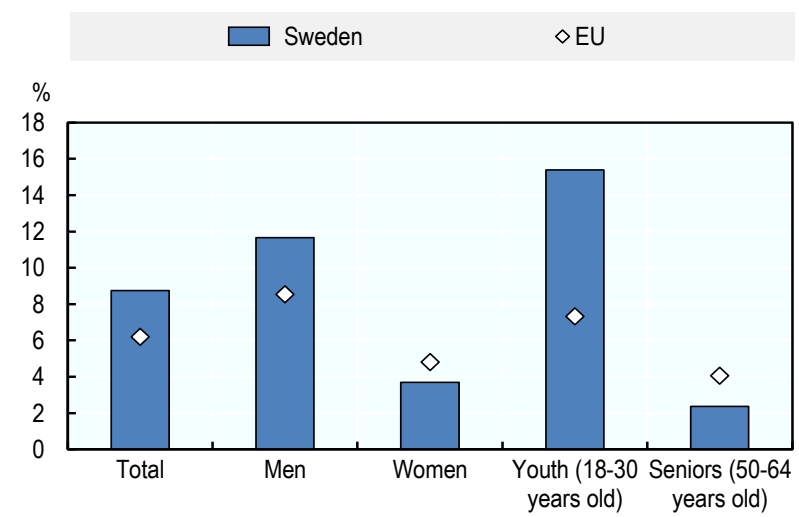

f. Share of self-employed with employees

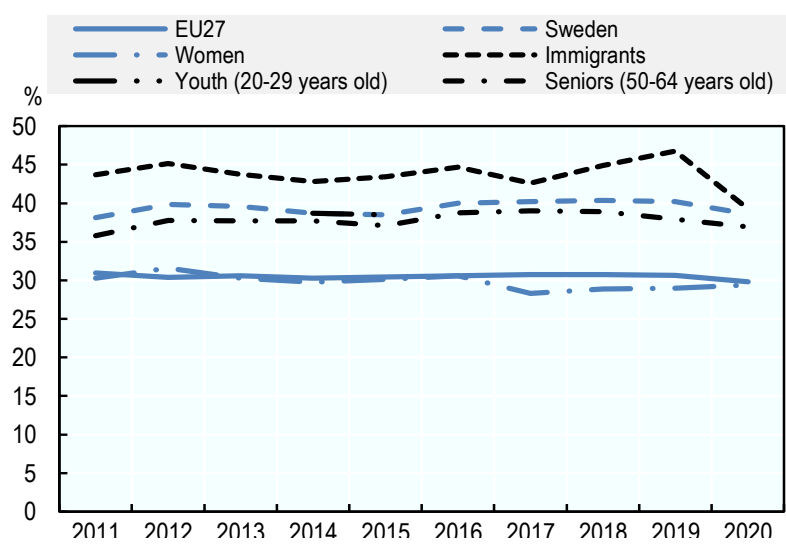

Note: The EU average in panels b-d excludes Belgium, Czech Republic, Denmark, Lithuania, Malta and Romania. Please see Chapter 9 for notes on the figures.

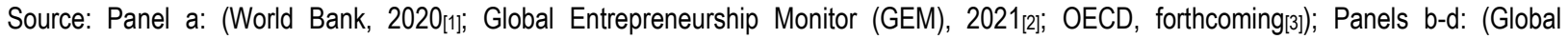
Entrepreneurship Monitor (GEM), 2021[2]); Panels e-f: (Eurostat, 2021[4]]). Please see Chapter 9 for the full citations. 


\section{The Missing Entrepreneurs 2021 \\ POLICIES FOR INCLUSIVE ENTREPRENEURSHIP AND SELF-EMPLOYMENT}

The Missing Entrepreneurs 2021 is the sixth edition in a series of biennial reports that examine how public policies at national, regional and local levels can support job creation, economic growth and social inclusion by overcoming obstacles to business start-ups and self-employment by people from disadvantaged or under-represented groups in entrepreneurship. It shows that there are substantial untapped opportunities for entrepreneurship in populations such as women, youth, the unemployed, and immigrants and highlights the need for more differentiated government entrepreneurship policies that respond to the specific barriers they face. The report includes an assessment of the impact of COVID-19 across these populations of entrepreneurs and the effectiveness of the policy response. It also contains thematic policy chapters on microfinance and leveraging the potential of immigrant entrepreneurs. These chapters present the range of current policy actions in EU and OECD countries and make recommendations for future policy directions. Finally, the report contains country profiles for each of the 27 EU Member States that identify for each county the major recent trends in entrepreneurship by women, youth, seniors and immigrants, the key policy issues and the recent policy actions. 